UNIVERSIDAD NACIONAL DE LA PLATA

FACULTAD DE HUMANIDADES Y CIENCIAS DE LA EdUCACIÓN

\title{
Entre la precarización y la autogestión: Estrategias laborales y subjetividades inherentes a los y las trabajadores de la industria pesquera de Mar del Plata y Necochea-Quequén (1997-2012)
}

\section{Lic. María Luciana Nogueira}

Tesis para optar por el grado de Doctora en Historia

Director: José Antonio Mateo, UNMDP

Codirector: Pablo Ghigliani, UNLP

La Plata, 8 de julio de 2018 
INDICE:

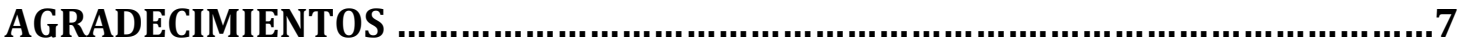

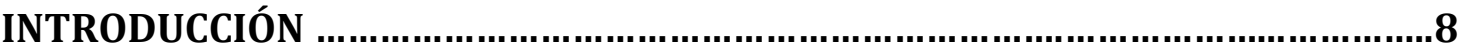

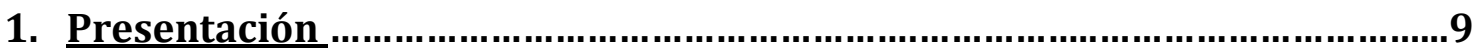

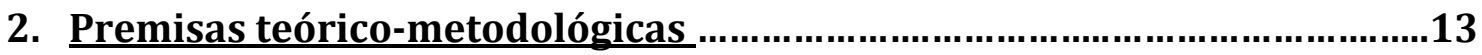

2.1 Definición del constructo subjetividad obrera ................................13

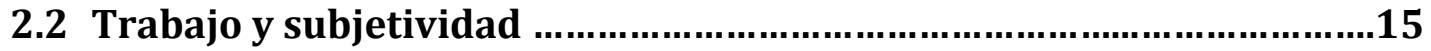

2.3 Discusión sobre el concepto “Burocracia sindical” ............................17

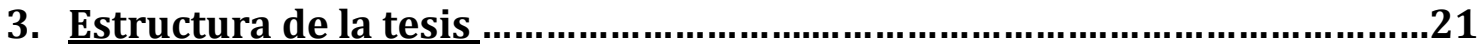

CAPITULO 1: INDUSTRIA PESQUERA Y SUBJETIVIDADES OBRERAS ................23

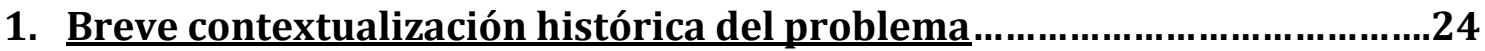

2. La actividad pesquera comercial marítima ................................................25

2.1 El sector pesquero en los albores del tercer milenio ............................27

2.2 Recorrido histórico nacional ........................................................29

2.2.1 Industria pesquera argentina y reestructuración capitalista: crisis y reconfiguración .....................................................................30

2.2.2 De pequeños artesanos del mezzogiorno a gigantescas corporaciones trasnacionales .................................................................................34

3. Entre la condensación y la evaporación: las industrias pesqueras de Mar del Plata y Necochea post reestructuración capitalista .............................41

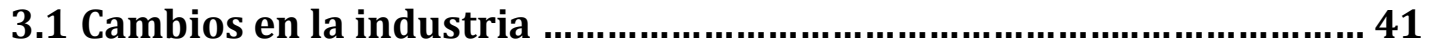

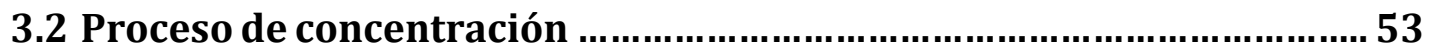

4. Entre la desocupación y la precarización laboral: El proceso de trabajo y los trabajadores de la industria pesquera argentina post reestructuración

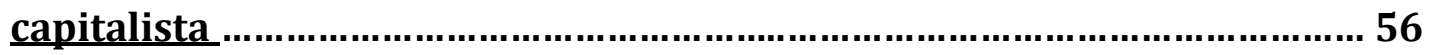

4.1 Características del proceso de trabajo y de las subjetividades de la industria pesquera argentina .........................................................5 57

4.2 Cambios la fuerza de trabajo ..............................................................62

4.3 Cambios en el proceso de trabajo ....................................................65

CAPITULO 2: EL AUGE DE LA COOPERATIVIZACIÓN EN LA INDUSTRIA PESQUERA ARGENTINA: ¿AUTOGESTIÓN O PRECARIZACIÓN LABORAL?.........68

1. Cooperativismo, economía social y capitalismo ......................................69

1.1 Del socialismo utópico al neoliberalismo ..........................................71

1.2 Economía social y cooperativismo ...................................................81

2. Cooperativismo, desocupación y trabajo no registrado en Argentina, 19912012

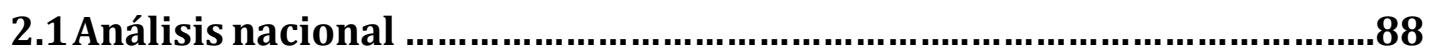

2.2 La realidad ocupacional de Mar del Plata y Necochea ..........................91

3. Cooperativización y desempleo en la industria pesquera argentina ..........98

3.1 Cooperativas en la actividad pesquera comercial marítima argentina.

Breve recorrido histórico ...............................................................98 
3.2 Subjetividades obreras y cooperativización fraudulenta en la industria pesquera marplatense ...............................................................100

3.3Subjetividades obreras y cooperativización en los procesos de recuperación de empresas pesqueras en Necochea 106

CAPITULO 3: LA RESISTENCIA OBRERA A LA PRECARIZACIÓN LABORAL EN LA INDUSTRIA PESQUERA DE MAR DEL PLATA (1997-2011): UNA BATALLA

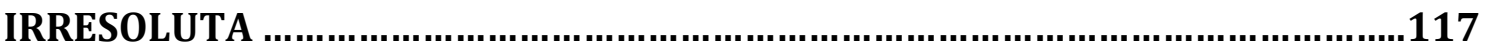

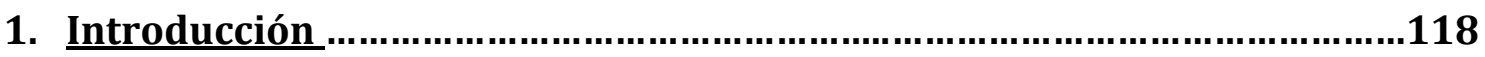

2. Revisión de los antecedentes...............................................................123

3. El ciclo 1997-2001: De la crisis de la merluza al acuerdo interburgués

3.1 La disputa interburguesa: la multisectorial marplatense vs. los pulpos pesqueros 127

3.2 La disputa intrasindical: entre la tregua y la combatividad .................................................................................132

3.3 La disputa capital/trabajo ...............................................................137

4. El ciclo 2002-2006: aparente calma ....................................................141

4.1 Del blanqueo a los convenios por empresa .........................................142

4.2 Nuevas disputas sindicales ..............................................................147

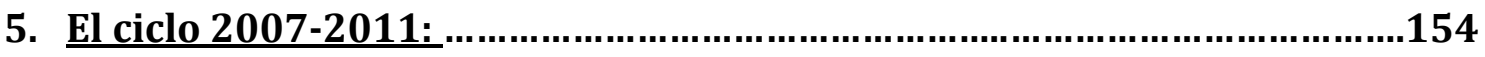

5.1 Del anexo Pyme a la puja salarial......................................................155

5.2 La siempre pospuesta demanda de blanqueo ...................................166

6. Voces obreras ¿por qué algunos trabajadores no luchan? .........................169

CAPITULO 4: LA RESISTENCIA OBRERA NECOCHENSE AL DESGUACE DEL SECTOR INDUSTRIAL PESQUERO (2010-2012) ..........................................175

1. Los procesos de recuperación de empresas por sus trabajadores en Argentina. Generalidades y perspectivas en clave subjetiva ....................178

1.1 Precursores y correlatos ..................................................................186

1.2 Recuperación de empresas y subjetividades obreras: estado de la

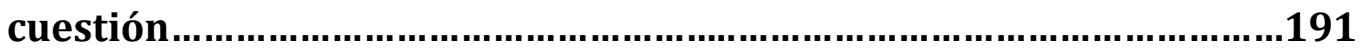

2. La Recuperada, ex-Industrial Pesquera...................................................199

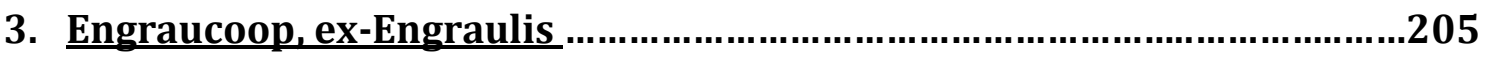

4. Análisis comparativo de los procesos de recuperación de empresas pesqueras de Necochea y Quequén........................................................210

4.1 Conflictividad sociolaboral y recuperación de empresas....................211

4.2 El plano sindical ...............................................................................218

4.2.1 El rol del Sindicato de la Alimentación...........................................218

4.2.2 El rol de los delegados sindicales fabriles.................................222

4.3 La conformación de los colectivos autogestivos ..............................231

4.4 Los cambios en el proceso de producción ..........................................235

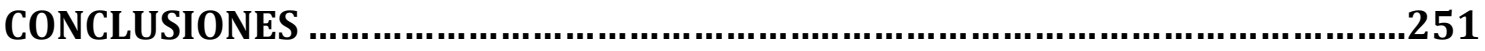

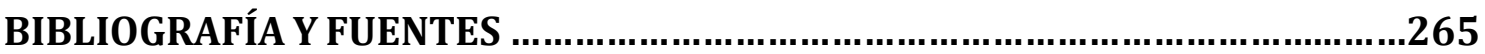




\section{Índice de tablas, gráficos e imágenes:}

Tabla №1. Capturas totales de las principales especies en Argentina, año 2013 ......29 Tabla №2. Cantidad de empresas de la industria pesquera en funcionamiento en la Provincia de Buenos Aires discriminada por localización portuaria, años 1982 y 1996

Tabla №3. Empresas de la industria pesquera Necochense y Marplatense en actividad discriminadas por rubro en relación con el total provincial, años 1982 y 1996

Tabla №4. Cantidad de trabajadores ocupados en el rubro procesado y fileteado, años 1982 y 1996

Tabla №5. Distribución porcentual de los tipos de flota en Argentina, 1961-2012...46 Tabla №6. Distribución porcentual de los desembarques en los puertos de Quequén/Necochea y Mar del Plata para las flotas costera y de altura en relación con los respectivos desembarques totales, período 1961-2012 48 Tabla №7. Distribución porcentual de los desembarques en los puertos de Quequén/Necochea y Mar del Plata para las flotas costera y de altura en relación con el total de desembarques del país, período 1961-2012

Tabla №8. Capturas en Puerto Quequén discriminadas por tipo de flota, período 1997-2012

Tabla №9. Exportaciones argentinas de productos pesqueros, períodos 1978-1984, 1993-1997 y 2001-2012

Tabla №10. Cantidad de trabajadores de la industria pesquera bonaerense desagregada por tipo de establecimiento industrial, años 1982 y 1996

Tabla №11. Empresas de la industria pesquera necochense cerradas desde 1970 hasta 2012, discriminadas por año y por el número de obreros despedidos

Tabla №12. Cantidad de cooperativas, discriminadas por tipo, años 2001 y 2014 ..77 Tabla №13. Cantidad de habitantes por condición de actividad, Mar del Plata y Necochea, años 1991, 2001 y 2010.

Tabla №14. Indicadores socioeconómicos en Mar del Plata y Necochea, años 1991, 2001 y 2010

Tabla №15. Distribución de la población ocupada por categoría ocupacional en Mar del Plata, años 1991, 2001 y 2010

Tabla №16. Distribución de la población ocupada por categoría ocupacional en Necochea, años 1991, 2001 y 2010

Tabla №17. Distribución de la población ocupada entre los principales rubros ocupacionales, Mar del Plata, 2010

Tabla №18. Distribución de la población ocupada entre los principales rubros ocupacionales, Necochea, 2010

Tabla №19. Asalariados y cuentapropistas con y sin aportes jubilatorios, Mar del Plata y Necochea, año 2010

Tabla №20. Resultados de las elecciones del SOIP, año 2002 136

Tabla №21. Cantidad de acciones conflictivas de acuerdo a los sujetos que las emprenden. Valores totales y discriminados por empresa recuperada 
Tabla №22. Cantidad de acciones emprendidas discriminadas por forma de rebelión. Valores totales y discriminados por cada empresa recuperada ................214 Tabla №23. Cantidad de acciones emprendidas de acuerdo a las metas perseguidas. Valores totales y discriminados por cada empresa recuperada ............................216 Tabla №24. Conformación inicial del colectivo obrero La Recuperada ..................231 Tabla №25. Conformación inicial del colectivo obrero Engraucoop ........................233 Gráfico №1. Cantidad de establecimientos de la industria pesquera en la provincia de Buenos Aires y en puertos patagónicos, años 1982 y 1996 .44 Gráfico №2. Desembarques por tipo de flota en relación a los desembarques totales y los años de captura máxima para el período 1961-2012 .47 Gráfico №3. Capturas en Puerto Quequén discriminadas por tipo de flota, período 1997-2012 .50 Gráfico №4. Exportaciones argentinas de productos pesqueros en toneladas y en miles de U\$S, en relación al precio por tonelada exportada. Períodos 1978-1984, 1993-1997 y 2001-2012

Gráfico №5. Distribución porcentual de cooperativas por tipo, años 2001 y 2014 ..77 Gráfico №6. Valores de las tasas de desocupación y trabajo no registrado en Argentina, 1995-2012

Gráfico №7. Distribución de la población ocupada en relación a los asalariados y asalariados no registrados

Gráfico №8. Distribución de la población ocupada por categoría ocupacional, Mar del Plata, años 1991, 2001 y 2010

Gráfico №9. Distribución de la población ocupada por categoría ocupacional, Necochea, años 1991, 2001 y 2010

Gráfico №10. Distribución de la población ocupada por categoría ocupacional, y de la población asalariada por registración laboral, Mar del Plata, año 2010 ................96 Gráfico №11. Distribución de la población ocupada por categoría ocupacional, y de la población asalariada por registración laboral, Necochea, año 2010

Gráfico №12. Evolución de la cantidad de casos en base a los datos de los cuatro relevamientos realizados por el Programa Facultad Abierta de la UBA ..................180

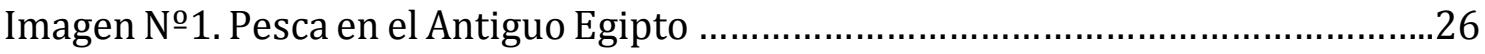

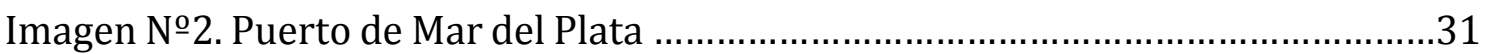

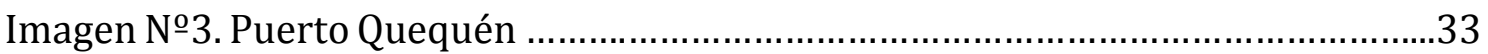

Imagen №4. Exterior de la COOMARPES. Puerto de Mar del Plata .............................99

Imagen №5. Protesta obrera por la registración laboral en la empresa Barilari, año

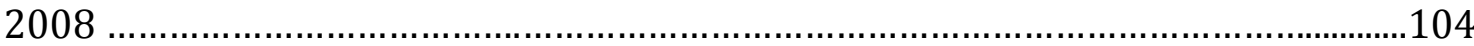

Imagen №6. Toma del SOIP, 29 de junio de 2000 ....................................................136

Imagen №7. Movilización de los obreros del pescado, año 2007 .............................163

Imagen №8. Asamblea y manifestación de trabajadores de la industria pesquera.

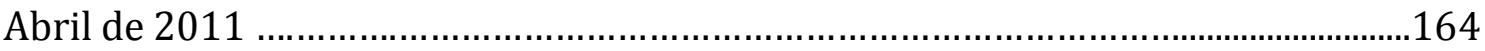

Imagen №9. Primeros integrantes de "La Recuperada” ........................................203 Imagen №10. Proceso de trabajo en "La Recuperada". Fileteado de lenguado en el interior de la planta procesadora 
Imagen №11. Exterior de la planta procesadora de "La Recuperada", marzo de 2012

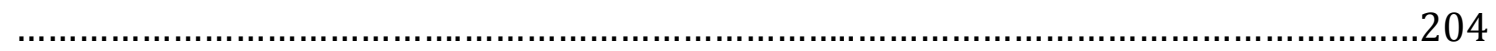
Imagen №12. Proceso de trabajo en Engraucoop. Elaboración en salado de filet de anchoas. Interior de la planta procesadora .......................................................208 Imagen №13. Integrantes del grupo inicial de Engraucoop .................................209 Imagen №14. Exterior de la Planta procesadora de Engraucoop ...........................209 


\section{Agradecimientos:}

Este trabajo no hubiese podido ser realizado sin el acompañamiento cotidiano de mi compañero Nicolás, mi pequeña hija Libertad, Valeria, próxima en llegar, mis padres, mi hermano, primas y abuelos, así como todos quienes son parte de mi familia cercana en el sentido vincular del término.

A su vez, lugares insustituibles y necesarios han ocupado mis directores de tesis y de mi formación en investigación, los doctores José Mateo, Pablo Ghigliani y Agustín Nieto, quienes no solo pusieron a mi disposición su extensa formación y sus lecturas críticas, sino también brindaron su calidez humana y acompañamiento personal durante el transcurso de los cinco años en los que desarrollé este trabajo.

Luego, en igual medida siento un profundo agradecimiento hacia todos aquellos que también contribuyeron de una $\mathrm{u}$ otra manera a enriquecer este trabajo, $\mathrm{o}$ directamente a producirlo. Los trabajadores y las trabajadoras de la industria pesquera de Mar del Plata y Necochea, quienes manifestaron su entera disposición a realizar los encuentros, entrevistas, permitiéndome inmiscuirme en su cotidianeidad laboral, aceptando mis repreguntas y planteos de nuevas dudas a medida que iba escribiendo esta tesis. Para con ellos, además de agradecimiento, guardo un profundo sentimiento de respeto y admiración por sus luchas, sus logros, sus resistencias y su determinación.

También mis colegas, compañeras, compañeros y amistades, que aportaron conocimientos, discusiones, nuevas perspectivas, tanto quienes conforman el grupo GESMar como compañeros de cursada de seminarios de posgrado y de la carrera de grado, y también con quienes compartí encuentros científicos. A los docentes de los seminarios de posgrado de la UNLP y la UNMdP, quienes colaboraron con correcciones, agregados, ideas, además de la formación pedagógica propuesta en cada curso. Quiero mencionar especialmente a las y los integrantes de la Biblioteca popular Andrés Ferreyra y de la Biblioteca del INIDEP, quienes me recibieron siempre con paciencia y dedicación, facilitándome material de archivo y bibliográfico en cada oportunidad en la que fue requerido. A todos aquellos que me prestaron alojamiento en sus hogares cada vez que tuve que viajar a realizar cursos o congresos.

Gracias al acompañamiento y aporte de todos ustedes es que he podido llegar a culminar este proyecto de tesis doctoral, sabiéndome más querida y más acompañada llegando a su final. Muchas gracias.

Necochea, 29 de junio de 2018 


\section{Introducción}




\section{Presentación:}

La actividad pesquera y sus trabajadores constituyen objetos de estudio que durante décadas fueron marginales en el campo académico argentino, lo cual se sintetiza en la frase del Dr. José Mateo: "Vivimos de espaldas al mar". Esta opacidad comenzó a disiparse en las décadas recientes, en las cuales un creciente número de investigadores provenientes de disciplinas diversas comenzaron a dedicarse a este campo. Sin embargo, el territorio aún se encuentra ampliamente vacante para seguir "cosechando el mar" y sus frutos.

Nuestro problema de investigación consiste en el impacto subjetivo y las estrategias laborales que conllevaron en los trabajadores de la industria pesquera bonaerense la integración en situaciones de cooperativización. Para su abordaje se utilizará una perspectiva comparada, tomando como referencia casos de Mar del Plata y Necochea entre los años 1997 y 2012, ya que responden a dos formatos cualitativamente distintos: cooperativas fraudulentas y empresas recuperadas, respectivamente.

Desde los primeros tiempos de la actividad pesquera comercial marítima argentina sus trabajadores han conformado asociaciones, a fin de afrontar colectivamente los problemas que implicaban las variaciones en la demanda del producto y las especificidades de la fuerza de trabajo (Mateo, 2011). Ya desde la década del 30 el encuadre jurídico adoptado fue el de las cooperativas, las cuales fueron implementadas principalmente por los patrones pescadores a fin de minimizar los perjuicios ocasionados por la venta del producto en los muelles.

Este tipo de cooperativas se contraponen al fenómeno de cooperativización iniciado en los 90, tanto en el mercado de trabajo en general como en la particularidad del sector industrial pesquero, ya que en la nueva coyuntura su conformación se asentó en una maniobra fraudulenta del empresariado para flexibilizar y precarizar a la fuerza de trabajo, mediante la tercerización enmascarada de legalidad (Mateo, Nieto y Colombo, 2010). En el puerto de Mar del Plata, enclave pesquero por excelencia a nivel nacional, utilizando la figura de las cooperativas muchos empresarios despidieron trabajadores asalariados y luego los re-contrataron como socios de sus cooperativas, a una magnitud que actualmente abarca más del 50\% de los obreros de dicha industria.

Por otro lado, enmarcados en procesos de recuperación de empresas, dos grupos obreros de la industria pesquera necochense conformaron en el año 2011 cooperativas de trabajo, como parte de las acciones de resistencia contra la desocupación ante el inminente cierre por quiebra de las plantas procesadoras en las que se desempeñaban. Si bien representan una considerable minoría en términos cuantitativos, configuran experiencias que contrastan cualitativamente con la cooperativización impuesta por el empresariado marplatense.

Nuestra perspectiva se centra en cómo vivencian los trabajadores el pasaje de asalariados registrados a cooperativizados en ambos casos, a fin de cotejar y establecer diferencias, semejanzas, categorías y ejes implicados en el análisis e 
interpretación de estos procesos. Para ello utilizaremos las categorías conceptuales de "subjetividad obrera" y "estrategias laborales" como constructos ordenadores de la investigación tanto a nivel teórico como metodológico.

El enfoque adoptado consiste en una perspectiva psico-socio-histórica, a fin de indagar las especificidades propias de estos casos otorgándole primacía a las subjetividades obreras, en vinculación con campos más amplios que incluyen la caracterización del trabajo en la actualidad y también la historia de la pesca argentina.

La brecha temporal propuesta, 1997-2012, se sostiene fundamentalmente en los procesos obreros desarrollados durante ese período: 1997 es el año de la crisis de sobreexplotación de la merluza, a partir de la cual el empresariado optó por reducir costos de producción a través de despidos masivos y reincorporación de trabajadores mediante el sistema de cooperativas fraudulentas. Si bien este mecanismo de tercerización comenzó a proliferar en la industria pesquera desde los inicios de la década del 90, la crisis de 1997 implicó su masificación y consolidación, al confluir la superexplotación obrera con la crisis del recurso pesquero. Esta crisis provocó que la cotidianeidad laboral se tornara incierta y quedara sujeta a la disponibilidad de materia prima por parte del empresariado.

Las nuevas condiciones de inestabilidad y precarización laboral fueron la base de numerosos episodios de rebelión y también de transformaciones en las subjetividades obreras, tanto por la imposición de los nuevos formatos de superexplotación como por su resistencia a ellos. De aquí que la lucha por la preservación de los puestos de trabajo y por revertir las modalidades precarizadoras impuestas continúa vigente hasta la actualidad.

Cerrando el ciclo delimitado, 2012 es el año de consolidación de las dos empresas pesqueras recuperadas de Necochea-Quequén, producto de la quiebra de dos firmas procesadoras de pescado, Industrial Pesquera y Engraulis, en donde se conformaron las empresas de autogestión obrera "La Recuperada" y "Engraucoop", respectivamente. El cierre de estas dos plantas procesadoras de pescado se enmarca en el desguace del sector industrial pesquero local iniciado en los 80, que culminó en el año 2012 con el cierre de la última empresa procesadora de pescado activa en la ciudad.

En síntesis, partimos desde una crisis de la industria ligada a la pesca y la quiebra de un considerable número de empresas del sector, lo cual habilitó en las/los trabajadoras/es del rubro la posibilidad concreta de enfrentar la inminente situación de desocupación articulando procesos de autogestión obrera en los casos de la ciudad de Necochea, y reinsertándose en la actividad en el marco de cooperativas fraudulentas en la ciudad de Mar del Plata.

Estos procesos históricos dieron cuenta de un reordenamiento de las relaciones productivas a la vez que provocaron la redefinición y reacomodo de las subjetividades propias de los agentes que los protagonizaron, sujetos que hasta ese momento eran trabajadores formales dependientes dentro de una estructura vertical de empleo asalariado registrado. 
Observamos que las consecuencias de estos procesos en el plano de las subjetividades tendieron a ordenarse en dos polos. Por un lado, el segmento de trabajadores/as precarizados/as e informales de las cooperativas fraudulentas de pescado, que dio origen a una multitud obrera contenciosa y rebelde a las nuevas condiciones impuestas por la hegemonía neoliberal. Por otra parte, el segmento de trabajadores/as autogestionarios/as que se enfrentaron en el terreno de la producción con el sistema de pensamiento hegemónico presente en la sociedad en su conjunto.

A partir de esta contextualización, surgieron varias preguntas que actuaron como guías en el transcurso de este proceso de investigación ¿Qué acciones llevaron a cabo los trabajadores de la industria pesquera bonaerense en un marco de inminente o concreta desocupación por crisis y quiebra empresarial? ¿Cuáles fueron los propósitos de dichas acciones? ¿Con qué representaciones sociales se imbricaron en los sujetos? ¿Cómo reaccionaron los distintos sectores sociales ante dichas acciones? ¿Cuáles fueron los resultados de las mismas? ¿Qué significantes aparecen en los discursos de los trabajadores al referirse al riesgo de la desocupación, a la cooperativización fraudulenta y a la recuperación de las empresas? ¿Cómo se vinculan acciones y discursos obreros con la ideología hegemónica? ¿Cómo se construyen las subjetividades obreras en los nuevos contextos laborales? ¿Cuáles fueron los efectos de la cooperativización/autogestión en el plano subjetivo? ¿Cómo resultaron afectadas las concepciones obreras acerca del trabajo en general y en el trabajo en la industria pesquera en particular?

Ensayando hipótesis de trabajo, llegamos a la proposición provisoria de que estos grupos obreros actuaron en dos tiempos: en primer término, buscaron evitar la desocupación por medio de distintivas estrategias laborales, ya sea ingresando en las cooperativas fraudulentas o creando sus propias cooperativas de trabajo. En segundo término, a raíz de las vivencias de precarización laboral y el perjurio del capital, las subjetividades obreras emprendieron una lucha contra ellas, con resultados diversos en ambos casos de cooperativización. Tomando en cuenta la globalidad del proceso, las acciones obreras se fundamentaron tanto en la supervivencia y la conservación del empleo como en la resistencia a la sumisión a las condiciones de superexplotación, al riesgo de desocupación y a sus vivencias de precarización laboral.

Entonces, sintetizando el objetivo general que orientó esta investigación, el mismo consistió en conceptualizar, en un marco de crisis y quiebra empresarial, las estrategias laborales y los procesos subjetivos que desarrollaron en su historia reciente los trabajadores de las cooperativas fraudulentas de Mar del Plata y de las empresas de autogestión obrera en Necochea-Quequén.

Nuestro encuadre metodológico buscó rastrear tanto en el decir de los sujetos y como en fuentes escritas las formas de experimentación y acción colectiva obreras de los procesos de cooperativización, y las estrategias laborales implementadas. La estrategia metodológica fue eminentemente cualitativa, la cual no excluyó el uso y análisis estadístico de datos, pero los mismos fueron utilizados de forma 
subordinada. Las técnicas de recolección consistieron en entrevistas semiestructuradas a trabajadores/as de las empresas autogestionadas y de las cooperativas fraudulentas, a dirigentes gremiales y otros actores involucrados en los procesos estudiados; la observación no participante en las empresas recuperadas de Necochea y Quequén; y la observación documental en hemerotecas (prensa), archivos empresariales y de las empresas recuperadas, expedientes y sentencias judiciales del fuero laboral. Las fuentes escritas abordadas consistieron en notas periodísticas de la prensa gráfica local de las ciudades portuarias en cuestión (específicamente los diarios La Capital, El Atlántico y Ecos Diarios), referidas tanto a la historia de la industria pesquera en Mar del Plata y QuequénNecochea como a la conformación y trabajo en las cooperativas fraudulentas y los procesos de autogestión obrera de La Recuperada (Necochea) y Engraucoop (Quequén). También se utilizaron otras fuentes periodísticas tales como archivos de la Revista Puerto y la Revista Redes, así como diversos medios de comunicación digitales. Por otra parte, se emplearon fuentes judiciales consistentes en expedientes y sentencias judiciales del fuero laboral y/o civil correspondientes a los procesos de quiebra de las empresas Industrial Pesquera y Engraulis, y causas judiciales contra las cooperativas fraudulentas. Finalmente, material documental de importancia fue obtenido de los propios archivos de las empresas recuperadas "La Recuperada" y "Engraucoop" y de los sindicatos que nuclean a los trabajadores en cuestión, el SOIP (Mar del Plata) y el STIA (Necochea).

En el transcurso de la investigación hallamos un estado de la cuestión parcial de la temática elegida, ya que actualmente contamos con estudios que se ocupan de determinados aspectos de los objetos abordados por esta investigación, sin haber hallado hasta el momento trabajos que los aborden de forma conjunta. Por un lado, existen numerosos autores dedicados a las cooperativas enmarcadas en empresas recuperadas por sus trabajadores desde una perspectiva centrada en las subjetividades en cuestión. Luego hallamos algunas investigaciones que abordan la cooperativización de los trabajadores de la pesca a lo largo de la historia en nuestro país, y específicamente unos pocos investigadores se han abocado al estudio de los trabajadores que integran las cooperativas fraudulentas de la industria pesquera marplatense desde el plano subjetivo. A falta de trabajos centrados específicamente en las empresas recuperadas pesqueras -hasta 2014, un universo exclusivamente necochense- $y$, por ende, también de literatura que las vincule con la cooperativización fraudulenta que predomina en el enclave marplatense, el estado de la cuestión incluirá una recopilación analítica de los trabajos mencionados a fin de acercarnos colateralmente a nuestros objetos y problema de investigación.

A continuación, sintetizaremos algunos de los principales constructos teóricometodológico que serán utilizados a lo largo de los capítulos de este trabajo de investigación, que actúan por ello de forma transversal, otorgando una perspectiva analítico interpretativa. 
No queremos dejar de señalar que la utilización del genérico masculino propio de la normativa oficial de la lengua castellana invisibiliza en gran medida a las trabajadoras involucradas en los casos de cooperativización abordados, quienes en Necochea constituyen el grueso de la fuerza de trabajo en la industria pesquera actual. En Mar del Plata, de la mano de la precarización laboral y la feminización de la fuerza de trabajo propia de las últimas décadas, también creció la proporción de fileteras y, como exponente de ello, la secretaría gremial del SOIP es desde hace años ocupada por una mujer. Ideando alternativas para contrarrestar el efecto masculinizante de los términos genéricos, desechamos la aclaración continua por medio de barras que implica el uso del "los y las", ya que consideramos que actuaría interrumpiendo la lectura y la interpretación de su contenido. En conclusión, en vistas de la imposibilidad de utilizar el denominado "lenguaje inclusivo" en la presentación de este trabajo académico optamos por presentar a las diversas identidades de género en el título y realizar esta aclaración inicial, destacando la presencia de mujeres trabajadoras durante todo el período aquí estudiado, cuya invisibilización se intentó suplir, en parte, con la expresión de sus voces mediante fragmentos de entrevistas expuestos a lo largo del trabajo.

\section{Premisas teórico-metodológicas:}

\subsection{Definición del constructo subjetividad obrera:}

La reconfiguración de la fuerza de trabajo, de los procesos de trabajo y de la concentración empresarial, productos de la avanzada capitalista desde la década del 70 impactaron, entre otros factores, en las subjetividades obreras, como muestran los estudios generales de Castel (1998), Silver (2003), Antunes (2007), Millones Espinosa (2012) y Dejours (2013). En este proceso investigativo entendemos al concepto "subjetividad obrera" como una construcción, constituida a partir de un orden material y simbólico instaurado que precede a los sujetos, ya que éstos desde su origen se encuentran inmersos en una determinada formación social, económica, política y cultural. De acuerdo a Marx, el ser humano nace en un mundo en donde se encuentran preestablecidas ciertas relaciones de producción, las cuales conforman el modo de producción de la vida material. Sin embargo, es en el terreno ideológico donde los sujetos adquieren conciencia de los conflictos sociales y luchan en la praxis por resolverlos (Marx, 1859). Por ello, aquí compartimos los desarrollos de Rudé (1981) y Williams (1997) los cuales hacen hincapié en la interacción entre los campos socioeconómico y político, cultural e ideológico, lo que podríamos homologar al concepto de "bloque histórico" de Gramsci (1970). Así como Gramsci, estos autores recalcan la indisolubilidad y la imposibilidad de considerar de forma fragmentada las categorías de base y superestructura. A partir del cuestionamiento a la dualidad en términos de oposición o de correlación temporal y/o espacial, postulan que, desde los planteos de Marx y Engels, el pensamiento y la actividad, la 
conciencia y la producción, la subjetividad y la sociedad, implican una interacción recíproca y una mutua retroalimentación.

Consideramos, entonces, a la subjetividad como producto mediatizado por las condiciones sociales que preexisten a los sujetos, un producto que es inacabado y se encuentra en devenir constante. A través del lenguaje y del vínculo, el ser humano ingresa en el orden histórico y sociocultural que lo precede, y a partir de allí su subjetividad se reconstruye continuamente, recreando significaciones, esquemas valorativos, representaciones, modalidades de acción, en interrelación con sus condiciones materiales de existencia.

Tanto la realidad social objetiva como la subjetiva son procesos dinámicos, siempre en movimiento e inacabados. En el plano subjetivo se incluyen los significados, las valoraciones, las prácticas y las expectativas, los cuales son indisociables de las relaciones sociales, de las relaciones de producción, y en definitiva de las relaciones de clase. En toda hegemonía hay elementos emergentes que implican nuevos vínculos, prácticas, significados y valores, que se recrean continuamente.

Lejos de considerar a la subjetividad como mero reflejo de los discursos circulantes, vemos que la influencia del complejo entramado simbólico sociocultural encuentra una configuración particular en cada sujeto, en toda subjetividad hay resquicios que escapan o van por fuera de los discursos circulantes, no solo en términos de interpretación sino también de una elaboración propia de la discursividad.

La subjetividad incluye la articulación entre psiquismo y experiencia, lo cual implica su reconfiguración a través del tiempo en constante negociación y fricción con los procesos sociales sedimentados (la historia), los procesos sociales actuantes (el presente) y los horizontes de expectativas (el futuro deseado). Desde la perspectiva adoptada las subjetividades son tanto productos como productoras del orden material y simbólico, parafraseando a Marx y Engels en "La Ideología Alemana" (1846:59) concebimos que las circunstancias hacen a los sujetos tanto como los sujetos hacen a las circunstancias, en el sentido en que son las distintas subjetividades las que habilitan o inhabilitan acciones en un sentido disruptivo o reproductivo: las subjetividades son siempre subjetividades históricas, que incluyen las dimensiones diacrónica y sincrónica. A su vez, las subjetividades se expresan colectivamente en términos de grupos y también de clase. Por ello, aquí prestaremos especial atención a las expresiones colectivas de las subjetividades obreras de la industria pesquera, plausibles de ser detectadas a través de acciones y discursos de los trabajadores.

A pesar de la explotación y las diversas formas de dominación operantes en el capitalismo, la clase obrera no se limita a padecerlas meramente, sino que manifiesta oposición, resistencia y combate contra las mismas. La lucha de clases se sitúa como el escenario de la conflictividad obrera a nivel social y subjetivo, tomando los aportes de la lectura de Marx por parte de Silver (2003) los mismos nos conducen a suponer una transformación permanente tanto de la clase obrera como de las formas de la conflictividad social, considerando que la mayor contradicción de las sociedades capitalistas continúa siendo la contradicción Capital/Trabajo. Por 
ello, nos parece fundamental precisar nuestro enfoque acerca de los vínculos entre trabajo y subjetividad.

\subsection{Trabajo y subjetividad:}

El desarrollo de la vida humana en el sistema socioeconómico capitalista imposibilita cualquier análisis del trabajo por fuera de su necesidad para la subsistencia, y de la fuerza de trabajo sin considerar su valor como mercancía. Sin desconocer que, desde tiempos remotos, la actividad laboral ha actuado como organizadora de la vida cultural, social y psíquica, con diferentes significaciones a lo largo de la historia desde los discursos hegemónicos, al estudiar el trabajo se superponen inevitablemente tanto su consideración como actividad humana, en sentido general, como la actualidad del trabajo asalariado, formato laboral preponderante desde el siglo XIX en adelante, que imprime determinadas características a la actividad laboral y a las subjetividades que la encarnan.

De acuerdo al marxismo, el trabajo conceptualizado desde esta doble vertiente es considerado como la actividad por la que el ser humano se autorreconoce como ser social y desarrolla capacidades psíquicas, cognitivas y motrices, pero que en la actualidad su modalidad asalariada genera una alienación provocada por la explotación del capitalista, quien se apropia de la producción del trabajador a la vez que lo somete a realizar sus tareas en condiciones de opresión y anulación subjetiva. Por lo tanto, el obrero no se afirma en su trabajo, sino que se niega, se deshumaniza, se aliena en su humanidad y en su relación con el género humano (Marx, K., 1844). Desde el origen del psicoanálisis, Freud (1927) también postuló que el desarrollo cultural fue y es posible gracias al trabajo y la renuncia pulsional que éste implica, compartiendo con el marxismo la reflexión de su necesidad para la conservación de la humanidad y la unificación social que de él subyace. En cuanto a la constitución psíquica, lo consideró como la más firme ligazón del sujeto con la realidad, la cual logra integrarlo en la comunidad humana: "la posibilidad de desplazar sobre el trabajo profesional y sobre los vínculos humanos que con él se enlazan una considerable medida de componentes libidinosos, narcisistas, agresivos y hasta eróticos le confiere un valor que no le va en zaga a su carácter indispensable para afianzar y justificar la vida en sociedad" (Freud, 1930:80). Empalmando esta conceptualización psicoanalítica del trabajo en sentido general con los actuales planteos de Dejours, este autor también valora positivamente el impacto subjetivo del trabajo, que es tanto producción (poiesis) como trabajo psíquico (arbeit). A través de la práctica laboral el trabajador se enfrenta con el mundo y su resistencia al propio saber hacer, a los propios conocimientos y la propia experiencia, lo cual le brinda la oportunidad de habitar el cuerpo propio y de instrumentalizarlo a partir de la tarea, y también de instrumentalizar el psiquismo en el acto productivo, transformando las subjetividades obreras: "la experiencia del trabajo se inscribe en la subjetividad y la transforma" (Dejours, 2012:13). No obstante y en concordancia con los planteos marxistas sobre el carácter de trabajo asalariado, Dejours señala la 
dimensión de sufrimiento que conlleva, que en su formato actual está caracterizado por la autonomación, la labor simultánea del obrero en varias máquinas, el modo just-in-time (por el cual el flujo de la producción está determinado por la demanda) y por el método Kan Ban (que mide de forma continua la productividad de cada obrero y sus falencias), la exigencia de autocontrol y la competencia entre trabajadores (Dejours y Gernet, 2014). La degradación y falta de dignidad que supone el trabajo asalariado actual en cuanto a condiciones de precarización y flexibilización provocan un aumento de su intensidad y de la penosidad que trae aparejada, causando psicopatologías laborales y diferentes grados de sufrimiento subjetivo ligado al trabajo: "La evolución contemporánea de las formas de organización del trabajo, de gestión y de dirección de empresa se apoya, después del giro neoliberal, sobre principios que precisamente sugieren sacrificar la subjetividad en nombre de la rentabilidad y de la competitividad" (Dejours, 2013:17).

El sistema socioeconómico capitalista implica tanto desde lo material como desde lo simbólico una ideología en la que el Otro es opresor, explotador, anulador subjetivo, alienador del trabajador y del Sujeto. El Otro del trabajo es el capital que se rige por el mercado y está personificado en el patrón, quien plantea la reducción de la subjetividad obrera a la fuerza de trabajo explotada a su servicio. Tal como lo refiere la teoría marxista desde el propio Marx (1844; 1859; 1867) hasta reflexiones recientes sobre la actualidad laboral tales como las de Antunes $(2005,2007)$, bajo el imperio de la mercancía la actividad laboral se vuelve impuesta, extrínseca, forzada y compulsiva.

En este sentido, Antunes también delimita una doble dimensión del trabajo en el capitalismo: "que, al mismo tiempo crea y subordina, emancipa y aliena, humaniza y degrada, ofrece autonomía pero genera sujeción, libera y esclaviza" (Antunes, 2007:29). Este autor puntualiza además cambios en el trabajo asalariado actual, diferenciando la mecanización y precarización propia de la organización laboral taylorizada y fordizada -dominante hasta la crisis estructural del sistema productivo que inició en los 70- de la que surgió posteriormente, la cual modificó los patrones laborales en términos de "flexibilización". El modelo toyotista contrasta con la fragmentación y el trabajo en cadena taylorista/fordista al establecer un nuevo perfil obrero que demanda emprendedorismo, polivalencia y multifuncionalidad, horarios rotativos, incorporando flexibilizaciones tanto al interior de las unidades productivas como en el mercado laboral a través de las tercerizaciones, las formas de trabajo part time o de subocupación y trabajo a destajo.

En cuanto a las especificidades de las transformaciones en el trabajo en el neoliberalismo, Castel (1998) puntualiza los mecanismos de flexibilidad, desformalización y desinstitucionalización, no solo de las relaciones laborales sino de todas las relaciones sociales, lo que provoca mayor riesgo de exclusión y desafiliación social. Por ello la lucha obrera no radica solo en la reinserción social sino en la transformación de las condiciones de trabajo y de vida, para resistir a los mecanismos de exclusión perpetrados por el capital. 
Desde nuestra perspectiva compartimos la necesidad de pensar al trabajo desde esta doble vertiente, reconociendo el lugar preponderante de la actividad laboral en relación a la configuración subjetiva y social, pero sin desconocer el carácter opresor, explotador y alienante del trabajo asalariado, y sus especificidades luego de la reestructuración capitalista a partir de los 70. Lo que aparece como coartado en el capitalismo es la capacidad creadora y transformadora del trabajo, que por ser una mercancía debe someterse a las condiciones del mercado y del salario y por ello estar más determinado por la supervivencia y en última instancia por la explotación y el sometimiento que por el desarrollo de facultades humanas.

Sin embargo, desde el trabajo y por el trabajo, las subjetividades obreras se expresan colectivamente mediante acciones de resistencia a las nuevas condiciones de precarización e incremento de desocupación instaladas desde la última reestructuración capitalista, disputando con el capital condiciones y modalidades de trabajo y contratación. El riesgo de desempleo, la búsqueda de condiciones laborales más favorables o la rebelión contra su empeoramiento con respecto a antaño actúan como importantes motivadores subjetivos obreros para emprender conflictos contra el capital. La implementación de determinadas estrategias laborales novedosas (con respecto al trabajo asalariado registrado) ante situaciones adversas, actúa como clivaje transformador de las subjetividades obreras. En los casos de la industria pesquera de Mar del Plata y Necochea, tanto el incremento de la modalidad de trabajo cooperativizada de forma fraudulenta como los casos encuadrados en empresas pesqueras recuperadas muestran la diversidad del impacto de los nuevos formatos laborales en los trabajadores. En este trabajo nos proponemos ahondar en ese impacto, desde una perspectiva que conjugue las condiciones objetivas con el desarrollo de procesos subjetivos de los trabajadores.

Las constelaciones implicadas en la lucha de clases que conlleva la contradicción capital/trabajo de la industria pesquera nacional en la actualidad, exhiben una multiplicidad de actores más allá de la oposición empresariado/trabajadores, como por ejemplo las conducciones sindicales que intervienen en el desarrollo de los conflictos o bien les imponen una dirección determinada. Por ello culminaremos este apartado conceptual con la discusión sobre el concepto "burocracia sindical".

\subsection{Discusión sobre el concepto "Burocracia sindical”:}

El concepto "Burocracia sindical" continúa en abierto debate en las ciencias sociales y humanas, por lo que aquí buscaremos sintetizar algunas de las posiciones ya formuladas y presentar la perspectiva adoptada para el análisis de nuestro problema de investigación.

En primer lugar, Paula Varela (2010) introduce conceptualizaciones desde el marxismo clásico para enmarcar su análisis desde una perspectiva histórica, en cuanto a la función posible de los sindicatos desde una concepción de lucha contra el capitalismo. De acuerdo a Marx y Engels, la importancia de los sindicatos radica 
en que los mismos permitirían anular la competencia entre los obreros (Hyman, 1978). De aquí que las luchas puntuales emprendidas no guardan como único resultado esperado la conquista de los reclamos que persiguen, sino que lo más importante reside en la generación de una unión cada vez más extensa de los obreros. Por ello, la autora sintetiza que la función -posible- de los sindicatos residiría en la superación de "la instancia de enfrentamiento de los obreros entre sí y del obrero individual con el patrón, y transformarla en enfrentamiento colectivo de clase" (Varela, 2010, s/n). Sin embargo, no es privativo de las últimas décadas la ineficacia de las políticas dirigenciales gremiales para combatir la fragmentación obrera, por lo cual no solo persisten en su interior exclusiones corporativas, nacionales, de calificaciones, de género, entre otras, sino que al interior de los mismos una minoría privilegiada ubicada en el lugar dirigencial se distingue de la gran mayoría obrera, que en la industria pesquera -por ejemplo- se encuentra en altos grados de precarización laboral. Aquí Varela ubica el rol de las conducciones o "cúpulas" sindicales, quienes en vez de garantizar unidad de la clase trabajadora consolidan capas a su interior, las cuales generan contraposición de intereses entre obreros. Esta división trae beneficios al capital, que se basa en la competencia intraobrera para rebajar salarios y empeorar condiciones laborales.

Uno de los mecanismos que desde las conducciones se utiliza para sostener esta división es el beneficio a una fracción minoritaria de trabajadores, la cual se transforma en base de apoyo a esa cúpula sindical. Aquí la autora define al concepto de "burocracia sindical" como "política de una cúpula sindical que desplaza la función del sindicato de instrumento de poder de la clase obrera a instrumento de beneficios de un sector de la clase obrera, incluidos los funcionarios sindicales como mediadores necesarios" (Varela, 2010, s/n). A su vez, otra característica de la burocracia es la autonomización de la dirigencia respecto de los trabajadores en cuanto a los procesos de toma de decisiones en relación a formas de lucha, objetivos, tiempos, alianzas, etc.

Por su parte, Mauricio Torme (2013) conceptualiza a la burocracia sindical como "fracción de la clase trabajadora que existe en la realidad y cumple una tarea fundamental en el capitalismo que es la de darles a los trabajadores una dirección política sindical que no busca su emancipación sino mantenerlos cautivos de la explotación por parte del capital" (2013:81). Los mecanismos que el autor señala como propios de las conducciones sindicales burócratas son la subordinación de la toma de decisiones de las bases, concentradas a su vez en el poder y saber de los dirigentes; la dilación y relegamiento de las demandas obreras inmediatas y mediatas; la desarticulación de toda organización combativa y el fomento de salidas obreras individuales en el marco de los valores liberales. A través de estos mecanismos, la burocracia sindical promueve una práctica y una ideología que sostiene al orden social vigente de forma conciliadora con el capital.

A partir de los aportes de estos autores, queremos introducir una delimitación necesaria entre las posiciones de las dirigencias y las bases obreras. Esto es, en un sindicato, consideramos dirigencia a quienes conforman la comisión directiva de 
dicho sindicato, que integran el núcleo de la/s agrupación/es ganadora/s de los últimos comicios de esa rama y gremio (secretario general, adjunto, tesorero, etc.). Dicho agrupamiento puede o no responder a la línea general de la agrupación u agrupaciones a las que pertenece en el caso de formar parte de una organización política supralocal, en parte por la agencia de los sujetos para su propia autodeterminación -quienes no son extensiones o partes de un grupo político sino personas con ideas y prácticas más allá de los colectivos de los que forman parte-, y además porque muchas listas se componen de integrantes de varias agrupaciones con líneas y prácticas políticas diversas, que luchan entre sí por la hegemonía. Por lo que la praxis política de cada miembro de la comisión directiva de un sindicato, además de su inclusión en una determinada organización con una línea política propia, depende de su trayectoria política, de la correlación de fuerzas, alianzas y luchas puntales en el escenario en el que se sitúen en cada momento, así como también de su propia ideología y otras motivaciones de índole coyuntural y subjetiva. Luego, una posición muy diferente a la de la dirigencia es la de las bases, es decir, el conjunto de trabajadores del sector económico que nuclee el sindicato, sean o no afiliados. En nuestra concepción, esta vinculación entre ambos grupos de sujetos no admite entrecruzamientos, ya que son localizaciones sociopolíticas mutuamente excluyentes: los trabajadores que conforman las bases lo hacen en tanto no ocupan lugares dirigentes. Luego, esta diferenciación no quita que posicionamientos políticos, ideas y/o acciones de ambas partes reciban o no apoyo y adhesión de la otra. Asimismo, la conducción sindical que asume el carácter de representante del conjunto obrero que nuclea, no se ubica en el mismo nivel de crítica que un trabajador en su plano personal, ya que se parte de una desigual localización, disposición y uso del poder político. El binomio aquí es el de representante/representados, o dirigencia/bases, que no implica adjudicar otros rasgos binarios por fuera de esta vinculación. Que las dirigencias sean burocráticas no implica que el conjunto de los trabajadores de base sea democrático, revolucionario, combativo, honesto, altruista, pero esto no niega la contraposición inicial entre dirigencia y base en cuanto a desiguales y asimétricas relaciones -y localizaciones- de poder. Aclaramos que aquí nos estamos refiriendo a la distribución y relaciones de poder al interior de un sindicato, lo cual no excluye otros escenarios en donde puede expresarse esta relación y exceden el ámbito institucional, por ejemplo, el escenario callejero. Sin embargo, el reconocimiento de esta asimetría en cuanto a la disponibilidad, uso y localizaciones de poder en los sindicatos resulta fundamental para analizar las luchas obreras, ya que la clase trabajadora ligada a la industria pesquera argentina tiende a buscar la referencia sindical en el marco de los conflictos con la patronal. Aquí queremos dejar asentado que la caracterización burocrática no se considera un atributo inmanente a los sujetos que corporizan la función dirigencial, sino a un aspecto vincular observable solo a través de la relación entre los distintos actores, entre los que podemos incluir a la dirigencia en vinculación con los obreros, la patronal, el Estado, otras 
agrupaciones sindicales opositoras, los delegados, juntas y comisiones internas y organizaciones sociales y políticas.

A fin de responder también a ciertas críticas que reciben los posicionamientos teóricos adoptados, nos parece importante recalcar que aquí la burocracia sindical no se concibe como carente de sustento entre las bases como adjudican a los autores citados anteriormente Ghigliani (2010), Colombo (2011), Nieto (2015), Iñigo Carrera y Donaire (2003) ${ }^{1}$, sino que se ubica justamente como la capa dirigencial que constituye una oligarquía con intereses propios y separados de los de las bases en cuanto a su búsqueda de perpetuarse en los cargos u espacios de toma de decisiones y otros privilegios. Esto implica justamente ciertas lógicas de funcionamiento y de vinculación entre los distintos actores, y aquí se incluye lo expuesto por Varela en cuanto a que la dirigencia otorga determinados "beneficios" a cierto grupo de trabajadores de base a fin de obtener su respaldo. Lo que queremos introducir en esta discusión es que no tomaremos estos términos como "modelos ideales" sino como materialización de determinadas relaciones sociales, políticas y de la ocupación de determinados lugares de poder. A pesar de compartir caracterizaciones desarrolladas por los autores ulteriormente mencionados sobre las dirigencias ${ }^{2}$, no acordamos con la relativización y la negación de la importancia de considerar el papel de la burocracia y toda la conceptualización que implica en el estudio de conflictos obreros e intrasindicales.

En franca discusión con estos planteos, concebir a la burocracia sindical en su funcionalidad capitalista y distanciamiento de las luchas obreras no se basa en la consideración de los obreros como inmanentemente revolucionarios ni armadores permanentes de la lucha contra el capital (Ghigliani, 2010) y tampoco se niega el individualismo y el conservadurismo existente en los trabajadores considerados en forma personal. Por el contrario, vemos necesario ubicar y considerar el rol de las conducciones gremiales en los conflictos laborales, así como en relación con las acciones llevadas a cabo por obreros de forma independiente y/o espontánea, y también por parte de agrupaciones sindicales opositoras a la línea dirigencial, ya que el mismo influye decididamente en los procesos en cuestión. Esta perspectiva

\footnotetext{
${ }^{1}$ A su vez, discutimos la idea de separación entre militantes o activistas y trabajadores presente en algunos trabajos, la cual concibe que si un trabajador forma parte de una agrupación política pierde su condición obrera para entrar en la categoría de militante, considerada como excluyente. Para nosotros, en este caso, la persona en cuestión comparte la localización subjetiva de trabajador y de militante. Luego, esta doble localización quizás implique una diferenciación respecto de otros trabajadores que no integran agrupaciones políticas o sindicales, pero no por ello el obrero que milita deja de ser obrero.

${ }^{2}$ Refiriéndose a las dirigencias sindicales, Ghigliani (2010) puntualiza que en ellas se pone en juego la búsqueda de perpetuarse en el cargo, la distancia con respecto a la experiencia laboral cotidiana, la consideración de su lugar como dador de prestigio social, la posibilidad de administrar recursos colectivos, el contacto asiduo con empresarios, funcionarios y otros dirigentes gremiales y, a su vez, la reticencia de dichas conducciones hacia las prácticas democráticas recurriendo al fraude, al impedimento de la presentación de listas opositoras, a la violencia física y al mantenimiento de estatutos restrictivos, desconfiando de las asambleas, los delegados y las formas de la democracia directa.
} 
analítica será aplicada en la casuística aquí en cuestión, como veremos posteriormente.

\section{Estructura de la tesis:}

Luego de esta breve introducción, resumiremos la estructura de esta tesis desde la trama de cada una de sus partes. Lejos de la linealidad y de una lógica temporal "ordenada", anticipamos que realizaremos algunos vaivenes y rodeos a lo largo del texto, con la intención de proponer una profundización a modo de espiral del problema de investigación abordado.

El primer capítulo ahonda en la caracterización de las condiciones objetivas y subjetivas del trabajo en la industria pesquera desde un enfoque histórico, analizando las principales transformaciones en las últimas décadas y su impacto específico en el período estudiado aquí, a la luz del recorrido histórico precedente. Luego se procede a conceptualizar, desde una perspectiva comparada, los cambios y continuidades en los enclaves portuarios de Mar del Plata y Necochea post reestructuración capitalista, tanto desde la órbita empresarial como desde la fuerza de trabajo y los procesos de trabajo.

El segundo capítulo se focaliza en un análisis crítico e interpretativo de la cooperativización como modalidad laboral impuesta fuertemente desde los 90, y específicamente su proliferación en Argentina y en la industria pesquera. Abordamos su vinculación con las transformaciones en las modalidades de trabajo y contratación, la tendencia estructural del empleo no registrado, el cuentapropismo y el incremento de la población desocupada. Partiendo de una descripción analítica de la realidad ocupacional de Mar del Plata y Necochea entre 1991 y 2012 y de la historicidad de la cooperativización en el sector pesquero nacional, se procederá a profundizar sobre las características de subjetividades inherentes a los trabajadores que integran cooperativas fraudulentas y empresas recuperadas, desde una perspectiva comparada entre las localizaciones portuarias y también en su distinción con respecto al empleo asalariado registrado.

En el capítulo tercero buscaremos profundizar conceptualizaciones acerca de la conflictividad sociolaboral propia de la industria pesquera en el caso marplatense, enfatizando el papel de los trabajadores cooperativizados en interacción con otros actores que se incluyen en las constelaciones conflictivas implicadas. Habiendo delimitado tres grandes ciclos de protesta para el período 1997-2011, se procederá a su desglosamiento a fin de describir e interpretar sus tendencias, atributos, formatos y dinámicas propias, a la luz del historial de luchas y de la crisis y reconfiguración del sector pesquero nacional en esos años. A la vez, prestaremos especial atención a las narrativas tanto obreras como de otros actores involucrados, a fin de precisar expresiones colectivas de las subjetividades obreras.

El capítulo cuarto estará enteramente abocado a la profundización de los casos de empresas pesqueras recuperadas en Necochea, como expresiones particulares tendencias entrecruzadas. Desde una arista, a la resistencia al desguace de la rama 
en determinadas localizaciones, y desde otro ángulo, a la autogestión y el cuentapropismo en vinculación con el incremento de la precarización laboral y los índices de desocupación y empleo no registrado. Las expresiones colectivas de las subjetividades obreras desde los primeros momentos de la lucha contra la desocupación hasta finalizado el segundo año como empresas recuperadas ordenarán la exposición de la interpretación de las cuestiones halladas.

En las conclusiones, se buscará sintetizar lo expuesto y también abrir interrogantes para futuras investigaciones.

En su conjunto, esperamos a partir de este trabajo contribuir a quitarle al mar algo de su desmesura, y aportarle algo de humanidad. Agradecemos nuevamente a todas $\mathrm{y}$ todos quienes nos acompañaron en esta tarea. 


\section{Capítulo I:}

Industria pesquera y subjetividades obreras 


\section{Breve contextualización histórica del problema:}

Las nuevas estrategias de acumulación capitalista implementadas por el gran empresariado transnacional a partir de la reestructuración iniciada en los 70 se sostuvieron en la desterritorialización del proceso productivo, por la cual éste se fraccionó en diferentes localizaciones geográficas (Antunes, 2007). Esta desterritorialización se basa en la premisa fundamental capitalista de la maximización de la ganancia, disminuyendo lo más posible los costos de la extracción de las materias primas, su procesamiento y distribución. Asimismo, otro de los mecanismos para el incremento de la tasa de ganancia se basa en la extracción de mayor plusvalía a costa de una mayor superexplotación obrera. Es así que desde los 70 y con mayor fuerza luego de la adopción de las medidas del Consenso de Washington en los 90, se produjo la avanzada capitalista sobre las condiciones de trabajo de los asalariados mediante dos mecanismos principales: la flexibilización y la dualización de la fuerza de trabajo. Ambos mecanismos promovieron la proliferación del empleo no registrado, el subempleo, empleo parcial, trabajo "en negro", trabajo en ramas ilegales, con la concomitante retracción del trabajo asalariado enmarcado en los denominados convenios colectivos de trabajo que fueran conquista del movimiento obrero durante las décadas de los 60 y los 70. Con el constructo teórico "dualización de la fuerza de trabajo" (Husson, 1997; Monereo Pérez, 2000, 2011) se conceptualiza la división dentro de la clase obrera en dos grandes grupos: uno que posee trabajo asalariado en relación de dependencia regido bajo contratos por tiempo indeterminado (Neffa, 2012), y otro que realiza actividades laborales no registradas, temporarias y/o informales que guardan un alto grado de inestabilidad, con mayor grado de precarización en las condiciones de trabajo y contratación que el primer grupo. Si bien en la realidad laboral de la clase obrera muchas veces coexisten y se articulan formatos laborales formales e informales, los mismos trabajadores registrados perciben en sus salarios sumas "en negro", y, en las propias trayectorias laborales, aparecen intermitencias entre distintos tipos de contratación, nos parece importante la conceptualización de la dualización de la fuerza de trabajo como tendencia estructural persistente en la nueva etapa de reestructuración capitalista, en la que los índices de empleo no registrado, subocupación y desocupación revisten valores mínimos estancados que superan los límites con respecto a etapas anteriores. Asimismo, la estrategia capitalista de acentuar la precarización laboral y borrar los límites entre trabajo formal e informal es otro de los rasgos del período que se acentúan en los $90 \mathrm{y}$ persisten luego, en el contexto de recuperación y crecimiento económico 20032008/2009.

La industria pesquera nacional no ha permanecido ajena a este patrón general de acumulación, que implicó la propagación de formas de trabajo tercerizado a través de cooperativas fraudulentas. Estas cooperativas no son creadas por iniciativa obrera sino por el empresariado, quien luego contrata esta fuerza de trabajo de forma temporaria para procesar materia prima, y así eximirse de determinados 
costes laborales que implicaría el trabajo asalariado registrado regido bajo el Convenio Colectivo de la rama 161/753. De acuerdo al último Censo nacional pesquero realizado por el INIDEP, para el año 1996 un total de 3.303 trabajadores de la industria pesquera se desempeñaba en estas cooperativas, vendiendo su fuerza de trabajo a otras empresas contratantes del rubro, representando más del $40 \%$ del total de trabajadores del sector (Bertolotti, Erratzi y Pagani, 1997).

Por otra parte, producto de la creciente monopolización y concentración de los capitales pesqueros, se produjo una disminución en la cantidad total de establecimientos que en determinadas situaciones provocó un desmantelamiento de enclaves industriales pesqueros producto de la absorción o cierre/quiebra de empresas más pequeñas, o cuyos recursos tecnológicos les impedía competir con las grandes firmas de la rama. El desguace del sector afectó a ciudades enteras, como en el caso de Necochea/Puerto Quequén, lo que produjo consecuencias sociales y económicas que impactaron en las subjetividades obreras de los trabajadores, quienes no solo quedaron desocupados sino con nulas posibilidades de reinsertarse en el sector pesquero a nivel local, y por ello se vieron obligados a la reconversión laboral en otras ramas económicas o bien debieron relocalizarse en otras ciudades para continuar trabajando en el sector haliéutico.

En este contexto, en Necochea se dio un acontecimiento inédito hasta ese momento para los obreros de la pesca: la recuperación de dos plantas procesadoras de pescado bajo gestión obrera. Si bien el movimiento de recuperación de empresas comenzó a visibilizarse en Argentina desde los 90 y se masificó luego de la crisis de 2001, hasta el año 2011 no se había producido ningún caso dentro de la industria pesquera, a pesar de los cientos de empresas del rubro que cerraron entre los $90 \mathrm{y}$ la primera década del nuevo milenio.

Luego de haber contextualizado -a grandes rasgos- al problema de investigación, continuaremos este capítulo con un recorrido histórico que permita situarlo en profundidad, en la complejidad de la que forma parte. Seguidamente abordaremos puntualizaciones acerca de la industria pesquera marplatense y necochense utilizando parámetros que permitan compararlas y situar su influencia recíproca y mutua determinación. Finalmente, abordaremos conceptualizaciones acerca de las particularidades del trabajo en la industria pesquera y sus transformaciones a partir de la década del 90

\section{La actividad pesquera comercial marítima}

Diversos estudios históricos, antropológicos y arqueológicos coinciden en señalar que la actividad pesquera fue parte de la vida humana desde sus orígenes (Mateo,

\footnotetext{
${ }^{3}$ Convenio logrado mediante el alzamiento de las luchas obreras en el contexto del "rodrigazo", durante el cual en diversos sectores productivos se lograron convenios colectivos de trabajo que aún continúan vigentes, y que expresan las condiciones laborales más favorables a los trabajadores en términos históricos.
} 
2003; Morán Angulo y otros, 2010). En sus comienzos, este procedimiento de captura y recolección fue un trabajo manual sin instrumentos específicos, que implicó la depredación ecológica de moluscos, peces, cefalópodos y algas, entre otras especies costeras. Con el tiempo se fue desarrollando la pesca artesanal desde la orilla, alcanzando mayor variedad de especies por medio de la utilización de determinadas herramientas tales como anzuelos (realizados con huesos, valvas de moluscos y metales, o de los restos óseos de los mismos peces), redes (producto del hilado con diferentes fibras), elementos punzantes como arpones o tridentes, y trampas como cestos o recovecos hechos de piedra, cañas o madera.

Para Cifuentes Lemus y Cupul Magaña (2002) desde épocas muy antiguas los egipcios, hebreos, asirios y fenicios practicaron la pesca en el Mediterráneo. En América, los códices antiguos de México demuestran que la pesca se practicaba con anterioridad a la llegada de los españoles. La investigación de Mateo $(2011,2003)$ también contienen evidencias del gran desarrollo de la actividad pesquera precolombina en los espacios geográficos que hoy conforman las naciones de México, Perú, Chile y Argentina. A nivel nacional, este desenvolvimiento se produjo mayormente en los territorios de la actual Provincia de Buenos Aires y Tierra del Fuego. Los pueblos aborígenes de Chile y Perú también utilizaban diversas técnicas de conservación del pescado, tales como salado, secado y ahumado. En Europa, además de estos métodos se aplicaba también la sumersión en aceite.

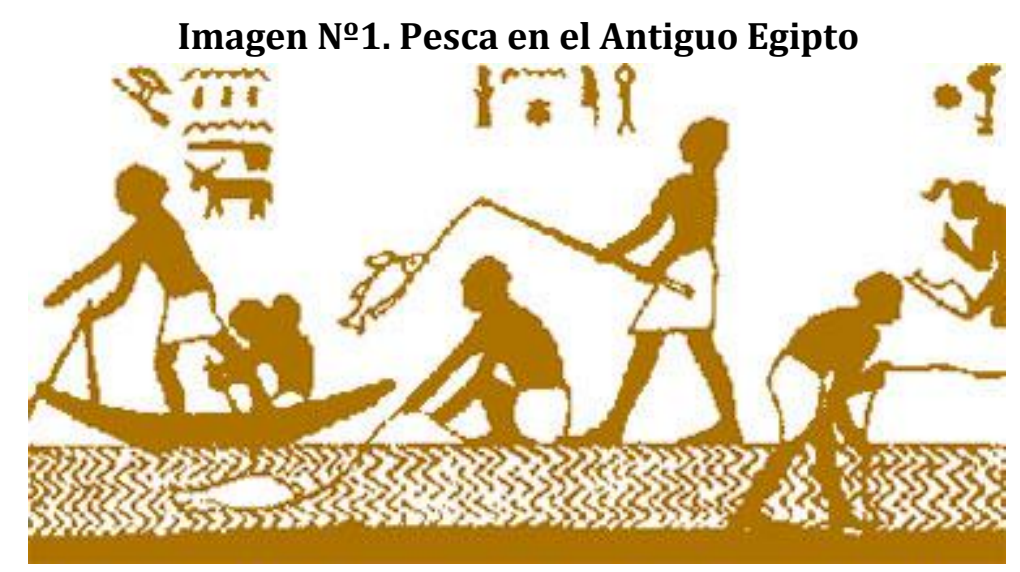

Fuente: Extraído de P. E. Newberry (1893-4). “Beni Hasan. Archaeological Survey Memoirs".

La construcción y uso de embarcaciones junto con el arte de la navegación complejizaron y diversificaron la actividad pesquera. La pesca costera y de altura implicaron un gran incremento en las capturas y en la capacidad de comercialización. La pesca artesanal fue cediendo paso a la pesca industrial, que remonta sus orígenes hasta los tiempos vikingos en las pesquerías noruegas del bacalao. El desarrollo de la pesca como actividad extractiva y mercantil a escala internacional comenzó en el siglo XVIII, cuando ya se encontraba fuertemente difundida la técnica de pesca de arrastre (Mateo, 2003). 
Tres siglos después, la ampliación de los mercados y del capital empresarial pesquero, así como las innovaciones tecnológicas y el incremento de la demanda mundial de productos de origen ictícola, provocaron una gran presión sobre las especies más capturadas. Esta presión por sobrepesca generó una crisis de la biomasa marina, que se manifestó tempranamente en los caladeros de las zonas geográficas aledañas a las grandes potencias pesqueras y luego se trasladó a los del Tercer Mundo -Argentina es un ejemplo de ello- producto del extractivismo de las flotas ligadas a las grandes potencias que debieron reubicarse en otras latitudes. Por ello, las últimas décadas del siglo XX se caracterizaron por la imposición por parte de los Estados del sistema de cuotas de pesca, a fin de preservar los recursos pesqueros ligados al comercio internacional de la sobreexplotación y, en definitiva, de su extinción. Sin embargo, mediante acuerdos bilaterales los estados han cedido permisos de pesca a terceros países, política que, al no acompañarse de mecanismos e instituciones garantes del control de los volúmenes de pesca, ha permitido de hecho la pesca furtiva en todo el mundo (Mateo, 2011).

\subsection{El sector pesquero en los albores del tercer milenio:}

Los productos alimenticios obtenidos por medio de la pesca en los ecosistemas marinos han sido -y continúan siendo- una significativa fuente de proteínas para el consumo humano y también para la alimentación animal. A su vez, sustentan una importante actividad económica generadora de capital intrincada en el comercio internacional. La producción pesquera, tanto en su sector primario extractivo como en su sector industrial, es realizada por millones de trabajadores y trabajadoras en todo el mundo. De acuerdo a la FAO (2016) para 2014 eran alrededor de 56,6 millones los trabajadores del sector primario de la pesca de captura y acuicultura, de los cuales un $36 \%$ trabaja a tiempo completo y un $23 \%$ a tiempo parcial. El restante $41 \%$ se compone de pescadores ocasionales.

Asia es el continente de mayor consumo de pescado a nivel mundial, donde Japón registra la ingesta per cápita más alta alcanzando los $71 \mathrm{Kg}$ anuales. Sin embargo, en muchos países el pescado constituye una proporción muy pequeña de la dieta (FAO, SOFÍA: 1998), debido a razones tanto culturales como políticas. Las discrepancias interconsumo entre las distintas localizaciones del planeta explica que, a nivel mundial, para el año 2014 la FAO estimara el consumo per cápita promedio en los $20 \mathrm{~kg}$ anuales, representando el 17 por ciento del aporte de proteínas animales y el 6,6 por ciento de todas las proteínas consumidas. En el caso de Argentina, una característica destacable de la dieta es el alto consumo de carnes rojas por habitante (junto con Uruguay y Nueva Zelanda son los tres países de consumo más alto del mundo). Esto actúa en detrimento del uso alimenticio de otras carnes, y en particular del pescado, a pesar de la amplia disponibilidad de diversas especies ictícolas en la plataforma continental nacional. Un informe de la FAO del año 2016 indica que actualmente Argentina es el país de América Latina y Caribe que consume menos pescado, con 4,8 kilos anuales. 
La difusión de la refrigeración y las mejoras del transporte y las comunicaciones han posibilitado un aumento progresivo de la demanda mundial de productos pesqueros de exportación. A su vez, la innovación tecnológica de las artes y métodos de pesca, así como la expansión de la flota congeladora y de factoría con procesado a bordo, significó un aumento del potencial extractivo en las últimas décadas. Todos estos factores han facilitado una vasta expansión del comercio internacional ligado al sector pesquero, el cual ha crecido aceleradamente en los últimos decenios. Para el año 2014, la FAO (2016) estimó en 167,2 millones de toneladas a la producción mundial de pescado, incluyendo crustáceos, moluscos y otros animales acuáticos. El $76 \%$ de estas capturas fue realizada por 21 países. Esto significó un volumen de capturas de 93,4 millones de toneladas, lo que representó un crecimiento del 0,8\% con respecto a 2013. De acuerdo a estos valores, los principales países pesqueros en la actualidad son China, Indonesia, Estados Unidos, India y Rusia. Se estima que en la actualidad un $45 \%$ de la captura mundial participa en el comercio internacional, $y$ el resto se destina al mercado interno y el consumo personal/familiar de los pescadores.

En cuanto a los volúmenes exportados, para 2014 el total fue de 148.000 millones de dólares, un 6\% más que en 2013. Sin embargo, los valores descienden levemente en las estimaciones para el año 2015. La Unión Europea es el mayor mercado mundial representando la mayoría de las importaciones con un 24\%. Los países preponderantes dentro de la UE son Francia, España, Alemania y Suecia. Luego le siguen Estados Unidos y Japón que en conjunto importan otro 25\%.

Entre los principales países exportadores China es, con gran diferencia, el preponderante, seguido de Noruega, Vietnam y Tailandia. Argentina ubica el puesto número 26 entre los exportadores, con 1,579 millones de USD en el año 2014, lo que representa un crecimiento del $5 \%$ con respecto a 2013 , y un $19 \%$ con respecto a 2012.

En lo que respecta a América latina, Argentina es el cuarto país exportador, ubicándose por debajo de Chile, Ecuador y Perú (FAO, 2016). La región se caracteriza por incluir tres grandes ecosistemas marinos altamente productivos con un número muy abundante de especies. El más importante es el Sistema de la Corriente de Humboldt, que incluye las costas de Chile, Perú y Ecuador. Este sistema integra casi el 20 por ciento del total de capturas a nivel mundial. Otro ecosistema importante en la región es la Plataforma Patagónica, que comprende las costas de Argentina y Uruguay, y, por último, la Plataforma Sur del Brasil (FAO, 2014).

En cuanto a las especies más utilizadas en la actividad pesquera comercial marítima, para el año 2013 el salmón y la trucha se convirtieron en los productos más comercializados en términos de valor. Los otros grupos principales de especies exportadas fueron camarones y langostinos, con cerca el 15\%, seguidos por las especies de fondo (por ejemplo, merluza, bacalao, eglefino y colín de Alaska) con el $10 \%$ y el atún, con el mismo porcentaje. En 2014, la harina de pescado representó el $3 \%$ del valor de las exportaciones y el aceite de pescado el $1 \%$. 
En este contexto internacional, Argentina se dedica a la extracción y comercialización de más de 80 especies ictícolas, entre las que se destacan cinco especies principales: merluza hubbsi, calamar, langostino, merluza de cola y corvina blanca, a las que siguen en orden de preponderancia la caballa y la anchoíta -ambas vinculadas a la industria conservera-, y finalmente el lenguado y la raya. Estas nueve especies conforman el $90 \%$ del total de capturas para el año 2013, como muestra la siguiente tabla:

Tabla №1. Capturas totales de las principales especies en Argentina, año 2013:

\begin{tabular}{|l|r|r|}
\hline Especie & Toneladas capturadas & \multicolumn{1}{c|}{$\%$} \\
\hline Merluza Hubbsi & $274.981,9$ & 33,5 \\
\hline Calamar & $191.838,3$ & 23,3 \\
\hline Langostino & $100.670,5$ & 12,3 \\
\hline Merluza de cola & $55.965,7$ & 6,8 \\
\hline Corvina blanca & $45.975,6$ & 5,6 \\
\hline Caballa & $18.160,8$ & 2,2 \\
\hline Anchoíta & $18.081,4$ & 2,2 \\
\hline Pescadilla & $17.617,8$ & 2,1 \\
\hline Raya & $16.003,3$ & 2,0 \\
\hline Total especies principales: & $739.295,3$ & 90,0 \\
\hline Total general: & $\mathbf{8 2 2 . 0 6 7 , 4}$ & $\mathbf{1 0 0 , 0}$ \\
\hline
\end{tabular}

Fuente: Elaborado en base a datos del MINAGRI, 2014.

El grueso de la pesca nacional se destina a la exportación, cuyos principales países compradores son España, China, Estados Unidos, Japón, Italia, Brasil y Vietnam. Durante 2015, el total de las exportaciones argentinas vinculadas a productos pesqueros significaron alrededor de 1.466 millones de dólares FOB 4 .

Con este marco general actual, abordaremos ahora específicamente el marco nacional de nuestro problema de investigación.

\subsection{Recorrido histórico nacional: La pesca comercial marítima Argentina. Orígenes, dinámicas portuarias y subjetividades obreras. Los enclaves industriales de Mar del Plata y Necochea.}

Un breve recorrido histórico que parta desde los orígenes de la actividad pesquera comercial marítima en Argentina puede proporcionar algunas pistas, ejes y factores clave para el entendimiento del contexto actual de surgimiento de cooperativas en la rama, tanto las fraudulentas como las recuperadas. Aquí presentaremos una narración que no mantendrá una lógica lineal -cronológica-, sino que tomará la forma de un bucle temporal: comenzado con un análisis del contexto de la industria pesquera bonaerense en el marco de la reestructuración capitalista iniciada en los

${ }^{4}$ Las siglas FOB remiten a la frase "free on board", es decir, "Libre a bordo, puerto de carga convenido". 
70 hasta la actualidad; para luego exponer en forma sintética el lugar de la industria pesquera en el marco de la historia de la actividad pesquera comercial marítima argentina desde sus comienzos. Mediante estas operaciones de anticipación y retroacción intentaremos reconstruir una narrativa que, a través del bucle, permita entender y reflexionar après coup ${ }^{5}$ sobre lo sucedido en las últimas décadas.

\subsubsection{Industria pesquera argentina y reestructuración capitalista: crisis y reconfiguración}

La reestructuración capitalista iniciada en los 70 tuvo como consecuencia el reforzamiento de su hegemonía bajo el formato neoliberal, lo que impactó negativamente en la clase trabajadora. La derrota obrera posibilitó el despliegue y la consolidación de un nuevo patrón de acumulación basado en la apertura financiera, fuga de capitales al exterior y endeudamiento externo (Grigera, 2011) cuyo correlato fue la precarización de las condiciones de vida y del trabajo. Del lado del capital, esta reconfiguración se caracteriza -a grandes rasgos- por una mayor centralización y concentración, la consolidación de grandes grupos económicos y la profundización del proceso de transnacionalización de la economía. En el polo laboral, algunas de las medidas que el empresariado adoptó para enfrentar la crisis provocaron desempleo y precarización laboral en múltiples expresiones, entre las que se destacan el empleo no registrado y el incremento del cuentapropismo, en consonancia con la retracción del trabajo asalariado y la dualización de la fuerza de trabajo.

En cuanto al sector industrial, en lugar de concebir sus transformaciones en este período desde el constructo "desindustrialización", preferimos la explicación de Grigera (2011) quien correlaciona dichas modificaciones con el proceso mismo de reestructuración capitalista. Las características económicas anteriormente mencionadas constituyen expresiones del nuevo patrón de acumulación, a las que se agregan la relocalización y desguace de enclaves industriales en determinadas coordenadas geográficas (Grigera, 2011).

Esta reestructuración global impactó de manera específica en el sector pesquero argentino. Durante los 70 y los 80 se dio paso a la implementación de novedosas políticas estatales que luego se fortalecerían en los 90: la extranjerización de la flota y la relocalización de parte del sector industrial pesquero en ciudades portuarias ubicadas en el sur del país. Estas operaciones generaron una división, centralización y especialización portuaria, polarizando al sector pesquero en los puertos de Mar del Plata y la Patagonia (especialmente en los puertos Madryn, Comodoro Rivadavia y Puerto Deseado. A su vez, se produjo una renovación tecnológica por la cual los

\footnotetext{
5 "Así nombró Lacan en segunda vuelta al Nachtraglich freudiano: un acontecimiento adquiere su significación por el suceso que le sigue; un hecho posterior redefine el valor de su antecedente", en Isidoro Vegh (1994) APRÈS-COUP, Trabajo presentado en las Jornadas Aniversario de la EFBA "20 años de Escuela", Buenos Aires, pp 1.
} 
buques congeladores y de factoría incrementaron su peso específico en la extracción y procesamiento, restándole supremacía a los barcos fresqueros e impactando decididamente en el aumento de los volúmenes de pescado extraídos del Mar Argentino. Estos elementos se conjugaron para provocar la sobreexplotación del recurso pesquero a fines de los 90, lo que generó consecuencias a nivel empresarial que profundizaron la brecha entre grandes grupos económicos y pequeñas y medianas empresas.

La apertura externa implicó una mayor competencia, la cual asociada a la sobreexplotación de la merluza condujo a parte del empresariado a la quiebra, con la concomitante concentración y aumento de la monopolización de la actividad en manos de un puñado de grandes grupos económicos de asociación de capitales nacionales y extranjeros (Joints Ventures). Estas corporaciones usufructuaron este contexto para adoptar medidas de superexplotación laboral a fin de intensificar su tasa de ganancia. El impacto de esta reestructuración en el plano empresarial fue a la vez divergente y convergente en las ciudades portuarias de la costa bonaerense abordadas: en Mar del Plata significó el fortalecimiento de los principales grupos económicos de la pesca a partir de la absorción de numerosos establecimientos industriales; en Necochea entrañó la desaparición del sector. Esto significó que la crisis y reconfiguración de la industria pesquera recayera sobre los trabajadores, tanto en términos de incremento de la desocupación como de tercerización y deterioro de las condiciones de trabajo y contratación.

En síntesis, la instauración neoliberal en el sector pesquero condujo a formas de superexplotación obrera que se masificaron en los 90 y derribaron las garantías que otorgaba el convenio colectivo de trabajo que regulaba las condiciones laborales de la rama desde el año 1975. A la vez, se produjo un notable incremento de la proporción de trabajadores cooperativizados. En este sentido, nuevamente ambas localidades expresan las dos caras de la moneda: cooperativas fraudulentas en el caso marplatense y cooperativas enmarcadas en empresas recuperadas en Necochea.

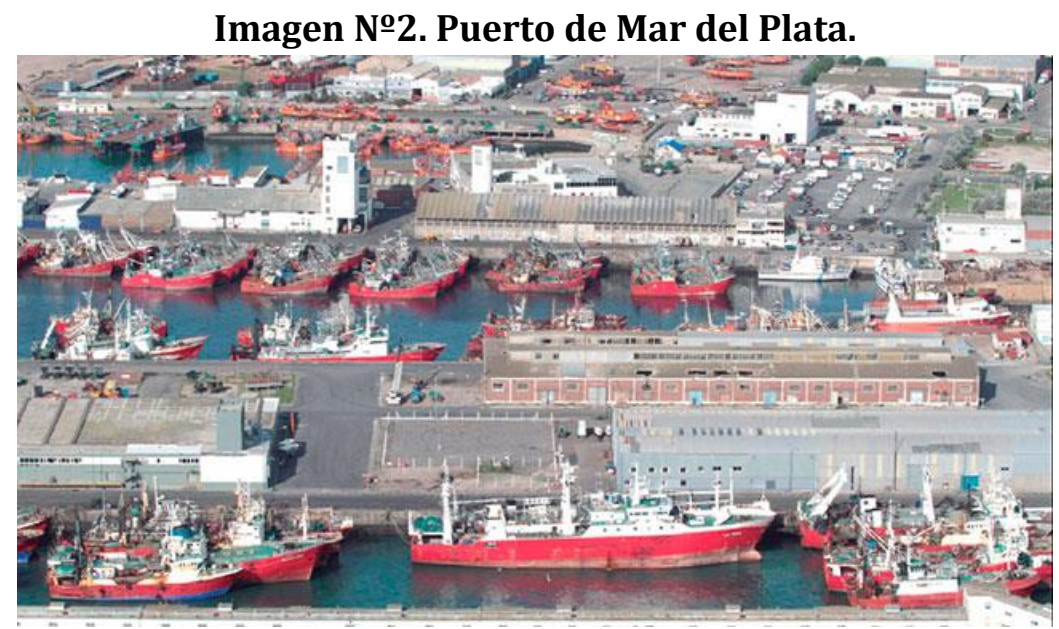

Fuente: www.mdphoy.com 
La cooperativización fraudulenta de obreros de la industria pesquera ya había iniciado en los primeros años de la década del 90, pero la crisis de sobrepesca de merluza en el año 1997 desencadenó su proliferación y consolidación. A través de esta maniobra empresarial, el trabajador aporta la fuerza de trabajo, pero tanto la materia prima como la posterior comercialización del producto y su ganancia están a cargo del propietario de la empresa. De esta forma se ejecuta una superexplotación obrera intensificando la extracción de plusvalía absoluta y relativa, extendiendo la jornada de trabajo, quitando las retribuciones por horas extras y otras licencias laborales, e intensificando el ritmo de producción -debido, por ejemplo, al fileteado de mayor cantidad de especímenes cuyo tamaño se encuentra en progresiva disminución, efecto de la sobrepesca año tras año. A su vez, las cooperativas eliminan para el empleador las obligaciones de las cargas sociales y los derechos que conlleva el empleo registrado: los trabajadores deben inscribirse como monotributistas, abonar sus propios aportes jubilatorios, obra social y aseguradora de riesgos de trabajo, con pérdida de las garantías horaria y salarial, salario familiar, sueldo anual complementario y licencias por enfermedad, entre otros perjuicios. Por otra, parte los empresarios pueden cesar contratos en cualquier momento sin que deban responder reclamo alguno de parte de los cooperativizados.

Desde los inicios de la industria pesquera se habían desarrollado modalidades de trabajo no registrado, en las llamadas "cuevas" o "fasoneras", durante ciertos lapsos temporales en los que el volumen de materia prima superaba la capacidad de procesamiento de la fuerza de trabajo que se desempeñaba en forma permanente las plantas procesadoras. Pero lo que previamente a los 90 era una situación mantenida en las sombras de la ilegalidad, luego se configuró como una norma, tanto por el amparo en el marco legal-institucional como por su extensión como política empresarial generalizada (Zelaya, 2013; Colombo, 2014). En estos casos, la asociación cooperativa de los trabajadores no es resultado de una voluntad asociativa sino una imposición del empresariado en el contexto de una seguidilla de quiebres empresariales, durante los cuales cientos de obreros fueron despedidos $u$ obligados a renunciar a sus puestos de trabajo para ser luego reincorporados como socios menores de las cooperativas fraudulentas.

En Puerto Quequén/Necochea a partir de la década del 80 se desarrolló un progresivo cierre de todas y cada una de las plantas procesadoras de pescado, provocando una cuasi-evaporación de la rama a nivel local y llevando a los trabajadores despedidos a la subsunción en la desocupación, a la relocalización o a la reconversión laboral en otra rama. En este punto la reforma en la ley de Quiebras de 1995 otorgó un marco legal que facilitó a los empresarios la consecución de despidos masivos sin indemnizaciones, con el justificativo de una crisis o desfinanciamiento de las firmas en proceso de quiebra. La permisividad gubernamental para la utilización de la Ley de cooperativas 20.337 como máscara legal para encubrir maniobras fraudulentas es otra muestra del consentimiento de 
los gobiernos de turno y el Estado ante diversos tipos de estafas laborales por parte de los empresarios.

Paradójicamente, la disminución en la cantidad de establecimientos industriales y de los puestos de trabajo registrados guardó una relación inversamente proporcional con una mayor productividad y extractivismo, sobre todo a partir de la década del 90. Este hecho, en relación con la exacerbación de las cooperativas fraudulentas, demuestra cómo la apelación a una mayor explotación del trabajador no se utiliza solamente como mecanismo para compensar la pérdida de ingresos generados por el comercio internacional (Marini, 1973) sino también como compensación ante otros tipos de pérdidas en la tasa de ganancia, -por ejemplo ante el caso de crisis por escasez del recurso-, o bien como respuesta política empresarial que en un marco neoliberal busca arremeter contra las condiciones de trabajo y contratación conquistadas previamente por el movimiento obrero.

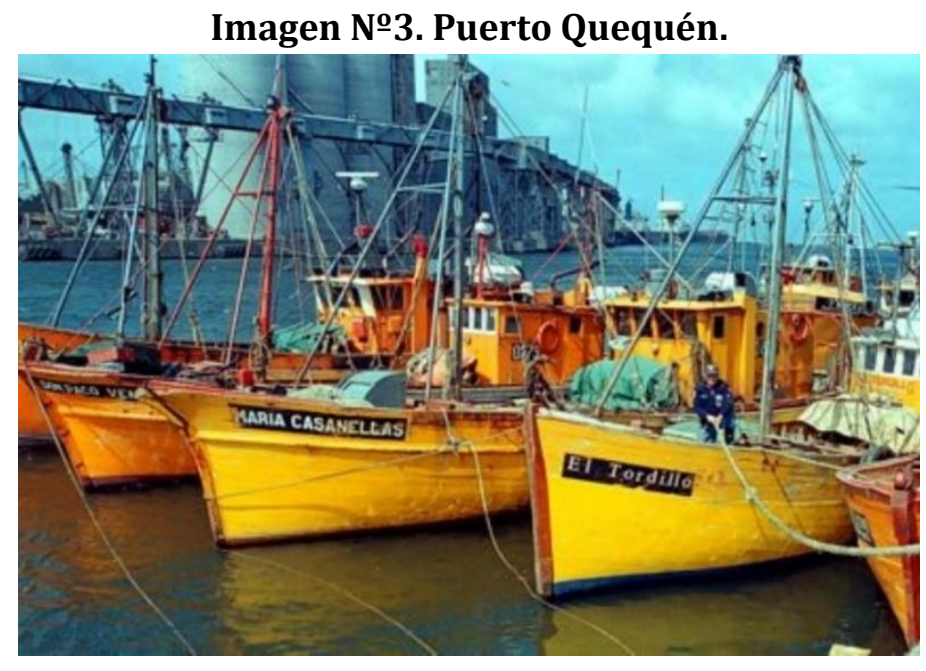

Fuente: Ecos Diarios.

Los trabajadores de Necochea y Quequén generaron una alternativa frente al contexto de crisis y cierre de empresas pesqueras que comenzó en la década del 70: dos pequeños grupos emprendieron la recuperación de las empresas y posterior conformación de cooperativas de trabajo. Los casos de "La Recuperada" y "Engraucoop" tienen el particular componente de ser las primeras empresas recuperadas del rubro pesca en Argentina. Apelando nuevamente al paralelismo entre ambas localizaciones portuarias, aquí se observa una nueva estrategia empresarial ante la caída de la tasa de ganancia: el cierre por quiebra, muchas veces fraudulenta, acarreando el despido masivo de los trabajadores de las firmas, quienes en la coyuntura actual generalmente no consiguen cobrar las indemnizaciones correspondientes.

Estos dos procesos diferenciados de cooperativización en ambas localidades portuarias expresan la contracara de un considerable número de trabajadores de la industria pesquera actualmente desempleados. La transformación en las condiciones objetivas de contratación y de trabajo de los que anteriormente eran 
trabajadores asalariados en relación de dependencia, se correlaciona con cambios en las subjetividades obreras y con la implementación de distintas estrategias laborales a fin de conservar el empleo en el sector.

En los casos necochenses, la adopción de la figura legal de Cooperativas de Trabajo -al igual que en la mayoría de los casos de empresas recuperadas- responde a la necesidad de interacción con las autoridades públicas para "obtener el reconocimiento jurídico necesario que les permita continuar con la producción" (Brunet y Pizzi, 2011:269), ya que es ésta la forma legal impulsada por el Estado tanto para solicitar subsidios y planes sociales como para ubicarse como sujeto de la expropiación de las unidades productivas, y también la figura prevista en la Ley de concursos y quiebras para solicitar la continuidad de la producción en la empresa fallida por parte de sus ex-trabajadores. Este tipo de cooperativas de trabajo originadas a partir de procesos de recuperación de empresas se diferencia tanto en su surgimiento como en su legalidad y legitimidad de las cooperativas fraudulentas conformadas según la estrategia patronal de precarización del empleo. Sin embargo, cabe preguntarse si la distinción es significativa en cuanto a condiciones de trabajo, inestabilidad y, por ende, precarización laboral.

Antes de seguir avanzando sobre la caracterización de la industria pesquera en las últimas décadas, nos desviaremos hacia un recorrido desde los inicios de la pesca comercial marítima argentina, a fin de volver a resituarnos en este punto con mayores elementos de análisis y comprensión de lo sucedido recientemente.

\subsubsection{De pequeños artesanos del mezzogiorno a gigantescas corporaciones trasnacionales:}

Retrotrayéndonos a sus inicios, la pesca comercial marítima argentina nació en Mar del Plata sobre finales del siglo XIX. La actividad fue impulsada por un creciente requerimiento de productos del mar por parte del mercado interno, tanto de turistas enriquecidos por la economía agroexportadora como del mercado central de Buenos Aires. Esta progresiva demanda promovió la llegada y asentamiento de pescadores inmigrantes del Sur de Italia en la localidad turística (Mateo, 2011), en la que el comercio estacionario acompañaba al -relativamente- constante del mercado central. La instalación del ferrocarril en el partido de General Pueyrredón también fue un importante estímulo para la actividad, fuertemente influida por el escaso tiempo de conservación del producto en condiciones aptas para el consumo humano.

El asentamiento de pescadores en Argentina guarda divergencias con los de otras localizaciones latinoamericanas. Estas discrepancias residen en que, tanto en Perú como en Chile, por tomar dos ejemplos, los pescadores aborígenes fueron contenidos en la actividad comercial pesquera posterior al proceso de colonización. En el caso de la actual Argentina, en cambio, si bien su costa marítima compartía con ambas regiones tanto la presencia de pescadores autóctonos como un mar excepcionalmente rico en especies haliéuticas (Mateo, 2003), los pescadores 
aborígenes no fueron subsumidos como tales en la economía colonial, sino que fueron introducidos en el circuito de la comercialización ligado a la expansión ganadera. A fines del siglo XIX su actividad pesquera comercial marítima era virtualmente inexistente, por lo que los inmigrantes italianos cumplieron aquí un rol originario preponderante.

Este grupo de pescadores suritálicos al llegar a la Argentina primeramente desembarcaron en las márgenes del riachuelo, pero seguidamente se trasladaron al sur del interior de la provincia, principalmente en Mar del Plata. Un registro que data del año 1895 realizado por el naturalista Fernando Lahille describe la presencia de pescadores napolitanos en Necochea y algunas características de su labor:

Catorce napolitanos reunidos en sociedad e instalados á inmediaciones de la Aduana son actualmente los únicos pescadores de la localidad. Los medios de que disponen son mediocres. Constituyen la mayor parte de su capital, cuatro pequeñas embarcaciones, pudiendo en caso necesario armarlas á balandras. Algunas líneas de fondo, algunos esparavelos y dos jabeques son los únicos aparatos de que se sirven (Lahille, 1895).

Estos datos permiten hipotetizar que el mismo proceso migratorio europeo de fines del siglo XIX que diera origen a la comunidad pesquera marplatense (Mateo, 2011) también tuvo como resultado una incipiente pesca comercial marítima en Puerto Quequén, que en sus inicios se destinaba exclusivamente al consumo local. Con el correr de los años el desarrollo de la actividad se incrementó en forma progresiva, de acuerdo al informe de Valette (1921) para 1920 Puerto Quequén se encontraba entre los puertos que generaban entre 100 y 500 toneladas anuales de producción pesquera, mientras que Mar del Plata lideraba cómodamente las extracciones con más de 5.000 toneladas por año. El mismo informe indica que el número de pescadores de oficio radicados en el país y dedicados a la pesca marítima era de 842 personas, de las cuales 743 (88\%) eran extranjeras. Mar del Plata era el lugar de residencia mayoritario comprendiendo a un total de 580 trabajadores, de los cuales 552 de ellos provenían del extranjero mientras que solo 28 eran nativos.

Luego, Lascano (1989) señaló una segunda radicación de pescadores mayormente italianos en el período entreguerras, y finalmente se produjo una tercera radicación producto de una nueva migración luego de la Segunda Guerra Mundial (Favero, 2013).

En los 30 la actividad tuvo un relanzamiento al confluir la crisis del modelo agroexportador y la caída de importaciones de productos pesqueros con el desarrollo de la industria conservera, la cual inició el proceso de industrialización pesquera en el país, en particular en la provincia de Buenos Aires. Allí comenzaron a instalarse saladeros de anchoíta y caballa en los puertos de Mar del Plata y -en menor medida- en Quequén-Necochea y Tres Arroyos, abastecidos por una creciente flota costera de lanchas sin cubierta (Nieto, 2014). 
En los años 40 la "fiebre del tiburón" otorgó un nuevo impulso a la pesca marítima, a partir de la gran demanda coyuntural estadounidense de aceite de hígado de esta especie ictícola generada durante la Segunda Guerra Mundial. Este contexto dio origen al inicio de la exportación internacional de derivadas de la pesca argentina, y a raíz de ello se incrementó el número de pescadores, la flota costera aumentó su potencia y se modernizó, el descubrimiento de nuevos caladeros de diferentes especies desembocó en la incorporación de nuevas terminales y también en el mejoramiento de las artes y los métodos de pesca, todo lo cual impactó decisivamente en el desarrollo de la industria a nivel nacional. Al finalizar la guerra este crecimiento se volcó hacia la subrama conservera, la cual predominó hasta los años 60. Cabe señalar que a finales de los 40, producto del capital acumulado durante esta época dorada de la pesca, algunos pescadores destinaron sus ganancias extraordinarias a la apropiación de almacenes navales y plantas de envasado, convirtiéndose así en empresarios industriales pesqueros. Este fue el origen de varias de los que luego serían los grandes grupos económicos de la pesca, como las firmas Valastro y Mellino, y también de otras empresas más pequeñas como el caso de Ventura S.A.

Retomando el recorrido pesquero, llegando a la década acontecieron dos cambios fundamentales en la actividad pesquera: la pesca de altura comenzó a sobrepasar a la pesca costera y la industria conservera comenzó a ser superada por la producción de frescos y congelados (Mateo, Nieto y Colombo, 2010). A su vez, se inició una asociación entre los pescadores y los empresarios que estableció la pesca a tarifa: un acuerdo entre ambas partes que implicaba suministros regulares por parte de las embarcaciones pagado a precios regulares por parte de los industriales, que otorgó protección a la actividad. El cambio de la industria conservera por la producción fresquera (centrada preponderantemente en la elaboración del filet de merluza) implicó transformaciones tanto en la organización laboral como en la demanda. Esta última se modificó por una profundización en la orientación hacia el mercado externo.

El caso de la industria pesquera y su desarrollo a partir de las décadas de los $30 \mathrm{y}$ los 40 ilustra el modelo de industrialización latinoamericano, nacido para atender las exigencias de las potencias mundiales desvinculado de la capacidad interna de consumo (Marini, 1973). A partir de este período el grueso de la producción de manufacturas pesqueras se destinó a la exportación, mientras que el mercado interno se mantuvo en proporción muy reducido dado el escaso consumo nacional de carne de pescado.

Vemos entonces que la industria pesquera argentina se desarrolló "a contramano" de las tendencias generales de la economía nacional: se originó por un fuerte impulso mercadointernista en las primeras décadas del siglo XX, durante el auge del modelo agroexportador, y se orientó a la exportación tímidamente desde los $30 \mathrm{y}$ más fuertemente desde los 40, es decir, las décadas iniciales del modelo de sustitución de importaciones en Argentina. La industria pesquera, a partir de allí, se 
asentó preponderantemente en el mercado externo, tendencia que predomina hasta la actualidad.

A partir de los años 70, cambios propios del sector se conjugaron con la transformación estructural capitalista de tal modo que rápidamente resultaron beneficiadas con amplitud las empresas asociadas a capitales extranjeros, tanto de origen nacional como internacional. Por un lado, el agotamiento de los caladeros de las grandes potencias pesqueras las condujo a promover su reemplazo en otras latitudes, como así también a renovar tecnológicamente su flota a fin de adaptarla a las nuevas condiciones extractivas. Esto las llevó también a vender a precios relativamente accesibles sus buques fresqueros, obsoletos para los nuevos caladeros, que fueron en parte incorporados a la flota argentina.

La traducción de esta situación al ámbito nacional fue la extranjerización de la flota, a través de políticas estatales que se promulgaron a tal fin. En 1974, el entonces Ministro de Economía José Ber Gelbard firmó un acta de intención que promovió acuerdos pesqueros con la URSS, la cual fue ratificada en los años 1976 y 1977 cuando el gobierno de facto autorizó el ingreso de más de 30 buques congeladores y/o factorías rusos y polacos con bandera argentina (Colombo, 2014). Años después, en 1986 el presidente Raúl Alfonsín firmó nuevos convenios de cooperación pesquera con la URSS y Bulgaria, conocidos como "Acuerdos Marco". Asimismo, luego de la guerra de Malvinas el gobierno británico isleño comenzó a otorgar licencias a terceros países para pescar en el Mar Argentino, restringiendo a su vez el ingreso de barcos nacionales en la zona adyacente a las islas. Según un trabajo del INIDEP, para 1986 el 54\% de los recursos de la zona patagónica quedaron fuera del alcance de la flota argentina. (Malaret, 1986, cit. en Bertolotti et al, 2001).

Iniciada la década del 90 nuevas políticas estatales profundizaron esta orientación político-económica, entre ellas se destacaron por su incidencia el decreto de charteo (alquiler de permisos de pesca a buques de terceros países) y el Acuerdo sobre las relaciones en Materia Pesquera con la Comunidad Económica Europea, ambos aprobados en el año 1992.

La extranjerización repercutió no sólo sobre la flota sino sobre las corporaciones empresariales industriales, conformándose como asociaciones de capitales nacionales y extranjeros (Joints Ventures). Estas empresas comenzaron a expandir sus mercados y su producción a expensas de la subsunción de pequeñas y medianas unidades productivas, incorporando grandes embarcaciones dispuestas para el congelado y procesado a bordo, abarcando la totalidad del proceso productivo desde la extracción a la comercialización. De esta forma operó en el sector pesquero la transnacionalización de los grupos económicos propietarios de las grandes empresas mediante la asociación, fusión, acuerdos o lazos financieros y/o tecnológicos con capitales extranjeros, integrándose al acelerado proceso de monopolización, concentración y creciente centralización del capital.

Paralelamente, en los 70 y los 80 se promocionó desde el Estado argentino la actividad pesquera en puertos patagónicos a través de reembolsos a las exportaciones de empresas instaladas al sur del paralelo 42 . Esta nueva orientación 
político-económica entró en conjunción con las transformaciones anteriormente mencionadas y su resultante fue el inicio de una nueva etapa en la actividad pesquera comercial marítima argentina. A partir de la década del 90 se profundizó la pérdida de preponderancia de la flota fresquera y del procesado en tierra con el incremento de los buques congeladores y de factoría con procesado a bordo, se masificó la quiebra de numerosas empresas con el correlato de una mayor concentración del capital en las grandes firmas de la rama y se reforzó el incentivo estatal para los puertos patagónicos. Esto generó la ya mencionada centralización y división de la operatoria portuaria en Mar del Plata y la Patagonia, lo cual no sucede con los grandes grupos económicos pesqueros que, dada su integración vertical y horizontal, poseen una doble localización.

Si bien la industria pesquera, comparada con la agrícola ganadera, pareciera no tener un peso significativo en la estructura productiva nacional, sí la tiene en la provincia de Buenos Aires -en particular en sus ciudades-puerto- siendo Mar del Plata su punta de lanza, secundada por Necochea y Bahía Blanca, las cuales ocupan una posición muy inferior con respecto a Mar del Plata. Estas ciudades al ser además turísticas ven acrecentada su demanda estacional, lo que le otorga rentabilidad a la producción pesquera. En 1996 ocurrió algo que relativizó la supuesta marginalidad de la actividad en el marco de la economía nacional: aquel año las exportaciones de productos pesqueros aventajaron en volumen y valores a las de carnes rojas. $\mathrm{Al}$ año siguiente la pesca exportó por 1.030 millones de dólares, mientras que la exportación de carne alcanzó los 906 millones de dólares. Por su parte, de los 400 millones de dólares registrados por las empresas marplatenses en 1997, el 92\% corresponde a la pesca, lo que representa el 6,3\% del total exportado por la provincia.

Esta performance expone, en parte, cómo la reestructuración de la actividad pesquera en los 90 desencadenó un esfuerzo de pesca por arriba de la posibilidad de renovación del caladero, provocando la sobreexplotación de la Merluza (Merluccius hubbsi) y la sobrecapitalización en el sector. La situación cobró el carácter de una fuerte crisis que tuvo su pico en el año 1997; hasta este año el volumen de las capturas se mantuvo ascendente y se superaron los niveles históricos. Ante una eventual extinción del caladero marplatense, el Estado nacional se vio impelido a promover decretos de paros biológicos, vedas y división de cupos para resguardar el recurso. Las restricciones a las capturas generaron una disputa interburguesa entre los grandes grupos económicos y los pequeños y medianos empresarios fresqueros, cuyos perdedores terminaron siendo los trabajadores.

En su conjunto, estas condiciones objetivas impactaron fuertemente en la fuerza de trabajo, transformando procesos productivos, modalidades de contratación, la conflictividad sociolaboral en la rama, el papel de los gremios y otros aspectos que serán analizados en este capítulo y los que le siguen.

Retomando el punto de partida de la periodización abordada en este trabajo, a partir del año 1997 y como consecuencia tanto de la fuerte crisis de escasez de pescado como de las políticas estatales, se acentuó la modalidad de trabajo tercerizado en el 
sector industrial pesquero, situación que habilitó distintos procesos conflictivos que dieron lugar a diversos formatos de protesta obrera marplatense contra la tercerización durante las últimas dos décadas. Según las últimas cifras oficiales, el personal cooperativizado marplatense alcanza el 40\% de los trabajadores, representando a 3.303 por sobre 8.205 obreros (INIDEP, 1996).

Entre los años 1998-2012 se presentaron tres escenarios económicos. Una primera etapa (1998-2003) se caracterizó por la lentitud del crecimiento tanto mundial como latinoamericano, tras la oleada de crisis financieras y la crisis propia del modelo neoliberal tal como estaba configurado en los 90. Luego, entre 2003-2008 se produjo una expansión económica acelerada tanto del mundo como de la mayoría de los países de la región, basada fundamentalmente en el rol de China como importador de productos básicos sin procesar o poco procesados y exportador de bienes manufacturados. Esto configuró un contexto internacional favorable para América Latina, ya que implicó el acceso a financiamiento externo y la mejora de los términos de intercambio con la suba de los precios de materias primas (commodities) extraídas y exportadas desde la región (Quenan, C. y Velut, S., 2014). Finalmente, el período entre 2008 y 2012 se caracterizó por una nueva crisis económica mundial, que sin embargo no afectó fuertemente al sector pesquero. En este sentido, para la industria pesquera el período de la convertibilidad estuvo marcado por la fuerte dependencia empresarial de la paridad cambiaria con el dólar, lo cual motivó en gran medida a la cooperativización fraudulenta como modo de incrementar la tasa de ganancia. Desde el año 2002, la devaluación implicó un incremento en los réditos empresariales en cuanto a las exportaciones y una caída del salario real, lo cual tuvo como correlato una conflictividad obrera ligada a la recomposición salarial, aunque se mantuvieron los reclamos históricos de registración laboral.

Vemos entonces que la reconfiguración de la economía mundial a partir de 2003 con su correlato latinoamericano y nacional y la transitoria recuperación del recurso pesquero conllevaron el incremento de las ganancias de los grandes empresarios de la pesca local con el aumento del precio internacional del pescado, el cual es considerado como uno de los nuevos commodities circulantes en el mercado mundial. A pesar de ello, en esta coyuntura los viejos problemas persisten observándose una continuidad del rumbo neoliberal en las características empresariales y laborales, en términos de apertura económica, aumento de la monopolización y de precarización laboral, expresada tanto en la flexibilización del trabajo como en la persistencia del empleo no registrado en el sector. En este sentido, y como veremos aquí, los momentos de recomposición económica empresarial no tuvieron como correlato una mejora en la calidad de vida obrera, manteniéndose las formas de precarización laboral enraizadas en los 90.

En Necochea, previamente al desguace de la rama también se produjo la conformación de cooperativas fraudulentas, desencadenando tanto una superexplotación obrera como la resistencia hacia ella. Focalizaremos en algunas de estas experiencias en el capítulo 3. 
A continuación, a modo de síntesis presentamos un cuadro que condensa las principales características del desarrollo de la pesca comercial marítima, haciendo eje en el sector industrial.

\section{Cuadro №1. Principales características del desarrollo de la actividad pesquera comercial marítima argentina por etapas:}

\begin{tabular}{|c|c|}
\hline ETAPA & Principales características \\
\hline $\begin{array}{l}\text { Fines } \\
\text { XIX } \text { siglo } \\
\text { los años } 30\end{array}$ & $\begin{array}{l}\text { Surgimiento y consolidación de la actividad pesquera comercial marítima. } \\
\text { Establecimiento de colonias de pescadores italianos en Mar del Plata. } \\
\text { Progresivo incremento de una demanda proveniente del mercado interno, } \\
\text { tanto de Buenos Aires como del influjo turístico de las ciudades costeras. }\end{array}$ \\
\hline $\begin{array}{l}\text { Década } 30 \text { a } \\
\text { los años } 60\end{array}$ & $\begin{array}{l}\text { Surgimiento y consolidación de la industria pesquera en los rubros conserva y } \\
\text { salazón. Instalación de plantas en Mar del Plata, Necochea y Bahía Blanca. } \\
\text { Inicio de la exportación de productos derivados de la pesca marítima argentina } \\
\text { a través de la gran demanda coyuntural de aceite de hígado de tiburón, lo que } \\
\text { otorgó un nuevo impulsó a la actividad que luego se volcó a la industria } \\
\text { conservera. Algunos pescadores se convirtieron en empresarios industriales, } \\
\text { producto de su acumulación de capital. Predominancia de la flota costera hasta } \\
1963 \text {. }\end{array}$ \\
\hline $\begin{array}{l}\text { Década del } \\
60 \text { hasta } \\
\text { fines de los } \\
80\end{array}$ & $\begin{array}{l}\text { Predominio de la flota de altura por sobre la costera y de la industria de } \\
\text { pescado fresco y congelado por sobre la industria conservera. En los } 70 \text { Inicia } \\
\text { la relocalización de la actividad en puertos patagónicos a partir de incentivos } \\
\text { estatales. Acuerdos con potencias extranjeras y la derrota en Malvinas } \\
\text { permiten la pesca de terceros países en jurisdicción nacional. Monopolización } \\
\text { creciente a partir de una progresiva concentración de las empresas pesqueras } \\
\text { con el correlato del desmantelamiento de enclaves de la industria pesquera de } \\
\text { menor envergadura (caso necochense). Creciente desalojo obrero del sector. }\end{array}$ \\
\hline $\begin{array}{l}\text { Desde fines } \\
\text { de } \quad \text { los } 80 \\
\text { hasta } \\
2002\end{array}$ & $\begin{array}{l}\text { Predominio de los buques congeladores y factoría por sobre los fresqueros de } \\
\text { altura. Conformación de Joints Ventures, empresas de asociación de capitales } \\
\text { nacionales y extranjeros. Extranjerización de la flota. Pérdida de puestos de } \\
\text { trabajo registrados y precarización laboral a través de cooperativas } \\
\text { fraudulentas (Mar del Plata) y empresas recuperadas (Necochea). } \\
\text { Conformación de grandes grupos económicos de la pesca con doble } \\
\text { localización (Mar del Plata y Patagonia). División y concentración de la } \\
\text { operatoria pesquera en Mar del Plata con preponderancia de flota fresquera } \\
\text { de altura y plantas de procesado en tierra, y la Patagonia con predominio de } \\
\text { buques congeladores y de factoría con procesado a bordo; cierre de pequeñas } \\
\text { y medianas empresas. Situación crítica del recurso pesquero. }\end{array}$ \\
\hline 2002-2012 & $\begin{array}{l}\text { Recomposición de la industria pesquera a partir de la devaluación de la } \\
\text { moneda y la virtual recuperación del recurso pesquero, considerado } \\
\text { commodity por el comercio internacional. Aumento del precio internacional } \\
\text { del pescado. Continúa la concentración de la actividad en grandes grupos } \\
\text { económicos integrados en Mar del Plata y la Patagonia, con el correlato de } \\
\text { desguace del sector en localidades de menor incidencia, como Necochea. } \\
\text { Primeras empresas recuperadas de la industria pesquera. }\end{array}$ \\
\hline
\end{tabular}

Fuente: Elaboración propia. 
Veamos ahora con mayor detalle el impacto de la crisis y reconfiguración de la industria pesquera en las ciudades portuarias escrutadas aquí.

\section{Entre la condensación y la evaporación: las industrias pesqueras de Mar del Plata y Necochea 1970-2012}

En este apartado profundizaremos acerca de los cambios en la industria pesquera de Mar del Plata y Necochea durante las últimas décadas, focalizando el análisis en las condiciones objetivas y en el plano empresarial. Veremos entonces las transformaciones en los tipos de empresas, el proceso de concentración en Mar del Plata y el desguace de la rama tanto en Necochea como en otras ciudades de la costa bonaerense.

\subsection{Cambios en la industria:}

En este apartado analizaremos datos provenientes de relevamientos realizados por el INIDEP (Instituto Nacional de Investigación y Desarrollo Pesquero) referidos a la industria pesquera de la provincia de Buenos Aires, comprendiendo que un alto porcentaje de la actividad provincial corresponde a la ciudad de Mar del Plata: 85\% en 1962, 75\% en 1982 y 92\% en 1996 (Nieto, 2014). De acuerdo a ello, lo que sucede en la localidad marplatense es en gran medida expresión bonaerense; Necochea históricamente ha secundado esta posición preponderante representando alrededor del 10\% de la actividad marplatense hasta 1996, cuando rondó el 6\%. Esto lo contrastamos con datos provenientes de trabajos académicos de Bertolotti y col. (1987), Erratzi y col. (2000) -ambos pertenecientes al INIDEP, Nieto (2014) y con datos obtenidos de la prensa gráfica y de la memoria obrera.

Cabe aclarar que, en el conteo general de las empresas, consideramos en forma separada al conjunto de establecimientos relevados bajo la denominación "Cooperativas de trabajo/servicios". Esta decisión fue conceptual y metodológica, en primer lugar, porque -como definimos anteriormente- estas cooperativas pesqueras constituyen segmentos de unidades empresariales mayores que las crean y utilizan su mano de obra para industrializar materia prima aportada por las firmas contratantes, que luego comercializan el producto. En segundo lugar, presuponemos que su inclusión en igualdad de términos con el resto de las empresas oscurecería el análisis de los resultados aparentando una realidad que no es tal, ya que de los 175 establecimientos relevados por INIDEP en el año 1996, 70 son cooperativas marplatenses y por ello no conforman entidades autónomas sino fuerza de trabajo no registrada de otras empresas, actuando para nosotros como instalaciones incluidas en ellas a pesar de situarse en otra localización geográfica. Esto queda constatado en el mismo informe del INIDEP cuando se refiere al ámbito de comercialización de las cooperativas: 
El 100\% de estas empresas comercializan en el mercado interno, esto se debe a la modalidad de operación y de proceso de estas empresas, Las Cooperativas de Trabajo venden sus servicios de mano de obra a empresas del rubro Procesado, Fileteado y Congelado (Bertolotti, Erratzi y Pagani, 1997:14).

Por lo expresado aquí preferimos tomarlas en cuenta en forma separada de los valores referidos a la cuantificación empresarial y luego ponerlas en relación con estos datos, a fin de captar más claramente su rol en la industria pesquera bonaerense y nacional.

En primer término, observamos en los registros oficiales una reducción del número de establecimientos industriales que se encontraban efectivamente operando tanto en Mar del Plata como en Necochea luego de la década del 70. Las siguientes tablas exponen, por un lado, datos sobre la cantidad de establecimientos industriales pesqueros en Mar del Plata y Necochea para los años 1982 y 1996 en forma desagregada por rubro principal y en correlación con el total provincial; por otra parte, la localización de las empresas de la industria pesquera bonaerense durante los mismos años:

Tabla №2. Cantidad de empresas de la industria pesquera en funcionamiento en la Provincia de Buenos Aires discriminada por localización portuaria, años 1982 y 1996:

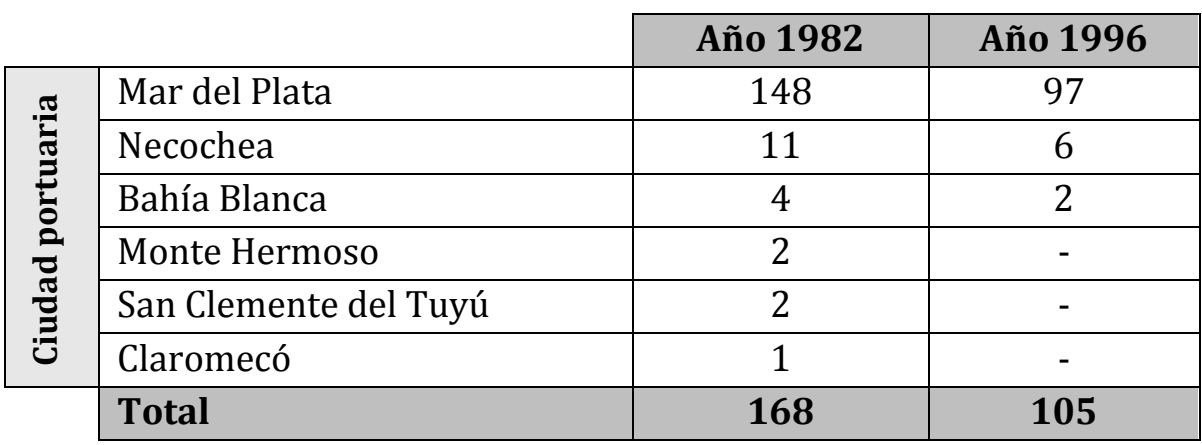

Fuente: Elaborado en base a datos de Bertolotti y col (1987) y Padrón del Censo Nacional Pesquero año 1996, INIDEP.

Tabla №3. Empresas de la industria pesquera Necochense y Marplatense en actividad discriminadas por rubro en relación con el total provincial, años 1982 y 1996:

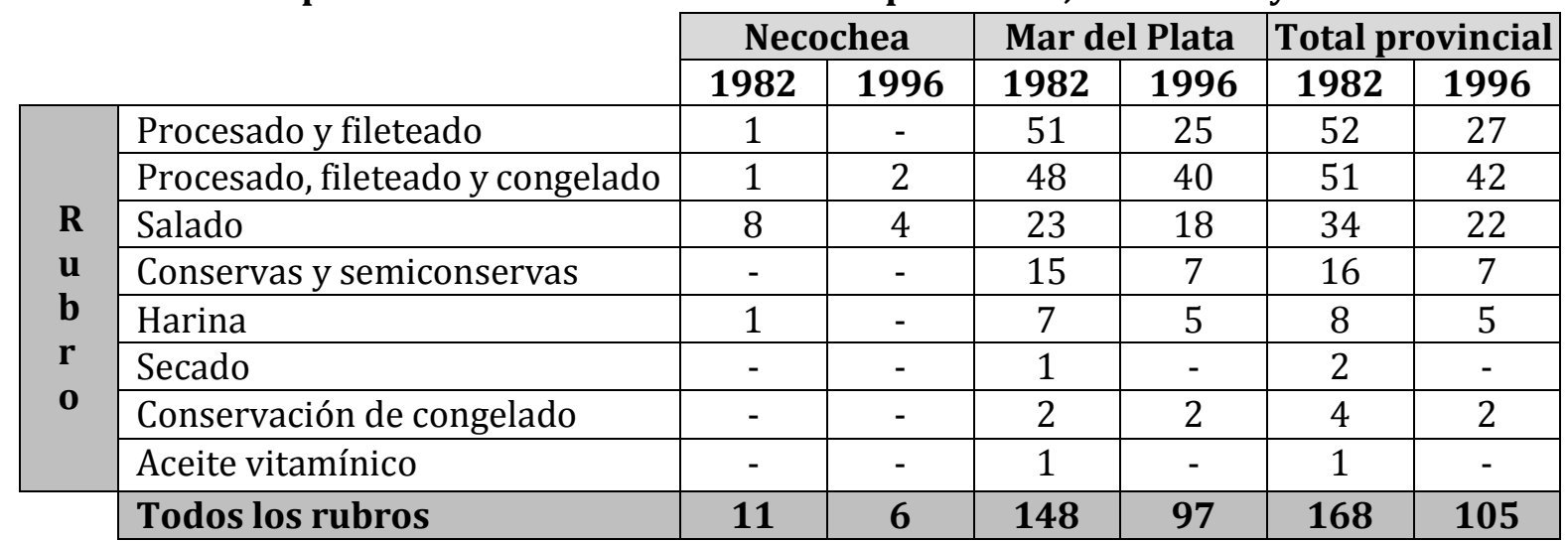

Fuente: Elaborado en base a datos de Bertolotti y col (1987) y Padrón del Censo Nacional Pesquero año 1996, INIDEP. 
A través de los datos vertidos en estas tablas podemos comenzar una primera caracterización de las transformaciones en la industria pesquera bonaerense en las últimas cuatro décadas. De las 168 empresas en actividad en 1982, el 88\% (148 establecimientos) se encontraba localizado en Mar del Plata, luego el 6,5\% (11 plantas procesadoras) se ubicaba en Necochea. Las ciudades-puerto abordadas reunían entre sí 159 establecimientos activos mientras que las restantes plantas procesadoras pesqueras operando en la provincia se situaban en el resto de las ciudades expuestas en la Tabla №2. Para 1996 los establecimientos industriales en actividad en la provincia de Buenos Aires descienden a 105, de los cuales 97 se encuentran en Mar del Plata, 6 en Necochea y 2 en Bahía Blanca (estas últimas corresponden al rubro de procesado y fileteado). En dicho año la mayoría de las unidades productivas realizaba tareas de procesado, fileteado y congelado (42) sumándose otras donde solo se procesa y filetea (27); luego en orden de importancia numérica siguen los establecimientos de salado (22), de elaboración de conservas y semiconservas (7) y harina de pescado (5). Por último, en dos plantas procesadoras se efectuaba exclusivamente la conservación de congelado.

Entonces, tomando como referencia los censos de los años 1982 y 1996, la reducción fue de 51 establecimientos en Mar del Plata (34\%) y 5 establecimientos en Necochea (45\%). En cuanto a los rubros desplazados observamos que el grueso de la disminución se encuentra en los segmentos de procesado y fileteado y de conservas, contemplando más del $50 \%$ de los establecimientos, seguidos por los de procesado, fileteado y congelado, salado y harina, aunque en estos últimos tres rubros la merma fue mucho menos significativa.

Aquí nos resulta relevante poner en consideración a las 70 "cooperativas de servicios" relevadas por el INIDEP en Mar del Plata para el año 1996, ya que la totalidad de las mismas se desempeñan justamente en el rubro procesado y fileteado. Si añadimos estos establecimientos a los que ya se encontraban contabilizados anteriormente, el número asciende de 27 a 97 unidades productivas, y si este número lo ponemos en relación a la cantidad de fuerza de trabajo empleada, los resultados obtenidos muestran que la industria ligada al procesado y fileteado no sólo no se redujo para 1996 con respecto a 1982, sino que presentó un leve aumento:

Tabla №4. Cantidad de trabajadores ocupados en el rubro procesado y fileteado, años 1982 y 1996:

\begin{tabular}{|c|c|c|}
\cline { 2 - 3 } \multicolumn{1}{c|}{} & \multicolumn{2}{c|}{ Número de trabajadores ocupados } \\
\cline { 2 - 3 } \multicolumn{1}{c|}{} & Año 1982 & Año 1996 \\
\hline Plantas de procesado, fileteado y congelado & 4.875 & 2.951 \\
\hline Plantas de procesado y fileteado & 1.347 & 376 \\
\hline Cooperativas de procesado y fileteado & - & 3.303 \\
\hline Total & $\mathbf{6 . 2 2 2}$ & $\mathbf{6 . 6 3 0}$ \\
\hline
\end{tabular}

Fuente: Elaborado a partir de Bertolotti y Col (1987) y Padrón del Censo Nacional pesquero 1996. 
Vemos entonces cómo la concentración empresarial operó precarizando la fuerza de trabajo a fin de reducir costos y aumentar la tasa de ganancia a costa de una superexplotación obrera, obteniendo mayor plusvalía al decrecer el costo del capital variable por la transformación de empleo asalariado registrado en trabajo tercerizado. Entonces, la extranjerización y la concentración económica consolidada en los 90 generó un crecimiento empresarial y un detrimento de las condiciones de trabajo y de contratación obrera.

En el caso de Necochea, de acuerdo a la prensa gráfica y a la memoria obrera, en el año 2012 cerró la última planta procesadora de pescado que se encontraba funcionando activamente en la ciudad, último caso de una seguidilla de cierres iniciada en los $80^{6}$. Sobre el final de este capítulo expondremos la información disponible en forma detallada, correlacionándola con las fuentes de trabajo perdidas en el sector.

Por otra parte, analizando el número total de establecimientos del país, para el año 1996 el total nacional fue de 167 plantas procesadoras de pescado -descontando, nuevamente, a las cooperativas. Los 62 establecimientos que no se ubican en la región bonaerense lo hacen en la región patagónica, la cual habría acrecentado el número de establecimientos en razón de casi un 200\% si consideramos a los 21 que se encontraban en actividad allí en 1982 (Bertolotti y col., 1987).

Gráfico №1. Cantidad de establecimientos de la industria pesquera en la provincia de Buenos Aires y en puertos patagónicos, años 1982 y 1996:

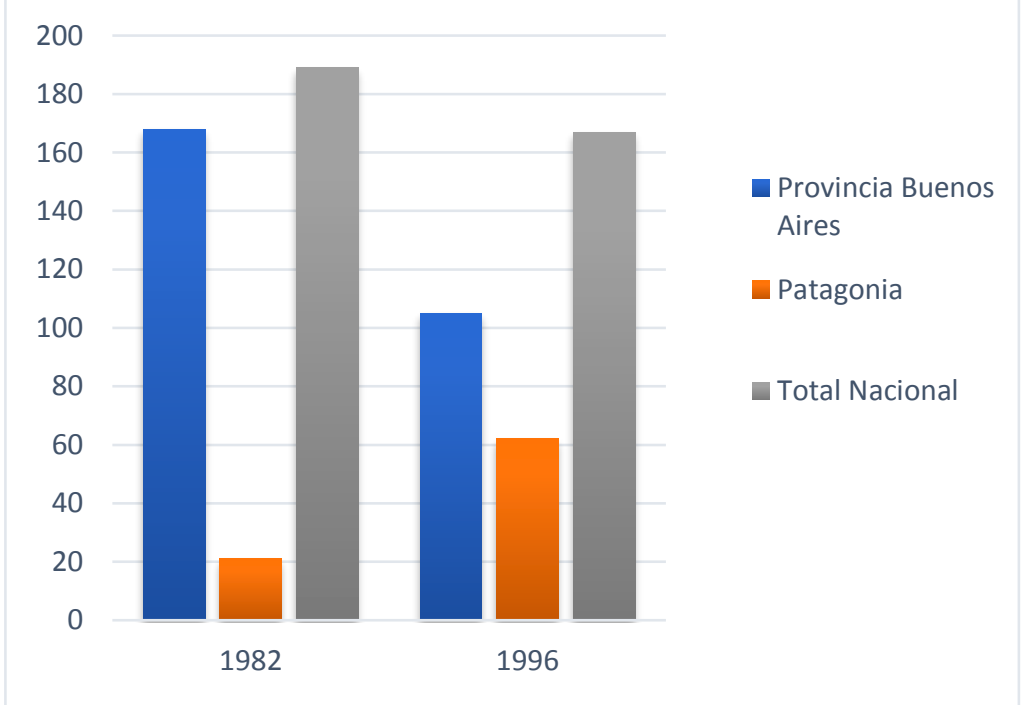

Fuentes: Elaborado en base a datos expuestos en Bertolotti y col (1987) e INIDEP Padrón del Censo Nacional Pesquero 1996.

Ahora bien, teniendo en cuenta los 63 establecimientos perdidos en la provincia de Buenos Aires y los 41 adquiridos en la Patagonia en el período 1982/1996, la disminución en términos absolutos se reduce notablemente. Vemos entonces cómo

\footnotetext{
${ }^{6}$ Ecos diarios, ediciones correspondientes a los días 6 de noviembre de 1980, 8 de marzo de 1981 y 2 de febrero de 2012.
} 
operó en la industria pesquera la reestructuración capitalista no solo por concentración sino también por relocalización (Grigera, 2011) a través del traslado de parte de este sector económico desde la provincia de Buenos Aires hacia la Patagonia, movimiento iniciado en la última dictadura cívico militar y reforzado durante las décadas subsiguientes.

Otro factor que debemos considerar para explicar tanto la disminución de la cantidad de establecimientos de cada rubro como su relocalización es la transformación en el tipo de flota predominante, ya que dependiendo cuál sea la flota que se desempeña, diversa será la especie ictícola extraída para su procesamiento y, por ende, diverso el desarrollo industrial por rubro en cada localización portuaria.

Haciendo un breve repaso por los tipos de flota existentes en la actualidad, vemos que se pueden clasificar en dos grandes grupos: la flota costera y la flota de altura. La flota costera comprende las embarcaciones más pequeñas, llamadas de ría o rada y también las lanchas costeras, mientras que la flota de altura se clasifica en buques fresqueros de altura, congeladores, poteros, palangreros, tangoneros, surimeros, congeladores para vieiras y buques factorías (FAO, 2014).

Tanto la flota de rada o ría como las embarcaciones costeras (las llamadas "lanchas amarillas") se desempeñan entre las 12 y las 180 millas náuticas correspondientes a la plataforma marítimo-continental. En este sector se encuentran diversas especies ictícolas para su comercialización, entre ellas: corvina, gatuzo, pescadilla, pargo, bagre de mar, besugo, brótola, trilla, lenguados, anchoíta, caballa, pejerrey, lisa, raya, pez ángel, mero, salmón, congrio, saraca, langostino, camarón y bonito. Estas especies que habitan las zonas litorales de la costa bonaerense hasta una profundidad de aproximadamente 50 metros se identifican como el "variado costero" (FAO, 2014).

Luego la flota de altura se desempeña en aguas más profundas dentro de la Zona Económico Exclusiva (ZEE), es decir, cercanas a las 200 millas náuticas. Las especies capturadas con fines comerciales por los buques fresqueros son: merluza, abadejo, merluza de cola, tiburón espinoso, castañeta, nototenia; y también especies del grupo anterior tales como anchoas, langostinos, bonito y caballa. Los barcos poteros se dedican exclusivamente a la pesca del calamar, mientras que los tangoneros realizan la pesca del langostino. Por último, los buques congeladores de factoría capturan fundamentalmente las especies merluza, abadejo, merluza de cola y anchoíta; y los llamados palangreros extraen abadejo, merluza negra, merluza austral y brótola.

Otra distinción entre ambos tipos de flota es su capacidad de almacenamiento. Las embarcaciones de rada tienen una capacidad de carga de entre 5 y 8 toneladas y los barcos costeros entre 10 y 20 toneladas, la flota de altura alcanza un volumen de 50200 toneladas y los buques congeladores unas 400-500 toneladas.

Como vimos en el punto anterior, los cambios en la demanda de productos pesqueros entre los 70 y los 90 se tradujeron en modificaciones en el tipo de industria y de flota predominante. La superación de la flota de altura por sobre la 
costera en la década del 60 se correlaciona con la preponderancia de la industria fresquera por sobre la conservera. Luego, la equiparación de las capturas de las flotas de altura y los buques congeladores y de factoría se empalma con el incremento del procesado a bordo y también con el incremento en la demanda de pescado sin procesar por parte del mercado externo. La flota congeladora en los 90 superó ampliamente a los buques fresqueros, pero luego de la sanción de la Ley de emergencia pesquera los volúmenes de captura de ambos tipos de flota de altura tendieron a equipararse.

En síntesis, si tomamos de conjunto de la flota costera y la flota de altura, se observa una tendencia a la disminución del peso relativo de la flota costera a partir de los 60 , como se expresa en la siguiente tabla:

Tabla №5. Distribución porcentual de los tipos de flota en Argentina, 1961-2012:

\begin{tabular}{|l|c|c|c|}
\hline Año & $\begin{array}{c}\text { Desembarques } \\
\text { totales }\end{array}$ & $\begin{array}{c}\text { \% Flota } \\
\text { costera }\end{array}$ & $\begin{array}{c}\text { \% Flota } \\
\text { de altura }\end{array}$ \\
\hline $\mathbf{1 9 6 1}$ & $77.362,0 \mathrm{t}$ & 51 & 49 \\
\hline $\mathbf{1 9 7 2}$ & $208.417,7 \mathrm{t}$ & 42,5 & 57,5 \\
\hline $\mathbf{1 9 8 0}$ & $376.863,5 \mathrm{t}$ & 22,5 & 77,5 \\
\hline $\mathbf{1 9 9 2}$ & $731.211,7 \mathrm{t}$ & 13 & 87 \\
\hline $\mathbf{2 0 0 2}$ & $889.664,3 \mathrm{t}$ & 11 & 89 \\
\hline $\mathbf{2 0 1 2}$ & $691.984,8 \mathrm{t}$ & 20,5 & 79,5 \\
\hline
\end{tabular}

Fuente: Elaborado a partir de datos de la Secretaría de Acuicultura y Pesca de la Nación.

Tomando como unidad de análisis a la flota costera, vemos que su participación en el total de los desembarques descendió notablemente entre 1961 y 2002, sus valores pasaron del 51\% al $11 \%$ con un repunte en 2012 que alcanzó el 20\%. Pero veamos ahora estos porcentajes en términos numéricos de acuerdo a las toneladas desembarcadas por cada tipo de flota: 
Gráfico №2. Desembarques por tipo de flota en relación a los desembarques totales y los años de captura máxima para el período 1961-2012:

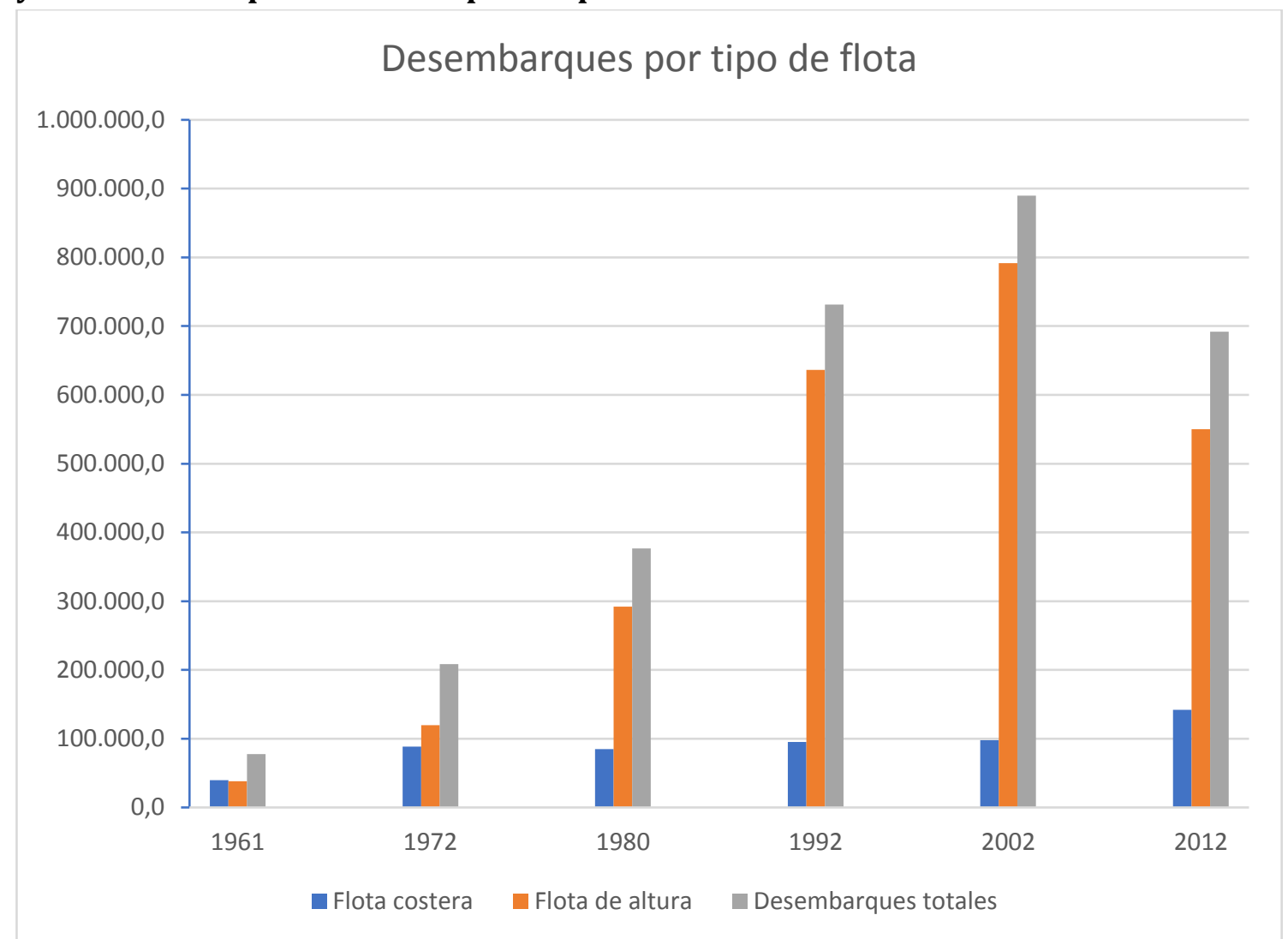

Fuente: Elaborado a partir de datos de la Secretaría de Acuicultura y Pesca de la Nación.

Si nos enfocamos en la distribución de las capturas en términos numéricos, vemos que, si bien se redujo el peso relativo de los desembarques propios de la flota costera en cuanto a la flota de altura, en términos absolutos las toneladas capturadas por la flota costera presentaron un estancamiento e incluso un aumento sobre el final del período. Esto significa que, si bien este tipo de flota perdió predominio, aún sigue manteniendo incidencia en la pesca comercial marítima nacional, ubicándose por encima de las 100.000 toneladas extraídas. Dos aspectos más adquieren preponderancia, el primero se refiere a que la flota costera también renovó tecnología -con la utilización del ecosonda, por ejemplo-, y el segundo a que el valor comercial de las especies que captura es superior a las de la flota de altura, como ocurre en el caso de la anchoíta. El aumento de sus capturas visible en 2012 se produjo fundamentalmente en los puertos de Mar del Plata y Rawson, mientras que Puerto Quequén/Necochea mostró un progresivo descenso a partir del año 1980. Más adelante veremos la dinámica puntual de Puerto Quequén a lo largo de los últimos años. Queda pendiente indagar en qué rubros industriales se utilizan estas capturas, o bien si las mismas se destinan mayormente a la exportación sin procesar. Ahora bien, ¿en qué modificaron las transformaciones en el tipo de flota a la dinámica pesquera de las ciudades portuarias Mar del Plata y Necochea? Vimos que actualmente en Mar del Plata predomina la flota y la industria ligada a los buques 
fresqueros y también a la flota costera, cuyas especies se utilizan para elaborar tanto productos frescos como conservas y salados. En términos porcentuales, en Mar del Plata el 70\% de la industria está ligada al rubro del pescado fresco mientras que el $30 \%$ se vincula con el congelado y procesado a bordo en los buques factoría, en una proporción inversa a la de los puertos patagónicos (Mateo, Nieto y Colombo, 2010: 201). Para el caso de Necochea, durante su "época dorada" predominó fuertemente la flota costera, pero veamos lo que sucedió luego:

Tabla №6. Distribución porcentual de los desembarques en los puertos de Quequén/Necochea y Mar del Plata para las flotas costera y de altura en relación con los respectivos desembarques totales, período 1961-2012:

\begin{tabular}{|l|r|c|c|c|c|c|}
\cline { 2 - 7 } \multicolumn{1}{c|}{} & \multicolumn{3}{c|}{ Necochea/Puerto Quequén } & \multicolumn{3}{c|}{ Mar del Plata } \\
\hline Año & $\begin{array}{c}\text { Desembarques } \\
\text { totales }\end{array}$ & $\begin{array}{c}\text { \% flota } \\
\text { costera }\end{array}$ & $\begin{array}{c}\text { \%flota } \\
\text { de altura }\end{array}$ & $\begin{array}{c}\text { Desembarques } \\
\text { totales }\end{array}$ & $\begin{array}{c}\text { \% flota } \\
\text { costera }\end{array}$ & $\begin{array}{c}\text { \%flota de } \\
\text { altura }\end{array}$ \\
\hline $\mathbf{1 9 6 1}$ & $7.135,6 \mathrm{t}$ & 100 & 0 & $58.175,6 \mathrm{t}$ & 50,5 & 49,5 \\
\hline $\mathbf{1 9 7 2}$ & $15.083,6 \mathrm{t}$ & 100 & 0 & $179.131,7 \mathrm{t}$ & 37,5 & 62,5 \\
\hline $\mathbf{1 9 8 0}$ & $29.318,3 \mathrm{t}$ & 14,5 & 85,5 & $238.561,8 \mathrm{t}$ & 25,5 & 74,5 \\
\hline $\mathbf{1 9 9 2}$ & $35.814,4 \mathrm{t}$ & 14 & 86 & $309.692,3 \mathrm{t}$ & 24 & 76 \\
\hline $\mathbf{2 0 0 2}$ & $5.467,0 \mathrm{t}$ & 79 & 21 & $392.775,5 \mathrm{t}$ & 15 & 85 \\
\hline $\mathbf{2 0 1 2}$ & $6.459,4 \mathrm{t}$ & 58 & 42 & $337.070,5 \mathrm{t}$ & 24 & 76 \\
\hline
\end{tabular}

Fuente: Elaborado a partir de datos de MINAGRI.

Tabla №7. Distribución porcentual de los desembarques en los puertos de Quequén/Necochea y Mar del Plata para las flotas costera y de altura en relación con el total de desembarques del país, período 1961-2012:

\begin{tabular}{|l|r|c|c|r|c|c|}
\cline { 2 - 7 } \multicolumn{1}{c|}{} & \multicolumn{3}{c|}{ Flota costera } & \multicolumn{3}{c|}{ Flota de altura } \\
\hline Año & Total país & $\% \mathrm{MdP}$ & $\% \mathrm{~N} / \mathrm{Q}$ & Total país & $\% \mathrm{MdP}$ & $\% \mathrm{~N} / \mathrm{Q}$ \\
\hline $\mathbf{1 9 6 1}$ & $39.369,1 \mathrm{t}$ & 73 & 12,5 & $37.993,4 \mathrm{t}$ & 77 & 0 \\
\hline $\mathbf{1 9 7 2}$ & $88.923,0 \mathrm{t}$ & 75 & 17 & $119.494,7 \mathrm{t}$ & 94 & 0 \\
\hline $\mathbf{1 9 8 0}$ & $85.591,0 \mathrm{t}$ & 71 & 5 & $291.272,5 \mathrm{t}$ & 61 & 8,5 \\
\hline $\mathbf{1 9 9 2}$ & $93.971,7 \mathrm{t}$ & 78,5 & 5 & $637.240,0 \mathrm{t}$ & 37 & 5 \\
\hline $\mathbf{2 0 0 2}$ & $101.094,3 \mathrm{t}$ & 58 & 4 & $788.570,0 \mathrm{t}$ & 42 & 0,15 \\
\hline $\mathbf{2 0 1 2}$ & $142.021,8 \mathrm{t}$ & 57 & 2,5 & $549.963,0 \mathrm{t}$ & 46,5 & 0,5 \\
\hline
\end{tabular}

Fuente: Elaborado a partir de datos de MINAGRI.

Tomando en cuenta estos datos, pasemos a enumerar las características de las trayectorias de los enclaves portuarios que se expresan aquí.

En un primer lugar y enfocándonos en la flota costera, se observa la gran supremacía bonaerense a nivel nacional hasta el año 1972. Sumando los porcentajes de Mar del Plata y Necochea, vemos que para 1961 representan el 85,5\% de los desembarques, y para 1972 el 92\%. Luego, tomando en cuenta cada localización portuaria por separado, se observa que Mar del Plata descendió su nivel de predominio en este tipo de flota de 78,5 \% al 57\% en 2012. Sin embargo, mantuvo la superioridad nacional en este tipo de capturas. En cambio, en Necochea se produjo un marcado 
descenso en su participación en el total de capturas a nivel nacional, de 17\% en 1972 hasta el 2,5\% alcanzado en 2012. Hasta 1972 en este puerto solo se desempeñaba la flota costera, pero para 1980 ya se encontraba activa la flota de altura.

Analizando ahora el desempeño de la flota de altura, para el caso de Necochea la misma no ha tenido una importante incidencia a nivel nacional, a excepción del año 1980 cuando alcanzó el 8,5\% del total de capturas del país. Sin embargo, su peso relativo en este puerto creció y superó a la flota costera como lo muestran los datos de los años 1980 y 1992, luego se observa un decrecimiento que llega hasta el año 2012. Para este último año vemos entonces que los porcentajes locales en relación con el total nacional son ínfimos: $0,5 \%$ para la flota de altura y 2,5\% para la costera. Tomando en conjunto los datos de la tabla №7 vemos entonces un descenso general de la influencia de Puerto Quequén en la extracción pesquera argentina desde 1980 hasta 2012.

En el caso de Mar de Plata, para 1972 representaba una enorme proporción del total nacional de capturas de la flota de altura (94\%), y luego fue perdiendo preponderancia hasta llegar al actual 46\%. La disminución del predominio marplatense en el total de los desembarques correspondientes a la flota de altura condice con la relocalización de la actividad pesquera en la Patagonia que inició en los 70. Esto explica el descenso en la participación portuaria en el total de las capturas del país a $61 \%$ en 1980 y a 37\% para 1992. En los últimos años, en cambio, volvió a incrementar sus porcentajes acercándose a la mitad del total de toneladas desembarcadas. Este último proceso se deduce que fue producto de la sanción de la Ley de emergencia pesquera en el año 2000, cuando Mar del Plata recuperó parte de su posición influyente en el cupo total de capturas máximas permisibles luego de la ya mencionada puja entre los empresarios fresqueros y los grandes grupos económicos de la pesca. ${ }^{7}$

Volvamos nuevamente a Puerto Quequén para exponer con mayor detalle lo sucedido en su sector extractivo durante los últimos años, en los cuales también culminó el desguace del sector industrial de la rama. Para ello veamos en la siguiente tabla las toneladas capturadas desde el año 1997 en adelante:

Tabla №8. Capturas en Puerto Quequén discriminadas por tipo de flota, período 1997-2012:

\begin{tabular}{|l|r|l|r|}
\hline Año & Flota costera & $\begin{array}{c}\text { Flota de } \\
\text { altura }\end{array}$ & $\begin{array}{c}\text { Desembarques } \\
\text { totales }\end{array}$ \\
\hline $\mathbf{1 9 9 7}$ & $3.020,9 \mathrm{t}$ & $40.737,5 \mathrm{t}$ & $\mathbf{4 3 . 7 5 8 , 4 ~ t}$ \\
\hline $\mathbf{1 9 9 8}$ & $4.698,0 \mathrm{t}$ & $34.147,3 \mathrm{t}$ & $\mathbf{3 8 . 8 4 5 , 3} \mathbf{~ t}$ \\
\hline $\mathbf{1 9 9 9}$ & $3.097,7 \mathrm{t}$ & $38.275,8 \mathrm{t}$ & $\mathbf{4 1 . 3 7 3 , 5} \mathbf{~ t}$ \\
\hline $\mathbf{2 0 0 0}$ & $3.445,6 \mathrm{t}$ & $28.738,6 \mathrm{t}$ & $\mathbf{3 2 . 1 8 4 , 2} \mathbf{~ t}$ \\
\hline
\end{tabular}

\footnotetext{
7 Para la lectura de un análisis pormenorizado de este conflicto, se recomienda la Tesis doctoral de Guillermo Colombo (2014) "De la revolución productiva a la crisis de la merluza", en Memoria académica, FAHCE - UNLP.
} 


\begin{tabular}{|c|c|c|c|}
\hline 2001 & $4.256,3 \mathrm{t}$ & $3.000,4 \mathrm{t}$ & $7.256,7 \mathrm{t}$ \\
\hline 2002 & $4.339,5 \mathrm{t}$ & $1.127,0 \mathrm{t}$ & $5.467,0 \mathrm{t}$ \\
\hline 2003 & $4.097,8 \mathrm{t}$ & $573,4 \mathrm{t}$ & $4.671,2 \mathrm{t}$ \\
\hline 2004 & $3.776,7 \mathrm{t}$ & $1.160,5 \mathrm{t}$ & $4.937,2 \mathrm{t}$ \\
\hline 2005 & $3.070,3 \mathrm{t}$ & $592,0 \mathrm{t}$ & $3.662,3 \mathrm{t}$ \\
\hline 2006 & $3.083,3 \mathrm{t}$ & $509,9 \mathrm{t}$ & $3.593,2 \mathrm{t}$ \\
\hline 2007 & $4.792,8 \mathrm{t}$ & $1.391,2 \mathrm{t}$ & $6.184,0 \mathrm{t}$ \\
\hline 2008 & $3.419,7 \mathrm{t}$ & $382,1 \mathrm{t}$ & $3.801,8 \mathrm{t}$ \\
\hline 2009 & $4.156,8 \mathrm{t}$ & $388,4 \mathrm{t}$ & $4.545,2 \mathrm{t}$ \\
\hline 2010 & $3.873,2 \mathrm{t}$ & $290,0 \mathrm{t}$ & $4.163,2 t$ \\
\hline 2011 & $3.493,4 \mathrm{t}$ & $1.152,9 \mathrm{t}$ & $4.646,3 \mathrm{t}$ \\
\hline 2012 & $3.763,3 \mathrm{t}$ & $2.696,1 \mathrm{t}$ & $6.459,4 \mathrm{t}$ \\
\hline
\end{tabular}

Fuente: Elaborado a partir de datos del MINAGRI.

Gráfico №3. Capturas en Puerto Quequén discriminadas por tipo de flota, período 1997-2012:

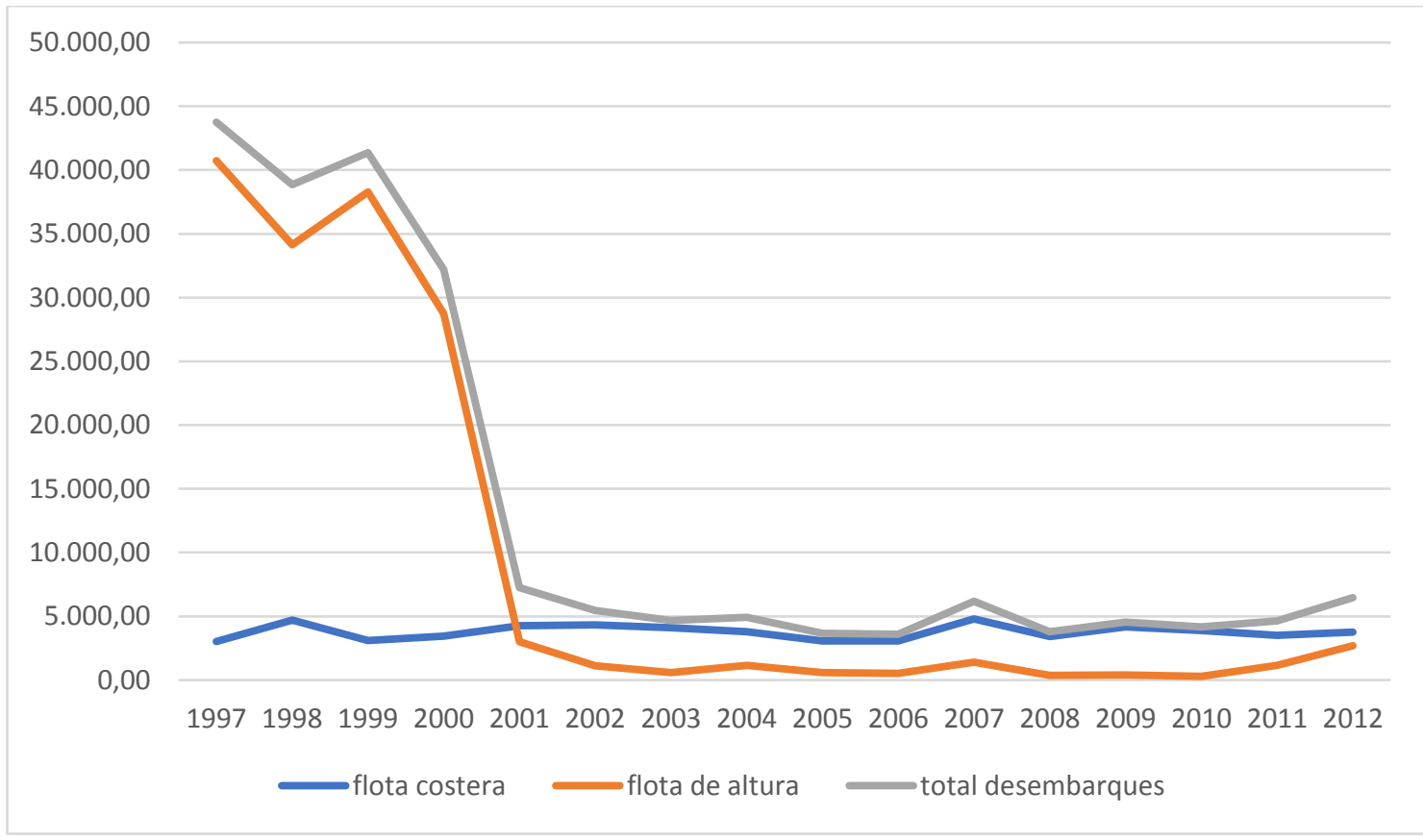

Fuente: Elaborado a partir de datos del MINAGRI.

La información aquí volcada nos muestra una dramática disminución de las capturas en Puerto Quequén a partir de 2001, cuando pasó de 32.000 toneladas en el año 2000 a 7.200 al año siguiente, tras lo cual los valores totales permanecieron dentro de un rango de desempeño que oscila entre las 3.000 y las 6.500 toneladas totales. La llamativa reducción del total de capturas se vincula a la disminución en las toneladas desembarcadas por la flota de altura, lo cual se explica por la mayor concentración de la operatoria pesquera en Mar del Plata y la Patagonia y que estos desembarques provinieron de una flota que no estaba vinculada a Puerto Quequén como puerto base. Por el contrario, el nivel de desembarques de la flota costera permaneció entre las 3.000 y las 4.800 toneladas sin mostrar grandes variaciones a lo largo de los años. Incluso yendo más atrás en el tiempo, como se deduce de la Tabla №7, para 1980 los desembarques costeros también se ubicaron dentro de 
esos valores. Si bien este número está muy por detrás de las 15.000 toneladas pescadas por la flota costera quequenense para el año 1972, no explica de por sí el desguace del sector industrial ligado a la flota costera en el período post 70.

Por otra parte, si nos ubicamos con anterioridad al 2001 vemos que la flota de altura aumentó significativamente la cantidad de pescado desembarcado en el puerto local. Realizando un análisis más fino de las extracciones de los distintos tipos de buques de altura, vemos que entre 1990 hasta el año 2001 -cuando descienden drásticamente las capturas ligada a la flota de altura- la gran mayoría de los desembarques correspondían a la flota congeladora. Luego, también se desempeñaban a nivel local barcos poteros, tangoneros y -en mucho menor medidapalangreros. Después del 2001 prácticamente desapareció la actividad de la flota congeladora en Puerto Quequén, donde continuó la actividad de buques poteros y comenzaron a aumentar significativamente las capturas de los barcos fresqueros, los cuales desde 2007 y hasta 2012 representaron prácticamente el total de extracciones de la flota de altura (MINAGRI, 2014).

Recapitulando, los valores numéricos de las capturas de la flota costera a nivel local no explican de por sí el cierre progresivo de todas y cada una de las plantas procesadoras pesqueras de Necochea y Quequén. De hecho, se observa que el volumen extractivo de conjunto creció entre 1962 y el año 2000. Recién a partir del año 2001 comienza el descenso de los desembarques que se vuelve francamente notorio desde 2002 hasta el 2012. Sin embargo, el desguace del sector industrial pesquero inició en los primeros años de la década del 80, como vimos anteriormente.

De aquí que nos surge la pregunta: ¿Cuál fue el destino de la gran mayoría de las capturas desembarcadas en Puerto Quequén a partir de los 70? Varios de los trabajadores de la pesca entrevistados nos responden la pregunta con la misma afirmación: "El 90\% del pescado se va para Mar del Plata". Aquí entra en juego la división y concentración de la operatoria portuaria, por la cual el Puerto de Mar del Plata y las empresas ligadas a esta localidad industrializan y/o exportan la mayor parte del pescado que arriba a Puerto Quequén. Por ello, se concluye que el potencial extractivo de este puerto no ha disminuido, y que el desguace de la rama industrial en la ciudad no es producto de ello sino de las decisiones imbricadas en las políticas propias de la reestructuración capitalista/neoliberal y su impacto en el sector a nivel local.

Es así que, con el correr de las décadas, para 2012 investigadores de la Estación Hidrobiológica de Puerto Quequén lo describen de la siguiente manera: "Puerto Quequén ( $S 48^{\circ} 40$ - $058^{\circ} 50$ ) es, principalmente, un puerto exportador de granos, que además alberga una pequeña flota de embarcaciones categorizadas como costeras y de rada o ría, cuya principal actividad es la pesca denominada "variado costero" utilizando como arte de pesca la red de arrastre de fondo con portones" (Pérez Comesaña y Nogueira, 2013:185). En este mismo estudio, se señala que el número total de embarcaciones de la flota costera "declinó de 26 barcos 2000 y 2002 a 16 barcos en el año 2010” (186). Seguidamente, de acuerdo a las entrevistas 
realizadas entre 2013 y 2014, para esos años habría descendido a 4 el número de embarcaciones costeras en Puerto Quequén ${ }^{8}$.

Otra de las explicaciones que tanto los trabajadores como la dirigencia gremial local del rubro dan sobre la disminución de la actividad extractiva pesquera es el alto precio de la estiba de los cajones de pescado desembarcados. El costo local de este servicio de descarga sería entre 3 y 4 veces más caro que el del Puerto de Mar del Plata, lo que de acuerdo a los actores genera que los barcos pesqueros "elijan otro puerto" ${ }^{\prime}$. También el alto precio del gasoil provocaría la falta de rentabilidad de la pesca local ${ }^{10}$.

La reestructuración capitalista, con la concentración y centralización que conlleva sumada a la división y especialización en la operatoria portuaria-, situó a Puerto Quequén como un enclave casi exclusivamente cerealero'11, mientras que Mar del Plata continuó con su rol de puerto pesquero. Las razones por las que los obreros explican la disminución de la pesca costera y de altura en Puerto Quequén están ligadas a la división y concentración de la operatoria portuaria producto de la decisión conjunta entre los gobiernos y las grandes empresas, que en el contexto de la reestructuración capitalista impusieron una creciente especialización portuaria hacia determinadas actividades económicas en detrimento de la diversificación (en Puerto Quequén siempre ha existido actividad ligada al agro, pero hasta los 70 conviviendo de forma pacífica con la actividad pesquera). Por esta decisión política, la pesca se radicó casi con exclusividad en los Puertos de Mar del Plata y la Patagonia, y de hecho la escasa actividad pesquera que perdura en otras localizaciones portuarias, como el caso de Necochea, está en su mayoría al servicio de los grandes grupos económicos, que son los compradores de la mayoría del pescado aquí extraído. Luego, Puerto Quequén quedó fuertemente ligado al sector agroexportador, en el que, a diferencia del rubro pesquero, la descarga de cereal se realiza de forma predominantemente mecanizada. En este rubro la maquinaria ha suplido enormemente a la fuerza de trabajo humana, por lo que los costos de la estiba del pescado no afectan a este sector. La preferencia empresarial por uno $\mathrm{u}$ otro puerto radica en los costos administrativos y logísticos que determinan los Consorcios de Gestión. Se habla de "puerto sucio" cuando estos costos están por encima de una media razonable, y por este motivo, como expresan los trabajadores, Quequén es considerado un puerto sucio. Sin embargo, en comparación con otros puertos, su calado permite el ingreso de las embarcaciones de mayor porte, lo que le otorga una condición de favorabilidad actualmente aprovechada por el sector cerealero.

El desalojo pesquero local con la correlativa relocalización de la extracción pesquera en Mar del Plata y la Patagonia se realizó por medio de diferentes mecanismos: la diferenciación de los costos del capital fijo en los distintos enclaves portuarios y la

\footnotetext{
8 Entrevista a Roque, pescadero necochense, realizada en abril de 2014.

${ }^{9}$ Entrevista grupal a La Recuperada, realizada en febrero de 2014.

10 Entrevista grupal a La Recuperada, realizada en octubre de 2013.

11 Entrevista a Guillermo Daniel, realizada en abril de 2017.
} 
ausencia de medidas proteccionistas para los pescadores y la industria en las localizaciones en donde el desarrollo del sector pesquero era de menor envergadura. Si bien de acuerdo a los estudios de Pérez Comesaña y Nogueira (2013:183) varios indicadores llevan a pronosticar un agotamiento en términos ecológicos por el cual la pesca ya no sería sustentable, esta predicción aún no se ha comprobado y la situación es variable dependiendo de qué especie se trate -por ejemplo, la anchoíta sigue siendo excedentaria (Mateo y Yunkevich, 2010). A su vez, dada la posterior disminución en el número de embarcaciones operando en Puerto Quequén, las características de su biomasa seguramente presentarán variaciones con respecto a los primeros años del tercer milenio.

Continuemos ahora con el desglose del proceso de concentración empresarial acaecido en la industria pesquera nacional.

\subsection{Proceso de concentración:}

De acuerdo con Agustín Nieto (2014) si bien se modificaron los valores absolutos con el correr de las décadas, la actividad pesquera siempre se caracterizó por su marcada tendencia a la concentración en pocas firmas, de aquí que tanto en los 40 como en los 90 "las primeras diez empresas concentraron entre un 60\% y un $80 \%$ de la producción pesquera de la provincia" (2014: 339). Datos del trabajo de Allen (2010) exhiben para el año 1974 un total de 30 grandes empresas marplatenses mientras que en el 2001 "seis grandes firmas concentraban el proceso local de captura y comercialización, subcontratando la mayoría del proceso productivo a manos de cooperativas de trabajo" (Allen, 2010: 158).

Los resultados de las investigaciones de Mateo, Nieto y Colombo (2010) también refieren el incremento en la monopolización del sector por parte de cuatro grandes grupos económicos de la pesca, firmas que se presentaban como "integradas" en 1997 y que participaron previamente en los acuerdos de charteo y conformación de sociedades mixtas con capitales extranjeros, fundamentalmente de la CEE. Estos grupos económicos, cuyas firmas son Barilari, Solimeno, Moscuzza y Valastro S.A., incrementaron su productividad y extracción de plusvalía recurriendo a la incorporación de tecnología, la modernización de la flota y la diversificación vertical y horizontal, implementando también la tercerización de fuerza de trabajo a través de cooperativas fraudulentas; poseen capital tanto en Mar del Plata como en la Patagonia y concentran 17 empresas, al menos 3.200 trabajadores y 44 buques (Mateo, Nieto y Colombo, 2010).

El crecimiento de estos "pulpos pesqueros" tiene como contrapartida la quiebra masiva de firmas más pequeñas que se produjeron desde los primeros años de la década de los 90 en la ciudad de Mar del Plata, como sucedió con las empresas Ventura, Arpemar, Estrella de mar, Tomar de Tobo, Pesquera San Andrés, Antonio D’Antonio Pesquera, Alfe Trade, Pesquera Bolívar, Mediterráneo y Frigocen, entre otras (Pradas, 2006). 
Si a estos datos incorporamos el cierre del universo total de la veintena de empresas pesqueras necochenses entre la década del 70 y el año 2012, vemos entonces cómo la condensación de la industria pesquera marplatense con la correlativa evaporación en Necochea es parte de una reestructuración capitalista que precarizó la fuerza de trabajo y aumentó la productividad y el extractivismo. Estas dos últimas características las constatamos observando la evolución de las exportaciones de productos pesqueros y del volumen de las capturas, información que se vuelca a continuación:

Tabla №9. Exportaciones argentinas de productos pesqueros, períodos 1978-1984, 1993-1997 y 2001-2012:

\begin{tabular}{|c|c|c|c|}
\hline AÑO & $\begin{array}{c}\text { Toneladas } \\
\text { exportadas }\end{array}$ & $\begin{array}{c}\text { Total } \\
\text { exportaciones } \\
\text { (en miles de U\$s) }\end{array}$ & $\begin{array}{c}\text { Precio por } \\
\text { tonelada } \\
\text { (en miles de U\$s) }\end{array}$ \\
\hline 1978 & 216.075 & 159.075 & 0,73 \\
\hline 1979 & 248.714 & 213.791 & 0,85 \\
\hline 1980 & 161.338 & 142.966 & 0,88 \\
\hline 1981 & 147.298 & 134.414 & 0,91 \\
\hline 1982 & 232.035 & 184.896 & 0,79 \\
\hline 1983 & 198.411 & 177.294 & 0,89 \\
\hline 1984 & 124.763 & 149.108 & 1,19 \\
\hline \multicolumn{4}{|c|}{} \\
\hline 1993 & 476.627 & 709.300 & 1,48 \\
\hline 1994 & 536.216 & 727.000 & 1,35 \\
\hline 1995 & 582.577 & 917.200 & 1,57 \\
\hline 1996 & 671.672 & 1.010 .900 & 1,50 \\
\hline 1997 & 687.944 & 1.033 .100 & 1,50 \\
\hline \multicolumn{5}{|c|}{} \\
\hline 2001 & 453.515 & 895.111 & 1,97 \\
\hline 2002 & 456.431 & 781.382 & 1,71 \\
\hline 2003 & 487.183 & 886.211 & 1,81 \\
\hline 2004 & 494.220 & 816.623 & 1,65 \\
\hline 2005 & 495.580 & 810.565 & 1,63 \\
\hline 2006 & 627.469 & 1.248 .804 & 1,99 \\
\hline 2007 & 540.367 & 1.104 .018 & 2,04 \\
\hline 2008 & 561.601 & 1.299 .282 & 2,31 \\
\hline 2009 & 484.816 & 1.118 .742 & 2,30 \\
\hline 2010 & 456.471 & 1.321 .874 & 2,89 \\
\hline 2011 & 471.169 & 1.490 .053 & 3,16 \\
\hline 2012 & 431.668 & 1.332 .558 & 3,08 \\
\hline \multicolumn{4}{|c|}{} \\
\hline
\end{tabular}


Gráfico №4. Exportaciones argentinas de productos pesqueros en toneladas y en miles de U\$S, en relación al precio por tonelada exportada. Períodos 1978-1984, 1993-1997 y 2001-2012:

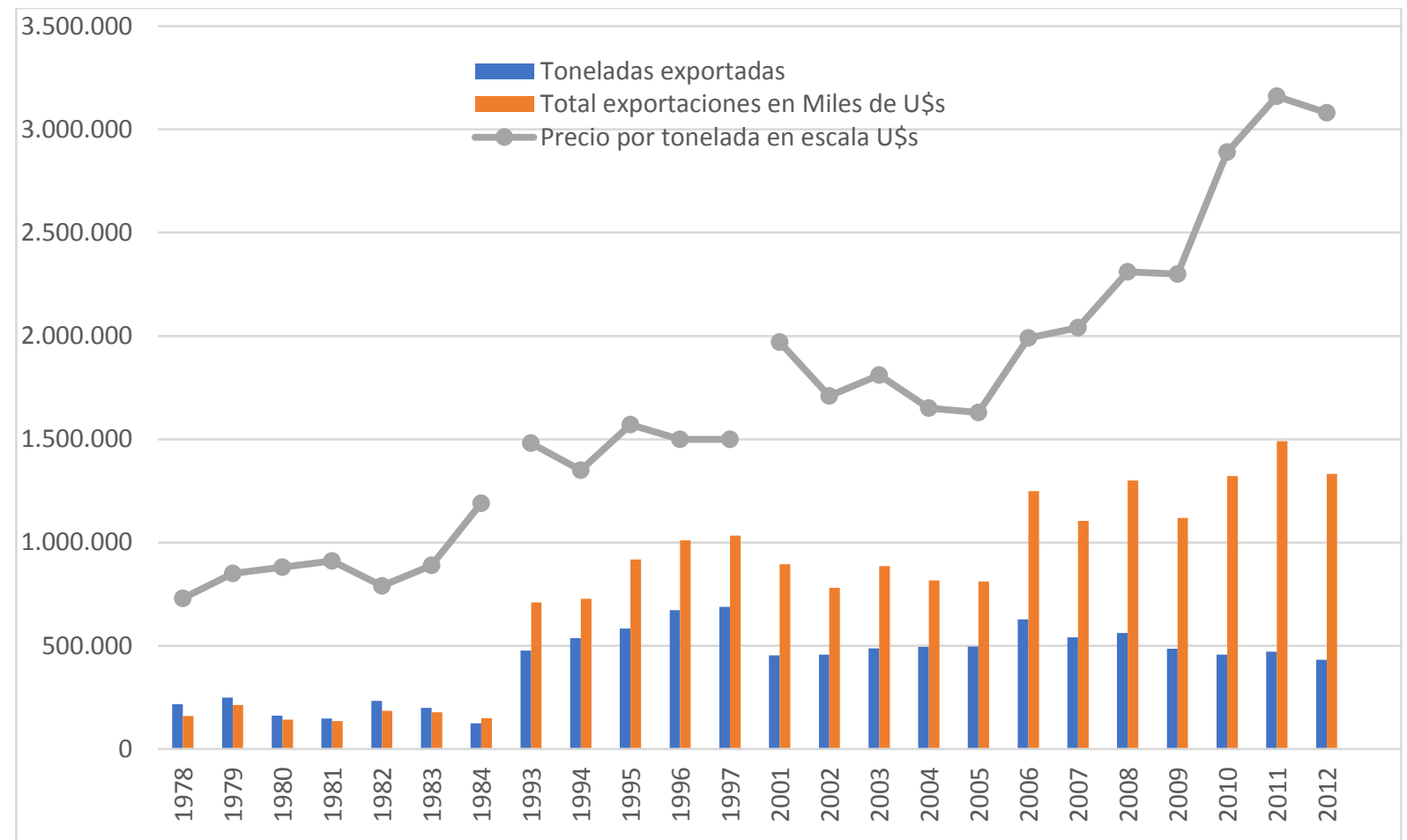

Fuentes: Período 1978- 1984, elaborado en base a datos de Bertolotti, I. Piergentili, G. y Cabut, D. (1987); período 1993-1997, elaborado en base a datos del Ministerio de Agricultura, Ganadería y Pesca y el INDEC; período 2001-2012, elaborado en base a datos del Ministerio de Agricultura, Ganadería y Pesca.

Este gráfico muestra que, si bien con algunos altibajos propios del funcionamiento del comercio mundial, el precio de la tonelada de pescado exportado fue en aumento creciente hasta cuadriplicarse entre 1978 y 2012. También se incrementaron las toneladas exportadas, pero aquí la curva guarda una diferencia importante: en primer lugar, en los primeros años de la década del 80 no se alcanzó el volumen exportado a finales de los 70, pero en los 90 estos valores se superaron ampliamente, llegando a representar para 1997 un aumento del $276 \%$ con respecto a la cifra más alta anteriormente alcanzada en 1979. En segundo lugar, las toneladas tendieron a descender en los últimos años, solo el año 2006 logró una performance similar a la de la década del 90, consiguiendo las 600.000 toneladas exportadas. Esto se corresponde con la sobrepesca y escasez del recurso pequero, no obstante lo cual no han mermado las ganancias empresariales al subir el precio de los productos pesqueros de exportación. Al respecto, una publicación oficial del Ministerio de Agricultura, Ganadería y Pesquera - la Revista alimentos Argentinos- señalaba en un informe referido al comercio pesquero mundial que: "El valor del comercio mundial del pescado y productos pesqueros ascendió a 58.200 millones de dólares en 2002 , un $5 \%$ más que en 2000 y un $45 \%$ más que en 1992 . El volumen de estas 
exportaciones fue de 50 millones de toneladas, lo que implica un crecimiento del $40,7 \%$ desde 1992, pero un ligero descenso (1\%) respecto a 2000. Es interesante señalar que, tras decenios de gran crecimiento, el volumen del pescado comercializado se ha mantenido relativamente estable en los últimos años"12. Estos datos permiten inferir que la escasez del recurso pesquero es un problema que se presenta no solo a nivel nacional, sino mundial, el cual hasta el momento no ha afectado fuertemente la rentabilidad de la industria pesquera pero cuyo destino es impredecible en gran medida.

Luego de haber sintetizado las cuestiones referidas a las condiciones objetivas de la industria pesquera bonaerense y específicamente de los puertos de Mar del Plata y Quequén/Necochea, resituaremos ahora el análisis desde las subjetividades obreras, y por ello, comenzaremos reflexionando sobre el lugar del trabajo en la sociedad actual.

\section{Entre la desocupación y la precarización laboral: El proceso de trabajo y los trabajadores de la industria pesquera argentina post reestructuración capitalista}

A partir de la reestructuración capitalista iniciada en los 70 se modificó la modalidad empresarial y su formato de trabajo unilateral, estandarizado, parcelado, fetichizado, cosificado y maquinal, se redujo la fuerza de trabajo viva y amplió la productividad, re-territorializando y des-territorializando el mundo productivo. El cambio en el proceso de trabajo estuvo determinado por varios factores postreestructuración capitalista, tales como la necesidad de aumentar la producción sin aumentar el número de trabajadores, reducir los tiempos de trabajo y producir solo lo necesario, la expansión internacional y a la vez la búsqueda de las grandes empresas de absorber también el mercado interno con productos diferenciados y pedidos pequeños (Antunes, 2005:35). Los resultados de estas transformaciones incluyen el desempleo explosivo, la precarización estructural del trabajo, rebajas salariales y pérdida de derechos, los cuales afectan a la fuerza de trabajo en general y en cada sector en particular. Veamos ahora el impacto de estas transformaciones en el universo específico del trabajo en la industria pesquera, focalizándonos luego en los trabajadores de las ciudades portuarias estudiadas.

12 Extracto de la Revista alimentos argentinos №29

http://www.alimentosargentinos.gob.ar/contenido/revista/html/29/2930 pesca exportacion adj graf.htm 


\subsection{Características del proceso de trabajo y de las subjetividades obreras de la industria pesquera argentina}

El proceso de trabajo es conceptualizado por Marx como una actividad humana orientada a un fin específico, el de la producción de valores de uso, por la cual el obrero crea un producto a partir del medio de trabajo y de sus operaciones sobre aquel. Este producto tiene un valor de uso específico, que al actuar como mercancía para el capitalista se convierte en un valor de cambio:

El proceso de trabajo es también el proceso de consumo de la fuerza de trabajo, tomada ella misma como mercancía comprada por el capitalista. Este consumo de la fuerza de trabajo no es más que el trabajo real y efectivo, de aquel que transforma materia y produce productos que satisfacen necesidades, del que implica el gasto de todo un conjunto de facultades físicas y mentales por parte del trabajador con el fin de generar, fundamentalmente, más valor que el que se ha vertido en él (Marx, 1867:190).

Este proceso de producción es regulado por el capitalista, el obrero trabaja bajo su control a fin de garantizar la mayor productividad posible y el menor desperdicio de capital:

...todos los ramos de la industria operan con un objeto que es materia prima, esto es, con un objeto de trabajo ya filtrado por la actividad laboral, producto él mismo del trabajo (...) Lo que en el trabajador aparecía bajo la forma de movimiento, aparece ahora en el producto como atributo en reposo, bajo la forma del ser. El obrero hiló, y su producto es un hilado (Marx, 1867:195).

Entonces, en el proceso de trabajo se incluyen todas las tareas realizadas por el trabajador para elaborar un determinado producto en el marco de determinadas condiciones de trabajo específicas. Desarrollaremos ahora sus características distintivas dentro de la industria pesquera para la producción de pescado fresco, congelado, conservas y salazón.

Cabe aclarar que, del conjunto de tareas laborales que puede desempeñar un obrero industrial pesquero, nos centraremos aquí en el puesto de filetero y dejaremos de lado por el momento las transformaciones en las tareas y condiciones de trabajo propias de los puestos de peón y envasador/empaquetador, que en conjunto con el fileteado conforman el grueso de las fuentes laborales involucradas en el procesamiento pesquero. Esta elección se basa en la pertinencia del puesto seleccionado para exponer con mayor claridad el modo en que la disponibilidad del recurso natural y las formas que asume la relación capital/trabajo modifican las condiciones laborales. Del resto de los puestos de trabajo implicados en la producción haremos una breve mención a fin de brindar un panorama íntegro del proceso de trabajo en la industria pesquera.

Anteriormente expusimos que la producción de filetes frescos enfriados comenzó a producirse en Mar del Plata a partir de la década del 60, cuando la merluza se 
convirtió en uno de los recursos más importantes del mar argentino (Mateo, Nieto y Colombo, 2010) y su extracción se vio acrecentada por el incremento del peso específico de la flota de altura, lo cual a su vez se conjugó con las renovaciones tecnológicas necesarias para almacenar y transportar el producto a mercados nacionales y -fundamentalmente- internacionales. Una vez que el pescado es extraído, ya en las embarcaciones se les coloca hielo, se lo descarga en el puerto colocándose en cajones de plástico, y finalmente es trasladado a las plantas procesadoras en camiones que cuentan con equipamiento apto para conservar congelada la materia prima. Aquí los peones se encargan de colocarlo en las cámaras de enfriamiento o congelado y también de trasladarlo hacia el sector en donde será procesado. Si bien hay maquinaria para realizar el fileteado, en la gran mayoría de los casos esta tarea se realiza en forma manual y se basa en aptitudes para el uso técnico del cuchillo; hasta el momento la mano humana es la que puede realizar mejor esta tarea, no encontrando aún efectivo reemplazo en la maquinaria por la fina destreza requerida tanto para el emprolijamiento del filet como para la evitación de desperdicios innecesarios.

El filetero trabaja de pie en una mesa alargada que se comparte con otros pares, quienes realizan en forma simultánea la misma tarea. A veces se apoya sobre una estructura elevada del ras del suelo, debido a que el piso suele estar mojado permanentemente por el continuo paso de agua. Los instrumentos de trabajo utilizados consisten en un cuchillo que mide $20 \mathrm{~cm}$ aproximadamente, una tabla generalmente de plástico en la que se corta el pescado y un guante con el que se lo sostiene. Su ropa de trabajo incluye las prendas camisa, pantalón y gorro blancos, un guardapolvo de plástico del mismo color y botas de goma.

El procedimiento del fileteado consiste en cortar la cabeza del pescado, la espina dorsal y las tripas con un movimiento del cuchillo que generalmente va desde la cabeza a la cola. Luego se recorta la aleta dorsal y la cola, obteniendo dos filetes por pieza de pescado. Esto se realiza sobre una mesa con canillas constantemente abiertas, que dejan correr agua fría con la cual se van limpiando las piezas obtenidas. Los desechos se descartan generalmente en el mismo cajón en el que llegó el pescado, o bien en una canaleta ubicada bajo las mesas de trabajo. El último procedimiento consiste en quitar el cuero de los filetes, los cuales una vez listos son colocados en una bandeja. Las mismas, una vez completas, son trasladadas por los peones hasta el sector de envasado y empaque.

La tarea de fileteado consiste en una operación monótona y repetitiva, en un ambiente frío y húmedo, ya que las recomendaciones bromatológicas indican que el producto no se aleje de $0^{\circ} \mathrm{C}$ en todo el proceso. Al estar de pie, el obrero involucra todo su cuerpo en la tarea, con especial compromiso de los músculos, articulaciones y tendones de la extremidad superior y la mano que utiliza para cortar el pescado, que realizan una secuencia de cuatro movimientos que se produce entre 250 y 500 veces por hora alternados con tareas complementarias como el lavado, vuelco del cajón sobre la mesa, y retiro de los desperdicios: 
La operación de fileteado es efectuada con gran rapidez, produciendo el operario una serie de movimientos vivos y de corto recorrido. El cuerpo recto, volcando sobre su mayor peso sobre la pierna derecha, mientras la cabeza permanece inclinada observando fija y atentamente la labor de las manos (Ministerio de Trabajo y Seguridad Social y P.I.A.C.C.T - O.I.T., 1986).

De acuerdo a trabajadores de Industrial pesquera, la interacción entre los trabajadores es mínima durante las horas de fileteado: se requiere gran atención y focalización en la tarea, además de la presencia de capataces y de cámaras filmadoras dispuestas justamente para evitar cualquier pérdida de tiempo de trabajo y también robos de mercadería -estos últimos son frecuentes en la industria pesquera como método de resistencia cotidiana a la explotación (Nieto, 2014).

Cabe destacar que los peones cobran por hora de trabajo -no por kilo, como los fileteros, ya que no procesan el pescado-, y en general perciben un salario significativamente inferior, lo cual también contribuye a la división obrera.

En diversos testimonios de trabajadores de la ex-Industrial Pesquera se expone el disciplinamiento fabril bajo el cual los obreros realizaban sus tareas, y también las maniobras empresariales para fragmentar a los trabajadores mediante el propio proceso de trabajo. Por un lado, operaba una división física de los obreros mediante la asignación de sectores de trabajo no compartidos, diferenciados a su vez de las oficinas de la patronal y los administrativos; también la asignación de tiempos de descanso separados para fileteros y peones, que impedía "compartir los mates" y vincularse más allá de la tarea a realizar. La diferencia de criterio para el cobro de los salarios (los fileteros cobraban a razón de los kilos producidos mientras que los fileteros lo hacían por hora de trabajo) se traducía en salarios mucho mayores para fileteros con respecto a los peones, llegando incluso a duplicarlos. A su vez, operaba una diferenciación en cuanto a derechos laborales y "beneficios" para ambos grupos obreros, como por ejemplo el otorgamiento de ropa de trabajo para los fileteros y no para los peones, o la obligatoriedad en la realización de horas extras para el caso de los peones ${ }^{13}$. Por otro lado, se observa que la tarea del fileteado se aprende en el mismo lugar de trabajo y es común que los peones al cabo de meses o años pasen a ser fileteros, como el caso de Darío. Por este motivo entra en juego también una verticalidad ligada a la antigüedad laboral y una competencia intraobrera basada en estadios impuestos por la patronal, por los cuales en primer término las condiciones de trabajo son más precarias y perjudiciales, y luego cuando el peón se convierte a ser filetero este pasaje es tomado como una suerte de premio de ascenso, y ello justifica no solo el mayor salario sino el otorgamiento de garantías y derechos laborales que, de acuerdo al convenio vigente en la rama, son propias de ambos puestos de trabajo. Estas condiciones diferenciadas de trabajo, junto con el aprendizaje que requiere la técnica del fileteado, operan en el plano subjetivo generando una consideración de inferioridad adjudicada a los peones con respecto

${ }^{13}$ Entrevista grupal a La Recuperada, octubre de 2013. 
a los fileteros ${ }^{14}$, y desde este posicionamiento se justifica la división obrera al interior de la planta.

Enfocándonos ahora en la industria conservera y la salazón, ésta tiene raíces anteriores al procesamiento fresquero, como vimos anteriormente. Para nuestro caso, puntualizaremos las etapas del proceso de producción propio de la industrialización de anchoas, ya que una de las empresas recuperadas necochenses estudiadas realiza este tipo de procesamiento. Para los trabajadores de las cooperativas fraudulentas de Mar del Plata y la restante empresa recuperada necochense cabe el proceso de trabajo descripto más arriba, ya que realizan en su conjunto tareas de procesado y fileteado de pescado fresco.

En cuanto al sector conservero, cabe destacar que las labores implicadas en este tipo de producción pesquera han sido tradicionalmente realizadas por mujeres. Desde comienzos del siglo XX las esposas de los pescadores efectuaban la salazón de determinadas especies en sus hogares, y fueron esas mismas mujeres las que luego formaron parte de la mano de obra de los primeros saladeros y también de la industria procesadora en general (Molinari, 2008). Con el correr de los años, siguieron siendo las mujeres la fuerza de trabajo mayoritaria de la industria de la conserva y la salazón -cuyas plantas procesadoras empleaban entre un 80 y $90 \%$ de personal femenino (Ruocco, 2010), para lo cual se han hallado diversas explicaciones. En primer lugar, la referida a la desvalorización del trabajo femenino (Molinari, 2008, Ruocco, 2010), que se traducía en sueldos más bajos para las mujeres en relación con los de los varones, lo que suponía una mayor extracción de plusvalía por parte del empresario que, por conveniencia, reclutaba personal femenino. En los trabajos consultados se observa que para el año 1942 un peón especializado cobraba $\$ 7$ pesos la hora mientras que una obrera cobraba $\$ 4,50$. Luego, según el Convenio laboral de la rama para el año 1948, los obreros adultos varones tenían un salario diario de $\$ 18,50$, mientras que los niños y las mujeres adultas percibían $\$ 12$ por día, y las niñas obreras $\$ 6,30$ diarios. Para 1957 , mientras que un obrero percibía por hora $\$ 73,60$, una trabajadora cobraba $\$ 52,80$ (Molinari, 2008, Ruocco, 2010).

Otra de las razones por las que se dedujo el predominio de trabajo femenino en esta subrama de la industria pesquera fue que la misma requiere de cualidades vinculadas a la paciencia y la minuciosidad para enlatar el pescado "condiciones que eran aceptadas como propias de la mujer" (Molinari, 1998:2). Queda pendiente la demostración de la mejor aptitud de las mujeres para la manipulación de anchoíta y otras especies pequeñas en relación con sus pares varones, ya que los mismos han demostrado ser más efectivos en el fileteado de las especies de la industria fresquera de acuerdo a estudios de Ruocco (2010). Las especies del procesado de pescado fresco son significativamente más grandes que las anchoas, por lo que restaría investigar el vínculo entre la efectividad del fileteado y aptitudes diferenciadas de acuerdo al género y el tamaño de la pieza de pescado.

${ }^{14}$ Entrevista grupal a La Recuperada, realizada en octubre de 2011. 
El proceso de trabajo específico para la anchoíta comienza con la inspección de pesca, compra y traslado a la planta de la materia prima, luego de lo cual ésta es descargada para su manipuleo, lavado, descamado y salado preliminar por un período que oscila entre 24 horas -mínimo- y 10 días -máximo- (Bertolotti y Manca, 1986). Seguidamente se procede al descabezado, eviscerado, salado y maduración del producto. En el caso del salado, los filetes son colocados en toneles entre capas de sal, para su conservación (Nieto, 2014). Luego se lleva a cabo el "sobado", que consiste en la eliminación de la piel de la anchoíta y de restos que no se utilizan para el consumo; a lo que le sigue el fileteado y emprolijado del producto. Por último, se realizan las tareas de envasado, agregado de aceite y cierre de latas y frascos, los cuales luego de ser lavados, son embalados y almacenados en cámaras de frío. Aquí el producto ya está listo para su embarque en los contenedores y los controles sanitarios internos y del SENASA, y requiere un período de estacionamiento de entre 5 y 6 meses para alcanzar su completa maduración (Bertolotti y Manca, 1986).

Vemos aquí que, tomados en forma conjunta, ambos procesos de trabajo ligados al procesamiento pesquero se basan en el régimen de manufactura y cooperación simple, dada la importancia del trabajo con herramientas manuales por sobre el uso de la maquinaria, por lo que el factor subjetivo contiene un alto valor en este tipo de industria. Si bien en el proceso de trabajo actual se imbrican estos elementos con los propios de la gran industria -por el uso de diversas maquinarias durante todo el proceso, más allá del momento del fileteado-, el régimen de gran industria no ha podido imponerse, por la ineficacia de la maquinaria para suplir la productividad del trabajador que filetea de forma manual con su cuchillo. En este sentido, distintos autores conceptualizan al fileteado como un "semi-oficio", el cual si bien implica una especialización y una destreza con herramientas manuales que se va perfeccionando a lo largo del tiempo, no requiere un extenso período de aprendizaje ni una alta cualificación.

En contraposición al régimen de trabajo artesanal, la manufactura comparte con la gran industria una doble vía para aumentar la productividad en el trabajo: la mayor intensidad en la realización de la tarea y el descenso de los "tiempos muertos" o improductivos de la fuerza de trabajo. Por ello, por las características del tipo de trabajo, las estrategias del empresariado para lograr el mayor rendimiento y productividad posibles y aprovechar al máximo los ritmos y tiempos de producción, consisten en el pago por productividad o pago a destajo, es decir, por kilo producido. Esta forma de pago, legalizada en los convenios colectivos de trabajo de la rama de los años 1966 y 1975, que perdura hasta la actualidad, en conjunto con la atomización de la organización productiva son los mecanismos de disciplinamiento obrero en el proceso de producción de la industria pesquera (Lanari, 2010). A través de los mismos el obrero es impelido a trabajar con mayor intensidad, filetear mayor cantidad de pescado y en el mayor tiempo posible -extendiendo la jornada laborala fin de ganar más, provocando para el empresario un aprovechamiento mayor de la extracción de plusvalía absoluta y relativa. 
De aquí que, para el obrero, la velocidad se ubica en conjunción con la destreza como cualidades laborales para obtener mayores remuneraciones en una determinada cantidad de tiempo, ya que no solo se requiere filetear aprovechando lo más posible la cantidad de pescado por filet sino realizarlo lo más rápido posible para obtener más kilos de pescado procesado, lo que da la medida de sus ingresos. La incidencia de la velocidad también provoca que los obreros más "rápidos" impongan los ritmos de producción al conjunto de trabajadores, y que también terminen fijando el precio del kilo procesado generando una media de productividad que el empresariado toma como base para el cálculo salarial. A su vez, ese "piso" salarial es utilizado para deducir la reducción salarial de los trabajadores que se desempeñan en negro, en el régimen cooperativa o el trabajo temporario, que cobran en proporción menos que el filetero registrado.

Antes de continuar, no queremos dejar de mencionar las enfermedades y los efectos en el cuerpo como resultado del desempeño obrero en la industria pesquera a través del tiempo. Es común que al dialogar con fileteros y fileteras acerca de su trabajo, lo primero que hagan sea exhibir sus manos, refiriendo los numerosos accidentes, cicatrices, malformaciones y dolores que padecen.

Schulze (2014) destaca el desgaste de los cuerpos obreros producto de su consumo como fuerza de trabajo en la industria pesquera, los cuales padecen malestares ligados a enfermedades tales como: tenosivitis, síndrome del túnel carpiano, quistes sinoviales de los extensores, artrosis, lumbalgias, várices, edemas de pies y piernas, espolón calcáneo, maceración de la piel, fisuras traumáticas, fisuras de los pliegues, dermatitis, alergias, trastornos vasculares periféricos en las manos, conjuntivitis irritación de vías respiratorias, catarros estacionales, cuadros bronquiales, enfermedades auditivas, entre los más frecuentes (Mateo, Nieto y Colombo, 2010: 262-263). A estas enfermedades cabe añadir la gran cantidad de accidentes originados por el uso de herramientas como el cuchillo, los cuales provocan desde cortes en las manos y brazos de los obreros hasta mutilaciones en dedos.

\subsection{Cambios en la fuerza de trabajo partir de 1970}

Analicemos ahora los cambios en fuerza de trabajo ocupada en el sector industrial pesquero durante las últimas décadas, de acuerdo a los registros oficiales, bibliográficos y los obtenidos a partir de los testimonios de los propios actores. Descontando a los trabajadores incluidos en las cooperativas fraudulentas, observamos que la fuerza de trabajo asalariada y registrada en la industria pesquera bonaerense -de acuerdo al Censo Nacional Pesquero del INIDEP de 1996- descendió en un $42 \%$ con respecto a 1982. En la siguiente tabla se muestra la disminución en la cantidad de puestos de trabajo en forma desagregada por rubro: 
Tabla №10. Cantidad de trabajadores de la industria pesquera bonaerense desagregada por tipo de establecimiento industrial, años 1982 y 1996:

\begin{tabular}{|c|c|c|c|}
\hline & \multicolumn{2}{|c|}{$\begin{array}{l}\text { Número de trabajadores } \\
\text { ocupados }\end{array}$} \\
\hline & & Año 1.982 & Año 1.996 \\
\hline \multirow{9}{*}{ 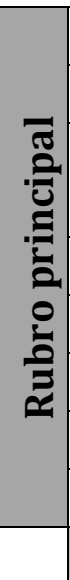 } & Plantas de procesado, fileteado y congelado & 4.875 & 2.951 \\
\hline & Plantas de procesado y fileteado & 1.347 & 376 \\
\hline & $\begin{array}{l}\text { Plantas de elaboración de conservas y } \\
\text { semiconservas }\end{array}$ & 1.445 & 762 \\
\hline & Saladeros* & 613 & 707 \\
\hline & Plantas de elaboración de harina de pescado & 128 & 106 \\
\hline & Otros & 4 & - \\
\hline & Subtotal & 8.412 & 4.902 \\
\hline & Cooperativas fraudulentas & - & 3.303 \\
\hline & Total trabajadores ocupados & 8.412 & 8.205 \\
\hline
\end{tabular}

Fuente: Elaborado en base a datos de Bertolotti y col. (1987) y Censo Nacional Pesquero (1996).

* De acuerdo al padrón censal y al trabajo consultado, del total de trabajadores ocupados en saladeros solo una cifra cercana al 50 \% se desempeña como personal estable, mientras el resto lo realiza en forma temporaria. En dicho padrón se encuentra desagregado el mismo dato para el resto de los establecimientos industriales, pero el porcentaje de trabajadores temporarios es insignificante, cuando no inexistente.

Observamos la pérdida de 2.895 puestos de trabajo dentro de los rubros de procesado, fileteado y congelado, a los que agregando los 683 del sector de conservas y semiconservas, en su conjunto suman 3.578 puestos de trabajo perdidos entre los años 1982 y 1996. Aquí nuevamente introducimos la categoría de cooperativas de trabajo para volver a constatar que el grueso de las fuentes laborales perdidas corresponde a la fuerza de trabajo asalariado registrada, ya que en el año 1996 se desempeñaban 3.303 trabajadores en las cooperativas -cuyo rubro principal es el de procesado y fileteado-. Si se suman estos obreros cooperativizados al resto, en total se contabilizan 8.205 ocupados en el sector para el año 1996, 207 menos que en 1982, lo que representa una disminución del 2,5\%. Considerando este período, entonces, la disminución de puestos de trabajo no es tan significativa en cuanto a la cantidad sino en relación con la calidad de los mismos, ya que al menos un $40 \%$ se encuentra cooperativizado/tercerizado y, por lo tanto, precarizado. Datos más actuales muestran que para octubre de 2012 el número de trabajadores en negro o "cooperativizados" fue del 67\% (Garrone, 2012) ${ }^{15}$. Este aspecto se vincula también con el despido y la posterior recontratación de los trabajadores bajo el régimen de cooperativización fraudulenta, luego del cierre por quiebra de varias firmas marplatenses a principios de los 90, cuando quedaron

15 Garrone , R. "67\% de informalidad en otro operativo en la pesca marplatense”, Revista Puerto, Octubre de 2012. 
desocupados más de 6.000 trabajadores de la industria pesquera (Pradas, 2006). Un importante porcentaje de este grupo es el que luego pasó a desempeñarse en las cooperativas.

Tomando otro punto de referencia, si consideramos los trabajos de Pradas (2006), Mateo, Nieto y Colombo (2010) y Colombo (2014), en su apogeo durante la década del 70 la industria pesquera marplatense albergó aproximadamente 20.000 trabajadores, por lo que la reducción operada entre esta década y el año 1996 corresponde aproximadamente a un 50\% de los puestos de trabajo totales y un $67 \%$ si consideramos al sector asalariado registrado. Actualmente, de acuerdo a las últimas mediciones académicas, el número total de trabajadores de la industria pesquera de Mar del Plata ronda los 7.000, ya sean asalariados registrados o no registrados (Mateo, Nieto y Colombo, 2010; Nieto, 2014). Las cuantificaciones oficiales, a su vez, solo contabilizan a los trabajadores que se desempeñan en las modalidades de trabajo legales, y no consideran a los que realizan sus tareas en las plantas procesadoras clandestinas, frecuentes a lo largo de la historia de la industria pesquera nacional (Molinari, 1998; Mateo, 2011; Nieto, 2014; Colombo, 2014).

En Necochea, de acuerdo a las memorias obrera y sindical hubo más de 3.000 puestos de trabajo en el ápice de la industria pesquera local. Esto se corresponde con datos aportados por un informante clave, trabajador de la sede necochense del Tribunal de Trabajo al momento de la realización del trabajo de campo, quien aportó información a la empresa autogestiva "La Recuperada" acerca de la nómina de empresas pesqueras que cerraron desde 1970 en adelante, junto al número de trabajadores desempleados por cada una de ellas. La información se vuelca en la siguiente tabla:

Tabla №11. Empresas de la industria pesquera necochense cerradas desde 1970 hasta 2012, discriminadas por año y por el número de obreros despedidos:

\begin{tabular}{|l|c|c|}
\hline Empresa & Cantidad de trabajadores & Año de cierre \\
\hline Promotora Pesquera & 31 & 1970 \\
\hline Popovich Hnos & 170 & 1977 \\
\hline Mar Claro S.A. & 250 & 1978 \\
\hline Cooperativa de Pescadores & 30 & 1978 \\
\hline Sitarp S.A. & 150 & 1978 \\
\hline Haripez & 30 & 1979 \\
\hline Complejo anchoero & 160 & 1980 \\
\hline Bruno & 60 & 1980 \\
\hline Alais & 20 & 1981 \\
\hline La Marplatense & 100 & 1981 \\
\hline La Portuguesa & 40 & 1981 \\
\hline Melluno Hnos. & 60 & 1981 \\
\hline Huemul & 700 & 1981 \\
\hline Transhue & 200 & 1981 \\
\hline Esca SRL & 170 & 1982 \\
\hline Papá Falcone & 100 & 1983 \\
\hline Alfe Trade & 100 & 1983 \\
\hline Roda Pesquera/Compesca & 200 & 1984 \\
\hline
\end{tabular}




\begin{tabular}{|l|c|c|}
\hline Bajamar S.A. & 300 & 1989 \\
\hline Argenpez S.A. & 50 & 1989 \\
\hline Vieyra Argentina S.A. & 80 & 1998 \\
\hline Industrial Pesquera S.A. & 27 & 2011 \\
\hline Engraulis S.A. & 60 & 2011 \\
\hline Incoop S.A. & 50 & 2012 \\
\hline $\begin{array}{l}\text { Total nominal de fuentes de } \\
\text { trabajo perdidas en el sector: }\end{array}$ & $\mathbf{3 1 3 8}$ & \\
\hline
\end{tabular}

Fuente: Elaborado en base a archivos de La Recuperada, entrevista con informante clave y ejemplares de Ecos Diarios.

De aquí que, si tomamos como referencia el año 2012, se habrían perdido el 100\% de los puestos de trabajo dentro del grupo de los asalariados bajo relación de dependencia, quedando solamente ocupados los aproximadamente 30 empleos correspondientes a las empresas recuperadas, que representan el 1\% del total máximo local registrado en la década del 70, que fuera de 3138 puestos de trabajo comprendidos en 24 plantas procesadoras que funcionaron en la ciudad.

Observamos entonces realidades contrapuestas en la industria pesquera de ambas localizaciones portuarias en este punto: mientras que en Necochea solo perduran los pequeños colectivos de trabajadores de las dos empresas recuperadas, en Mar del Plata no varió tanto el número desde 1982 en adelante sino el tipo de contratación y las condiciones de trabajo, es decir que lo que aquí se incrementó fue el grado de precarización laboral, mientras que los valores absolutos no mostraron grandes modificaciones.

\subsection{Cambios en el proceso de trabajo:}

La labor de filetero se encuentra regulada por el Convenio №161/75, propio de la rama y emitido en el año 1975, el cual incluye garantías salariales y horarias, control de las balanzas por parte del delegado de planta y un tamaño mínimo de la merluza a procesar, entre otros puntos. Pero dicho convenio solo rige para los trabajadores en relación de dependencia, el resto de obreros se encuentra o bien cooperativizado -es decir, no goza de ningún tipo de convenio de contrato laboral- o bien bajo el convenio Pyme, anexo del CCT 161, el cual contiene sustanciales diferencias con el mismo. Entonces, las condiciones de trabajo y contratación se modificaron sustancialmente para una gran cantidad de trabajadores a partir de los 90, con el incremento de la cooperativización fraudulenta y la desprotección que ésta implica para los trabajadores en términos de legislación laboral.

Una primera modificación se refiere no directamente al proceso de trabajo dentro de las plantas procesadoras sino al momento previo a la obtención del puesto laboral. A partir de la cooperativización fraudulenta se impuso un modo de contratación a través de las emisoras radiales, las cuales transmiten un llamado a desempeñar tareas temporarias en la industria pesquera pocas horas antes del inicio de la jornada laboral. Por este medio las empresas convocan a los obreros 
desde la noche o madrugada para presentarse a la mañana siguiente. Otra práctica que se generalizó es la espera de obreros fuera de las empresas durante la noche a fin de solicitar empleo a la mañana siguiente. Esto implica una disposición permanente de los trabajadores para ingresar en una rutina laboral irregular (Lanari, 2010).

En cuanto a las transformaciones en el proceso de trabajo dentro de las plantas, uno de los principales cambios se refiere a la desregulación de la jornada laboral amparada por la ley, haciendo que la misma se extienda y se determine diariamente en base a la cantidad de pescado disponible. Si bien el pago a destajo ya era la forma de retribución salarial a los obreros de la pesca desde 1966, una de sus diferencias con antaño consiste la desconsideración de las "horas extras", que no son retribuidas como tales sino que forman parte de la jornada laboral normal, ampliamente flexibilizada. Por otra parte, actualmente el obrero no goza del derecho de optar entre realizar o no dicha jornada laboral extendida, sino que forma parte de su contrato en el caso de estar bajo el convenio Pyme o de su necesidad de cumplimentar con los tiempos de la producción en caso de integrar una cooperativa. Otro de los cambios sustanciales fue producto de la disminución del tamaño general del pescado a procesar, debido fundamentalmente a la crisis del caladero por sobrepesca y la depredación del recurso pesquero. Con el correr de los años, esto desembocó en que, para alcanzar el nivel extractivo demandado por el empresariado, los barcos debían capturar especímenes que no lograban llegar al tamaño mínimo de pescado apto para procesar dispuesto por el CCT 161. Esto se traduce en que los fileteros deben cortar pescados más pequeños, debiendo entonces procesar más cantidad de filetes -es decir, trabajar más- para ganar lo mismo que antaño, lo cual implica una intensificación del trabajo de acuerdo a Coriat (1982). Si bien esta intensificación alcanza a la totalidad de obreros de la industria pesquera, por el mismo mecanismo de dualización de la fuerza de trabajo, los obreros cooperativizados lo padecen con mayor crudeza. Al respecto, el Convenio Pyme especifica, en sus lineamientos generales que fundamentan toda su reglamentación, que:
...en virtud de la escasez del recurso ictícola y la necesidad impostergable de lograr una optimización de los mismos, las partes están de acuerdo en que todos aquellos productos que puedan ser calificados como aptos para el consumo humano, deben ser procesados evitando el desperdicio y la ineficiencia que ha perjudicado a este sector industrial, en detrimento de las empresas y de las condiciones de labor de los trabajadores ${ }^{16}$.

Se observa aquí que la disminución del tamaño de las piezas esta prevista en el convenio, pero no así el incremento de productividad que esto le exige al obrero por kilo de pescado. Entonces, al ser las piezas más pequeñas, el precio de la fuerza de

${ }^{16}$ Convenio colectivo de trabajo de pequeña y mediana empresa (rama fileteros) 506/07. Artículo II a). 
trabajo disminuye al requerir más tiempo para procesar igual cantidad, y asimismo incrementa el desgaste corporal obrero al requerir más movimientos osteoarticulares por kilo procesado con respecto a antaño.

En la industria pesquera necochense hemos podido hallar que previamente a su desguace también existieron cooperativas fraudulentas a principios del nuevo milenio. Entre los cambios en el proceso de trabajo que implicó la instauración de este régimen de trabajo se destacan la extensión de la jornada de trabajo, el pago a destajo en menor proporción que los trabajadores en relación de dependencia y la carestía de otros derechos vigentes en la legislación laboral (horas extras, vacaciones, aguinaldo) ${ }^{17}$. Esto generó una superexplotación obrera que para los trabajadores significó tanto una intensificación como una extensión de la jornada de trabajo. Además, se suman otros elementos de precarización como la falta de ropa de trabajo, de condiciones de higiene y seguridad, y, en el caso de las cooperativas, falta de cobertura de riesgos laborales. Luego, en este ámbito laboral se acentúan los riesgos de los padecimientos propios de la historia industria pesquera, ya que la falta de registración laboral abre las puertas para el detrimento de las condiciones de seguridad laboral en los establecimientos. Más adelante, en el Capítulo 4, abordaremos las transformaciones específicas en el proceso de trabajo en las dos empresas pesqueras recuperadas de Necochea.

Sintetizando brevemente lo expuesto en este capítulo, nuestra intención fue de presentar las condiciones objetivas sobre las que se sustentaron las transformaciones en la industria pesquera durante las últimas décadas, a fin de situar el período y los objetos de estudio abordados desde un marco histórico, social, económico y político, en vinculación con la última reestructuración capitalista y las consecuencias que generó en los campos del capital y del trabajo.

A continuación, nos focalizaremos en los formatos de cooperativización y sus características en la industria pesquera entre 1997 y 2012, para luego profundizar en las subjetividades obreras propias de los trabajadores del sector en las ciudades de Mar del Plata y Necochea. Prestaremos especial atención a cómo enfrentaron los embates del capital, sus estrategias laborales, formatos de lucha y organización, así como también a sus representaciones, concepciones y vínculos forjados en sus praxis.

${ }^{17}$ Entrevista grupal a La Recuperada, realizada en octubre de 2011. 


\section{Capítulo II:}

El auge de la cooperativización en la industria pesquera argentina: ¿autogestión o precarización laboral? 


\section{Cooperativismo, economía social y capitalismo}

El auge de las cooperativas en el sector industrial pesquero a partir de la década del 90 es un fenómeno social enmarcado en un proceso más amplio a nivel nacional e internacional, vinculado a las transformaciones en el mundo del trabajo y del capital en el marco neoliberal. A partir de la crisis del petróleo de 1973 inició este nuevo patrón de acumulación que se consolidó en la década del 80, el cual trajo aparejada la precarización laboral, el crecimiento del empleo no registrado y el otorgamiento de garantías legales desde el Estado hacia los empresarios para llevar a cabo distintas formas de trabajo tercerizado. En Argentina, tanto la Ley de Quiebras como la Ley de Cooperativas actúan como marcos institucionales para ocluir los incumplimientos en materia de derechos laborales en pos de una mayor superexplotación obrera.

A su vez, desde los discursos dominantes neoliberales comenzó a ensalzarse la autogestión, el emprendedorismo y el cuentapropismo bajo la premisa de que la propia persona es la responsable de encontrar una salida a su situación de desempleo y/o su imposibilidad de alcanzar los medios de subsistencia. Desde el mundo académico proliferaron discursos basados en estas tendencias neoliberales, encumbrando el enaltecimiento personal y el empoderamiento, haciendo eje en las propias capacidades para generar una mejora en la propia calidad de vida. Gran parte de los teóricos de la psicología comunitaria desplazaron este individualismo hacia las comunidades, situándolas en el lugar de protagonistas y encargadas de su propio bienestar. Estas posiciones, cuando consideraban al sistema capitalista como el responsable de las situaciones de vulneración, exclusión, miseria y desigualdad, no proponían la lucha por otro modelo social y político. Por el contrario, los planteos quedaban circunscriptos a la esfera personal o comunitaria, fomentando la participación en el propio lugar de inserción territorial pero no más allá de él, deteniéndose en medidas parciales y paliativas basadas en un procedimiento de elaboración e implementación de "estrategias" (Montero, 2003) para mejorar las propias situaciones de vida dentro del sistema actual, sin implicar soluciones que atañan a las causas estructurales de dichas situaciones o cambios profundos.

Algunos limitantes de este tipo de planteos se encuentran en las propias realidades de los "nuevos formatos laborales" señalados más arriba. Los microemprendimientos y el cuentapropismo fueron las opciones laborales que se fomentaron desde los Estados a partir de los 80 y más aún desde los 90, cuando el paradigma de la flexibilización laboral se impuso en el mercado de trabajo. Ante el retiro del Estado y la ofensiva del capital, se formularon discursos referidos al "tercer sector", actor social que cobró preponderancia en el renovado formato capitalista. Este tercer sector, compuesto de ONGs, cooperativas y otras entidades localizadas por "fuera del mercado y del Estado", vendría a ocupar el espacio vacío dejado por el Estado y a incluir de alguna manera a la fuerza de trabajo asalariada expulsada por el empresariado. Los desplazados, despedidos, relocalizados y trabajadores temporarios se vieron impelidos a "integrarse" en este tercer sector, 
recurriendo a distintas formas de trabajo por cuenta propia a fin de garantizar su subsistencia, ante los contratos precarios y las bajas remuneraciones.

En este contexto, la clase obrera recurrió a la autogestión como trabajo posible cuando escaseaban otras alternativas, generando experiencias que expresan una lucha contra el desempleo y la precarización de la vida y se distinguían del formato laboral tradicional del empleo en relación de dependencia. Sin embargo, la actual configuración capitalista, con su creciente monopolización y concentración del capital deja poco margen para la rentabilidad de la producción cuentapropista, que debe competir con los precios fijados por la gran empresa. Estos precios se calculan de acuerdo a niveles de producción en masa y venta de grandes cantidades, en base a condiciones imposibles para los pequeños emprendimientos. De aquí que el fomento estatal de las llamadas "formas de la economía social", lejos de materializarse como la opción más deseable, no es más que una reproducción de la precariedad y un atenuante temporario a la miseria.

El lado oscuro del cuentapropismo termina de develarse en los casos de cooperativas fraudulentas y de la tercerización laboral: aquí los trabajadores son falsos cuentapropistas y cooperativistas, puesto que se ven impelidos a vender su fuerza de trabajo a una empresa que luego comercializa su producción. La subcontratación de una cooperativa por parte de una empresa es uno de los métodos para reducir el costo del capital variable, ya sea en alguno o bien en todos los segmentos del proceso de producción. De esta forma, se extrae mayor plusvalía y se precariza la fuerza de trabajo y las condiciones de producción.

Recordemos que la Ley 25.877/97, en lo relativo a las cooperativas de trabajo, ratifica la prohibición de actuar como intermediarios (en tanto agencias de colocación y/o empresas de servicios eventuales) en la contratación de personal. Según esta ley, si se constatara que los socios son en realidad trabajadores en relación de dependencia encubiertos, esto significaría la utilización en forma fraudulenta de la figura de la cooperativa y se procederá a su juzgamiento y sanción. De acuerdo al artículo 40 de dicha ley:

Los servicios de inspección del trabajo están habilitados para ejercer el contralor de las cooperativas de trabajo a los efectos de verificar el cumplimiento de las normas laborales y de la seguridad social en relación con los trabajadores dependientes a su servicio, así como a los socios de ella que se desempeñaren en fraude a la ley laboral. Estos últimos serán considerados trabajadores dependientes de la empresa usuaria para la cual presten servicios, a los efectos de la aplicación de la legislación laboral y de la seguridad social. Si durante esas inspecciones se comprobare que se ha incurrido en una desnaturalización de la figura cooperativa con el propósito de sustraerse, total o parcialmente, a la aplicación de la legislación del trabajo denunciarán, sin perjuicio del ejercicio de su facultad de constatar las infracciones a las normas laborales y proceder a su juzgamiento y sanción, esa circunstancia a la autoridad específica de fiscalización pública a los efectos del artículo $101 \mathrm{y}$ concordantes de la Ley №20.337. Las cooperativas de trabajo no podrán actuar como empresas de provisión de servicios eventuales, ni de temporada, ni de 
cualquier otro modo brindar servicios propios de las agencias de colocación (Ley 25877, art. 40).

Las instituciones estatales que debieran velar por la erradicación de este tipo de fraude laboral han permitido, desde la escasa acción y la negligencia, la consecución de la cooperativización fraudulenta y de otras formas de trabajo no registrado. Lo demuestra el elevado porcentaje de trabajo no registrado que persiste en Argentina desde los 90, y específicamente en el sector pesquero la existencia de 70 cooperativas pesqueras de "servicios" que fueran censadas por el INIDEP en el año 1996, descriptas en el informe de este organismo como "vendedoras de sus productos a otras empresas del sector".

La cooperativización a lo largo del tiempo ha sido instrumentalizada de formas diversas, con distintos fines. Comenzaremos este capítulo con una breve historización de las cooperativas, para luego continuar con sus concepciones actuales desde el marco de la Economía Social. Seguidamente abordaremos su nexo con el trabajo no registrado y la tercerización, y finalmente las especificidades de las cooperativas en la industria pesquera argentina. Veremos cómo los diferentes marcos ideológicos que atravesaron la constitución de cooperativas continúan provocando efectos en el presente, y los mismos surgen en los discursos y praxis implicadas en las cooperativas de trabajo situadas aquí.

\subsection{Del socialismo utópico al neoliberalismo}

La institucionalización de las cooperativas durante el siglo XX se acompañó de un determinado marco legal y de la promoción estatal de este tipo de asociaciones. Por ello, una organización cuyos orígenes se vincularon a la iniciativa propia de un colectivo mediante la libre adhesión voluntaria de sus miembros, fue mutando producto de diversas motivaciones que promulgaron la creación de cooperativas desde sectores ajenos a ellas, tanto empresariales como estatales.

Si bien pueden rastrearse orígenes del cooperativismo anteriores a la instauración del sistema capitalista, a nuestros fines nos limitaremos a exponer las experiencias que iniciaron desde el siglo XVIII, ya como crítica a esta formación económico social. Para realizar esta reconstrucción retomaremos ejemplos de cooperativización situados en bibliografía específica sobre los temas tratados en este trabajo de investigación (industria pesquera argentina, transformaciones en el mundo del trabajo y empresas recuperadas), y de forma complementaria haremos uso de material hallado acerca de la historicidad del movimiento cooperativo.

Una de las primeras experiencias a las que hace referencia la bibliografía es la cooperativa panadera de los astilleros de Woolwich y Chatham, ensayo de corta vida en el año 1760, que culminó con un incendio intencional de su molino. Pocos años después, durante 1769, en Escocia se conformaron las primeras cooperativas de consumo. Seguidamente, las experiencias de Owen -precursor en la ideología cooperativista bajo el marco del socialismo utópico- excedieron las cooperativas 
para conformar, en 1825, una comunidad llamada New Harmony, en la que tanto el trabajo como la educación se realizaban de forma colectiva. Estas ideas prosperaron tanto que para 1830 se estimaba la existencia de entre 300 y 500 cooperativas (Magnani, 2003). Incluso Owen llegó a crear una moneda propia y una "Bolsa nacional de cambio equitativo del trabajo", que expresaba un tipo de cambio basado en el tiempo y los medios de producción invertidos en la fabricación de productos. El relativo éxito y difusión de este proyecto puede medirse por los violentos ataques que recibió por parte del Estado inglés, que terminaron por destruirlo mediante una cruel represión, que incluyó ahorcamientos y deportaciones, descargada sobre los trabajadores más radicalizados.

El francés Fourier, otro de los representantes de la doctrina del socialismo utópico, también tuvo una propuesta similar con los llamados "falansterios", cooperativas agricultoras con principios autogestivos que preveían la repartición igualitaria de la producción y también roles rotativos entre sus miembros. Este proyecto se presentó en su libro "Tratado sobre la asociación agrícola doméstica" que fue publicado en el año 1822, y su aplicación subsistió por un corto período.

Pero la experiencia que suele citarse como pionera del movimiento es la cooperativa de consumo Rochdale Society of Equitable Pioneers, fundada en 1844 por un grupo de 28 tejedores desocupados - 27 varones y una mujer- influenciados por las ideas de Owen. Este grupo elaboró un programa de siete máximas: adhesión abierta, control democrático de los socios, devolución o bonificación sobre las compras, interés limitado al capital, neutralidad política y religiosa, ventas al contado y fomento de la enseñanza. Para su conformación los ex tejedores tomaron como ejemplo reglamentaciones de instituciones sin fines de lucro propias de la época, como las sociedades de socorros mutuos. La emblemática Tienda de Rochdale consistía en un almacén para la venta de provisiones y ropa. La cooperación de consumo fue el puntapié para la cooperación de viviendas, mediante la adquisición de tierras para la construcción y el empleo productivo de las mismas. Finalmente, la cooperativa también incluyó tareas de producción.

A partir de esta época comenzó a institucionalizarse la fórmula cooperativa, que fue adoptada por agrupamientos obreros radicalizados en contextos de crisis económicas. Sin embargo, a pesar de haber nacido como crítica al capitalismo, paradójicamente las cooperativas se mostraron ineficaces como instrumentos de transformación de las relaciones sociales capitalistas, mostrando una apacible convivencia con el sistema socioeconómico vigente y sus instituciones. Esto puede ejemplificarse desde sus orígenes, con la elaboración del estatuto legal avalado por Napoleón III en 1867, que contemplaba derechos para trabajadores de cooperativas. No obstante, algunos resquicios de sus vínculos con ideales más disruptivos respecto del capitalismo retornaron en otros momentos históricos, como por ejemplo en 1871 durante la Comuna de París, donde el gobierno obrero promulgó la conformación de sociedades cooperativas para el reanudamiento de la producción en fábricas que habían sido abandonadas por sus propietarios. Con el correr los años y tras la derrota del gobierno comunero, las concepciones más 
revolucionarias fueron diluyéndose, mientras que los preceptos más voluntaristas, corporativistas y emprendedoristas que decantaron de la experiencia de Rochdale se impusieron como concepción cooperativista dominante.

A fines del siglo XIX se conformó en Londres la Alianza Cooperativa Internacional (AIC), una federación de cooperativas. En sus sucesivas reuniones actualizaron los denominados "principios rochdaleanos", los cuales se reformularon en seis preceptos: 1) adhesión abierta y voluntaria, 2) control democrático (un miembro igual un voto); 3) interés limitado, si alguno, sobre el capital; 4) no hay ganancias sino excedentes, sobrantes, 5) provisión para la educación; y 6) cooperación entre las cooperativas. Balbi (2010) describe al movimiento cooperativista internacional actual como una "auténtica burocracia dedicada a la promoción cooperativa. Como es lógico, esta burocracia tiene una visión acrítica del modelo" (Balbi, 2010:32). De acuerdo a este autor, la promoción cooperativa desde las entidades nacionales y supranacionales no contempla la diversidad de las cooperativas concretas, las cuales están lejos de reflejar esos seis principios enunciados, que incluso llegan a ser desconocidos por sus propios miembros.

La inmigración europea insertó al cooperativismo en América Latina entre finales del siglo XIX y principios del XX. Algunos de los europeos radicados en Argentina habían integrado organizaciones políticas y sociales vinculadas a ideologías socialistas y anarquistas en sus países de origen. Entre ellos, se destacaron el francés Alejo Peyret, el catalán Bartolomé Victory y Suárez y el alemán Germán AvéLallemant, quienes además de pregonar el cooperativismo fueron intelectuales, políticos y dirigentes de izquierda en Argentina durante este período.

Los orígenes del cooperativismo argentino aún se encuentran en discusión, por lo que es plausible hallar discrepancias entre los estudiosos del tema, en términos de fechas y primeras manifestaciones concretas de cooperativas en nuestro país. De acuerdo a Plotinsky (2015), el cooperativismo nacional se inició en la rama del consumo, cuya primera expresión fue la "Asociación Panadería del Pueblo", fundada en Paraná -Entre Ríos- en 1857. En 1905, Juan B. Justo y Nicolás Repetto fundaron el "Hogar obrero", primera cooperativa argentina de origen no europeo en ser admitida por la AIC (Montes y Ressel, 2003). A diferencia de las anteriores -ligadas al sector agrícola- esta cooperativa incluyó las tipologías de consumo, crédito y vivienda. En sus inicios contó con 19 asociados, con el paso del tiempo fue creciendo y llegó a ocuparse de la construcción de cientos de casas, algunos barrios y departamentos.

En este punto es pertinente realizar una delimitación en base a los tipos de cooperativas. Según cuál sea el objeto social por el cual fueron creadas, las cooperativas pueden clasificarse en agropecuarias, de vivienda, de provisión de servicios públicos, de consumo, de crédito, de provisión, de trabajo o bancos cooperativos. A partir de aquí, nos ocuparemos con mayor énfasis de las cooperativas de trabajo, ya que expresan la tipología propia de las experiencias cooperativas abordadas por nosotros. 
Las primeras cooperativas de trabajo situadas en Argentina datan de fines del siglo XIX, a pesar de que su normativa legal fue creada mucho después, en el año 1926 con la Ley 11.388. Para el año 1957 se registraban 94 cooperativas de trabajo con aproximadamente 10.000 asociados, que constituían apenas un 3,3\% del conjunto de cooperativas de todo orden existente y asociaban al 0,7\% del total de miembros de esas organizaciones (Slutzky, Di Loreto y Rofman, 2003). En 1973 se dictó la ley de cooperativas 20.337, reglamentación que rige hasta la actualidad.

Antes de proseguir, nos parece pertinente exponer algunas de las contradicciones intrínsecas de la reglamentación cooperativa a través de un caso ilustrativo, esto es, discrepancias entre los principios democráticos y el funcionamiento verticalista que la normativa cooperativa promulga, a través de mecanismos de desigualdad de poder y participación entre los socios. A su vez, esto nos muestra contradicciones entre las realidades cooperativas y su ideal originario de crítica y emancipación con respecto del capitalismo, que pretenden emprender. Uno de los dispositivos garantes de esta desigualdad es el Consejo de Administración, figura en la que se deposita la toma de decisiones cotidianas. De acuerdo a la ley de Cooperativas, este Consejo puede estar conformado por un mínimo de 4 personas y reunirse periódicamente cuando se requiera, mientras que el número mínimo de asambleas generales de socios prevista es de una por año.

En la década del 60 se originó una experiencia que luego continuaría hasta el presente como empresa recuperada: el caso de la metalúrgica IMPA, fundada en 1910 y nacionalizada en 1945. Este ejemplo muestra la realidad interna de muchas cooperativas, que lejos de implicar una práctica igualitaria entre sus miembros, reproducen jerarquías a través de mecanismos basados en la asimetría y el verticalismo, otorgándole un papel predominante al consejo de Administración, y las figuras del síndico y contador. La preminencia de estas figuras sobre las decisiones de la cooperativa e incluso sobre la realización y la periodicidad de las asambleas, provoca un vínculo desigual entre sus miembros y el resto de los asociados. Esta supremacía se conjuga con su relativa independencia, posibilitándole ejecutar propias resoluciones cotidianas sin consultar al conjunto e incluso suspender las respuestas a los reclamos colectivos e individuales por un lapso de tres meses. De esta forma, ante un vínculo democrático entre iguales se contrapone un vínculo de dominancia por parte de una oligarquía sobre la masa de asociados. Otra inconsistencia son los "gerenciamientos" (el nombramiento de un gerente que dirige la institución), comunes en muchas cooperativas, entre ellas la COOMARPES -experiencia a la que nos referiremos más adelante.

El caso de la metalúrgica IMPA expone los alcances de los conflictos que suscita la desigualdad entre sus miembros que la normativa cooperativa impregna. Esta cooperativa desde 1961 -año de su conformación- mantuvo un funcionamiento antidemocrático por el cual el Consejo de Administración sistemáticamente concentraba las decisiones e impedía la participación del resto de los socios. Con la crisis económica que desde los 90 afectó fuertemente a esta empresa, la desigualdad traspasó el ámbito resolutivo afectando también los ingresos monetarios de los 
trabajadores/socios, quienes percibían cantidades insuficientes e inferiores en relación con los miembros del consejo. El malestar que generó la conjunción entre las prácticas antidemocráticas, los bajos y desiguales ingresos y el riesgo de desaparición del emprendimiento cooperativo por supuestos problemas de rentabilidad, impulsó a los trabajadores a organizar un boicot al consejo de administración a través de una asamblea de socios en 1997. En esta asamblea, una mayoría de asociados expulsó a los miembros del consejo, y al año siguiente cerca de 150 trabajadores comenzaron un nuevo proceso autogestivo en la empresa que perdura hasta hoy bajo el lema "IMPA: La Fábrica Cultural". Esta experiencia de recuperación tiene la particularidad de provenir de una cooperativa precedente, en lugar de hacerlo -como la gran mayoría- de sociedades anónimas que representaban a los empresarios. También demuestra los riesgos de la aplicabilidad acrítica de la reglamentación cooperativa en los procesos de recuperación, que de por sí incluye mecanismos burocráticos y desigualdades de poder entre los socios.

Reanudando la contextualización más general, en América Latina a partir de la década del 80 se produjo un incremento del cooperativismo como correlato de la retracción del trabajo asalariado. Desde la ideología neoliberal, cimentada sobre el individualismo, la meritocracia y el autoemprendedorismo, se comenzó a promover la cooperativización desde el Estado como "alternativa" al desempleo.

A nivel nacional, una primera oleada aconteció entre 1990 y 1993, en el marco de la privatización de empresas públicas y la expulsión de su fuerza de trabajo. Surgieron así cooperativas que realizaban determinadas fracciones de la actividad general de la empresa privatizada, como por ejemplo los talleres ferroviarios de Pérez y Laguna Paiva y las cooperativas constituidas a partir de las ex empresas contratistas de YPF en la destilería de La Plata y en Gral. Mosconi. Luego, una significativa cantidad de cooperativas se originó como forma de tercerizar tareas de mantenimiento y limpieza de instalaciones públicas, así como de calles, paseos y jardines.

En un segundo período, entre los años 1995 y 1999 se conformaron alrededor de cincuenta cooperativas ante el cierre de empresas privadas, generalmente como producto de la quiebra de las mismas. Ejemplos de estos procesos son la Cooperativa Industrial Argentina Metalúrgica Julián Moreno (CIAM) -heredera del histórico complejo industrial SIAM Di Tella- y el Frigorífico Yaguané, que contaron con el apoyo del Instituto Provincial de Acción Cooperativa, creado por el entonces presidente Carlos Saúl Menem en 1996 (Slutzky, Di Loreto y Rofman, 2003).

Luego, en el contexto más agudo de la crisis neoliberal en Argentina, a partir del 2001 se multiplicaron las experiencias de cooperativas enmarcadas en procesos de recuperación de empresas, movimiento que continúa hasta la actualidad.

En el año 2000, mediante el decreto №721, el ex presidente De La Rúa reformuló el INACyM, que pasó a denominarse INAES: Instituto Nacional de Asociativismo y Economía Social, un actor institucional de suma importancia para todas las cooperativas conformadas con posterioridad a su creación. Los objetivos del INAES, de acuerdo a la normativa, son: 
1.-Ejercer en el ámbito nacional las funciones que le competen al Estado Nacional como autoridad de aplicación del régimen legal que regula el funcionamiento de las Asociaciones Mutuales y las Cooperativas establecido por las Leyes Nros.20.321 y 20.337, sus modificatorias y complementarias y por las normas que en el futuro se dicten al respecto.

2.-Fomentar el desarrollo, educación y promoción de la acción cooperativa y mutual en todo el territorio nacional.

3.-Reconocer a las Asociaciones Mutuales y Cooperativas efectuando el otorgamiento, denegatoria o retiro de la personería jurídica para su funcionamiento, como así también su superintendencia y control público.

4.-Ejercer, con el mismo alcance, el control público y la superintendencia de Asociaciones Mutuales y Cooperativas, fiscalizando su organización, funcionamiento, solvencia, calidad y naturaleza de las prestaciones y servicios y su disolución y/o liquidación.

5.-Apoyar, a través de la asistencia técnica, económica y financiera a las entidades y propender a la capacitación de directivos y grupos sociales para el mejoramiento de la eficiencia en la administración y prestación de servicios considerando prioritariamente la atención de sectores o estratos menos favorecidos.

6.-Gestionar ante los organismos públicos de cualquier jurisdicción y ante las entidades representativas del mutualismo y del cooperativismo, la adopción de medidas y la formulación de programas y planes que sirvan a los objetivos del Instituto.

7.-Elaborar políticas, objetivos y acciones atinentes al desarrollo y consolidación de las Cooperativas y Mutuales, como así también la actualización de la legislación aplicable con la participación de los sectores involucrados (Decreto 721/2000:18).

Esta entidad es la que hasta el presente ha regido como reguladora de la conformación de cooperativas, las cuales no solo avala legalmente, sino que también impulsa y promueve su conformación, tanto en el sector de trabajadores en riesgo de desempleo como en el sector ya desocupado.

Veamos algunas cifras referidas a la evolución de la cantidad y tipo de cooperativas en Argentina tomando los años 2001 y 2014, a fin de contar con una visión panorámica de la realidad nacional cooperativa y de la incidencia de las cooperativas de trabajo en la misma. La siguiente tabla ofrece datos sobre ello: 
Tabla №12. Cantidad de cooperativas, discriminadas por tipo, años 2001 y 2014:

\begin{tabular}{|l|r|r|r|r|}
\cline { 2 - 5 } \multicolumn{1}{c|}{} & \multicolumn{2}{c|}{$\mathbf{2 0 0 1}$} & \multicolumn{2}{c|}{$\mathbf{2 0 1 4}$} \\
\hline Tipo de Cooperativa & \multicolumn{1}{c|}{ № } & \multicolumn{1}{c|}{ № } & \multicolumn{1}{c|}{$\%$} \\
\hline Agropecuaria & 2.236 & 14,0 & 1.297 & 4,5 \\
\hline Consumo & 252 & 1,5 & 195 & 0,1 \\
\hline Crédito & 341 & 2,0 & 290 & 1,0 \\
\hline Provisión & 1.544 & 9,6 & 1.582 & 5,5 \\
\hline Seguros & 51 & 0,3 & 19 & 0,7 \\
\hline Servicios públicos & 1.889 & 11,6 & 1.167 & 4,0 \\
\hline Trabajo & 6.686 & 42,0 & 22.516 & 78,0 \\
\hline Vivienda y construcción & 3.060 & 19,0 & 1.787 & 6,2 \\
\hline Total & $\mathbf{1 6 . 0 5 9}$ & $\mathbf{1 0 0 , 0}$ & $\mathbf{2 8 . 8 5 3}$ & $\mathbf{1 0 0 , 0}$ \\
\hline
\end{tabular}

Fuente: Vuotto, M. (2014).

Gráfico №5. Distribución porcentual de cooperativas por tipo, años 2001 y 2014:
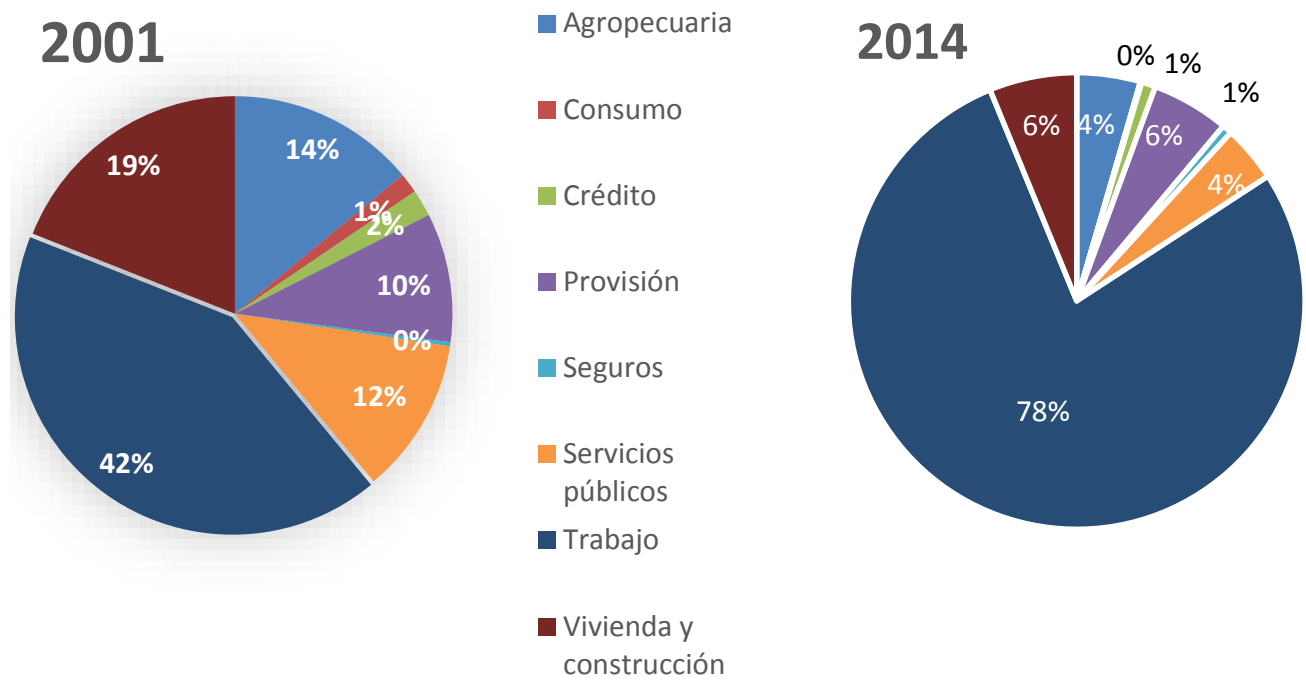

Elaborado en base a la tabla anterior.

Estos datos nos muestran dos cuestiones centrales en cuanto al desarrollo de la cantidad y tipo de cooperativas entre 2001 y 2014. En 2001 se observa una preminencia de las cooperativas de trabajo con respecto al resto de las tipologías, las cuales representan el $42 \%$ del total, seguidas por las de vivienda (19\%), agropecuaria (14), servicios públicos $(11,6 \%)$ y provisión $(9,6 \%)$. Los tres tipos restantes (seguros, crédito y consumo), tienen una menor incidencia representando entre los tres menos del 4\% de las más de 16.000 cooperativas argentinas. Resituándonos en el 2014, la realidad cooperativa es marcadamente distinta: si bien creció significativamente (un 75\%) el número total de cooperativas, casi todos los 
rubros disminuyeron drásticamente ${ }^{18}$, a excepción del rubro de previsión -que se mantuvo prácticamente igual a los valores expresados en 2001- y la tipología de cooperativas de trabajo, que representa un aumento del $336 \%$ respecto del año 2001, pasando de 6.686 a 22.516 asociaciones. Este crecimiento de más de 15.000 unidades, que ubica a las cooperativas de trabajo en un lugar mucho más preponderante que en el anterior contexto -expresando el 78\% del total-, se explica por dos motivos. Por un lado, una minoría de casos corresponde a los procesos de recuperación de empresas, que conformaron 311 nuevas cooperativas producto de la gestión obrera de la producción hasta el año 2013 inclusive (Ruggeri, 2014), es decir, se refieren a la conservación de fuentes de trabajo en su gran mayoría correspondientes al sector privado. Luego, un gran número de casos corresponden a la creación de empleo mediante la promoción estatal a través de los programas: Integración Socio Comunitaria, Manos a la Obra, Centros Integradores Comunitarios, Agua más Trabajo A+T, Capacitación con Obra, Inversión Social (PRIS), Ingreso Social con Trabajo (PRIST) y Obra Pública Provincial y/o Municipal (Vuotto, M. 2014). Y otro número de casos, ocultos en estos datos oficiales, se refiere a la incalculable cantidad de cooperativas fraudulentas creadas por el empresariado para precarizar fuerza de trabajo, como ocurre en la industria pesquera, así como a grandes empresas que utilizan el formato de cooperativa para obtener beneficios impositivos y fiscales ${ }^{19}$. Las cifras más actuales son más impresionantes si se las compara con la escasa incidencia de las cooperativas de trabajo relevada para el año 1957, cuando representaban al 3,3\% del total de cooperativas. Esto nos habla de las transformaciones del trabajo y del capital en las últimas décadas, y de los efectos de la reestructuración capitalista en su interrelación.

En la práctica, el incremento de las cooperativas y los cooperativizados ha degenerado en nuevas formas de precarización a través de tercerizaciones y trabajo a destajo, enmarcadas en una ideología meritocrática y mecanismos de desmoralización y culpabilización por los cuales se deposita en el trabajador tanto la mantención del empleo mediante la cooperativa como su rentabilidad, bajo la premisa de que ambas cuestiones dependen en gran medida de su propia persona. De esta forma, se niegan sus límites estructurales mientras que las dificultades, frustraciones y fracasos propios de este tipo de emprendimientos son adjudicados a sus integrantes, incidiendo negativamente en la valorización personal. Entonces, mediante un mecanismo perverso, la promoción cooperativa por parte del Estado y de las entidades financieras internacionales no solo precariza a los trabajadores impulsándolos a cooperativizarse y "monotributizarse", desentendiéndose de los derechos sociales propios de la legalidad del trabajo asalariado, tales como aportes jubilatorios, obra social, aguinaldo, vacaciones, etc., sino también vulnera y debilita

\footnotetext{
${ }^{18}$ La disminución del número de cooperativas de crédito se explica en gran parte por la concentración efectuada por el Banco Credicoop, que absorbió muchos bancos cooperativos que quebraron como los Bancos Mayo y Patricios.

${ }^{19}$ Ejemplos de ello son la cooperativa Sancor, y, en Necochea, la central eléctrica Usina Popular Cooperativa.
} 
subjetividades obreras en el destino de fracaso impuesto. Los bajos ingresos generados a costa de un enorme esfuerzo personal de los cooperativizados -que permanecen igualmente en la incertidumbre y la inestabilidad laboral- frustra, decepciona y desmoraliza a los trabajadores, a la vez que cercena su organización colectiva para enfrentar dicha situación con el predominio de la concepción individualista. En este sentido, más que una política asistencialista, la cooperativización es una política pública de desentendimiento estatal de la desocupación y la pobreza, que perpetúa la exclusión social y la dualización de la fuerza de trabajo. Aun cuando fueran genuinas -es decir, cuando no formasen parte de una estrategia de superexplotación obrera mediante un mecanismo fraudulento realizado por el empresariado- las cooperativas tienen grandes dificultades de funcionamiento debido a las lógicas capitalistas imperantes en el mercado, con las que se encuentran al poner en circulación los productos que elaboran o los servicios que brindan. De aquí que los incentivos estatales para este tipo de empleos tienen como finalidad o bien la contención social del malestar de la clase obrera ante la desocupación y la pobreza o bien la salvaguarda del capital, perpetuando la inestabilidad y precarización laboral a la vez que la dualización de la fuerza de trabajo. El individualismo y la meritocracia son entonces las bases ideológicas que desde el Estado y el mercado se infunden hacia el cooperativismo en la actualidad. Profundizando este análisis, diversos autores consideran que, aun cuando las cooperativas fueran rentables y su motivación obrera y anticapitalista, tampoco generarían un cuestionamiento al sistema. Al respecto, Pablo Ghigliani realiza una revisión de argumentos teóricos que discuten el supuesto potencial emancipatorio de la autogestión obrera dentro del capitalismo. En primer lugar, cita a Marx, quien entre sus concepciones sobre el cooperativismo resalta como puntos positivos su aporte a la discusión sobre el proceso de trabajo y el papel de la supervisión, volviendo superfluo el lugar del capitalista o de los capataces y demostrando que es posible una organización del trabajo sobre concepciones más democráticas. Sin embargo, Marx nunca desconoce las presiones mercantiles capitalistas que operan sobre las cooperativas, y por ello elabora una serie de preceptos a partir de los cuales posibilitar su supervivencia, como por ejemplo: "la prohibición de emplear trabajo asalariado, la creación de organizaciones de tipo nacional que las cobijen, la necesidad de destinar parte del ingreso de las cooperativas a un fondo para la ayuda mutua y la creación de nuevas cooperativas" (Ghigliani, 2009:3). Sin embargo, aun adoptando estas reservas, las mismas no eximen a las cooperativas de reproducir y subordinarse a la lógica capitalista a través de la mercantilización de su producción, entrando en la competencia incluso con otras cooperativas. Además, son impotentes para disputar la hegemonía capitalista que cuenta con los recursos políticos, legales, financieros y militares (Ghigliani, 2009). El autor también retoma argumentos de Rosa Luxemburgo (1900) en su contrapunto con Eduard Bernstein (1899) sobre la potencialidad cooperativa, marcando la diferencia entre las esferas de producción y circulación capitalista. En cuanto a ello, reafirma que, si bien en las cooperativas se da una "producción socializada", la circulación de sus productos ocurre en el 
intercambio capitalista. En este sentido, para acercarse a los estándares de competencia en el mercado las cooperativas deben recaer en la autoexplotación o la explotación de trabajo ajeno, de aquí su contradicción principal y su imposibilidad de plantear por sí mismas una alternativa económico-social. Por su parte, Mandel (2005) retoma la posición de Luxemburgo señalando que al concebir una estrategia revolucionaria basada en la autogestión obrera desde fábricas aisladas se deja de lado el rol del Estado en la dominación capitalista y su perpetuación.

Concluyendo este apartado, vemos que la síntesis histórica expuesta, nos permite distinguir cinco tendencias entre las motivaciones que conllevaron a la conformación de cooperativas a lo largo de la historia, las cuales aportan claves para la comprensión de las bases materiales e ideológicas que sustentan la conformación de los dos tipos de cooperativas pesqueras que abordamos en el presente estudio. Un grupo de las mismas fueron creadas por sectores obreros con el fin de liberarse de la explotación capitalista o, por lo menos, atenuar sus efectos. En estos casos se incluyen las primeras cooperativas fundadas bajo la ideología del socialismo utópico. Otro grupo de entidades fueron promovidas por integrantes de las capas medias y la pequeña y mediana burguesía, con el objetivo de buscar soluciones a sus problemas socioeconómicos y poder desarrollar su actividad comercial o industrial. Ejemplos de ello son las cooperativas agrarias o de crédito, como las que crearon grupos inmigrantes en Argentina, o pequeñas agrupaciones de propietarios en busca de proteccionismo comercial frente a consignatarios. En este segundo grupo también podemos ubicar a las primeras cooperativas pesqueras, que abordaremos a continuación. Luego, puede distinguirse una motivación estatal que impulsa la conformación de cooperativas a través de planes sociales y subsidios a fin contener las demandas sociales vinculadas al desempleo y la pobreza. Esta motivación se acentuó fuertemente en el período post 1980, producto de la reestructuración capitalista iniciada en los 70 que redujo la fuerza de trabajo asalariada registrada. En cuarto lugar, encontramos una motivación empresarial para la conformación de cooperativas fraudulentas, útiles para reducir salario y las cargas sociales, y, por ende, aumentar la extracción de plusvalía de la fuerza de trabajo. Este mecanismo se vio facilitado por la flexibilización laboral que se impuso tras la adopción de las medidas del consenso de Washington, mediante las cuales se redujo notoriamente la intervención regulatoria estatal en las empresas y el mercado -y por ello, en el mercado de trabajo-, permitiendo en gran medida la consecución de formatos ilegales tales como la tercerización laboral y el empleo no registrado. De acuerdo al Ministerio de Trabajo:

Resulta un hecho indiscutible que a partir de la década de los 90 ha proliferado la constitución de Cooperativas de Trabajo como entidades permeables al fraude laboral, es decir, instituciones bajo las cuales se enmascaró la existencia de verdaderas relaciones laborales, con el objeto de escapar a la aplicación de las normas tutelares en la materia (MTEySS, 2013:175). 
Dentro de este grupo podemos ubicar a las actuales cooperativas fraudulentas de la industria pesquera marplatense. Por su parte, trabajos de Urrea Giraldo (2010) y de la Garza Toledo (2010) dan cuenta de experiencias de cooperativización fraudulenta similares a las argentinas en México y Colombia, respectivamente. Por último, un quinto grupo de cooperativas se encuentra enmarcado en procesos de recuperación de empresas con autogestión obrera. En este caso, la motivación para conformar la cooperativa proviene de la necesidad de otorgar a la lucha obrera un marco legal que avale la continuidad del uso de las instalaciones de la empresa fallida y el pedido de expropiación. Sin embargo, estos casos guardan semejanzas con el tercer grupo de cooperativas fundadas en la promoción estatal, y también con las del grupo anterior, ya que muchas veces para subsistir deben subsumirse en la tercerización o subcontratación de fuerza de trabajo.

A continuación, expondremos algunas de las conceptualizaciones que enmarcan este auge del cooperativismo post 80 desde la llamada "Economía Social", paradigma desde el cual se fundamenta la promoción de las empresas recuperadas en Argentina y otros países de América Latina.

\subsection{Economía Social y cooperativismo}

La Economía Social (en adelante ES) comenzó a plasmarse como teoría y enfoque a partir de los 80 desde diversos autores tales como: Espínola Soriano de Souza Nunes (2002), Zamagni (2000), Singer (2002), Valle (2002), Gaiger (2000), Razeto (2002), Coraggio (1994), Laville (2002), Gandulfo (2014), entre otros. Paul Singer es uno de sus exponentes brasileros, quien la define como "una estrategia de supervivencia a la que recurren cada vez más trabajadores" (Singer, 2014:21). Dentro de este rubro se enmarcan distintas experiencias de pequeñas empresas cuya finalidad no es la acumulación de capital sino la reproducción ampliada de sus integrantes, tales como cooperativas de trabajadores, redes de trueque, familias productoras de alimentos, asociaciones de campesinos y emprendedores, artesanos y feriantes, empresas recuperadas y otros diversos microemprendimientos.

Podemos diferenciar dos grandes grupos de teóricos de la ES: los promotores y los críticos. Ambos enfoques coinciden en la vinculación entre ES, crisis social y reestructuración capitalista, conceptualizando que la proliferación de "estrategias laborales de supervivencia" guarda relación con la retracción del trabajo asalariado, el aumento de la pobreza, desempleo y marginalidad social.

Entre sus partidarios se encuentra El Banco Mundial (2001), que considera que la ES se vincula con la capacidad de empoderamiento de los sujetos, la atención de los problemas de la pobreza e incluso a la generación de capital social para la mejora de oportunidades de desarrollo económico y humano. De la mano de este planteo, una considerable cantidad de autores exponen que la ES invierte la relación entre los términos capital/trabajo, propia de la lógica capitalista, otorgándole supremacía al trabajo humano y las necesidades sociales por sobre la ganancia de capital. Este es 
su punto de partida, luego del cual insisten en señalar los llamados "principios" y "valores" de la ES. Entre los más nombrados cabe mencionar: emprendedorismo, autogestión, participación, autovalimiento, democracia, prácticas igualitarias, solidaridad, cooperación, fraternidad y compromiso.

Con respecto a la pregunta por los sujetos de la ES, si bien los autores reconocen que los sectores que mayormente integran estos emprendimientos son los más pobres, apuestan a que la ES sea una propuesta para el conjunto social. De igual manera, se esfuerzan por recalcar que los formatos de ES no se conciben meramente como instrumentos de reducción de la pobreza o paliativos del desempleo, sino que además "generan ciudadanía" mediante la "inclusión social con trabajo" y desarrollan capacidades tales como el trabajo en equipo, la creatividad y "nuevas fuerzas emprendedoras" (Federico-Sabate, 2003:24). Estas experiencias generarían un "empoderamiento" político, simbólico y subjetivo en las personas que las integran, además de los ingresos económicos para su subsistencia. Al respecto, Bastidas-Delgado y Richer afirman que es necesario adoptar una "nueva mirada" sobre el sector informal y sus implicancias sociales, y comenzar a considerarlo como una "posible trayectoria hacia el desarrollo económico y la integración social" (2001:21).

Gaiger, por su parte, refiere que, al desaparecer el antagonismo con el capital en este tipo de trabajo, se supera la alienación producto de la explotación capitalista y se elimina la propiedad privada: "No estando más ajeno a las determinaciones y al producto de su trabajo, ahora sobre su dominio, el trabajador recupera las condiciones necesarias, sino suficientes, para una existencia integral" (2001:206). Desde su concepción, la ES no solo sería beneficiosa para sus trabajadores sino deseable y preferible por sobre la tradicional explotación capitalista. Coraggio $(1994,1998)$ también considera a la ES como una forma alternativa a la economía capitalista; y por su parte Svampa (2005) y Rebón (2004) la plantearon como una matriz alternativa de organización y poder popular.

Este tipo de economía también es defendida y proclamada por exponentes teóricos que simpatizan o forman parte de agrupaciones políticas vinculadas a los proyectos progresistas/reformistas en Latinoamérica, como el lulismo en Brasil, el correísmo en Ecuador, el moralismo en Bolivia y el kirchnerismo en Argentina. A nivel nacional, uno de sus referentes más actuales es Alberto Gandulfo, reconocido sociólogo quien fuera a su vez funcionario del Ministerio de Desarrollo Social de la Nación durante el último gobierno de Cristina Fernández. En uno de sus artículos al respecto, este autor refiere que:

En la medida en que la ESS se multiplica, genera espacios solidarios que enfrentan a la economía concentrada y disputan el mercado local, se generan nuevos puestos de trabajo, aumentan los ingresos en los hogares populares, se avanza en integración comunitaria, surgen nuevos espacios organizativos que transforman realidades complejas (Gandulfo, 2014:30). 
Desde esta posición vemos que la ES no es planteada como una estrategia defensiva ante el desempleo y la precarización laboral sino una ofensiva contra los grandes grupos económicos y la misma reestructuración capitalista, proponiendo que estos pequeños emprendimientos se encuentran en condiciones de entrar en una contienda por el mercado interno contra el gran capital.

Finalizando esta sintética exposición sobre las posturas de los adeptos a la ES, cabe señalar lo expresado por Pastore (2015), quien expone que la ES constituye un término polisémico que en su dimensión empírica abarca tipos de emprendimientos y asociaciones que se distinguen de las lógicas dominantes de la empresa lucrativa y de la organización jerárquica-burocrática. En relación a este último punto, en la ES resaltan los principios organizativos de gestión democrática, participación voluntaria y autonomía decisional. Este autor, sin embargo, reconoce las problemáticas propias de índole económica, tecnológica y su escasa visibilidad.

En contrapartida, entre los críticos de la ES podemos mencionar a Aníbal Quijano (2011), Ricardo Antunes (2005), Agustín Salvia (2005), Susana Presta y Liliana Landabaru (2008) y José Francisco Puello-Socarrás (2010). Estos autores señalan dos aspectos que confluyen para la desestima de estas experiencias como garantes de trabajo y de derechos: por un lado, su vínculo con la precarización laboral y la pérdida de derechos obreros. Por otra parte, el hecho objetivo de que los actores principales que integran los diversos formatos de emprendimientos de la ES son los denominados excluidos, marginalizados, pobres o personas desaventajadas (Mance, 2001; Razeto et al., 1990).

En cuanto al primer señalamiento, la inserción de este tipo de emprendimientos en el modo de acumulación dominante se traduce como una subsunción al capital, no solo porque coexisten y son funcionales al capital concentrado, sino porque son parte constitutiva de las nuevas condiciones laborales signadas por la informalidad, las tercerizaciones y la disminución salarial.

Por otra parte, de acuerdo a Martínez Valle (2009) en la generalidad estos microemprendimientos no han logrado resultados económicos que muestren una viabilidad y perdurabilidad en el tiempo con ingresos acordes a una modesta subsistencia de sus integrantes por un extenso período de tiempo. Esto se vincula no tanto con la baja calificación del trabajo que realizan como con la competencia en el mercado con las grandes empresas capitalistas, que fijan los precios, los ritmos de producción, la disponibilidad de materia prima, y una performance en cuanto al marketing y la publicidad propios de la difusión mediática masiva. Lejos de establecerse una disputa entre las empresas de la ES y el capital concentrado, la realidad es que los microemprendimientos no guardan otra perspectiva que no sea la de una resistencia temporaria a la desocupación, o bien la integración como segmento del proceso de producción de la gran empresa. Al respecto, Giavedoni (2015) concluye que estas experiencias integran las "nuevas" formas del trabajo precarizado, parcial, tercerizado, que lejos de ser efectos no deseados del modo de producción capitalista, son producto y resultado intencional del mismo. 
Comentario aparte merece el origen de los distintos tipos de financiamiento a partir del cual las empresas de la ES obtienen oxígeno para continuar subsistiendo en la atmósfera capitalista. Uno de los grandes promotores ya mencionados es el Banco Mundial mediante los llamados "programas de empoderamiento" de las comunidades pobres. La iglesia católica es otra de las fuentes de subsidios y programas destinados al sostenimiento de este tipo de experiencias, así como ONGs y también los mismos Estados, que financian o co-financian en conjunto con las organizaciones mencionadas dichos proyectos. Por este motivo Antunes (2005) concluye que la promoción de la ES por los estados y organismos supranacionales es utilizada como modo de gestión del conflicto social, como muro de contención frente al estallido social. Al respecto, Martínez y Ruggeri (2005) destacan que estas formas de la economía informal clausuran y/o postergan la lucha obrera por el retorno a la estructura productiva formal. De aquí que Giavedoni llegue a la conclusión de que la ES "puede leerse como una forma de producción alternativa y con potencialidades emancipatorias o, al mismo tiempo, como modalidad de gestión de la fuerza de trabajo, incorporándola de una determinada manera al proceso de producción en su dimensión económica y, al mismo tiempo, logrando que la responsabilidad de su reproducción a través del salario que antes recaía en la patronal, ahora sea responsabilidad de los mismos protagonistas" (2015:209).

La implementación de políticas públicas ligadas a la ES por parte de los estados capitalistas cumpliría el fin de reproducir el modo de acumulación capitalista neoliberal, manteniendo la enorme brecha entre los grandes grupos económicos que acrecientan su dominio y los medianos y pequeños emprendimientos -más aún con respecto a los integrados por obreros en riesgo de ser despedidos o ya sumidos en la desocupación- que corren un constante riesgo de extinción y subsisten en la incertidumbre. A su vez, este tipo de políticas perpetúan el desligamiento del Estado para con las poblaciones más desfavorecidas y pobres, en quienes se deposita la responsabilidad de "salir adelante" de la mano de la ES.

La proliferación de cooperativas desde los 90 en América Latina se incluye en este paradigma de gestión de la pobreza y de la precariedad laboral por parte de los gobiernos y las grandes empresas, ya que estos formatos asociativos posibilitan la evasión legal de las normativas laborales vigentes. La autonomía, la creatividad y el emprendedorismo no son sino eufemismos para los preceptos neoliberales de individualismo y meritocracia que actúan como justificativo de la miseria y la desigualdad.

En consonancia con estos planteos, nos parece oportuno tomar los aportes de Aníbal Quijano, quien en un recorrido conceptual por las formas de lucha organizada contra la explotación menciona a las cooperativas de Owen y los falansterios de Fourier como parte de estos intentos de superación del capitalismo, a la par de la idea sainsimoniana de "sociedad de productores", la estatización de los medios de producción, la experiencia de la Comuna de París en 1871 y los consejos obreros del socialismo europeo, entre otras. A diferencia del resto de los proyectos políticos mencionados, las cooperativas lograron sobrevivir hasta el presente mediante 
drásticas distorsiones -tanto desde la socialdemocracia europea como desde las corrientes democrático-nacionalistas de Asia y América Latina- y ocupando un lugar marginal en el mercado:

...como todas esas corrientes políticas, se replegaron, finalmente, a la lucha por reformar el capitalismo para moderar la explotación de los trabajadores y a la correspondiente administración de las relaciones entre capital y trabajo en los países donde accedieron al gobierno, el cooperativismo fue vinculado a la concepción y práctica de tales reformas (Quijano, 2011:371).

Por ello, Quijano concluye que la ES no es una "economía alternativa" ya que casi en su totalidad estas experiencias no van más allá de ser "estrategias de supervivencia" (Quijano, 1998) que, si bien en ocasiones permiten sobrevivir e incluso mejorar relativa y temporalmente condiciones de existencia de sectores empobrecidos cuyas necesidades de empleo e ingresos son urgentes, no constituyen un cuestionamiento al capitalismo, sino que forman parte de su reestructuración actual. Asimismo, este autor expone que la existencia de estos emprendimientos se debe en gran medida al financiamiento externo, que al interrumpirse provoca generalmente su cese. Las experiencias que logran sobrevivir lo hacen a costa de su "transformación" en "pequeñas y medianas empresas dedicadas explícita y concientemente al lucro individual, bajo el control y en beneficio de los que administraban esas organizaciones" (2011:385).

Una perspectiva similar pero que ejerce una crítica más profunda es la de Agustín Salvia, quien denomina a la ES como "Economía política de la pobreza" (2005:1). Este autor define los formatos de ES con el término "microestrategias de subsistencia" encuadradas en el crecimiento del sector de trabajo informal que "reproduce de manera ampliada una matriz socio-política cada vez más polarizada y fragmentada" (Salvia, 2005:2). Asimismo, cuestiona la naturalización del deterioro de las condiciones de vida y de trabajo para un considerable sector de la población, que estos emprendimientos no resuelven. También destaca el aspecto en el que según él- radica el efecto más conservador de estas formas de subsistencia: el traslado del conflicto social desde la lucha política al plano de lo privado o comunitario, adjudicando al Estado el papel de "sostén". Al respecto dice:

el mayor problema que presentan los sectores < desplazados $>$ no es haber caído sino no poder salir de los encadenamientos socioeconómicos y políticoinstitucional que generan las condiciones iniciales de marginalidad y que se actualizan bajo las renovadas formas de subsistencia que instalan los propios sectores populares a través de sus estrategias de vida (Salvia, 2005:6).

A su vez, la falta de amplitud de los mercados de venta de sus productos y el enquistamiento de estos emprendimientos en una progresiva dependencia del Estado y de las agencias promotoras (como iglesias u ONGs) conducen a la convalidación de la marginalidad social, la precariedad laboral y sus condicionantes políticos e ideológicos. Por ello, a pesar de que la llamada ES evidencia "el potencial 
disponible por parte de la sociedad informal y marginada para atender su propia reproducción" (2005:17), en los hechos no genera otro resultado que el evitamiento del desempleo, ya que la reacción dominante no va más allá del reconocimiento del derecho a la subsistencia desde las propias condiciones de carestía y precarización, sin ir más allá de las reglas de reclusión y confinamiento propias de ese sector informal. El efecto de sentido que produce la proclamación y el aval estatal a las formas de la ES se traduce en la legitimación de la exclusión social, en una formalización del empleo informal y su circunscripción a una salida inofensiva para el gran capital.

Finalmente, Ghigliani al analizar casos de empresas recuperadas asevera que "no hay economía solidaria, popular, social o alternativa dentro del capitalismo" (2003: 18), en referencia a la falta de horizonte de cambio social de estas iniciativas autogestionarias.

Desde nuestra parte, consideramos que, a partir de la última reestructuración capitalista, parte de la resistencia del movimiento obrero pasó en gran medida por asegurar su subsistencia, debiendo recurrir, no por idealismo ni elección sino como única alternativa, a la inserción en la economía informal dentro del llamado "Tercer sector". Paralelamente, los capitalistas comenzaron a utilizar similares formatos de trabajo informal para avanzar en la superexplotación de parte de la fuerza de trabajo, mediante mecanismos legales e ilegales para proceder a la "desregulación" del trabajo bajo el amparo gubernamental y judicial. La semejanza entre las estrategias de los sectores obreros excluidos del mercado laboral formal, su promoción por parte de los Estados, la institución católica y los organismos financieros internacionales, y las nuevas modalidades de trabajo que actualmente conviven con el trabajo asalariado "tradicional", creemos que expresa el crecimiento de una tendencia a precarizar a la fuerza de trabajo. Esta tendencia sería una respuesta ante la caída de la tasa de ganancia y las dificultades que empresarios de ciertos sectores económicos encuentran para superar ciertos límites en el incremento de la productividad. Por ello, recurren a la extracción de mayor plusvalía reduciendo salarios o derechos laborales, mediante la apelación a la subcontratación o tercerización de la fuerza de trabajo y la producción. En esta ofensiva empresarial los trabajadores son sometidos a "formas presalariales de explotación", formas mucho más perversas que el trabajo asalariado tradicional. De aquí que la "economía social" hoy tenga el sentido práctico y utilitario de dualizar la fuerza de trabajo, conllevando rebajas salariales, pérdida de derechos y garantías y jornadas laborales más extensas y extenuantes. Estas conclusiones demuestran a su vez que el Tercer Sector, lejos de guardar autonomía con respecto al Estado y las corporaciones empresariales, se encuentra fuertemente atado a los mismos.

En síntesis, estamos en condiciones de afirmar que, tanto la ES como la mayor parte del cooperativismo en la actualidad, más que una herramienta de resistencia y lucha obrera contra el capital operan como formatos de precarización laboral y estrategias de supervivencia que en la práctica contribuyen al salvataje del capital y de los Estados, que se desligan de la problemática social del desempleo y la 
superexplotación obrera y contienen la conflictividad social en torno a ella. Bajo el paradigma de la ES, el empresariado utiliza la maniobra de la cooperativización fraudulenta para obtener mayor plusvalía y el Estado promueve la creación de cooperativas como modo de trasladar al plano subjetivo el problema de la desocupación y la inestabilidad laboral, bajo la premisa de que, con esfuerzo, dedicación y recursos estatales, los microemprendimientos se abrirán espacio y rentabilidad en una economía imperialista y neoliberal.

Para continuar con este análisis de los formatos laborales actuales en la reestructuración capitalista, nos centraremos ahora en su vinculación con la realidad objetiva de la desocupación y el trabajo no registrado en Argentina desde los 90 hasta el 2012, y luego en las localidades portuarias Mar del Plata y Necochea, a fin de enmarcar nuestro análisis específico.

\section{Desocupación y trabajo no registrado en Argentina, 1991-2012}

La desocupación y la precarización laboral son tendencias crecientes a nivel mundial. El informe de la OIT para el año 2012 señala un 6\% de desempleo sobre el total de la fuerza de trabajo mundial, significando 200 millones de personas, 27 millones más que en el año 2007. A su vez, dentro de ese conjunto se presenta un total de 75 millones de jóvenes desempleados entre 15 y 24 años, 4 millones más que en 2007.

En Latinoamérica, durante la década del 70 el cambio de modelo de acumulación trajo aparejado una reconversión del sector industrial, una concentración y descentralización de las fuerzas productivas de este sector que afectó fuertemente al mercado de trabajo formal, causando una contracción del empleo asalariado. Paralelamente se produjo un leve aumento del empleo en el sector de los servicios que no llegó a compensar los puestos de trabajo perdidos en la industria, lo cual conllevó una caída del índice de empleo que se profundizó en los 90 con las políticas de flexibilización laboral y tuvo su pico en la coyuntura más álgida de la crisis de las políticas económicas neoliberales, que en Argentina aconteció entre los años 20012002.

Luego de la crisis y con el nuevo ciclo que inició en 2002/2003 y se caracterizó por una recuperación y crecimiento económicos (Grigera y Eskenazi, 2013) que produjo, entre otras consecuencias, el aumento del PBI y las exportaciones, tanto en Argentina como en América Latina continúan siendo notorias las tasas de desempleo y empleo informal. Contrastando estas cifras con las de los 90 puede observarse que la supuesta recomposición es cuestionable, ya que se mantienen los niveles de los primeros años de la convertibilidad. El empeoramiento en las condiciones de vida y del trabajo que provocó la reestructuración capitalista en América Latina es drástico: mientras que en 1980 había 136 millones de pobres y 62 millones de indigentes, para 2005 las cifras se incrementaron a 209 millones y 81 millones respectivamente. De acuerdo al programa CLASCO, para el año 2008 "cerca del $40 \%$ de la población de América Latina y el Caribe vive en la pobreza" 
(CLACSO, 2008: 13). Millones Espinosa (2012) especifica las condiciones de desigualdad y precarización laboral en América Latina, en donde para el año 2010 de acuerdo a la CEPAL la pobreza fue del 31,4\% de la población en general, incluyendo a un $12,3 \%$ en extrema indigencia, lo cual en términos numéricos significan 177 millones de personas pobres de las cuales 70 millones estarían en condiciones de extrema pobreza. Luego, el 20\% más rico de la población percibe un ingreso 19,3 veces mayor que el quintil más pobre, y casi la mitad de la población posee trabajos informales en condiciones precarias. Además, el empleo formal vio también acrecentadas sus condiciones de flexibilización, lo que hace que se difuminen sus diferencias con las condiciones de trabajo informal (2012:103). Las cifras del 80 expresan la magnitud de la miseria que provoca el capitalismo, mientras que las más actuales demuestran que la clase capitalista ha logrado avanzar aún más en las condiciones de dominación y sometimiento de las grandes mayorías.

En cuanto al crecimiento del sector de trabajo informal en Argentina, su presencia dentro del mercado laboral se ha enquistado y cristalizado, perdurando a pesar de los años de bonanza económica post 2003 (Esponda y Basualdo, 2014). A nivel nacional, a partir del año 2003 se ha producido un aumento del trabajo asalariado con un descenso de la desocupación y el trabajo no registrado con respecto a los años más álgidos de la crisis neoliberal. Sin embargo, el empleo no registrado aún mantiene un alto porcentaje con índices similares a los de la década del 90, afectando a 1 de cada 3 trabajadores. Asimismo, los trabajadores no registrados ganan entre 2 y 3 veces menos que los trabajadores registrados, sus hogares son casi 4 veces más pobres y realizan jornadas más extensas con respecto a sus pares asalariados bajo relación de dependencia (Esponda y Basualdo, 2014). A su vez esta diferenciación o dualización de la fuerza de trabajo provoca un fraccionamiento de la clase trabajadora, debilitando la potencia y la organización dentro de los lugares de trabajo, de la misma rama y del sector en general (Monereo Pérez, 2011).

Tomando en cuenta estos desarrollos, la acentuación de la precarización laboral puede sintetizarse como expresión de un fenómeno estructural relativo a las transformaciones en el mundo del trabajo en el marco de la reestructuración capitalista.

\subsection{Análisis nacional}

En la década del 90, se masificó el empleo no registrado como estrategia empresarial para la mayor extracción de plusvalía, disminuyendo el costo del capital variable al disminuir los salarios y las cargas sociales que implican su formalización. Las características e implicancias de este aumento de trabajo no registrado se expusieron en el capítulo anterior, por lo que al respecto aquí solo agregaremos que, tomando en cuenta un nivel macro socioeconómico, el trabajo no registrado implica una pérdida de ingresos no solo para el obrero sino para el conjunto social, ya que 
por la evasión impositiva y previsional que conlleva, el empleador no realiza aportes fiscales.

A continuación, se muestran los índices de trabajo no registrado y de desocupación en Argentina en un lapso que abarca las últimas dos décadas:

Gráfico №6. Valores de las tasas de desocupación y trabajo no registrado en Argentina, 1995-2012:

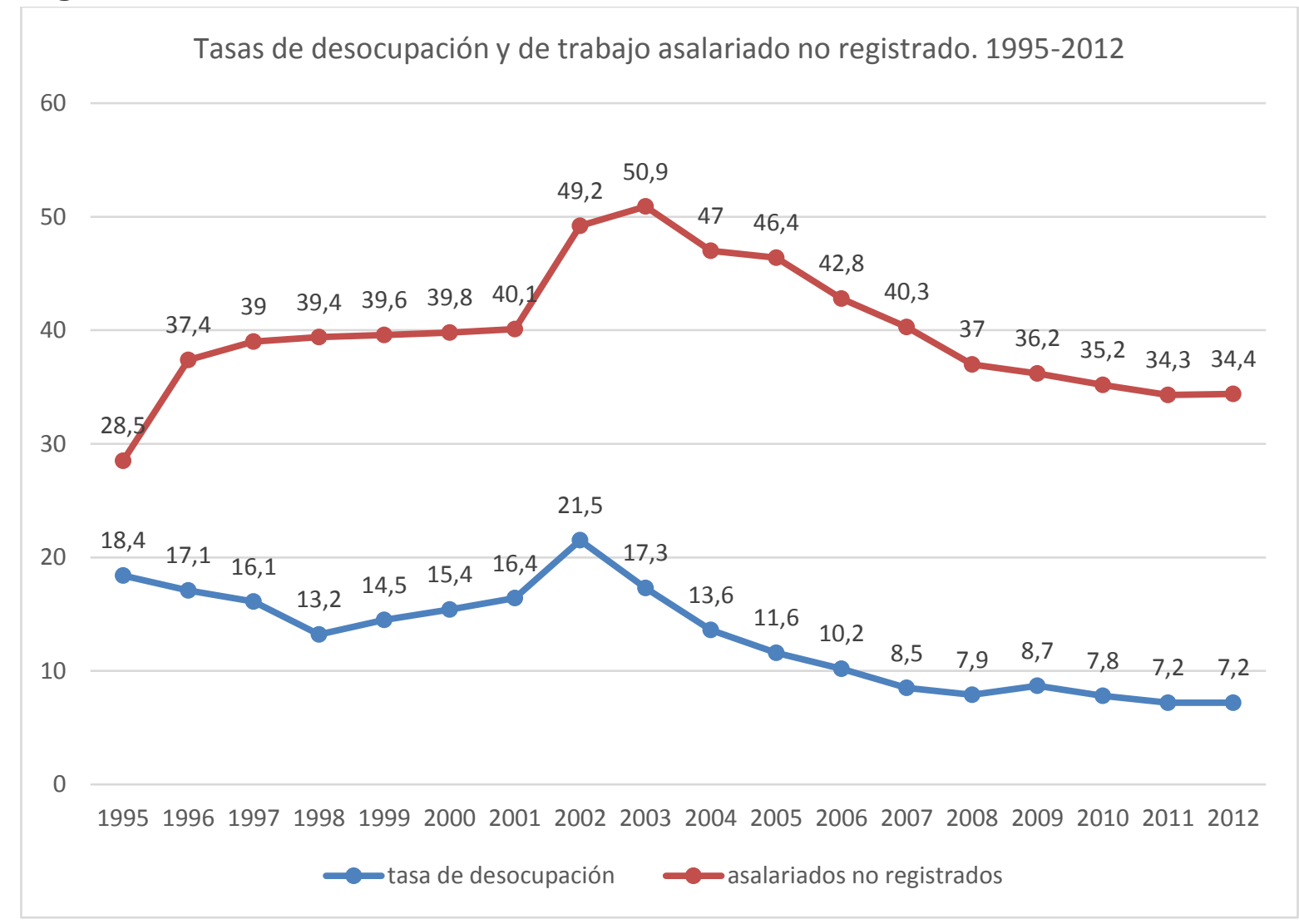

Fuente: Elaborado en base a datos del INDEC y del Ministerio de Economía y Finanzas Públicas.

Antes de analizar estos datos, valen algunas aclaraciones. Consideramos que estas cifras expresan porcentajes mínimos de desocupación y empleo no registrado, ya que si se realiza un análisis más pormenorizado de los mismos en los aglomerados urbanos considerados por el INDEC se observan llamativos números, como por ejemplo 1 y 0 \% de desocupación en Chaco y 1,9 \% en Formosa ${ }^{20}$. Teniendo en cuenta estas posibles discrepancias, tomando los datos oficiales del año 2010 podemos estimar que para una población económicamente activa de 19 millones de personas (MTEySS, 2012), 17,5 millones de ellas estaban ocupadas, 1,5 millones desocupadas (7,8\%), y dentro de la población ocupada 4,7 millones eran asalariados no registrados $(26,9 \%)$. Para visualizar estos datos se expone el siguiente gráfico:

20 INDEC, Anuario Estadístico de la República Argentina 2013, Buenos Aires, marzo de 2015. 
Gráfico №7. Distribución de la población ocupada en relación a los asalariados y asalariados no registrados:

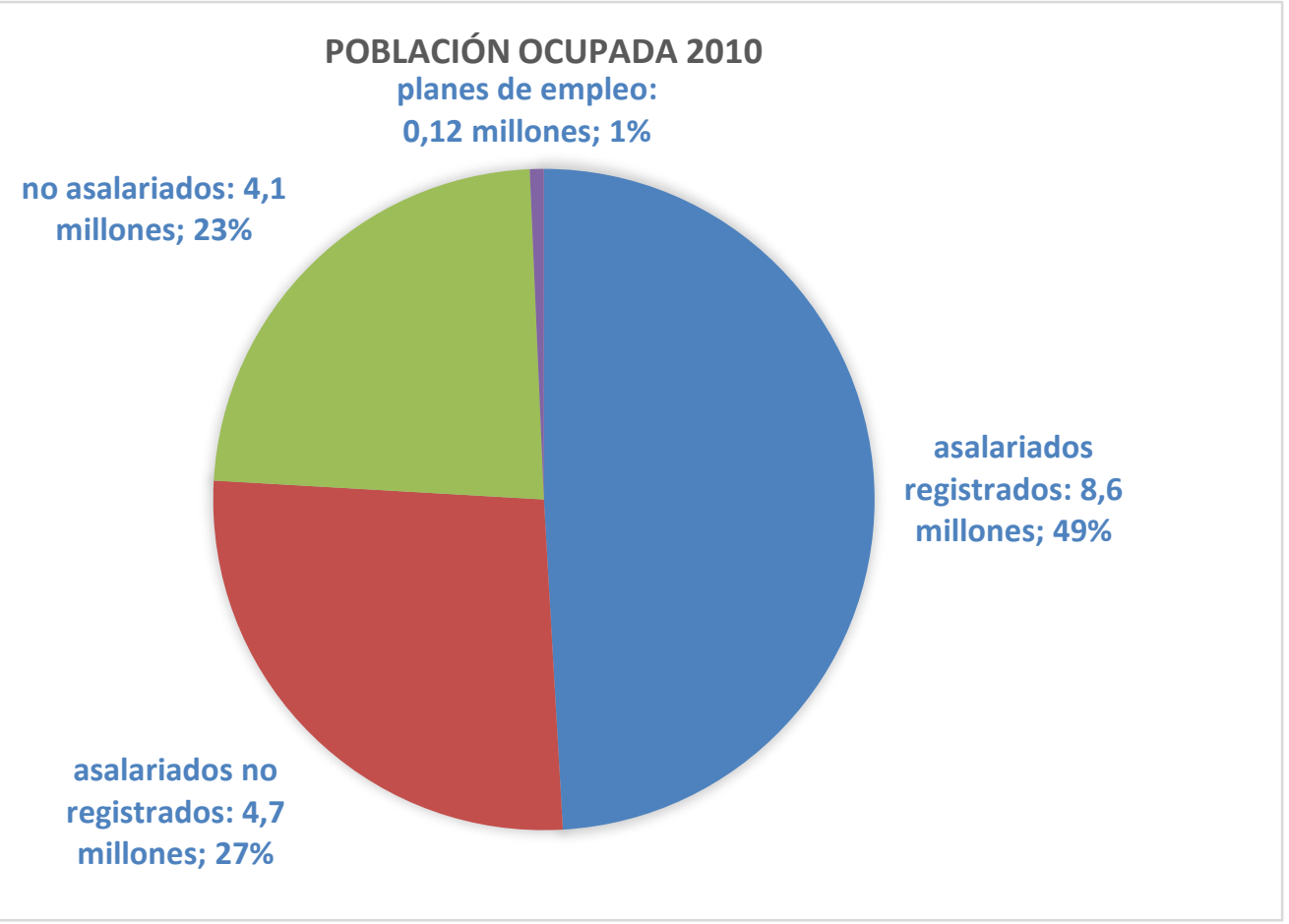

Fuente: Extraído de CIFRA (2012).

Por otro lado, se observa que, si bien ambos índices descendieron en forma significativa (alrededor de 15 puntos) en comparación con los años más álgidos de la crisis (2001-2002), se mantienen en cifras similares a las de inicios de la década del $90^{21}$, lo que expresa que el acceso al trabajo formal y al empleo en general no se vio alterado con respecto a las condiciones neoliberales.

De acuerdo a CIFRA ${ }^{22}$, en 2003 había 4,2 millones de trabajadores no registrados que representaban el 29,2\% de ocupados, mientras que en 2010 había aumentado la cantidad de estos trabajadores a 4,7 millones pero representando a un $26,6 \%$ de ocupados totales, lo cual se correlaciona tanto con el aumento del número de trabajadores registrados (de 5,4 a 8,6 millones respectivamente) como con una disminución de los perceptores de planes de empleo (de 0,99 a 0,12 millones respectivamente) teniendo en cuenta ese mismo período.

Las estadísticas oficiales señalan la creación de 3.743.582 puestos de trabajo en la década 2002-2012, los cuales se corresponden con el incremento de trabajadores asalariados registrados, que variaron del 37,1 \% del total de ocupados en 2003 al $50,2 \%$ en el año 2011. Este incremento del empleo registrado no incidió mayormente sobre el porcentaje de trabajadores no registrados, que se mantuvo en niveles significativos para el conjunto de la población ocupada y de los asalariados, ascendiendo en 500.000 trabajadores entre 2003 y 2011. Esto nos lleva a

\footnotetext{
${ }^{21}$ Para el año 1992 la tasa de desocupación nacional era del 6,9 \% (INDEC, 1997).

${ }^{22}$ CIFRA, CTA DT №10, julio de 2011, disponible en www.centrocifra.org.ar/docs/CIFRA\%20\%20DT\%2010\%20-\%20Mercado\%20de\%20trabajo.pdf
} 
considerarlo como una problemática social de relevancia, expresión de una tendencia estructural que afecta a gran cantidad de la población desde hace décadas.

\subsection{La realidad ocupacional de Mar del Plata y Necochea}

Veamos ahora estas cifras en las ciudades portuarias que nos ocupan aquí. En las siguientes tablas y gráficos se expresan datos cuantitativos y porcentuales acerca de las características de la población económicamente activa, las principales tasas socioeconómicas y características ocupacionales de ambas ciudades portuarias, tomando los años de los tres últimos censos nacionales ${ }^{23}$ :

Tabla №13. Cantidad de habitantes por condición de actividad, Mar del Plata y Necochea, años 1991, 2001 y 2010:

\begin{tabular}{|l|r|r|r|r|r|r|}
\cline { 2 - 7 } \multicolumn{1}{c|}{} & \multicolumn{3}{|c|}{ Mar del Plata } & \multicolumn{3}{c|}{ Necochea } \\
\cline { 2 - 7 } \multicolumn{1}{c|}{} & $\mathbf{1 9 9 1}$ & \multicolumn{1}{|c|}{$\mathbf{2 0 0 1}$} & $\mathbf{2 0 1 0}$ & $\mathbf{1 9 9 1}$ & \multicolumn{1}{c|}{$\mathbf{2 0 0 1}$} & \multicolumn{1}{c|}{$\mathbf{2 0 1 0}$} \\
\hline PEA & 234.206 & 251.065 & 296.495 & 35.456 & 37.948 & 46.297 \\
\hline Ocupados & 217.578 & 176.186 & 271.736 & 33.295 & 27.455 & 43.393 \\
\hline Desocupados & 16.628 & 74.879 & 24.759 & 2.161 & 10.493 & 2.904 \\
\hline Población total & 532.845 & 564.056 & 618.989 & 85.581 & 89.096 & 92.933 \\
\hline
\end{tabular}

Fuente: Elaborado en base a INDEC, Censos Nacionales de los años 1991, 2001 y 2010 y la EPH.

Tabla №14. Indicadores socioeconómicos en Mar del Plata y Necochea, años 1991, 2001 y 2010:

\begin{tabular}{|l|r|r|r|r|r|r|}
\cline { 2 - 7 } \multicolumn{1}{c|}{} & \multicolumn{3}{c|}{ Mar del Plata } & \multicolumn{3}{c|}{ Necochea } \\
\cline { 2 - 7 } \multicolumn{1}{c|}{} & $\mathbf{1 9 9 1}$ & $\mathbf{2 0 0 1}$ & $\mathbf{2 0 1 0}$ & $\mathbf{1 9 9 1}$ & \multicolumn{1}{|c|}{$\mathbf{2 0 0 1}$} & \multicolumn{1}{c|}{$\mathbf{2 0 1 0}$} \\
\hline Tasa de actividad & $43,9 \%$ & $44,5 \%$ & $47,9 \%$ & $41,4 \%$ & $42,5 \%$ & $49,8 \%$ \\
\hline Tasa de empleo & $40,8 \%$ & $31,2 \%$ & $43,9 \%$ & $38,9 \%$ & $30,8 \%$ & $46,6 \%$ \\
\hline Tasa de desocupación & $7,1 \%$ & $29,8 \%$ & $8,4 \%$ & $6,1 \%$ & $27,6 \%$ & $6,3 \%$ \\
\hline
\end{tabular}

Fuente: Elaborado en base a INDEC, Censos Nacionales de los años 1991, 2001 y 2010 y la EPH.

\footnotetext{
${ }^{23}$ Aclaración metodológica: los datos aquí presentados corresponden a estimaciones, no a valores absolutos, por tres motivos. El primero se refiere a lo expresado por el propio organismo estadístico nacional (INDEC), que expone que todos los datos correspondientes al período 2007 a 2015 deben ser considerados "con reservas". En segundo lugar, al haber explorado en el transcurso de esta investigación las bases de datos de los Censos Nacionales y la Encuesta Permanente de Hogares, se han hallado discrepancias entre los resultados para la ciudad de Mar del Plata. Por ejemplo, en la base REDATAM de los datos del Censo 2010 se extrae que en la ciudad había un 6,7\% de desocupación, mientras que la EPH expresa un 8,4 como promedio de dicho año. Por ello, se recurrió a la base REDATAM solo cuando no se hubiere encontrado otra fuente de información, ya que la EPH posee un sistema de obtención de la información más preciso, elaborado en forma puntual y aplicado en forma permanente. Por último, para el caso de Necochea la carencia de datos estadísticos es notable, ya que esta localidad no está incluida en la EPH ni en la EHE que se realiza en localidades del interior de la provincia de Buenos Aires, y tampoco se han llevado a cabo estudios cuantitativos desde el Estado municipal, que carece de una sección de estadística propia. De aquí que, todo estudio regional y local que aborde esta ciudad, creemos que merece especial atención y relevancia.
} 
Se observa que las ciudades portuarias abordadas comparten las tendencias nacionales en cuanto al descenso de la tasa de desocupación en 2010 con respecto a los años más álgidos de la crisis neoliberal, pero que sin embargo no expresan significativas diferencias con esos valores con respecto al año 1991. A lo largo de las dos décadas examinadas, la desocupación no solo creció en cantidad de personas sino también en términos de proporción con respecto a la población total: en Mar del Plata los desocupados representaban un 3,1\% del total de habitantes en 1991, mientras que en el año 2010 esta proporción ascendió al 3,9\%. En el caso de Necochea, el porcentaje de desocupados era de 2,5\% respecto al total de habitantes en 1991, mientras que para 2010 esta proporción ascendió al 3,1\%. Esto significa que, por cada 100 habitantes, en Mar del Plata hay 4 desocupados, mientras que en Necochea hay 3 desocupados. Y si tomamos como referencia a la población económicamente activa, vemos que en Mar del Plata hay 9 desocupados por cada 100 ocupados, y en Necochea casi 7 desocupados por cada 100 ocupados.

Veamos ahora la distribución de la población ocupada por categoría ocupacional:

Tabla №15. Distribución de la población ocupada por categoría ocupacional en Mar del Plata, años 1991, 2001 y 2010:

\begin{tabular}{|l|r|r|r|r|r|c|}
\cline { 2 - 7 } \multicolumn{1}{c|}{} & \multicolumn{9}{c|}{ Mar del Plata } \\
\cline { 2 - 7 } \multicolumn{1}{c|}{} & \multicolumn{2}{c|}{$\mathbf{1 9 9 1}$} & \multicolumn{2}{c|}{$\mathbf{2 0 0 1}$} & \multicolumn{2}{c|}{$\mathbf{2 0 1 0}$} \\
\cline { 2 - 7 } \multicolumn{1}{c|}{} & Cantidad & \multicolumn{1}{c|}{$\%$} & Cantidad & \multicolumn{1}{c|}{$\%$} & \multicolumn{1}{c|}{ Cantidad } & \multicolumn{1}{c|}{$\%$} \\
\hline Obrero o empleado & 134.898 & 62,0 & 120.276 & 68,0 & 191.302 & 70,4 \\
\hline Patrón & 20.887 & 9,6 & 13.384 & 7,6 & 15.217 & 5,6 \\
\hline Cuentapropista & 53.742 & 24,7 & 37.824 & 21,4 & 63.043 & 23,2 \\
\hline Trabajador familiar & 8.051 & 3,7 & 4.072 & 2,6 & 2.174 & 0,8 \\
\hline $\begin{array}{l}\text { Total Población } \\
\text { Ocupada }\end{array}$ & 217.578 & 100 & 176.186 & 100 & 271.736 & 100 \\
\hline
\end{tabular}

Fuente: Elaborado en base a INDEC, Censos Nacionales de los años 1991, 2001 y 2010 y la EPH.

Tabla №16. Distribución de la población ocupada por categoría ocupacional en Necochea, años 1991, 2001 y 2010:

\begin{tabular}{|l|r|r|r|r|r|r|}
\cline { 2 - 7 } \multicolumn{1}{c|}{} & \multicolumn{9}{c|}{ Necochea } \\
\cline { 2 - 7 } \multicolumn{1}{c|}{} & \multicolumn{1}{c|}{$\mathbf{1 9 9 1}$} & \multicolumn{2}{c|}{$\mathbf{2 0 0 1}$} & \multicolumn{2}{c|}{$\mathbf{2 0 1 0}$} \\
\cline { 2 - 7 } \multicolumn{1}{c|}{} & Cantidad & \multicolumn{1}{c|}{ \% } & Cantidad & \multicolumn{1}{c|}{$\%$} & \multicolumn{1}{c|}{ Cantidad } & \multicolumn{1}{c|}{$\%$} \\
\hline Obrero o empleado & 19.977 & 60,0 & 17.484 & 63,6 & 26.904 & 62 \\
\hline Patrón & 3.662 & 11,0 & 2.719 & 9,9 & 5.641 & 13 \\
\hline Cuentapropista & 7.924 & 23,8 & 6.260 & 22,9 & 9.112 & 21 \\
\hline Trabajador familiar & 1.732 & 5,2 & 992 & 3,6 & 1.736 & 4 \\
\hline $\begin{array}{l}\text { Total Población } \\
\text { Ocupada }\end{array}$ & 33.295 & 100 & 27.455 & 100 & 43.393 & 100 \\
\hline
\end{tabular}

Fuente: Elaborado en base a INDEC, Censos Nacionales de los años 1991, 2001 y 2010.

En el caso de Mar del Plata observamos un crecimiento del porcentaje de la población asalariada entre 1991 y 2010, pasando del 62 al 70 \%. En contraste, 
vemos un descenso significativo en la categoría de los patrones, quienes descendieron un $27 \%$ durante las dos décadas. Un descenso igualmente importante se observa en la categoría de trabajadores familiares (del 3,7 al 0,8\%), mientras que la proporción de cuentapropistas no sufrió grandes modificaciones en cuanto a la distribución total, aunque aumentó significativamente su número entre $1991 \mathrm{y}$ 2010, pasando de 53.000 a 63.000 trabajadores. Los asalariados junto con los cuentapropistas y los trabajadores familiares representaban un $94,6 \%$ de la población ocupada para el año 2010, mientras que el 5,6 restante corresponden a la categoría "patrones".

Gráfico №8. Distribución de la población ocupada por categoría ocupacional, Mar del Plata, años 1991, 2001 y 2010:

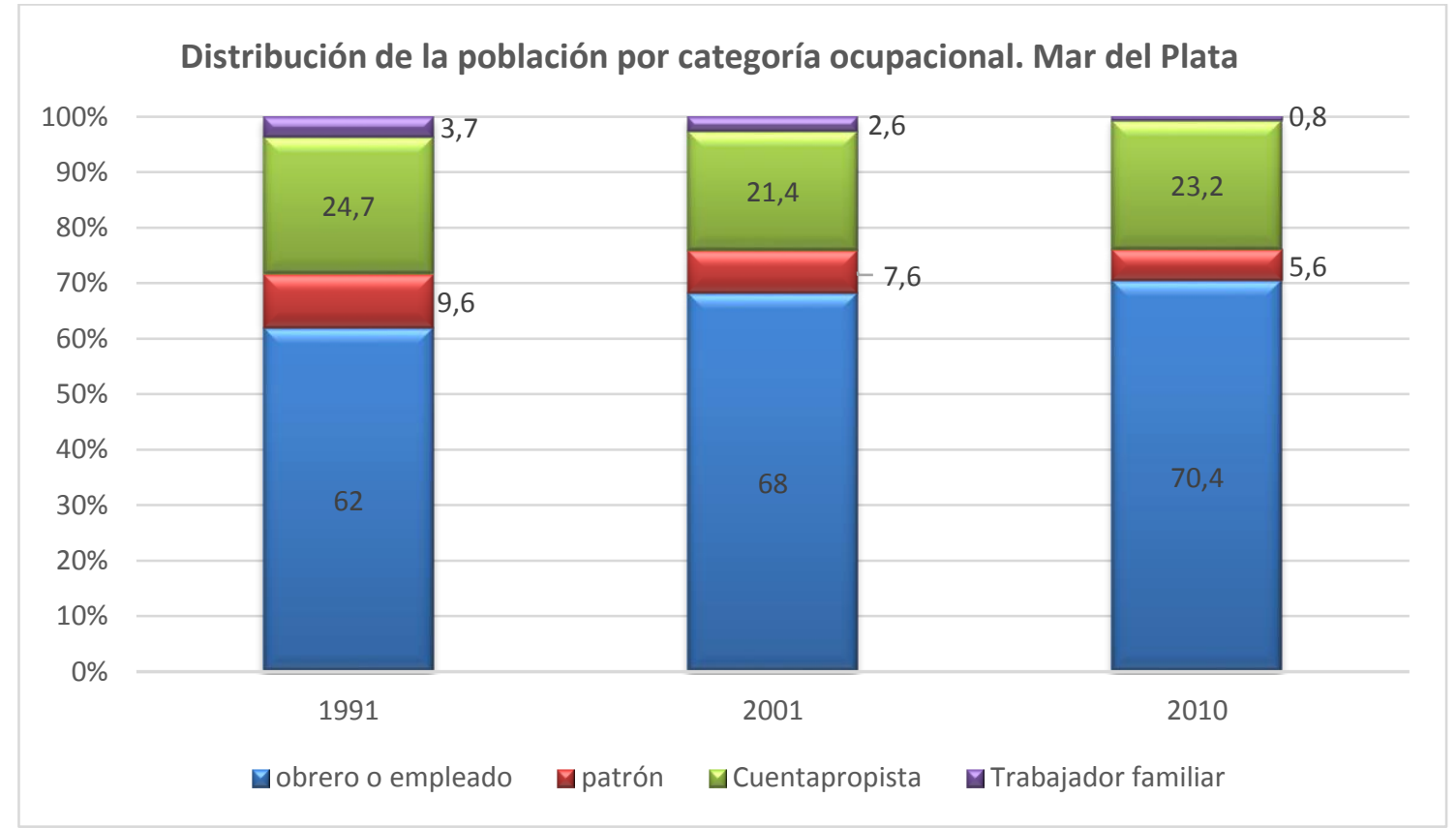

Fuente: Elaborado en base a INDEC, Censos Nacionales de los años 1991, 2001 y 2010.

En cuanto a la distribución de la población por categoría ocupacional en Necochea entre 1991 y 2010, se observa que las variaciones no han sido demasiado significativas en el caso de los asalariados y cuentapropistas. Por el contrario, los trabajadores familiares, que descendieron drásticamente en el año 2001 y para el 2010 presentaron una recomposición. El predomino de los asalariados es significativo -aunque no tanto como en Mar del Plata-, quienes junto con los cuentapropistas y los trabajadores familiares abarcaban aproximadamente el $87 \%$ de la población ocupada tomando como referencia el año 2010, mientras que para ese mismo año los patrones sumaban un total del 13\%. A diferencia de Mar del Plata, esta última categoría creció significativamente entre 1991 y 2010. 
Gráfico №9. Distribución de la población ocupada por categoría ocupacional, Necochea, años 1991, 2001 y 2010:

Distribución de la población por categoría ocupacional. Necochea

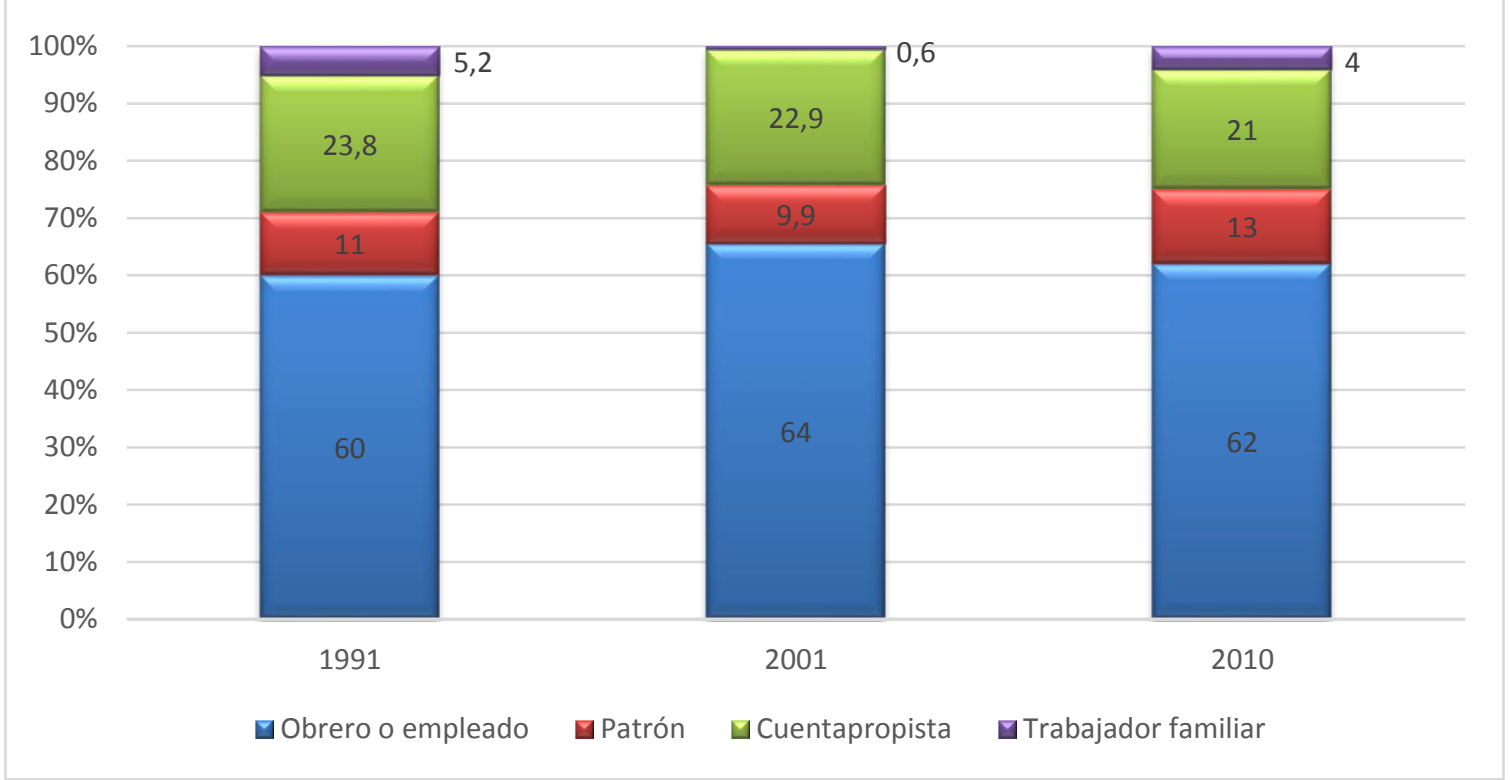

Fuente: Elaborado en base a INDEC, Censos Nacionales de los años 1991, 2001 y 2010.

Veamos ahora las ocupaciones principales en cada localidad y el lugar del sector pesquero en esa distribución:

Tabla №17. Distribución de la población ocupada entre los principales rubros ocupacionales, Mar del Plata, 2010:

\begin{tabular}{|l|r|}
\hline Rubro & $\begin{array}{c}\text { \% de } \\
\text { ocupados }\end{array}$ \\
\hline Gestión administrativa, jurídica, contable y financiera & 12,0 \\
\hline Limpieza doméstica y no doméstica & 10,7 \\
\hline Comercio & 10,6 \\
\hline Dirección y gerencia de PYMES & 8,7 \\
\hline Construcción e infraestructura & 8,4 \\
\hline Producción industrial y artesanal & 7,7 \\
\hline Educación & 6,7 \\
\hline Transporte y almacenaje & 6,6 \\
\hline Salud y sanidad & 4,6 \\
\hline Gastronomía y turismo & 4,6 \\
\hline Otros servicios varios & 4,5 \\
\hline Servicios de seguridad estatal y privada y de las FFAA & 2,6 \\
\hline Otros Servicios Sociales básicos & 1,7 \\
\hline Reparación de bienes de consumo & 1,6 \\
\hline Total & $\mathbf{9 1}$ \\
\hline
\end{tabular}

Fuente: Elaborado en base a INDEC, base REDATAM.

Observamos en el caso de Mar del Plata que la producción industrial se ubicó en el sexto lugar entre los rubros con mayor cantidad de población ocupada, representando aproximadamente a 20.900 ocupados. Del total de ellos, por los datos 
expuestos en el capítulo 1, vemos que aproximadamente 7.000 corresponden a los asalariados ligados a producción industrial pesquera, los cuales representan un tercio de los ocupados en la industria marplatense y el 3,6\% del total de asalariados de la ciudad. Luego, la producción pesquera -es decir, el sector extractivocomprende alrededor de 3.600 ocupados, significando un 1,2\% del total de ocupados de la ciudad.

Tabla №18. Distribución de la población ocupada entre los principales rubros ocupacionales, Necochea, 2010:

\begin{tabular}{|l|r|}
\hline Rubro & $\begin{array}{r}\text { \% de } \\
\text { ocupados }\end{array}$ \\
\hline Dirección y gerencia de Pymes privadas & 12,9 \\
\hline Construcción e infraestructura & 12,5 \\
\hline Gestión administrativa, jurídica, contable y financiera & 10,0 \\
\hline Comercio & 9,9 \\
\hline Limpieza doméstica y no doméstica & 8,6 \\
\hline Transporte y almacenaje & 6,9 \\
\hline Educación & 6,4 \\
\hline Producción industrial y artesanal & 4,8 \\
\hline Otros servicios varios & 4,6 \\
\hline Salud y sanidad & 3,4 \\
\hline Producción ganadera, apícola-avícola, forestal y de caza & 3,4 \\
\hline Producción agrícola & 2,8 \\
\hline Servicios de seguridad estatal y privada y de las FFAA & 2,8 \\
\hline Gastronomía y turismo & 2,5 \\
\hline Reparación de bienes de consumo & 1,8 \\
\hline Total & $\mathbf{9 3 , 3}$ \\
\hline
\end{tabular}

Fuente: Elaborado en base a INDEC, REDATAM.

En el caso de Necochea, la producción industrial se ubica en el octavo lugar entre los rubros con mayor cantidad de población ocupada, significando alrededor de 2.000 ocupados. De acuerdo a la prensa gráfica local y al sindicato de la Alimentación, para 2010 había alrededor de 400 puestos de trabajo en el sector industrial pesquero, los cuales comprenden el $20 \%$ del total de ocupados de la industria necochense y el 1,5\% del total de asalariados de la ciudad. Para 2012, se habrían perdido la totalidad de estos puestos de trabajo dados los cierres de las tres plantas procesadoras de pescado que continuaban funcionando en la ciudad. Por su parte, la producción pesquera -sector extractivo- para el año 2010 abarcaba alrededor de 403 ocupados en Necochea.

Por último, veamos la distribución de los trabajadores no registrados. Aquí tomaremos las categorías de asalariados de acuerdo a la percepción o no de aportes jubilatorios y también al sector de cuentapropistas, ya que como vimos anteriormente, dentro de este sector se ubican trabajadores cooperativizados, microemprendedores, trabajadores artesanales y de oficios que se desempeñan en altos niveles de precarización laboral y bajos ingresos. 
Tabla №19. Asalariados y cuentapropistas con y sin aportes jubilatorios, Mar del Plata y Necochea, año 2010:

\begin{tabular}{|l|r|r|r|r|}
\cline { 2 - 5 } \multicolumn{1}{c|}{} & \multicolumn{2}{c|}{ Mar del Plata } & \multicolumn{2}{c|}{ Necochea } \\
\hline Asalariados con aportes jubilatorios & 136.469 & $71,7 \%$ & 17.355 & $69,3 \%$ \\
\hline Asalariados sin aportes jubilatorios & 54.026 & $28,3 \%$ & 7.721 & $30,7 \%$ \\
\hline Cuentapropistas con aportes jubilatorios & 21.268 & $32,2 \%$ & 2.825 & $34,1 \%$ \\
\hline Cuentapropistas sin aportes jubilatorios & 44.587 & $67,8 \%$ & 5.597 & $65,9 \%$ \\
\hline
\end{tabular}

Fuente: Elaborado en base a INDEC, REDATAM.

Gráfico №10. Distribución de la población ocupada por categoría ocupacional, y de la población asalariada por registración laboral, Mar del Plata, año 2010:

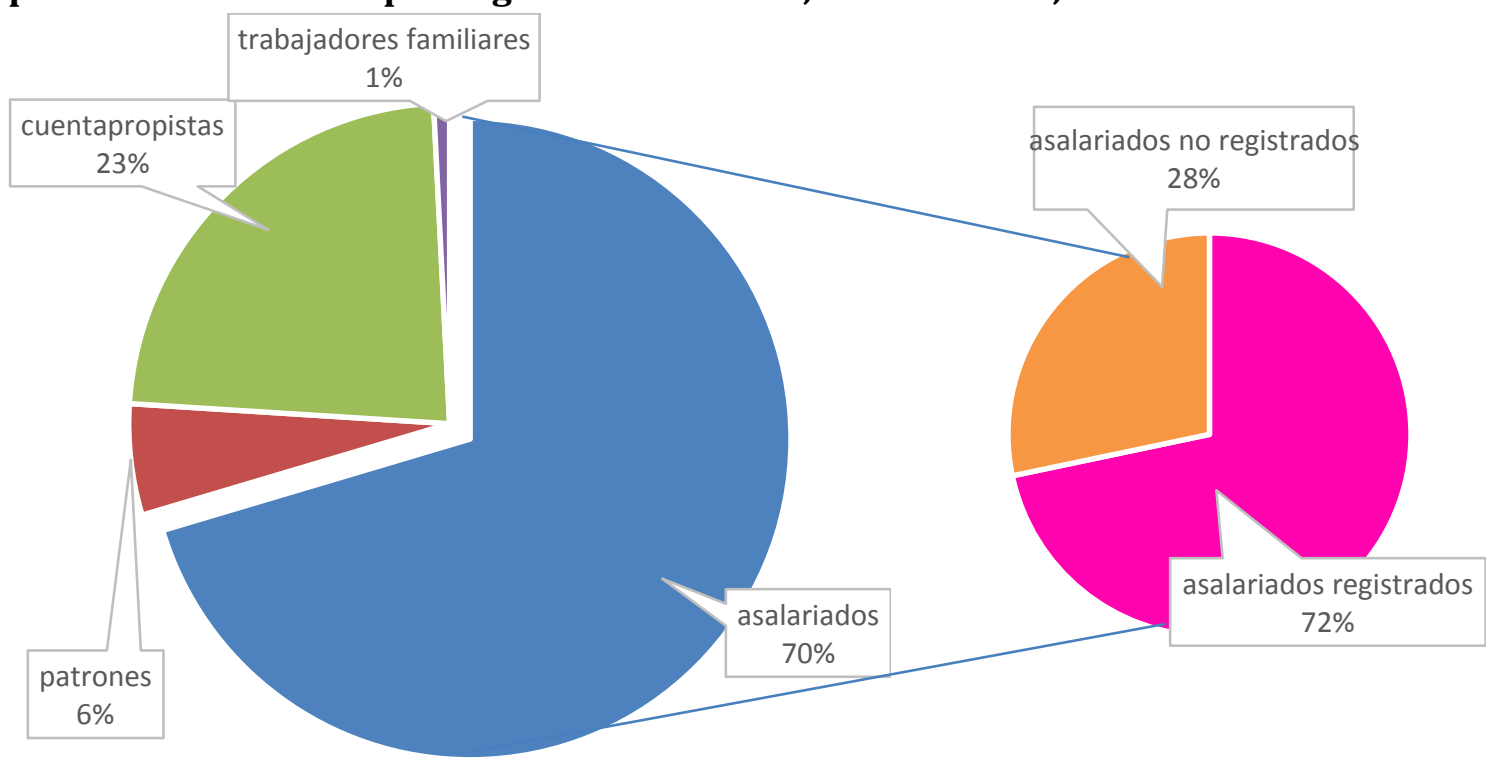

Fuente: Elaborado en base a INDEC.

Gráfico №11. Distribución de la población ocupada por categoría ocupacional, y de la población asalariada por registración laboral, Necochea, año 2010:

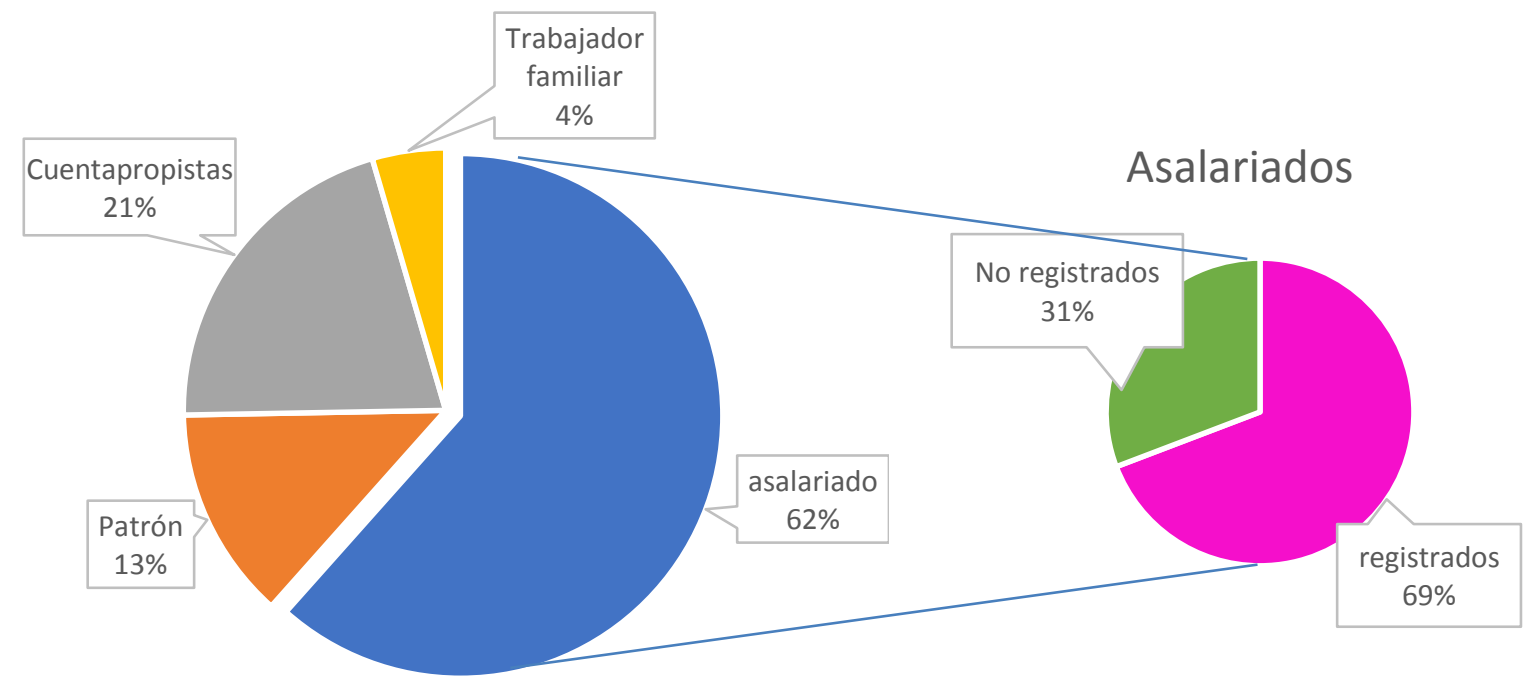

Fuente: Elaborado en base a INDEC. 
Analizando estos datos como tendencias generales, vemos que alrededor del 30\% de asalariados no se encuentran registrados en ambas localidades; $y$, por otra parte, aproximadamente 2/3 de los cuentapropistas no realizan aportes jubilatorios, lo que muestra un alto grado de precariedad dentro de este grupo ocupacional. Esta información se corresponde con el aumento de cooperativas y pequeños emprendimientos ligados a planes sociales para personas desocupadas. De acuerdo a la oficina de empleo de Necochea, para el año 2017 se habían acumulado alrededor de 7.000 personas que concurrieron a solicitar trabajo, entre las cuales se incluyen desocupados, trabajadores del sector informal, inscriptos en planes sociales o el monotributo social, lo que representa el 15\% de la población económicamente activa para el año 2010. Este porcentaje puede ser aún mayor si consideramos que un número de habitantes -incierto, pero existente- no concurre a las dependencias municipales a exponer su problemática de desempleo. Esto significa que al menos el $15 \%$ de la población económicamente activa de Necochea subsiste con ingresos monetarios inferiores al salario mínimo, vital y móvil 24 .

Enfocándonos ahora en la localidad de Mar del Plata, contamos también con datos expuestos en un informe del relevamiento por el Ministerio de Trabajo, Empleo y Seguridad Social entre los años 2003 y 2012 sobre trabajo no registrado en el rubro de la producción de pescado, fileteado y envasado. Para el año 2008 se contabilizaron 930 trabajadores no registrados sobre un total de 2.773 trabajadores relevados dentro de este sector (2013:113), mientras que para el año 2012, una nueva inspección detectó 1.204 trabajadores no registrados de un total de 1.575 trabajadores relevados (2013:119). Luego, agreguemos a estas cifras lo expuesto por Mateo, Nieto y Colombo (2010) en cuanto a la sanción de fraude laboral por parte del Ministerio de Trabajo de la provincia de Buenos Aires a 25 cooperativas en el año 2004, las cuales involucraban a 1.844 trabajadores. Este fraude laboral involucró a 21 empresas contratantes y, al menos, dos de los grandes grupos económicos de la pesca, Solimeno y Valastro. Este dato nos muestra que más allá del índice de trabajo no registrado posible de estimar a través de las estadísticas oficiales del mercado laboral -mediante la fórmula que correlaciona trabajo registrado con los descuentos por aportes jubilatorios-, la cooperativización fraudulenta y el trabajo a façon realizado por muchas empresas recuperadas expresa un gran porcentaje de empleo no registrado que se encuentra oculto tras la categoría de "trabajadores por cuenta propia", ya que los socios de las cooperativas se incluyen en ese rubro.

El entrecruzamiento de estos datos devela que detrás de las cifras oficiales se esconde un universo mucho mayor de empleo informal, teniendo en cuenta las distintas formas que puede asumir la tercerización, que de acuerdo a Basualdo (2012) se clasifican en:

${ }^{24}$ Entrevista a Romina Casal, coordinadora de la Oficina de Empleo de Necochea, 6 de julio de 2017. 
1- Subcontratación de una empresa madre a una segunda empresa para que realice determinadas actividades laborales;

2- Intermediación de una segunda empresa en la gestión de contratación de personal que luego trabajará en la firma principal contratante;

3- Intermediación de una agencia de empleo eventual para suministrar trabajadores que presten servicios eventuales en la empresa principal;

4- Contratación de trabajadores en calidad de monotributistas o con contratos de servicios o independientes dentro de una planta de producción.

La cooperativización fraudulenta y la contratación de cooperativas que integran empresas recuperadas implica una conjunción entre las distintas formas de tercerización, ya que generalmente incluye la contratación de la empresa cooperativa por parte de una empresa mayor; asimismo, sus trabajadores son monotributistas, muchos de ellos se desempeñan de forma eventual y puede cumplir funciones en las instalaciones de la propia empresa contratante. Por ello la estrategia de conformación de cooperativas es una de las más utilizadas en la industria pesquera argentina, la cual abordaremos a continuación.

\section{Cooperativización y desempleo en la industria pesquera argentina}

Como vimos en el capítulo anterior, el auge del desempleo y la tercerización laboral en la industria pesquera es producto de la crisis y reconfiguración propia de la actividad pesquera argentina que a su vez se enmarca en el proceso global de reestructuración capitalista a nivel mundial. Si bien la gran mayoría de los obreros pesqueros cooperativizados forma parte de la maniobra fraudulenta empresarial de tercerización encubierta, un pequeño grupo de Necochea conformó cooperativas enmarcadas en el proceso de recuperación de las empresas en las que se desempeñaban. Algunos de estos trabajadores habían tenido experiencias dentro de las llamadas "Cooperativas truchas", por ello se esforzaban por delimitar el nuevo formato autogestivo del anterior, nombrándolo como "cooperativa genuina".

Antes de continuar con los dos formatos de cooperativización en la historia reciente de la industria pesquera, haremos un breve repaso histórico sobre los antecedentes de cooperativización en esta rama, a fin de detectar continuidades y rupturas con el presente y características particulares.

\subsection{Cooperativas pesqueras en la actividad pesquera comercial marítima argentina. Breve recorrido histórico}

Desde los primeros tiempos de la actividad pesquera comercial marítima argentina, sus trabajadores han conformado asociaciones, a fin de afrontar colectivamente los problemas que implicaban las variaciones en la demanda del producto y las especificidades de la fuerza de trabajo (Mateo, 2011). La necesidad de organizarse 
dio origen en 1907 a la Sociedad de Pescadores Unidos y en 1921 surgió la Sociedad de Propietarios Pescadores Unidos, fundadas por los propietarios de las embarcaciones costeras ${ }^{25}$. Desde sus comienzos estas asociaciones estuvieron atravesadas por nudos conflictivos, por ello era frecuente que se armasen y desarmasen sucesivamente. Las cooperativas fueron la respuesta organizada ante determinados problemas comunes de los pescadores, es decir, no estuvieron motivadas por la propiedad común de los medios de producción sino por la necesidad de incrementar su poder de negociación (Balbi, 2010), expresando la tendencia corporativista de la pequeña y mediana burguesía a asociarse a fin de afrontar problemas comunes. En las décadas del 30 y el 40, con el relanzamiento de la actividad pesquera nacional se conformaron organizaciones más sólidas tanto en Mar del Plata como en Necochea y otros puertos, con participación de iglesias católicas en algunos casos. En Mar del Plata se conformó la "Corporación Pesquera de Ayuda Mutua" con el apoyo del sacerdote Wikilson (Nieto, 2013). En 1939 se creó la Asociación Pesquera de Patrones Unidos Cooperativa Ltda., integrada por 55 propietarios de lanchas (Álvarez et al, 1991). A fines de los 40, con el impulso del Estado surge la Cooperativa Marplatense de Pesca e Industrialización (COOMARPES), como organismo de interlocución colectiva entre propietarios de lanchas, industriales, el Estado y el Mercado Central.

Ya desde la década del 30 el encuadre jurídico adoptado fue el de las cooperativas, las cuales fueron implementadas principalmente por los patrones pescadores a fin de minimizar los perjuicios ocasionados por la venta del producto en los muelles, en términos de la dificultad para fijar los precios a los compradores y consignatarios. En el relevamiento realizado no se hallaron cooperativas basadas en principios de horizontalidad, ya que en las que se incluían pescadores primaban los propietarios de lanchas por sobre los marineros, y en las del sector industrial solo incluían empresarios, sin integrantes obreros.

25 Cabe aclarar que, en las primeras etapas de la actividad pesquera en Mar del Plata, las tripulaciones solían estar conformadas por integrantes el grupo familiar del patrón y que la fase extractiva de la pesca costera se caracteriza por la repartición de ganancias “a la parte”, por las cuales se destinaban partes al patrón y una parte para cada tripulante (Mateo, 2009). 


\section{Imagen №4. Exterior de la COOMARPES. Puerto de Mar del Plata}

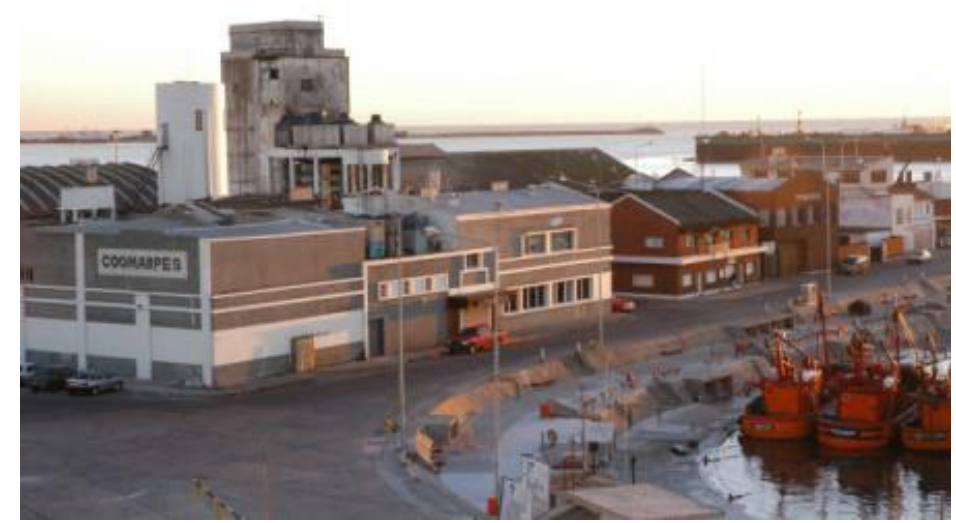

Fuente: Página web de la COOMARPES.

Para fines de la década del 60 existían varias cooperativas de pesca, siendo la COOMARPES una de las más importantes. Si bien en sus primeros años contaba con mayor cantidad de socios, para 1968 la integraban 358 trabajadores y 134 lanchas, y en ese año representó el $80 \%$ de las capturas de la flota costera. Sus principales funciones eran la venta de producción, un almacén de insumos pesqueros -tales como redes y máquinas-, un frigorífico y servicio de grúa, taller naval, túnel de congelación, provisión de hielo en escamas y planta de fileteado propia. Por ello era una cooperativa de producción y consumo. En las localidades portuarias de Necochea y Bahía hallamos ejemplos similares para la misma época. (Fundación Argentina de Estudios Marítimos, 1968).

A diferencia de esta primera etapa en la cual la conformación de cooperativas pesqueras responde mayormente a los intereses corporativos de los patrones pescadores con el objetivo de buscar soluciones a sus propios problemas particulares, a partir de los 90 proliferan las cooperativas apócrifas -fraudulentasconforme a una estrategia empresarial de precarización de la fuerza de trabajo, de acuerdo a un procedimiento ya explicitado en el primer capítulo. Seguidamente abordaremos aspectos ligados a las subjetividades obreras de los trabajadores que integran estas cooperativas.

\subsection{Las subjetividades obreras ligadas a la cooperativización fraudulenta en la industria pesquera marplatense}

Comenzando por un repaso de la literatura académica en relación a las subjetividades y estrategias laborales propias de los trabajadores que integran cooperativas fraudulentas en la industria pesquera marplatense, encontramos estudios de María Estela Lanari, Romina Cutuli, y María Soledad Schulze.

Las dos primeras -en especial, Romina Cutuli- se abocan al abordaje de las obreras de la industria pesquera marplatense tomando como brecha temporal los años 1980 y 2008, desde un enfoque sociohistórico y de género. Sus investigaciones parten 
desde la historicidad de la industria pesquera nacional y de los efectos de los procesos sociales y macroeconómicos en el trabajo asalariado, profundizando la observación de la precarización laboral, la cual se observa de forma más marcada en las mujeres debido a las desigualdades de género a nivel social. Algunas de sus principales conclusiones remiten a la comprensión de las trabajadoras como actoras cuyas prácticas laborales y domésticas se condicionan recíprocamente, al cuestionamiento de la ruptura entre trabajo remunerado y no remunerado y a los efectos laborales en el cuerpo en cuanto a las diversas enfermedades degenerativas y otros daños físicos que provocan la tarea del fileteado (Cutuli, 2009; Lanari y Cutuli, 2010). La inestabilidad y la irregularidad tanto en el salario como en las condiciones de seguridad en el espacio fabril y en el tiempo de contratación, caracterizan a grandes rasgos la forma de la precarización en la pesca en la actualidad, por lo que la inserción de trabajadoras en cooperativas fraudulentas afecta tanto su lugar laboral como su ámbito familiar.

Asimismo, otro aspecto problematizado es la dificultad para la reinserción laboral, cuyos motivos involucran tanto condiciones objetivas como subjetivas. Por un lado, dadas las escasas posibilidades de reconversión laboral, las trabajadoras terminan por incluirse en sectores peor pagos -tales como el trabajo doméstico-; por otra parte, se expresa una fuerte negativa obrera a abandonar la actividad vinculada con la añoranza de un pasado mejor en términos de remuneración salarial (Cutuli, 2009:7-8). En muchos de los discursos de las obreras, éstas achacan la precarización y el desempleo a los empresarios por haber sobreexplotado el recurso pesquero, considerando además al Estado como cómplice por acción u omisión.

Por otra parte, Schulze (2014) se dedica al estudio de las representaciones de los obreros en torno a la labor de fileteado, en relación con las condiciones y la modalidad laboral y la elección ocupacional. Recalca que el trabajo de fileteado es un oficio que valoriza en gran medida la mano de obra artesanal para el que no existe hasta hoy tecnología eficaz que la sustituya, y también puntualiza la transmisión de este saber-hacer de manera familiar intergeneracional, que va formalizando la labor filetera como un conocimiento riguroso (Schulze, 2014:162). Estas características del oficio se conjugan con las condiciones laborales y provocan consecuencias tanto orgánicas como psíquicas en los trabajadores/as, funcionando como una tecnología regularizadora de los cuerpos obreros. De acuerdo a ello, Schulze problematiza que, a pesar de cierta disconformidad expresada en los discursos obreros acerca de sus condiciones de precariedad laboral y de su participación en acciones de lucha directa contra ellas, las mismas se encuentran ampliamente naturalizadas y ocultas tras una supuesta racionalidad técnica, por ello las subjetividades trabajadoras "no han logrado un reordenamiento de los cuerpos y las relaciones sociales en las que estén involucrados como productores y hacedores del proceso" (Schulze, 2014:167).

También hay estudios que vinculan las transformaciones en la industria pesquera nacional (y sus impactos en Mar del Plata y en menor medida, Necochea) con las acciones de protesta obrera por parte de los trabajadores cooperativizados. Entre 
estos investigadores podemos ubicar a Agustín Nieto, Guillermo Colombo, Gonzalo Yunkevich y trabajos en conjunto entre estos autores y José Mateo. Sus conclusiones referidas al plano de las subjetividades se enmarcan en un encuadre histórico centrado en la conflictividad obrera y también en los efectos del trabajo en el cuerpo -compartiendo en este último aspecto corolarios similares a las de Cutuli, Lanari y Schulze.

Siguiendo a estos autores podemos afirmar que, si bien se toleran a disgusto las diversas formas de precariedad laboral, en diversas coyunturas de crisis y/o luchas el malestar cotidiano se condensa en una fuerte ira obrera dando lugar a estallidos sociales y formatos de protesta disruptivos del orden social y laboral impuesto, tales como ataques a plantas pesqueras, tomas de la sede sindical y dependencias estatales, secuestros y ataques a empresarios y sus viviendas. Las diversas acciones de conflictividad obrera se asientan en determinadas bases económicas y sociales signadas por la precariedad laboral, las cuales habilitaron diversos formatos de protesta que han alcanzado un alto grado de radicalización, tanto por el alto grado de implicancia corporal, de desobediencia y producción de energía de los cuerpos, como por sus objetivos y persistencia en el tiempo. Un análisis pormenorizado es estas experiencias entre 1997 y 2012 se realizará en el capítulo siguiente.

A continuación, exponemos dos testimonios de trabajadores marplatenses cooperativizados acerca de los significados que le atribuyen a su situación laboral y las acciones realizadas en torno a modificarla:

...a principios del 97 ingresé en el frigorífico Mardi, que abrió ese año en Ortiz de Zárate y Edison. Desde entonces ya nunca más estuve efectivo: pasé a depender de la cooperativa Bella vista, que manejaba Carmen Pozo. Me descontaban para pagar el monotributo, pero cuando siete meses después averiguo en el ANSES por mis aportes, descubro que tenía aportado un mes solo. (...) Después estuve un tiempo en la planta San Remo, trabajando para Industrial Coop, pero me fui porque a esos monstruos no podés amagarles siquiera: les decís "a" y al otro día no entrás. Me descontaban un tres por ciento para mantenimiento de asociado. (...) Cuando vi que empezó este conflicto de ahora estaba trabajando en la cooperativa San Francisco, y había visto desde el lunes que estaba la gente en la puerta de Giorno. Cuando pasé el jueves y me dijeron que estaban cortando los accesos al puerto ya entonces fui, y me quedé, porque ese fue siempre el lugar soñado por nosotros, sabíamos que la única forma de que nos escuchen era ahí, la entrada del puerto y la salida (José, filetero de la cooperativa San Francisco) ${ }^{26}$.

Con lo poco que ganamos hay que pucherear. Hace como diez años que venimos mal. Por eso estamos en este conflicto, para ver si nos blanquean y tener el beneficio de un seguro o una obra social. Y ver si llegamos al convenio del 75 . Hace 25 años trabajo en la industria del pescado. Antes del 92 -época en la que se hicieron estas cooperativas- estaba efectivo en Escobar Hermanos: ahí tenía la garantía horaria, la jubilación, aguinaldo, vacaciones, y me pagaban los bonos de la obra social. Después se empezó a hablar de cooperativas (...) y nosotros no sabíamos qué era una cooperativa, ni qué significaba esa palabra. Pero

${ }^{26}$ Revista De acá, año I, septiembre de 2007, №9, pp. 9-10. 
además nos obligaron, porque si no aceptábamos la propuesta, no podíamos trabajar (Carlos, filetero de la Cooperativa Marea del Sur) ${ }^{27}$.

En el primer testimonio expuesto vemos la situación de un trabajador cooperativizado que previamente había trabajado en relación de dependencia por más de 18 años, por lo que tenía conocimientos acerca de la diferencia entre este modo de contratación y la cooperativización. Aquí vemos no solo la pérdida de derechos con respecto al convenio 161/75 y la falta de registración laboral, sino otras tácticas empresariales de superexplotación mediante la retención de parte del porcentaje estipulado de pago, que muestran iniciativas empresariales de precarizar aún más el trabajo ya precarizado. Se observa también el pasaje por varias cooperativas, encontrándose con las mismas condiciones de trabajo en cada una de ellas, incluso la misma práctica de ilegalidad más allá de la cooperativización fraudulenta. En todos los establecimientos lo que se recalca es la derrota vivida en el destino impuesto de cooperativización, producto de la arremetida empresarial contra los obreros en cuanto al proceso de trabajo y modo de contratación. En este testimonio vemos también la esperanza del trabajador depositada en la medida de lucha consistente en el bloqueo del puerto, medida que para él se diferenciaba del resto de acciones conflictivas llevadas a cabo porque era la única que podía tener un desenlace favorable a los obreros. La referencia a esa acción combativa como "lugar soñado" expone la contracara de la bronca sentida, oculta tras la resignación cotidiana, las ansias de superar la precarización laboral y la certeza de que la única manera de lograrlo sería mediante la rebelión obrera.

En el segundo testimonio podemos distinguir otras apreciaciones. En primer lugar, el desconocimiento del obrero que durante décadas trabajo en relación de dependencia respecto del trabajo en una cooperativa, no solo en términos conceptuales sino también prácticos. Las promesas, pero fundamentalmente la imposición, configuraron una cooperativización que inicialmente se "aceptó" a disgusto, y posteriormente quedó confirmada la precarización laboral que implicaba. Las condiciones precarias del trabajo que provocan las dificultades para una reproducción mínima diaria constituyen los motivos principales del conflicto señalado.

Estos análisis comparten con los desarrollos investigativos anteriormente mencionados la apreciación de que los trabajadores que conocieron la modalidad laboral registrada bajo el convenio 161/75 guardan la añoranza de un pasado mejor (Cutuli, 2009) y por ello buscan recuperar las condiciones de trabajo perdidas. Para estos trabajadores, la cooperativización es sinónimo de empeoramiento de condiciones de vida y trabajo, además de constituir un formato laboral impuesto desde arriba, mediante la fuerza y los engaños. Lejos se encuentra del ideal de autoorganización democrática y reparto de la producción de los libremente asociados pregonado por los impulsores del cooperativismo. Tampoco se vincula a

${ }^{27}$ Revista De acá, año I, septiembre de 2007, №9, pp. 6. 
la protección mutua ante los prejuicios externos que persiguieron los primeros cooperativistas pesqueros marplatenses. El marco actual vivido por los obreros muestra claramente la tendencia neoliberal en la que se basa la cooperativización, es decir, su relación con los despidos y la flexibilización laboral, con la precarización y dualización de la fuerza de trabajo, cuyo sustento es el ataque capitalista hacia la clase obrera, con las instituciones estatales como garantes de dicho ataque.

\section{Imagen №5. Protesta obrera por la registración laboral en la empresa Barilari, año} 2008.

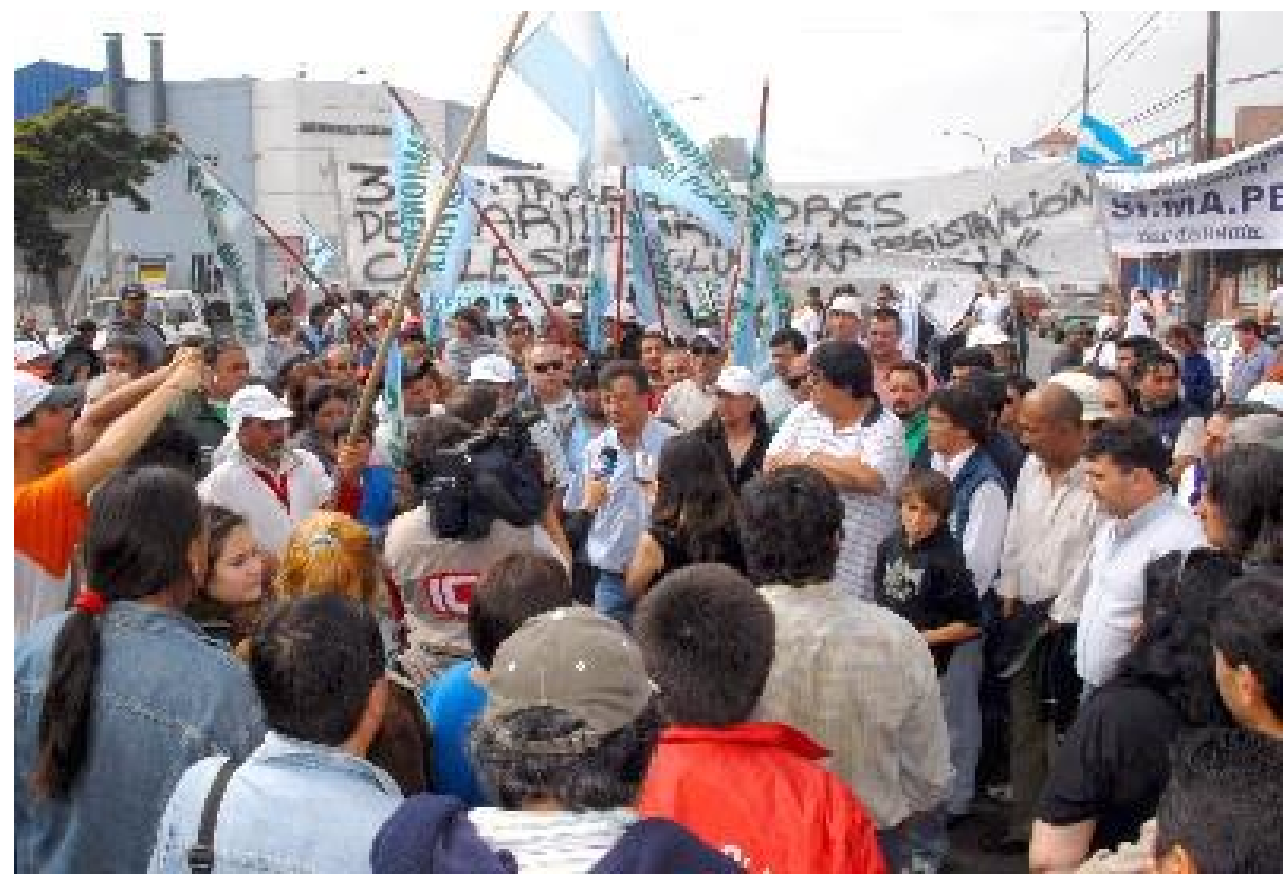

Fuente: Diario digital Nuestro Mar, www.nuestromar.org

Para finalizar este apartado, tomaremos un ejemplo de Necochea, narrado por Darío, uno de los trabajadores que luego formó parte de La Recuperada. Así como él, varios de los obreros que lucharon por la mantención de sus fuentes de trabajo en la empresa Industrial Pesquera, previamente habían integrado cooperativas fraudulentas y también lucharon contra esta forma de precarización. En los últimos años, en esta ciudad las cooperativas fraudulentas fueron reduciéndose a la par del desguace general de la industria pesquera. Veamos el testimonio obrero:

En el 2004, entré por una cooperativa trucha que nos anotábamos unos cuantos en un lugar y de ahí te mandaban a una fábrica o te mandaban a otra, te anotabas y te tocaba cualquier lado y al otro día tenías que ir temprano. (...) Yo tuve suerte en quedar efectivo, porque a los tres meses que entro en la cooperativa hay un problema que arranca con otros trabajadores de otra fábrica que se llama Incoop. Con otro delegado allá empiezan a darse cuenta de que los estaban explotando y todo lo demás y tratando de renunciar a esa cooperativa trucha. Y ahí nos empiezan a invitar a nosotros, yo en ese momento no sabía bien de qué se trataba y fue que un día nos juntamos todos los trabajadores de las distintas fábricas y fuimos hasta el lugar en donde estaba esa cooperativa y renunciamos. Y como renunciamos todos en masa y se hizo una denuncia al 
Ministerio de Trabajo por fraude laboral, ellos nos ofrecieron aumentar la hora, nos ofrecieron dos pesos con cincuenta la hora para que no renunciemos... Nosotros ya estábamos decididos a renunciar, nos ofrecieron tres pesos y darnos guantes... Y no. (...) Y yo creo que a nosotros en ese momento nos arrastró otra gente que nos llevó a tomar la decisión, que nos abrieron los ojos, que en verdad nos estaban explotando, pero uno en cierta forma estaba asustado, de qué hacer ¿renunciar?, si será buena la decisión o no porque uno necesitaba trabajar y la mayoría de la gente que trabajaba en esa cooperativa lo hacía por necesidad muy grande, o sea, no te quedaba otra. Entonces creo que en ese momento nos arrastraron a nosotros a tomar esa decisión que fue muy buena. Y como te decía yo tuve suerte de quedar efectivo a los tres meses que entré en la cooperativa, surge este tema, se renuncia y ahí yo quedo efectivo (Darío, 35 años, filetero) ${ }^{28}$.

Realizando un análisis desde la experiencia colectiva de estas subjetividades obreras, podemos señalar en esta experiencia tres aspectos. Primeramente, se observa que los trabajadores cooperativizados lograron una cierta conciencia de la superexplotación -nombrada por ellos como "explotación"- que padecían al integrar la cooperativa. Esta conciencia fue producto de la alianza con algunos trabajadores de planta permanente, específicamente con el delegado sindical de la planta Incoop, quienes "les abrieron los ojos", según Darío. Sin embargo, hasta el momento de emprender la lucha por la registración, no veían una salida que no implicara el desempleo seguro. Por ello, creemos que más que naturalizar la precarización, lo que se encontraba naturalizado es la falta de posibilidad de luchar contra ella, sin que esa misma lucha los termine dejando en una posición peor que la inicial, es decir, desocupados. Tomando los planteos de Thompson (1979), la explotación fue primeramente experimentada como clase y luego dio origen a las formaciones de clase. Sin embargo, cabe destacar que la lucha contra la superexplotación tenía como horizonte la mejora de las condiciones de trabajo y contratación accediendo a la registración laboral, es decir, no cuestionaba la explotación en sí misma sino, más bien, la dualización de la fuerza de trabajo al interior de las unidades productivas.

En segundo lugar, retomando la coalición entre un pequeño grupo de trabajadores registrados que apoyó y promovió la lucha del grupo de obreros cooperativizados, consideramos que la misma ha sido un componente que propició una "moral de lucha" capaz de perdurar hasta el logro de su objetivo, sin ceder a las ofertas patronales intermedias, y también porque logró superar la dualización de la fuerza de trabajo y la competencia intraobrera impuesta por el empresariado.

En tercer lugar y sin menoscabo de lo antedicho, se observa una diferencia entre el grupo más radicalizado de trabajadores -entre los cuales se encontraba el delegado de Incoop- y el grupo de trabajadores en peores condiciones de trabajo y contratación. Sin embargo, esta diferencia terminó por resolverse a favor de la propuesta política del grupo más radicalizado. Entonces, las malas condiciones de trabajo y los bajos salarios que percibían fue el desencadenante de la lucha por la registración laboral, para la cual los trabajadores optaron por la vía

${ }^{28}$ Entrevista grupal a La Recuperada, realizada en octubre de 2011. 
institucional/judicial pero de forma colectiva, una vía muy utilizada por los obreros de la industria pesquera desde la creación del fuero laboral en los años 40 (Nieto, 2014).

Desde el plano personal de este trabajador, cabe destacar que esta experiencia de lucha es señalada por Darío como precursora de su interés por las cuestiones sindicales y de su participación y promoción de siguientes acciones de rebelión. Producto de ella también queda efectivizado en Industrial Pesquera, primero como peón y luego como filetero, siendo elegido delegado sindical de planta al poco tiempo. Volveremos sobre su participación en el proceso de recuperación de La Recuperada en el capítulo 4.

Finalizando este capítulo, expondremos algunas de las características subjetivas de los trabajadores cooperativizados que integran las empresas pesqueras recuperadas en Necochea y Quequén.

\subsection{Las subjetividades obreras ligadas a las cooperativas que integran empresas pesqueras recuperadas en Necochea}

En contraposición con los casos anteriormente mencionados, ubicamos a la conformación de cooperativas pesqueras dentro de los procesos necochenses de recuperación y autogestión de empresas. Aquí presentaremos algunos aspectos referidos a la transformación en la situación laboral de los trabajadores, primero asalariados bajo relación de dependencia y luego cooperativistas.

En términos genéricos, las empresas recuperadas por trabajadores se caracterizan por el hecho de que trabajadores asalariados de unidades productivas en crisis, ante el cierre o eventual cierre de las mismas, deciden y logran continuar con la producción y comercialización bajo su propia gestión asumiendo en la mayoría de los casos la forma organizativa y legal de Cooperativas de trabajo.

En Argentina, estas experiencias se enmarcan en los cierres por quiebra de numerosas empresas en el contexto de la reestructuración capitalista bajo el modelo neoliberal, los cuales dejaban desempleados a miles de obreros en todo el territorio nacional. En la década del 80 pocos casos dieron como resultado procesos de recuperación. Una de las pioneras fue Adabor, empresa productora de garrafas y silos, donde la patronal cedió sus créditos a cambio de sus deudas con los trabajadores tras su quiebra en el año 1988. En los 90, un puñado de nuevos casos emergieron como antesala de un movimiento que proliferó y se consolidó a partir de la crisis de 2001

Las cifras oficiales señalaron la existencia de 323 empresas recuperadas para el año 2012 (MTEySS, 2012), mientras que desde el ámbito académico se contabilizó que hasta el año 2013 inclusive en Argentina existían 311 empresas recuperadas, integradas por 13.462 trabajadores (Ruggeri, 2014) que comprenden los sectores alimenticio, metalúrgico, hotelero, manufacturas y servicios ${ }^{29}$.

${ }^{29}$ Programa Facultad Abierta de la UBA, 2013. 
La recuperación de empresas nació de un contexto de precarización y vulneración socio-laboral (altas tasas de desempleo estructural, pobreza e indigencia) en el que la situación de inminente desempleo significaba engrosar las filas de desocupados sin posibilidad de encontrar otro trabajo en el mercado ni de cobrar indemnización ni seguro laboral que asegure la reproducción de las mínimas condiciones de subsistencia obrera. A partir de este contexto es que algunos autores enmarcan el proceso de recuperación como una estrategia defensiva. Fajn y Rebón definen un perfil arquetípico de empresas recuperadas como un observable que:

“...corresponde a una fábrica de una antigüedad aproximada de cuarenta años, que en momentos de mayor expansión ocupó de cuarenta y cinco a cien trabajadores y que durante las últimas dos décadas fue sufriendo progresivamente procesos de achicamiento que significaron desde la perspectiva de la fuerza de trabajo ocupada la expulsión de la mayoría de sus asalariados" (Fajn y Rebón 2005:4).

Más adelante, en el capítulo 4, abordaremos las especificidades de estos procesos desde la óptica de las subjetividades obreras, a la par que discutiremos en detalle la consolidación de los procesos de La Recuperada y Engraucoop. Aquí nos centraremos en lo que implicó para estos colectivos el pasaje a la forma cooperativa, el cual -como suele suceder en este tipo de experiencias- no fue producto de una voluntad inicial de asociatividad cooperativista por parte de los trabajadores, sino que responde a la forma legal impulsada por el Estado (Brunet y Pizzi, 2011) y también por agrupamientos y referentes del movimiento de ERT. La conformación de una cooperativa de trabajo es la figura jurídica que les permite a los trabajadores solicitar el aval judicial para continuar con la producción en el momento en que la patronal decide cerrar la planta, y también es la prevista por la ley de Quiebras para que el colectivo obrero pueda solicitar la expropiación de los bienes inmuebles y muebles -todo el capital fijo de la empresa-. Es por ello que, al iniciarse la lucha por la conservación de sus fuentes laborales en un contexto de cierre por crisis y riesgo de quiebra empresarial, es común que los obreros que la emprenden reciban el consejo de conformar una cooperativa de trabajo lo antes posible.

Sin embargo, la cooperativización no implica solo beneficios en términos legales para los obreros, sino también significativas pérdidas. Al respecto, Calloway, Colombari y Iorio (2015) problematizan las categorías tributarias bajo las cuales son clasificados estos trabajadores y el modo en que se incorporan al sistema de seguridad social. La inexistencia de una figura tributaria que contemple las características específicas del trabajador asociativo y autogestionado y lo diferencie de la categoría de autónomo (que engloba a la vez a trabajadores cuentapropistas y pequeños empresarios) deriva en que las cooperativas se encuentren con grandes dificultades para solventar el pago de seguros contra accidentes de trabajo, jubilaciones, seguros de salud y asignaciones familiares. Esta cuestión implica dificultades tanto conceptuales como prácticas de las políticas públicas para abordar la singularidad de estas experiencias (bottom-up) constituidas desde una 
lógica colectiva, y no desde una lógica individualista que la consideración de autónomo conlleva. En este sentido, aunque al interior de las unidades productivas se borre la división entre trabajadores y capitalistas, esto no transforma a los obreros en empresarios sino en trabajadores autogestivos que, de acuerdo a la legalidad institucional del Estado, serían un "conjunto de cuentapropistas". Entonces, desde la órbita estatal se nombra a los obreros que fueron despedidos como una cooperativa de monotributistas, quienes en los meses anteriores a la recuperación generalmente no cobraron sus salarios o bien cobraron parte de los mismos, y por ello no cuentan con un capital monetario suficiente como para renovar tecnológicamente la empresa o invertir en una gran cantidad de materia prima. Solo poseen su propia fuerza de trabajo y los recursos disponibles en las unidades productivas para reanudar la producción, a la par que deben enfrentarse con una nueva serie de tareas propias de la gestión y comercialización que anteriormente estaban en manos de puestos gerenciales, administrativos o de los mismos patrones. Estos grupos de trabajadores tampoco puedes considerarse como "nuevos propietarios" de la empresa, ya que la guarda provisoria de las instalaciones que los jueces suelen otorgar a las cooperativas de trabajo en el marco de procesos de quiebra -como su nombre lo indica-, es temporal y puede culminar si no se logra la expropiación obrera y el juez dicta la subasta del inmueble. Este es el desenlace de muchos casos, ya que para cumplir con las condiciones de solicitud de la expropiación la cooperativa debe reunir a los dos tercios de los obreros de planta permanente de la empresa fallida, o en su defecto a los dos tercios de los acreedores laborales de la misma (que pueden ser trabajadores despedidos con anterioridad a la causa de la quiebra empresarial, a los que aún se les adeuden las respectivas indemnizaciones). Con el correr de los meses o años que conlleva la causa judicial es común que muchos trabajadores que en sus inicios fueron parte de la recuperación de la empresa desestimen la participación en la cooperativa por diversos motivos (falta de rentabilidad y de ingresos monetarios considerados suficientes, obtención de otro trabajo, entre otros). Por ello, la conformación de la cooperativa de trabajo con el correlato de la recuperación de la empresa bajo gestión obrera no significa aquí la terminación del conflicto sino un momento particular del mismo, en el que el sujeto patronal se desdibuja y aparenta desaparecer, aunque sigue estando presente en las acciones judiciales correspondientes a la quiebra y los juicios laborales.

Más allá de ello, vemos que la figura de la cooperativización es la que desde la ley avala la consecución de las luchas por la recuperación de las empresas, otorgando ciertas garantías, pero también promoviendo la desatención de los trabajadores recién despedidos, que se proponen enfrentar de forma inmediata la puesta en marcha de la producción bajo su propia gestión. Asimismo, esta figura jurídica fue la que ambas empresas recuperadas pesqueras adoptaron una vez emprendida la autogestión.

En cuanto a los procesos concretos de las empresas pesqueras recuperadas que aquí nos ocupan, tomaremos en primer lugar el de la conformación de la Cooperativa de 
Industria Pesquera y Alimenticia "La Recuperada", que actuó como antesala de Engraucoop, proceso temporalmente posterior.

En los trabajadores de la ex Industrial Pesquera los debates sobre la continuidad de la producción bajo gestión obrera y la constitución de la cooperativa de trabajo confluyeron en un mismo momento, si bien un reducido grupo de obreros ya venía realizando labores en forma autogestiva semanas antes, como forma de subsistencia mientras ocupaban las instalaciones fabriles. Esta práctica autogestiva fue planteada por un grupo de trabajadores como forma de obtener un ingreso monetario durante los primeros días del conflicto, sin constituir aún un proyecto cooperativo ni ser nombrado de esta forma por sus mismos actores. Luego de un mes de ocupación del lugar de trabajo y ante el anuncio de la inminente quiebra, este grupo junto con dirigentes y el abogado del sindicato de la Alimentación realizaron una reunión con la totalidad de los obreros y se propuso la idea de la cooperativa. El grueso de los trabajadores desestimó esta posibilidad por varias razones. En primer lugar, algunos no creían que los obreros podrían poner en funcionamiento la planta procesadora por sí mismos, es decir, se basaron en un prejuicio que consideraba inviable al proyecto autogestivo obrero. Por otra parte, la patronal había hecho una reunión anterior excluyendo a los obreros más radicalizados, en la cual prometió indemnizaciones a los que se retiraran de la planta. Finalmente, un poderoso motivo que repelió a los trabajadores de la conformación de la cooperativa fue su asimilación a las cooperativas fraudulentas: en este sentido, la sola mención de la palabra "cooperativa" implicaba precarización, sobreexplotación y -sobre todoescasos ingresos para mucho trabajo. Por el contrario, desde el Estado se instó a los trabajadores a cooperativizarse, otorgando avales legales para su funcionamiento temporal y precario- con rapidez y sin obstáculos legales ${ }^{30}$.

De los testimonios obreros se desprende también el desconocimiento del movimiento de empresas recuperadas a nivel nacional, en parte porque a nivel local aún no había transcendido ningún caso de recuperación de una empresa ligado a una lucha obrera. Incluso los propios trabajadores de La Recuperada refieren que ellos mismos en un primer momento rechazaban la "idea de la cooperativa", por sus propias experiencias en las "cooperativas truchas". Por ello, también recalcan que la iniciativa de la conformación de la cooperativa fue propuesta por el sindicato y también por el colectivo Cruz del sur, organización local integrante del Frente Popular Darío Santillán que formó parte de los primeros meses de la lucha por la recuperación de esta empresa. El grupo obrero llevó a cabo la cooperativización luego de haber sido convencido por la dirigencia sindical e integrantes de Cruz del Sur de su viabilidad y también de su diferencia con respecto al trabajo en una cooperativa fraudulenta, como expresa un trabajador: "una cooperativa trucha, como te digo, no una cooperativa genuina como la que hemos formado nosotros..." 31 . Solo después de establecer esa distinción entre los formatos cooperativos los

${ }^{30}$ Entrevista grupal a La Recuperada, realizada en octubre de 2011.

${ }^{31}$ Entrevista grupal a La Recuperada, realizada en octubre de 2011. 
trabajadores transformaron conceptualmente la ocupación de la planta procesadora en recuperación de la fábrica bajo gestión obrera, con la mediación de la tramitación de la cooperativa.

La proliferación de las cooperativas fraudulentas en el sector pesquero provocó esta particular resistencia que logró ser superada por un grupo minoritario del total de trabajadores de Industrial Pesquera, mientras que la gran mayoría optó por retirarse del proyecto autogestivo y de las instalaciones de la planta.

Seguidamente, los integrantes de la Cooperativa de Industria Pesquera y Alimenticia "La Recuperada" se enfrentaron con las nuevas tareas administrativas y de gestión fabril, lo que generó nuevos problemas y nuevas transformaciones laborales y subjetivas.

En primer lugar, la imposibilidad de obtener suficiente materia prima para procesar ocasionó problemas de rentabilidad y dificultades para mantener un ritmo estable de trabajo. Esto provocó que algunos de los integrantes abandonaran la cooperativa al obtener puestos de trabajo en relación de dependencia en otras empresas locales, o bien porque apostaron a otras salidas laborales individuales. Esto generó desánimo y frustración en los trabajadores que persistieron, que aún con el paso de los años continuaban anhelando que la empresa recuperada estuviera integrada por la totalidad de ex-trabajadores de Industrial Pesquera ${ }^{32}$. En menos de dos años de conformación se redujeron de 8 a 3 los obreros de La Recuperada que provenían de la firma originaria. Por este motivo, los que permanecieron debieron incorporar nuevos trabajadores, y para ello adoptaron primeramente la contratación temporal y luego de un tiempo de evaluación mutua eran incorporados como socios de la cooperativa. El retiro materia de los 5 trabajadores fue vivido como una muestra de fracaso del emprendimiento autogestivo, que se añadió a las dificultades para mantener un ritmo de producción y comercialización cotidiano que permitiera un ingreso mínimo acorde a la subsistencia y reducir la incertidumbre diaria.

Por otra parte, se observa que en los inicios del proceso todas las tareas que formaban parte de la gestión y administración de la empresa fueron realizadas por Darío, ex delegado sindical que fue uno de los impulsores del proceso, quien cumplía el rol de presidente de la cooperativa. De acuerdo a él, con el correr del tiempo estas funciones fueron distribuyéndose entre otros miembros ${ }^{33}$. En esta cuestión se esboza una diferenciación y una dependencia del colectivo obrero en la figura de Darío, es decir, una tendencia a delegar y centralizar tareas de importancia colectiva en una persona. Con esto queremos resaltar que la rotación de las tareas y la realización colectiva de las mismas -no solo las que implica el proceso de producción, sino también las vinculadas con todo el proceso de trabajo, repartición de los ingresos, circulación de la producción, tareas legales-, así como su definición grupal, expresan tendencias contrahegemónicas al interior de la clase obrera, adoctrinada y disciplinada por la patronal y el Estado capitalista en la sumisión y el

32 Entrevista grupal a La Recuperada, febrero de 2014.

33 Entrevista grupal a La Recuperada, febrero de 2014. 
sometimiento. Este caso permite hipotetizar que las prácticas hegemónicas no son cuestionadas automáticamente en los casos de cooperativas en empresas recuperadas, sino que deben ser explícitamente abordadas por el colectivo de trabajadores para ser, primero reconocidas, y luego plausibles de ser modificadas, tanto en la práctica como en la conciencia obrera. Para revertir la centralización unipersonal en La Recuperada, de acuerdo a los entrevistados fueron necesarias numerosas discusiones y replanteos sobre la praxis cotidiana, a fin de poder aplicar de forma duradera la variante contrahegemónica a la delegación de las tareas no productivas en un solo miembro. Asimismo, estas nuevas prácticas debieron reafirmarse, rediscutirse y reactualizarse en forma más o menos continua, es decir, su aplicación puntual no redunda en instalación permanente y supresión definitiva de los formatos anteriores semejables al formato de trabajo bajo patrón, sino que son necesarias operaciones reiteradas para reafirmar la nueva lógica que, a pesar de su práctica y experiencia, no deja de ser contrarrestada por el oleaje del sistema capitalista que permanece sin pausa aun en la interioridad de las empresas recuperadas. Esta centralización y delegación, de acuerdo a nuestros hallazgos, se vincula también con un prejuicio ligado a la incapacidad de la masa obrera para asumir tareas por fuera del proceso de producción. Volveremos sobre este aspecto al abordar el caso de Engraucoop.

Finalmente, vemos que los trabajadores de La Recuperada establecen una diferencia entre las cooperativas cuya rentabilidad puede definirse como "exitosa" y las cooperativas que no logran ingresos mínimos ni un funcionamiento continuo que permita a sus integrantes asegurar mínimas condiciones de subsistencia, incluyendo en este segundo grupo a la que ellos integran. En este sentido, reconocen diferentes objetivos y situaciones, y, por ello, la heterogeneidad propia del cooperativismo en la actualidad, que en muchos puntos se distancia de la idea de autogestión con la que se lo continúa enlazando. Uno de los motivos que adjudican a esta diferenciación es su propia falta de formación en instituciones de educación superior, es decir, opera la representación de una falla obrera en cuanto a falta conocimientos académicos sobre rentabilidad y administración de empresas, que, como contrapartida, poseerían los empresarios ${ }^{34}$. Aquí hallamos nuevamente un prejuicio obrero que ensalza a la figura del patrón/empresario/propietario de los medios de producción, y adjudica estas condiciones de superioridad no a la propiedad de los medios de producción fabriles, sino a conocimientos acerca de la administración empresarial de forma tal que se logre el "éxito". Esta visión de superioridad de la clase capitalista basada en conocimiento adquiridos es en parte cuestionada con la quiebra empresarial, pero no por ello los trabajadores se asumen como sujetos de ese saber, y luego, ante las dificultades propias de la producción y comercialización autogestiva en un mercado capitalista, las mismas refuerzan esta idea de que no son capaces de llevar a cabo con éxito una empresa autogestiva por esta falta de formación. Las experiencias de las cooperativas de crédito y de servicios

${ }^{34}$ Entrevistas grupales a La Recuperada, realizadas en octubre de 2011 y febrero de 2014. 
de electricidad de Necochea, las cuales conforman el grupo de cooperativas señaladas como exitosas por obreros de La Recuperada, tienen en común que no son cooperativas de trabajo, no estarían entonces conformadas por trabajadores como ellos, sino que por el contrario sus integrantes poseerían el conocimiento necesario para triunfar económicamente. Por ende, vemos que en parte opera una premisa de responsabilidad propia ante los fracasos o dificultades que se le presentan al emprendimiento obrero, lo cual muestra la efectividad del discurso hegemónico para instalarse en las subjetividades obreras de ERT. Aunque en parte los trabajadores de la Recuperada reconocen factores estructurales y mercantiles para sus bajos ingresos y discontinuidad laboral, en la misma operación aseveran que sus principales herramientas son el esfuerzo, la perseverancia, el conocimiento del proceso de trabajo y la voluntad de querer sortear la situación de desocupación, no así la posesión de un saber obrero que tenga la potencia de generar una superación de su situación precaria, ni al interior ni al exterior de la fábrica.

Veamos ahora las consideraciones acerca de la cooperativización en las trabajadoras de Engraucoop. En este proceso la promoción de la cooperativización provino del Estado, luego de que las trabajadoras solicitaran asistencia socioeconómica en agencias municipales. A diferencia del caso de La Recuperada, al confirmarse el ingreso a concurso preventivo de la firma Engraulis, la gran mayoría de las trabajadoras continuó ocupando las instalaciones de la planta y desempeñándose como trabajadoras tercerizadas, elaborando productos para otras empresas o bien pedidos puntuales que habían quedado pendientes de entrega, con materia prima que habían logrado retener en la planta procesadora al momento del retiro de la patronal.

Sin embargo, en este proceso se conformaron dos colectivos obreros que entraron en confrontación. Uno de los grupos estaba comandado por Analía, una de las delegadas sindicales de planta y también por Claudia, una trabajadora que además había sido accionista minoritaria de la firma ${ }^{35}$, quienes proponían conservar los puestos de trabajo continuando con la producción autogestiva. El otro grupo se encontraba liderado por Patricia, quien se desempeñaba como capataza y también mantenía vínculos con una de las representantes legales de la empresa Engraulis y su postura fue la del rechazo a la propuesta autogestiva e incluso del uso de las instalaciones, alegando que su mejor opción era retirarse de la planta procesadora y luchar por el pago de las indemnizaciones correspondientes. Entre las razones para irse del lugar de trabajo resaltaba la idea de que al continuar usando los bienes de la empresa esto acarrearía el deterioro de los mismos y por ende se perdería capital para abonar las indemnizaciones y salarios adeudados a las y los obreros ${ }^{36}$.

\footnotetext{
35 En el capítulo 4 daremos más detalles al respecto, pero aquí nos parece importante aclarar que esta trabajadora formó parte de un cambio en el formato empresarial de Engraulis al conformarse como Sociedad anónima en 2003, cuando los empresarios le solicitaron, dada su antigüedad laboral en la firma, que acceda a figurar como una de las socias accionistas, sin contar por ello con capital propio ni parte de la sociedad. La trabajadora accedió para colaborar con los empresarios, a quienes sentía como "parte de su familia" (Entrevista a Lilian, realizada en abril de 2018). ${ }^{36}$ Causa judicial ENGRAULIS s/quiebra №3574-7011, expediente №37489 Fs. 535.
} 
De esta manera, situaba al otro agrupamiento como enemigo de los propios intereses, bajo la premisa de que el cobro de las indemnizaciones y la recuperación de la empresa eran destinos mutuamente excluyentes.

Esta situación ambivalente en el conjunto obrero de los ex trabajadores Engraulis será abordada en el capítulo 4, pero aquí nos ocuparemos de sus implicancias en la cooperativización. Ambos grupos convivieron en permanente conflicto en la planta procesadora durante varios meses; de acuerdo a miembros de Engraucoop, la situación era muy dificultosa: "teníamos que cuidar el trabajo que habíamos hecho porque nos saboteaban, nos llenaban de agua las botas, nos insultaban" (trabajadora de Engraucoop, 2012). En el contexto de hostilidad, la incertidumbre e inestabilidad del trabajo, algunas integrantes del grupo que luego conformó Engraucoop comenzaron a recorrer oficinas municipales en busca de recursos que les permitiesen sobrellevar su precaria situación de vida. Una mañana, obtuvieron una respuesta favorable desde la Secretaría de Producción, quien los contactó con el INAES. Esta agencia envió a dos empleados provinciales a Necochea durante dos meses a fin de asesorar a las trabajadoras y conformar la cooperativa de trabajo. En el transcurso de este tiempo, el agrupamiento liderado por la ex-capataza de Engraulis se retiró de la planta, pero continuó con la disputa en el ámbito judicial, conformando una segunda cooperativa con el único objetivo de solicitar al Juez que llevaba la causa el cese de actividades en la planta por parte del grupo autogestivo. Este pedido fue denegado por el Juez interviniente, quien desde los inicios del proceso judicial otorgó la guarda de las instalaciones a las obreras de Engraucoop. Cabe destacar que el agrupamiento que buscó recuperar la empresa no se posicionó como excluyente del grupo que solo quería cobrar las indemnizaciones, sino que ubicaron como enemiga a la que consideraban su líder, es decir, a Patricia. A ella responsabilizaban de la división y enemistad intraobrera, y también del abandono patronal, dada la vinculación y representación anterior de la patronal que efectuara Patricia. Con el correr de los años, este posicionamiento se rectificó cuando, luego de obtener contratos como trabajadores tercerizados de diferentes empresas, el grupo inicial de Engraucoop superó su propia capacidad productiva y contrató nuevas trabajadoras, muchas de ellas integrantes del "grupo de Patricia", de forma permanente, aunque sin asociarlas a la cooperativa. Volveremos sobre este punto en el capítulo 4.

Retomando los momentos iniciales de la constitución de la cooperativa Engraucoop, superado el escollo relativo a la confrontación entre las obreras, otro punto a recalcar en este proceso se refiere a las características del consejo de administración. Consideramos que la intervención estatal y las peculiaridades de este proceso de recuperación ha provocado que la división entre las trabajadoras que conforman el Consejo de Administración y el resto de las asociadas se encuentre fuertemente marcada. Por otro lado, a diferencia del caso de La Recuperada, que contó con un número reducido de trabajadores -entre los 8 y 9 miembros-, en Engraucoop fue un colectivo de 20 trabajadores los que se nuclearon en la cooperativa (sin contar al segundo grupo obrero, que también rondaba en la 
veintena de participantes). Si bien el conjunto de trabajadores de Engraucoop realizaban en forma rotativa las tareas propias de la producción, la gestión y los trámites recayeron en determinadas obreras, sobresaliendo la ex delegada sindical, la ex accionista minoritaria y otra de las anteriores administrativas. Puede observarse aquí un liderazgo fuertemente centralizado, que abre las puertas para la instalación de lógicas verticalistas y jerárquicas, lo cual es avalado por las propias implicancias de la legislación cooperativa, como se ha visto más arriba. En este sentido, la diferencia que observamos es que mientras que para el aprendizaje de las tareas de producción las obreras recurrieron a la autocapacitación al interior del propio grupo, esta formación conjunta no se replicó para el aprendizaje colectivo de las labores administrativas. Este aspecto se vincula con el prejuicio obrero hallado en La Recuperada, acerca de la incapacidad obrera para llevar a cabo ciertas tareas vinculadas a la comercialización y la administración. Este prejuicio limita el accionar obrero y ubica al conocimiento en cuestión como reservado para unos pocos, considerados como un grupo más competente que el resto, reproduciendo de esta forma una relación jerárquica, homologable a la sancionada por el formato de trabajo bajo patrón. La agencia del colectivo obrero se escinde y se deposita en un grupo minoritario (que posee saberes, que realiza determinadas acciones en nombre del grupo de trabajo), mientras que la gran parte vuelve a posicionarse como pasiva ante las decisiones del sector "activo". Esto nos lleva a pensar que la mera apropiación de los medios de producción no borra de forma automática la vinculación verticalista establecida previamente, sino que es necesaria la reflexión y nuevas prácticas colectivas vinculadas a la horizontalidad, la democratización integral y la socialización no solo de la producción sino del trabajo en general en las ERT para que no se repitan lógicas patronales en las cooperativas.

Una última mención acerca de este proceso puntual es la tercerización en la que la cooperativa quedó subsumida, por la cual otras empresas efectuaban contratos por pedidos, de los cuales las trabajadoras recibían un monto determinado calculado a partir de cada frasco de anchoas elaborado.

En síntesis, ambos procesos de cooperativización en las empresas recuperadas exponen la precarización laboral propia de estos emprendimientos obreros, que para su subsistencia se sumergen en el circuito de trabajo informal signado por los bajos ingresos, la inestabilidad y la incertidumbre laboral. Asimismo, se observa el pasaje del trabajo asalariado en relación de dependencia, bajo convenios colectivos de trabajo hacia el empleo no registrado, y su ocultamiento bajo la figura del cuentapropismo o cooperativismo. Como contracara, opera la trasmutación de una situación de inminente o consumada desocupación hacia la cooperativización de la fuerza de trabajo, que desliga responsabilidades empresariales y estatales en relación a los derechos laborales y las deposita en los propios obreros.

Por otra parte, se expresa una tendencia de cooperativización impuesta desde arriba por las patronales a fin de superexplotar a los trabajadores, o por el Estado a fin de contener la irrupción social de la población desocupada. Por este motivo, no se 
manifiesta como un ideal laboral sino como un último -o único- recurso ante el desempleo.

En el caso marplatense, la autogestión nunca se concreta como tal ya que la misma guarda el carácter ficticio de trabajo no registrado encubierto, y por ello cooperativización es sinónimo de derrota obrera y de precarización laboral ante la imposición patronal. En el caso necochense, la constitución de cooperativas como parte de la lucha por la recuperación de las empresas guarda similitudes y diferencias con el caso marplatense. Si bien también se manifiesta una añoranza con respecto a la condición asalariada en relación de dependencia, al no mediar en estos casos la exigencia patronal de cooperativizarse y en cambio expresarse como voluntad obrera, la misma no se presenta como una derrota, sino como una victoria sobre el destino de desocupación impuesto. Aquí, la oposición desempleo vs. cooperativización no fue planteada por el empresariado, ya que su posición de quiebra en el marco del desguace de la rama solo planteaba como única consecuencia a la desocupación y pérdida de todas las fuentes laborales. En Mar del Plata, en cambio, la constitución de cooperativas fue estrategia patronal para abaratar la fuerza de trabajo ante la concentración de la industria pesquera. Por ello, los trabajadores necochenses que emprendieron la recuperación de las empresas concibieron que este camino constituía una estrategia obrera para imponer al empresariado la continuidad laboral, y en este marco la cooperativización fue emprendida como formato basado en la independencia obrera de la patronal. Por ello, puede vincularse con la finalidad propia de la cooperativización en los orígenes de la misma en el sector pesquero, es decir, una finalidad corporativista -en este caso obrera- para enfrentar problemas comunes de trabajo y subsistencia. En ello reside la consecución de estos proyectos obreros, es decir, no guardan el carácter de cuestionamiento del capitalismo y del trabajo asalariado -por lo menos en sus inicios-, sino que se plasman como una estrategia laboral para permanecer dentro del sector ocupado. La emancipación lograda se experimenta como contracara de la amenaza de desocupación, no en relación con el anterior formato laboral bajo patrón. Aunque en ambas localizaciones portuarias la contrapartida impuesta por la patronal era el desempleo, mientras que en Necochea desapareció el empresariado pesquero, en Mar del Plata la clase empresarial continuaría enriqueciéndose y precarizando a la fuerza de trabajo. Por esto, la cooperativización fue alternativa para los obreros necochenses y derrota para los marplatenses.

No obstante, con el correr de los meses, los trabajadores autogestivos de Necochea se encontraron con dificultades laborales que impusieron nuevas significaciones a la recuperación de sus puestos de trabajo, vinculadas a la precarización laboral, a la autoexplotación y al menoscabo obrero. Esta última cuestión se relaciona con la ideología hegemónica impuesta en el marco neoliberal acerca de la cooperativización y la llamada economía social, a partir de la cual se deposita en los propios sujetos la responsabilidad del fracaso de los emprendimientos autogestivos, negando el papel de los Estados y del mercado, y en general, del sistema capitalista, cuya lógica obstaculiza enormemente la rentabilidad de las pequeñas cooperativas 
por sus desiguales condiciones con respecto al gran capital. Por ello, la precarización laboral vivida en las empresas recuperadas, si bien en parte se concibe como resultado de su inmersión en el sistema capitalista, en gran parte se conceptualiza como resultado de una supuesta incapacidad obrera para llevar a delante de forma rentable una empresa autogestiva.

En los siguientes capítulos abordaremos en mayor profundidad los avatares de los procesos de lucha en los que se enmarcaron ambos tipos de cooperativas en las localizaciones portuarias abordadas, y sus implicancias en las subjetividades obreras. En el capítulo tercero examinaremos el caso marplatense durante el período 1997-2012. Para su análisis e interpretación haremos foco en las constelaciones conflictivas propias de los tres ciclos de conflictividad delimitados, deteniéndonos en la conformación y desarrollo de las fuerzas sociales en pugna y en las expresiones colectivas de las subjetividades obreras durante los procesos de lucha. 


\section{Capítulo III}

La resistencia obrera a la precarización laboral en la industria pesquera de Mar del Plata (1997-2011): una batalla irresoluta 


\section{Introducción:}

A lo largo de la historia de la lucha de clases $^{37}$, desde la instauración del modo de producción capitalista, la clase obrera ha resistido y combatido la explotación, utilizando para ello diversos métodos, expresados en un enorme caudal de acciones conflictivas.

El conflicto capital/trabajo continúa siendo el tipo de conflicto predominante en el sistema capitalista, en términos de cantidad de acciones de rebelión y de relevancia social (Silver, 2003). No obstante, la conflictividad social es más amplia e incluye otros sujetos, identidades, organizaciones en lucha, con objetivos, tradiciones y métodos propios, aunque muchas veces también compartidos con los de la lucha obrera contra el capital.

En un sentido amplio, la conflictividad social es la sociedad en movimiento, reconfigurándose mediante correlaciones de fuerzas en pugna que disputan la dirección social y las modalidades de vida humana. La historia de la organización social humana ha demostrado que ésta no es estática, sino dinámica, que se transforman tanto las condiciones materiales y las prácticas como las condiciones simbólicas e ideológicas, que se reconfiguran las formas de subjetivación, de socialización, de transmisión y reproducción social y cultural. Vemos, en el mismo sentido, que estos cambios no se producen sin lucha social entre grupos humanos con intereses contrapuestos. Retomando a Marx (1975), entendemos que esta dimensión conflictiva de la historia explica la actual división social entre una clase dominante propietaria del capital y otra dominada, desposeída, explotada y oprimida. La perspectiva de lucha de clases como intrínseca a la organización de las sociedades capitalistas actuales implica la existencia de una conflictividad social constante, que toma diversas formas de acuerdo a variables determinadas por la correlación de fuerzas de cada momento histórico, con su base material, sus fundamentos ideológicos y sus contradicciones internas.

En este sentido, cabe mencionar una revitalización de la lucha organizada del movimiento obrero argentino en las últimas décadas (Nieto, 2010) que, sin desconocer la persistencia de la lucha y resistencia en la totalidad del período

\footnotetext{
37 Aquí consideramos al concepto de clase desde E. Thompson (1962), quién la sitúa como experiencia social y como resultante de determinadas relaciones de producción, y por ello, relaciones sociales. En este sentido, retomamos las siguientes definiciones: "la clase cobra existencia cuando algunos hombres, de resultas de sus experiencias comunes (heredadas o compartidas), sienten y articulan la identidad de sus intereses a la vez comunes a ellos mismos y frente a otros hombres cuyos intereses son distintos de (y habitualmente opuestos a) los suyos", la clase es una "formación social y cultural que surge de procesos que sólo pueden estudiarse mientras se resuelven por sí mismos a lo largo de un período histórico considerable" [Prefacio. La formación de la clase obrera en Inglaterra]. Por otra parte, siguiendo al mismo autor consideramos la conformación de la clase como resultante de un proceso lógicamente posterior a la lucha de clases: "las gentes se encuentran en una sociedad estructurada en modos determinados (crucialmente, pero no exclusivamente, en relaciones de producción), experimentan la explotación (o la necesidad de mantener el poder sobre los explotados), identifican puntos de interés antagónico, comienzan a luchar por estas cuestiones y en el proceso de lucha se descubren como clase, y llegan a conocer este descubrimiento como conciencia de clase" [Lucha de clases sin clases].
} 
neoliberal, marca un nuevo pulso en la protesta social desde fines de los 90. Durante las dos décadas anteriores, y más aún en los 90, predominó el consenso, la fragmentación y el individualismo (Izaguirre, 1994) hasta que, ante el empeoramiento en las condiciones de vida y trabajo de la clase obrera, la protesta callejera comenzó a ampliar su notoriedad. Particularmente, dentro de la rama pesquera a nivel nacional la conflictividad creciente se expresó de forma contundente en el marco de la crisis de un sistema productivo ligado fuertemente a la convertibilidad y atado a la sobreextracción de la merluza (Nieto, 2010; Colombo, 2008). Posteriormente, el contexto de la posconvertibilidad posibilitó una recuperación y crecimiento económicos empresariales y a la vez generó transformaciones en las luchas obreras, en las subjetividades de la industria pesquera marplatense y en las organizaciones que las nucleaban. Estos cambios, a su vez, se conjugaron con la continuidad de ciertas demandas y formas de lucha precedentes.

Para analizar la conflictividad sociolaboral en la historia reciente de la industria pesquera bonaerense aquí plantearemos que las consecuencias de la reestructuración capitalista en la rama habilitaron diversas acciones de rebelión obrera ante las duras condiciones impuestas por el capital, así como también disputas en torno a la organización sindical y entre la propia burguesía. Dentro del campo obrero, diversos factores darán especial preminencia al grupo de trabajadores en lucha conformado por obreros de las cooperativas fraudulentas de fileteado de Mar del Plata, un sector contencioso y rebelde a las nuevas condiciones impuestas por la hegemonía neoliberal.

En capítulos anteriores vimos que el Puerto de Mar del Plata fue concebido y concretado como el complejo pesquero argentino por excelencia desde los inicios de la actividad pesquera comercial marítima nacional (Mateo, 2011). Desde la década del 70, la relocalización de parte del sector extractivo e industrial en los puertos patagónicos -impulsada por el estado y las grandes empresas, en alianza con el capital trasnacional- restó preminencia al puerto marplatense, que igualmente continuó destacándose en el sector de procesamiento fresquero y la pesca de altura; mientras que la Patagonia se dedicó mayormente a la pesca con buques factoría y con congelado a bordo. Esta relocalización y concentración de la operatoria pesquera se conjugó con los acuerdos marco con terceros países realizados por los gobiernos de Alfonsín y Menem, y con el otorgamiento de permisos de pesca a flotas extranjeras.

Vimos asimismo que estos cambios, sumados a las características mencionadas del período 1997-2012, permitieron una ofensiva patronal contra las condiciones de trabajo y contratación, fomentando la proliferación de cooperativas fraudulentas en la industria pesquera marplatense. Esta maniobra de fraude empresarial, en connivencia con el Estado y los gobiernos, desencadenó el engrosamiento en las filas de trabajadores no registrados, así como las de los desocupados en la rama. El gran incremento de la cooperativización en la industria pesquera argentina logró 
instalarse -a nuestro parecer- fundamentalmente por dos razones. Por un lado, por las características del proceso productivo, que presenta una fuerte dependencia de las posibilidades extractivas extremadamente variables, ya que se encuentran sujetas a diversos factores, algunos de ellos imposibles de prever y controlar por el capital (tales como condiciones climáticas y devenir de la biomasa pesquera). Estas características provocaron que incluso la lucha por el convenio más avanzado en cuanto a derechos laborales del sector pesquero nacional -el Convenio 161/75- no consiguiera eliminar el trabajo a destajo en el rubro de procesado y fileteado de pescado fresco, subrama en la que se crearon la mayoría de las cooperativas fraudulentas. Al estar la producción tan afectada por la materia prima disponible, las condiciones de producción no logran ser regulares ni previsibles, argumentos que los empresarios aducen para derribar y/o negarse a otorgar ciertas garantías a los trabajadores. La cooperativización fraudulenta puede definirse como una masificación del trabajo a destajo sin ningún tipo de derechos incluidos en el convenio colectivo del sector, a la vez que se eliminan aportes patronales y otras cargas sociales a cargo del empleador. De esta forma, se transfieren al trabajador los riesgos propios de la producción y comercialización del sector pesquero. Es así que el trabajo antes considerado "en negro" comenzó a realizarse dentro de las fábricas, a la luz de todos, pero con las mismas prerrogativas para la patronal. El otro motivo es el amparo legal con que los empresarios pesqueros contaron para utilizar fuerza de trabajo no registrada sin ningún tipo de obstáculo jurídico, incluso mediante las facilidades que la Ley de Cooperativas 20.337 les otorgó, sumado a la complicidad de los organismos del poder judicial y del Ministerio de Trabajo que desconocieron la denuncias obreras y sindicales sobre el trabajo no registrado enmascarado bajo la forma de las cooperativas. Todo esto en el marco de la ofensiva del capital desde la década del 70 a nivel nacional e internacional, acentuándose en los 90 las formas de explotación laboral mediante la llamada "flexibilización", con un gran retroceso en las condiciones de trabajo y contratación en términos generales en todos los sectores y ramas de la economía. En este contexto adverso, ante la avanzada del empresariado en la industria pesquera, los trabajadores resistieron a través de un diverso caudal de acciones de rebelión.

Aquí abordaremos un análisis de la conflictividad sociolaboral en la industria pesquera marplatense, focalizándonos en las acciones de protesta vinculadas a los trabajadores cooperativizados a partir del contexto de crisis del recurso merlucero, sin por ello descuidar la referencia a las acciones del resto de sectores en pugna. Para ello tomaremos los aportes de Tarrow $(1997,2002)$, quien constata que bajo una determinada constelación de circunstancias el conflicto protagonizado por uno o varios movimientos sociales se generaliza en el sistema social hasta constituir un ciclo de protesta. Este ciclo constituye una fase de intensificación del conflicto y del enfrentamiento a lo largo del sistema social, incluyendo: 1) una rápida difusión de la acción colectiva desde los sectores más movilizados; 2) una aceleración de las pautas de innovación en las formas de acción colectiva; 3) una combinación de participación organizada y no organizada; 4) la creación de nuevos "marcos" que 
vinculan las acciones de grupos originalmente dispares entre sí, y 5) secuencias de interacción intensificada entre los grupos desafiantes y las autoridades que pueden culminar en reforma, represión y, en ocasiones, en revolución. Además, incorporamos desarrollos de Tilly (1993), quien apunta que la generalización de un conflicto en un ciclo de protesta se produce cuando se abren oportunidades políticas aprovechadas por determinados sujetos que inician la movilización, cuando éstos plantean exigencias que encuentran eco en los reclamos de otros grupos, y cuando estas exigencias dan lugar a coaliciones objetivas entre actores dispares y crean o refuerzan situaciones de inestabilidad en los grupos dominantes. Para este autor, los ciclos de protesta se producen como consecuencia de la evaluación de los costes y beneficios que los individuos esperan obtener a través de la movilización, y de los recursos que las organizaciones ponen a su disposición. En este sentido, son indicadores de la aparición y cambios en las oportunidades políticas vinculadas a ciertos repertorios de acción colectiva, y a la vez puntos de inflexión para el cambio social y político. En el mismo sentido, Gourevitch (1986) plantea que, en momentos de graves crisis políticas o económicas, por ejemplo, tras una guerra o una fuerte recesión, podía darse lo que denominaba un momento abierto, un contexto en el que los actores sociales y políticos disponen de mayores oportunidades reales para establecer un nuevo orden político. En tal sentido, por ejemplo, ¿podría pensarse la revolución rusa sin el contexto de la I Guerra Mundial? En consonancia con estos planteos, Kingdon (1984) utiliza el concepto de ventana política, un espacio que se abre temporalmente ofreciendo oportunidades para la obtención de ciertas demandas. Estos aportes teóricos serán instrumentalizados a fin de llevar a cabo una interpretación analítica del período 1997-2011.

Además de analizar los conflictos en sí, aquí abordaremos la perspectiva de los actores sobre ellos, a través de testimonios con informantes clave que permitan incluir a las subjetividades en cuestión desde un enfoque etnográfico. De esta forma buscamos recuperar el decir de los sujetos a la vez que "humanizar" el discurso científico acerca de las acciones conflictivas, superando las categorizaciones y datos cuantitativos con la inclusión y análisis de las motivaciones y lecturas nativas sobre los procesos estudiados. La elección de las fuentes orales se fundó en la búsqueda de formas de aprehensión de experiencias pasadas por parte de los actores, focalizando la dimensión subjetiva, las significaciones que marcaron las experiencias y la elaboración e interpretación de los actores respecto de lo vivido, asumiendo que "el trabajo con informantes muchas veces nos enfrenta al doble lado de la historicidad, es decir, cuando los sujetos que narran están involucrados en los procesos sociohistóricos y a la vez en las condiciones narrativas sobre esos procesos" (Gil, 2007:41).

Desde este marco, adoptaremos la definición de conflicto social que lo entiende como: "disputa general (material y/o simbólica) entre clases dominantes y clases subalternas, articuladas en torno a fuerzas sociales y/o políticas, y/o al interior de cada una de éstas" (SISMOS, 2014: 8). 
En estos conflictos podemos delimitar constelaciones que configuran una lógica que excede la linealidad y, por el contrario, exhibe una yuxtaposición de redes de relaciones sociales que expresan la multiplicidad de intereses detentados por los distintos actores. El término constelación fue elegido para metaforizar la diversidad de acciones conflictivas, dado que las mismas pueden subagruparse en campos de disputa marcados por variables que plasman "figuras" específicas. En su conjunto, los campos de disputa intrincados se vinculan en forma dialéctica unos con otros (Marx, 1873; Mandel, 1979) en una recíproca influencia y mutua co-construcción. A fin de detectar y precisar los rasgos constitutivos de estas constelaciones de la conflictividad de la industria pesquera bonaerense, se utilizaron categorías analíticas propias de la Base de datos del Seminario de Investigación sobre el Movimiento de la Sociedad (SISMOS) ${ }^{38}$, tales como las modalidades de acción, los sujetos que las llevan a cabo, los objetivos que persiguen, las alianzas con otros actores sociales -incluyendo a la organización sindical- y las demandas que efectúan.

Para la obtención de la información se apeló a una diversidad de fuentes, a fin de contrastar los datos obtenidos de cada una de ellas mediante un análisis crítico multicausal. Por un lado, se realizó un minucioso análisis de la prensa gráfica local, a partir del Diario La Capital. Asimismo, fueron consultados otros diarios digitales marplatenses a fin de rescatar datos no incluidos en la prensa gráfica, así como algunos ejemplares de la Revista Puerto. Considerada en forma global, la información extraída de las notas de prensa seleccionadas proporcionó datos acerca de las acciones conflictivas realizadas y asimismo fue posible localizar citas de declaraciones que contenían valoraciones de los propios actores involucrados: trabajadores, dirigentes gremiales, empresarios, funcionarios gubernamentales. Por otra parte, apelamos a entrevistas a los actores, principalmente trabajadores, pero también algunos dirigentes sindicales. Una decena de ellas fueron realizadas y transcriptas por estudiantes avanzados durante la cursada de la materia "Metodología cualitativa" correspondiente a la carrera de Sociología de la UNMdP, en el marco de un trabajo práctico aplicado de Investigación cualitativa dirigido por la docente Alejandra Navarro durante el año 2009. Otras fueron publicadas por medios periodísticos tales como la Revista Puerto. A su vez, como fuentes secundarias se utilizaron trabajos previos de otros investigadores dedicados principalmente a los obreros pesqueros marplatenses, las cuales aportaron un gran caudal de variada información al respecto que se encuentra debidamente citada en

\footnotetext{
38 El Seminario de Investigación sobre el Movimiento de la Sociedad (SISMOS) es un proyecto de investigación integrado por investigadores y estudiantes de diversas disciplinas sociales y humanísticas de las ciudades Mar del Plata, Bahía Blanca y Necochea. Este grupo, dirigido por el Dr. Agustín Nieto, diseñó un modelo de carga de acciones de conflictividad social con el objetivo de confeccionar posteriormente una base de datos que permita identificar, contabilizar, describir y realizar análisis cuantitativos y cualitativos de estos hechos de rebelión, a fin de "procurar un minucioso y concienzudo (pero no infalible) seguimiento de la conflictividad social local" (SISMOS, Manual de carga, versión 2014).
} 
los desarrollos que prosiguen. Por último, para determinadas referencias gremiales se hizo uso de archivos sindicales.

Como vimos anteriormente, en el año 1997 estalla la crisis por la sobrepesca -y consiguiente escasez- de Merluza hubbsi, uno de los principales recursos de la extracción e industria pesquera vinculada al comercio exterior. Este hecho objetivo actuó como desencadenante de un período abierto de conflictividad sociolaboral que perdura hasta el día de hoy en la escena portuaria marplatense. Realizando un corte en el año 2011, podemos distinguir tres ciclos de rebelión agrupados en quinquenios: 1997-2001, 2002-2006 y 2007-2011, los cuales abordaremos en las próximas páginas. Durante todo el período se distinguen lapsos de aparente calma y merma en la conflictividad en contraposición con otros momentos de disrupción aguda y estallidos de ira obrera (Nieto, 2009) con altos grados de radicalidad. Por ello, la conflictividad sociolaboral en la industria pesquera marplatense puede expresarse gráficamente en una línea ondulada cuya pendiente varía, experimentando alzas, declives y nuevas elevaciones sucesivamente, perdurando en forma constante.

Si bien, como dijimos, el factor desencadenante de la conflictividad se condensa en la crisis del recurso pesquero en 1997, determinadas condiciones objetivas venían preparando el terreno, esto es, la precarización de las condiciones de trabajo y de contratación que comenzó a instalarse desde los 90 y acrecentó la masa obrera cooperativizada en el sector. Luego de interpretar los datos desde las variables previamente delimitadas se detectaron tres campos de disputa intrincados: interburgués, intrasindical y capital/trabajo.

\section{Revisión de los antecedentes}

Antes de adentrarnos en el análisis del período delimitado, nos parece pertinente considerar al menos en forma sintética, la conflictividad sociolaboral en la industria pesquera marplatense a lo largo de su historia. Comenzaremos a partir de la década del 30, en la que el crecimiento de la industria conservera y, por ende, de los trabajadores involucrados en ella, impulsó el surgimiento de los primeros sindicatos propios de la rama. Anteriormente, más precisamente desde el año 1920, hubo varios intentos de organización que no coagularon, con nombres similares al SOIP y con presentación de petitorios de reivindicaciones obreras. En 1942 se conformó el SOIP (Sindicato Obrero de la Industria del Pescado), cuyo accionar inicial se centró en la negociación de "pliegos de condiciones" referidos a derechos laborales intrafabriles. Su método de lucha primordial fue la huelga, llegando a realizar una de 29 días de duración en su año fundacional, obteniendo como principal triunfo la eliminación del pago a destajo en la industria conservera. A partir de 1948, se produjo un cambio en el objetivo gremial, el cual se definió como la lucha por Convenios colectivos de trabajo (CCT), el primero se obtuvo en 1948, firmándose uno por año hasta 1952, y luego reescrituras en 1954 y 1956. A partir de ese año se firmó un convenio colectivo de trabajo cada 6 o 12 meses, siendo el último en el año 
1975. El derecho a organizarse sindicalmente fue otro eje de lucha originario que se prolongó durante las décadas subsiguientes.

Con gran preponderancia de personal femenino en sus comienzos, la industria pesquera se expandió, modificando condiciones de trabajo y contratación. La inestabilidad fue un rasgo que comenzó a instalarse (Nieto, 2014), alternando períodos de alta y baja actividad de acuerdo a las temporadas de "zafra" en las que el volumen de pescado ingresado en las terminales portuarias determinaba la cantidad de mano de obra necesaria en las plantas, lo que provocaba a su vez que durante épocas de baja actividad las trabajadoras debieran reinsertarse en otras ramas. El pago a destajo se instituyó como la forma predominante de retribución monetaria a la labor obrera en la industria fresquera, que incentivaba la competencia y la superexplotación laboral y perpetuaba la inestabilidad. Por ello las principales demandas se basaron en la obtención de un salario mínimo y un horario garantizado, independientemente de la materia prima procesada.

Por su parte, las obreras que predominaban en la fuerza de trabajo de la industria conservera, desde la década del 40 emprendieron luchas con las que obtuvieron aumentos salariales y reconocimiento del trabajo femenino, reconocimiento del horario de ingreso y egreso, condiciones de higiene y seguridad para las mujeres, abolición de tareas de fuerza y también reconocimiento salarial de tareas externas (Ruocco, 2010; Molinari, 2008). Con una importante huelga de 29 días en el año 1942, obtuvieron la eliminación del trabajo a destajo en la industria conservera. Todo esto en el marco de la incipiente conformación del SOIP durante ese mismo año (Nieto, 2008) .

Durante la década del 60, cuando la producción fresquera comenzó a superar a la industria conservera, se transformó la composición obrera aumentando significativamente en términos cuantitativos la fuerza de trabajo masculina. En ese contexto reapareció y se impuso con fuerza el trabajo a destajo, incentivando la competencia de los obreros entre sí (Ruocco, 2008).

En cuanto a la línea de la conducción del SOIP, en sus inicios tuvo raíces anarquistas, y sus miembros disputaron la dirección primero con comunistas, luego con una alianza de comunistas y peronistas, y finalmente con el peronismo, fuerza que desde 1969 condujo el gremio hasta el año 2002 (Nieto, 2014).

En relación a los métodos de lucha, además de las huelgas eran frecuentes las reclamaciones individuales y colectivas en el tribunal de trabajo (por despidos, indemnizaciones, cobertura por enfermedades, accidentes, salarios adeudados, etc.) y también las ocupaciones de plantas con rehenes -capataces y directivos-, como las que se produjeron en el marco del conflicto por el nuevo convenio colectivo de trabajo en el año 1965 (Nieto, 2014). La toma de la sede sindical también fue recurrente en los momentos de disputa por la conducción gremial. Luego, las jornadas de trabajo a reglamento fueron muy utilizadas durante la década el 50 para reclamar la recomposición salarial, mientras que la retención de tareas fue la modalidad implementada luego de la última dictadura para reclamar salarios 
adeudados en el contexto inicial de la crisis pesquera que se prolonga hasta la actualidad.

Hacia mediados de los setenta la conflictividad laboral se basó en paros activos con el objetivo de firmar un nuevo convenio colectivo de trabajo, que desembocó en la conquista del CCT №161/75, aún vigente. Este convenio incluyó garantías salariales y horarias, control de las balanzas por parte del delegado de planta, un tamaño mínimo de la merluza a procesar y un significativo aumento salarial (Nieto, 2014). Posteriormente, entre los 80 y los 90 la demanda fundamental de la conflictividad sociolaboral fue la lucha por reajustes salariales y la regulación del mercado de trabajo, cuya condición inestable y precaria se acentuó fuertemente. La toma de establecimientos a fin de evitar cierres de plantas fue la acción conflictiva obrera predominante en el marco de las luchas entre 1989 y 1991 (Colombo, 2014), las cuales fracasaron ante la expulsión de mano de obra y su cooperativización con pago de porcentajes mínimos -cuando no, inexistentes- de indemnizaciones a los obreros. De acuerdo a estudios al respecto y a los testimonios hallados, los trabajadores cooperativizados marplatenses mostraron ampliamente su disconformidad con la realidad laboral del sector a partir de los 90, cuando los cierres empresariales desembocaron en la cooperativización fraudulenta. En este contexto, concentración de la actividad en pocas grandes firmas y tercerización de la fuerza de trabajo, además de las ocupaciones de plantas pesqueras, los obreros también realizaron tomas de la sede sindical y agencias estatales, que buscaron inicialmente la continuidad laboral y luego debieron resignarse al objetivo del cobro de las indemnizaciones. La organización del grueso de la fuerza de trabajo en cooperativas se dio inicialmente en un período de 4 meses entre 1991 y 1992 (Allen, 2010). Diversos testimonios obreros que integran los trabajos de Lanari y Cutuli (2010) y Colombo (2014) relatan cómo el temor al desempleo, maniobras e incluso promesas empresariales -que versaban sobre el traspaso de la propiedad de los bienes capitales hacia los trabajadores de las cooperativas- se conjugaron como condicionantes que dieron lugar al surgimiento de las mismas. Incluso algunos obreros prefirieron rechazar la indemnización a fin de integrar una cooperativa, eligiendo la continuidad mediante la precarización laboral por sobre el desalojo del sector. El descenso de la cantidad de firmas producto del incremento de la concentración empresarial junto con el crecimiento de la cooperativización en la rama fue una derrota muy sentida entre los obreros, abriendo un período signado por la supervivencia individual en el puesto de trabajo y la incertidumbre ante el creciente desalojo de la rama. Por ello, entre 1992 y 1996 los niveles de conflictividad descendieron (Colombo, 2014) hasta que la crisis de sobrepesca y escasez de merluza en 1997 marcó un nuevo ascenso, en el que principalmente los desocupados y cooperativizados de la industria pesquera marplatense retomaron con fuerza su lucha en las calles portuarias y agencias estatales.

En síntesis, reseñar estos precedentes tiene para nosotros la finalidad de señalar que la aguda conflictividad sociolaboral que describiremos posteriormente cuenta con importantes precedentes en la historia de la fracción obrera en cuestión aquí, 
por la cual los procesos implicados en los ciclos abordados deben leerse a través de la lente de esta tradición de lucha, que forma parte de las subjetividades obreras de la industria pesquera. A continuación analizaremos los tres ciclos conflictivos comprendidos en el período 1997-2011.

\section{El ciclo 1997-2001: De la crisis de la merluza al acuerdo interburgués}

En los desarrollos que siguen veremos cómo se reiteran algunos de los reclamos obreros originarios, tales como la lucha contra la incertidumbre salarial y a favor de la posibilidad de organizarse. En relación a este último reclamo, la carencia de legalidad propia de los trabajadores cooperativizados para sindicalizarse no provenía de la regulación estatal sino de la propia normativa sindical. La cooperativización fraudulenta no solo precarizó las condiciones de trabajo y contratación, sino también dejó por fuera de la afiliación gremial a los trabajadores cooperativizados, ya que el estatuto vigente en el SOIP solo contempla la inclusión de obreros en relación de dependencia. Así como sucede en muchos otros gremios adheridos a la CGT, no así a la CTA, las dirigencias se han negado a modificar los términos estatutarios para la inclusión de los trabajadores tercerizados, desestimando así a una cada vez más amplia masa obrera de su base social sindical. Además, con la crisis del recurso pesquero recrudeció la expulsión obrera de las plantas de procesamiento y acortó períodos de contratación de los trabajadores no registrados. Esto significa que la sobrepesca actuó como elemento reactivo que, al empeorar aún más las condiciones de vida y trabajo que ya venían en detrimento, acentuó el carácter explosivo de las masas en combate contra la precarización laboral, los bajos ingresos y el desempleo. El descontento de los obreros cooperativizados no solo se dirigió hacia la patronal, sino también contra la dirigencia sindical, que se había mostrado mayormente inactiva, impotente y expulsiva ante el ataque a las condiciones de contratación obrera. Asimismo, la crisis de la merluza desató un conflicto interburgués durante los primeros años del período en cuestión. Comenzaremos la exposición por este último campo señalado, ya que marcó en parte el rumbo de la lucha obrera y la disputa intrasindical durante los primeros años estudiados.

Antes de comenzar el análisis, queremos introducir como premisa conceptual para la lectura de los datos el concepto de "Fuerza social obrera", constructo teórico que nos parece pertinente para abordar la heterogeneidad y complejidad de las luchas obreras, y, asimismo, evitar el exceso de interpretaciones verticalistas y caricaturas dicotómicas que en general dejan por fuera aspectos significativos de la conflictividad sociolaboral. Este concepto nos orientará sobre cómo visualizar la conflictividad y también sobre cómo operativizar nuestras concepciones sobre las subjetividades y la clase obrera. Este concepto promueve un enfoque analítico que recupere la heterogeneidad propia de la clase obrera, la experiencia material de esta diversidad de grupos, capas, fracciones, sexos, edades, geografías, razas y lenguas que la componen. En consonancia, también se refiere a las múltiples y complejas 
mentalidades, culturas, componentes ideológicos y conciencia de clase, de género y étnica que atraviesan y confluyen en la composición de la clase. Todos estos aspectos señalados implican la intersección de diferentes clivajes y contradicciones en permanente proceso constitutivo en función de las diferentes situaciones y coyunturas, por ello "este articularse y devenir en sujeto político clasista es lo que llamamos fuerza social obrera” (Nieto, Laitano, Nogueira, Marioli y Teijón, 2018). Asimismo, toda fuerza social obrera incluye alianzas con otras personificaciones sociales que toman parte en los conflictos, como por ejemplo estudiantes, campesinos, artistas, vecinos, funcionarios políticos, sectores de la burguesía, etc. La intención aquí es observar la conflictividad obrera como enfrentamiento entre fuerzas sociales obreras, donde cada fuerza social presenta sus bases y sus direcciones. En los conflictos podemos distinguir una fuerza social obrera hegemónica y fuerzas sociales obreras subalternas, que se oponen a la dirección de la lucha y/o estrategia implementada por la fuerza social hegemónica. Si bien los niveles de correlaciones de fuerzas varían, y la misma existencia de una fuerza hegemónica implica mayores posibilidades de imponer su perspectiva política, prácticas y concepciones sobre las otras, cada enfrentamiento constituye una posibilidad nueva y abierta en la que la misma constitución de cada fuerza social obrera se recrea, permitiendo transformaciones y reconfiguraciones en la "constelación de fuerzas sociales obreras". De esta forma, intentamos no reproducir las visiones que solo conciben los enfrentamientos intraobreros como enfrentamientos entre bases y direcciones, o visiones que despojan a las bases obreras de toda capacidad de acción política propia. Veremos a continuación cómo es posible aplicar este concepto y esta perspectiva a la conflictividad sociolaboral en la industria pesquera.

\subsection{La disputa interburguesa: la multisectorial marplatense vs. los pulpos pesqueros}

La crisis originada en 1997 fue el punto de inflexión para que saliera a la luz una latente disputa entre dos sectores empresariales diferenciados en la ciudad de Mar del Plata. Esta crisis significaba para el conjunto del empresariado la contracción de posibilidades de extracción, debido no solo a las vedas y cupos impuestos por el Estado sino también a la escasez real del recurso producto de la sobredepredación previa. Las capturas debían reducirse inevitablemente, lo que generó un conflicto interburgués que se presentó como la disputa por dirimir quién restringiría menos su tasa de ganancia a causa de la escasez de materia prima, o, dicho de otra manera, quién pagaría el costo de la previa sobrepesca y sobrecapitalización de la industria. La división y pugna entre un empresariado pesquero dedicado exclusivamente a la producción fresquera, por un lado, y los grandes grupos económicos de la pesca que habían acrecentado su monopolización enormemente en las últimas décadas, por el otro, se acentuó y consolidó como una pulseada ante la crisis del recurso. Al respecto, de acuerdo a Colombo (2014) si bien las disidencias entre ambos grupos 
de la burguesía marplatense existían previamente, hasta ese momento había primado la ausencia de conflicto entre ambos, a pesar de sus discrepancias en cuanto determinadas políticas pesqueras, tales como el ingreso de buques congeladores y la firma de los Acuerdos Marco con potencias extranjeras-: "sobre todo se generó un consenso hacia finales de los 80 y comienzos de la presidencia de Menem respecto de la necesidad de implementar reformas orientadas a la reactivación de la pesca, la posibilidad de incorporar tecnología y mejorar la inserción exportadora de la industria (Colombo, 2014:343). La ruptura se generó cuando cada sector buscó que la crisis recaiga sobre el otro, de aquí que la obtención de cuotas de captura disponibles y luego la orientación de una nueva Ley de Pesca que incluía determinadas restricciones, beneficios y protecciones- fueron los objetivos de ambos bandos empresariales. Esta disputa implicó agrupamientos y alianzas en cada bando, conformándose dos facciones principales: la Multisectorial pesquera y el Consejo de Empresas Pesqueras de Argentina (CEPA).

La Multisectorial pesquera marplatense estuvo integrada por empresas dedicadas a la industrialización de pescado fresco incluidas en la Cámara Argentina de Armadores de buques Pesqueros (CAABP) y la Cámara de procesadores, a la que se sumaron tanto funcionarios gubernamentales, entre los que se encontraba el propio intendente marplatense Elio Aprile, como gremios pesqueros, entre los que se destacan el SOIP (Sindicato Obrero de la Industria del Pescado), el SOMU (Sindicato de Obreros Marítimos Unidos) y el SUPA (Sindicato Unidos Portuarios Argentinos). Estos gremios traccionaron también a una amplia base de trabajadores de la pesca tanto marineros como estibadores y obreros industriales- que apoyaba esta alianza y participaba de las acciones que impulsaba. La Unión Obrera del Pescado (UOP), organización a la que nos referiremos en detalle más adelante, criticaba esta alianza y se oponía a ella. Es decir que, desde 1997, podemos observar la discrepancia entre dos fuerzas sociales obreras que formaban parte de la constelación marcada por el conflicto entre dos fuerzas sociales burguesas. En una de ellas, la dirección era impulsada por dirigencias sindicales junto a las bases que las apoyaban. En la otra, la orientación de la lucha estaba encarnada en trabajadores que eran a su vez militantes del Partido Obrero, que conformaron una organización tanto intrasindical como exógena al sindicato, junto a trabajadores registrados, no registrados y desocupados.

La Multisectorial se enfrentaba a los llamados "Pulpos pesqueros"39, denominación que representaba a los empresarios de origen marplatense pero que, a raíz de la reestructuración capitalista y de su asociación con capitales extranjeros, se convirtieron en empresas integradas, incluyendo todo el circuito pesquero desde la extracción hasta la comercialización, contando con su propia flota de altura y de

\footnotetext{
39 Mateo, Nieto y Colombo. (2010). Capítulo 10: Precarización y fraude laboral en la industria pesquera marplatense. El caso de las cooperativas de fileteado de pescado. Estado actual de la situación y evolución humana de la rama 1989-2010. En Concurso Bicentenario de la Patria, Premio Juan Bialett Massé (págs. 177-203). Buenos Aires: Ministerio de Trabajo de la Provincia de Buenos Aires.
} 
factoría, con producción de pescado fresco y congelado, y localización tanto en Mar del Plata como en ciudades portuarias de la Patagonia. Las firmas integrantes de la CEPA eran: Moscuzza e Hijos S.A., Giorno S.A., Valastro, Luis Solimeno e Hijos S.A. y Santa Elena S.A.

Esta disputa interburguesa se produjo, entonces, entre una "burguesía fresquera" vs. los "grandes grupos económicos de la pesca", con lo cual queda caracterizado el cariz de este campo de conflicto: los avatares empresariales luego de la reestructuración capitalista neoliberal post 70 , con las concomitantes crisis y reconfiguraciones propias de la actividad pesquera desde aquellos años.

Las precursoras de la Multisectorial fueron reuniones entre empresarios fresqueros, gremios e intendente y otros funcionarios locales, que impusieron como su enemigo común a las grandes empresas y a los buques congeladores. En su discurso predominaba el relato del proyecto local marplatense para la provincia de Buenos Aires fundamentado en el valor de la "tradición" y la generación de empleo con tintes localistas y nacionalistas. Recalcaban que los empresarios eran patagónicos y su conexión con capitales extranjeros para destacar esta cuestión, a pesar de la doble localización de las empresas que poseían, la cual incluía su asiento y origen marplatense (Colombo, 2008). La designación de Héctor Auguste como Subsecretario de Pesca desencadenó la unión policlasista, ya que Auguste hasta entonces había sido presidente de la CAPECA, nucleamiento comandado por los grandes grupos económicos de la pesca, y, por lo tanto, era fácil prever a qué intereses burgueses favorecería (Colombo, 2014). El proyecto de la Multisectorial apuntaba a obtener para el empresariado marplatense los mismos beneficios que gozaban los puertos del Sur -es decir, los buques con procesado a bordo- en términos de subsidios y reducciones impositivas, así como también lograr la expulsión bajo el paralelo 48o de los buques factoría y disponer de la prioridad en las capturas permitidas. Para garantizar la posibilidad de plantear este proyecto contra los grandes grupos económicos, la burguesía fresquera confluyó en una "alianza de clases" con una fracción de los trabajadores y los sindicatos (Colombo y Nieto 2006).

Por su parte, los empresarios pesqueros nucleados en la CEPA proyectaban un "plan de promoción a la producción y a las exportaciones pesqueras" (Colombo, 2014), el cual incluía un reintegro por las exportaciones, reducciones impositivas, rebaja de aranceles para la importación de maquinarias y equipos y tasas preferenciales de créditos, cuyo fundamento residía en la mayor eficiencia, tecnificación y modernización.

Las modalidades de acción de ambos bandos empresariales fueron diversas, abarcando un espectro que fue desde reuniones entre partes con distintos funcionarios gubernamentales a nivel provincial $\mathrm{y}$ nacional hasta masivas movilizaciones a Buenos Aires, como medio de presión al gobierno nacional para la promulgación de leyes, decretos y disposiciones a su favor. La primera marcha a Buenos Aires con bloqueo del puerto fue realizada por la multisectorial a raíz de la amenaza del cierre del caladero de Mar del Plata, motivada por una estricta veda 
impuesta desde el Consejo Federal Pesquero en mayo de 1999. La movilización se realizó el 2 de junio y participaron más de 90 barcos y 4.000 manifestantes, contando con el apoyo de más de 80.000 personas que fueron al puerto o se congregaron a lo largo de la costa de Mar del Plata para despedir a los barcos que partían hacia la Casa Rosada, o más específicamente hacia el puerto de Buenos Aires con intención de bloquearlo (Colombo y Nieto, 2006). Como resultado de esta movilización se logró la aprobación de la Ley de Emergencia pesquera 25.109, sancionada el 23 de junio de 1999, la cual contenía la mayoría de las demandas del empresariado fresquero y fortaleció así la alianza policlasista. Sin embargo, si bien fue el objetivo primordial del agrupamiento multisectorial, su conquista no implicó mayores pérdidas para los grandes grupos económicos. Esto se debió a que su sanción fue precedida por un decreto presidencial que levantó la veda, cuyo texto permitía que los grupos empresarios que contaran con buques congeladores y plantas en tierra pudieran seguir pescando -situación que es generalidad en las empresas nucleadas en la CEPA (Colombo, 2014).

Tras la ambigua resolución que no modificó el contexto conflictivo inicial, la situación de los trabajadores no mostró grandes cambios, lo que produjo un momentáneo quiebre de la multisectorial con el retiro del SOMU y el SOIP a causa de la desatención de los reclamos propiamente obreros, cuyos ejes principales se referían a la obtención de trabajo y registración laboral. No obstante, como las conquistas de la sanción de la ley precedente no tuvieron el impacto buscado por el empresariado y persistía del problema de la escasez del recurso, ello produjo un recrudecimiento del conflicto interburgués y, por ende, la reinstalación de la alianza multisectorial basada en la hipótesis del "enemigo en común".

En el año 2000, luego de meses de numerosas movilizaciones locales, el 10 de mayo se realizó una nueva manifestación en la ciudad de Buenos Aires organizada por la Multisectorial. Más de 6 mil personas vinculadas a la pesca se movilizaron a Plaza de Mayo, obteniendo un nuevo compromiso del gobierno nacional para declarar la emergencia pesquera ${ }^{40}$. No obstante, al día siguiente movilizó la CEPA y también obtuvo por parte del entonces Secretario de Pesca el compromiso que habilitaba a las empresas allí nucleadas a continuar con las tareas de pesca (Colombo, 2014: 392). En síntesis, el gobierno nacional no se decidía por favorecer a uno de los sectores en pugna por sobre el otro, lo cual dilataba el conflicto interburgués, a la vez que perpetuaba la precarización laboral, el desempleo, y la crisis del recurso. El agotamiento de la merluza era real, como lo demostró el INIDEP en numerosos estudios sucesivos (INIDEP, 2003), y los gobiernos solo aplicaron medidas breves y parciales, dado que no tenían intención de modificar la política económica de fondo. Según nuestra interpretación, la actuación gubernamental fue la de permitir a todos los empresarios -grandes y pequeños, nacionales, extranjeros y mixtos- la captura del recurso pesquero según su disponibilidad y las posibilidades tecnológicas de cada uno. No sorprende entonces que la resolución de este conflicto se vinculase con

${ }^{40}$ Diario La Capital, edición del día,11/05/2000. 
la necesidad del ajuste fiscal impositivo impuesto por la crisis de la convertibilidad en Argentina con la concomitante crisis de deuda y de reservas -entre otros aspectos-, ante el anuncio del cobro de una tasa por parte del Estado destinada a las empresas que realizaran la extracción ictícola en aguas nacionales. En consecuencia, ambos bandos empresariales se unieron para repudiar esta medida anunciada por Ernesto Godelman, quien fue funcionario de la Dirección de Pesca durante el gobierno de De la Rúa -hasta el nombramiento de Domingo Cavallo en la cartera de Economía. Esta resolución además incluía la reducción general de los cupos de pesca de merluza y el cobro de aranceles en calidad de derechos de extracción destinados a un fondo nacional pesquero (Resolución №965/2000). Ante ello, iniciado el 2001, la Cámara de Procesadores, la CAABPA, UDIPA y el CEPA -es decir, el conjunto del empresariado- entregaron al intendente marplatense un documento en el que proponían medidas generales para la continuidad de la actividad pesquera nacional. Este posicionamiento actuó como una eficiente presión al gobierno nacional, generando que el mismo presidente De la Rúa se expresase públicamente a favor de modificar la normativa de acuerdo a lo solicitado por el empresariado pesquero, y seguidamente la SAGPyA declaró la resolución 73/2001, la cual otorgaba estas demandas (Colombo, 2014:400). A partir de la victoria en la pulseada conjunta contra esta medida gubernamental, ambos bandos burgueses sellaron una tácita tregua, no sin fricciones.

La posterior virtual recuperación del recurso pesquero fue otro de los sustentos materiales para la unificación del empresariado, quien retomó su convivencia pacífica en el marco de la competitividad mercantil. Por ello, podemos considerar que este álgido conflicto interburgués caducó en 2001, y desde 2002 continuó sin mayores disrupciones la tendencia al incremento de la concentración en la rama, con crisis y absorción de algunas de las empresas más pequeñas.

Muchos trabajadores y todos los sindicatos que los nucleaban, al ver la disminución de las fuentes laborales y la precarización de las condiciones de trabajo, se identificaron en primer término con las demandas del empresariado fresquero, bajo la premisa de que sin pescado no habría trabajo. Sin embargo, en el camino se encontraron con disputas tanto con el capital como intragremiales.

\subsection{La disputa intrasindical: entre la tregua y la combatividad}

En este campo de disputa nos centraremos en las acciones del SOIP, por ser el gremio que nuclea a los obreros de la industria pesquera en la ciudad de Mar del Plata. En el marco del conflicto iniciado en 1997, si bien tanto el SOIP como el SOMU apoyaron al empresariado fresquero aliado con el gobierno local, la conducción del SOMU impulsó al mismo tiempo medidas de protesta propias que incluían métodos de acción directa por reivindicaciones laborales y salariales. Estos reclamos obtuvieron respuesta positiva por parte del empresariado, pero en todas las ocasiones con mediación de huelgas (Colombo, 2011). La dirigencia del SOIP, en cambio, mantuvo una posición de tregua con respecto a las demandas obreras, 
argumentando que la metodología del paro beneficiaría a los grandes grupos económicos de la pesca y, por ello, no había que utilizarla hasta tanto se dirimiera el conflicto interburgués (Nieto, 2010). De esta forma relegaba las demandas propias de los trabajadores por la pulseada empresarial, política que rápidamente fue cuestionada por sectores obreros, sobre todo debido a la gran proliferación de cooperativas fraudulentas en ese contexto -es decir, el crecimiento significativo del trabajo no registrado-. Si bien el SOIP venía denunciando en los canales institucionales a las cooperativas fraudulentas, mantuvo sus reclamos dentro de las vías formales (tales como presentación de cartas a distintos organismos del estado) sin realizar otras acciones combativas al respecto, y quedando las mismas sin efecto (Colombo, 2014). Como vimos, dentro de este gremio primaba un paradigma de división obrera que excluía a los trabajadores cooperativizados y también a los crecientes desocupados de la rama, imposibilitados de afiliarse y tomar parte en los comicios u otras instancias de participación gremial una vez concluida la relación de dependencia. El desamparo gremial de los grupos obreros más castigados y precarizados -que anteriormente habían sido parte de las filas asalariadas- sumado a la falta de combate contra la patronal fresquera entre los años 1997 y 2000, terminó de desatar un fuerte conflicto entre la conducción gremial y otras organizaciones que nucleaban a gran parte de la masa obrera desafiliada forzosamente a causa de la desocupación o tercerización laboral.

Al empeorar las condiciones de producción y restringirse la contratación de fuerza de trabajo, estos grupos de obreros avanzaron en su descontento con la línea dirigencial, llegando al punto de denunciar la complicidad del SOIP en la conformación de cooperativas fraudulentas por parte del empresariado. Así lo expresa una obrera, quien hasta mediados de los 90 estuvo afiliada al SOIP y luego fue despedida e incluida en una cooperativa:

E: ¿Vos en los 90 estabas sindicalizada?

M: Sí, en el SOIP

E: ¿Y ahora?:

$\mathrm{M}$ : $\mathrm{Y}$ hoy en ninguno. Porque no estamos en blanco, porque estamos en negro, porque el sindicato tampoco reclama nuestros derechos. Al contrario fue... Yo creo que el que inició este tema de las cooperativas si bien fueron los grandes empresarios, fueron amparados por el sindicato, por el SOIP. Porque el personal, nuestros dirigentes iban a las fábricas y nos decían porque estar en las cooperativas no es malo, es bueno, van a ser como patrones y hay gente de todo, hay boludos y hay algunos que no somos tan boludos. No me consideraba más viva pero tampoco la más boluda. Es decir, pero vamos, sos mi patrón ¿me vas a dar a mi este establecimiento para que yo lo labure, que yo? vamos, no podés ser tan boludo... ¿entendido? Hay algo que no va. Pero fueron convenciendo de tal manera a la gente que muchos de ellos sí, empezaron a hacer cooperativas ahí mismo, ahí adentro. Si porque Mellino les vende pescado, ¡qué pelotudos! Si yo soy tu patrón y veo lo que gana el tipo te vas a cagar para que te de mi empresa que me llevó años, no te la voy a regalar ¿entendés? ¿A cambio de qué? No, es mío ¿te parece? (...) Hubo luchas, hubo luchas, pero muy pocas, habíamos perdido mucha fuerza porque el SOIP no nos amparaba, el SOIP nos empujaba a las cooperativas. Nuestro sindicato se 
vendió. (...) Yo participé sí, no fui cabeza, no no no, no las cabezas... mirá yo pienso esto: en una lucha tenemos que estar todos si se trata de defender nuestros derechos. Pero sabés qué comprendí de esta lucha, que fue una avivada, que fue una estrategia patronal y sindical para evadir otras cosas. Porque las cabezas se llevaron sus buenos pesos, y yo creí en esas cabezas iqué boluda! No era la más viva, era boluda, tengo mi grado de boludez. Este... yo creí en esa gente... Y esta gente que inició todo esto no tenía huevos, tenía intereses personales ¿entendés? Por ejemplo, yo creo que fue algo así porque he escuchado comentarios de que "mirá, hay que hacer un revuelo porque tal y tal cosa. Lo hacen y tenés tanto". Entonces este tipo empezó a hacer todo esto y salió beneficiado él, si bien yo fui como una pelotuda caminando por todo Mar del Plata manifestando, queriendo que escucharan mis derechos... que fueron dichos nuestros derechos, pero sin nada, sin ganar nada, fue decepcionante para mí, fue humillante, porque yo creí que había gente en la cual podías confiar y no podés confiar en nadie (María, filetera, 42 años) ${ }^{41}$.

En este testimonio de una obrera cuya antigüedad laboral ronda los 30 años se distinguen varias concepciones nativas acerca de la dirigencia gremial. Como trasfondo de todas ellas insiste la idea de que el sindicato actúa "a espaldas" de los trabajadores, como desde "otra escena" que no se ve, pero "se sabe" de su existencia. Esta sospecha gana el estatuto de certeza como resultado de las sucesivas derrotas obreras, es más, aparece como la explicación última de dichas derrotas. Opera entonces, a posteriori, la representación de una derrota planificada por la dirigencia sindical recubierta con acciones que, bajo la apariencia de lucha, esconderían cierta estrategia sindical de "evasión", cuyo objetivo radicaría en evitar la lucha por los "verdaderos" problemas a resolver. Esto podría sintetizarse con la idea de un "como si" de lucha, sin buscar un cambio material en la vida obrera. Algunas de las consecuencias subjetivas de la participación de Mirta en estas acciones fueron la decepción y el sentimiento de humillación, así como una pérdida de confianza y referencia en la conducción sindical, no solo por considerar que perjudicó a los trabajadores avalando la cooperativización por recibir dádivas empresariales, sino también por la estrategia fallida -en forma premeditada o no- en cuanto a cómo llevar adelante una lucha obrera que redunde en la conquista de sus reclamos. Como contracara, se expresa una práctica obrera de delegación a la dirigencia gremial de las decisiones acerca del método, grado de radicalidad, inicio y fin de las acciones, etc., mientras que las bases aparecen como carentes de iniciativa y perspectiva política con anterioridad al emprendimiento de las acciones conflictivas. Por último, la obrera también deja entrever una concepción nativa de diferenciación entre las conducciones sindicales de los 90 con respecto a décadas previas, cuando los dirigentes "sí tenían huevos". Una concepción nativa que en este caso se aplica a las transformaciones en la política sindical, no a una cualidad de un dirigente particular, ya que el SOIP tuvo al mismo secretario gremial entre 1969 y 1997. En esta idea

\footnotetext{
41 Entrevista realizada el 23 de mayo del año 2009 por Cristian Tibaldi, durante la cursada de la materia Metodología Cualitativa, correspondiente a la carrera de Sociología de la UNMdP, en el marco de un trabajo práctico aplicado de Investigación cualitativa dirigido por la docente Alejandra Navarro en el año 2009.
} 
entra en juego la tradición de lucha señalada como característica de las subjetividades obreras de la industria pesquera, la cual es reconocida en numerosos testimonios de trabajadores como parte de su raigambre.

Podemos presuponer que la generalización de esta visión desprestigiada de la dirigencia sindical fue uno de los motores que promovió el crecimiento de las organizaciones paralelas al SOIP y la inclusión de gran parte de la masa obrera a las mismas. Entre ellas se destacaron por su incidencia a la Unión Obrera del Pescado (UOP) liderada por trabajadores que militaban en el Partido Obrero, ex militantes del PC, la Unión de Trabajadores del Pescado y Afines (adherida a la Central de Trabajadores de la Argentina) y otra frustrada experiencia del Sindicato de Trabajadores del Pescado y Afines de la República Argentina (SIPES) impulsada por militantes gremiales comunistas con sede en el Sindicato de Luz y Fuerza de Mar del Plata (ambos adheridos a la CTA). A diferencia de la UTPyA y el SIPES, la UOP tenía una trayectoria que databa de los años 80, conformándose como una agrupación interna del SOIP (Yurkievich, 2012). Hacia fines de la década del 90 se consolidó al incluir tanto trabajadores registrados como no registrados, que iban quedando excluidos de la industria pesquera marplatense y por ello también del SOIP.

Haciendo un breve paréntesis en el conflicto, cabe destacar que esta experiencia de organización alternativa al SOIP no fue la primera dentro de la industria pesquera. En determinadas coyunturas anteriores surgieron temporarias agrupaciones gremiales, como por ejemplo el "Sindicato de Obreros Fileteros del Pescado y Afines" conformado durante la década del 60, cuyos principales dirigentes se enfilaban dentro del comunismo. Por lo tanto, la coexistencia de variadas fracciones entre la base obrera, sus dirigencias, y también la coexistencia de diversos proyectos políticos, era ya experiencia adquirida por los trabajadores de la industria pesquera. Retomando la disputa sindical en el período que nos ocupa, otro elemento trascendental para su comprensión es un acontecimiento a nivel personal que, por tratarse de la dirigencia gremial, desencadenó efectos y modificó la estructura de oportunidades políticas y generó mayor apertura para la modificación del estado actual de las cosas: en el año 1997 muere Abdul Saravia, quien fue secretario general del SOIP desde el año 1969 de forma ininterrumpida -salvo un interregno durante la dictadura de Videla. De tradición peronista y con una política excesivamente personalista, este líder no pudo ser suplantado en su capacidad para influir sobre las bases obreras en la coyuntura conflictiva de la pesca durante los 90 (Colombo, 2014). Este hecho, sumado a la previa deslegitimación que la conducción sindical venía acrecentando dada su infructuosa inacción -o complicidad- con la cooperativización fraudulenta y cierre de empresas, desencadenó un abrupto llamado a elecciones en el que la conducción provisoria, de línea saravista, desaprobó la inclusión de las listas opositoras, alegando que algunos de sus integrantes eran desocupados o cooperativizados. Con este criterio reafirmaban la exclusión sindical de este sector de trabajadores, cuyo número iba creciendo con el correr de los años. De esta forma, motivaban su bronca contra esta política sindical 
y sus efectores, la cual se acoplaba a la que generaba la patronal con las condiciones de trabajo precarias.

Así, mientras transcurrían las reuniones multisectoriales y la disputa interburguesa, y con la muerte de Saravia como desencadenante de una situación conflictiva que se enervaba con el tiempo, desde marzo de 1997 se sucedieron tres meses de conflicto ininterrumpido entre las listas y sus adherentes, con repudios, movilizaciones, presentaciones, golpes de puños y denuncias de fraude de ambos lados (Colombo, 2014). Este conflicto desembocó en la suspensión de los comicios, por lo que la dirigencia sindical se mantuvo bajo la figura de custodio de bienes. También continuó la política de alianza del SOIP con el empresariado fresquero, mayormente pasiva ante la cooperativización, la desocupación y la precarización laboral en general de los trabajadores de la industria pesquera. Aquí se ve cómo la conducción saravista fue funcional a la dualización de la fuerza de trabajo impuesta por el neoliberalismo, actuando a corriente con el debilitamiento y la fragmentación del movimiento obrero organizado y en lucha. Pero una buena parte de la base social más precarizada de los trabajadores de la industria pesquera hizo carne el anhelo de una mayor combatividad y comenzó a prestar apoyo y presencia en las organizaciones alternativas al SOIP y en las acciones que impulsaban. Las ansias de lucha sumadas a la ira acumulada día tras día mostraron una nueva dirección de la conflictividad, diferente de la predominante pasivización de la comisión directiva, que sin embargo no renunciaba a su lugar tras la muerte de su líder.

La influencia de estas fuerzas sociales obreras de oposición en la conflictividad del período creció de tal modo que al cabo de tres años derivó en la toma del sindicato con la expulsión del saravismo. Esto ocurrió el 29 de junio 2000, un día después de un gran motín obrero contra los pulpos pesqueros que abordaremos en el siguiente apartado. Cientos de obreros de la pesca que veían agudizadas sus condiciones de precarización laboral realizaron una asamblea en las calles portuarias. El día anterior se había desplegado una gran manifestación que incluyó el ataque a grandes empresas pesqueras, con una fuerte represión policial como respuesta. Por ello, el lugar continuaba repleto de policías junto a personal de infantería y bomberos, quienes se hallaban custodiando la zona en vistas de contener un nuevo motín. Entonces, un grupo de 300 trabajadores encabezados por la Unión Obrera del Pescado decidieron dirigirse hacia la sede del SOIP para exigirle que adhiera al paro que mantenían los marineros nucleados en el SOMU (Colombo, 2014). 
Imagen №6. Toma del SOIP, 29 de junio de 2000.

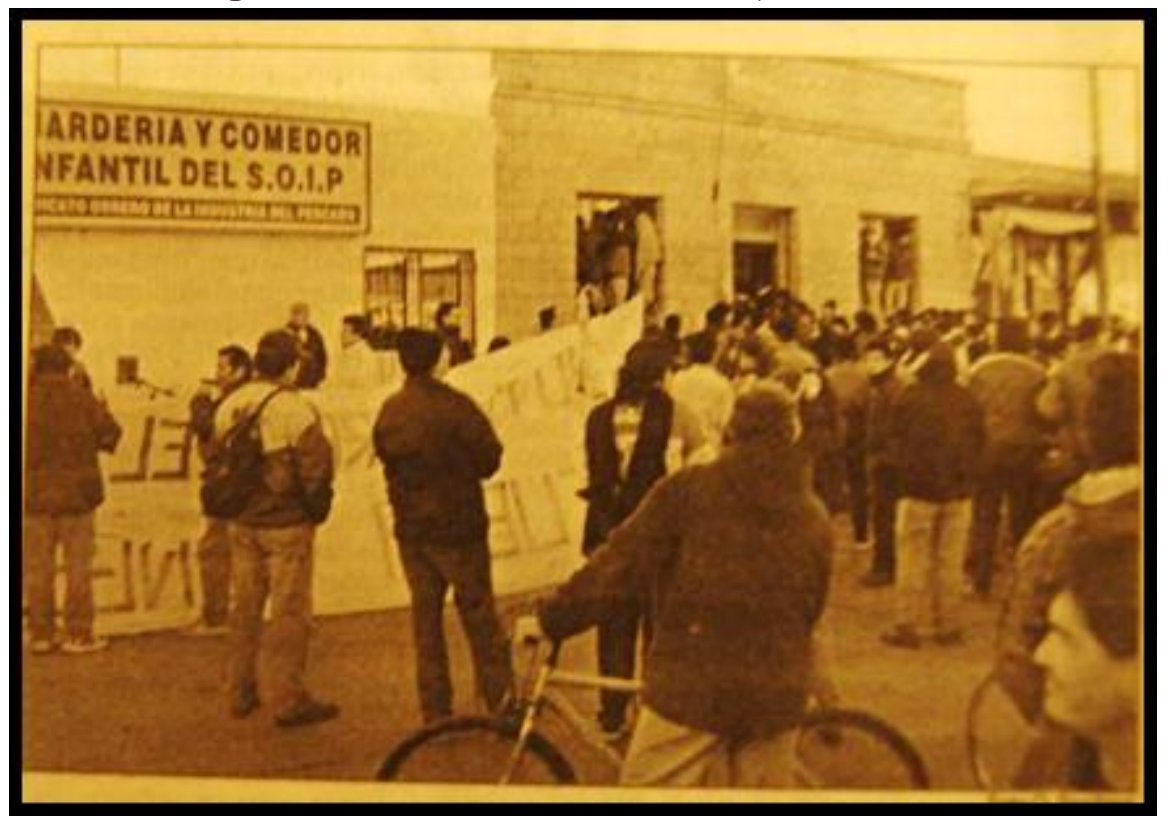

Fuente: Yurkievich, 2012.

Al llegar al gremio desalojaron por la fuerza a los dirigentes y ocuparon el edificio, solicitando al Ministerio de Trabajo "que avale la comisión de base elegida en una asamblea y que convoque a elecciones dentro de 90 días" (Colombo, 2014: 443). El programa reivindicativo de la UOP incluía la registración de todos los trabajadores cooperativizados, la actualización salarial y garantía horaria y el dictado de una amnistía que permitiera la afiliación de todos los trabajadores que desarrollaban sus labores bajo el régimen de las cooperativas "truchas". Aquí se termina de definir una disputa entre las fuerzas sociales obreras que involucraban, por un lado, a la dirigencia peronista/saravista y, por otro, a la UOP. Días después de la toma la sede fue devuelta a su antigua conducción, pero el conflicto perduró y esta acción tuvo como saldo la consolidación de una nueva dirección obrera de parte de esta agrupación denominada "clasista", que dos años después como Lista Celeste ganó la conducción del SOIP por la vía electoral. El sufragio se llevó a cabo el 15 de marzo, y arrojó los siguientes resultados:

Tabla №20. Resultados de las elecciones del SOIP, año 2002:

\begin{tabular}{|c|c|c|c|}
\hline Nombre de la lista & $\begin{array}{c}\text { Candidato a } \\
\text { Secretario General }\end{array}$ & $\begin{array}{c}\text { VOTOS } \\
\text { (positivos) }\end{array}$ & $\%$ \\
\hline CELESTE (UOP) & SALAS & 377 & 29,4 \\
\hline BLANCA (saravismo) & CASARIEGO & 324 & 25,3 \\
\hline $\begin{array}{c}\text { Otras listas, fracturas } \\
\text { del saravismo }\end{array}$ & - & 582 & 45,3 \\
\hline TOTALES & - & $\mathbf{1 2 8 3}$ & $\mathbf{1 0 0 . 0}$ \\
\hline
\end{tabular}

Fuente: Archivo del SOIP. 
Tal como se ve en la tabla, la victoria de la lista Celeste se produjo por una diferencia de votos muy acotada, en un contexto de crisis y división del saravismo tras la muerte de Saravia, lo cual explica la división de la fuerza oficialista en cuatro listas en aquellas elecciones de 2002 (Yunkevich, 2012). Este proceso expresa que en este ciclo de protesta se generó un momento abierto que ofreció una oportunidad política única y concreta a los integrantes de la UOP, dada la conjunción de distintos factores que decantaron del conflicto interburgués: una coyuntura de crisis del recurso pesquero, una disputa empresarial, la deslegitimación de la histórica conducción gremial dada la creciente precarización laboral y la falta de resultados de sus acciones al respecto y la pérdida material del referente gremial por más de tres décadas. En esta confluencia de procesos imbricados, la correlación de fuerzas actuó contraria a la fuerza social obrera hegemónica y posibilitó el ascenso de la fuerza social obrera de oposición, mediante acciones tanto legales como ilegales, tanto institucionales como callejeras.

En este período podemos ver, entonces, una oscilación entre política de tregua de la dirigencia saravista y la voluntad combativa de los sectores obreros más precarizados, que ante el fracaso en la obtención de sus demandas hacia el empresariado se dirigieron contra la conducción sindical. Esta orientación política se materializó luego de concluir, a partir de su experiencia en la lucha de clases, que la política de la dirigencia no representaba sus intereses, en un contexto de cada vez mayor precarización e incertidumbre laboral. El sector organizado en la UOP fue el que disputó electoralmente y sus líderes quienes pasaron a ocupar la comisión directiva sindical a partir de 2002.

La dilución del conflicto interburgués no eliminó la problemática de la falta de pescado, que de tiempo en tiempo provocaba momentos agudos de escasez que repercutían en los puestos de trabajo, tanto en su estabilidad como en el grado de precarización. El acuerdo interempresarial tampoco generó ningún cambio en la situación laboral de los trabajadores cooperativizados y temporarios. Pero la recomposición virtual del recurso pesquero se conjugó con el cambio en la dirigencia del SOIP en el 2002 para abrir un nuevo período que contrastó con el anterior.

\subsection{La disputa capital/trabajo}

Al imponer el régimen de las cooperativas fraudulentas a un porcentaje considerable de trabajadores en los primeros años de la década del 90, el empresariado buscó no solo disciplinar a los asalariados incrementando la explotación y la opresión, sino también dividir las filas obreras. De esta forma redujeron derechos laborales y al mismo tiempo buscaron reducir las luchas de los trabajadores registrados, en quienes la amenaza de desocupación, cooperativización o trabajo en negro se vio acrecentada con la escasez del recurso a partir de 1997, amenaza que se concretó en gran parte de los casos. Cada vez que escasea la materia prima se reducen inmediatamente los puestos de trabajo 
disponibles, dejando temporariamente desempleados a los trabajadores eventuales y cooperativizados. La situación para este grupo de obreros se vuelve desesperante en pocos días, lo cual fue motivo de expresión de formatos de protesta variados contra la patronal y la dirigencia sindical, exigiendo una respuesta urgente a su situación de escabrosa precariedad.

El objetivo de las luchas, en primer término, fue la registración laboral, pero luego de que los empresarios hicieran oídos sordos y ni las agencias estatales ni el sindicato presionaran de forma efectiva para revertir la operación fraudulenta de cooperativización, el combate fue cediendo a un objetivo menor: la obtención de asistencia estatal. Asimismo, muchos desocupados, temporarios y cooperativizados se integraron a las demandas empresariales de materia prima y expulsión de los buques congeladores del puerto, considerándolas como un paso previo a la consecución de oportunidades laborales. Al mismo tiempo exigían reivindicaciones propias entre las que predominaban los subsidios para desocupados, contrato en relación de dependencia para temporarios y cooperativizados y denuncias a las cooperativas fraudulentas. Sin embargo, las reclamaciones propiamente obreras nunca fueron abordadas por la multisectorial, por ello fue rasgo general del período que, al regreso de cada movilización a Buenos Aires realizada de forma conjunta entre empresarios, funcionarios, gremios y trabajadores, ante la falta de respuesta a los propios reclamos obreros estos últimos se manifestasen por su propia cuenta, emergiendo la disputa capital/trabajo que quedaba temporalmente sumergida en la disputa interburguesa.

Sin embargo, la división obrera entre asalariados registrados y no registrados también se hizo palpable en las acciones realizadas, al centrarse cada grupo en distintos objetivos que no estaban aunados en la lucha gremial, lo que produjo acciones separadas. En el año 1999, por ejemplo, a la vuelta de la movilización en Buenos Aires con la obtención de la promesa por una Ley de emergencia pesquera por parte del Ejecutivo nacional, desde la multisectorial se instó a los trabajadores a retomar las tareas. Sin embargo, los obreros se reunieron en asambleas sin participación de las dirigencias gremiales y decidieron realizar un paro hasta la sanción definitiva de la ley. Esta medida de fuerza se mantuvo hasta el 23 de junio, día en que el presidente Menem le dio su aprobación definitiva. Pero aquí retomaron las tareas los trabajadores asalariados registrados y de planta permanente, mientras que temporarios, cooperativizados y desocupados continuaban sin trabajo; por ello, una facción lanzó un plan de lucha con ollas populares y movilizaciones por un subsidio de 500 pesos. Finalmente, este subsidio se obtuvo, pero no así el pase a planta permanente ni el "blanqueo" (Colombo, 2014).

En el año 2000, la presidencia de De la Rúa continuó con la aplicación de la emergencia pesquera y con los subsidios a los desocupados, pero la escasez del recurso volvió a tensar la situación hasta que el 12 de mayo todos los gremios a excepción del SOIP convocaron a un paro de actividades, debido a la falta de respuesta empresarial ante los reclamos obreros. Días después, ante la persistencia 
de la situación y la creciente presión obrera, desde el 26 de mayo el SOIP se plegó a esta demanda ${ }^{42}$.

La tensión continuó hasta el 27 de junio, día en que se declararon en huelga todos los gremios pesqueros. Al día siguiente aconteció el primer estallido social de los obreros de la pesca, quienes atacaron la sede de la CAABPA y tomaron delegaciones municipales. Esta manifestación cobró rasgos espontáneos al producirse como acto seguido de una asamblea en el puerto integrada por trabajadores tanto marineros como fileteros, en la que se hallaba la UOP mientras que estuvieron ausentes los representantes de la dirigencia gremial. En esta oportunidad los trabajadores se movilizaron y atacaron 6 plantas pesqueras propiedad de los "pulpos pesqueros", ataque que perduró por un lapso de dos horas durante las cuales los obreros fueron reprimidos por la policía con gases lacrimógenos y balas de goma (Colombo y Nieto, 2008). Al día siguiente se produjo la movilización y toma de la sede sindical, descripta en el apartado anterior. De allí que uno de los principales resultados de este ciclo de conflictos en torno al estallido social del año 2000 es la catálisis de los líderes de la Lista Celeste que luego gana las elecciones gremiales en el año 2002.

Aquí podemos concluir que la derrota obrera en la disputa contra el capital fue uno de los motores de la disputa sindical. La ira obrera contra el saravismo como expresión de una fuerza social obrera eminentemente corporativa, y su falta de acciones ante la precarización y expulsión laboral provocó que el sector de obreros más radicalizados, una vez disciplinados por las fuerzas represivas durante el ataque a las principales patronales pesqueras el día anterior, se dirigieran contra la conducción de la organización gremial. Aquí se expresa claramente la "alineación" o confluencia de las órbitas de estos tres campos de disputa, cuando al disolverse el conflicto interburgués la lucha se trasladó al ámbito gremial. En este primer ciclo lo que decantó finalmente fue el enfrentamiento entre las organizaciones representantes de los trabajadores más precarizados y la fuerza social obrera hegemónica, dirigida por la conducción sindical, considerada impotente o "traidora" bajo la premisa de que, en lugar de combatir y resistir la precarización obrera junto a los trabajadores, actuó a favor de la patronal, avalando por acción u omisión el nuevo auge en la cooperativización y su consolidación. En este contexto, una fracción de trabajadores que se había autoorganizado y venía realizando acciones de lucha sin participación de la dirigencia gremial, llevó a cabo una ruptura con la misma hasta provocar su derrota tanto en el plano legal como en el plano material. La militancia en partidos de izquierda por parte de algunos de esos trabajadores indudablemente fue otro de los elementos que influyó en la conflictividad del período. La correlación de fuerzas en este caso permitió superar el status quo intrasindical al demostrarse superior la fuerza de la dirección impulsada por la UOP y otras organizaciones obreras. Esta victoria fue lograda en un contexto de hambre, escasez laboral y bronca compartida contra el empresariado y la dirigencia gremial. Por ello, además de la obtención de subsidios como resultado de este ciclo de

${ }^{42}$ Diario La Capital, 3 de junio de 2000. 
conflictos, la organización de obreros desocupados y cooperativizados obtuvo como mayor logro una precaria inclusión gremial, precaria porque no se modificó el estatuto vigente y por ello tanto los cooperativizados como los desocupados continuaron -como veremos- sin posibilidad de afiliación al SOIP.

Puede observarse que, en este primer ciclo, tanto la burguesía como la dirigencia sindical y el resto de organizaciones obreras tuvieron al gobierno y al Estado como destinatarios de sus acciones. Los dos sectores del empresariado demandaron política pesquera a su favor, las organizaciones de trabajadores opositoras a la conducción del SOIP se integraron en esta demanda y a su vez solicitaron subsidios e intervención para erradicar el trabajo en las cooperativas fraudulentas y obtener la registración laboral bajo el convenio 161/75, y la dirigencia sindical pidió actuación de agencias estatales para restringir la acción de la lista opositora, además de incluirse también en el pliego de demandas de la multisectorial. Mientras que el conjunto del empresariado se dirigió hacia el gobierno nacional en mayor medida, los otros sujetos también incluyeron a funcionarios provinciales y locales entre los destinatarios de sus luchas.

Las acciones obreras tuvieron asimismo otros receptores, entre los que se ubica al empresariado -en cuanto a la demanda de registración laboral y trabajo- y la dirigencia sindical -en la exigencia de mayor combatividad, la solicitud de afiliación gremial y de elecciones ante la muerte de Saravia.

La tregua que predominó en la línea dirigencial del SOIP e este ciclo provocó que sus acciones contra la patronal fueran minoritarias y respondan más a presiones de los trabajadores y las organizaciones obreras que a iniciativas propias.

Tomando los aportes teóricos anteriormente señalados, podemos ver que el ciclo 1997-2001 puede considerarse como un "ciclo de protesta" de acuerdo a lo precisado por Tarrow, en el cual se acentuó como rasgo la combinación de la participación entre sectores organizados y no organizados de trabajadores. Estos grupos fueron disciplinados por la represión estatal en sus acciones más radicales cuando arremetieron contra los empresarios, pero sí obtuvieron lo que consideramos una reforma cuando uno de los grupos representantes de los obreros más precarizados logró imponerse sobre la dirigencia gremial imperante.

Sin embargo, como conclusión provisoria de este ciclo, vemos que quienes lograron mayores beneficios fueron los empresarios, quienes obtuvieron políticas estatales y gubernamentales a su favor -por presión o concesión- y no se vieron impelidos a modificar la superexplotación obrera y del recurso pesquero en las que sustentaban sus ganancias. Fue la burguesía la que aprovechó el contexto de agudización de la crisis nacional neoliberal y las "oportunidades políticas" (Tilly, 1993) que dicha crisis abrió y se imbricó con la escasez por sobrepesca del recurso. Los empresarios pesqueros salieron fortalecidos de este ciclo, fortaleza que se consolidó con la posterior devaluación de la moneda y el aumento del precio internacional de los principales commodities ligados a las exportaciones pesqueras.

En cuanto a las subjetividades obreras, vemos que este primer ciclo se asentó en una experiencia de lucha junto a la burguesía y la histórica conducción gremial que 
generó, como resultado de la infructuosidad de las acciones tendientes a revertir la desocupación y las nuevas condiciones precarias de trabajo, un desencanto con la táctica de la coalición de clases bajo el programa del empresariado fresquero. La masividad tanto de la cantidad de acciones como del número de trabajadores que participaron de ellas -sobre todo de las manifestaciones callejeras y movilizaciones a la Casa rosada- demostró una predisposición al combate contra las repercusiones de la crisis pesquera en las condiciones de trabajo y contratación. En las direcciones que tomó el conflicto, un sector de trabajadores tomó la línea propuesta por el SOIP, mientras que otro grupo cuestionó esta perspectiva y conceptualizó al propio gremio como uno de los responsables de la precarización laboral impuesta durante los 90, y a partir de esta premisa generó acciones combativas propias independientes de las llevadas a cabo por el SOIP en el marco de la alianza multisectorial. La consolidación de la UOP como dirección alternativa al SOIP se conjugó con la persistencia de las dificultades en la reproducción obrera y la crítica obrera al accionar de la dirigencia saravista, obteniendo como resultante la expulsión gremial de la fuerza política que lo había conducido por más de tres décadas. De esta forma, el grupo de obreros cooperativizados y desocupados que fuera desplazado, precarizado y derrotado durante los 90, obtuvo un nuevo lugar protagónico sobre los inicios del nuevo milenio, formando parte del sector que combatió no solo al empresariado sino también a la dirigencia gremial, resultando victorioso en esta última contienda. Desde la perspectiva obrera, entonces, la belicosidad de este ciclo guarda un final agridulce: no se revirtió la superexplotación y desocupación impuesta por el capital, pero para el grupo más radicalizado la conquista del gremio por parte de la dirigencia de la UOP abrió nuevas perspectivas y esperanzas de modificar esta situación.

\section{El ciclo 2002-2006: aparente calma}

Llegado el año 2002 los stocks de merluza mostraron una recuperación parcial y permitieron al empresariado reducir las pérdidas producto de la sobrecapitalización anterior. A su vez, se incrementaron las exportaciones y el precio internacional del calamar y el langostino, lo que permitió atenuar la dependencia exclusiva del recurso merlucero en cuanto a su papel casi exclusivo en las ganancias empresariales. Por ello, las políticas económicas implementadas por el nuevo gobierno nacional beneficiaron mayormente a los grandes grupos económicos de la pesca, quienes por la lógica propia de la etapa imperialista se encontraban en mejor posición para la competencia mercantil ligada a la exportación del recurso respecto de las pequeñas y medianas empresas fresqueras. No obstante, la recuperación económica no repercutió en las condiciones de trabajo que continuaron en alto grado de precarización, las cuales empujaron a los obreros a una dinámica conflictual intermitente. Esta dinámica, si bien fue menos intensa 
que la del período anterior, no dejó de revelar que la calma era solo aparente, con un horizonte de lucha siempre cercano.

\subsection{Del blanqueo a los convenios por empresa}

Desde la perspectiva obrera, la devaluación y creciente inflación con que inició el ciclo 2002-2006 provocó la depreciación de la fuerza de trabajo, dada por la reducción de los salarios. Por ello, la puja entre capital/trabajo en este período se basó mayormente en la lucha por la recomposición salarial, con la huelga como principal método y acción. Este período, entonces, se caracterizó por la recomposición del recurso pesquero y la ausencia de crisis empresariales generalizadas que mantuvo cierta demanda de fuerza de trabajo, con el grado de incertidumbre y acotamiento que caracteriza en general a la industria pesquera. Por ello, la problemática de la desocupación permanente no se presentó fuertemente, pero sí la continuidad del trabajo no registrado y sus condiciones de superexplotación y la puja salarial, dada la depreciación de la fuerza de trabajo que conllevó la devaluación. La demanda de recomposición salarial era apoyada por los trabajadores cooperativizados ya que, por añadidura, provocaba el aumento de valor de su fuerza de trabajo tercerizada.

La nueva dirección del SOIP quiso impulsar en 2003 una huelga por tiempo indeterminado, aunando objetivos de lucha de los trabajadores en relación de dependencia y los cooperativizados: la recomposición del salario y la registración laboral. Esta huelga no cumplió sus objetivos y fue levantada a los pocos días por pedido de algunos de los propios afiliados, contribuyendo a la instauración de una nueva crisis al interior del gremio (Colombo y Nieto, 2008). Podemos inferir que, al no compartir objetivos comunes ambos grupos de trabajadores, la base obrera registrada no expresaba acuerdo en la prosecución de acciones conflictivas una vez obtenido el aumento salarial, relegando la demanda propia de los cooperativizados. Por ello, la medida de huelga perdía efectividad, dado que los cooperativizados no cuentan con este derecho y las posibilidades de hacer uso del mismo disminuyen notoriamente al cesar el acatamiento de los obreros registrados. La unidad entre los trabajadores con distintos tipos de contratación aún no se encontraba sellada, y en nada contribuían en ello las maniobras empresariales implementadas para sostener y perpetuar esta diferenciación. Las mismas consistían, por ejemplo, en la convivencia de obreros registrados y no registrados en un mismo establecimiento a fin de disciplinar a quienes se encuentran bajo el CCT №161/75, o la rotación continua de obreros cooperativizados por diversas plantas de procesamiento, para evitar la consolidación de una organización y una solidaridad que luego se traduzca en acciones combativas. Vemos al respecto que desde el accionar empresarial la recuperación y crecimiento económicos propio de la nueva etapa no fue motivo para retroceder en su ofensiva sobre las condiciones de trabajo y contratación, sino que más bien se centró en prolongar la precarización laboral extendida en los 90. Para el empresariado, la lucha consistió en imponer que la etapa de "sufrimiento" con el 
CCT №161/75 se había terminado. Sin embargo, el renovado contexto internacional beneficioso, el recambio en la conducción gremial y la amenaza de huelga general generó en los empresarios la necesidad de ofrecer una alternativa a la cooperativización, que no modificara en gran medida la avanzada sobre las condiciones de producción.

Algunas otras claves obreras para entender la temprana derrota de la huelga general por la registración laboral las proporcionan los testimonios de dos fileteros. El primero es un trabajador en relación de dependencia:

Menem nos dejó indefensos, pero la culpa no es de los trabajadores y su desunión; lo que pasa es que las necesidades básicas son tan grandes que si parás dos días, al tercero no tenés nada para darle de comer a los hijos y volvés a la planta. Contra eso no se puede hacer nada. Y los empresarios, como siempre, se abusan y nos humillan (Manacho, filetero, 45 años) ${ }^{43}$.

El segundo es un filetero de 78 años que cuenta con más de 40 años de antigüedad laboral, quien al momento de la entrevista continuaba trabajando en una cooperativa fraudulenta debido al incumplimiento del pago de aportes jubilatorios por parte de 2 de las 4 empresas en las que trabajó años anteriores:

El otro día algunos muchachos pidieron el blanqueo en la cooperativa. Nos reunió el patrón y dijo que los que estuviésemos con él, bajáramos a trabajar y los que no, que se fueran. Y yo bajé despacio, con la cabeza gacha... las cosas que hay que hacer para mantener un laburo Eleuterio, filetero, 78 años) ${ }^{44}$.

Aquí se observa que estos obreros desestimaron la prosecución de las medidas de fuerza a pesar de estar de acuerdo con las mismas. Este tipo de testimonios habla de los duros golpes recibidos por los trabajadores en el contexto de la crisis neoliberal tanto pesquera como nacional, lo cual repercutió en sus condiciones materiales de tal modo que debilitó la perspectiva de lucha, con el alto riesgo que corren los trabajadores cooperativizados de resultar despedidos luego de participar en acciones contra la patronal. Asimismo, vemos que la política propuesta por la dirigencia gremial no era posible de llevar a cabo en todas las plantas, lo que nos habla no solo de falta de solidaridad, sino también de falta de organización por lugar de trabajo a fin de materializar acciones que apunten al logro de objetivos generales que plantearan una contienda con el empresariado por imponer nuevas condiciones de trabajo.

La imposibilidad de consecución de la huelga general generó un impacto específico en algunos miembros de la dirigencia, cuya reacción fue un viraje tanto conceptual como metodológico y práctico. El mismo consistió en el cambio en los objetivos de lucha, los formatos de las acciones de rebelión y los sujetos involucrados en dichas acciones. De acuerdo a los testimonios de los nuevos dirigentes gremiales desde

43 Revista Puerto №28, marzo de 2004, pág. 64.

${ }^{44}$ Revista Puerto №28, marzo de 2004, pág. 65. 
2005 hasta el final del período estudiado, la nueva política de convenios por empresa y luego del Convenio Pyme acordados con el empresariado aparecieron como la mejor solución, o bien el único camino viable.

La implementación de convenios por empresa constituía un objetivo mucho menor, que implicaba combates parciales en determinados lugares de trabajo. En estos años, entonces, la lucha por la registración laboral se dio mayormente de forma fragmentada, aunque contando con la presencia gremial en muchas de las manifestaciones y conflictos contra la patronal. Por ello, en comparación con el período anterior, la dirigencia tuvo una performance más combativa -superando el reclamo institucional/legal- y activa por la registración laboral. Sin embargo, el viraje en los objetivos de lucha y el abandono de la consigna general de registración bajo el convenio 161/75 abrió una crisis al interior del gremio, tanto entre la dirigencia como por fuera de ella, generando nuevas fracciones obreras y, por ello, nuevas fuerzas sociales obreras en pugna.

Asimismo la firma de un acuerdo que implicaba la "paz social" entre la CIPA y el SOIP labrado el 29 de junio de 2004, fue otro de los detonantes de la ruptura de la nueva conducción gremial. En dicho acuerdo, los empresarios se comprometieron a abonar una asignación remunerativa de 125 pesos en carácter de emergencia a los trabajadores que registren una asistencia perfecta. Esto significaba ceder ante el reclamo patronal por excelencia: la reducción del ausentismo laboral, señalado por los empresarios como la causa de sus problemas de rentabilidad y hasta de su fracaso comercial, problemas que el trabajo no registrado vino a "solucionar". Así lo expresan las declaraciones de Mario Ordiales, empresario industrial pesquero de la Patagonia propietario de la firma Harengus, quien luego de declarar que "el modelo marplatense está agotado por completo y se apoya en una base ilegal e injusta que es el trabajo en negro" 45 , señalaba que el ausentismo es una importante causal de los problemas de rentabilidad: “iqué empresa puede sobrevivir pagando cien sueldos cuando quienes trabajan son setenta!"46. Este aspecto también era señalado por Alberto Castro Aran, un empresario industrial fresquero marplatense, empleador de 300 trabajadores y propietario de 4 embarcaciones, cuya facturación en el año 2004 alcanzaba los siete millones de dólares anuales:

Los empresarios marplatenses, que del 72 para acá sufrieron un convenio como
fue el del 75, cruzaron la raya para el otro lado. (...) Creo que hubo oportunidad
de hacer algo intermedio entre el 75 y la cooperativa. Nosotros intentamos
hacer algo así, lo logramos en el 96 porque nos pusimos firmes en lograr un
sistema que nos permitiera laburar y cumplir con las obligaciones que cualquier
sociedad le impone a quien genera puestos de trabajo. Estuvimos seis meses
para sentar las bases de algo que no es ninguna maravilla, pero eliminaba vicios
del convenio del 75, tomaba algunas cuestiones de remuneración por
producción, pero contemplando las obligaciones de la relación laboral. En la
cooperativa no hay horarios, cualquier día a cualquier hora tienen que salir a

45 Revista Puerto № 47, marzo de 2008, página 23.

${ }^{46}$ Revista Puerto № 47, marzo de 2008, página 24. 
hacer una cola para ver si trabajan, salen en bicicleta con las botas, la tablita, el cuchillo, y después hablamos de trazabilidad. Como contraparte de esto, las empresas que se mantienen con el convenio del 75 tienen un ausentismo del 40 por ciento y en el caso nuestro, que es más moderno, igual tenemos el 10 o 12 por ciento, que significa un 10 o 12 por ciento menos de producción ${ }^{47}$.

Vemos en este testimonio una comprobación de la veracidad de las declaraciones obreras cuando relatan las condiciones de trabajo en las cooperativas fraudulentas. Como lo señalan estos empresarios, el Convenio de 1975 otorga licencias laborales pagas por ausentismo, pero solo en los casos de enfermedad inculpable, accidente de trabajo, nacimiento y fallecimiento de familiares directos, y en caso de rendir examen (CCT №161/75). Para el resto de los casos:

Las ausencias a jornadas laborables se deducirán del total de cajones garantidos, a razón de siete cajones por jornada de ausencia. Para empaquetadoras y peones se deducirá a razón de ocho horas garantizadas por cada día de ausencia. Los feriados nacionales o los días de enfermedad inculpable o accidente de trabajo se liquidarán de acuerdo a este convenio, no resultando en consecuencia acumulables a la garantía convenida (CCT №161/75).

El lamento empresarial a causa del ausentismo, entonces, no encuentra justificativo en el marco de la legislación laboral vigente, pero sí contrasta con los beneficios que le otorgan al capital las modalidades de trabajo no registrado tales como las cooperativas fraudulentas, las cuales impiden a los obreros el ejercicio de estos derechos laborales. Las numerosas enfermedades propias del medioambiente laboral en las plantas pesqueras expuestas en el capítulo 1, causadas por las características de las condiciones de trabajo -que, como vimos, empeoran en los establecimientos donde solo trabajan cooperativas fraudulentas- explican los motivos de gran cantidad de las ausencias por enfermedad o accidentes laborales. En contrapartida, la falta o la deficiencia de los seguros de riesgo de trabajo y cobertura social en los casos de cooperativización fraudulenta provoca que los trabajadores opten por presentarse a trabajar a pesar de sus impedimentos de salud y otros. Vemos también que estos empresarios, aunque reconocen como "excesiva" la precarización laboral propia del formato cooperativo, no plantean en ningún momento retornar a la contratación y condiciones laborales del CCT №161/75, sino, a lo sumo "algo intermedio".

Volviendo al acuerdo de paz social que firmó la nueva dirigencia del SOIP junto al conjunto de los empresarios, el mismo consistió en un premio a la asistencia perfecta, lo cual indica claramente que el mismo se trataba de una iniciativa empresarial para reducir el factor que -según ellos- más afecta sus ganancias. El texto del acuerdo escribe:

47 Revista Puerto №33, marzo de 2005. 
el pago será íntegro cuando el trabajador registre una asistencia perfecta durante todos los días laborables de la quincena respectiva en los cuales haya sido convocado para trabajar (...) Se computarán como ausencias aun las que resultaren justificadas y/o que respondan al goce de una licencia legal o convencional, con o sin pago de salarios ${ }^{48}$.

Ceder a este reclamo patronal se sumó al compromiso de tregua implicado en el acuerdo -que significaba que el SOIP se abstenía de realizar cualquier tipo de medida de fuerza durante el plazo de vigencia del acta ${ }^{49}$-, y al abandono de la consigna general de registración laboral bajo el Convenio 161/75, trocada por la firma de convenios de registración por empresa.

Estas fueron todas las causales halladas para la fractura de la dirigencia de la Lista Celeste en dos bloques, y bifurcarse nuevamente las direcciones del conflicto: por un lado, la registración paulatina de cooperativizados bajo los nuevos convenios por empresa, por otra parte, continuar con la exigencia de registración bajo el convenio $161 / 75$. Veamos un testimonio sobre las apreciaciones de una dirigente disidente a los convenios por empresa, del año 2005:

...No con el convenio colectivo del 75, ellos lo que quieren es un convenio que contemple una cantidad de trabajadores eventuales de por vida. Esa fue una de las cláusulas que nosotros nunca aceptamos, porque perder la estabilidad laboral, o ser convocados dos días y cuatro no, es lo mismo o peor que estar en negro pero bajo una figura legal (...) lo que quisieron implementar este último tiempo es un convenio que firmaron con Giorno, para tomar gente en relación de dependencia con un convenio flexible, que contemple doce horas de trabajo (Patricia Comparada, filetera, dirigente de la UOP) ${ }^{50}$.

La facción de la dirigencia a la cual representa esta dirigente propuso el rechazo total de los nuevos convenios propuestos por el empresariado por acentuar su carácter precario, mientras que el sector de la conducción gremial que los promulgaba sostenía que los mismos constituían la posibilidad de avanzar en una mejora progresiva para los trabajadores cooperativizados tanto en condiciones de trabajo como en número de obreros registrados. Lo cierto es que ambas direcciones entraron en confrontación y aun compartiendo acciones de lucha conjunta perseguían objetivos diferenciados, primando la falta de consenso entre ambas fuerzas sociales obreras. Los convenios por empresa fueron los antecedentes al anexo Pyme al CCT №161/75 firmado en 2007, que como vimos comparte estas concesiones a la patronal que se traducen en la perpetuación de gran parte de las características del proceso de trabajo en cooperativas fraudulentas, pero bajo un marco legal.

Las fracciones de la comisión directiva del SOIP se identificaban con Samuel Salas y los hermanos Luis y Mamerto Verón, por un lado, y Patricia Comparada y María

\footnotetext{
48 Revista Puerto № 34, marzo de 2005, página 61.

${ }^{49}$ Revista Puerto № 34, marzo de 2005, página 61.

${ }^{50}$ Revista Puerto №36, septiembre de 2005, página 34.
} 
Demateis, por el otro. Ambas direcciones eran apoyadas por una masa obrera, conformando nuevas luchas al interior del SOIP que se enlazaban con el conflicto Capital/trabajo. Más adelante veremos nuevos actores en esta disputa sindical, que cobran mayor relevancia en el ciclo posterior.

Desde nuestra perspectiva, la fuerza social que proclamaba la integración a los convenios por empresa guardaba una perspectiva conciliadora con la patronal a pesar de emprender acciones de combate contra la misma, ya que esta patronal que no garantizaba la inclusión de trabajadores en los convenios por empresa si no era con mediación de conflictividad. Es decir, buscaba mantener las mayores condiciones de precarización posible por el mayor tiempo posible, y solo cuando era forzada a modificarlas por las acciones obreras concedía la inscripción en dichos convenios con la intermediación del acuerdo con los dirigentes gremiales. La fuerza social obrera que no se resignaba al abandono de la registración bajo el convenio 161/75 tenía una perspectiva más disruptiva en cuanto a que perseguía objetivos más allá de los que se encontraba dispuestos a acceder la patronal, y para su justificación recurría a la tradición de lucha obrera en la rama, de la cual el CCT №161/75 fue su mayor logro.

A continuación, analizaremos lo que consideramos una de las variables fundamentales para la caracterización de este ciclo, el formato que fue adquiriendo la nueva conducción sindical y sus mutaciones a lo largo de los primeros años de conducción, desde el concepto de burocracia sindical.

\subsection{Nuevas disputas sindicales}

En cuanto a los avatares de la conducción sindical, lo que se ve es la modificación del propio programa de lucha por parte de los líderes de la Lista Celeste, reduciendo sustancialmente sus objetivos luego de ingresar en la conducción gremial, en comparación con las reivindicaciones planteadas durante el ciclo 1997-2001. Esto provocó conflictos y divisiones internas: en el año 2004 la Lista Celeste se escindió, quedando fuera de ella y del sindicato militantes del Partido Obrero. Estos integrantes luego se separaron de la comisión directiva y conformaron la Lista Bordó, que obtuvo el segundo lugar en estas elecciones. En los comicios del año 2006 se presentaron dos listas que provenían de la originaria Celeste, obteniendo la victoria la que contenía integrantes de la UOP. Esta división de la agrupación originaria ganadora de los comicios de 2002 perduró más allá del ciclo aquí abordado, extendiéndose hasta el final de período.

En la conflictividad sociolaboral de la industria pesquera marplatense durante el período estudiado, vemos que algunos de los dirigentes de ciertas organizaciones que cuestionaban y se contrapusieron a la dirigencia saravista anteriormente, en el año 2002 asumieron el lugar dirigencial y fueron también cuestionadas, tanto al interior de las agrupaciones que conformaron la Lista Celeste como por trabajadores que no formaban parte de ninguna agrupación en particular. En este punto vemos la importancia de analizar el lugar de la dirigencia sindical y de su dinámica 
burocrática -o no-, dinámica que se actualiza aunque una nueva agrupación ocupe el cargo. Esto es, una lógica burocrática a la que las dirigencias adhieren -o no- en cada caso, pero que de cualquier manera esas dirigencias están en una posición de uso de determinados dispositivos de poder vedados a las bases, porque poseen recursos materiales, económicos y legales para impulsar y avalar ciertas acciones e imponer una dirección hegemónica en las luchas, recursos que no están igualmente disponibles para la masa obrera. Asimismo, también portan una capacidad de movilización dada por la referencia obrera hacia el sindicato, referencia identitaria que suele mantenerse a pesar de no estar alineado con la política de la conducción e incluso desconociéndola o sin siquiera estar afiliado.

El caso de los obreros de la industria pesquera de Mar del Plata arroja luz sobre estas cuestiones, con la particularidad de que el SOIP históricamente ha sido uno de los sindicatos con mayor peso específico en la ciudad de Mar del Plata, tanto en términos de la cantidad de afiliados como en cuanto a la localización estratégica de su fuerza de trabajo, cuya posibilidad de paralizar los circuitos de producción y circulación del capital es importante dada su vinculación con el enclave portuario local. Esta particularidad es producto de que la actividad pesquera es una de las de mayor peso específico en la economía marplatense, disputando esa primacía incluso con el turismo. Asimismo, la combatividad de la numerosa masa obrera integrante del sector, como vimos, se ha manifestado a lo largo de su historia, resistiendo hasta el día de hoy a la inestabilidad y precarización laboral característica de la rama. Las cifras respecto de la cantidad de afiliados del SOIP expresan su vínculo con la tercerización y el desalojo obrero de la industria pesquera: si para el año 1975 el gremio contaba con alrededor de 15.000 afiliados (Mateo, Nieto y Colombo, 2010), actualmente posee alrededor de 4.200; y esta cifra fue menor en el ciclo 1997-2001. A su vez, también merece resaltarse aquí que muchos de los trabajadores cooperativizados que hoy se encuentran impedidos de la afiliación -debido a la falta de registración laboral- han sido anteriormente parte del SOIP.

Veamos algunos testimonios de dirigentes y trabajadores de base acerca de estas cuestiones para ir desarrollando la vinculación entre las conceptualizaciones teóricas y la evidencia empírica estudiada. En primer lugar, presentamos la narrativa de Luis Verón, dirigente gremial integrante de la Lista Celeste entre 2002 y 2006, anterior líder de la UOP:

Hay veces que hay que tener mucho cuidado porque vos no estás en un país socialista... Vos estás dentro de un capitalismo y dentro del capitalismo vos tenés que tratar de mejorar las cosas para la gente [...] yo me di cuenta de una realidad cuando yo vine al gremio. Yo, antes de estar en el gremio, yo quería una gran asamblea y una huelga por tiempo indeterminado para lograr los objetivos de los trabajadores. Y cuando vine al gremio, la realidad es que hicimos una huelga, una asamblea dentro de un gremio de seis mil trabajadores [...] terminamos en una asamblea de trescientos trabajadores y peleándonos con muchas tendencias políticas dentro de esa asamblea [...] [en] lo único que 
terminamos de acuerdo en conjunto fue [en] votar un paro por tiempo indeterminado [...]. A eso la gente no respondió, nunca respondió [...]. A la gente le metiste dos paros y te dice "bueno, pará un cachito la mano, sacate el acelerador. Yo no te puse para que vos me tengás parado permanentemente. Yo te puse para que vos me gestionés dentro del sindicato". Y a veces, [a] quien no está dentro del sindicato la gestión le parece que es de burocracia, pero dentro de todo es el mandato de la mayoría de la gente [...]. La mayoría en el gremio es trabajadora, no es militante. El militante quiere el paro permanentemente. Yo como militante también quería el paro permanentemente, pero era yo el militante. Después en el gremio yo me di cuenta [de] que era yo, [de] que no era lo que pensaba la gente (Luis Verón, exmilitante del Partido Obrero y asesor gremial del SOIP) 51 .

Este dirigente sindical, quien anteriormente fue líder de la UOP, ex militante del Partido Comunista y del Partido Obrero, expresa el cambio en su propia posición antes y después de haber ingresado a la comisión directiva del SOIP. En primer lugar, vemos una transformación de sus concepciones sobre el dispositivo asambleario de democracia directa con participación masiva de trabajadores en las decisiones relativas a las acciones de lucha, cuya nueva perspectiva se basa en la desestimación de este dispositivo como garante del accionar colectivo obrero. Esta transformación se basó en la experiencia del rápido abandono de la huelga por tiempo indeterminado votada en la asamblea masiva, que para el dirigente constituyó una vivencia desmoralizante, para no repetir. En segundo lugar, se observa una modificación en lo que él mismo como trabajador y militante exigía a la dirigencia anterior y lo que luego considera que los obreros le exigen a él como dirigente, marcando una diferencia entre las perspectivas de lucha desde afuera y desde adentro de la conducción gremial, diferencias aparentemente inconciliables. En tercer lugar, una idea de gestión que previamente a la asunción en la conducción no era tenida en cuenta, junto con una evaluación de lo que parecerían límites en las demandas, objetivos y formas de lucha. Además, se expresa una idea verticalista adjudicada a la base votante que "pone" a tal o cual dirigente para que actúe de acuerdo a lo que considera una mejoría con respecto a sus condiciones de vida y de trabajo.

En los fragmentos de la entrevista vemos cómo el dirigente establece una separación tajante entre un nosotros/dirigencia y un ellos/trabajadores, denominado "la gente". Aquí vemos que la diferenciación entre ambos lugares no es solo teórica sino práctica. Este dirigente años antes formó parte de esa "gente" -base obrera- que participaba en acciones de combate y exigía combatividad a la conducción sindical, la cual era criticada por "pasiva y traidora". La respuesta que da el actual dirigente al sector que ubica como "militante" -es decir, el sector propenso a llevar a cabo

\footnotetext{
51 Entrevista realizada por Guillermo Colombo el 12 de febrero de 2009, citada en Colombo, (2011) De clasistas a burócratas: el devenir de una traición. Acerca de la construcción moral del enemigo político en un sindicato de la industria del pescado (Mar del Plata - Argentina, 1997-2007). Revista Colombiana de Antropología, Vol. 47 (1), 43-68.
} 
acciones de rebelión- es que la mayoría no acuerda con las acciones de lucha. Esto a pesar de que anteriormente, cuando la UOP se manifestaba por la registración laboral y denunciaba a la dirigencia saravista por no tomar parte en el conflicto, tampoco era la mayoría de los miles de obreros las que participaban en los reclamos, sino un sector organizado o minoritario en relación con la totalidad de la base obrera. Recordemos que fueron 300 los trabajadores que, encabezados por la Unión Obrera del Pescado, realizaron la toma del SOIP en junio del 2000. Este número representa cerca del 5\% del total de obreros de la industria pesquera. Entonces, la práctica de combatividad llevada a cabo por esa minoría activa "militante", busca aplicarse como ideal al conjunto de la masa obrera, y el resultado de la discrepancia entre el ideal y la realidad que muestra a la mayoría de la base como pasiva, desorganizada o despolitizada redundó en el cambio en la dirección de la lucha propuesto por la dirigencia, adaptándolo a esa mayoría. Entonces, el papel adjudicado a la minoría activa también sufrió modificaciones entre el antes y el después de la ocupación del lugar dirigencial. Mientras que en el ciclo anterior esa minoría fue determinante para imponer una dirección alternativa al saravismo y torcer a su favor la obtención de la conducción gremial, en este ciclo se concibe desde la práctica y la conciencia como "a contramano" de la mayoría obrera y, por lo tanto, seguir su curso se expresa como una práctica "antidemocrática" e "impotente".

En síntesis, se observa una transformación en sus prácticas e ideas actuales respecto de las que tenía previamente, asumiendo una perspectiva reformista, planteando la obtención de concesiones parciales a las patronales en base a objetivos posibles de lograr, mucho menores en sus alcances que las planteadas en el pliego de reivindicaciones construido en el ciclo anterior, y de aquí proviene el abandono del CCT №161/75.

¿Qué explicación encontramos para este viraje en la dirección del conflicto, los objetivos gremiales y en las ideas de los que continuaron siendo sus dirigentes? En primer lugar, recordemos las sucesivas derrotas de las luchas por la registración laboral entre 1997 y 2001 . A pesar de las masivas y combativas movilizaciones, la UOP y el resto de organizaciones y trabajadores independientes que acompañaron estas acciones vieron por sus resultados que las mismas no lograban imponer sus reclamos a los empresarios, quienes no estaban dispuestos a modificar las precarias condiciones de trabajo y contratación. En este sentido, vimos que el empresariado pesquero contaba con un gran "ejército de reserva" disponible, justamente en una de las ciudades con mayor índice de desocupación, cuya fuerza de trabajo cooperativizada le resultaba fácilmente desechable sin pagar ningún costo económico ni político, ya que los gobiernos no ejercían multa ni sanción alguna contra la tercerización o las quiebras fraudulentas en la gran mayoría de los casos. Suponemos que la ola de luchas por la registración antes derrotada, relanzada con la fallida huelga de 2003, sustentó en parte la reformulación de las reivindicaciones sindicales. 
Sin embargo, queremos incorporar otro aspecto que nos parece central. Esta nueva conducción anteriormente reunía a obreros cooperativizados y desocupados, logrando superar la fragmentación de la clase obrera producto de la dualización de la fuerza de trabajo en la industria pesquera impuesta por la patronal, pero ahora como dirigencia debía legitimarse entre la base de obreros afiliados, quienes eran justamente los trabajadores en relación de dependencia y no los cooperativizados. Pocos meses después de llegar a la conducción, ante la falta de solidaridad y de unificación en la lucha por la registración laboral -expresadas en los pedidos de levantamiento de la huelga por tiempo indeterminado- advirtieron los límites de esta diferencia de intereses entre obreros con distintos tipos de contratación. Desconocemos aún si esta división fue abordada en discusiones mediante el dispositivo asambleario al interior del gremio y en los lugares de trabajo. Sin embargo, sabemos cuál fue el resultado siguiente: el abandono de la lucha por la registración bajo el CCT №161/75 y la búsqueda de la elaboración de nuevos convenios por empresa, involucrando sectores mucho más minoritarios en relación con los interpelados en las acciones anteriores, en una perspectiva de lucha mucho más corporativa y fragmentada. La nueva dirigencia resolvió suspender el reclamo contra las condiciones precarias de trabajo del conjunto de obreros no registrados y centrarse en las condiciones de contratación de algunos de ellos: estos trabajadores pasarían a tener registración laboral y determinados derechos implicados en la relación de dependencia, sin modificar por ello otros rasgos de la superexplotación laboral en el terreno de la producción.

Se observa que la necesidad de obtener al menos "algo" concreto para "algunos" fue un incentivo para las acciones en pos de obtener los convenios por empresa. Asimismo, esta reivindicación parcializaba la lucha obrera reduciéndola al ámbito de cada empresa en particular y no de la generalidad de la industria, lo cual generaba acciones menos disruptivas cuyas consecuencias en el terreno de la producción y circulación eran fácilmente neutralizables para la patronal (haciendo trabajar a los obreros en otra cooperativa fraudulenta correspondiente a la misma firma ubicada en otro sitio, por ejemplo). Así quedó definida la nueva política gremial en un documento de divulgación de la línea dirigencial:

No se trata de reducir todo a la lucha en defensa del Convenio del 75 cuando hay compañeras y compañeros que sufren la tortura del trabajo en negro o de las cooperativas truchas, se trata de luchar cotidianamente en pos de lograr mejorar las condiciones de trabajo y de vida de miles de obreras y obreros del pescado (Boletín Lista Celeste, 2006, p. 4).

¿Cuál fue el impacto de este cambio en la dirección de la conflictividad propuesta por la nueva dirigencia gremial? En primer lugar, cabe resaltar que este viraje no obtuvo consenso ni aun entre la dirigencia, y por ello fue detonante de sucesivas rupturas de la Lista celeste, tanto en lo referido al delineamiento de la política gremial como en la militancia partidaria de estos trabajadores, algunos de los cuales 
fueron expulsados del partido obrero, y otros de la conducción sindical. En segundo lugar, generó la bifurcación en dos propuestas de lucha, es decir, continuar con la fórmula en base al CCT №161/75 o aceptar los convenios por empresa. La hegemonía de esta segunda propuesta generó no solo beneficios para un grupo sino también perjuicios para otro, como veremos más adelante.

En el apartado siguiente continuaremos con el análisis crítico de los cambios en la política de la nueva dirigencia sindical, pero antes de ello queremos señalar que esta concepción verticalista ubicada en los dichos del dirigente también se encuentra impregnada en los discursos obreros, que depositan en la conducción sindical la "solución" de sus problemas laborales. Veamos cómo se refleja esta idea en la entrevista a un trabajador:

\section{E: ¿Conoce alguna organización?}

$\mathrm{N}$ : Y sí al sindicato lo conocía, pero ahora, que se yo...no existe. Pero ahora uno va y es lo mismo con las cooperativas...uno llama al sindicato y no te dan pelota. Ponele, si te despiden antes se llamaba al sindicato, cuando uno estaba efectivo ellos venían y te arreglaban las cosas, y te ibas tranquilo, pero ahora no, el sindicato no, no pasa nada. Lo mismo que Villaola ponele, que quieren hacer como un sindicato, que se yo, pero tampoco le dan bolilla, habla, habla, anda por todos lados, pero no (...) antes iba al sindicato cuando estaba efectivo, te atendían, te daban la mutual, teníamos todo ahí...y bueno...pero después con las cooperativas no había mutual, no había nada (...) A veces voy y el habla, nos dice...que se yo... Ahí nada más, no es cosa que voy ahí siempre. Hay gente que está siempre ahí con ellos, pero yo no, no... (Natividor, 59 años, filetero) ${ }^{52}$.

Si ubicamos este testimonio en vinculación con el de otra filetera, María (Pág. 15) ambos muestran que, si bien los obreros no abandonan en sus discursos la referencia sindical, en la práctica la misma se encuentra deslegitimada, pesando un fuerte descreimiento hacia ella. Aquí localizamos entonces una superposición de dos concepciones contrapuestas en las subjetividades obreras de los trabajadores de la industria pesquera respecto de su gremio: por un lado, siguen esperando que el "sindicato" -esto es, la dirigencia- entre en una disputa contra la patronal para obtener reivindicaciones o resistir ataques. En este sentido, las acciones y perspectiva propuesta por la conducción gremial guardan una preminencia con respecto a los planteos individuales o de otras agrupaciones. Por otra parte, se descree que esta dirigencia pueda hacer algo para obtener dichas demandas, o bien por falta de valor o conocimiento, como dice una trabajadora, o bien por corrupción y alianza con la patronal. Estas concepciones ofrecen también una explicación del por qué los trabajadores deciden no participar de acciones de lucha contra la patronal propuesta por las dirigencias gremiales o sus representantes.

52 Entrevista realizada el 6 de mayo del año 2009 por María Soledad Schulze, durante la cursada de la materia Metodología Cualitativa, correspondiente a la carrera de Sociología de la UNMdP, en el marco de un trabajo práctico aplicado de Investigación cualitativa dirigido por la docente Alejandra Navarro en el año 2009. 
Ambas ideas comparten una concepción pasivizada de las bases, que no tendrían otra opción más allá del seguidismo a las decisiones de la dirigencia o bien ser víctima de su "traición". Sin embargo, como contrapunto de esta idea de pasivización, vemos que aún se encuentra instalada una práctica sindical de baja o nula participación de las bases en la planificación de acciones y estrategias de lucha, como contracara de la burocratización de la dirigencia. Presuponemos que el balance negativo de aquella huelga por tiempo indeterminado que no se pudo sostener conllevó a que la nueva conducción comience a basar sus decisiones más en una especie de capacidad de "lectura mental obrera" que en dispositivos asamblearios y discusión política. Esta autoadjudicada capacidad de saber "lo que quiere la gente" guarda en sí una idea de voluntad obrera colectiva y uniforme. Luego, se reprocha a los trabajadores la falta de concurrencia en las medidas y acciones decididas por la dirigencia sindical, bajo la premisa de que carecen de combatividad y militancia.

Veamos ahora otro testimonio de Patricia Comparada, quien como dijimos anteriormente, formó parte de la comisión directiva inicial de la Lista Celeste y luego se alejó por diferencias políticas:

Traicionada al igual que la mayoría de la gente que esperaba de esta comisión directiva otra cosa. Nosotros asumimos con la propuesta de terminar con el trabajo en negro, de luchar por el salario que teníamos congelado desde el año 89. Durante los dos años que nosotros estuvimos siempre se convocó a asamblea, siempre se consultó al conjunto de trabajadores del sector, se dijo cuáles eran los pasos a seguir ante la negativa de la patronal de registrar a la gente (...). Un sector de la gente que está en negro recuperó la relación laboral, después eligieron paritarias y fue cuando nos dimos cuenta de que un sector de la comisión directiva se había corrompido, se había vendido, se había entregado a los requerimientos de la patronal y firmó la paz social. La traición la viven los miles de compañeros que confiaron en ellos... (Patricia Comparada, filetera, dirigente de la UOP) ${ }^{53}$.

Aquí se expresa claramente el conflicto intradirigencial, que, al cabo de tres años de la nueva conducción, las diferencias en las posiciones políticas de sus miembros generaron una ruptura insalvable que produjo, inicialmente, dos facciones principales. La posición de Patricia es la del sector que se retiró de la comisión directiva y luego conformó otra lista manteniendo la consigna de registración bajo el convenio 161/75.

En síntesis, en este período señalamos como características fundamentales:

-la ruptura de la nueva conducción del SOIP, con el triunfo del sector que abandonó las consignas iniciales -incluyendo a lucha por la registración bajo el CCT №161/75e impulsó la registración obrera bajo convenios por empresa;

-la preminencia de conflictos salariales dada la depreciación del salario real producto de la devaluación;

53 Revista Puerto №36, septiembre de 2005, pp. 25. 
-una nueva vinculación entre el sector de la dirigencia que continuó en la comisión directiva del SOIP y los empresarios, con la firma de la paz social asociada a una reducción del ausentismo mediante el pago de un bono compensatorio. Esta vinculación contrasta con la fuerte oposición presentada inicialmente con el llamado a huelga por tiempo indeterminado hasta tanto se proceda a la registración laboral; -en el polo empresarial, una recuperación y crecimiento económicos vinculada con la recuperación y crecimiento económico post 2002 en la Argentina (Grigera y Eskenazi, 2013), que significó la superación de la crisis de los últimos años de la década de los 90.

-la sanción, por parte del Ministerio de Trabajo, del carácter fraudulento de decenas de cooperativas de la industria pesquera. En este punto vemos una toma de posición discursiva y legal del Estado en sancionar como tales a las cooperativas fraudulentas. Sin embargo, las multas aplicadas fueron minoritarias en relación al total de trabajadores cooperativizados y no modificaron el porcentaje de trabajo no registrado, como veremos en el análisis del próximo ciclo.

Cabe aclarar al respecto que de acuerdo a Mateo, Nieto y Colombo (2010:209) en el año 2004 el Ministerio de Trabajo sancionó a empresas pesqueras por la conformación de 23 cooperativas fraudulentas que empleaban 1.844 trabajadores en el año 2004. Esta sanción en masa fue seguida por otras sentencias-como por ejemplo en las empresas Terramare y Melilla en el año $2006^{54}$, las cuales no solo fueron sancionados por el empleo de trabajadores no registrados sino también por empleo de menores de edad.

En el ciclo siguiente se afianzan y acentúan características del actual período, a la vez que retorna la crisis por escasez del recurso pesquero.

\section{El ciclo 2007-2011:}

Llegado el año 2007 resurgió el problema de la escasez, lo cual agudizó nuevamente la situación de los cooperativizados cuyo tiempo de trabajo se rige de acuerdo a la disponibilidad del recurso. La falta de trabajo y su precarización provocó nuevas luchas impulsadas por este grupo obrero, cuyos motivos residían preponderantemente en la actualización salarial y la registración laboral. En este punto se elaboró el anexo al CCT №161/75 denominado CCT 506/07, destinado a la pequeña y mediana empresa de las ramas fileteros y envasadoras, el cual fue firmado el 4 de octubre de 2007 por el SOIP y la Cámara de la Industria Pesquera Argentina.

\subsection{Del anexo Pyme a la puja salarial}

En las elecciones de 2006 del SOIP Samuel Salas renovó su puesto de secretario gremial. Luego, la lista Bordó, resultante de una escisión de la originaria lista Celeste

${ }^{54}$ Revista Puerto №44, 2007:34. 
-con Cristina Ledesma como secretaria gremial-, condujo el sindicato desde 2010 hasta el final del período estudiado. Esta dirigencia, unificada, impulsó los conflictos que desde 2007 tomaron la demanda de la firma del anexo al CCT del llamado Convenio Pyme 55 , la forma de convenio por empresa generalizado que fue expuesta en el capítulo 1. Es decir que los empresarios debieron transformar a sus cooperativas en PyMES y de esta manera los trabajadores fueron registrados, pero como vimos en el capítulo 1- en condiciones muy distintas a las del CCT №161/75. Luego de meses en los que transcurrieron acciones conflictivas diversas promovidas desde el SOIP y llevadas adelante por un gran grupo de obreros, a través de este convenio entraron bajo relación de dependencia más de 1.000 trabajadores (Nieto, 2010). Sin embargo, el mismo fue sistemáticamente denunciado por algunos sectores movilizados de las cooperativas quienes lo consideraron "peor que estar en negro". Por ello concluimos que el Convenio Pyme se constituyó como una nueva legalidad para amparar la precarización laboral, por la cual los empresarios mantuvieron condiciones de trabajo similares a las de una cooperativa fraudulenta con la diferencia de la registración laboral y posibilidad de afiliación gremial.

Veamos en palabras de la dirigente Cristina Ledesma qué significado tiene este convenio y su perspectiva al respecto:

CL: -A lo que yo apunto, primero que nada, es a registrar a la mayor cantidad posible de compañeros. Y si después podemos, analizaremos un nuevo convenio.

RP: $-¿$ Y te da igual registrarlos bajo cualquiera de los convenios?

CL: -Nosotros vemos cuál es la opción del momento. Siempre apuntamos al convenio del 75, pero si no se puede... será dentro del PyME.

RP: -Entonces, tu fin justifica sus medios...

CL: -Yo creo que sí. Para nosotros, lo primero en importancia es la registración. En algunas empresas es entendible sólo por el convenio PyME, porque se trabaja todo a producción. Pero de esa manera, el trabajador gana más que el que está registrado bajo el convenio del 75. Esa es una realidad y una verdad. Sabemos que el PyME tiene alguna diferencia con el del 75, porque se trabaja una hora y media más, pero en la cooperativa te hacen laburar 12, 13 o 14 horas, y un trabajador con el convenio PyME está registrado y con todo lo que le corresponde legalmente.

RP: -Al gremio, evidentemente, le es más fácil negociar la registración a través del convenio PyME...

CL: -Es más fácil. Esa es una realidad. Nuestra idea es apuntar en un futuro, cuando tengamos una importante cantidad de trabajadores registrados que representen otra fuerza, a luchar por una unificación de criterios en un único convenio. Pero no por ahora. No podemos porque no es viable todavía (Entrevista a Cristina Ledesma, Secretaria General del SOIP). ${ }^{56}$

\footnotetext{
55 Ratificado mediante la Resolución 584/2007 de la Secretaría de Trabajo de la Provincia de Buenos Aires.

${ }^{56}$ Revista Puerto, archivo digital, https://revistapuerto.com.ar/2011/12/el-puerto-marplatensees-el-mas-precarizado-del-pais/
} 
Como se desprende de sus palabras, para la conducción sindical la lucha por el CCT №161/75 pasó al orden de lo inviable con el correr de los años. Por ello se ve como una conquista el hecho de haber obtenido la registración a través del Convenio Pyme, contrastándolo con las condiciones de contratación propia del trabajo cooperativizado. La inclusión paulatina de trabajadores en el Convenio Pyme se plantea como una etapa previa a la lucha por la homologación de convenios en un futuro -incierto-, una vez que aumente la proporción de trabajadores registrados. En dicha entrevista, la gremialista expresa que, según sus datos, de los 4.200 afiliados al gremio la mitad están bajo el CCT №161/75 y la otra mitad bajo el convenio Pyme. Luego, estima que entre 4.000 y 8.000 obreros de la pesca estarían aún cooperativizados, es decir, se mantienen los mismos porcentajes de trabajo no registrado que en los 90. Desde nuestra perspectiva, la registración bajo convenio Pyme significó la incorporación a una relación de dependencia más precarizada con respecto a las condiciones del Convenio 161/75, en un contexto de crecimiento económico para el empresariado del sector pesquero. Comparando las condiciones de trabajo con el trabajo en negro o cooperativizado, el Convenio Pyme contempla la extensión del horario de trabajo 2 horas antes y 2 horas después de la jornada diaria de 9 horas. Aunque las cooperativas no contemplen un horario de ingreso, el convenio Pyme permite a los empleadores convocar antes de las 5 de la mañana "en caso de ser necesario". Las formas de pago y los adelantos carecen de regulación en ambos tipos de contratación. Mientras que en las cooperativas no hay regulación al respecto acerca de la materia prima a ser procesada, en el convenio Pyme este aspecto se regula por el SENASA, tomando como criterio la calificación del producto como apto para el consumo humano, independientemente de la preservación del recurso natural. En cambio, comparando condiciones de contratación entre el Convenio Pyme y el CCT №161/75, los aspectos que se comparten residen en los derechos a vacaciones, licencias, aguinaldo, jubilación y cobertura e indemnización por accidentes de trabajo. Las diferencias principales residen en que en el convenio Pyme no se contempla el pago de un plus por presentismo ni por antigüedad, tampoco se provee de ropa de trabajo, y la garantía salarial es fija, a diferencia del convenio 161/75 que se calcula en base a cajones/kilos de materia prima ${ }^{57}{ }^{58}$. En síntesis, la registración bajo el Convenio Pyme mantiene gran parte de las condiciones de trabajo propias de las cooperativas y otras formas de trabajo en negro, y otorga algunas de las condiciones de contratación propias de la relación de dependencia. Si tomamos como variable los objetivos de lucha vemos una continuidad en la puja propia del ciclo anterior, es decir, entre dos propuestas principales de registración: continuar exigiendo la incorporación bajo el convenio 161/75 o aceptar el Convenio Pyme, cuyas condiciones de trabajo fueron acordadas

\footnotetext{
57 De acá, Boletín mensual de los vecinos de los barrios marplatenses- Año 1, №9, septiembre de 2007:15-21.

58 Convenio Colectivo de Trabajo 506/07.
} 
entre los representantes sindicales, funcionarios del Ministerio de Trabajo y el empresariado pesquero marplatense.

De acuerdo a Mamerto Verón, otro de los impulsores sindicales del Convenio Pyme, los que se expresan en contra del Convenio persiguen intereses "ocultos" que buscarían la perpetuación del trabajo en negro ${ }^{59}$. Pero lo que se puede detectar en el discurso de la dirigencia sindical es una especie de "escalonamiento" en las demandas, con una concepción etapista que contrastó con la propuesta inicial contemplada en el pliego de reivindicaciones presentado en la disputa con el saravismo hacia el año 2000: en el lugar de la exigencia del CCT №161/75, se plantea como paso previo el Convenio Pyme para lograr la registración laboral. Este fue el discurso que acompañó las prácticas obreras y sindicales que confluyeron en la obtención del nuevo convenio. Su aplicación generó una consolidación de la división obrera ya no en dos, sino en tres estamentos de trabajadores de la industria pesquera de acuerdo al modo de contratación: los registrados bajo el CCT №161/75, los registrados bajo el convenio Pyme y los cooperativizados.

Presuponemos que una de las consecuencias de esta registración a cuentagotas fue la consolidación de un cuarto sector de obreros, conformado por quienes a causa de su participación en las acciones combativas por la registración laboral, sin haberla obtenido quedan desalojados de la industria pesquera por medio de la suscripción en una "Lista Negra". Este es el lado más oscuro de la lucha "parcial" por los convenios por empresa o el convenio Pyme. Veamos su impacto en las subjetividades obreras a través de los testimonios de dos fileteras y un filetero:

M: Yo, sin trabajo, despedida y desocupada, me despidieron el año pasado y hasta la fecha a las plantas no dan trabajo por el solo hecho de salir a rechazar la registración, haber sido despedida y haber estado participando del conflicto durante todo este tiempo, ya un año y medio, estoy en la lista negra, por salir a reclamar a la calle, por ir a los piquetes, haber cortado el puerto, haber estado detrás del sindicato y seguir a las marchas que a veces hacemos por cooperativas que están en conflicto, que echan gente y nosotros vamos en apoyo a ellos y bueno, ya quedas marcada, te pasan en la lista negra, y bueno, sos persona no grata para los empresarios y los cooperativistas

E: ¿Y qué consecuencias te trae a vos estar en esa lista negra? ¿A qué no tenés acceso?

M: Y a trabajar en una fábrica, no podés trabajar, y después tampoco por esa lista negra o que te fotografían...y todo eso después cuando conseguís trabajo ya te vieron en el diario, en una revista o en la televisión te dicen ¡Ah, no! Porque usted tuvo problema acá o allá... Y después conseguir trabajo en otro trabajo también, porque o sea, yo salí de la primaria a estar en una fábrica, o sea que no tuve posibilidad de estudio, porque hoy te piden secundario en todos lados y después también experiencia en otras cosas, también me falta, y después también como me dijo Tettamanti el año pasado, estoy fuera de sistema por la edad (Mirta, 54 años, filetera) ${ }^{60}$.

\footnotetext{
${ }^{59}$ Revista Puerto №47, año 2008, pág. 23.

${ }^{60}$ Entrevista realizada el 15 de mayo del año 2009 por Claudia Marcela Bruschetti, durante la cursada de la materia Metodología Cualitativa, correspondiente a la carrera de Sociología de la UNMdP, en el
} 
$\mathrm{N}$ : ¿Por qué te crees que estoy en una lista negra que no te dejan entrar? Sabes que en algún momento lo vas a perder el trabajo. Si echaban a un filetero yo me juntaba con dos o tres y parábamos toda la fábrica. $Y$ haces acuerdo con las patronales...pero si te toca a vos y nadie organiza...

E: ¿Cuándo te echaron del puerto?

$\mathrm{N}$ : Cuando perdimos la última elección del sindicato...no me acuerdo cuando...creo que en el 2005 o 2006.

E: ¿Así que vos laburaste desde el 87 hasta el 2006 en el puerto?

$\mathrm{N}$ : Yo sigo trabajando. Cada vez que hay trabajo, que me puedo infiltrar me infiltro y trabajo. Pero el año pasado fui a una planta y donde se dieron cuenta que estaba trabajando cerraron. Prefieren cerrar...después abrirán de vuelta...no quieren a la organización.

E: ¿Y vos desde cuando estas en una lista negra? ¿Quién la hace?

$\mathrm{N}$ : El sindicato. La lista negra el único que tiene poder para hacerla es el sindicato, porque es un lugar de poder, el que más tiene poder sobre los trabajadores (Entrevista a Nancy, filetera y militante del Partido Obrero, 55 años) ${ }^{61}$.

Sinceramente, la verdad que no. Bue, bah, lo que único que me acuerdo cuando se tomó el puerto... parecía que la gente iba a salir a protestar que por ahí íbamos a ganar toda la efectividad, lo único. Me puse un poco contento, pero después volví a la normalidad porque fue todo falso, y más bronca me dio porque después de haber venido los ministros, vino acá a firmar. Firmaron todo, en eso que no iban a echar a ninguna persona, ahí tenían cien días hasta que firmaban el acuerdo que iban a poner todo en blanco y no iban a echar a ninguna persona. Y bueno... a mí me echaron, por pedir la efectividad, para los compañeros. Me cerraron la puerta y no me dejaron entrar. A mí y a cuatro personas. Por pedir el blanco, yo había hecho una lista y la llevé al Ministerio de Trabajo. Me echaron. Fui al Ministerio de Trabajo y les dije "mirá, me echaron, porque yo traje la lista para poner a todos los compañeros en blanco. Porque nosotros estamos en negro. No queremos cooperativa". Fui. Hablé con San Martín y me dice "no, pero tenés que ir al sindicato". Fui al sindicato. Le expliqué las razones ¿Sabe qué? Nadie me dio... tuve que ir con los otros, mis compañeros, ir a quemar gomas, para que me den aunque sea algo de plata, porque estaba en la calle. Tenemos que mantener a la familia (Entrevista a Héctor, 42 años, filetero) ${ }^{62}$.

La confección de listas negras no solo generó la expulsión de los trabajadores más "revoltosos" de las plantas procesadoras, sino también actuó como un mecanismo disciplinador contra quienes permanecieron y también quienes ingresaron contratados bajo este nuevo convenio.

marco de un trabajo práctico aplicado de Investigación cualitativa dirigido por la docente Alejandra Navarro en el año 2009.

61 Entrevista realizada el 18 de mayo del año 2009 por Estefanía Martynowskyj, durante la cursada de la materia Metodología Cualitativa, correspondiente a la carrera de Sociología de la UNMdP, en el marco de un trabajo práctico aplicado de Investigación cualitativa dirigido por la docente Alejandra Navarro en el año 2009.

${ }^{62}$ Entrevista realizada el 21 de mayo del año 2009 por Gladys Marcela Luca, durante la cursada de la materia Metodología Cualitativa, correspondiente a la carrera de Sociología de la UNMdP, en el marco de un trabajo práctico aplicado de Investigación cualitativa dirigido por la docente Alejandra Navarro en el año 2009. 
En el primer testimonio vemos el caso de una trabajadora que participó en las movilizaciones sin formar parte de una organización en particular, sino para apoyar los reclamos colectivos -y propios.

En el segundo caso vemos que la trabajadora es además militante de un partido de izquierda y que formó parte de la conducción gremial entre 2002 y 2006, por lo que además de conflictos con la patronal fue parte de la disputa intrasindical vinculada a la escisión de la Lista Celeste originaria. Vemos entonces dos versiones sobre quiénes confeccionan las listas negras: por un lado, el empresariado, por otro, la propia dirigencia del SOIP. Estas concepciones guardan en sí diferentes concepciones sobre quién es el enemigo obrero, lo cual puede enlazarse con las jornadas de rebelión del 28 y 29 de junio de 2000. Nuevamente emerge la hipótesis obrera de traición y alianza entre dirigencia sindical y los empresarios en contra de los trabajadores, obteniendo prebendas monetarias a cambio de la desmovilización, sumisión y disciplinamiento. Haciendo un paréntesis en este análisis, vemos que la superposición de la posición de obrera y la de militante de Nancy -y también de otros trabajadores expuestos a lo largo de este capítulo- se contrapone con muchos planteos académicos que localizan a la militancia partidaria por fuera de la base obrera, adjudicándole un lugar meramente externo a la organización y activismo obreros de un sector y también en los lugares de trabajo. No es nuestra intención aquí analizar el vínculo entre activismo obrero y militancia en partidos de izquierda, pero simplemente queremos exponer esta cuestión objetiva ante ciertas críticas e interpretaciones abstractas que desconocen que cierto número de obreros son a su vez militantes políticos, y separan las acciones de una y otra personificación.

Retomando los testimonios, vemos que el tercer caso corresponde a otro trabajador que no estaba vinculado a la dirigencia sindical. En su testimonio vuelve a emerger la bronca y la desilusión tanto con la patronal como con los funcionarios estatales y la conducción gremial. A su vez, demuestra que lejos de unificar a los trabajadores, este tipo de luchas generó beneficios para un grupo -que luego están en condiciones de afiliarse al SOIP y avalar a la conducción, mediante la concepción de devolución de favores o de lealtad paternalista con la dirigencia que "le gestionó" la registración laboral-, mientras que perjudicó notablemente la situación de otro sector que terminó excluido de todas las formas de trabajo en la industria pesquera. En este caso, el resultado del despido producto de su inclusión en la lucha conlleva un desconcierto sobre sus causas y sobre el desamparo de la conducción gremial y del funcionario del Ministerio de Trabajo.

Entonces, el abandono por parte de la dirigencia gremial de la consigna general de registración bajo el convenio 161/75 a la lucha parcial por convenios por empresa generó resultados desiguales, contrapuestos, acentuando la división entre capas obreras: las beneficiadas, las perjudicadas y las que no vieron alterada su situación. Vemos entonces impactos negativos diferenciados de esta dirección de la lucha en las subjetividades. Creemos que en este impacto negativo se asienta la persistencia de la consigna de registración bajo el Convenio 161/75, la cual se expresa en distintos testimonios obreros, como los que se presentan a continuación, que fueron 
expuestos en un boletín impreso que se repartía por las distintas fábricas y en el propio barrio del puerto marplatense:

El año pasado, los peones, envasadores y camaristas entraron en el convenio Pyme, y los fileteros siguen en la cooperativa, pero todos están pidiendo ahora la efectividad con el convenio del 75 (José, filetero en la Cooperativa San Francisco) ${ }^{63}$.

Que el convenio del 75, que costó tanta lucha y sangre de compañeros, no sea basureado, flexibilizado, con anexos y agregados (volante anónimo, firmado "De los trabajadores para los trabajadores") ${ }^{64}$.

Utilizando la fuerza de la gendarmería y el poder del Estado, puestos desde siempre a su disposición, los empresarios de la pesca arremeten contra los trabajadores que, en cada una de sus plantas, reclaman el reconocimiento de la relación de dependencia y la registración laboral con el convenio 161/75 sin modificaciones ni anexos (Norma, Cooperativa San Julian, empresa Giorno, grupo Valastro) ${ }^{65}$.

...compañeros, que no nos engañen más. El trabajo registrado es ley y lo contempla nuestra constitución. Además, nuestro convenio colectivo de trabajo $161 / 75$, que costó la sangre de muchos compañeros que lucharon por él, no solo da derechos sino que también protege al recurso. en cambio con los convenios basura lo único que se busca es más explotación de los trabajadores y más depredación (Ricardo Muñoz, trabajador de la pesca integrante de una lista negra, integrante del colectivo "Memoria portuaria") ${ }^{66}$.

Vemos que, producto de sus prácticas colectivas de lucha y registración bajo el convenio Pyme, opera en las subjetividades obreras la concepción de que este convenio no es la solución a su situación laboral ni el objetivo buscado inicialmente, y por ello retorna con fuerza la consigna de registración bajo el CCT №161/75. Veamos ahora discursos empresariales en relación al conflicto y a la registración bajo el convenio Pyme. Al respecto contamos con una entrevista realizada por la Revista Puerto a Oscar Gerez, representante legal del Grupo Valastro y abogado de la empresa Giorno:

Hubo un error estratégico al contratar a tantas cooperativas cuando no había materia prima suficiente. No se previó que faltaría pescado (...) hay grupos que presionan para que no trabajen, hay piquetes, bloqueos, amenazas. La gente no va a trabajar porque está amenazada. Todo el mundo lo sabe y nadie hace nada. El intendente se comprometió a garantizar la seguridad, pero fueron nada más que declaraciones de buena voluntad (...) acá se ha instalado el prejuicio de que

\footnotetext{
63 De acá, Boletín mensual de los vecinos de los barrios marplatenses- Año 1, №9, septiembre de 2007:9.

64 De acá, Boletín mensual de los vecinos de los barrios marplatenses- Año 1, №9, septiembre de 2007:20.

65 De acá, Boletín mensual de los vecinos de los barrios marplatenses- Año 1, №9, septiembre de 2007:21.

${ }^{66}$ De acá, Boletín mensual de los vecinos de los barrios marplatenses- Año 1, №9, septiembre de 2007:28.
} 
cooperativa es sinónimo de fraude, cuando esa calificación depende del estado psicológico del asociado. Un día se sienten socios y pasan años sin que haya conflictos, pero de un día para el otro, aparece un movimiento y piden la relación de dependencia (...) son todos agitadores, políticos que buscar hacer pie en un gremio como el del pescado para fortalecerse ante la controversia que tienen con la CGT, de la cual el SOIP es miembro (...) Hay un sistema como el cooperativo que es una forma de relación laboral, que es el trabajo asociado, que no es ni bueno ni malo, ni mejor ni peor que otras formas. El trabajo asociado merece tanto respeto y es tan lícito como el de relación de dependencia. De hecho, los dos tienen protección constitucional. En la medida en que haya cooperativas que cumplan con sus requisitos de funcionamiento, es una forma lícita, respetable y digna de trabajar. La aspiración máxima del trabajador es tener estabilidad en sus tareas. En el sistema de relación de dependencia no hay estabilidad, salvo en los trabajadores estatales sin causa justificada, ya que el empleador te manda un telegrama y puede despedirte; a vos te queda la posibilidad de reclamar una indemnización. En el sistema cooperativo asociado, si no es a través de un sumario y de una sustanciación, una instancia donde se le permite al asociado tener derecho a defensa, no puede ser excluido, y una vez excluido tienen derecho a reclamar su reincorporación a través de una revisión ante la justicia. (...) Acá sucede que a la gente le interesa más reclamar una relación de empleo, ir a juicio, ganarse unos mangos (sic) que articular todas las defensas que les da el sistema cooperativo (...) Nosotros entregamos pescado a una empresa que se llama Mia S.A. En su planta, contrató los servicios de la cooperativa "La Armonía". Mia cortaba para Giorno y para otras empresas más. Cuando se agudizó la falta de materia prima, Mia se desentendió de esos trabajadores y los mandó a reclamar ante nosotros. Eso es un clásico (...) Así como en su momento tercerizamos el servicio de fileteado porque no queríamos hacerlo, ahora podemos cambiar (...) Giorno, a través de tres pymes, fue la primera que incorporó personal con el acuerdo PYME con el SOIP para envasadoras, peones y camaristas. Como empresario tengo derecho a conformar tres, cuatro, 25 empresas. Es absolutamente legal, pago los aportes, la gente cobra los salarios. Hace tres años que funciona y no ha habido problemas. Pero no se puede hacer depender la legalidad o ilegalidad del sistema la falta o abundancia de materia prima (...) Las cooperativas tienen su propio establecimiento, en dónde quieren que meta a la gente, esas plantas son independientes de las empresas que contratan el servicio. Hay cooperativas que nos prestan servicio a nosotros y a otras empresas. ¿de quién serían dependientes esos, ahora asociados? Muchos dicen que, con poco pescado, el sistema cooperativo se adapta mejor, es más elástico, se puede repartir el poco pescado. En el sistema de relación de dependencia, los costos fijos son altos y solo trabajarán aquellos que están encuadrados en el sistema. ${ }^{67}$

De este testimonio se desprenden varias cuestiones. En primer lugar, para el representante empresarial el convenio pyme no es excluyente con la continuidad de las cooperativas, a las que les niega ilegalidad, a pesar de admitir la subcontratación de mano de obra para el fileteado de una empresa madre, mientras que el pago del mismo fileteado era realizado por la misma empresa. Se observa una total impunidad por parte del abogado empresarial en cuanto a sus maniobras ilegales, impunidad tal que llega a expresar que la empresa "tercerizaba el fileteado porque

${ }^{67}$ Revista Puerto №46, diciembre de 2007. 
no quería hacerlo en sus instalaciones", y que la ilegalidad del sistema cooperativo depende del "estado psicológico del asociado", desconociendo que la realidad de este sistema son más horas de trabajo, menos salario, inestabilidad permanente, falta de derecho a indemnizaciones por despido, falta de licencias laborales, y todas las características que reiteramos ya en este trabajo. Queda claro en este texto que la conveniencia del sistema cooperativo es enteramente rédito empresarial, y también la semejanza de este sistema con el Convenio Pyme. Quizás la mayor derrota obrera que inició y se consolidó en los 90 y luego se perpetuó hasta la actualidad resida en esta convicción empresarial -que se expresa en la vida materialdel desmedro de la contratación en relación de dependencia, el desconocimiento del CCT №161/75 a la hora de contratar nuevos trabajadores (en base a las ganancias multimillonarias que esperan obtener con la materia prima de la que disponen), la perpetuación de la tercerización laboral mediante cooperativas y, en todo caso, la registración laboral bajo sus condiciones, que implican una similar superexplotación laboral en el terreno de la producción a la que aplican en las cooperativas fraudulentas. La estabilidad aducida no es tal, ya que se basa en la "elasticidad" y la cantidad de materia prima disponible, por lo cual los contratos a las cooperativas no son permanentes sino atados al tonelaje de pescado obtenido en cada ocasión. Al finalizar el fileteado de la materia prima entregada por la empresa madre, en tiempos previamente estipulados por la misma empresa, cesa la relación laboral. La conflictividad obrera en la industria pesquera, para el empresario, no se vinculan con las propias condiciones de trabajo, sino con intereses ajenos, sindicales, políticos, o de otros agentes externos que no cumplen con sus funciones, negando no solo la situación de superexplotación sino también la agencia de los sujetos. Este es el disfraz empresarial para la relación de explotación desde el capital hacia el trabajo, bajo las nuevas condiciones impuestas bajo la avanzada capitalista desde los 70 hasta el final del período alcanzado.

Tomando en cuenta esta práctica empresarial, vemos que a este análisis se incorporan otros elementos además de la lucha entre fuerzas sociales obreras. La avanzada capitalista en la industria pesquera se propuso con éxito derribar garantías laborales logradas por luchas anteriores, cristalizadas en el convenio $161 / 75$. Aquí vemos las determinaciones materiales y de la correlación de fuerzas en esta derrota aún vigente, justo a las diferentes significaciones que muestran la heterogeneidad de la clase obrera y la falta de una estrategia organizada que logre torcer esta imposición empresarial. Primero con despidos, luego con cooperativización y más tarde con los convenios por empresa y el convenio Pyme, estas han sido las metodologías patronales para evitar la contratación bajo el convenio vigente para la rama.

En cuanto a los resultados concretos, vemos que el ingreso al convenio Pyme de algunos provocó la expulsión total de otros, aún bajo condiciones tercerizadas y temporarias. El empresariado resignó parte de la organización de la fuerza de trabajo en cooperativas, pero la trastocó por una nueva forma de superexplotación legal, en un conflicto que a su vez tuvo como consecuencia la expulsión de 
trabajadores radicalizados y el incremento del disciplinamiento en los que continuaron desempeñándose con altos grados de precarización. El importante índice de desocupación siempre latente en la ciudad de Mar del Plata provoca que el empresariado no se vea afectado por la elaboración de listas negras, ya que nueva fuerza de trabajo proveniente del gran ejército industria de reserva local siempre se hace presente en largas filas ubicadas en las puertas de las fábricas de madrugada, tal como lo relatan los obreros.

Retomando las definiciones de burocracia sindical previamente expuestas, vemos cómo la conducción del SOIP -proveniente de la originaria lista opositora a la conducción saravista- reactualizó bajo un nuevo formato el abandono de parte de los trabajadores más precarizados de la rama. En este sentido, reprodujo la dualización de la fuerza de trabajo impuesta por las condiciones neoliberales e incluso subdividió aún más a los obreros del sector, consolidando las capas a su interior y fomentando la contraposición de intereses de cada una con respecto a las otras. Aquí, el beneficio de las acciones emprendidas se circunscribe a un grupo minoritario de nuevos registrados, que se convierte en base propensa a apoyar a la nueva dirigencia que promovió su registración. Como resultado, favoreciendo a un grupo minoritario de trabajadores con la registración bajo el convenio Pyme, la nueva dirigencia apostó a obtener como beneficio propio el perpetuarse en el cargo a partir del apoyo de una nueva base obrera, la cual es un desprendimiento del sector de obreros cooperativizados con los que luchaban en el primer ciclo. Asimismo, esta política también fragmentó a los obreros fomentando salidas individuales ante las situaciones de precarización, las cuales se asocian al incremento de la competencia y, por ende, la ruptura de lazos de solidaridad en pos de la preservación o mejora de la condición laboral personal. No obstante, la contradicción capital/trabajo como tendencia estructural en determinadas situaciones continuó imponiéndose decididamente sobre la fragmentación hacia adentro de la gran masa de obreros de la industria pesquera, quienes con o sin el acompañamiento de la conducción sindical continuaron rearmándose y presentando combate a través de sucesivas acciones conflictivas.

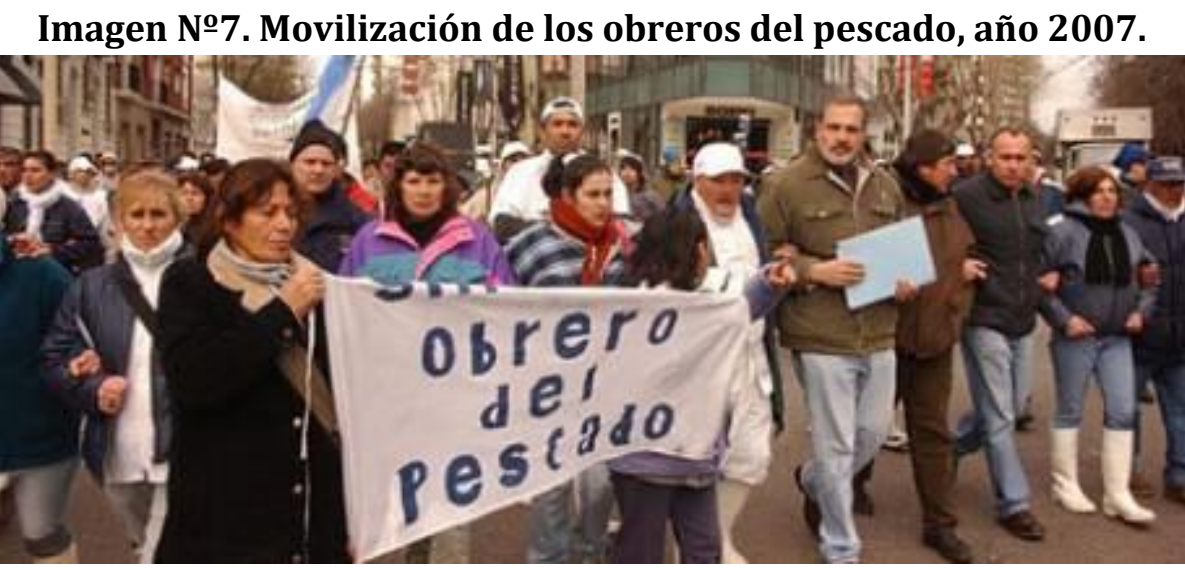

Fuente: Perfil.com, edición del día 27 de septiembre de 2007. 
Concluyendo este ciclo y a su vez el período al que nos abocamos, hacia fines de febrero de 2011 comenzó a manifestarse una nueva y álgida conflictividad, que duró meses e implicó varias huelgas consecutivas. Uno de los primeros hechos partió de los cooperativizados con el reiterado reclamo de registración laboral en dos plantas a la vez, con el "convenio colectivo del SOIP"68, es decir, el Convenio Pyme. En una de ellas -llamada Romano- los trabajadores realizaron una toma y se declararon en asamblea permanente, mientras que en la otra -Frigosur- los obreros armaron una carpa frente a la empresa manteniendo una retención de tareas.

Entre abril y mayo de 2011 el conflicto se centró en la actualización salarial de los trabajadores registrados. El SOIP inició una huelga por 72 horas con el objetivo del incremento salarial del 35\%, con un paro total de actividades contra la Cámara Industrial Pesquera Argentina. Como en otras oportunidades, la demanda de aumento salarial para los obreros en relación de dependencia se conjugaba con la de registración laboral para los trabajadores cooperativizados. La medida incluyó movilizaciones y un bloqueo de todos los accesos al puerto local que se mantuvo por varios días, lo que provocó desabastecimiento de pescado en los principales mercados bonaerenses, además de restringir las exportaciones durante esos días. A raíz de ello, el Ministerio de Trabajo dictó la conciliación obligatoria y amenazó con el quite de personería jurídica del SOIP, pero los trabajadores y el gremio persistieron con las medidas.

\section{Imagen №8. Asamblea y manifestación de trabajadores de la industria pesquera.}

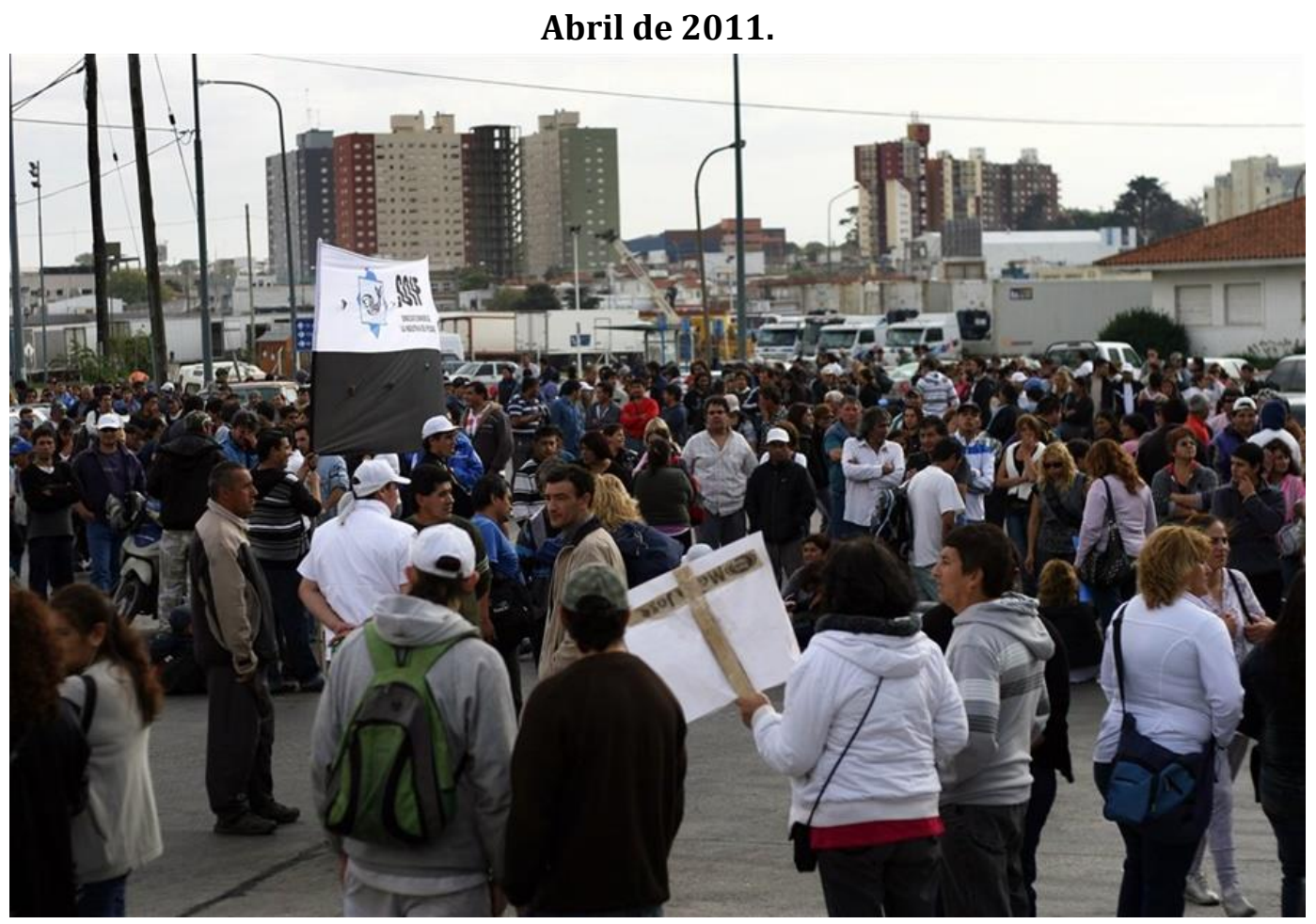

Fuente: Diario La Nación, 18 de abril de 2011.

${ }^{68}$ Revista Puerto, nota correspondiente al día 15 de marzo de 2011. 
Al acercarse la fecha de Semana Santa, la cuantiosa ganancia empresarial prevista aceleró la resolución del conflicto con una propuesta de aumento salarial del 30\%, que fue aceptada por el gremio. Sin embargo, volvió a quedar pendiente la demanda de los más precarizados de la rama, ya que este conflicto, como tantos otros, cesó al obtener el aumento salarial. Como aconteció en reiterados conflictos y ciclos de protesta en la industria pesquera, la registración laboral, cuando es tomada como parte de un pliego de reclamos entre las que se incluye la actualización salarial, termina quedando como reclamo "simbólico", sin que repercuta en un cambio material concreto para los obreros cooperativizados. Por otra parte, se observa que la medida de corte y bloqueo del puerto, el "lugar soñado" de la lucha obrera, fue convocada por el SOIP y emprendida por trabajadores del conjunto de la base obrera y se utilizó para llevar a cabo la lucha salarial, la cual obtuvo resultados exitosos. En contrapartida, las acciones cuyo objetivo fue la registración laboral fueron convocadas por trabajadores de las propias plantas -es decir, fueron medidas parciales, no generales- que recibieron el apoyo del SOIP y se localizaron en el lugar del trabajo y sus inmediaciones, con resultados infructuosos.

Finalmente, sobre el mes de junio de 2011, se desencadenó un nuevo e importante conflicto por atrasos salariales y deudas de la firma Barilari (uno de los grandes grupos económicos pesqueros). Los 8 gremios que involucraban a la masa obrera que allí se desempeñaba se declararon en estado de alerta, paro y movilización, mientras que los trabajadores ocuparon la fábrica y paralizaron la flota de camiones. En esta oportunidad se nuclearon en una acción conjunta el SOIP y el SOMU con el Sindicato de Conductores Navales de la República Argentina (Siconara), el Sindicato Marítimo de Pescadores (Simape), el Sindicato de Empleados de Comercio (SEC), el Sindicato de Choferes de Camiones, el Sindicato Argentino de Obreros Navales (SAON) y Asociación Argentina de Capitanes, Pilotos y Patrones de Pesca. La toma se extendió a otras plantas, como las del grupo Solimeno, llegando a abarcar a 15 establecimientos durante ese mes. También se produjeron ataques y escraches tanto a las unidades productivas como a los domicilios de los propietarios, agregándose como acción el secuestro del padre del empresario Salvatore como presión para que éste acuda a negociar con los obreros. Aquí, el ingreso de una gran cantidad de materia prima en el puerto marplatense con destino a esta empresa fue el principal factor que influyó en la resolución de este conflicto, que, tal como sucedió con las luchas por la registración en las plantas pesqueras durante los primeros meses de 2011, también guardó un carácter parcial. A diferencia del resto, la unidad de distintos gremios posibilitó el ataque generalizado a esta gran empresa, con una radicalización de los formatos de protesta incluyendo una participación masiva, acciones ilegales y alta implicancia corporal en las mismas.

La gran diversidad y cantidad de acciones de la conflictividad sociolaboral de la industria pesquera rompe la aparente calma o "pasivización" de determinados momentos, con la irrupción de la ira obrera de una gran masa de trabajadores que día a día acumulan bronca y esperan modificar las condiciones de explotación, superexplotación y opresión que soportan -a regañadientes- cotidianamente. 
En general, vemos que en las luchas predomina la vertiente defensiva, de reacción ante determinados ataques de la patronal, sobre el colchón de la gran derrota que significó la imposición de los nuevos formatos de precarización laboral desde los 90, y su consolidación desde 1997. Torcer esta correlación de fuerzas dependerá de la iniciativa, experiencias y recreaciones obreras en las luchas más o menos constantes, más o menos intermitentes, contra el capital.

\title{
5.2. La siempre pospuesta demanda de blanqueo
}

Retomando el análisis del abandono de la lucha por la registración bajo el CCT №161/75 por parte de la conducción del SOIP, y de la negación del mismo por parte del empresariado pesquero, testimonios muestran que desde la óptica obrera el reclamo de derechos laborales sustentados en dicho convenio conserva plena vigencia, y demuestra la conciencia lograda mediante la identificación y rechazo de la situación de superexplotación percibida. En este punto vemos que, aunque muchos obreros no cuestionen de raíz a la explotación capitalista, sí consideran que el empeoramiento de las condiciones de trabajo y contratación en las cooperativas traspasó el límite de lo soportable. Asimismo, la proporción de trabajadores cooperativizados continúa siendo elevada considerando al conjunto de obreros de la industria pesquera, lo cual generaliza ampliamente este reclamo. Desde las propias palabras de la conducción sindical, entre 4.000 y 8.000 obreros de la pesca continúan cooperativizados o trabajando en negro en plantas clandestinas. A pesar de ello se observa como rasgo general de todo el período que la demanda de blanqueo en general se mantiene pospuesta, obteniéndose solo en forma minoritaria con respecto al total de obreros no registrados y manteniéndose un porcentaje elevado de los mismos. No obstante, la posposición en la obtención de esta demanda no provocó el cese de sus luchas, ni tampoco el descenso en su grado de radicalidad, reapareciendo el conflicto sucesivamente.

La bronca que día a día se va acumulando contra los empresarios, que aumenta la fuerza de las demandas que se van sintiendo cada vez más básicas y necesarias, se expresa con claridad en el discurso de este trabajador:

\begin{abstract}
V: Me da bronca... ¡bah! Yo a los empresarios... no entiendo... porque, ganan mucha plata, muchísima plata ganan, pero uno lo que les pide es poner efectivo, tener una vacación, un aguinaldo. Tener unas vacaciones, pero pagas. Tener quince días pero pagos, aunque sea. Nada más, es lo único que se pide. Porque no puede ser que laburés tantos años y no tengas una vacación. El ser humano tiene un montón... necesitamos una vacación... que nos paguen el aguinaldo, las vacaciones, como tiene que ser. Y laburar ocho horas. Y si tiene mucho laburo, que haga dos turnos. Pero no matar a la gente, quince horas, veinte horas ahí, un peón y un filetero, es muchísimo (Héctor, filetero, 42 años) ${ }^{69}$.
\end{abstract}

\footnotetext{
${ }^{69}$ Entrevista realizada el 21 de mayo del año 2009 por Gladys Marcela Luca, durante la cursada de la materia Metodología Cualitativa, correspondiente a la carrera de Sociología de la UNMdP, en el marco
} 
Se observa que, a pesar de continuar trabajando en las precarias condiciones propias de la cooperativización, no por ello los trabajadores dejan de cuestionar la superexplotación a la que se ven expuestos, ni de parecerle injusta y por ello motivo de enojo y lucha contra la burguesía. El reclamo de derechos anteriormente conquistados y actualmente vedados para una gran masa de trabajadores se encuentra "a flor de piel" obrera, lo que impide aún sellar de forma tajante su derrota en esta lucha. A su vez, al relatar las consecuencias en el plano productivo del avance capitalista bajo el formato neoliberal, los obreros se posicionan como opuestos a la patronal y pueden identificar al empresario como explotador, al capital como Otro del trabajo. En este sentido vemos que la dualización de la fuerza de trabajo no logra un consenso entre los obreros, ni tampoco la resignación, sino, por el contrario, continúa incentivando la rebelión a pesar de las derrotas pasadas y los riesgos de expulsión definitiva. Sin embargo, aquí dos cuestiones se superponen con esta perspectiva combativa: en primer lugar, la apelación a la "humanidad" de los empresarios, a la adopción de una ética que contemple el sufrimiento obrero y, mediante una especie de empatía para con los mismos, conceda los formatos laborales reclamados. La esperanza de un accionar empresarial basado en esta empatía y no en el afán de lucro a fin de obtener mayores ganancias a partir de la explotación obrera, es una muestra de la distancia que aún persiste en relación a una ruptura obrera con la clase empresarial, que actúa como dique de contención a la lucha de clases para torcer la relación de fuerzas a su favor. En segundo lugar, lo que aparece aun vedado es una estrategia de lucha que logre imponerse sobre el empleo no registrado y su enquistamiento estructural en la etapa capitalista actual, y aquí entra en juego no solo la desunión, sino también la desprotección obrera en cuanto a garantías legales para llevar a cabo acciones de rebelión. En este sentido, la consolidación de la precarización laboral por parte de los empresarios, enmarcada en una "fuga del derecho laboral" (Ackerman, 2005), ataca no solo las condiciones laborales y de contratación sino también las posibilidades de lucha contra esas condiciones, abriendo las puertas a los despidos ante las huelgas u otros tipos de acciones conflictivas. Esta desprotección, junto con el ejército de reserva latente, ocluyen las salidas obreras que para los sujetos guarden una convicción de victoria posible como resultado de las mismas, y actúa como un obstáculo más a vencer antes de emprender las luchas.

Por otra parte, en diversos testimonios puede leerse otra demanda pospuesta, que es la de la afiliación gremial al SOIP de los trabajadores no registrados. Además de la desestima o suspensión indefinida de la lucha por la registración del CCT №161/75, este es otro aspecto que llama la atención de este período en cuanto a las transformaciones en la práctica de la nueva conducción sindical, ya que esta reivindicación se hallaba presente desde el ciclo 1997-2001 y era impulsada por las agrupaciones integrantes de la originaria Lista Celeste, obteniendo gran apoyo de la

de un trabajo práctico aplicado de Investigación cualitativa dirigido por la docente Alejandra Navarro en el año 2009. 
base obrera. Recordemos que la dirigencia saravista, además de ser denunciada por su inacción en la lucha contra la precarización, desocupación y cooperativización, también fue cuestionada por dejar al margen de la cobertura gremial a los obreros cooperativizados y desocupados. La nueva conducción de la Lista Celeste se presentó como crítica de estos aspectos y con un programa reivindicativo propio, el cual fue proclamado al momento de la toma de la sede sindical en junio del 2000 e incluía la registración de todos los trabajadores cooperativizados, la actualización salarial, garantía horaria y el dictado de una amnistía que permitiera la afiliación de todos los trabajadores que desarrollaban sus labores bajo el régimen de las cooperativas "truchas". Lo que resulta llamativo es que para dictar esta resolución no habría impedimento alguno para su consecución, dependiendo en gran medida la voluntad política de la conducción. Sin embargo, no se realizó. Los trabajadores señalan como pérdida o falencia esta imposibilidad de agremiación en reiterados testimonios, con una concepción de empeoramiento de derechos y condiciones laborales como resultado de esta desafiliación. Este desamparo gremial es otro de los elementos que cuestionan la dirección de la lucha propuesta por la conducción gremial, y que impide a su vez una organización y participación mayor en las acciones combativas en base a la garantía legal que ofrece la posibilidad de afiliación. En este sentido, el Convenio Pyme no legisla la representación gremial mediante delegados en los lugares de trabajo, conformando este un aspecto más de desmedro en comparación con el Convenio 161/75.

\section{6. ¿Por qué algunos trabajadores no luchan?}

Finalizando este último apartado, no queremos dejar de aludir a las voces obreras disidentes de las acciones conflictivas enmarcadas en las luchas colectivas durante el período. Nos parece importante rescatar estos discursos para exponer la heterogeneidad dentro de la masa obrera, la existencia de capas en la misma que demuestran nuevamente una subjetividad heterogénea, con diversas prácticas, grados de conciencia y de disposición a la lucha contra el capital. En los primeros apartados expusimos dos testimonios de fileteros que argumentaban que la necesidad de ingresos monetarios y el riesgo a perder el empleo en negro eran motivos para no llevar a cabo medidas de fuerza de forma sostenida, aunque fueran concientes de la explotación, se reconocieran como clase en contraposición al empresariado -concebido como explotador y opresor- y estuvieran de acuerdo con el reclamo. Veamos otros testimonios al respecto para luego interpretarlos:

Cuando fue el tema del puerto en el 2007, que había problemas, yo, por ahí, yo no estoy en contra de los reclamos, porque yo en este momento estoy reclamando algo que sé que es justo, pero en ese momento ellos estaban reclamando para ellos, o sea ellos en ese momento pedían la efectividad para determinadas personas, si vos entrabas o no, no era problema de ellos. Entonces el que fueran a la fábrica y rompieran el portón y te intimaran para que no fueras a trabajar de forma agresiva, porque iban y te querían pegar, prenderte fuego la planta, tu lugar de trabajo, a mí me implicó que todo eso me llevara a 
que yo hoy tengo cuentas que tenía que pagar y no las pude pagar, porque el puerto paró un mes y pico y yo me quedé con todas esas deudas, inclusive cuando nos fueron a buscar nos dijeron, No, porque ustedes tienen que acompañarnos y yo le digo Mirá, tu reclamo es muy justo pero a mí me lloran nueve chicos y aunque vos no lo quieras creer, hasta un nieto que viene en camino, y vos a mí por acompañarte a hacer marchas, a romper, a quemar fábricas, no me vas a dar de comer, porque yo cuando termine la marcha, tengo que volver a mi casa, y ¿qué les digo a mis hijos cuando me pidan un pedazo de pan y yo no tengo para dárselo? Mirá, ellos dependen de mí, yo no trabajo, yo no gano, o sea yo te entiendo a vos y vos me tenés que entender a mí. Aparte de la forma que ellos están haciendo el reclamo, a mí no me parece bien, creo que no era la forma. Por ejemplo, yo lo veo ahora y no tuve la oportunidad de hablar con nadie del puerto, pero nosotros conseguimos algo sin tener que ir a quemar la municipalidad, por ahí si pintando, haciendo escraches, pero sin perjudicar a nadie, no rompiendo, no quemando (Soledad, envasadora, 36 años) ${ }^{70}$.

No me gusta el sindicalismo. Me gusta la política, pero no me gusta el sindicalismo porque es muy sucio. Porque yo he visto a los mismos sindicalistas vender un compañero. ¿Me entendés? A los que ellos van, les palmean la espalda y les dicen compañeros... Entonces nunca me gusto el sindicalismo... (Sonia, filetera, 49 años) $)^{71}$.

No nada, nada.... solo cobrar esos quinientos pesos...No, si cuando se tomó el sindicato y el Ministerio no participamos, tratábamos de conseguir algún trabajo... No nos gustan las marchas, él si va porque conoce a Villaola y estamos muy mal... (Entrevista a Ana Maria y Julio Cesar, fileteros, de 60 y 64 años respectivamente) ${ }^{72}$.

Yo no comparto las cosas que dicen, o sea, los sindicalistas. Yo no digo que la gente no tiene que ganar porque cada uno va a su trabajo y obviamente que vos tenés que recibir un sueldo ¿verdad? Pero no comparto que se haga un paro. Yo creo que trabajando se pueden lograr cosas que haciendo un paro, que... o quizás mi mente está cambiada, o sea, a mí me dicen yo soy capitalista... yo siempre digo que si eso compre esto (toma un objeto que estaba sobre la mesa y lo apoya sobre la mesa haciendo énfasis en lo que dice) y yo a la persona que me trabaje en esto yo no le pedí nada para que me ayude, yo con mi plata, aposté a esto y bueno... Mis ganancias son las mías y yo a vos te pago lo que te corresponde, listo. 0 sea, a mí el dueño de la planta a mí no me pidió plata para decir mirá, voy a poner una planta, contribuí, tampoco puedo pretender que si él puso su dinero después tenga que ganar igual que él, eh... Cada cosa tiene que... son como escalas. Y de eso del puerto no comparto que hagan un paro

\footnotetext{
${ }^{70}$ Entrevista realizada el 15 de mayo del año 2009 por Humberto Lohiol, durante la cursada de la materia Metodología Cualitativa, correspondiente a la carrera de Sociología de la UNMdP, en el marco de un trabajo práctico aplicado de Investigación cualitativa dirigido por la docente Alejandra Navarro en el año 2009.

${ }^{71}$ Entrevista realizada el 28 de mayo del año 2009 por María Soledad Schulze, durante la cursada de la materia Metodología Cualitativa, correspondiente a la carrera de Sociología de la UNMdP, en el marco de un trabajo práctico aplicado de Investigación cualitativa dirigido por la docente Alejandra Navarro en el año 2009.

72 Entrevista realizada el 27 de mayo del año 2009 por Carolina Dumrauf, durante la cursada de la materia Metodología Cualitativa, correspondiente a la carrera de Sociología de la UNMdP, en el marco de un trabajo práctico aplicado de Investigación cualitativa dirigido por la docente Alejandra Navarro en el año 2009.
} 
porque no, o sea, eh... a veces hay gente paga, ¿viste? Que están pagadas por atrás y, que te llevan a vos y que dicen... bueno mira, vamos a hacer paro, es como que le pagan a que esa persona y llevan a la otra gente como si fueran ovejitas al matadero, y la gente reacciona de una forma y hay gente que está paga. Yo lo sé porque yo he visto eso, he tenido acceso a ver esas cosas. Entonces yo no comparto todo eso, a veces cuando hacen paro en la planta, que a veces los saben hacer por equis motivo, bueno, yo nunca me adhiero al paro ni nada. Tengo muy buena relación con la gente, la gente o sea, la gente en la planta a mí me aprecia porque yo no soy, trato de no ser una persona no tan... trato de no ser injusta, trato de ser equitativa en todas las cosas. Pero este... nunca hice paro, o sea, muchos dicen ¡Eh sos una... una alcahueta!. No, pero bueno... ellos sabrán por qué lo dicen. Yo no soy alcahueta de nadie, este... hago mi trabajo y trato de que todo salga bien (Marta, 49 años, empleada de control de calidad) ${ }^{73}$.

En estos testimonios de cinco trabajadores de la industria pesquera observamos diferentes motivos por los cuales no participan de las acciones conflictivas en el marco de reclamos colectivos obreros, entre los que podemos distinguir los siguientes fundamentos:

- El reclamo de registración laboral era para un grupo de trabajadores mientras que excluía a otros.

- La dirigencia gremial utilizaba métodos de presión no compartidos para imponer la participación en la medida de fuerza, que incluían agresiones, golpes y amenazas.

- Ingresos insuficientes para la propia subsistencia y la de sus familias, productos de los descuentos salariales.

- El método de lucha adoptado se concibe como excesivamente radical por implicar ataques a la propiedad privada empresarial u edificios públicos.

- Prácticas corruptas de los dirigentes gremiales, quienes en vez de defender a los trabajadores benefician a los empresarios, brindando información que posibilita represalias patronales contra ellos.

- La necesidad -dada por la supervivencia del obrero y grupo familiar- de mantener el contrato de explotación entre obrero y patrón en cuanto a la venta de fuerza de trabajo, a pesar de que no se paguen temporariamente los salarios.

Hasta aquí los fundamentos de los motivos en los que se basan los obreros de la pesca para decidir la abstención de su participación en las acciones conflictivas emprendidas. Se observa nuevamente la pérdida de legitimidad, confianza y referencia hacia la dirigencia sindical, con concepciones similares a las de trabajadores que participaron activamente de las luchas por la registración laboral. La fragmentación de la registración por empresa o convenio Pyme que dejaba por

\footnotetext{
${ }^{73}$ Entrevista realizada el 24 de mayo del año 2009 por Maia Morgenstern, durante la cursada de la materia Metodología Cualitativa, correspondiente a la carrera de Sociología de la UNMdP, en el marco de un trabajo práctico aplicado de Investigación cualitativa dirigido por la docente Alejandra Navarro en el año 2009.
} 
fuera a muchos trabajadores -quienes luego no recibían ningún tipo de amparo gremial- también aparece como argumento para no participar, lo que indica desacuerdo con el programa gremial referido a la conquista paulatina de registración laboral para determinados grupos de trabajadores. La cuestión de la necesidad salarial para la supervivencia diaria nos habla de una razón para no formar parte de la acción combativa a pesar de estar de acuerdo con la misma y/o con el reclamo que conlleva. La falta de un fondo de huelga durante los períodos de protesta nos muestra otra necesidad obrera para superar el impedimento material de continuar con una medida de fuerza duradera, y en este sentido también la cuestión señalada en el punto anterior sobre la falta de representación gremial, ya sea mediante la afiliación como a través de delegados de planta. En una de las trabajadoras, que no forma parte del proceso de trabajo implicado en el fileteado del pescado, sino que se ocupa del control de calidad -y por tanto se desempeña bajo otras condiciones laborales menos precarizadas en relación con los fileteros y percibe un salario mayor-, aparece como motivo para no luchar la falta de cuestionamiento a la superexplotación capitalista, a pesar de que el empresario no cumpla con el pago de los salarios. En este único caso hallamos la asimilación de la perspectiva patronal que justifica los ataques hacia los obreros por el hecho de ser los propietarios de los medios de producción. Por último, una razón para formar parte de los hechos de rebelión aun estando en desacuerdo con el formato de protesta gremial, es la paupérrima situación económica y la necesidad de cobrar un subsidio que la propia organización gremial gestiona (en el caso de la CTA).

En conclusión, lo que aquí se expresa es la perpetuación de la perspectiva individualista que se impone en ocasiones sobre la lucha colectiva, y no por una cuestión ideológica, sino material. La necesidad de conservar el precario puesto de trabajo ante la falta de opciones y los desamparos legal y gremial impera en los obreros cooperativizados muchas veces allí donde la superación de su precarización laboral es ya una convicción irrefutable.

Sintetizando lo expuesto a lo largo de este capítulo, el ciclo de protesta abierto en 1997 fue aprovechado por el sector empresarial, el cual mediante sus alianzas con funcionarios de gobierno -y, en el caso de la burguesía fresquera, también con gremios y trabajadores- y sus acciones contra la reducción de las capturas, logró recomponerse hacia 2002 superando la crisis del recurso pesquero. La diversificación de los commodities con la inclusión y la suba del precio del langostino contribuyó a la recuperación de las ganancias empresariales. Por otra parte, la tregua mantenida entre empresarios y el SOIP mientras perduró la disputa interburguesa permitió mantener las condiciones de superexplotación mediante la precarización laboral impuesta previamente. El aumento en las ganancias empresariales sostenido año tras año hasta el final del período en 2012 terminó de sellar la victoria empresarial, cuyas concesiones hacia la clase obrera durante ese lapso se basaron en sus propias reglas. 
En cuanto al campo de la disputa de clases, vemos que el contexto de la crisis de la merluza y el conflicto interburgués que generó configuraron una "situación extraordinaria" (Tilly, 1993) pero cuyo aprovechamiento por parte de los sectores más movilizados -los trabajadores de las cooperativas o desempleados- no redundó en un cambio en su situación laboral; aunque en el plano gremial sí obtuvieron la victoria de una de las organizaciones que los nucleaban, cuyos líderes ingresaron en la conducción sindical. Luego del año 2002, en un primer tiempo la nueva dirigencia gremial unificó en una sola medida -la huelga- las luchas de los sectores registrados y no registrados. Sin embargo, la tendencia hasta el final del período fue la desmovilización luego de obtenerse el reclamo salarial de los obreros en relación de dependencia, mientras que la demanda de blanqueo aún se ubica entre los límites de lo insatisfecho y lo imposible dentro de la lucha obrera. Los cambios en las conducciones sindicales y en los convenios de contratación vigentes no han solucionado los problemas estructurales de fondo signados por la inestabilidad, la superexplotación, la precarización laboral y el riesgo de desocupación. A estos problemas se les agregó, sobre los últimos años abordados, la actualización de listas negras que expulsan definitivamente a los trabajadores precarizados de cualquier tipo de contratación en la industria pesquera, listas cuya confección se basa en la desprotección ante participación en acciones de rebelión y resistencia.

La disputa interburguesa continúa vigente en forma latente y silenciosa, dada la configuración del mercado mundial que actúa determinando ciertos límites para las pequeñas y medianas empresas e impulsando a los grandes grupos económicos a una mayor concentración y monopolización. En este sentido, si bien actualmente no se expresan abiertamente grandes conflictos interempresariales, persiste la tendencia de acrecentamiento de la brecha entre empresas grandes y pequeñas, llevando a estas últimas al límite marcado por el cierre por quiebra o la absorción. El recambio en la conducción sindical no guardó consolidación sino nuevas crisis, aunque acrecentó niveles de participación en determinadas medidas y contextos de lucha. A pesar de agrandar su campo de representación gracias a la afiliación de trabajadores registrados bajo el convenio Pyme, aun no pudo incidir fuertemente en la dualización de la fuerza de trabajo que afecta a la rama. En este sentido sigue primando la división entre "trabajadores de primera" y "trabajadores de segunda" que se expresan en diferentes condiciones de trabajo y de contratación, distintos niveles de inestabilidad laboral y, por ende, de explotación y opresión por parte de la patronal.

En cuanto a la persistente pasivización y concepción paternalista de los trabajadores en relación con la participación gremial, creemos que solo un importante cúmulo de nuevas experiencias de lucha sindical que redunden en mayor unidad obrera y por ello contrasten con los desprestigiados recuerdos de la antigua conducción del SOIP -la que alguna vez luchó y obtuvo el CCT №161/75-, pueden reactualizar la confianza de las bases obreras en las acciones de lucha y dispositivos asamblearios que redunden en organización, tanto en consonancia como en discrepancia con la conducción gremial. 
La interpenetración de estos campos de disputa es fundamental para la comprensión de la conflictividad obrera del período, la cual posibilita analizar cómo las acciones de lucha obrera en torno al conflicto generado por la crisis del recurso pesquero se imbrican con las condiciones materiales propias de la industria pesquera, incluyendo la crisis económica interempresarial y la crisis de representación gremial. El carácter irresoluto de las principales demandas obreras contra el capital provoca que estos escenarios no dejen de repetirse, reapareciendo sujetos, organizaciones y formas de lucha. Por ello la actualización salarial y la registración laboral continúan siendo los pivotes que configuran la conflictividad obrera de la industria pesquera marplatense, en un contexto signado por la precarización e inestabilidad laboral con un constante riesgo de desocupación, que configura tendencias individualistas que conspiran contra la organización y lucha obreras.

En relación a la organización, vemos que a pesar de las críticas resurge como rasgo general en los discursos obreros un anhelo expresado hacia la dirección sindical, que es justamente un anhelo de una dirección política que combata a la patronal, que no actúe contra los obreros y que se ponga a la cabeza de las luchas. Este anhelo coexiste con la decepción y la visión desprestigiada de las conducciones sindicales que los obreros de la pesca consolidaron en los 90, con la derrota masiva que significó la proliferación de cooperativas fraudulentas y otros formatos que se tradujeron en el empeoramiento de las condiciones de trabajo y contratación con respecto a antaño. En este punto, vemos que la falta de participación sumada a las decepciones decantó en una concepción paternalista de la conducción sindical, impresa en varios puntos del discurso obrero, lo cual actúa como obstáculo para la masificación y unidad en las acciones conflictivas.

Sin embargo, las bases obreras de la industria pesquera han demostrado iniciativas de lucha tanto espontáneas y con alto grado de combatividad como duraderas y pacientes. A los trabajadores de la industria pesquera no les ha faltado "activismo", incluso sin pertenecer a una agrupación puntual. Por lo tanto, a partir del análisis del accionar y el discurso obrero vemos varias concepciones o tendencias que coexisten entre los trabajadores de la industria pesquera. Por un lado, una pasivización obrera ligada al paternalismo con respecto a la dirigencia que se pivotea con un activismo por propia iniciativa. Por otro lado, la contraposición entre la resignación ante las condiciones precarias de trabajo impuestas por la patronal enlazadas con una impotencia de la organización gremial y obrera para arremeter contra ellas, y una exaltación de las posibilidades de lucha obrera -con o sin la conducción gremial- para enfrentar al capital y sus condiciones. Vemos que estas tendencias se expresan de modo pendular en las prácticas de lucha, prevaleciendo una u otra de acuerdo a la configuración de cada situación puntual, en la que el vínculo con la dirigencia y el papel que asume la misma entran en juego, así como también la implicación de otras organizaciones o facciones en las disputas puntuales, conformándose diversas fuerzas sociales obreras en pugna. Asimismo, la debilidad o fortaleza del empresariado, la intervención estatal y la situación del 
recurso pesquero también inciden en la conformación de las constelaciones conflictivas en la industria pesquera, y al papel que juega su sector obrero más precarizado.

En el capítulo siguiente nos abocaremos a las subjetividades obreras inherentes a los trabajadores de las cooperativas que se conformaron en el marco de las dos empresas pesqueras recuperadas en Necochea. Veremos los contrapuntos con el caso marplatense y también características propias, analizando cada uno de los procesos, las acciones conflictivas emprendidas, los vínculos con el gremio que los nuclea y la conformación de fuerzas sociales obreras en ambos casos. 


\section{Capítulo IV}

La resistencia obrera necochense al desguace del sector industrial pesquero (2010-2012) 
En capítulos anteriores vimos que, en la ciudad de Necochea, luego de cuatro décadas de progresivo desmantelamiento de la industria pesquera mediante el cierre progresivo de las más de 20 plantas de procesamiento de pescado que hubo en los 70, actualmente sobreviven del total de ese conjunto solo dos empresas pesqueras recuperadas. Ambas se originaron a partir de la quiebra de dos firmas radicadas en la ciudad durante la década del 70 e iniciaron sus procesos de recuperación en el año 2011. La Recuperada proviene de Industrial Pesquera S.A., dedicada al procesamiento de pescado fresco para exportación. Engraucoop proviene de Engraulis S.A., empresa que realizaba conservas de anchoa también con destino principalmente extranjero.

En ambas unidades productivas acontecieron secuencias típicas de la generalidad de los procesos de recuperación propios de la historia reciente argentina: atrasos salariales, retiro inusual de materia prima, anuncio de ingreso a concursos de acreedores y quiebra, despidos sin indemnizaciones, abandono patronal. En ambos casos también un grupo de trabajadores emprendió la salida autogestiva, ocupando la planta de procesamiento y reanudando la producción. Como sucede en la mayoría de este tipo de emprendimientos obreros, conformaron cooperativas de trabajo a fin de poder gestionar subsidios, ingreso a programas estatales y también guardar el carácter jurídico necesario para solicitar los permisos provisorios para la continuidad laboral inmediata y la expropiación de la unidad productiva.

El primer proceso en concretarse fue el de la Recuperada, donde prevalecieron los trabajadores de género masculino. En el segundo proceso de recuperación, Engraucoop, la gran mayoría fueron mujeres. En los dos casos, fue una minoría la que dio los primeros pasos y finalmente llevó a cabo la recuperación de las empresas, contando inicialmente con un importante apoyo comunitario. La Recuperada se conformó con 8 empleados - 6 varones y 2 mujeres- de los más de 50 que entre efectivos y temporarios formaban parte de Industrial Pesquera. En Engraucoop el colectivo obrero inicial fue de 20 trabajadores, 17 mujeres y 3 hombres, que anteriormente cumplían en su mayoría funciones vinculadas al área de producción de Engraulis, donde se desempeñaban más de 100 empleados entre efectivos y temporarios.

En las páginas que siguen analizaremos estos casos tomando como tópicos a las subjetividades obreras y las estrategias laborales, interpretadas en clave sociohistórica. Comenzaremos con una síntesis de la caracterización del movimiento de recuperación de empresas en Argentina, articulado luego con un breve -en relación con su vasta extensión- resumen analítico de correlatos y precursores tanto a nivel nacional como internacional. Esta articulación nos permitirá situar de forma contextual a los procesos actuales y a la vez delimitar lazos y rupturas con experiencias similares en términos diacrónicos y sincrónicos. Tanto los anudamientos como los quiebres con respecto a otros procesos, en apariencia similares, en otros marcos temporales y espaciales, nos aportarán a la caracterización del actual movimiento de empresas recuperadas en Argentina y de las experiencias de la industria pesquera aquí analizadas. 
Cabe destacar que tanto La Recuperada como Engraucoop fueron las dos primeras empresas pesqueras recuperadas, sumándose luego un tercer caso en la ciudad de Mar del Plata en una fecha posterior al período analizado en esta tesis doctoral. La conformación de cooperativas de trabajo por iniciativa obrera es un modelo atípico en la industria pesquera nacional actual que, como vimos, se encuentra inundada de cooperativas fraudulentas. Esto procesos se sucedieron en un contexto de creciente concentración de este sector económico, en el que prima la comercialización mediante exportación de materia prima procesada y sin procesar con destino -no exclusivo, pero sí importante- hacia grandes potencias mundiales. Entonces, nos preguntamos: ¿Cómo fue posible el surgimiento empresas pesqueras recuperadas en este contexto, en un momento alejado y distante de la más importante oleada de empresas recuperadas a nivel nacional y en un sector económico en el que predomina el capital transnacional? En gran medida se explica por las subjetividades obreras aquí en cuestión, subjetividades anudadas a un determinado marco sociohistórico y también comunitario. Pero no nos adelantaremos a su análisis sin antes ahondar en determinadas pistas a la luz de un rastreo histórico, ya que todo proceso humano es producción nueva en términos actuales y a la vez resultante de otras experiencias socioculturales, al mismo tiempo escritura y reescritura.

Seguidamente, nos centraremos en determinadas interpretaciones académicas acerca de la vinculación entre recuperación de empresas y subjetividades obreras, y también desarrollos que aporten a la caracterización de las subjetividades obreras de la industria pesquera. Es decir que prestaremos especial atención a los significados, las valoraciones, las prácticas y las expectativas de los actores, consideradas como indisociables de las relaciones sociales, de las relaciones de producción, y en definitiva de las relaciones de clase. A través del análisis de los discursos y de las prácticas obreras buscaremos ahondar en esa articulación entre psiquismo y experiencia, considerando a la subjetividad como producto y productora de los procesos sociales en los que está implicada. Retomaremos aquí nuestra definición que parafrasea a Marx y Engels en La Ideología Alemana (1846: 59): "las circunstancias hacen a los sujetos tanto como los sujetos hacen a las circunstancias", es decir, un sentido histórico de las subjetividades, quienes habilitan o inhabilitan acciones en un sentido disruptivo o reproductivo.

Luego realizaremos una crónica analítica de los procesos de recuperación en cuestión, tomando en cuenta determinados tópicos teórico-metodológicos tales como: contexto de surgimiento, posicionamientos obreros, sindicales, comunitarios, gubernamentales, empresariales, y su mutua interrelación. En uno de los apartados finales describiremos en forma desagregada las acciones conflictivas implicadas en ambas recuperaciones, y en otro profundizaremos en la conformación de los colectivos obreros en cuestión, focalizándonos en su desarrollo a través del tiempo y en las expresiones de la subjetividad obrera propia de los trabajadores de empresas recuperadas pesqueras. 
En su conjunto, tanto este panorama general como su desglosamiento en los distintos planos de análisis, nos permitirán ahondar en el entrelazado social, comunitario y subjetivo propio de ambos procesos, a fin de ampliar lo más posible el estudio de las "constelaciones conflictivas" habitadas por los sujetos de la industria pesquera nacional, bonaerense y necochense.

\section{Los procesos de recuperación de empresas por sus trabajadores en Argentina. Generalidades y perspectivas en clave subjetiva.}

En el Capítulo 2 vimos que el presente movimiento de empresas recuperadas comenzó a manifestarse en Argentina desde los 90 y cobró mayor auge durante los años que siguieron inmediatamente a la crisis neoliberal del año 2001, y que el mismo se caracteriza por el hecho de que trabajadores asalariados de unidades productivas en crisis, ante el cierre o eventual cierre de las mismas deciden y logran continuar con la producción y comercialización bajo su propia gestión, asumiendo en la mayoría de los casos la forma organizativa y legal de Cooperativas de trabajo. La utilización del método de la ocupación del lugar de trabajo como estrategia de lucha por reivindicaciones referidas a las condiciones laborales o al incumplimiento de derechos de los trabajadores guarda una vasta tradición en la historia del movimiento obrero. En los casos de ERT, esta práctica fue adoptada a fin de garantizar la continuidad laboral expropiando de forma temporaria los medios de producción capitalistas. Otro formato de acción obrera que insiste en los casos de recuperación de empresas es la realización continuada de asambleas, las cuales también forman parte de la tradición del obrero organizado. El matiz particular que adquieren en los procesos de recuperación de empresas es que las mismas habilitan instancias de deliberación democrática asentadas en vínculos igualitarios entre pares no solo vinculadas a acciones de lucha en el marco de un conflicto con la patronal, sino también sobre el mismo proceso de producción, las condiciones de trabajo y la circulación de lo producido. En este sentido se anudan con la supresión de la figura del patrón asentada en la desigualdad entre burguesía y proletariado, entre la clase poseedora de los medios de producción, compradora de fuerza de trabajo y la clase desposeída de medios de producción, vendedora de fuerza de trabajo. La instancia asamblearia, entonces, no solo nos indica la realización de una reunión puntual, sino que nos habla de la instalación de cierta lógica obrera de toma de decisiones y de una vinculación basada en la igualdad en cuanto a las posibilidades de participar en el funcionamiento cotidiano de la unidad productiva y la empresa obrera.

Este masivo movimiento de recuperación de empresas nació de un contexto de precarización y vulneración sociolaboral (altas tasas de desempleo estructural, pobreza e indigencia) en el que la situación de inminente desempleo significaba engrosar las filas de desocupados sin posibilidad de encontrar otro trabajo en el mercado ni de cobrar indemnización ni seguro laboral que asegure la reproducción de las mínimas condiciones de subsistencia obrera. A partir de este contexto, 
algunos autores enmarcan estos casos como parte de una estrategia defensiva de los obreros. Sin embargo, dentro de un conjunto de miles de empresas en proceso de cierre, hasta la actualidad solo poco más de trescientas fueron recuperadas, son muchos más los casos en los que los trabajadores no emprendieron dicho proceso de recuperación que los que sí lo hicieron. Esto genera interrogantes acerca de la existencia de recursos y condiciones que favorecerían el proceso que de no estar presentes no podrían hacer efectivo el mismo: recursos políticos, organizativos y subjetivos que posibilitan la acción colectiva orientada a la autogestión (Brunet y Pizzi, 2011). En el sector industrial pesquero, como vimos, la oleada de quiebras que incluyó grandes, medianas y pequeñas empresas inició en el año 1991, con la quiebra de la empresa Ventura (Yurkevich, 2012). Esta situación se reprodujo hasta el final del período estudiado, pero sin embargo no se vieron procesos de recuperación hasta el año 2011, prevaleciendo la reinserción de los miles de obreros expulsados por despido mediante la tercerización laboral en cooperativas fraudulentas.

Como antecedentes inmediatos de la recuperación de empresas a nivel nacional, vemos que, durante la década del 80 , la generalidad de conflictos ligados a una quiebra empresarial finalizaba cuando los propietarios pagaban las indemnizaciones -en un tiempo relativamente cercano al momento de los despidos. Aquí, el destino obrero oscilaba entre la reinserción laboral y la puesta en marcha de un emprendimiento personal con el dinero obtenido de la indemnización. En esta mayoría disintieron algunos pocos casos, algunos de ellos sintetizados en el capítulo 2. En la década de los 90 emergieron nuevas experiencias que luego se consolidaron como los antecedentes más inmediatos del fenómeno expansivo de recuperación de empresas post 2001 en Argentina. El frigorífico Yaguané, ubicado en La Matanza, fue ocupado por sus trabajadores a partir del anuncio de despido de 250 de los asalariados. Otro caso fue el de Gip Metal, cuyo conflicto inició en el año 2000 a raíz de una quiebra fraudulenta, en el cual los trabajadores se contactaron con la Federación de Cooperativas de Trabajo, entidad que impulsó la recuperación. Luego, otra experiencia que fue hito del movimiento actual de empresas recuperadas argentino es la fábrica ceramista ZANON/Fasinpat en Neuquén, también iniciado en el año 2001. Este proceso conjugó la acción de base de los trabajadores con experiencias sindicales combativas, alianzas con grupos de desocupados, estudiantes universitarios, organizaciones políticas y otros actores comunitarios. Al ser un caso que se incluye dentro del período en el cual el Estado reprimió las ocupaciones de empresas, los obreros debieron resistir varios intentos de desalojo, así como ocurrió en el caso de la textil Bruckman en la ciudad de Buenos Aires. En el caso de Zanón, vemos además que la militancia sindical y política previa de algunos trabajadores en la izquierda trotskista fue clave para la consecución del proceso de recuperación. A su vez, a diferencia de la crisis de rentabilidad que golpeaba a la mayoría de ERT, en sus primeros años el volumen de comercialización de Zanón se conjugó con la obtención de materia prima y el relativo buen estado de las maquinarias, todo lo cual permitió mantener una productividad bajo gestión obrera 
tal que les permitió incorporar nuevos trabajadores y mantener un alto número de integrantes.

Andrés Ruggeri (2005, 2009, 2010 y 2014) determina que las recuperaciones de empresas bajo gestión obrera no se limitaron a los años más álgidos de la crisis, sino que la emergencia de nuevos procesos fue ininterrumpida hasta el último año relevado. Veamos la progresión numérica de empresas recuperadas a nivel nacional tomando como base estos relevamientos:

\section{Gráfico №12. Evolución de la cantidad de casos en base a los datos de los cuatro relevamientos realizados por el Programa Facultad Abierta de la UBA}

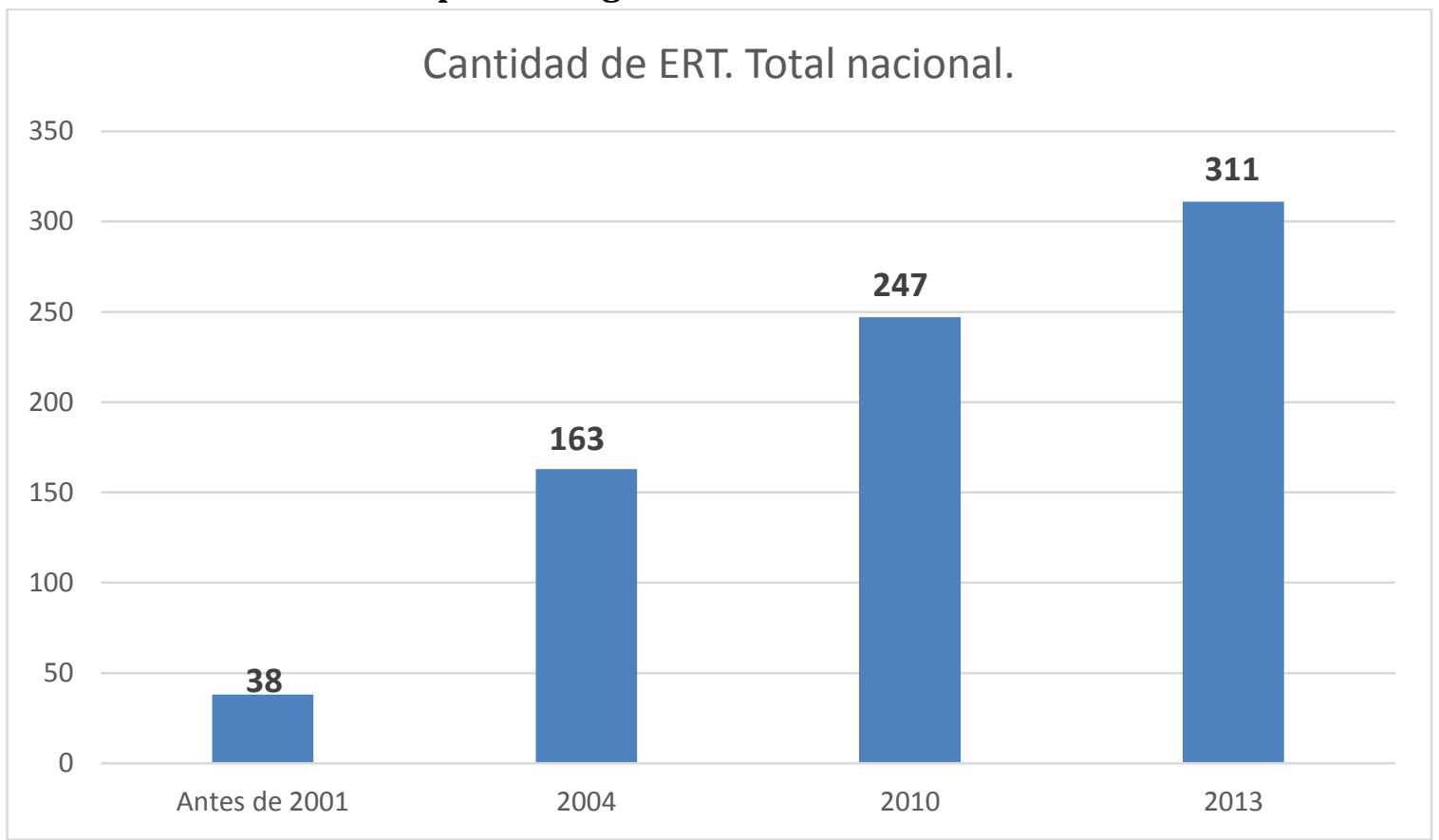

Fuente: Extraído del Informe del IV Relevamiento de Empresas Recuperadas en Argentina (2014),

En este gráfico vemos que una vez superados los momentos de mayor recesión, entre 2004 y 2013 se sucedieron al menos 148 nuevas recuperaciones ${ }^{74}$. Esto nos habla de una perdurabilidad tanto del movimiento de recuperación de empresas argentino y también de ciertos rasgos de la crisis neoliberal en la economía mundial que continúa provocando cierre de empresas por quiebra o fraude. La progresión en aumento del número de ERT a través del tiempo muestra, además, su inclusión definitiva dentro del repertorio de formas de lucha obrera contra las consecuencias laborales del capitalismo en la actualidad.

En los momentos iniciales de los conflictos que luego desembocan en empresas recuperadas, un grupo de trabajadores toma la decisión de quedarse en el lugar de trabajo y emprender la producción de forma colectiva y autogestiva, creando nuevas formas de organización, nuevos vínculos entre los sujetos, nuevas representaciones

\footnotetext{
${ }^{74}$ Aclaramos que se sucedieron "al menos" 148 casos porque el Programa Facultad Abierta releva solo unidades que al momento del relevamiento continúan en funcionamiento.
} 
y significantes en torno al trabajo. También, surgen nuevas prácticas, todo lo cual produce nuevas subjetividades obreras, una transformación cualitativa "que los impulsó a desafiar su destino de desafiliación social" (Brunet y Pizzi, 2011:189). Durante el proceso -y como consecuencia del mismo- se conforma un colectivo de trabajo autónomo que reconfigura las subjetividades obreras que lo integran, resignificando y revalorizando sus actividades laborales y su lugar en las tramas comunitarias, modificando la dinámica grupal, las lógicas de trabajo y los vínculos entre compañeros, basados en una mayor horizontalidad y democracia directa, procesos subjetivos que implican "mayor afirmación, independencia y protagonismo" (Fernández y col., 2006:237). A su vez, el atravesamiento de las recuperaciones supone en los sujetos procesos de cuestionamiento a la ideología dominante y concientización, posibilitando la construcción de alternativas distintas a las del orden hegemónico. A modo de ejemplo, la posibilidad de situarse como obreros capaces de llevar adelante un emprendimiento productivo conlleva el cuestionamiento y la supresión del prejuicio de la necesidad del patrón/capitalista. Además del colectivo de trabajo autogestivo, es destacable la participación de otros actores sociales que influyen y en muchos casos posibilitan la recuperación de empresas. Entre ellos se destacan organizaciones como los sindicatos, organizaciones políticas y asambleas barriales, que actúan como promotores sociales aportando conocimientos, experiencia organizativa, recursos jurídicolegales, y/o siendo mediadores de las empresas recuperadas con el Estado. Luego, personificaciones sociales tales como vecinos, estudiantes y otros trabajadores que forman parte de la comunidad laboral o barrial también se vinculan a estas luchas obreras en términos de acompañamiento, apoyo y presencia en las diversas acciones conflictivas. La recuperación de empresas es entonces un proceso organizado bajo una dirección obrera que se asienta en lazos comunitarios en el que la expansividad por fuera del colectivo obrero que emprende la lucha se convierte en un factor fundamental, cuya existencia posibilita su iniciación, desarrollo y continuidad. Esta expansividad implica planos de apoyo directo como indirecto, a través de la construcción de fuerza social, consenso y legitimidad en las tramas comunitarias y político-institucionales en las que se hallan insertos los colectivos obreros en su cotidianeidad.

En cuanto a la figura legal de Cooperativas de Trabajo, adoptada por la mayoría de las empresas recuperadas la misma no solo responde a la necesidad de interacción con las autoridades públicas para "obtener el reconocimiento jurídico necesario que le permita continuar con la producción” (Brunet y Pizzi, 2011:269), sino que, a su vez, muchas organizaciones que surgieron de la articulación de distintas empresas recuperadas, también fomentaron la conformación de cooperativas como salida legal para solicitar a los jueces intervinientes la autorización para el uso de las instalaciones hasta tanto se resuelva la quiebra y también para realizar el pedido de expropiación. Con la creciente articulación de estas agrupaciones con el Estado, fundamentalmente a través del INAES y del MTEySS, la conformación de las 
cooperativas también se convirtió en requisito para la solicitud de subsidios, planes e ingreso a programas de financiamiento y asistencia estatal.

En los años que mostraron el mayor auge del movimiento de empresas recuperadas cobraron mayor relevancia estos agrupamientos interfabriles, entre los que se destacaron por su incidencia el MNER (Movimiento Nacional de Empresas Recuperadas) y el MNFRT (Movimiento Nacional de Fábricas Recuperadas por sus Trabajadores). Luego otros procesos se vincularon también a la FECOOTRA (Federación de Cooperativas de Trabajo), la FENCOOTER (Federación Nacional de Cooperativas de Trabajo de Empresas Reconvertidas), la FACTA (Federación Argentina de Cooperativas de Trabajadores Autogestionados), la ANTA (Asociación Nacional de Trabajadores Autogestionados) y la Comisión Nacional de Empresas Recuperadas y en Lucha. Esta última agrupación se vinculó con partidos de izquierda, mientras que las tres federaciones son producto del agrupamiento de varias cooperativas y la ANTA fue impulsada por la CTA. Siguiendo a Ghigliani, mientras la mayoría de estas agrupaciones se esforzaron por mantener alianzas con el Estado y su legalidad, y declararon abiertamente que no buscan ser una amenaza para el capital, también se expresó en forma minoritaria otra posición, a través de ERT que se integraron en la Comisión Nacional de Empresas Recuperadas y en Lucha, que se caracterizó por una mayor confrontación con la burguesía y el Estado (Ghigliani, 2003).

Se observa una paulatina pérdida de la preponderancia del conjunto de entidades aglutinadoras de ERT con respecto a su participación en sus primeros años. De acuerdo al Informe del VI relevamiento de ERT realizado por el Programa Facultad Abierta (UBA), para el año 2013 se observa una mayor dispersión y heterogeneidad organizativa, con un marcado descenso en el nivel de organicidad (variable que mide la participación en agrupamientos que incluyen empresas recuperadas), del 78\% en 2010 al 48\% en 2013 (2014:58). Para el 2013, entonces, se observa un descenso en la preminencia organizativa y en particular en la preponderancia del MNER, con un mayor peso del MNFRT y la FACTA en el aglutinamiento de ERT. Asimismo, a pesar de esta disminución en la articulación interERT, se continúan creando o retomando alianzas al calor de las luchas por reclamos puntuales al gobierno nacional, o al momento de tratamiento en el Congreso de las leyes de expropiación.

Desde nuestra perspectiva, ubicamos esta disminución en la organización entre empresas recuperadas en correlación con las dificultades de supervivencia y rentabilidad que cada empresa debe enfrentar en el mercado. A pesar de estar compuestas íntegramente por obreros es inevitable la contradicción que conlleva este tipo de empresas con el sistema capitalista y el modelo neoliberal, que acentúa una marcada tendencia al aislamiento de cada fábrica en su destino particular. La lucha por la preservación del puesto de trabajo se trastoca por la lucha por poder trabajar lo suficiente y/o vender los suficientes productos como para alcanzar ingresos mínimos que permitan la subsistencia obrera. Por ello la tendencia al aislamiento no puede desvincularse de los problemas y obstáculos materiales que 
surgen en estas empresas, vinculados a las condiciones objetivas estructurales del sistema capitalista.

En cuanto al vínculo entre el Estado y las ERT vemos que, en primer lugar, el desarrollo de políticas de promoción de la llamada "economía social" y del autoempleo implementadas se basaron en la adopción de experiencias asociativas que se venían desarrollando desde distintos sectores obreros y que proponían soluciones parciales e improvisadas, pero originales, a la crisis (Abramovich, 2008). Para el caso argentino, de acuerdo a Calloway, Colombari e Iorio (2015) tanto los gobiernos nacionales como los provinciales y municipales han desarrollado políticas para fortalecer, formalizar y financiar las múltiples experiencias de trabajo asociativo -entre ellas, las empresas recuperadas- desde un relato que ensalzaba el valor del trabajo como espacio para la reproducción material y también como articulador social y comunitario. Desde esta perspectiva se implementó el denominado Programa de Trabajo Autogestionado (PTA) a fin de asistir a las empresas recuperadas en cuanto a sus problemas de rentabilidad, capacitación y comercialización.

De acuerdo al Informe del Programa de Trabajo Autogestionado del Ministerio de Trabajo, Empleo y Seguridad Social de la Nación del mes de noviembre del año 2013, hasta esa fecha habían sido relevadas un total de 786 unidades productivas destinatarias del programa, de las cuales 318 eran empresas recuperadas y 468 no provenían de procesos de recuperación. En su conjunto involucraban aproximadamente 28.000 trabajadores en todo el país. Si tenemos en cuenta que para el año 2012 de acuerdo al Ministerio de Trabajo existían 323 empresas recuperadas en el país (MTEySS, 2012), vemos que casi la totalidad de las mismas fueron incluidas en este programa recibiendo algún tipo de financiamiento o recurso -las empresas pesqueras recuperadas estudiadas también recibieron fondos de este programa en su período inicial. Esta información nos permite deducir que las dificultades de rentabilidad de las empresas recuperadas son problemáticas generalizadas y continuas para el universo de este tipo de empresas de autogestión obrera.

En un sentido similar, Hopp (2012) destaca las condiciones en las que se desarrolla el trabajo asociativo y autogestionado y las dificultades en la generación de ingresos de quienes integran las unidades productivas, que limitan el alcance de las políticas públicas, en cuanto a su incidencia en las posibilidades de reproducción de la propia unidad productiva y su expansión. Aquí entra en juego una tensión, vinculada con la dependencia tanto del financiamiento estatal como del sector capitalista, para la obtención y el desarrollo de tecnologías que favorezcan la innovación y las condiciones de reproducción y ampliación de las formas de trabajo alternativas. Empalmando esta visión con los planteos de Calloway, Colombari e Iorio (2015) sobre la inexistencia de una figura específica para los obreros de empresas recuperadas, que los diferencie de los monotributistas o cuentapropistas, provoca que, por ejemplo, tengan muchas dificultades para el acceso a créditos, a los que los propietarios de empresas pueden garantizar con la propiedad de sus bienes 
fungibles. Las apremiantes necesidades de reproducción de sus trabajadores y dificultades que encuentran estos emprendimientos llevan a que la preocupación principal de los obreros y de los agentes que implementan las políticas socioproductivas desemboque en una lógica pragmatista y cortoplacista, que no impide el fracaso de este tipo de emprendimientos luego de unos pocos años de funcionamiento. Esto conduce a reafirmar nuestra consideración de que las empresas recuperadas y similares experiencias de la "Economía Social" constituyen soluciones precarias y temporarias al desempleo estructural.

Por su parte, Dinerstein (2007) realiza un análisis específico sobre el impacto del Programa Trabajo Autogestionado (PTA) aplicado en casos de empresas recuperadas. Centra su argumentación alrededor de la premisa de que el PTA fue un instrumento que provocó la institucionalización y la despolitización de los procesos de gestión obrera. Desglosando su razonamiento, en primer lugar, la autora señala tres momentos correspondientes a tres posicionamientos gubernamentales en cuanto a las ocupaciones de empresas por parte de sus trabajadores en un contexto de crisis y cierre empresarial. En un período previo a la expresión de la crisis neoliberal en 2001, las recuperaciones recibieron apoyo explícito de otras organizaciones sociales, pero no del gobierno. Inmediatamente luego de la crisis, las autoridades intentaron desmantelar las tomas a través de la represión e intentos de desalojo, a lo cual los trabajadores respondieron de forma combativa, resistiendo, expulsando a las fuerzas policiales e iniciando determinados procedimientos legales para conservar las empresas recuperadas, y también se fortaleció su marco de apoyo social y político. A partir del 2003, inicia la etapa marcada por la búsqueda del consenso sin represión por parte del Estado, buscando la contención de las múltiples formas de conflictividad social. En este marco, el programa PTA fue lanzado en 2004 para apoyar directa e indirectamente a las cooperativas de trabajadores, y dentro de ellas a las enmarcadas en empresas recuperadas.

Para los administradores del programa, el PTA tiene la intención de "Fortalecer la autogestión mediante la prestación de una serie de servicios, desde Asistencia técnica y financiera a proyectos concretos de corto y mediano plazo" (MTEySS, Entrevista 1, 16 de agosto de 2005). No obstante, Dinerstein recuerda que, aunque el Estado no puede resolver las contradicciones inherentes a las sociedades capitalistas, puede, sin embargo, "contener el impacto político de esas contradicciones" (Clarke, 1992: 136) a través de la formulación de políticas. En este sentido, el Estado capitalista vela por los intereses de la burguesía y a través de determinadas concesiones busca contener los conflictos sociales derivados de la resistencia de la clase trabajadora ante los efectos de las crisis que se descargan sobre ellos. El PTA refleja tanto una renovación en la formulación de políticas como un cambio en la actitud del movimiento de las empresas recuperadas, que luego de 2003 manifestó una disposición hacia el apoyo institucional, resignando ciertos reclamos más radicales a fin de subsistir y permanecer en las unidades productivas. Para Dinerstein, entonces, la posición gubernamental post 2003 tuvo como objetivo 
principal despolitizar las acciones más radicales al ofrecer este programa a los trabajadores.

Además del PTA, situándonos en la esfera estatal jurídica, vemos que no hubo una política uniforme en relación a los procesos de recuperación. Lo que primó ha sido el activismo puntual de cada ERT para obtener la expropiación, la cual ha sido lograda en pocas ocasiones mediante un gran caudal de acciones conflictivas, un importante apoyo comunitario y asesoramiento jurídico adecuado. Son muchos los casos que quedan atorados en callejones jurídicos sin salida, o bien en los que por no cumplimentar alguno de los puntos de la ley de expropiación se procede a la sentencia de subasta del bien inmueble. En los últimos tiempos no han faltado ejemplo de vetos a las leyes de expropiación dictadas ${ }^{75}$. La nebulosa jurídica que implica a las ERT, basada principalmente en la inexistencia de una normativa que contemple las especificidades del sector y favorezca la expropiación obrera de los bienes inmuebles y los medios de producción, hace que la imprevisibilidad e incertidumbre envuelvan a todos y cada uno de los procesos, cuyo cauce legal se vuelve impredecible. Actualmente, tanto las leyes de expropiación como la ley de concursos y quiebras se encuentran configuradas como normativas que, con sus agujeros legales, enmarcan la recuperación de las empresas (Schujman, 2010:12) ${ }^{76}$. Sintetizando lo expuesto vemos que el Estado ha actuado de forma inconstante en este tipo de procesos, mostrando discrepancias entre el gobierno nacional, los gobiernos provinciales y municipales, y también entre los poderes ejecutivo, legislativo y judicial. Si bien la lógica predominante fue la contención social a través de planes, programas y otras políticas públicas acotadas en tiempo y extendidas en alcance, lo que termina imperando es el desligamiento del Estado con respecto a la cotidianeidad y el destino de los procesos obreros de recuperación. Al respecto citamos la posición de Ruggeri (2014) quien expresa que:

\begin{abstract}
Además de un sistema judicial hostil y un legislativo muy vulnerable a los cambios de humor de la "opinión pública", el Poder Ejecutivo en sus distintos niveles no ha desarrollado hasta el momento más que instrumentos de ayuda parcial y de efectividad variable. Algunos subsidios llegan a las ERT y representan un apoyo importante, aunque no decisivo (a pesar de la opinión contraria que suelen tener los funcionarios que otorgan estos beneficios). Pero hasta el momento no hay una política pública definida ni consecuente con una concepción que fortalezca la autogestión de los trabajadores. Existe, en cambio, una carencia de marco jurídico que, por una parte, deja demasiadas cosas libradas a la interpretación de los jueces y, por la otra, coloca a las ERT en una situación de ilegalidad o precariedad (2014:45) ${ }^{77}$.
\end{abstract}

\footnotetext{
75 Ejemplos de ello son los vetos del presidente Macri a la expropiación obtenida por el Hotel Bauen en septiembre de 2016, política que en 2017 fue replicada por la gobernadora Vidal hacia las empresas recuperadas Cintoplom, la Cooperativa de Precisión Limitada (CDP), la metalúrgica Raimat de Quilmes y la fábrica recuperada Petinari. Esta última había obtenido la expropiación en el año 2015 por unanimidad en ambas cámaras de la legislatura bonaerense.

76 Schujman, M. (2010). Políticas Públicas para el tercer sector: Empresas Recuperadas y Cajas de Crédito Cooperativas. Facultad de Ciencias Económicas de la Universidad de Buenos Aires.

${ }^{77}$ Revista del Plan Fénix, año 5, №38, septiembre 2014.
} 
En consonancia con esta posición, vemos que en la mayoría de los casos los trabajadores obtienen concesiones, asesoramiento y financiamiento estatal en la primera etapa autogestiva, y luego quedan abandonados a su suerte en el mercado. Estas dificultades se traducen en incertidumbre, bajos ingresos, autoexplotación o subempleo, incluso la aceptación de tercerización laboral por parte de una empresa tradicional como método de subsistencia. A su vez, la larga extensión de las causas judiciales implica un desgaste extra y a su vez contribuye a la disminución de posibilidades de solicitar la expropiación. Una de las explicaciones de esta disminución se refiere a que, en muchas ocasiones, al no prosperar la empresa obrera, algunos de sus trabajadores se retiran al recibir otras ofertas laborales. De esta forma, la cooperativa pierde las dos terceras partes de ex trabajadores o acreedores, condición legal necesaria sin la cual difícilmente un juez se emita favorablemente al dictamen de expropiación.

En conclusión, el accionar estatal se ha orientado entre los polos intervencionista y laissez-faire con distintos objetivos. La intervención estuvo orientada hacia dos grandes ejes: por un lado, subsumir a las ERT en la legalidad vigente o modificar la misma de forma escueta y sin perjudicar al gran capital; por otra parte, intentar desarticular procesos mediante desalojo y represión. La modalidad lasseiz-faire fue aplicada para no tomar partido, más allá de subsidios minoritarios y programas acotados, ni en la redituabilidad económica de las ERT, ni en que sus trabajadores alcancen ingresos acordes a un salarios mínimo, vital y móvil, con los mismos derechos que un trabajador asalariado registrado. El intervencionismo se basó en la protección al capital y al sistema político imperante, mientras que el "dejar hacer" se aplicó en el sentido neoliberal de desamparar a los trabajadores y no garantizar determinados derechos laborales.

A continuación, nos parece pertinente adosar una perspectiva histórica de precursores y correlatos referidos al control obrero de la producción sobre la cual se empalma la reciente oleada nacional de procesos de autogestión obrera, ya que esta respuesta ante procesos de cierre por quiebra empresarial en el contexto de crisis neoliberal recupera elementos de la tradición de lucha obrera organizada y también de políticas gubernamentales y sindicales en diferentes coyunturas. La comparación con otras experiencias pasadas y presentes nos aportará perspectivas de análisis e interpretación del actual proceso argentino.

\subsection{Precursores y correlatos}

Precursores y correlatos de estas experiencias se produjeron en contextos diversos, que incluyen el alzamiento revolucionario de sectores obreros y populares, guerras nacionales, posguerras, gobiernos democráticos, dictatoriales y obreros. Experiencias tan disímiles como las acontecidas durante la Comuna de París, el Bienio Rojo italiano, y la revolución boliviana del 52, por citar algunos de los casos expuestos en la espesa bibliografía sobre ERT, expresa la gran heterogeneidad que 
caracteriza al movimiento, y también determinados rasgos o particularidades a partir de los cuales es posible modelizar y establecer tipologías a fin de comprender e interpretar los movimientos de recuperación de empresas en la actualidad, y en particular los procesos nacionales pesqueros que se incluyen en ellos.

Analizando esta diversidad de casos, podemos distinguir tres vertientes del control obrero de la producción. En primer lugar, una vertiente más "ofensiva” producto de un contexto de sucesivas conquistas y creciente organización resultantes de las luchas obreras contra el capital. En estas coyunturas, los trabajadores avanzaron sobre la propiedad privada y los medios de producción capitalistas, como lo muestran los casos de la Comuna de París, de los obreros de Turín y de Bolivia y los cordones industriales populares en Chile. Una segunda vertiente se vincula con la promoción estatal de la gestión obrera, considerando procesos muy diversos y contrastantes como lo exhiben los casos de la Yugoslavia socialista de Tito y la dictadura militar peruana comandada por Velasco Alvarado. En este último caso la supervisión estatal y gubernamental actuó como limitante del control obrero intrafabril, restringiendo las diferencias con relación al trabajo asalariado tradicional. Ejemplo de esta restricción fue la paradójica situación de los trabajadores peruanos que realizaron huelgas contra sus propias empresas por reivindicaciones laborales. Finalmente, una tercera vertiente es la que podemos denominar como "defensiva", es decir, la autogestión obrera ante la amenaza de desocupación en procesos de quiebra y abandono patronal. En esta categoría pueden localizarse a las empresas peruanas que fueron recuperadas por sus trabajadores luego de 1975, y también todos los casos que sobrevinieron tanto en Brasil como en Argentina desde los 80 hasta la actualidad. Sin embargo, en las últimas décadas predominan situaciones híbridas que conjugan las vertientes de defensiva obrera y promoción estatal, acentuándose uno u otro aspecto de acuerdo a cada caso particular.

Tomando en cuenta experiencias correlativas temporalmente y situadas en otras latitudes, hallamos que, en el caso de Brasil, a pesar de no haber ganado el revuelo propio del movimiento de empresas recuperadas argentino, la autogestión obrera de empresas que cierran por crisis inició varios años antes. Luego de las primeras experiencias aisladas en la década del 80, los casos crecieron aceleradamente en los 90 durante la valorización cambiaria y la apertura comercial del gobierno de Fernando Enrique Cardoso, y a partir del año 2000 la autogestión obrera brasilera continuó en un menguado pero constante crecimiento.

Dos de los primeros casos que provocaron la posterior constitución del movimiento de autogeridas brasileño fueron la industria de máquinas de escribir Remington y la fábrica de calzados Makerly, en San Pablo. En esta última experiencia es crucial la participación de miembros del Sindicato de químicos, quienes por fuera de la estructura sindical formaron la ANTEAG (Asociación Nacional de Trabajadores y Empresas de Autogestión) en el año 1994. Esta entidad en sus comienzos agrupaba 6 fábricas autogeridas y tenía la fórmula de la ocupación de los lugares de trabajo como método para negociar la continuidad de la producción en manos de los 
trabajadores. Esta organización influyó e impulsó procesos posteriores, con una fuerte articulación entre los mismos. Luego, también incidieron integrantes del sindicato de metalúrgicos, quienes en el año 2000 conformaron la UNISOL cooperativas, que rápidamente logró alcance nacional (Ghibaudi, 2004; Novaes, 2009).

En el año 1999, el gobierno de Sao Pablo estableció una alianza con la ANTEAG para que intervenga en nuevos casos de empresas en crisis y también solicitando su colaboración en la creación de cooperativas de trabajo. Aquí la autogestión brasilera tomó un viraje desde la autoorganización obrera hacia el aparato estatal, mediatizado por la organización sindical. Al igual que la experiencia venezolana que expondremos más adelante- en el caso brasilero el movimiento y las organizaciones de las empresas autogestionadas se ligan fuertemente a los gobiernos de turno, primero de Cardoso y luego del PT. Aunque desde estos gobiernos se ha promovido desde el discurso la autogestión obrera, el investigador Henrique Novaes señala que: "El Banco Nacional de Desarrollo Económico y Social da migajas a los trabajadores de las fábricas recuperadas y millones de reales para las corporaciones multinacionales" (2009:219) ${ }^{78}$.

Como expusimos anteriormente en referencia al caso nacional, las políticas públicas en estos casos están al servicio de la contención de la disrupción obrera, otorgando una salida institucionalizada al conflicto social. Por ello, la experiencia brasilera es una muestra de que la recuperación de empresas en sí misma no encierra un problema para el gran capital, pudiendo coexistir y también actuar como salvaguarda del mismo.

El caso de Colombia ilustra otro aspecto del movimiento de empresas recuperadas en Latinoamérica. En este país, las empresas de autogestión obrera tienen la particularidad de haber sido previstas, de alguna manera, por el Estado y su legalidad.

Ante la multiplicación de los cierres de empresas en los 90 como contracara de la concentración de capital, en el año 1999 el gobierno colombiano expidió la ley 550, cuyo objetivo es que las empresas no lleguen a liquidarse definitivamente y puedan ser reactivadas por sus trabajadores. La ley 550 prepara el terreno para la "dación en pago", estrategia que habilita el traspaso de bienes desde la empresa hacia los obreros, como parte de pago por las indemnizaciones en procesos de cierre por crisis financiera. La Superintendencia de Sociedades es la entidad estatal ocupada de llevar a cabo este procedimiento y también de capacitar a los trabajadores en la gestión empresarial.

Esta aparente extrañeza es analizada por algunos autores como método de resguardo del capital, explicando que muchas iniciativas de recuperación de las empresas respondieron más al interés empresarial que a la defensa de los puestos

\footnotetext{
78 Novaes, H. (2009) Capítulo 17. "Un balance de las Fábricas Recuperadas brasileñas frente a un contexto de crisis avasalladora", en Las empresas recuperadas: autogestión obrera en Argentina y América Latina, Ruggeri, Andrés (comp.). Editorial de la Facultad de Filosofía y Letras: Buenos Aires.
} 
de trabajo, sobre todo en aquellos casos en las que las empresas eran líderes en su rubro a nivel nacional:

Para el caso colombiano, la entrega fue mediada por una serie de mecanismos de trámite legal que muchas veces hicieron que el proceso liquidatorio durara varios años, período en el cual se iba descapitalizando la empresa y en el que algunas fábricas llegaron a ser insostenibles (Huertas, Dávila y Castillo, 2011: 586).

En el sector rural se llevó a cabo una forma diferente de traspaso de las empresas a los trabajadores, la cesión: cuando las mismas no eran lo suficientemente rentables los empresarios cedieron las firmas a los trabajadores nucleados en cooperativas, pero sin declararse en quiebra.

En la práctica, las recuperadas colombianas tienen los mismos problemas que anteriormente referimos, con relación a la desigual posición en la competencia con el gran capital. Los trabajadores se ven envueltos en situaciones de precarización laboral, autoexplotación y bajos ingresos, todo ello a pesar de ser ahora "dueños" de las unidades productivas. Un trabajador sintetiza su situación en una corta frase: "cuando no éramos accionistas ganábamos mucho más, ahora que somos accionistas, ganamos menos... de socio solo el nombre, pues la plata no se ve" (Huertas, Dávila y Castillo, 2011:594) ${ }^{79}$.

Desde 2002, el caso venezolano aporta otro ejemplo de la preponderancia de la promoción estatal de la recuperación de empresas en quiebra por parte de trabajadores, ya sea por iniciativa de las mismas firmas como del gobierno. En este país solo una minoría de los casos respondió a una iniciativa obrera de autogestión de empresas fallidas, mientras que la mayoría de los casos fueron producto de la intervención estatal mediante la llamada "cogestión", por la cual el Estado actúa como ente de financiamiento y como accionista directo, los trabajadores actúan como accionistas y poseedores legítimos de los medios de producción y el empresario que en algunos casos aparece como accionario de la nueva forma jurídica y en otros no:

\begin{abstract}
Según fuera el caso, el Estado concede créditos financieros a los trabajadores a través de la forma jurídica de cooperativas, para que estos pudieran acceder a porcentajes accionarios de la empresa, si era una empresa recuperada por adquisición forzosa, el otro agente participante era el Estado quien aparecía con un punto por encima a diferencia de los trabajadores, de la cantidad accionaria total de la empresa (Ríos y Picone, 2010: 23).
\end{abstract}

En Venezuela se observa entonces una variedad de casos entre los que podemos distinguir la presencia de "propiedades mixtas" entre el Estado, los empresarios y

79 Huertas, O., Dávila, R. y Castillo, D. (2011) “Transformaciones en las subjetividades de los trabajadores: casos de empresas colombianas recuperadas", en Universitas Psychologica, Vol. 10 No. 2, mayo-agosto 581-594. 
los trabajadores, que ameritaría estudios profundos de casos para desentrañar cómo funcionan estas empresas y el papel de la autogestión obrera.

En países europeos actualmente se han producido reducidos casos de empresas recuperadas. En Grecia se constituye la primera empresa recuperada en el año 2013, en un contexto de surgimiento similar al de la mayoría de los casos argentinos. El contacto de los trabajadores griegos con un referente del MNER fue crucial para terminar de convencerse en la materialización colectiva de esta experiencia autogestiva. Luego, Antonino Infranca (2013) describe la existencia de 29 fábricas recuperadas por 600 trabadores en Italia para ese mismo año, y asimismo expresa que estas experiencias son la "vanguardia de un fenómeno que se está extendiendo en el resto de Europa. En España, Inglaterra y Francia ya han ocurrido estos fenómenos" (2013:110). Asimismo, de acuerdo a Ruggeri (2014: 6), también existen algunos casos en Estados Unidos.

La extensión internacional de empresas recuperadas muestra, sin embargo, un crecimiento lento y un descenso de combatividad en relación a los primeros momentos de expresión de esta tendencia defensiva propia de las últimas décadas, lo cual se vincula con el tipo de intervención estatal característico de los últimos años.

En el movimiento de empresas recuperadas en Argentina vemos similitudes y diferencias con estos procesos sincrónicos. De acuerdo a los aportes de Aníbal Quijano (2011) que retoma la experiencia brasileña, vemos que una cuestión particular del movimiento de recuperación de empresas en la actualidad es el triple origen de las mismas, que puede residir tanto en los propios trabajadores y su resistencia a la desocupación como de los mismos empresarios, accionistas y el Estado, como forma de resolver la situación de empresas en bancarrota. Con el correr del tiempo los procesos van ganando apoyo institucional y financiamiento estatal o privado, que en la mayoría de los casos se vuelve indispensable no solo para garantizar ingresos mínimos a los trabajadores, sino la propia existencia de las cooperativas conformadas. En términos económicos, la cantidad de casos que culminan por falta de rentabilidad se confrontan con otros que subsisten en una cotidianeidad signada por grandes dificultades tanto de producción como de adecuación tecnológica y circulación de su producción. De acuerdo a su estudio, las que sobreviven lo hacen estableciendo redes regionales, nacionales y supranacionales, y a su vez vinculándose con el empresariado en términos comerciales y financieros. Otras características observadas por el autor son la tendencia a la disminución de la cantidad de trabajadores en las cooperativas y la condición de pertenencia a un sector y/o actividad económica en el que no predomine el capital concentrado ni la necesidad de tecnologías de última generación (Quijano, 2011: 382) ${ }^{80}$.

${ }^{80}$ Quijano, A. (2011) “Sistemas alternativos de producción?”, en Santos (Coord.) Producir para vivir. Los caminos de la producción no capitalista. México, Fondo de Cultura Económica. 
Sin embargo, cabe destacar que, en términos de las subjetividades obreras, la recuperación mediante la autogestión se considera una conquista mediante la cual se reivindica a los trabajadores que luchan por mantenerse dentro del sector ocupado, en un contexto adverso y signado por la exclusión y la precarización. En el próximo apartado profundizaremos acerca de las vertientes subjetivas propias de este formato de conflictividad social orientado en base a una estrategia de continuidad laboral.

\subsection{Recuperación de empresas y subjetividades obreras: estado de la cuestión}

En este apartado nos abocaremos exclusivamente al análisis del estado de la cuestión de estudios referidos al vínculo entre la recuperación de empresas como estrategia laboral y las subjetividades obreras, a fin de extraer elementos de interpretación de las empresas pesqueras que aquí nos ocupan y elaborar un propio marco de análisis. A modo general, encontramos que los diversos estudios al respecto consideran que, tanto los primeros momentos y acciones de lucha y resistencia que se inscribieron en la conformación de este tipo de empresas como su posterior reorganización bajo gestión obrera, generaron un impacto en dichas subjetividades. Cada investigador resalta determinados aspectos o perspectivas de esta transformación, lo cual será detallado a continuación.

Esteban Magnani realizó uno de los primeros trabajos nacionales extensos acerca de las Empresas Recuperadas por sus Trabajadores (en adelante ERT). En su libro "El cambio silencioso" postula que las experiencias de recuperación de empresas implican un cambio en la subjetividad obrera en términos de desarrollo de la conciencia de clase y de su poder, tomando como hipótesis que cuando la actividad laboral se modifica también lo hace la subjetividad, porque el trabajo: "en tanto es una de las tareas más esenciales de la reproducción de las fuerzas del hombre, modifica también la forma en que estos sujetos se relacionan con los demás, construyen su vida, conciben el mundo y lo abordan" (Magnani, 2003:13). Sostiene además que, aunque no todos, buena parte de quienes están reabriendo fábricas tienen como objetivo un cambio social "más profundo", y que en general estos procesos implican un cuestionamiento a la propiedad privada como base fundamental del sistema capitalista. Encontramos también otras referencias a las modificaciones en las subjetividades en términos de enfrentamiento de prejuicios internos y externos y diferentes grados de compromiso y participación, considerando que las limitaciones provienen de la esfera personal, no de la organización interna ni de las leyes del mercado. Además, Magnani supone el surgimiento de una nueva energía, una potencia que los trabajadores no sabían que tenían y que los procesos de recuperación permiten su despliegue, así como la puesta en acción de un saber obrero que se encontraba vedado. Este autor relativiza la autoexplotación que generalmente termina siendo parte de los procesos de 
recuperación, considerándola como parte de las modificaciones en la calidad del trabajo propio de la nueva forma autogestiva.

De acuerdo a Pablo Ghigliani $(2007 ; 2003)$ el desarrollo de la conciencia política de los trabajadores que recuperan empresas se expresa en la organización interna fundada en la horizontalidad- propia de las primeras etapas, visible en los procesos de toma de decisiones, la distribución de tareas, tiempos y ritmos de trabajo y demás aspectos vinculados a la esfera de producción. Sus trabajos versan sobre la importancia de prestar debida atención al circuito completo del capital, es decir, a las determinaciones estructurales mercantiles propias de la esfera de circulación en los comportamientos sociales y en cómo dichos límites objetivos operan sobre la esfera de producción constriñendo las prácticas igualitarias. Para este autor dichas determinaciones son claves para entender la posterior de burocratización y las limitadas modificaciones en los procesos de trabajo de las ERT con respecto al trabajo asalariado, las cuales se expresan en diferentes prácticas de autoexplotación obrera y en sus dificultades de inserción y rentabilidad. Asimismo, recalca la realidad diversa y contradictoria de estas cooperativas criticando las interpretaciones automáticas y atribuciones románticas/idealistas de cambio social y/o desarrollo de cierta conciencia política en sus miembros, sosteniéndose en la idea de que su potencial emancipatorio está destinado a degenerar debido a la lógica mercantil.

Otro de los investigadores que se ocupan de la temática es Andrés Ruggeri, quien dirige un programa de investigación y relevamiento sobre el total nacional de empresas recuperadas, a partir del cual ha realizado hasta el momento cuatro informes y relevamientos correspondientes a los años 2002, 2005, 2010 y 2014. También ha escrito artículos acerca del movimiento de ERT y sus principales características, proveyendo una síntesis acerca de la fisonomía general de las empresas recuperadas en Argentina de acuerdo a diferentes indicadores.

Según su interpretación, las subjetividades obreras se expresan a través de la organización interna, de la "solidaridad" entre sus miembros y de la relación con la comunidad. A diferencia de Ghigliani, este investigador pone en duda si las presiones mercantiles impactarán en las prácticas igualitarias y promoverán la repetición de lógicas patronales, considerando que la memoria obrera es el principal antídoto contra ello y también el desarrollo de una racionalidad económica autogestionaria, inclusive cuando el proceso de producción deba atenerse a las reglas de competencia del mercado (Ruggeri, 2009). También encontramos en sus análisis el reconocimiento de cierto sentimiento de "orgullo" en quienes recuperan empresas.

Por su parte, Patricia Dávolos y Laura Perelman (2004) se abocan a las representaciones ligadas a la desocupación comparando trabajadores metalúrgicos asalariados y de ERT. Los resultados de sus investigaciones indican que estos últimos recurren menos frecuentemente que los primeros a aquellos discursos dominantes que penalizan e incriminan moralmente a las fracciones de trabajadores más desprotegidos, concluyendo que el haber pasado por la inminente 
desocupación y posterior recuperación de la empresa habría provocado cierta transformación en la conciencia de clase de estos trabajadores. Esta transformación radicaría, entonces, en la superación de los intereses corporativos propios por intereses con la generalidad de la clase obrera.

Fernández Álvarez (2007) analiza los cambios en las subjetividades obreras incluidas en procesos de ERT, tomando como variables la nueva organización interna del colectivo de trabajo y también los sentidos que otorgan al trabajo los sujetos involucrados en estos procesos, puestos en relación con las modalidades de acción colectiva. De acuerdo a sus investigaciones, la autora encuentra que la significación "dignidad" (Fernández Álvarez, 2007:104) aparece como "eje articulador de sentidos" contraponiendo los términos trabajo y desempleo, este último considerado como "situación no digna". Siguiendo este razonamiento, significantes como "esfuerzo", "sacrificio" y "responsabilidad" estarían ligados a la significación del trabajo en los colectivos abordados.

Por su parte, Mario Hernández (2013) destaca las actividades culturales que trascienden la lógica mercantil capitalista (tales como la conformación de centro culturales, bibliotecas, centros educativos, proyectos de construcción de viviendas), la orientación de la producción en función de necesidades "sociales" y fundamentalmente el modo colectivo de gestión. Estos aspectos -en especial el último- son para Hernández el principal capital político y simbólico de estos procesos, que además implicaría un salto en la conciencia obrera y la liberación de energías y creatividades.

Eduardo Lucita (2009) -en la misma línea señalada- entiende que los cambios en la subjetividad se expresan como ruptura de la alienación a partir de la comprensión integral del proceso administrativo y productivo, la ruptura con la propiedad privada, la compresión del origen de las ganancias empresariales y el carácter de la explotación capitalista. Postula que los avances propios de las recuperaciones se resumen en la nueva organización de la producción, que conlleva cambios en las relaciones sociales en términos de instalación de valores democráticos y humanización de las relaciones de producción. Los resultados de estas transformaciones se expresan, por ejemplo, en la adecuación de ritmos de trabajo, la extensión de tiempos de descanso y los permisos adicionales justificados. Sin embargo, reconoce que luego de un período heroico inicial, en las ERT "se cuela la lógica capitalista" (Lucita, 2009:44) por la necesidad de rentabilidad y productividad empresarial.

Ignasi Brunet y Carlos Pizzi (2011) destacan, por un lado, el componente de temor y desesperación obrera ante el desempleo como lo que habilitó la consecución de las recuperaciones y, además, la puesta en juego de ciertas condiciones, recursos políticos, organizativos y subjetivos que se sumaron a los incentivos sociales que aportó el contexto (deslegitimación política, autorresponsabilización ciudadana, mecanismos de democracia directa, desocupación, flexibilización laboral), para instaurar esta novedosa forma de lucha obrera dentro de las nuevas modalidades de acción colectiva. En relación con las transformaciones en las subjetividades obreras, 
los autores ubican la generación de una liberación cognitiva en estos casos, vinculada a un mayor grado de conciencia sobre situaciones de injusticia y a la posibilidad de modificar ellos mismos las circunstancias desfavorables con un saldo positivo. A la vez, la expansión del movimiento implicó la socialización de saberes acerca del vaciamiento empresarial y cómo actuar ante él, además de la toma de conciencia de otras manipulaciones empresariales pretéritas. Asimismo, la idea de dignidad laboral es otro componente que se reitera en cuanto a representaciones de obreros al reposicionarse como trabajadores autogestivos, vinculada a un sentimiento de orgullo por haber evitado la desocupación y mantener una actividad productiva. De acuerdo a estos autores, tanto la edad como la antigüedad laboral de los obreros confluyeron con la falta de oportunidades de recolocación laboral como condiciones objetivas que impulsaron las recuperaciones. También coinciden con Hernández y Magnani en cuanto a la conquista simbólica y conceptual de las ERT como un aspecto preponderante que decanta de estos procesos.

Julián Rebón es otro investigador que se aboco de forma exhaustiva al estudio de las ERT, con algunos escritos referidos en mayor medida al plano subjetivo de sus protagonistas (Rebón, 2006; 2005; 2004). En ellos resalta que los principales cambios valorados por los trabajadores residen en los nuevos grados de libertad, un sentimiento de apropiación y pertenencia que provoca mayor involucramiento activo y compromiso de los trabajadores en su actividad y un embrionario "cambio de mentalidad" producto de la ruptura de la heteronomía capitalista (Rebón, 2005:8). Asimismo, se valora el compañerismo y la igualación resultantes de la experiencia de lucha y producción, que lleva a los trabajadores a depositar una gran confianza inicial en el proyecto autogestivo. La utilización de aprendizajes que provienen de experiencias previas de lucha y organización, la tranquilidad y el trabajar sin maltratos, la posibilidad de almorzar juntos, tomar mate, escuchar música, son otros de los aspectos subrayados por los obreros, aunque también enfatizan rasgos negativos o desventajosos como la incertidumbre, inestabilidad y la dificultad para resolver conflictos entre compañeros en la nueva modalidad autogestiva. Los cambios subjetivos los conceptualiza en base al constructo identidad (Rebón, 2006:266), entendiendo que los trabajadores habrían sufrido una transformación identitaria a nivel social al dejar de ser trabajadores estables y luchar por la conservación y el valor del trabajo digno, y la recuperación se constituiría como un modo de enfrentar la puesta en crisis de su identidad obrera. Aquí Rebón considera que operó una “desobediencia” (Rebón, 2004: 21) contra el destino de desocupación y exclusión a través de la acción directa y con diferentes modalidades de conciencia. En los más "luchadores" observa mayor claridad en el antagonismo de clase con respecto al empresario, una valoración más profunda de los cambios en el proceso de producción y un manifiesto rechazo a las concepciones meritocráticas del empleo y desempleo (Rebón, 2004:137).

Este autor también investiga las razones obreras para no conformar ERT, hallando que la falta de confianza en el proyecto autogestivo, el desánimo, la obtención de otro trabajo y un sentido de compromiso con la patronal serían los motivos que 
aparecen preponderantemente. Según su interpretación, mientras que los tres primeros darían cuenta de una forma pasiva de obediencia, el último supondría una afirmación activa de la relación capitalista, de la desigualdad de clases en cuanto a la posesión de los medios de producción.

Hasta aquí los estudios enumerados provienen en mayor medida de la sociología, mientras que Ana María Fernández y su equipo desarrollan nuevos aspectos desde la psicología comunitaria. Parten de una definición de subjetividad que va más allá de la noción de conciencia de clase o conciencia política -a la que la circunscriben muchos estudios- y a la vez no la reduce al sujeto psíquico: "La subjetividad (...) engloba acciones, prácticas, cuerpos, se produce en el entre-con otros y es nudo de múltiples inscripciones deseantes, históricas, políticas, económicas, simbólicas, psíquicas, sexuales" (Fernández y col. 2006:10-11). A su vez destaca el carácter de devenir de lo subjetivo, y la articulación entre los modos de sujeción y un resto no sujetado. Puntualiza que no necesariamente las transformaciones en las subjetividades implicarán una mayor conciencia de clase, voluntad revolucionaria o un tipo de anhelo político predeterminado, y por otro lado resalta las producciones de subjetividad emanadas de las nuevas prácticas imbricadas en el trabajo y en la vida, las formas de vincularse y afectarse diferentes de las habituales. De acuerdo a sus investigaciones, las experiencias autogestivas parten de "estrategias de supervivencia" que no guardaban la necesidad de la instalación de una voluntad política horizontal y autogestiva, por ello la presencia de este aspecto es lo que sorprende en primer lugar (Fernández y col, 2006: 15). La construcción común de espacios de resistencia e invención de nuevos modos de existencia contendrían una innegable radicalidad al situarse en el límite de lo establecido, tanto contra los destinos de exclusión y expulsión como contra la lógica de lo Uno (Fernández y col, 2006:31) predominante en el espacio fabril tradicional comandado por el patrón. Además, sostiene que los dispositivos de horizontalidad no producen por sí mismos paridades políticas, compartiendo las conclusiones anteriormente mencionadas al referirnos a otros autores acerca de impactos diferenciados y diversos niveles de politización e implicación en el proyecto autogestivo. Fernández concluye que las transformaciones subjetivas consisten en una redefinición de los posicionamientos laborales, políticos y de las vidas de los trabajadores, con base en el empoderamiento y la construcción colectiva de sentidos. Su resultante consiste en la conformación de una subjetividad más activa, decidida y valiente, apasionada, potenciada, capaz de investir intensamente su proyecto desde un marco de alianzas y redes sociales comunitarias. El pasaje por estas experiencias provoca en los trabajadores una ganancia de afirmación subjetiva y protagonismo, por lo que pueden instrumentalizar saberes y prácticas para luchar con energía, accionar sus potencias y producir trabajo con coraje colectivo y alegría de los cuerpos (Fernández y col., 2006:231).

Finalmente, abordaremos las conclusiones de la Tesis Doctoral en Psicología de la investigadora Marcela Parra, quien recientemente se abocó al estudio de trabajadores de empresas recuperadas en Córdoba y Neuquén desde la psicología 
social, focalizándose en la dimensión subjetiva de los procesos colectivos (Parra, 2012). Adoptando concepciones de Butler (1997), Parra utiliza como categorías analíticas a las tensiones entre sujeción/subjetivación y entre poder/potencia para dar cuenta tanto de la reproducción como de la transformación que las experiencias de recuperación de empresas conllevan. Cabe destacar que la autora no solo estudia dichas experiencias, sino que las correlaciona con asambleas barriales, redes de trueque y movimientos de desocupados, las cuales según ella comparten la perspectiva anticapitalista de cambio social. Refiriéndose específicamente a las empresas recuperadas, sostiene que en sí mismas "transforman el mundo" en términos de transformación del sistema capitalista, ya que la demostración de que la producción puede estar en manos de los propios trabajadores conlleva consecuencias subjetivas y crea una "relación más humana" entre el obrero y el producto de su trabajo (Parra, 2012:586). A su vez, encuentra que en las subjetividades se produce una resignificación de las concepciones obreras de "trabajo" y "estabilidad laboral", por la cual en el primero se incluyen todas las prácticas autogestivas e instancias de decisión y coordinación colectiva que implica la gestión empresarial; mientras que, en cuanto a la estabilidad, se concibe como dependiente en gran medida de los propios trabajadores. Asimismo, hay transformaciones vinculadas a la concepción del producto del trabajo -que no se considera tanto como una mercancía sino en su sentido social más allá de la esfera económico-mercantil-, en la que se pone en juego una tensión entre ser propietarios y trabajadores.

Finalizando con esta autora y con esta síntesis del estado de la cuestión, cabe destacar que Parra sostiene que a nivel subjetivo ocurren modificaciones profundas en la conciencia política de los trabajadores que recuperan empresas, en una mayor medida que el resto de los autores mencionados.

Desde nuestro punto de vista problematizamos la asimilación de subjetividad obrera al "grado" de conciencia política de los trabajadores, por ello consideramos necesario ampliar el alcance conceptual de este constructo teórico incluyendo en el mismo las vivencias, emociones, representaciones sobre el trabajo y la posición obrera, pesquisando estas variables a través del discurso de los actores, a fin de explorar la diversidad de consecuencias en el campo subjetivo que decantan de estos procesos, que se expresan en las prácticas colectivas obreras. Al respecto, nos parece importante retomar no solo la organización interna que decantó luego de la decisión de recuperación de la empresa sino también los primeros momentos de la lucha, para abordar así el amplio espectro de acción y subjetivación obrera. Nos parece importante destacar la idea de una subjetividad en proceso no lineal, con modificaciones e intermitencias, avances y retrocesos, en contraposición con una concepción progresiva de la conciencia política. Aquí la temporalidad se entrecruza con las experiencias, generándose saltos y caídas, mesetas y picos, de acuerdo al curso de los acontecimientos y del accionar subjetivo y organizativo en los mismos, y también influenciados por las condiciones materiales que atraviesan a las ERT más allá de sus integrantes. Por ello creemos que la posterior adaptación a las lógicas 
mercantiles y estatales que conspiran contra la combatividad y acrecentamiento de la conciencia de clase que de por sí implican las recuperaciones de empresas, no niega los primeros tiempos en los que los colectivos obreros enfrentaron directamente a la patronal y a la racionalidad hegemónica, en el marco de la construcción de una creciente fuerza social obrera cuya dirección era la continuidad laboral autogestiva, con múltiples alianzas sociales. El orden dominante imponía el retiro de la empresa en quiebra y el camino individual tanto legal como laboral, y, no obstante, en estos casos la salida fue desde la colectividad de la clase y enfrentando al capital, y también al Estado en mayor o menor medida. La adaptación posterior no anula el período "heroico", sino que todos los momentos del proceso de recuperación actúan a modo de capas superpuestas en la subjetividad obrera, que permanecen como sedimentos de prácticas disponibles para futuros contextos.

A continuación, realizaremos una breve crónica de los dos procesos de recuperación de empresas pesqueras necochenses, incluyendo algunos testimonios de sus protagonistas a fin de transmitir la dimensión de dichas subjetividades -únicas e irrepetibles. Para evitar reiteraciones innecesarias remitimos aquí a la relectura de los primeros párrafos del capítulo 1 , en los que se sintetiza el origen y la caracterización de las empresas pesqueras que luego fueron recuperadas.

Pero antes, queremos adelantar algunas de las cuestiones generales halladas a partir del análisis casuístico. Aquí retomamos la valorización de la vertiente subjetiva que habilita la consecución de los procesos de recuperación, atendiendo a que solo en una minoría de casos se plantea esta salida obrera y, a su vez, una minoría de obreros de aquellas fabricas son los que la emprenden. En los casos particulares analizados de las empresas pesqueras recuperadas, vemos que los trabajadores que las integran se caracterizan por las siguientes experiencias compartidas:

-en primer término, la vivencia del desguace del sector pesquero a nivel local, lo cual generaba como conclusión inmediata la imposibilidad de reinserción laboral dentro de la rama en la ciudad de residencia, a diferencia de los casos marplatenses en los cuales los trabajadores tenían probabilidades de reinsertarse de forma precarizada en cooperativas u otros formatos de trabajo en negro;

-en segundo lugar, trayectorias laborales enmarcadas en el modo de contratación asalariado con varios años de antigüedad laboral. Esta cuestión se vincula a su vez con la valoración positiva de la tarea laboral realizada y las ansias de continuar realizándola, lo que muestra un sentido de pertenencia para con la tarea y el rubro (es "lo nuestro", dice un obrero) que lleva a la búsqueda de la prolongación de la subjetividad obrera industrial pesquera. Este aspecto lo vinculamos, por un lado, con las reducidas posibilidades de la clase obrera para elegir alternativas laborales en la actualidad en base a aspectos vocacionales, en el marco de la precariedad laboral, la desocupación creciente y la necesidad de reproducción de la fuerza de trabajo para su subsistencia; por otra parte, el anhelo de proseguir realizando similares tareas también expresa la estimación de cierta seguridad, predictibilidad en el trabajo y los ingresos obtenidos, así como también una apreciación positiva del 
trabajo como actividad cotidiana más allá de la explotación y las deficientes condiciones de trabajo.

-En tercer término, las experiencias previas de precarización laboral vividas en carne propia o conocidas a través de otros obreros, la incertidumbre ante el cese de contratos y la falta de oportunidades palpables de reinserción laboral produjo que la apuesta a la autogestión se evaluara como el mejor escenario realizable ante el retorno a aquellas situaciones vividas por fuera del trabajo asalariado en relación de dependencia. En estos casos los obreros priorizaron la conservación del tipo de trabajo que ya venían desempeñando hace años, lo cual se prefirió ante otro futuro incierto o más precario.

Estas tres cuestiones se imbrican mutuamente, retroalimentándose como variables objetivas y subjetivas que condujeron hacia el desenlace autogestivo.

-En cuarto lugar, la disputa contra dos prejuicios intrincados: la necesidad del patrón capitalista y el carácter irremplazable de su función en una empresa, y la incapacidad obrera de administrar la producción y circulación de la producción en las unidades productivas. La autogestión se enlaza con la idea del requerimiento de saberes ajenos a los obreros, dado que estas prácticas no eran ni habían sido realizadas en su posición de vendedores de fuerza de trabajo. Estos saberes, en el transcurso de la lucha, cambian su carácter de vedados y se transforman en plausibles de ser adquiridos por el colectivo de trabajadores. En el caso de la Recuperada, las alianzas sociales fueron fundamentales para esta apropiación de conocimientos. En el caso de Engraucoop esta operación fue propiciada por la integración de trabajadoras administrativas en el proyecto autogestivo y también por el propio organismo estatal que asesoró al colectivo obrero en los primeros tiempos de constitución de la cooperativa.

-En quinto lugar, las discrepancias entre los momentos iniciales en los que primaron las prácticas obreras de lucha contra el destino de desocupación impuesto y la adaptación a la cual estos colectivos son empujados mediante las dificultades cotidianas propias de procesos de producción autogestiva, obtención de clientes, materia prima, competencia contra el gran capital, provocan una frustración colectiva obrera. El contraste entre la fuerza social obrera constituida con preminencia de vínculos de solidaridad propia de la primera etapa y la soledad y la competencia en el mercado de las etapas posteriores genera que las transformaciones y aprendizajes logrados en el nivel de la conciencia no puedan volver a aplicarse en la práctica por los condicionantes objetivos señalados. Es decir que, los procesos de lucha que generaron las transformaciones subjetivas iniciales no guardan luego nuevos correlatos materiales en los cuales sustentarse y quedan por ello truncados, obturados en su continuidad y desarrollo, e incluso negados por los nuevos contextos signados por la lógica mercantil. Este desfasaje genera contradicciones a nivel de las subjetividades, que viven la recuperación a la vez como una conquista y un fracaso, por los motivos expuestos. El fracaso posterior, a la vez, vuelve a cuestionar la conclusión previa relativa a la superfluidad de la figura 
del patrón y, por ende, de la capacidad obrera de emprender una autogestión exitosa.

-En sexto lugar, el accionar inicial predominantemente colectivo enmarcado en la conformación de una fuerza social obrera va cediendo paso a una tendencia al individualismo, depositando en algunos pocos miembros el rumbo del proyecto autogestivo, la conducción de los dispositivos de toma de decisiones y la responsabilidad de su viabilidad en el tempo. Esto se empalma con los condicionantes objetivos que el sistema capitalista impone a las ERT, y genera una contradicción entre nuevos vínculos entre compañeros de trabajo basados en la horizontalidad con la aparición de nuevos verticalismos intraclase.

-En último lugar, queremos señalar una particularidad de estos casos, la cual reside en el hecho de que las empresas recuperadas pertenezcan a un sector económico en el que predomina el gran capital transnacional y por ello, guarda mayores desventajas estructurales para los emprendimientos a pequeña escala.

\section{La Recuperada, ExIndustrial Pesquera}

El conflicto en Industrial Pesquera inició a raíz de la parálisis de la unidad productiva, falta de pago de los salarios y desabastecimiento de materia prima. Los dueños y gerentes de la firma desde sus inicios en los 70 fueron una mujer y sus dos hijos, Concepción Ursino, Pablo Bruno y Carmelo Bruno, quienes al momento de la parálisis de la unidad productiva -en diciembre de 2010- se dividían las acciones en partes iguales. En el marco del desabastecimiento y la crisis, los empresarios ofrecieron a los trabajadores tomarse unas "vacaciones impagas", una licencia sin goce de sueldo a causa de la suspensión de las tareas de producción en la planta. La mayoría de los trabajadores no aceptó esta licencia, que significaba pasar varios días sin ingresos, en fechas que incluían los festejos de fin de año. Por eso, decidieron continuar yendo a la planta procesadora ubicada en la zona portuaria local a cumplir horario con la ropa de trabajo. Las jornadas se aletargaban ya que no había tareas que realizar, por lo que las horas transcurrían tomando mate en la cocina y charlando, acciones que no eran habituales en la cotidianeidad obrera fabril en la cual solo se disponía de quince minutos de descanso por jornada laboral en forma separada para fileteros, peones y envasadoras. Luego de varios días, al no obtener respuestas por parte de la patronal, un grupo de obreros planteó la idea de salir a la vereda de la planta y quemar gomas en la calle aledaña, para visibilizar que estaban sin trabajo y sin ingresos. Darío y Rubén, delegados gremiales de planta, interpelaban todos los días a los empresarios para exigirles el pago de los salarios atrasados, sin obtener respuesta. La bronca se incrementaba día a día, y se encendió cuando uno de los trabajadores encontró a una de las dueñas de la empresa en un hipermercado local, con su carro de compras lleno de productos. Eso motivó a que, tras una insistencia telefónica de Darío, los empresarios concurrieran a la planta con $\$ 2.200$ pesos para distribuir entre todos los trabajadores que allí se encontraban, lo que dio un total de $\$ 120$ para cada uno: 
Julio: Más que nada que había gente que por las fiestas necesitaba un mango, y un compañero la vio a la Chola (una de las dueñas) en el supermercado con el carro lleno y nosotros nada.

Darío: Ellos sí se la guardaban y la tuvieron. El tema que a veces te pegaban una llorada bárbara que te daba ganas de salir a hacer una vaquita para prestarles plata. En ese principio ni pensábamos en la autogestión, no pensábamos en nada de eso ni se nos cruzaba en la cabeza, el pensamiento era cobrar, cobrar la quincena y después cobrar el aguinaldo y después salir de vacaciones. Yo pensaba que se iba a poder solucionar en un principio. Inclusive antes de que yo entrara a la fábrica hubo un año, creo que el 2001, que cerraron seis meses y después volvieron a abrir con toda la gente de vuelta. Muchos decían que esto iba a salir adelante, pero por lo visto ya fue que no. Y bueno ahí en diciembre pasamos las fiestas penosas porque no teníamos un peso...81

Como valor de referencia, en el año 2010 el sueldo básico garantizado de un filetero era de $\$ 1.120$, por lo que el dinero entregado por la patronal significaba no mucho más del $10 \%$ de ese salario mínimo. En el fragmento de la entrevista señalado se advierte una primera diferenciación entre las clases sociales, conceptualizada por los trabajadores a partir del hecho irrefutable que contrastaba el "chango lleno" de la propietaria con respecto a sus "bolsillos vacíos", tras haber transcurrido un mes sin cobrar sus salarios. Si en la fábrica había crisis, los obreros eran los únicos que se habían quedado sin ingresos. Volveremos sobre este aspecto más adelante.

En ese momento fue que un trabajador, Julio, expresó a Darío la idea de utilizar esos 120 pesos para comprar pescado en la banquina del puerto, procesarlo y luego venderlo, a fin de acrecentar ese monto inicial. Darío estuvo de acuerdo con esa idea, y ambos la compartieron con el resto de los trabajadores que allí se encontraban. Solo dos aceptaron unirse a ese proyecto autogestivo que convirtió a su dinero en capital -es decir, en medio para obtener más dinero. Un quinto obrero fue el encargado de realizar la compra de pescado en la banquina, ya que era el que efectuaba esta tarea en Industrial Pesquera y tenía vínculos previos con los capitanes de barco que allí desembarcaban. Filetearon el pescado entre los cuatro, pero solo Darío y Julio salieron a venderlo de forma ambulante. Una vez terminada la venta de la totalidad de pescado procesado, los integrantes del grupo autogestivo lograron duplicar los $\$ 120$ iniciales. En las semanas siguientes repitieron el procedimiento cada vez que lograron obtener pescado en el puerto, dejando un fondo de \$50 con el cual realizar una nueva compra. Haciendo un breve paréntesis, cabe mencionar que ya en estos primeros momentos comenzó a presentarse un problema que posteriormente se continuó durante los meses y años siguientes, una vez conformada ya la empresa recuperada: no cualquiera podía comprar cajones de pescado fresco en Puerto Quequén, y por este motivo en muchas ocasiones los obreros no contaban con pescado para procesar a pesar de que tuviese el dinero para adquirirlo. Había una lista de compradores prioritarios encabezada por los grandes empresarios marplatenses.

${ }^{81}$ Entrevista grupal a La Recuperada, realizada en octubre de 2011. 
Retomando los meses iniciales del conflicto, en el punto de la conformación de un incipiente grupo y procedimiento autogestivo de forma espontánea, la situación cobró un nuevo viraje una mañana de enero, cuando al llegar los trabajadores se encontraron con la planta cerrada sin la presencia de la patronal. Darío fue el encargado de consultar qué sucedía al sereno de la fábrica de hielo lindante a la planta procesadora, empresa cuyos propietarios eran los mismos dueños de Industrial Pesquera. Este empleado refirió que tenía la llave de la planta, pero también órdenes patronales de no abrir la puerta a los trabajadores. Darío extendió la noticia al resto de obreros de Industrial Pesquera que iban llegando, y a los pocos minutos ya circulaba la idea de entrar a la planta y ocuparla, para que los empresarios no vuelvan a impedirles el ingreso. A tal fin, un grupo fue con otros obreros a buscar gomas por el barrio para cortar la calle nuevamente. Uno de los propietarios acudió prontamente a la planta, y tras una discusión les dejó a los trabajadores la llave para que pudiesen entrar:

\begin{abstract}
Darío: Y bueno cuando llegamos a ese momento a mí me cayó re mal y a los compañeros también, ¡cómo nos iban a dejar afuera! Y ahí empezamos a pensar seriamente la idea de entrar, teníamos que entrar adentro de la planta. Pero lo empezamos a hablar con algunos compañeros, no decírselo a todo el resto porque había gente que tenía un poco de miedo viste, no sabían cómo manejarlo y era como decir, meterse adentro, va venir algún policía... mucha gente grande además, yo los entendía. Claro entonces buscábamos la vuelta de cómo entrar acá adentro sin romper nada, entrarnos acá adentro y no salir más. Y fue así, fuimos a buscar un viaje más de gomas y cuando volvimos estaba el dueño, uno de los dueños y ahí le dije, un poquito de todo le dijimos...

Julio: Y dejó la llave.

Darío: Y el tipo me decía que no tenía nada que ver, y a mí me decía que no tenía nada que ver y más bronca me daba, cómo que no tenía nada que ver. Y bueno la cuestión que el tipo vino y dejó la llave. Tomá, acá tienen la llave, se la dio a Julio y dijo: Yo no quiero tener problema, acá tienen la llave, entren.

Julio: Y a mí lo que me extrañaba también en ese tiempo era que por ahí a mí el darme las cosas... yo ahí no cortaba ni pinchaba ni nada, poca participación, me conocían, pero poca participación, no me tenían. Yo creo que esto que me haya quedado acá eso también les sorprendió, pero como que veían que éramos los que estábamos más firmes al lado de Darío.

Matías: Y cuando dio la llave también estaría pensando así no queman más gomas...

Julio: Sí fue para eso, más que nada para calmar el tipo...

Darío: Sí claro porque estábamos re calientes. ${ }^{82}$
\end{abstract}

Como se desprende de estos fragmentos de testimonios obreros, el hecho de haber encontrado la planta cerrada sin previo aviso acrecentó la bronca y produjo una radicalización del conflicto atacando directamente la propiedad privada empresarial. El accionar patronal motivó la medida de la ocupación permanente de la planta como forma de impedir la exclusión de los trabajadores, y al mismo tiempo también reforzó la idea del desempleo masivo y el cierre definitivo de la empresa.

${ }^{82}$ Entrevista grupal a La Recuperada, realizada en octubre de 2011. 
A partir de allí un grupo de trabajadores permaneció haciendo guardias en la planta una vez cumplido el horario de trabajo. Además de Darío y Julio, otros obreros se sumaron a pasar la noche. Uno de ellos no era trabajador de planta permanente, sino que había sido trabajador eventual tiempo antes.

En estas primeras semanas, dirigentes del Sindicato de la Alimentación se reunieron sucesivamente con los empresarios en la sede local del Ministerio de Trabajo. Los empresarios aducían una crisis por la cual habían contraído grandes deudas que no podían pagar con proveedores y entidades públicas, debido a un descenso de la rentabilidad. Por esta misma razón, decían, tampoco no poseían dinero para abonar los sueldos atrasados. Entonces, como resultado de estas primeras audiencias en la dependencia estatal, se procedió a la solicitud de ayuda financiera tanto al gobierno nacional como provincial, con intermediación de funcionarios y concejales locales. En sus inicios las gestiones realizadas fueron en vistas de obtener subsidios o créditos estatales, concretamente el ingreso al Programa REPRO destinado a empresas en crisis y los créditos Bicentenario, lanzados desde el año 201083. Sin embargo, con el correr de los días quedó en evidencia la distancia entre los montos que ofrecían los planes financiamiento estatal y la suma que según los propietarios era necesaria para reactivar la fábrica ${ }^{84}$. La situación de quiebra era inminente. En esas semanas iniciales empezaron a acercarse algunas organizaciones políticas y otros actores comunitarios, entre los que se destacaron el STIA, obreros de otras plantas de procesamiento de pescado, colectivo Cruz del Sur, integrante del Frente Popular Darío Santillán, y docentes y estudiantes de la carrera de Trabajo Social de un instituto terciario. Durante enero y febrero se sucedieron varias audiencias en el Ministerio de Trabajo hasta que, finalmente, una mañana de marzo llegó el anuncio del cierre definitivo. En este nuevo contexto la conformación de una cooperativa de trabajo se presentó como la única posibilidad de continuidad laboral.

Como resultado del acercamiento y las alianzas con las organizaciones y personificaciones sociales mencionadas, los trabajadores refieren que a partir de allí conocieron experiencias de empresas recuperadas tales como las de Zanón y el Hotel Bauen, y las enlazaron con su accionar autogestivo del fileteado por cuenta propia realizado durante esas semanas previas. De esta manera, lo que inició como proceso espontáneo de supervivencia diaria se transformó en un proyecto laboral colectivo, enmarcado en un movimiento más amplio a nivel nacional e internacional:

Hubo gente que nos acompañó mucho, sobre todo los compañeros de Engraulis, no solamente los compañeros de Incoop, no solamente el Sindicato de la Alimentación, sino también para no olvidarme, gente de Tres Arroyos también pasaron noches con nosotros y nos acompañaron al concejo, los chicos del frente de Cruz del sur, los chicos de la Escuela 31 de Trabajo social que siempre están con nosotros, toda esa gente nos acompañó... Yo creo que sin el apoyo de esa gente que nos pudo orientar... Es como dijo Julio una vez, nosotros somos los obreros, después esa parte de todo lo que es manejarse y que nos iban

\footnotetext{
${ }^{83}$ Ecos Diarios, 18 de febrero de 2011.
}

${ }^{84}$ Ecos Diarios, 31 de marzo de 2011. 
orientando fue parte de la gente de Cruz del sur que nos acompañó y nos iba guiando (Mario, 53 años, filetero de La Recuperada) ${ }^{85}$.

Por esta influencia decisiva en el origen mismo del proyecto de la recuperación de la empresa es que consideramos que para el caso de La Recuperada la conformación de una fuerza social basada en un amplio marco de alianzas fue clave para su desarrollo, ya que no solo se instaló la proyección de que la autogestión constituía su mejor escenario posible, sino que, en un momento lógicamente anterior, permitió que la autogestión fue considerada como una posibilidad. De acuerdo a los integrantes de las organizaciones política y sindical, se necesitaron varias reuniones para convencer a los obreros de que el tipo de cooperativa enmarcada en una empresa recuperada era diferente a las cooperativas fraudulentas tan generalizadas en su rama y sector económico. Al respecto cabe destacar que en la ciudad la tradición de lucha enmarcada en procesos de recuperación era prácticamente nula ${ }^{86}$, a pesar de que el movimiento nacional de empresas recuperadas contaba ya con varios años de trayectoria.

El grupo autogestivo, a excepción de Darío y Julio, fue fluctuante en cuanto a sus miembros durante sus primeros días. Poco a poco fueron incorporándose los 6 trabajadores que luego, junto con ambos, conformaron "La Recuperada". Como en algunas oportunidades tenían dificultades para adquirir materia prima en la banquina, buscaron otras tareas laborales que les permitiera obtener algún ingreso, tales como lavado de autos en la planta, venta de hielo y organización de peñas.

Finalmente, entre fines de abril y principios de mayo del año 2011, se terminó de conformar la Cooperativa de Industria Pesquera y Alimenticia "La Recuperada". En los apartados siguientes profundizaremos en diversos aspectos de la conformación y consecución de esta empresa pesquera recuperada.

\footnotetext{
${ }^{85}$ Entrevista grupal a La Recuperada, octubre de 2011.

${ }^{86}$ De acuerdo al estado de nuestros rastreos sobre la historia local de las empresas recuperadas en Necochea, hasta el momento hemos podido hallar una primera experiencia de corta vida entre los años 1999 y 2000, en la panadería llamada "La Central". La cesión de los bienes inmuebles y maquinarias se realizó de forma pacífica por un mutuo acuerdo entre el empresario y los trabajadores. Luego, en el año 2003 se conformó como empresa recuperada la cooperativa de Salud "Libra", que funcionaba en la ciudad como sociedad anónima desde el año 1979. Los casos que prosiguieron fueron los de La Recuperada y Engraucoop, respectivamente, en el año 2011. Luego, en el año 2015 se conformó una segunda recuperada panificadora en la firma CEPAN; y finalmente, en el 2018, una segunda experiencia como cooperativa de salud tras la quiebra de la sociedad anónima "Clínica Regional".
} 


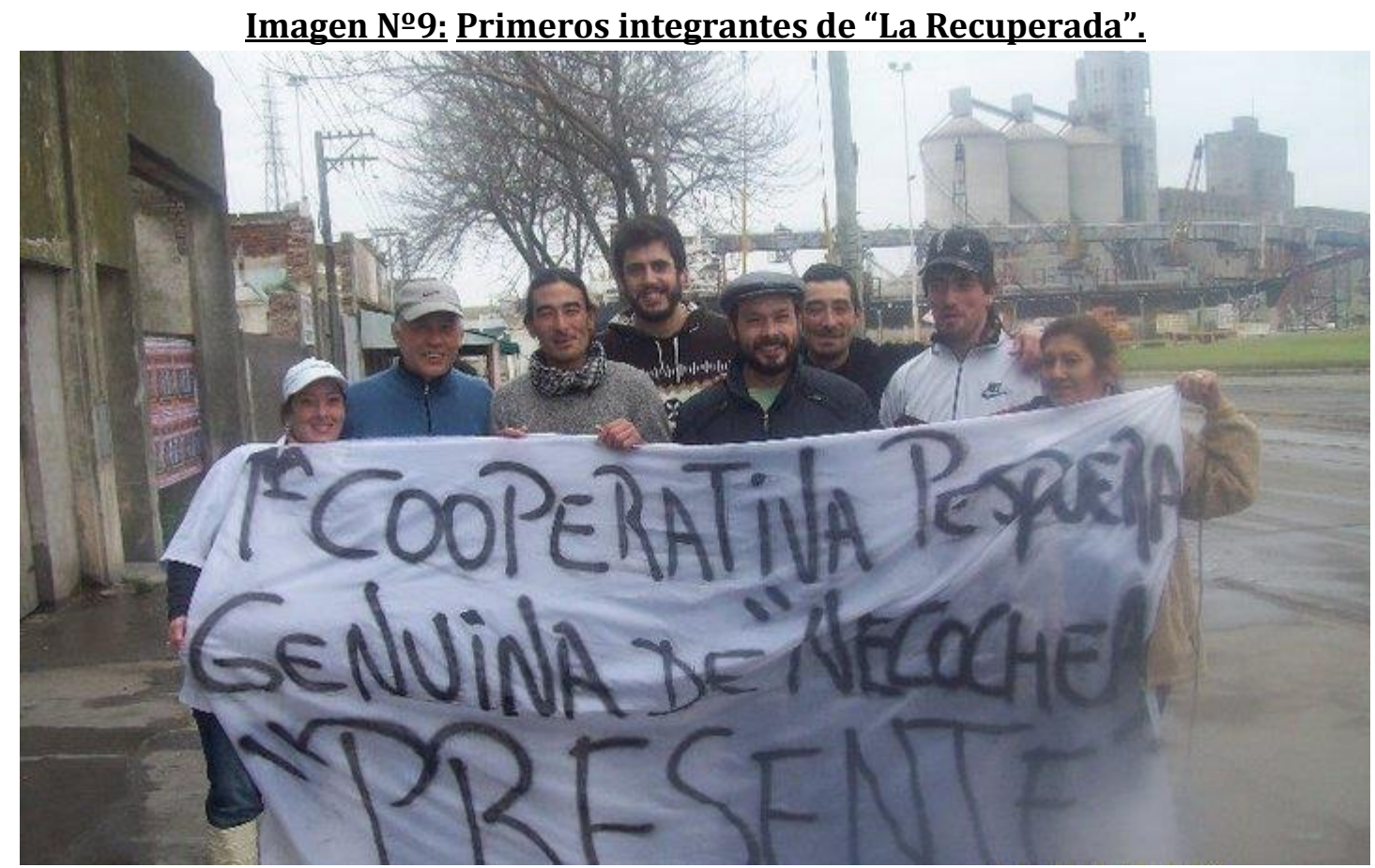

De izquierda a derecha: Natalia, Mario, “El Flaco”, Matías, Darío, Julio, Julián y Angélica. Está ausente en la foto Hugo.

Fuente: Archivo La Recuperada.

\section{Imagen №10: Proceso de trabajo en "La Recuperada". Fileteado de lenguado en el} interior de la planta procesadora.

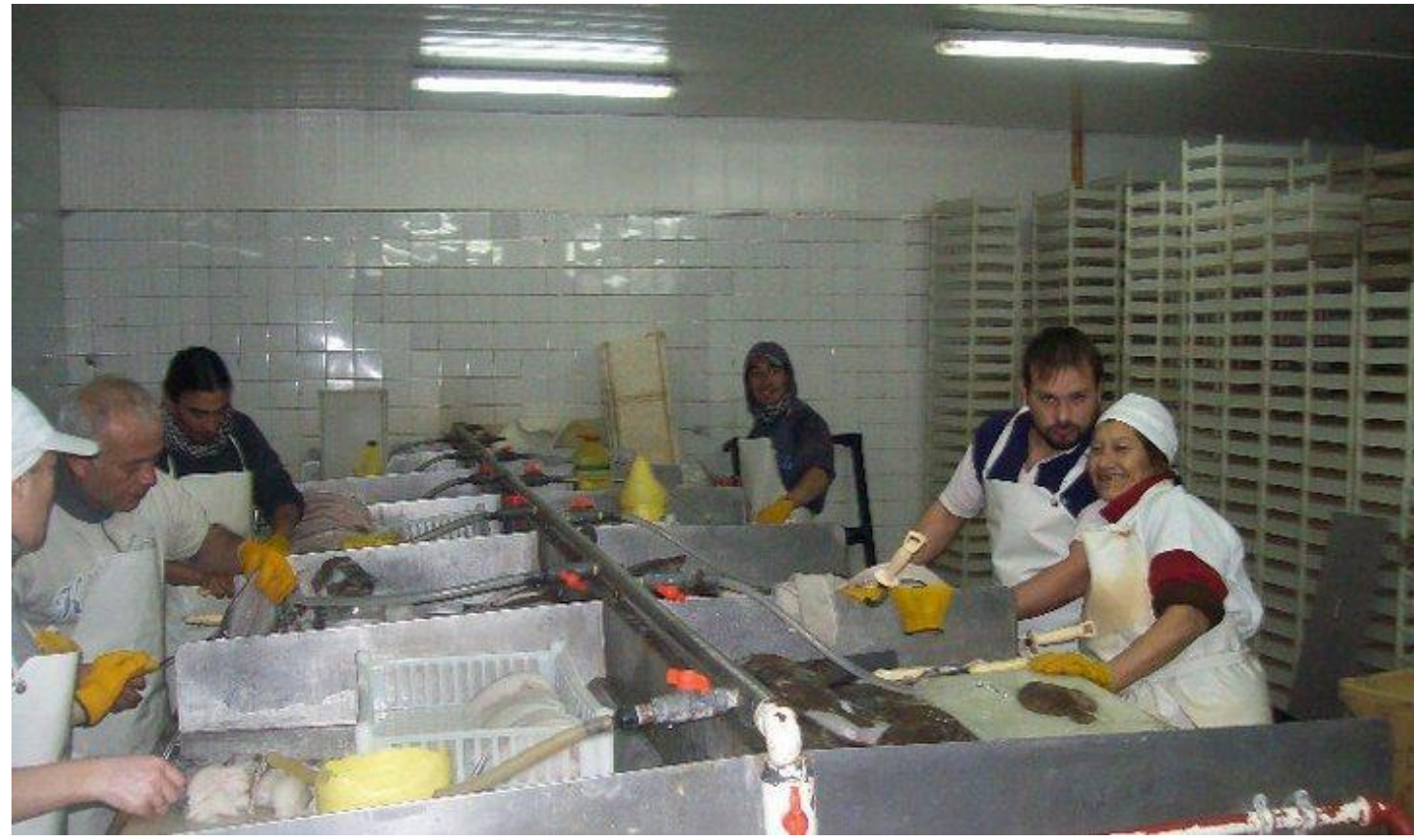

Fuente: Archivo La Recuperada. 
Imagen №11: Exterior de la planta procesadora de "La Recuperada", marzo de 2012.

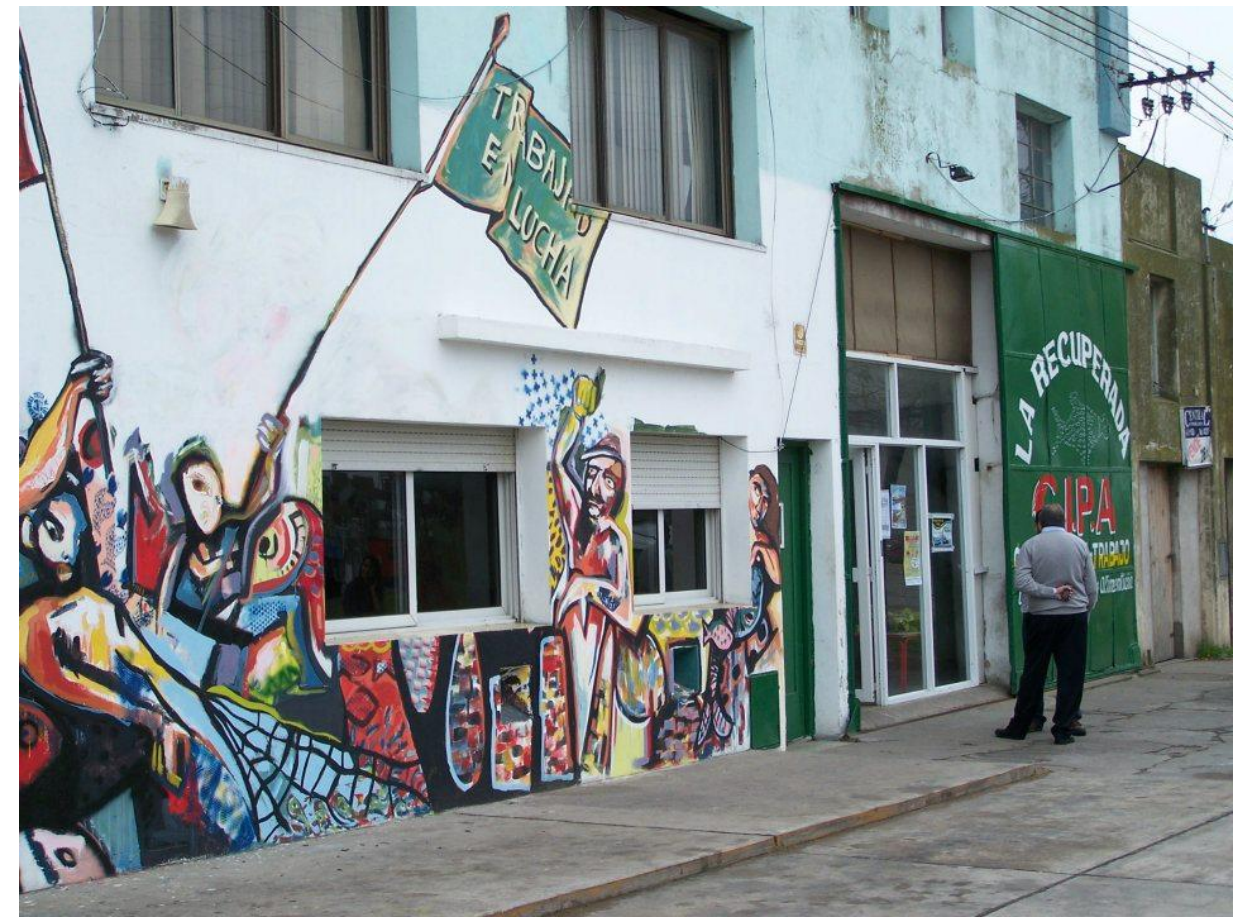

Fuente: Archivo La Recuperada.

\section{Engraucoop, ExEngraulis}

En el caso de Engraucoop el proceso de recuperación se presentó en dos tiempos. El primer período ocurrió entre mayo y julio de 2010 y tuvo como desencadenante el anuncio de alrededor de 30 despidos que la patronal denominó "plan de achique de personal"87. Esta planta dedicada a la producción de anchoas en conserva tenía como propietarios a dos italianos, Giorgio y Roberto Nasari, quienes poseían a su vez otra firma asociada en España, llamada "Fedro Conservas". El rumor que circuló entre los trabajadores en los primeros momentos del conflicto fue que los empresarios querían despedir a la totalidad de obreros para mudar a Perú el proceso de producción, ya que allí era menor el precio de la fuerza de trabajo. En ese momento ocuparon la unidad productiva, además de realizar un bloqueo para impedir el retiro de materia prima de la planta y diversas manifestaciones:

El pasado viernes la empresa informó que iba a despedir a 43 compañeros, por no contar con materia prima para procesar, y propuso pagarles el $35 \%$ de la indemnización, lo que no aceptamos. A ello se sumó que prepararon 80 barriles de anchoa para llevárselos a Perú y nos plantamos impidiendo que los cargaran, pues nos sacaban nuestro trabajo. Tras ello despidieron a 43 personas, ante lo que acudimos al Ministerio de Trabajo y ayer se firmó la conciliación obligatoria. Hoy nos presentamos a trabajar y la planta estaba cerrada y sin sus directivos. Como encontramos un portón abierto, sin romper nada ingresamos

${ }^{87}$ Ecos Diarios, 2 de junio de 2010. 
y nos quedaremos hasta tanto alguien nos dé respuestas... (Gastón Gallop, delegado gremial de Engraucoop) ${ }^{88}$.

La reacción de solidaridad ante el anuncio de los despidos masivos, sumado al riesgo de la continuidad del proceso de producción generó acciones obreras que cuestionaron la propiedad capitalista de los medios de producción. La toma, que persistió durante un mes, enfrentó intentos de represión tales como amenazas de desalojo y presencia permanente de personal policial en las inmediaciones de la planta. En el transcurso de ese tiempo, delegados de planta, junto al Sindicato de la Alimentación concurrieron a reuniones entre partes con directivos y representantes de los empresarios en la sede local del Ministerio de Trabajo ${ }^{89}$. Finalmente, las medidas lograron revertir la voluntad patronal de los despidos, aunque se redujo en una pequeña parte la fuerza de trabajo al sancionarse cuatro jubilaciones anticipadas ${ }^{90}$. Luego de ello, aunque se reactivó parcialmente la planta para realizar algunos pedidos puntuales ${ }^{91}$, Patricia Ortega, empleada administrativa y representante legal de la empresa Engraulis, refirió que el conflicto seguía latente. La empresa quedaba a la espera de ayuda financiera estatal y no se vislumbraba una solución alternativa ${ }^{92}$.

Sin embargo, poco después los propietarios realizaron una inversión millonaria en la planta, en reparaciones de maquinarias y mantenimiento del edificio como preparación para la temporada de zafra 2010 -a llevarse a cabo entre los meses de septiembre, octubre y noviembre. Pero llegado el momento de iniciarla concurrió a la planta un auditor español, quien luego de realizar estimaciones acerca de la rentabilidad de la misma concluyó que el balance económico sería negativo y que la crisis financiera de Engraulis proseguía.

El conflicto volvió a manifestar visibilidad una vez concluida la zafra, al mermar los ritmos de producción. En enero de 2011, luego de que las trabajadoras no percibieran el aguinaldo y desde la empresa se les informara que no dispondrían de vacaciones pagas, se retomaron las huelgas, resultando un total de 5 hasta el mes de agosto, siendo la más extensa de una semana de duración. Durante estos meses se atrasó o se efectuó en partes el pago de las quincenas, y en ocasiones no se percibió el salario.

En agosto de 2011 se produjo la segunda toma marcando el segundo tiempo del conflicto, como consecuencia del anuncio de ingreso a concurso de acreedores, antesala de la quiebra empresarial, junto a lo cual los propietarios refirieron que no abonarían ni los últimos salarios ni las indemnizaciones de las trabajadoras por falta de activos líquidos ${ }^{93}$. Los reclamos obreros en esta oportunidad se vincularon, por

\footnotetext{
${ }^{88}$ Ecos Diarios, 2 de junio de 2010

${ }^{89}$ Ecos Diarios, 12 y 24 de junio de 2010.

90 Entrevista a Guillermo Daniel, abogado del STIA, mayo de 2017.

${ }^{91}$ Ecos Diarios, 2 de julio de 2010.

92 Ecos Diarios, 2 de julio de 2010.

93 Ecos Diarios, 31 de agosto de 2011.
} 
un lado, con la conservación de las fuentes de trabajo, y por otro con el pago de las indemnizaciones.

Un profesional de la empresa Engraulis nos aseguró en las últimas horas que se iniciaba el concurso de acreedores, que no habría temporada de zafra y tampoco continuidad de trabajo. (...) Quienes están a cargo de la fábrica pretenden que cobremos la indemnización con la poca materia prima que nos queda para procesar, yo tengo 24 años de antigüedad y no puedo irme a mi casa con 10 pesos cada 15 días (Analía Morino, 49 años, delegada gremial de Engraulis) $)^{94}$.

Llegado este punto se concretó la totalidad de los despidos y se anunció el inicio del proceso de quiebra de la firma Engraulis ${ }^{95}$, a lo que un grupo de trabajadores respondió realizando una ocupación de la planta procesadora y luego recuperó la empresa bajo gestión obrera, conformando una cooperativa de trabajo.

Una de las obreras relata que estuvieron varios meses trabajando en base a unos pedidos puntuales que habían quedado pendientes de entrega por la firma anterior, lo que muestra una gestión obrera de hecho, sin que se enuncie como empresa recuperada, al igual que en el caso de los trabajadores de Industrial Pesquera. No obstante, a diferencia de lo que sucedió en La Recuperada, en donde los trabajadores que no mostraron acuerdo con integrar la cooperativa se retiraron de la planta procesadora, aquí se generó una división entre dos agrupamientos obreros, como adelantamos en el capítulo 2. La recuperación y la autogestión tuvieron, entonces, una fuerte resistencia a nivel interno desde el mismo conjunto obrero en particular. En los apartados que siguen continuaremos analizando este y otros aspectos de este proceso de recuperación, pero antes queremos adelantar que esta división obrera se conjuga a su vez con el carácter híbrido de dos trabajadoras integrantes de cada uno de los grupos: en la cooperativa Engraucoop, una de sus trabajadoras y líderes también había sido durante algunos años accionista minoritaria en la empresa, mientras que en el otro agrupamiento, una de las obreras era a su vez apoderada legal de la firma. Ambas personificaciones guardaban al mismo tiempo carácter obrero, jerárquico y patronal, ya que ambas eran a su vez empleadas administrativas, posición considerada jerárquica por el conjunto obrero, en comparación con las obreras del área de producción. Esta contradicción será abordada luego en mayor detalle.

La decisión de la recuperación se concretó una mañana de enero, luego de meses de realizar pedidos como trabajadoras tercerizadas de otras empresas pesqueras, a la par que realizaban peñas, participaban con stands en eventos públicos y elaboraban empanadas y pastas artesanales para la venta a domicilio:

Ya no sabíamos qué hacer, pero sabíamos que estaban los chicos de La Recuperada. Estábamos recorriendo la municipalidad y leí un cartel que decía

\footnotetext{
94 Ecos Diarios, 31 de agosto de 2011.

95 Ecos Diarios, 15 de septiembre de 2011.
} 
Producción, y pensé que era para nosotras, que lo que hacemos es producir. Entramos y nos atendió Sampron (el Secretario de Producción municipal), le dejamos nuestro contacto y nos comunicó con el INAES. Y ahí empezamos a armar la cooperativa (Analía, 49 años, filetera de Engraucoop) ${ }^{96}$.

Seguidamente dos empleados del INAES (siendo una de ellas oriunda de Necochea) se instalaron en la ciudad en los meses de febrero y marzo, para acompañar y asesorar a los trabajadores en las gestiones necesarias para conformar una cooperativa de trabajo y solicitar la expropiación de la planta. Se observa entonces que, además del impulso estatal, la experiencia precedente fue otro de los incentivos que llevó al grupo obrero a emprender la autogestión y recuperación de la unidad productiva, sin intervención aquí del Sindicato de la Alimentación u otras organizaciones externas como propulsores de la salida autogestiva. El caso de Engraulis tampoco tuvo la cobertura y difusión mediática del primer proceso de recuperación luego de que fuera difundida la quiebra de la firma.

La unificación de los dos grupos trabajadoras no se logró, por lo que, luego de algunas situaciones de conflicto interno, en el mes de marzo de 2012 el grupo que sostenía la idea de continuar trabajando en relación de dependencia se retiró de la planta y continuó la disputa en el plano judicial, mediante sucesivas presentaciones en las que solicitaron al juez interviniente el retiro de la cooperativa Engraucoop de la planta procesadora. Sin embargo, el Juzgado civil y comercial №2 junto al Ministerio de Trabajo otorgaron el aval para la conformación de la cooperativa Engraucoop, que quedó conformada por 20 integrantes, 17 mujeres y 3 hombres, y asimismo autorizaron la utilización de las instalaciones para la consecución del proyecto autogestivo año tras año "hasta tanto se efectúe la subasta del inmueble"97. Por estas características señaladas aquí, vemos que en este caso no se constituyó una fuerza social obrera con una expansividad más allá del colectivo de trabajadores. En consonancia con este aspecto, el apoyo estatal obtenido no fue resultante de acciones de confrontación, sino como resultado de un pedido realizado, y por ello los trabajadores de Engraucoop consideran a los trabajadores del INAES como actores fundantes del proceso de recuperación. La presencia de fotografías de los mismos en el interior de la fábrica, ante las cuales los trabajadores expresan palabras de afecto, señala una de las particularidades de este caso.

\footnotetext{
96 Entrevista grupal a Engraucoop, realizada en octubre de 2012.

${ }^{97}$ Causa judicial ENGRAULIS s/quiebra, №3574-7011, expediente №37489, №/fj 1152.
} 


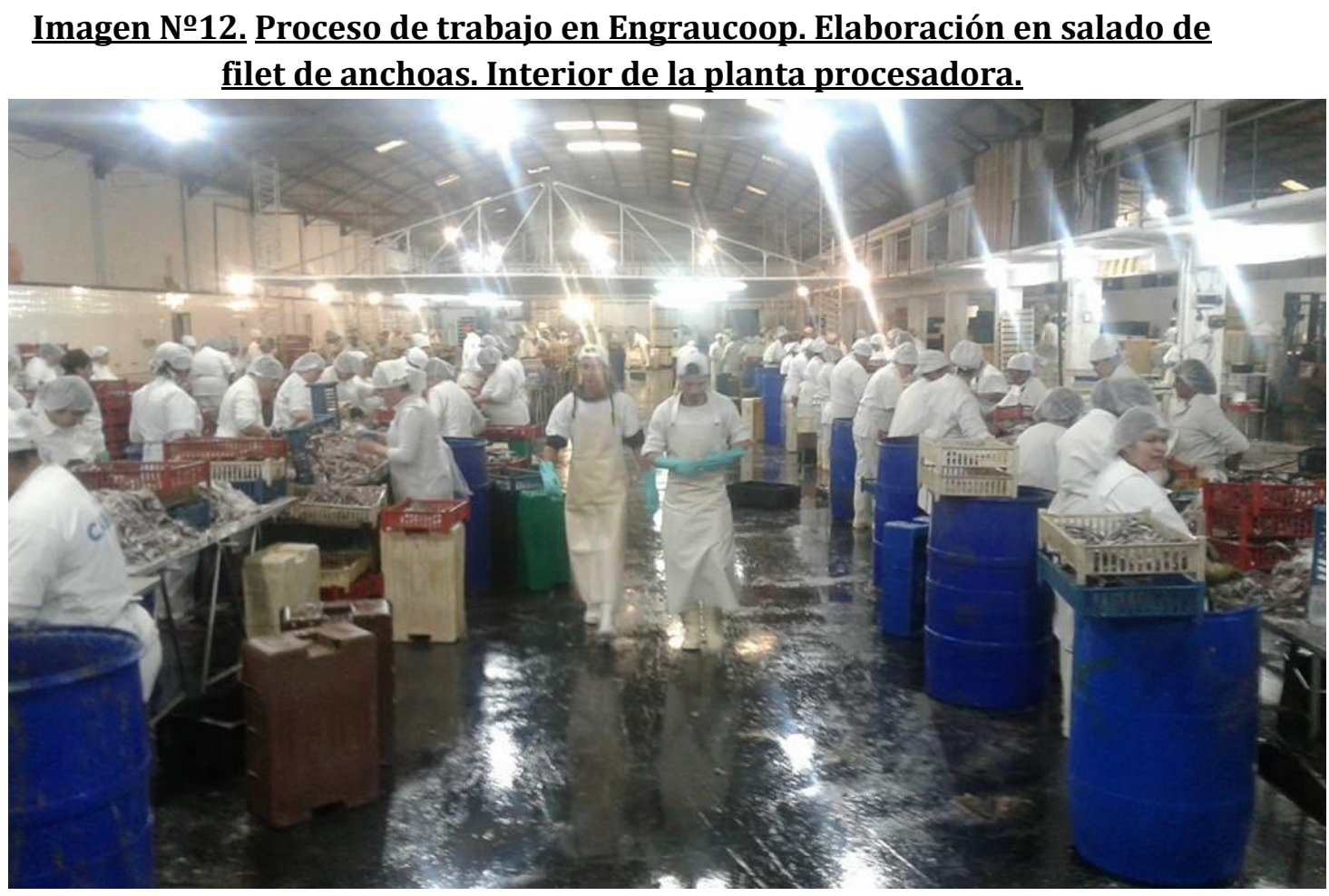

Fuente: Archivo Engraucoop.

$\underline{\text { Imagen №13. Integrantes del grupo inicial de Engraucoop. }}$

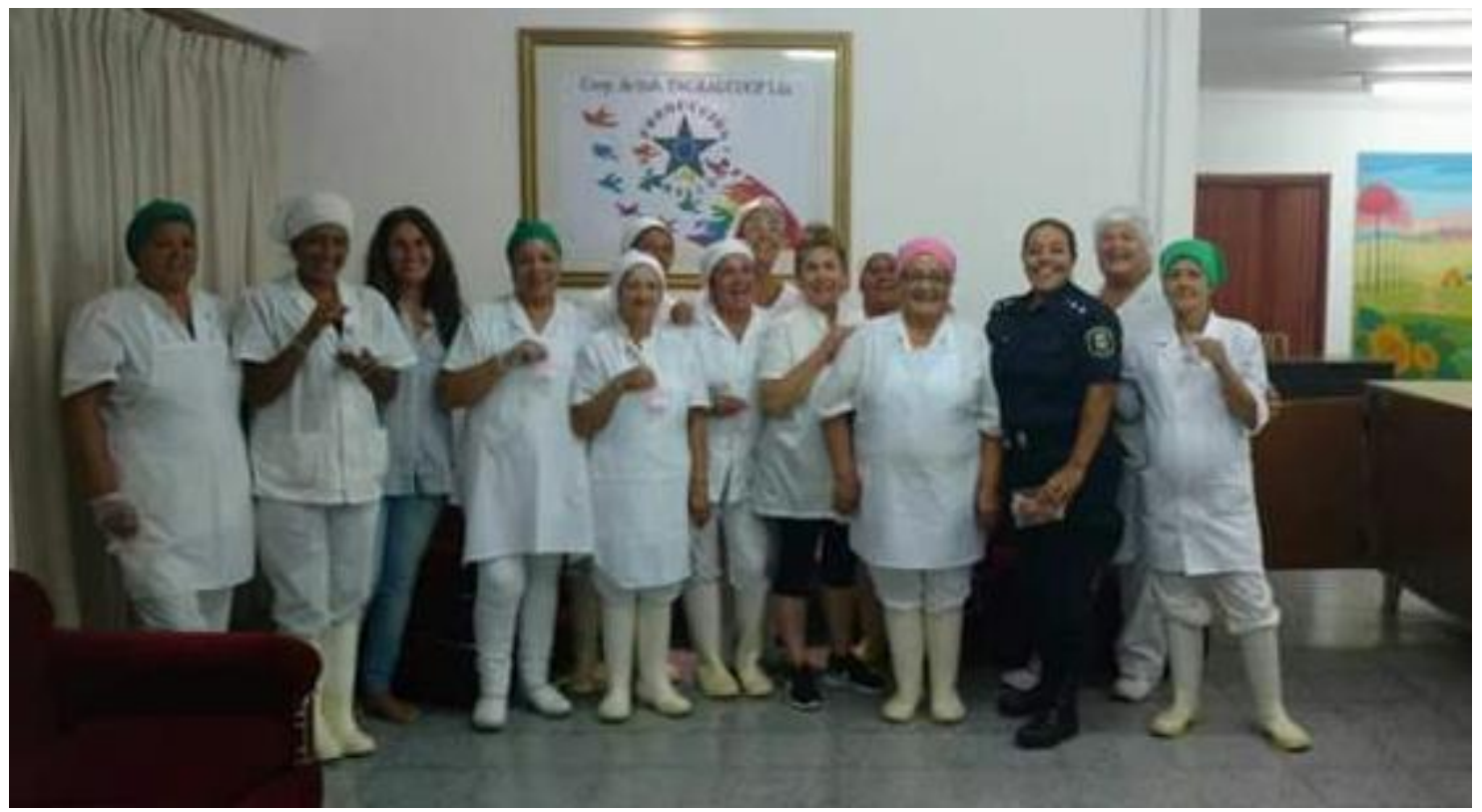

De izquierda a derecha: Alicia, Solveig, Pabla, Teresa, Teresa, Claudia, Juana, Mónica, Mónica, Moni, Analía, Angie ${ }^{98}$.

Fuente: Archivo Engraucoop.

${ }^{98}$ Las mujeres ubicadas en la posición $3^{\circ}$ y $12^{\underline{0}}$ en la foto no pertenecen a la cooperativa, por lo que sus nombres no están en el epígrafe. 


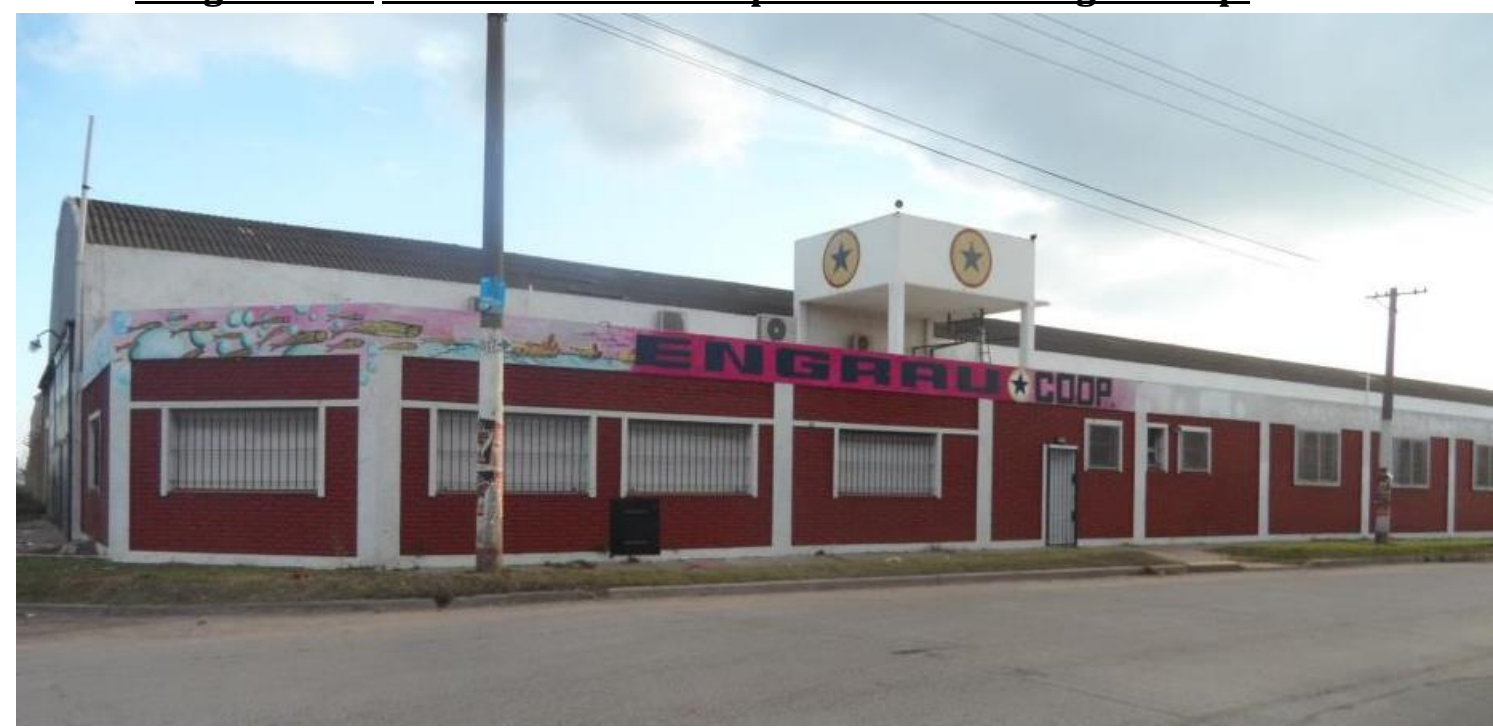

Fuente: Archivo Engraucoop.

\section{Análisis comparativo de los procesos de recuperación de empresas pesqueras de Necochea y Quequén}

Este apartado está subdividido en cuatro partes. En la primera, retomaremos las definiciones expresadas en el capítulo 3 acerca del conflicto social y de su expresión en la industria pesquera argentina y bonaerense, a fin de abordar una muestra del conjunto de acciones de conflictividad sociolaboral ligada a la recuperación de las empresas pesqueras. Para ello nos valdremos del instrumento de carga del Seminario de Investigación Sobre el Movimiento de la Sociedad, creando una base de datos con la totalidad de hechos de rebelión relevados de la prensa gráfica local de acuerdo al manual de carga diseñado por este grupo de investigación. La base de datos resultante permitirá identificar, contabilizar, describir y analizar cuantitativa y cualitativamente estos hechos de rebelión.

A fin de focalizar la especificidad de la dimensión social conflictiva propia de estos procesos y sus modalidades de consecución, primeramente se describirán y tipificarán las acciones cargadas, los sujetos que las llevaron a cabo y el contexto en las cuales aparecen, luego se efectuará una comparación con las modalidades típicas de accionar obrero en la generalidad de los procesos de recuperación de empresas y finalmente se abordarán las particularidades de estos casos a la luz de la carga de datos obtenida.

Retomamos la definición de conflicto social presentada en el capítulo precedente, mientras que la unidad de análisis que utilizaremos es la acción conflictiva, entendida como "toda acción colectiva o individual llevada a cabo por personificaciones de relaciones sociales clasificables como económicas, sociales o políticas, dirigida contra alguna expresión del estado de cosas existente" (SISMOS, 2014:9). Los casos analizados se engloban bajo la subcategoría "conflicto 
sociolaboral" tanto por los sujetos que los emprendieron como por los objetivos y desencadenantes de las acciones que efectuaron.

En la segunda parte, analizaremos el rol del Sindicato de la alimentación y de los delegados de planta en ambos procesos, que a nuestro entender actuaron como factores cruciales en cuanto a la dirección y consecución del conflicto y la amalgama de una fuerza social obrera capaz de llevar adelante dicha dirección. En tercer lugar, nos focalizaremos en la conformación de los colectivos autogestivos, caracterizando a los sujetos obreros que los integraron en los primeros tiempos de la recuperación de las empresas. Por último, nos centraremos en los cambios en el proceso de producción atendiendo los a procesos grupales y subjetivos alrededor de los mismos, tomando como ejes: los procesos de producción y circulación, los dispositivos de toma de decisiones, las funciones administrativas y el devenir del colectivo obrero, entre otras variables de análisis.

\subsection{Conflictividad social y recuperación de empresas}

En este apartado partiremos de la sistematización de las acciones conflictivas en torno a las cuales los trabajadores lograron recuperar las empresas pesqueras Industrial Pesquera y Engraulis en la ciudad de Necochea. Un conjunto de preguntas guía la tarea propuesta, y específicamente nos interesa saber: ¿Cuáles fueron las acciones de lucha que llevaron adelante estos grupos de asalariados/as? ¿Qué demandas organizaron los procesos de enfrentamiento en los que participan? ¿Cuáles fueron los resultados de sus acciones? Además de los trabajadores/as del pescado, ¿participaron otras organizaciones en la lucha?

Avanzando en el análisis podemos afirmar que los sujetos que protagonizaron las acciones colectivas de conflictividad fueron sujetos asalariados de las empresas recuperadas, y en determinadas acciones se sumaron otras organizaciones y personificaciones sociales que, en alianza con estos grupos de asalariados, acompañaron sus luchas y protestas. Específicamente quienes llevaron adelante las acciones son: los trabajadores de Engraulis, los trabajadores de Industrial Pesquera, Sindicato de la Alimentación, dirigentes gremiales de la Corriente Nacional del Sindicalismo Peronista y artistas. La organización Cruz del sur y los estudiantes y docentes de la carrera de Trabajo social no fueron mencionados en ninguna de las notas de la prensa, a pesar de las reiteradas referencias obreras a los mismos durante las entrevistas.

Analizando las organizaciones convocantes, se observa que en ambos procesos de recuperación la participación de grupos externos a los trabajadores fue disímil, mientras que La Recuperada realizó acciones en conjunto con otros actores, en el caso de Engraucoop sólo participó el STIA como organización localizada por fuera del espacio fabril.

El Sindicato de la Alimentación manifestó apoyo tanto en forma declarativa como con la presencia de sus dirigentes en las acciones iniciales de lucha en ambos casos. Asimismo, fue parte de las reuniones con la patronal en la delegación local del 
Ministerio de Trabajo ${ }^{99}$. De acuerdo a ello, vemos que el accionar sindical formó parte de las acciones más combativas como así también de la mayoría de las reuniones entre partes, mientras que no se incluyó en las manifestaciones de baja intensidad realizadas por los trabajadores.

A continuación, presentamos tres cuadros con los valores totales y discriminados por proceso de recuperación. En el primero se clasifica la cantidad de acciones emprendidas por los distintos sujetos, sistematizando lo enunciado precedentemente:

Tabla №21. Cantidad de acciones conflictivas de acuerdo a los sujetos que las emprenden. Valores totales y discriminados por empresa recuperada:

\begin{tabular}{|l|c|c|c|c|}
\cline { 2 - 5 } \multicolumn{1}{c|}{} & \multicolumn{4}{c|}{ Cantidad de acciones emprendidas } \\
\hline $\begin{array}{l}\text { Sujetos que emprenden la } \\
\text { acción }\end{array}$ & $\begin{array}{c}\text { La } \\
\text { Recuperada }\end{array}$ & Engraucoop & Ambas & Total \\
\hline Trabajadores & 9 & 9 & 1 & 19 \\
\hline Trabajadores y Sindicato & 3 & 8 & 2 & 13 \\
\hline $\begin{array}{l}\text { Trabajadores y otras } \\
\text { organizaciones políticas }\end{array}$ & 5 & - & - & 5 \\
\hline $\begin{array}{l}\text { Trabajadores y otras } \\
\text { personificaciones sociales }\end{array}$ & 1 & - & - & 1 \\
\hline $\begin{array}{l}\text { Dirigentes gremiales y } \\
\text { organizaciones políticas }\end{array}$ & 1 & - & - & 1 \\
\hline Total cantidad de acciones & $\mathbf{1 9}$ & $\mathbf{1 7}$ & $\mathbf{3}$ & $\mathbf{3 9}$ \\
\hline
\end{tabular}

Fuente: Elaboración propia en base al relevamiento realizado.

Aquí vemos que los trabajadores de ambas empresas junto al Sindicato de la alimentación fueron los principales protagonistas de la conflictividad sociolaboral ligada a los procesos abordados. Luego, en el caso de La Recuperada se añadieron otras 7 acciones más realizadas junto a otras personificaciones sociales. La mayor cantidad de acciones comunes entre el sindicato y los trabajadores de Engraulis en comparación con el proceso de Industrial Pesquera se remite a los dos tiempos del conflicto, durante los cuales transcurrieron varias reuniones entre partes en la sede local del Ministerio de Trabajo.

En relación al modo en que estos trabajadores luchan, es posible observar que las formas de rebelión adoptadas son variadas y se cristalizan en los ya conocidos nuevos y viejos repertorios de protesta: toma de lugar de trabajo, bloqueos, cortes de calle, manifestaciones, comunicados de prensa, actividades artísticas y festivales, huelgas, reuniones entre las partes y ocupación de edificios públicos. Estas formas de rebelión pueden agruparse según sean acciones discursivas, acciones institucionales o acciones directas. Según el manual de cargas de SISMOS, los diferentes tipos de acciones registradas nos hablan de desiguales niveles de

\footnotetext{
99 Nogueira, M.L. (2017). Las trincheras de la resistencia obrera en la industria pesquera bonaerense. Análisis comparativo a partir de una conflictividad social heterogénea (1997-2012). Ponencia presentada en las VII Jornadas Interdisciplinares de Estudios Portuarios, Universidad de Cádiz, 13, 14 y 15 de septiembre de 2017.
} 
implicancia corporal en las acciones ${ }^{100}$. Para el caso de las acciones analizadas la mayoría de ellas fueron directas y solo algunas de ellas discursivas -como los comunicados de prensa. Es decir que, siguiendo estos criterios, podemos afirmar que la mayoría de las acciones emprendidas por estos grupos obreros tuvo un alto grado de implicancia corporal.

Las tomas de los lugares de trabajo fueron las únicas acciones que se prosiguieron en el tiempo, en un primer momento con la finalidad de regularizar la situación laboral y luego como parte de la lucha por la recuperación de la empresa bajo gestión obrera. De las tres ocupaciones, la primera se extendió por un mes, y las dos restantes se continuaron luego bajo la forma de constitución de empresas recuperadas. Las ocupaciones, entonces, fueron las acciones transversales de estos conflictos, a las que se superpusieron otras formas de rebelión transitorias -de menos de 12 horas de duración- desde las manifestaciones en la vía pública hasta las reuniones entre partes; estas últimas predominaron hacia el final del período conflictual.

También cabe destacar que luego de meses de lucha la acción ilegal "ocupación del lugar de trabajo" -en tanto así es nombrado por la legislación vigente el hecho de la apropiación obrera de la propiedad privada empresarial- se transformó en una acción legal, tras haber obtenido el permiso de los jueces intervinientes en las causas de las quiebras para continuar con la producción como cooperativas de trabajo ${ }^{101}$. El cambio en el carácter legal de esta misma acción se obtuvo en el transcurso del proceso de quiebra empresarial, al modificarse los destinatarios de la acción, no los objetivos, ya que en ambos casos el fin buscado fue la reactivación de la unidad productiva. En un principio este destinatario fue la patronal, y posteriormente el Estado, a cuyas entidades pertinentes los trabajadores solicitaron el permiso para la continuación de la producción bajo su propia gestión. Esta obtención de legitimidad social y política nos habla de cambios en las relaciones de fuerzas durante el conflicto, que permite que el reclamo obrero avance temporalmente sobre la propiedad capitalista de los medios de producción con el aval del propio Estado. Este pasaje se llevó a cabo también al interior de la fábrica y del grupo obrero que la ocupaba, autorizándose ellos mismos a ser los ocupantes del edificio excluyendo a los patrones. Esta auto-autorización se produjo luego de semanas en las que la planta ocupada permaneció abierta para los empresarios, quienes continuaban instalándose en las oficinas del piso superior. En La Recuperada, el viraje práctico y conceptual que significó la autorización obrera para apropiarse de su lugar físico de trabajo, propiedad patronal, se produjo una mañana, por iniciativa de los trabajadores, cuando su bronca e incertidumbre crecientes se impusieron

100 SISMOS (2014). Óp. Cit., pp. 3.

101 Causas INDUSTRIAL PESQUERA NECOCHEA S.A.I.C. S/ QUIEBRA (GRANDE) Número de Expediente: 29758 y ENGRAULIS S.A. S/ QUIEBRA (GRANDE) Número de expediente: 37489. La causa judicial de la firma Industrial Pesquera se encuentra en proceso en el Juzgado Civil y Comercial №1 de Necochea, mientras que la de Engraulis transcurre en el Juzgado Civil y Comercial №2 de la misma localidad. 
sobre los patrones, echándolos de la planta y diciéndoles que no volviesen a entrar: la fábrica ya era propiedad de los obreros ${ }^{102}$. En Engraucoop, una trabajadora se instaló a vivir allí para impedir el ingreso de los patrones y personas ajenas al colectivo obrero más allá de la jornada laboral.

Volviendo al análisis de la diversidad de acciones emprendidas, la siguiente tabla refleja la cantidad y la modalidad de las acciones de rebelión para ambos colectivos obreros:

Tabla №22. Cantidad de acciones emprendidas discriminadas por forma de rebelión. Valores totales y discriminados por cada empresa recuperada:

\begin{tabular}{|l|c|c|c|c|}
\cline { 2 - 5 } \multicolumn{1}{c|}{} & \multicolumn{4}{c|}{ Cantidad de acciones emprendidas } \\
\hline $\begin{array}{l}\text { Tipo de acción / Forma de } \\
\text { rebelión }\end{array}$ & La Recuperada & Engraucoop & Ambas & Total \\
\hline Reunión entre partes & 3 & 8 & 2 & 13 \\
\hline Manifestación & 5 & 3 & - & 8 \\
\hline Festival & 5 & 1 & 1 & 7 \\
\hline Toma del lugar de trabajo & 1 & 2 & - & 3 \\
\hline $\begin{array}{l}\text { Conformación de una cooperativa/ } \\
\text { Recuperación }\end{array}$ & 1 & 1 & - & 2 \\
\hline Toma de un edificio público & 2 & - & - & 2 \\
\hline Huelga & - & 1 & - & 1 \\
\hline Comunicado de prensa & 1 & - & - & 1 \\
\hline Bloqueo de materia prima & - & 1 & - & 1 \\
\hline Corte de calle & 1 & - & - & 1 \\
\hline Total cantidad de acciones & 19 & 17 & 3 & 39 \\
\hline
\end{tabular}

Fuente: Elaboración propia en base al relevamiento realizado.

Se observa que las manifestaciones en la vía pública tuvieron un rol predominante en el accionar obrero, mientras que el grueso de las acciones en las que participaron los dirigentes gremiales fueron las reuniones entre las partes. La baja frecuencia en la utilización del formato de la huelga nos habla de la particularidad de estos casos, en los que la detención de la producción es promovida por la patronal, mientras que los trabajadores luchan por la reactivación de la misma. Aquí el motor del reclamo es el temor a la desocupación, no reivindicaciones salariales ni de condiciones de trabajo, por lo que la huelga careció de efecto y solo fue utilizada en la primera etapa el conflicto de Engraulis ante el anuncio de despidos. El bloqueo de materia prima también fue una táctica para preservar la fuente laboral: "prepararon 80 barriles de anchoa para llevárselos a Perú y nos plantamos impidiendo que los cargaran, pues nos sacaban nuestro trabajo", fue el comentario de un trabajador de Engraulis en la prensa local ${ }^{103}$. Vemos entonces cómo las ocupaciones se ubican como las acciones primordiales en este tipo de procesos, en los que el lugar de trabajo y los medios de producción que allí se encuentran son las únicas vías de presión obrera hacia una

102 Entrevista grupal a La Recuperada, realizada en octubre de 2011.

103 Ecos Diarios, edición del día 2 de junio de 2010. 
patronal en quiebra, que anunciaba además imposibilidad de pagar las indemnizaciones por despidos por falta de activos, como ocurrió en ambos casos ${ }^{104}$. Por otra parte, la realización conjunta de uno de los festivales por parte de ambos colectivos en lucha nos muestra indicios de construcción de una solidaridad de clase entre los agrupamientos obreros, lo cual fue reafirmado durante las entrevistas realizadas a ambos grupos, que exponen un apoyo mutuo durante los primeros períodos de los conflictos.

En cuanto a los propósitos de las acciones emprendidas, encontramos que los principales motivos que impulsan la lucha son la reactivación de la unidad productiva y el percibimiento de los salarios adeudados, los cuales junto con la regularización de la producción y la reincorporación de los trabajadores despedidos conformaron el conjunto de las metas de las acciones emprendidas por los obreros en un tiempo previo a la consolidación de la quiebra y el cierre de las empresas. Una vez sobrevenida esta situación, las metas se vincularon específicamente con la recuperación de las empresas bajo gestión obrera; y en un tiempo posterior los objetivos fueron la reactivación del sector pesquero local. Las acciones que buscaron la obtención de ingresos monetarios para los trabajadores ocurrieron esporádicamente durante casi todo el período relevado, ya que las situaciones de escasez obrera se enmarcaron tanto en el detenimiento de la producción y cese de pago de los salarios por parte de la patronal como en las dificultades de rentabilidad y continuidad laboral una vez iniciada la autogestión. Cabe destacar que cada acción generalmente conllevó más de una meta en su consecución. En el siguiente cuadro se puntualizan las acciones emprendidas de acuerdo a sus metas inmediatas:

104 Nogueira, M.L. (2012). La Recuperada. Primeros pasos en la experiencia de autogestión de trabajadores/as del procesamiento pesquero. En Revista Temas de Patrimonio Cultural 30. Argentina de Puertos III Jornadas Red de Estudios Portuarios, Buenos Aires 2011, Weisser, M. (comp.) 1a ed. - Buenos Aires: Ministerio de Cultura, y Nogueira, M.L. (2014). Recuperación de fábricas y subjetividades obreras: el caso de las trabajadoras de Engraucoop (Quequén). En Grande, E., Cuerpo y subjetividad, 1ํEd., CABA: Asociación Argentina de Profesionales de la Salud Mental. 
Tabla №23. Cantidad de acciones emprendidas de acuerdo a las metas perseguidas. Valores totales y discriminados por cada empresa recuperada:

\begin{tabular}{|l|c|c|c|c|}
\cline { 2 - 5 } \multicolumn{2}{c|}{} & \multicolumn{3}{c|}{ Cantidad de acciones emprendidas } \\
\hline \multicolumn{1}{|c|}{ Meta inmediata de la acción } & $\begin{array}{c}\text { La } \\
\text { Recuperada }\end{array}$ & Engraucoop & Ambas & Total \\
\hline $\begin{array}{l}\text { Reactivación de la unidad } \\
\text { productiva }\end{array}$ & 10 & 10 & - & 20 \\
\hline $\begin{array}{l}\text { Percibimiento de los salarios } \\
\text { adeudados }\end{array}$ & 8 & 2 & - & 10 \\
\hline $\begin{array}{l}\text { Obtención de ingresos monetarios } \\
\text { para los trabajadores de los }\end{array}$ & 6 & 1 & 1 & 8 \\
\hline $\begin{array}{l}\text { Reincorporación } \\
\text { trabajadores despedidos }\end{array}$ & - & 5 & - & 5 \\
\hline Regularización de la producción & - & 4 & - & 4 \\
\hline $\begin{array}{l}\text { Reactivación de la industria } \\
\text { pesquera local }\end{array}$ & 1 & 1 & 1 & 3 \\
\hline $\begin{array}{l}\text { Declaración de utilidad pública y } \\
\text { sujeto de expropiación }\end{array}$ & 3 & - & - & 2 \\
\hline $\begin{array}{l}\text { Defensa y recuperación de las } \\
\text { fuentes de trabajo }\end{array}$ & 2 & - & 1 & 2 \\
\hline $\begin{array}{l}\text { Generar conciencia social sobre la } \\
\text { situación crítica del sector } \\
\text { pesquero local }\end{array}$ & 1 & & & 3 \\
\hline
\end{tabular}

Fuente: Elaboración propia en base al relevamiento realizado.

Vemos que los destinatarios de las acciones emprendidas por ambos colectivos obreros fueron diversos: la patronal, el Estado Provincial y Municipal (entre los que se incluyen funcionarios del poder ejecutivo, legislativo y judicial) y la comunidad en general. En la primera etapa de los conflictos, el destinatario principal fue la patronal, a través de las demandas de regularización de la producción y del trabajo y posteriormente la reincorporación de los despedidos y el pago de las indemnizaciones. En la etapa que prosiguió a la recuperación de las empresas, el principal sujeto demandado fue el Estado, dadas las condiciones de precarización y dificultades de funcionamiento y subsistencia -con los consiguientes bajos ingresos monetarios- de ambas empresas recuperadas. La comunidad fue interpelada a lo largo del proceso, y sobre todo a través de las acciones de los festivales y peñas en las plantas procesadoras, buscando no solo el apoyo económico sino también una alianza social y política con los obreros que brindara apoyo moral para continuar la lucha y resistir los obstáculos que se les iban presentando.

La reacción de apoyo por parte de otras organizaciones sociales y políticas, como así también de los concejales y el juez local, permite considerar que en estos casos de empresas recuperadas se pusieron en juego reglas similares a los hechos inscriptos en momentos políticos "abiertos" (Gourevitch, 1986) o "ventanas políticas" (Kingdon, 1984), ya que los conflictos orientados por la demanda de mantención de las fuentes de trabajo obtuvieron legitimidad tanto social como política y gubernamental, y a la vez implicaron la apropiación temporaria de propiedad 
privada empresarial por parte de los colectivos obreros, es decir, revistieron un carácter contrahegemónico.

Mediante el análisis de la información obtenida concluimos que la principal motivación que impulsó a los/as trabajadores/as fue la amenaza a sus posibilidades reproducción dada su situación de inminente desocupación. En el caso de Necochea, el desguace del sector industrial pesquero acontecido desde fines de los 70 hasta el final del período abordado limitaba enormemente las posibilidades de reinserción laboral en la rama, y por el mismo motivo actuó como uno de los determinantes centrales de la elección de la lucha por la autogestión.

Las ocupaciones/tomas de los lugares de trabajo fueron entendidas como acciones transversales de estos conflictos, los cuales estuvieron atravesados por otras formas de rebelión. De este modo, los actos de conformación de cooperativas de trabajo con el correlato de la recuperación de las empresas bajo gestión obrera no implicaron necesariamente la resolución de los conflictos sino un período particular de los mismos. Las ocupaciones prosiguieron y la conservación de las fuentes de trabajo no guardó estabilidad sino importantes dificultades de subsistencia, continuidad productiva y rentabilidad, lo que generó nuevas acciones conflictivas. Por ello, la conformación de la cooperativa de trabajo con el correlato de la recuperación de la empresa bajo gestión obrera no significó aquí la terminación del conflicto sino un momento particular del mismo, en el que el sujeto patronal se desdibujó y aparentó desaparecer, aunque siguió estando presente en las acciones judiciales correspondientes a la quiebra y los juicios laborales.

Tanto la diversidad en las acciones emprendidas por los obreros como la radicalidad alcanzada señala un vínculo entre un alto grado de implicancia corporal y la gran necesidad de obtener los resultados buscados ante la limitación de alternativas laborales. Al respecto, estos casos muestran que, si la organización obrera a fin de evitar la desocupación logra adelantarse a la consumación del cierre de la empresa y la efectivización de los despidos, puede alcanzar una radicalidad tal que consiga impedir el desenlace buscado por el empresariado, esto es, el retiro individual de los obreros, sin mediar procesos de lucha. Para lograr este nivel de organización y lucha a fin de imponer la dirección obrera ligada a la recuperación de la empresa consideramos como factores determinantes a la historia previa de luchas colectivas, el rol de los delegados de planta, las trayectorias laborales de los obreros y las vivencias de desguace de la rama. Estas particularidades de las subjetividades obreras propias de los trabajadores de la industria pesquera necochense confluyeron aquí para incidir en el desarrollo de los procesos emprendidos. Las mismas serán abordadas en los siguientes apartados.

Finalizando esta síntesis vinculada a las acciones conflictivas implicadas en los procesos de Engraucoop y La Recuperada, mediante un análisis global de estos resultados en correlación con sus repercusiones a nivel comunitario, social e institucional -tanto en el ámbito nacional como internacional-, y su similitud con las acciones conflictivas propias de la generalidad de los procesos de recuperación de empresas, nos aventuramos a hipotetizar que este tipo de respuesta obrera nacida 
en un contexto de crisis profunda ha adquirido la suficiente legitimidad y potencia como para continuar reproduciéndose en la actualidad, dado que se conjuga en gran medida con el proceso de concentración y aumento del monopolio propios de la actual etapa imperialista del capital, que deja a su paso empresas que cierran por no ajustarse a este esquema de acumulación. Empalmando estos resultados con los datos cuantitativos aportados por Ruggeri -que contabiliza 63 empresas recuperadas conformadas entre 2011 y 2013- y la extensión de estos procesos en otros países, hipotetizamos que el ciclo de protesta que posibilitó la multiplicación de este tipo de experiencias en Argentina hoy se sintetiza en el afianzamiento de esta modalidad de accionar obrero, como parte de su repertorio de lucha y resistencia contra la precarización laboral y la desocupación que impone el capitalismo. La recuperación de empresas ha adquirido una legitimidad que se extiende más allá del contexto de álgida crisis que la propulsó, y, asimismo, el Estado reforzó esta respuesta obrera impulsando la misma mediante políticas públicas vinculadas a la cooperativización de las ERT. Ambos planos del fenómeno permiten hipotetizar el surgimiento de nuevos casos de empresas recuperadas, procesos que, como vimos, guardan en sí un carácter abierto, dinámico y sujeto a grandes modificaciones, tanto en relación a su supervivencia y rentabilidad como en su grado de combatividad.

\subsection{El plano sindical}

El Sindicato de Trabajadores de la Industria de la Alimentación era el gremio que nucleaba a todos los trabajadores de la industria pesquera de Necochea al momento de los conflictos por cierre que desembocaron en la constitución de las empresas recuperadas. En cuanto a su rol en estos procesos, lo primero que llama nuestra atención fue la disparidad en su política, que consistió en un gran apoyo al colectivo obrero de Industrial Pesquera mientras que unos meses más tarde se comportó de forma llamativamente diferente ante la misma situación vivida por los trabajadores de Engraulis. Este hecho aparece como significativo porque, a su vez, este sindicato no vivió un recambio de dirigencia ni a nivel de la línea política ni de las personas que ocupaban los cargos en la comisión directiva, es decir, fueron los mismos integrantes del sindicato quienes actuaron de forma disímil en ambos procesos.

En ambos procesos de recuperación, los delegados sindicales ocuparon un rol significativo, y existía un vínculo previo entre estos referentes obreros y los dirigentes gremiales. También en los dos casos el gremio se hizo presente en el marco de las acciones conflictivas contra los despidos y el cierre por quiebra anunciado. No obstante, tras el retiro de los empresarios, el sindicato tomó caminos opuestos. Veamos qué sucedió.

\subsubsection{El rol del Sindicato de la Alimentación}

El rol de los sindicatos en los procesos de recuperación fue conceptualizado como ampliamente heterogéneo. Tras analizar caso a caso cientos de experiencias de ERT 
en Argentina, se registró un espectro de actividad que fue desde el acompañamiento codo a codo a los trabajadores hasta el boicot y/o la indiferencia total en otros procesos.

De acuerdo Antivero, Elena y Ruggeri, la participación sindical fue registrada en el $87 \%$ de los procesos de recuperación relevados hasta 2010, pero en ellos solo en el 50\% de las actuales ERT valoran positivamente la intervención sindical (2012: 22). Por ello, la gran mayoría de trabajadores de las ERT no conservó vínculos con el gremio que los nucleaba hasta el momento de los despidos en el marco de la quiebra. Pocos fueron los ejemplos de continuidad en la afiliación gremial de los obreros luego de los despidos, tal como ocurrió en el caso de la cerámica Zanón que modificó el estatuto gremial a fin de incluir a los trabajadores autogestivos cooperativizados. En los casos abordados, ambos grupos obreros se encontraban agremiados al Sindicato de la Alimentación, alineado con la CGT ${ }^{105}$. La conducción sindical del STIA necochense, entre los años 2010 y 2012 tuvo como representante a Juan Pablo Moreno, de alineación política peronista. Como vimos en el apartado anterior, tanto él como Guillermo Daniel, abogado gremial, formaron parte de muchas de las acciones conflictivas obreras en ambos procesos de recuperación, con la diferencia de que en el caso de La Recuperada continuaron haciéndose presentes en la planta procesadora, colaboraron con recursos materiales para los trabajadores (cajas de alimentos, donaciones para festivales), y brindaron representación legal durante toda la causa de la quiebra y el pedido de expropiación, que prosigue hasta la actualidad. Los trabajadores de La Recuperada mantienen una representación paternalista del sindicato, que según ellos "actuó como un padre con un hijo", acompañando y apoyando al colectivo obrero en la reactivación de la unidad productiva.

En el caso de Engraucoop, de acuerdo a los trabajadores el vínculo con la dirigencia gremial finalizó tiempo después de la consumación de los despidos, generándose desde los obreros una fuerte enemistad y una pérdida de referencia sindical. Por ello, mientras que los trabajadores de La Recuperada (ex-Industrial Pesquera) asiduamente elogian el accionar sindical al referir su lucha por la autogestión obrera y recalcan que "el sindicato se portó muy bien"106, obreras de Engraucoop dicen de los mismos dirigentes frases como "quedamos en la calle y se olvidaron de nosotras"107.

Por otra parte, podemos diferenciar claramente el tinte de las acciones conflictivas impulsadas por los propios trabajadores y de las que fueron promovidas por la dirigencia gremial. Como vimos en el subapartado anterior, la combatividad y las acciones más radicalizadas fueron impulsadas por las propias bases obreras. En algunas de ellas el STIA prestó acompañamiento con presencia y recursos, mientras

\footnotetext{
${ }^{105} \mathrm{Al}$ respecto, cabe destacar que el SOIP, en su surgimiento, tuvo seccionales en Necochea y también en Bahía Blanca, que con los años desaparecieron. Por ese motivo los obreros de la industria pesquera quedaron agremiados por el Sindicato de Trabajadores de la Industria Alimenticia (STIA).

106 Entrevista grupal a la Recuperada, realizada en octubre de 2011.

107 Entrevista grupal a Engraucoop, realizada en octubre de 2013.
} 
que en otras se mantuvo ausente. Pero el origen de todas las acciones conflictivas por fuera de las reuniones de partes fueron los mismos trabajadores autoorganizados. Vemos aquí nuevamente cómo puede ubicarse la combatividad obrera por fuera de la dirigencia sindical, pero que sin embargo retorna hacia ella y busca su apoyo y referencia cada vez. Esta cuestión se vincula a las trayectorias laborales enmarcadas en el trabajo asalariado compartidas por el colectivo obrero, las cuales poseían un enlace previo con la agrupación sindical, un sentido de pertenencia constituido en relación con la misma y la vivencia de imbricación entre la sindicalización, el puesto de trabajo en el sector y sus condiciones laborales. Por ello, los trabajadores de La Recuperada recalcan que la idea de recuperar la empresa mediante la conformación de una cooperativa fue propuesta por el sindicato. El grupo obrero llevó a cabo la cooperativización luego de haber sido convencido por la dirigencia sindical de su viabilidad y también de su diferencia con respecto al trabajo en una cooperativa fraudulenta. Solo después de ello, los trabajadores transformaron conceptualmente la ocupación de la planta procesadora en recuperación de la fábrica bajo gestión obrera, a pesar de haber previamente materializado las acciones propias de este proceso por sus propios medios, sin conocer otros casos, con el único objetivo de sobrevivir mediante su trabajo. En el caso de Engraucoop, de acuerdo a las trabajadoras, el Sindicato no impulsó la cooperativización, sino que se limitó a dar consejos sobre no quedar cautivas del trabajo tercerizado ${ }^{108}$. ¿Por qué esta actuación disímil en ambos casos, que en muchos puntos son similares entre sí?

Al entrevistar al abogado gremial, Ernesto Daniel, hallamos que el motivo de la discontinuidad sindical en este último proceso se debió al "conflicto de intereses" entre los mismos trabajadores: como vimos anteriormente, un grupo de ellos quería recuperar la empresa mientras que el resto prefería que se proceda lo más rápidamente posible a la subasta de los bienes empresariales y a retirarse del lugar de trabajo, a fin de cobrar sus indemnizaciones. Por este motivo, el segundo grupo se oponía a la consecución de la ocupación y de la producción bajo gestión obrera, entrando en abierta confrontación legal y material con el primer grupo, que luchaba por la continuidad autogestiva inmediata. La posición del gremio en este conflicto fue retirarse de la situación, desvinculándose del conjunto de ex-empleados de Engraulis, a fin de no tomar parte en este conflicto intraobrero. No obstante, durante la entrevista Daniel dio muestras de apoyo hacia la salida autogestiva, mostrando su conveniencia para el conjunto de trabajadoras, incluso para las que rechazaron la idea de recuperación:

El grupo que no quiso la autogestión no entendió que la permanencia en la planta y el uso de las instalaciones las favorecía igualmente en su reclamo por las indemnizaciones, ya que esto genera la conservación y el mantenimiento de la planta. De lo contrario, el edificio se deteriora por el abandono, y se corre el riesgo de rotura del inmueble o saqueo del mobiliario, licuándose de esta forma

${ }^{108}$ Entrevista grupal a Engraucoop, realizada en octubre de 2012. 
el monto que la empresa en quiebra obtendría de la subasta, disponiendo de menos activos para pagar las indemnizaciones (Guillermo Daniel, abogado del STIA seccional Necochea) ${ }^{109}$.

A pesar de simpatizar con la salida autogestiva, y de haber realizado junto con las obreras de Engraucoop las primeras presentaciones en la causa judicial solicitando el uso de las instalaciones para continuar con la producción vía autogestiva, al recibir la disconformidad del agrupamiento obrero que insistía con el retiro de las instalaciones por parte de Engraucoop, la conducción gremial se ubicó por fuera de la disputa intraobrera, y en esta decisión se retiró del conflicto en general y también del acompañamiento a cada trabajadora en particular. Por ello, las trabajadoras de Engraucoop refieren tanto un abandono patronal como un abandono sindical, y en ese camino recurrieron al Estado en sus distintos estamentos (ejecutivo, legislativo y judicial) para obtener apoyo en su proyecto autogestivo. Este desenlace señala también otro aspecto del proceso que viene al caso, que es el hecho de que ninguna otra organización se involucrase en el conflicto como sí lo hizo el grupo Cruz del sur y los estudiantes y docentes de la carrera de Trabajo Social en el proceso de La Recuperada. Aquí, puede pensarse que las organizaciones y personificaciones sociales que se aliaron con los obreros de La Recuperada influyeron en la mayor implicación del gremio y en su mayor su apoyo al emprendimiento autogestivo.

En estos dos casos se confirma, entonces, la heterogeneidad del accionar sindical en los procesos de ERT, ya que incluso una misma dirigencia gremial con pocos meses de distancia temporal llevo a cabo una política contrapuesta. Esto permite hipotetizar que:

1) En principio, los sindicatos no tienen una línea política uniforme ni preconcebida en los casos en que, por quiebra o vaciamiento o cese de la producción con despidos, un colectivo obrero decide recuperar la empresa bajo su propia gestión;

2) por ello, tanto las cuestiones coyunturales como el grado de presión y convencimiento de la base obrera que apuesta por la recuperación, y las alianzas sociales que se generan en cada proceso, pueden ocasionar respuestas disímiles de un mismo gremio. De acuerdo a ello, podemos establecer como variable fundamental las correlaciones de fuerzas al momento de los conflictos, y las características de las fuerzas sociales obreras constituidas al calor de los mismos.

3) Por otra parte, sea cual fuera la directriz del accionar sindical, los obreros en lucha por la recuperación guardan expectativas de apoyo y acompañamiento sindical. En este sentido, los trabajadores adjudican un rol activo y facilitador a las dirigencias gremiales, cuya diferencia con la realidad provoca mayor 0 menor decepción, sobre la base de esta expectación previa.

4) Finalmente, se verifica aquí que la concreción del proyecto autogestivo en ambos casos tuvo cierto apoyo sindical, pero que lo decisivo fue la voluntad

${ }^{109}$ Entrevista realizada en mayo de 2017. 
del grupo reducido de obreros que emprendió la continuidad laboral. En ninguno de los casos fueron procesos impuestos desde arriba por la dirigencia, sino que el protagonismo fue claramente obrero, con el acompañamiento sindical, social o estatal desde un papel secundario.

\subsubsection{El rol de los delegados sindicales fabriles}

Diversos autores coinciden en señalar en los procesos de recuperación el papel decisivo de los delegados gremiales de planta, quienes influenciaron desde su activismo y referencia previa al colectivo obrero que llevó a cabo la lucha por la recuperación de las empresas, más allá de la implicación o no del gremio que los nucleaba (Magnani, 2003; Ghigliani, 2003; Rebón, 2004, Ruggeri, 2010).

Al respecto, Ruggeri (2010:49) señala que los antiguos delegados sindicales de la firma en quiebra integran el 35\% de los consejos administrativos de las respectivas cooperativas conformadas en el marco de la recuperación de la empresa en cuestión. Indagando acerca de las causas de la presencia de delegados de planta en los procesos, Antivero, Elena y Ruggeri (2012:25) señalan que la experiencia en luchas y los conocimientos previos que los delegados adquieren en el ejercicio de su función son factores a destacar. Brunet y Pizzi (2011:234) también atribuyen a los delegados de planta un rol fundamental, actuando como conductores de las acciones colectivas en todas las empresas recuperadas. Estos autores agregan, a los causales señalados anteriormente, saberes de los delegados con respecto a negociaciones con la patronal y el Estado, la generación de alianzas sociales y políticas, la predisposición para actuar como representantes de un colectivo y de ser considerados como tales por parte del resto de trabajadores. Es decir, la militancia gremial intrafabril previa se transforma luego en un factor de conducción e incidencia en la conformación de las fuerzas sociales obreras enmarcadas en los procesos de recuperación. No sorprende entonces que en los casos necochenses veamos como característica el rol preponderante de los delegados de planta: Darío en el caso de La Recuperada, Analía y Gonzalo, en el caso de Engraucoop. Sin embargo, también hallamos la influencia de otros delegados sindicales pero en sentido contrario a la recuperación.

Ordenando los resultados obtenidos en este punto a partir del trabajo de campo realizado, vemos que en las entrevistas realizadas constatamos la existencia de luchas obreras previas encabezadas por Darío contra la patronal, por varias reivindicaciones. Veamos los fragmentos de los testimonios al respecto:

Darío: Después que entré efectivo al año hubo elecciones de delegados acá dentro y nosotros en ese momento estaba muy dividido en el trabajo lo que eran los fileteros y los peones (...). Y yo ahí al año es que me postulo delegado también por la decisión de mis compañeros que quisieron. (...) Y bueno en el transcurso de ese tiempo a mí personalmente me pasaron muchas cosas, principalmente uno querer informarse, interiorizarse, cuáles son las cosas que te corresponden, yo empecé a leer el tema del convenio colectivo de trabajo, leí todo lo que correspondía, y ahí es donde empecé a notar que a nosotros no nos 
cumplían muchas cosas. 0 sea, estábamos mejor al pasar de una cooperativa trucha a ser efectivos, pero no teníamos beneficios que nos correspondía, había cosas que no nos daban.

Entrevistadora: $¿$ De eso vos te informaste por tu cuenta o por medio de otras personas?

Darío: En el sindicato, yo fui allá a informarme y no tenía buenas referencias de lo que era el sindicato. Y lo primero que yo hice es ir allá a decirles que no estaba de acuerdo cómo se manejaban las cosas, que notaba que nos faltaban cosas que nos correspondía y que no nos daban, y lo que yo decía era que acá había que hacer algo y que nos tenían que dar lo que nos correspondía. Principalmente porque era ropa necesaria de trabajo, todas las herramientas de trabajo, los horarios de descanso no nos respetaban, las horas de trabajo tampoco, teníamos horas extras pero era obligación quedarte, no era que te podías ir, o sea la persona que se quería ir al otro día no venías más. Esa era otra diferencia que había con los fileteros, el filetero a las tres se iba, el peón no se podía ir, se tenía que quedar. Esa es otra cosa que, con el tiempo, con ayuda -no mía sino de mis compañeros-, nos pusimos en contra y fuimos cambiando la mentalidad de los patrones hacia nosotros... Ya en ese momento empezamos a ponernos firmes y ya nos tomaban más en cuenta110.

De este testimonio se desprende que, una vez superado -de manera victoriosa- el conflicto en la cooperativa fraudulenta mencionado en el capítulo 2, ya siendo trabajador efectivo Darío continuó expresando una motivación interna por emprender acciones relativas a mejorar condiciones de trabajo, y en el camino encontró eco entre sus compañeros de trabajo. En Industrial Pesquera comenzó su experiencia y su formación como delegado de planta impulsando una lucha reivindicativa por el incumplimiento de derechos laborales contenidos en la legislación vigente, incumplimientos detectados por él mismo y transmitidos al colectivo obrero. Esta lucha, a su vez, se enmarca en un trato desigual referido a las condiciones de trabajo de los peones con respecto a los fileteros, división obrera que, mediante las exigencias de cumplimiento de derechos negados al grupo más precarizado, Darío propuso. La adhesión de otros trabajadores al reclamo expresó que esta iniciativa individual cobró carácter colectivo, y por ello la metodología en general fue exigir reuniones con la patronal, y cuando las mismas no lograban su cometido realizaban huelgas de brazos caídos hasta obtener lo demandado:

Darío: Arrancamos con los reclamos y medidas para mejorar las condiciones laborales de los trabajadores: pago de horas extras, entrega de ropa de trabajo, se consiguió que nos den los tiempos de descanso según la ley de contrato de trabajo, que nos paguen en tiempo y forma, se efectivizó a personas que estaban pasadas en tiempo de contrato eventual, se dejó de utilizar mujeres para trabajar dentro de la cámara de frío, como así también se eliminó la tarea de trabajo pesado a mujeres.

Entrevistadora: ¿Qué medidas tomaron para obtener esos reclamos?

110 Entrevista grupal a La Recuperada, octubre de 2011. 
Darío: Nunca fue necesaria una medida de paro total de la planta, fue un trabajo de presión en conjunto entre el sindicato, la comisión interna y los compañeros para lograr las mejoras laborales que necesitábamos. Hacíamos reuniones y cuando no cumplían parábamos de trabajar. Ellos nos respetaban mucho porque nosotros siempre íbamos en apoyo cuando había conflicto en otras fábricas, y sabían que si llegamos a tener que tomar una medida de fuerza grande íbamos a contar con mucho apoyo y no querían tener un quilombo grande (Darío, 35 años, filetero de La Recuperada) ${ }^{111 .}$

Además de demostrar de qué forma los obreros transformaron en lucha las condiciones de trabajo previamente aceptadas, como rasgo a destacar en este testimonio situamos también la mención de las alianzas con obreros y delegados de otras fábricas, considerada por Darío como una herramienta de presión ante la patronal, a la vez que expresión de solidaridad obrera interfabril. Es decir que la solidaridad y compañerismo más allá del propio lugar de trabajo se conceptualizó, desde la práctica, como favorecedora de las luchas futuras al interior de la planta procesadora, potenciando el poder obrero en combate con determinada patronal. A su vez, vemos en el testimonio de Darío la detección de que este marco de lucha "cambió la mentalidad de los patrones hacia nosotros ${ }^{112 ", ~ q u i e n e s ~ f u e r o n ~ i m p e l i d o s ~}$ a conceder las cuestiones reclamadas. En este proceso, los empresarios reconocieron la conformación de una fuerza social obrera al interior de la planta procesadora capaz de disputar condiciones de trabajo y contratación, y actuaron en consecuencia.

Por otra parte, vemos que las luchas previas emprendidas en Industrial Pesquera cuestionaron una desigualdad intraobrera aparentemente naturalizada al interior de la unidad productiva, la diferenciación entre fileteros y peones que iba más allá del salario y la tarea, sentida como una injusticia y en desmedro de estos últimos. Bajo la premisa de la unidad obrera en el marco del cumplimiento para ambos sectores -y no solo para uno- del convenio colectivo de trabajo vigente, presuponemos que las luchas emprendidas bajo esta dirección obtuvieron una serie de conquistas que no solo se tradujeron en reivindicaciones materiales, sino que también elevaron la moral obrera de los peones. Vemos también que se cuestionó una estrategia patronal de dualizar la fuerza de trabajo al interior de la unidad productiva, a fin de extraer mayor plusvalía mediante la superexplotación de un sector obrero. Entonces, a una desigualdad objetiva en términos de diferentes tareas a realizar, la patronal superponía una desigualdad en la aplicación de los términos jurídicos de un mismo convenio laboral. De esta forma, mediante la vivencia cotidiana de esta desigualdad, no solo se reducían los ingresos de los peones y se extraía más plusvalía absoluta y relativa a partir de la explotación de su fuerza de trabajo, sino también se promovía en los fileteros un sentimiento de superioridad. En base a la diferencia objetiva producto de la división de tareas (en la cual, la labor filetera requería mayor tiempo de formación, especialización, y destreza que la

111 Entrevista a Darío, filetero y delegado de Industrial pesquera, realizada el 2 de marzo de 2018.

112 Entrevista grupal a La Recuperada, realizada en octubre de 2011. 
realizada por los peones) los empresarios desigualaron mediante salario y derechos laborales las condiciones de explotación de la fuerza de trabajo, creando una competencia y enemistad intraobrera a fin, no solo de implementar la superexplotación, sino también de impedir la organización del conjunto obrero contra la patronal.

Por este cuestionamiento a la enemistad que la patronal impuso al conjunto de los trabajadores -más allá de la división objetiva de tareas-, presuponemos que el accionar de Darío en sus inicios generó resistencia en los fileteros, quienes probablemente no visibilizaban la situación de injusticia, discriminación o desigualdad en las condiciones laborales, o bien la consideraban como inobjetable. Sin embargo, la orientación de la lucha impulsada por la igualación jurídica terminó imponiéndose por sobre la dualización de la fuerza de trabajo preestablecida por la patronal:

\begin{abstract}
Eso es otra cosa que se fue cambiando también, antes que pasara el conflicto. Siempre se daba un adelanto acá, o cuando se pagaba la quincena lo que hacían antes era darlo proporcional, el que más tenía se le daba un poco más porque tenía más para cobrar y el que menos tenía se le daba menos, cuando no alcanzaba para todos, el que tenía tres mil se le daba, no sé 1500, y el peón que tenía 700 se le daban 350. Entonces fue esa otra cosa que hablándolo con mis compañeros los peones, no veía justo que, aunque ellos tengan más para cobrar, a nosotros nos den la mitad. Entonces yo agarré y dije, bueno, si hay tanta plata que sea parejo para todos, si hay mil que sea mil para todos y bueno si un peón tiene 800 se le paga el total y al filetero bueno... Y patalearon pero bueno, se la tuvieron que comer (Darío, 35 años, filetero de La Recuperada) ${ }^{113 .}$
\end{abstract}

En síntesis, conjeturamos que los reclamos vinculados a la mejora en las condiciones de trabajo por incumplimiento patronal de regulaciones previstas, luego actuaron como precursores de la resistencia a los despidos y recuperación de la empresa.

Llegado el momento del conflicto por el detenimiento de la producción a fines de 2010, se observa una adjudicación, por parte del colectivo obrero, de roles de conducción hacia los dos delegados de planta, Darío y Rubén. En el caso de Darío este rol fue luego asumido: él fue quien actuó como portavoz de las demandas obreras de salarios adeudados y reanudamiento de la producción, y luego condujo a la fracción obrera más radicalizada. El accionar de Rubén fue disímil, como veremos a continuación.

Una cuestión que merece destacarse y se extrae a partir de los testimonios obreros es la existencia de capas, o más bien fracciones de trabajadores, de acuerdo a su predisposición hacia la lucha y al cuestionamiento del orden laboral impuesto por la patronal. Tomando esta conceptualización a partir del famoso texto de León Trotsky "Clase, partido y dirección"-muy olvidado por la academia-, el autor no solo plantea la heterogeneidad de la clase obrera sino también su predisposición para seguir una o varias direcciones. A la dirección, a pesar de presentarse muchas veces encarnada por una o varias personas que conducen los conflictos, aquí la definimos

113 Entrevista grupal a La Recuperada, octubre de 2011. 
como una orientación política determinada que guía la lucha tanto en sus objetivos como en su metodología y alianzas para lograr esos objetivos. En el caso de Industrial Pesquera, constatamos aquí una división fundamentalmente entre un sector obrero más radicalizado, que encabezó las acciones de resistencia y rebelión y luego llevó a cabo la recuperación, cuyo liderazgo recayó en Darío, y otro sector de trabajadores más conservador, que, o bien no creía que con organización y lucha se podría revertir la situación, o desconfiaba de la cooperativa autogestiva o de la viabilidad del trabajo sin patrón, o bien no consideró cuestionar la explotación capitalista aún en un contexto de abandono patronal. Este sector adoptó la dirección acorde a la ideología dominante y aceptó el retiro del lugar de trabajo y el destino de desocupación impuesto. Ambos sectores obreros se conformaron como fuerzas sociales obreras y disputaron la dirección de la lucha.

Este aspecto es fundamental para el cuestionamiento de las conceptualizaciones que parten de considerar a la clase obrera de forma homogénea, desestimando las acciones de las fracciones más radicalizadas por no representar a la totalidad o a la amplia mayoría. En ocasiones, como sucede aquí, la lucha surge por iniciativa de unos pocos, y no se da sin resistencia e incluso boicot de una parte de la misma clase, la cual adopta otra dirección política o bien busca impedir la consecución de la dirección más radicalizada:

Las acciones directas fueron siempre por iniciativa de unos pocos, y esos pocos éramos nosotros... Decir ¿vamos a prender gomas? Y los que prendíamos gomas éramos nosotros, el resto no, tiraba la idea pero no querían poner el cuerpo. Cuando hubo que bloquear el hielo en la esquina también, se bloqueó. Cuando se bloqueó el hielo fue cuando no me quisieron abrir la puerta acá. Dijimos: Ah, ¿no nos quieren abrir la puerta? Entonces nosotros le bloqueamos el hielo. No trabajamos nosotros, entonces vos tampoco trabajás. Fuimos a la esquina con dos gomas cada uno y se las prendimos, al ratito el sereno que está en la esquina se agarró la bici y se fue... (Darío, 35 años, filetero de La Recuperada) ${ }^{114}$.

La fuerza social obrera más conservadora, que adoptó la línea promovida por el empresariado, fue conducida por el otro delegado de planta, Rubén. Es decir que, a su vez, este caso ejemplifica como determinados miembros de la dirección de un conflicto pueden "de un solo golpe" (Trotsky, 1940) pasarse al bando enemigo, en este caso, un delegado obrero que venía formando parte de las luchas precedentes por las condiciones de trabajo y contratación representó en esta ocasión los intereses de los patrones y transmitió sumisión a esta política. Los empresarios también quisieron cooptar a Darío, quien recuerda una llamada telefónica en la que intentaron que promueva el cese de una medida de fuerza ofreciéndole dinero a cambio de ello, lo que fue rechazado por él:

Entonces en una oportunidad me toca que recibo un llamado para ofrecerme cuánta plata quería para levantarle el bloqueo del hielo. Y yo ahí estaba con Julio

${ }^{114}$ Entrevista grupal a La Recuperada, octubre de 2011. 
y me acuerdo que le ponía el teléfono a él para que escuche lo que me estaban hablando, y me quería chantajear, me decía: Vamos a tomar un café, me decís cuánta plata es, pensalo, si querés te la quedás para vos, si no querés la repartís... No lo podía creer... Yo lo mandé un poco más a la mierda porque no me pareció bien. Me tuvo un rato largo hablando (Darío, 35 años, filetero de La Recuperada) ${ }^{115}$.

La fuerza social obrera más resignada y menos combativa se dejó conducirse, entonces, por los empresarios. La concreción de la división aconteció una mañana en la que el empresariado reunió a los obreros sin dar aviso de ello al sector radicalizado, a fin de prometer indemnizaciones si "se iban tranquilos", y también aduciendo que de proseguir el proyecto autogestivo la empresa no obtendría los subsidios estatales y por ello no se reactivaría la producción. En síntesis, la patronal intentaba dividir y confrontar a los obreros entre sí, y para eso se apoyaba en la figura de un delegado de planta quien ya poseía representatividad entre los obreros:

En ese momento ya estaba un poco abierto, estaban por decirte algo los delegados, Darío y Deschamps, y se notaba que había gente con el otro delegado y otros que acompañaban Darío. Y ellos creían que yo estaba en el medio, que estaba bien con unos y estaba bien con los otros. Y fue que ellos hicieron una reunión, la parte de la gente del otro delegado, el día sábado. Y me invitaron a mí a las seis de la mañana, y yo tenía que venir a fichar a las 7, y la armaron ahí para que no se enteraran ni Julio ni Darío. Y se me invita a mí y me dice: No te preocupes si vos no podés ir no vayas, nosotros te contamos, me dice el delegado, el otro. Pero como yo había faltado a reuniones anteriores decido venir. Entonces cuando llego a la reunión, estaban con Pablo Bruno, estaban todos presentes, me miraron así con asombro y me extrañó no ver a Julián, a Julio y a Darío, tuve la intención de mandarle un mensaje a Darío para... Eran los últimos días que estábamos todos juntos, eran ya los últimos días, y bueno ahí estaban el tema de los Repro y todas las cosas que se nos iban a dar, y estaba el tema de la cooperativa también, y entonces yo le pregunto a Pablo Bruno " ¿Y qué pasa armamos la cooperativa?" y me dice: "Y se pierden los Repro y créditos que puedan venir" Entonces yo me voy diciéndoles a ellos que si bueno, si el tema de la cooperativa nos iba a hacer perder los Repro y los créditos, sigamos... que no se haga la cooperativa (Mario, 53 años, filetero de La Recuperada) ${ }^{116 .}$

Y esa fue otra traba que tuvimos nosotros, porque nos tocó estar divididos con el resto de los compañeros, no porque nosotros quisiéramos, pero teníamos otro compañero delegado que laburaba para la otra parte y dividía, un poco se dividió y... Me acuerdo en otra oportunidad que organizan una reunión con los patrones todos menos nosotros cuatro, para decirle al dueño que nosotros estábamos planeando hacer una cooperativa acá adentro...

Julio: Y que ellos no estaban de acuerdo...

Darío: Y que ellos no estaban de acuerdo. Y bueno nosotros llegamos más tarde ese día, porque como nosotros habíamos estado toda la noche acá adentro, nos habíamos ido y para cuando habíamos vuelto ya habían hecho la reunión ellos. Y el propio dueño de acá nos llama y nos dice: Eh, no vinieron a la reunión ustedes, ¿Qué reunión? le decimos nosotros... La reunión que hicieron los

115 Entrevista grupal a La Recuperada, octubre de 2011.

116 Entrevista grupal a La Recuperada, realizada en octubre de 2011. 
compañeros de ustedes ¿Vos querés armar una cooperativa con los chicos?, Sí es cierto, nosotros queremos armar algo para empezar a trabajar, es verdad, y dijo Ah, no, está bien... Siempre se hizo el boludo el tipo, siempre. Lo que sí nos dijo es que si nosotros hacíamos la cooperativa los Repro no se los daban (Darío, 35 años, filetero de La Recuperada) ${ }^{117}$.

Vemos entonces que la división en dos direcciones principales constituidas como dos fuerzas sociales obreras en el proceso de Industrial Pesquera no solo provino de disímiles niveles de conciencia, predisposición a la lucha y perspectivas políticas, sino que fue producto a la vez de una maniobra patronal que perseguía el objetivo de que no se conformara la cooperativa de trabajo, a fin de que no prosiguiera la recuperación de la empresa y así poder disponer de forma inmediata de sus bienes en proceso de quiebra. La presencia del "otro delegado" fue utilizada por los empresarios para obtener credibilidad ante los trabajadores de que su mejor opción era no conformar la cooperativa.

En conclusión, la posición de las subjetividades obreras de los delegados tuvo en este caso desenlaces diferentes, hasta opuestos, pero ambas coinciden en que el hecho de que ocupar el lugar de delegado habilitó luego el rol de conducción de las fracciones obreras en conflicto, ya que el grueso de trabajadores delegó su respuesta política en las orientaciones propuestas por ambos delegados, uno enlazado a su vez con el secretario gremial del STIA y la organización Cruz del sur, y el otro aliado con la patronal y su intención de dilución del conflicto. En el caso de Darío, consideramos que su liderazgo se basó -más allá de cualidades personales- en el rol de portavoz del sector obrero que buscó resistir la amenaza de desocupación. Más allá de la determinación y el carisma que le son adjudicados al ex-delegado por el resto de trabajadores, las acciones realizadas fueron colectivas, no individuales, y en ocasiones la sugerencia de emprender tal o cual metodología de lucha provino de otros trabajadores, no de Darío. Si bien su aval fue fundamental para la concreción de las praxis de lucha y los debates que se daban en torno a ellas, esta influencia se debió para nosotros, a este lugar de portavoz y por ello, de la captación de cierta subjetividad colectiva, o de una disposición para materializar dicha subjetividad.

En el caso de Engraucoop el rol de los delegados guarda más matices, ya que, si bien también se produjo una bifurcación en las direcciones del conflicto propuesta por dos delegadas y, nuevamente, una formó parte de la lucha por la recuperación mientras que la otra se incluyó en la fracción que proponía retirarse del lugar de trabajo y esperar la subasta del inmueble, ambos trabajadores emprendieron alianzas con otras personificaciones "híbridas" implicadas en la planta procesadora. Estas personificaciones son híbridas porque, además de ser ambas trabajadoras administrativas y por ellos guardar una mayor jerarquía con respecto a las obreras (por trabajar en lugares separados y tener una vinculación directa con la patronal), una de ellas, Claudia, había sido accionista minoritaria durante un lapso de

117 Entrevista grupal a La Recuperada, realizada en octubre de 2011. 
aproximadamente 8 años en Engraulis S.A., mientras que Patricia adoptó el lugar de apoderada legal de la empresa durante los dos períodos de agudización del conflicto en 2010 y 2011.

Analía y Gonzalo, delegados que condujeron el colectivo que conformó Engraucoop, emprendieron una alianza con Claudia; mientras que otra delegada gremial del sector de producción, Mirta, se integró en un agrupamiento liderado por Patricia. La diferencia con el caso de La Recuperada se sitúa fundamentalmente en que la fracción detractora de la lucha por la recuperación sí se conformó como agrupamiento, creando una cooperativa de trabajo paralela y disputando el lugar de trabajo al grupo de Engraucoop, y asimismo intentando por vía judicial que el Juez impida su permanencia en las instalaciones de Engraulis.

Como aspecto similar al caso anterior vemos aquí nuevamente una división entre grupos obreros con distintas tareas, en este caso, entre las trabajadoras administrativas y las trabajadoras del sector de la producción. Las dos fracciones de delegadas se aliaron con estas personificaciones en vistas de obtener mayor fuerza social para su proyecto político. En el caso de la fracción liderada por Patricia con Mirta como ex delegada, podemos hipotetizar que, o bien descreían en su inicio sobre la viabilidad autogestiva, o bien priorizaron la posibilidad de cobrar las indemnizaciones lo antes posible y por ello actuaron bajo la premisa de que, de proseguir en funcionamiento la cooperativa, se dificultaría o atrasaría la subasta del inmueble. Sin embargo, en esta decisión cabe también ponderar los intereses patronales, que Patricia representaba. Al igual que en el caso de la Recuperada, podemos suponer que el empresariado prefería guardar para sí la propiedad del inmueble y los bienes al interior de la planta que cederla, aunque sea temporalmente, a los trabajadores, ya que también es moneda corriente la dilación de los procesos judiciales de quiebra y la asiduidad con la que los mismos terminan beneficiando a la parte empleadora, a desmedro de los trabajadores despedidos resultantes de la quiebra.

Pero volviendo al tema central de este apartado que es el rol de los delegados en los procesos, vemos que como sucedió en el caso anterior, aquí también la actuación de los delegados fue disímil y contrapuesta, y que junto a las trabajadoras administrativas vinculadas a la patronal también fueron ubicadas en un lugar de liderazgo de la lucha o conducción del conflicto, por parte del colectivo obrero.

También aquí se verifican luchas previas encabezadas por Analía y Gonzalo, por reclamos referidos a atrasos salariales fundamentalmente, a través de acciones en las que mediante huelgas o retención de tareas paralizaban la producción de la planta hasta obtener lo reclamado118. Este recorrido de lucha habilitó la construcción de la referencia obrera para con los delegados, que luego se convirtió en conducción de la lucha por la recuperación de la fábrica y en última instancia en liderazgo de la cooperativa y del funcionamiento autogestivo posteriormente

${ }^{118}$ Entrevista a Claudia, trabajadora de Engraucoop, realizada en marzo de 2018. 
asumido, ya que ambos delegados integraron el consejo de administración de Engraucoop.

Aquí también cabe resaltar, por un lado, la cuestión de género, ya que como vimos la mayoría de los trabajadores de Engraulis eran mujeres, con muchos años de trabajo en el sector. Volvemos a constatar aquí que la antigüedad laboral fue un factor de importancia para la consecución de la lucha, confrontándolo con la resignación de abandonar sus extensas trayectorias laborales a la incertidumbre de una indemnización ilusoria y reinserción en otra rama. La importancia de estas trayectorias obreras se enlaza en este proceso con el rol de cuidado adjudicado a la mujer/madre, la feminización del fileteado en el rubro conservero y la amenaza hacia la reproducción no solo de la propia vida, sino la de sus hijos, siendo muchas de ellas, además, jefas de hogar ${ }^{119}$. La necesidad de autonomía e independencia como mujeres trabajadoras y madres se enlazó en este proceso con la salida autogestiva. Analía, como delegada de planta, compartía este rasgo generalizado en el caso de Engraulis, y además vemos que con el correr del tiempo, su posición de conductora del proceso de recuperación contribuyó a que adquiriera saberes en cuanto a derechos y destinatarios de reclamos laborales más allá de la patronal y de la planta procesadora. Esto se vuelve visible analizando los trámites y procesos de negociación que luego del ingreso al concurso de acreedores recayeron en el ámbito estatal, fundamentalmente en la municipalidad, lugar que Analía desconocía hasta ese momento: "Al estar acá todo el día, yo nunca iba al centro y no sabía dónde quedaba la municipalidad"120, comentó la trabajadora.

Esta delegada resaltó por su conducción en el proceso mucho más que el delegado varón, ya que fue a ella y a las trabajadoras administrativas a quienes las obreras adjudicaron el rol de liderazgo, a una por su previa referencia en las luchas, a otra por sus saberes con respecto a la administración de la empresa y circulación de la producción, respectivamente. La consolidación de una fuerza social obrera basada en la alianza entre el grupo de trabajadores del área de producción y las trabajadoras administrativas que integraron Engraucoop, con la intermediación de los delegados de planta, fue uno de los rasgos que influyeron en el desarrollo de este proceso, junto con la manifestación de expresiones de una subjetividad obrera feminizada que, no solo por la preponderancia de su número sino también por sus características particulares, condujo el proceso de recuperación.

La fuerza social obrera más conservadora, en este caso, sumó a la alianza obrera un nexo con los empresarios y propuso una dirección del conflicto que estos últimos buscaban promover para diluir la organización obrera. En este sentido, no primó en este agrupamiento la expresión colectiva de una subjetividad obrera preponderantemente femenina, sino los intereses patronales. En este sector más conservador, a diferencia del proceso de La Recuperada, la delegada de planta cobró

119 Ecos Diarios, edición del 24 de junio de 2010.

120 Entrevista grupal a Engraucoop, realizada en octubre de 2012. 
un papel secundario en la conducción del grupo, ya que el mismo fue ocupado por la trabajadora administrativa representante de la patronal.

En síntesis, en este apartado quisimos visibilizar el rol del sindicato y los delegados de planta en ambos procesos de recuperación de empresas, para destacar las expresiones de estas personificaciones sociales y su incidencia tanto en la conformación de las fuerzas sociales obreras en pugna como en las manifestaciones colectivas de las subjetividades obreras de la industria pesquera necochense. Caba aclarar que nuestra perspectiva no considera que solo los delegados tuvieron un rol preponderante, sino, como expresamos anteriormente, fueron una de las partes constitutivas de la lucha desde su localización subjetiva diferenciada. Los colectivos obreros conformados, sus acciones de lucha y direcciones políticas tienen para nosotros la centralidad en el desarrollo de los conflictos. Por ello culminaremos este capítulo con un análisis pormenorizado de su caracterización desde los inicios de los procesos hasta el año 2012.

\subsection{La conformación de los colectivos autogestivos}

Aquí precisaremos la conformación de cada uno de los grupos que llevaron adelante los procesos de recuperación, a fin de poder visualizar cuántos integrantes emprendieron la conformación de la cooperativa autogestiva, qué puestos ocupaban en la empresa en quiebra, el tipo de contratación laboral que los enmarcaba, qué tareas realizaban en el momento inmediatamente anterior al conflicto y qué cargo ocuparon luego una vez conformada la cooperativa. También nos interesa especificar las expresiones colectivas de la subjetividad obrera señaladas anteriormente, partiendo de la evidencia empírica hallada en el campo.

Veamos en primer lugar el grupo que constituyó La Recuperada:

Tabla №24. Conformación inicial del colectivo obrero La Recuperada:

\begin{tabular}{|l|l|l|l|}
\hline Nombre & $\begin{array}{l}\text { Puesto } \\
\text { anterior }\end{array}$ & Tipo de contratación & $\begin{array}{l}\text { Cargo en } \\
\text { cooperativa }\end{array}$ \\
\hline Darío & Filetero & Planta permanente & Presidente \\
\hline Julio & Peón & Planta permanente & Secretario \\
\hline Mario & Filetero & Planta permanente & Síndico \\
\hline Julián & Peón & Eventual & Vocal \\
\hline Angélica & Envasadora & Planta permanente & Vocal \\
\hline Natalia & Envasadora & Eventual & Vocal \\
\hline El Flaco & Peón & Eventual & Vocal \\
\hline Hugo & Peón & Eventual & Tesorero \\
\hline Matías & Desocupado & - & Vocal \\
\hline
\end{tabular}

Fuente: Elaboración propia en base a las entrevistas realizadas.

Observamos que, de los 9 integrantes de la recuperada, 8 de ellos eran trabajadores de Industrial Pesquera, de los cuales 4 eran efectivos y 4 eran eventuales, y solo 1 de ellos -Julián- al momento del conflicto no se encontraba trabajando allí. Los 
obreros decidieron incluirlo a partir de una mañana en la que Julián pasó por la planta vendiendo cornalitos de forma ambulante, momento en el que entre Darío y Julio le contaron la situación laboral que estaban atravesando y le pidieron entre bromas que les regalase una porción de su producto: “№ nos vas a cobrar a nosotros que estamos en lucha!", relata Julio ${ }^{121}$. Desde ese día Julián concurrió a apoyar a los obreros todos los días, y luego incluso permaneció durmiendo en la planta al iniciar la ocupación de la misma.

El integrante que no provenía de Industrial pesquera es Matías, militante de la organización Cruz del Sur. Su inclusión fue el resultado de la solidaridad obrera por la cual los trabajadores de La Recuperada ofrecieron un puesto de trabajo a Cruz del Sur como agradecimiento por su acompañamiento durante todo su proceso de lucha. Esta vinculación culminó en una ruptura total con la organización en el año $2012^{122}$.

En síntesis, en el período inicial de la conformación de la empresa recuperada, quienes decidieron conformar la empresa recuperada representaron un $25 \%$ del total de los obreros de planta permanente, todos ellos trabajadores del área de producción. En la cooperativa de trabajo conformada, $22 \%$ de los puestos son ocupados por mujeres y 78\% por varones. Los cuatro trabajadores contratados en planta permanente poseían entre 7 y 20 años de antigüedad laboral, mientras que los cuatro restantes habían tenido experiencias de trabajo temporario. Tanto Mario como Angélica, por sus extensas trayectorias laborales en la industria pesquera, como Darío por el hecho de ser hijo de un trabajador del sector, habían vivido en carne propia o por intermedio de sus familias la diferencia en las condiciones de trabajo entre los 80 y las décadas siguientes, enmarcadas en el desguace del sector como particularidad local y la flexibilización y precarización laboral como característica general del trabajo que se acentuó en la década de los 90. En ellos, el sentido de pertenencia con relación a la tarea y el rubro laboral fue una expresión subjetiva que resaltó en las entrevistas, durante las cuales se referían a "la vida que habían dejado en la planta" y al utilizar la expresión "lo nuestro" para hablar del trabajo del fileteado. Estas trayectorias laborales, en conjunción con las experiencias de precarización de los otros cuatro trabajadores, se conjugaron para presentar a la posibilidad autogestiva como el mejor escenario posible en el contexto de riesgo de cierre por quiebra de la firma.

En cuanto a la disputa de los prejuicios vinculados a la necesidad del patrón capitalista, su carácter irremplazable y la incapacidad obrera para administrar una empresa de forma autogestiva, vemos aquí que la inclusión del miembro de Cruz del Sur se presenta como explicación del modo en que los trabajadores vencieron esos prejuicios, ya que la alianza con esta organización fue clave para la apropiación obrera de aquellos saberes de los que se sentían vedados "por ser obreros" y "no

121 Entrevista grupal a La Recuperada, realizada en octubre de 2011.

122 Por motivos de extensión no podemos describir aquí en qué consistió ese conflicto, el cual será abordado en posteriores trabajos, por ello solo mencionaremos a modo aclaratorio que se trató de un rechazo a determinada posición política de Cruz del Sur. 
tener estudios". La orientación y el acompañamiento por parte de Cruz del Sur, los dirigentes gremiales y docentes de Trabajo Social en relación a las cuestiones administrativas y otras relativas a trámites en dependencias estatales y la circulación de la producción una vez que se consumó el retiro patronal fueron señaladas por los trabajadores como factores cruciales para su posterior autovalimiento como trabajadores autogestivos. Si bien estas alianzas se diluyeron hasta casi desaparecer con el correr de los meses, su firmeza durante las primeras semanas y meses del conflicto fue crucial para la consecución del proceso de recuperación.

Veamos ahora la conformación de Engraucoop:

Tabla №25. Conformación inicial del colectivo obrero Engraucoop:

\begin{tabular}{|l|l|l|l|}
\hline Nombre & Puesto anterior & $\begin{array}{l}\text { Tipo de } \\
\text { contratación }\end{array}$ & $\begin{array}{l}\text { Cargo en } \\
\text { cooperativa }\end{array}$ \\
\hline Analía & Filetera & Planta permanente & Vocal \\
\hline Monica E. & Filetera & Planta permanente & Vocal \\
\hline Teresa & Filetera & Planta permanente & Vocal \\
\hline Silvia C. & Filetera & Planta permanente & Vocal \\
\hline Solveig & Control de calidad & Planta permanente & Tesorera \\
\hline María José & Administrativa & Planta permanente & Síndica \\
\hline Claudia & Administrativa & Planta permanente & Secretaria \\
\hline Alicia & Filetera & Planta permanente & Vocal \\
\hline Pabla & Filetera & Planta permanente & Vocal \\
\hline Gonzalo & Empleado de máquina & Planta permanente & Presidente \\
\hline Mónica A. & Filetera & Planta permanente & Vocal \\
\hline Angélica & Filetera & Planta permanente & Vocal \\
\hline Nora & Filetera & Planta permanente & Vocal \\
\hline Marcos & Empleado de máquina & Planta permanente & Vocal \\
\hline María T. & Filetera & Planta permanente & Vocal \\
\hline Leonardo & Empleado de máquina & Planta permanente & Vocal \\
\hline Mónica G. & Filetera & Planta permanente & Vocal \\
\hline Verónica & Filetera & Planta permanente & Vocal \\
\hline Mirta & Filetera & Planta permanente & Vocal \\
\hline Silvia G. & Filetera & Planta permanente & Vocal \\
\hline Juana & Filetera & Planta permanente & Vocal \\
\hline
\end{tabular}

Fuente: Elaboración propia en base a las entrevistas realizadas.

En el caso de Engraucoop vemos que todas las trabajadoras y los trabajadores provenían de la firma Engraulis, de las cuales 18 se desempeñaban en el área de producción (15 mujeres y 3 varones, estos últimos no fileteaban el pescado sino que realizaban tareas de envasado y almacenaje) y 3 trabajadoras pertenecían al área de administración y control de calidad. Las trabajadoras del sector administrativo realizaban sus tareas en un espacio separado del área de producción.

En relación al total de obreras de planta permanente de la firma Engraulis, aproximadamente un 33\% decidió emprender la recuperación de la empresa, 
siendo un $85 \%$ mujeres y 15\% varones, 85\% del área de producción y 15\% del área administrativa.

Cabe aclarar que a partir del año 2014 muchas de las integrantes de la segunda cooperativa comandada por Patricia Ortega -que se posicionaba contraria a la autogestión-, se unieron al grupo de Engraucoop.

En este caso se profundiza la tendencia hallada referida al peso de las extensas trayectorias laborales asalariadas en la rama con respecto a la decisión de la propuesta autogestiva, enlazado con el hecho de que el máximo nivel de estudios alcanzado por la mayoría de los obreros del área de la producción era el secundario. En el caso de Necochea, además, el desarrollo del sector industrial en la actualidad es reducido, y en el caso de las mujeres, priman las ocupaciones femeninas en el sector de los servicios de limpieza, en el comercio, la gastronomía y el turismo, salud, educación y administración pública. Por ello, y a sabiendas del desguace de la rama, eran escasas las posibilidades de las trabajadoras no solo de reinsertarse en el sector pesquero, sino de hacerlo incluso en cualquiera de los sectores industriales. Aquí, el trabajo de la "producción" y la identificación de las obreras como "productoras" en el marco de un proceso de elaboración de productos, también se ubicó como valorado en relación con otro tipo de trabajos durante las entrevistas. En general las trabajadoras se visualizaban como empleadas domésticas, en negro y a tiempo parcial, en caso de perder la continuidad laboral en Engraulis. La incertidumbre en los ingresos y su inferior cantidad en relación a los salarios que venían percibiendo en calidad de fileteras hizo que el grueso de las mismas prefiriese la salida autogestiva en su lugar de trabajo previo.

En este sentido, considerando ambos procesos de recuperación, vemos que la elección de la autogestión fue producto de una multicausalidad que la situó como la mejor estrategia laboral por sobre otras, por implicar una continuidad tanto con la condición ocupada como con la tarea realizada, y generaba perspectivas de ingresos monetarios aceptables por los trabajadores y/o preferibles por sobre otras opciones laborales consideradas como plausibles de ser efectuadas. El vínculo previo entre los integrantes de los colectivos obreros y la solidaridad entablada no solo en los primeros momentos de la lucha sino de las etapas previas en las que compartieron el ámbito laboral también creemos fue factor influyente para elegir esta salida colectiva al retiro individual del lugar de trabajo.

El último punto de este apartado está dedicado a caracterizar a los colectivos obreros desde el nuevo proceso de trabajo autogestivo, desde una perspectiva comparada considerando tanto las similitudes y diferencias entre las dos empresas recuperadas como otras formas de cooperativización en la industria pesquera. A su vez, se expondrán las relaciones entre los primeros momentos de la lucha y sus etapas posteriores, desde la perspectiva de las subjetividades obreras. 


\subsection{Cambios y continuidades en el proceso de trabajo}

Para visualizar los cambios en el proceso de producción, no nos limitaremos a lo momentos iniciales de conformación del colectivo autogestivo, sino que tomaremos como lapso temporal el período entre los seis meses y los dos años posteriores al momento de concreción de la recuperación de la empresa, ya que consideramos que solo superada la fase inicial de ensayo-error y desorganización comienzan a instalarse ciertas lógicas de funcionamiento, las cuales permiten caracterizar con mayor precisión a la organización interna de las ERT.

Tomaremos los siguientes ejes de análisis:

- Procesos de producción y circulación

- Dispositivos de toma de decisiones

- Funciones administrativas

- El devenir del colectivo obrero

Antes de comenzar con la caracterización, queremos exponer que en ambas experiencias observamos ciertos rasgos que actuaron como factores transversales, tanto al común de las experiencias, en términos sincrónicos, como a través del tiempo en cada una de las ERT, en términos diacrónicos. En este sentido, creemos que en estos casos opera una relocalización de las subjetividades obreras, las cuales se reubican desde un lugar resignificado a partir de la lucha y resistencia a ser desalojados de su lugar de trabajo y de su lugar como trabajadores; y también desde el pasaje de la modalidad de trabajo asalariado al formato autogestivo. Con el acto obrero de la recuperación de la empresa se obtiene como resultado una reapropiación subjetiva: a través de la ocupación de los espacios laborales las subjetividades vuelven a adquirir su posición como trabajadores, subvirtiendo la desocupación y la exclusión social impuesta por las empresas empleadoras en quiebra. En estos casos, los trabajadores realizan una operación de inversión del destino social atribuido: en lugar de someterse a la desocupación aceptando los despidos y, en consecuencia, dejar de concurrir a su lugar de trabajo, ocupan los establecimientos laborales para no "desocupar" su lugar de obreros. Para ello se apropian de su ubicación material de trabajo a partir de una auto-restitución de su posición simbólica y material de trabajadores, localización social y subjetiva inmersa en el entrelazado social: económico, comunitario y cultural. Por ello consideramos que, más allá de que con el correr de los años el Estado comenzó a promover e incentivar -en forma parcial- procesos de recuperación, estos casos muestran que las mismas son llevadas a cabo por un grupo minoritario de obreros con respecto al total de despedidos de las empresas fallidas, quienes luchan contra una tendencia hegemónica impuesta por la patronal de abandonar el proyecto autogestivo y retirarse de la situación sin combate, y por ello, son contrahegemónicas en sus orígenes. Veamos ahora las mutaciones a través del tiempo, que coexisten con esta tendencia señalada. 


\section{- Procesos de producción y circulación}

De acuerdo a las entrevistas realizadas, uno de los cambios más significativos en el proceso de producción es la multifuncionalidad de tareas y el aprendizaje colectivo de las mismas mediante autoformación colectiva, lo cual se expresa en la frase: "todas hacemos todo el trabajo, nos vamos nosotras mismas capacitando, aprendiendo más para poder hacerlo"123. Esta multifuncionalidad no es vivida como sobrecarga sino como ganancia subjetiva en términos de capacitación y apropiación del producto de su trabajo. A su vez, en el caso de La Recuperada la eliminación de la división entre fileteros y peones generó un marco de igualdad que suprimió la relación de superioridad/inferioridad que la patronal había instalado entre ambos puestos de trabajo. En este sentido hay una reapropiación de la propia producción por haber participado en todo el proceso de su elaboración, superando en parte la alienación capitalista que se produce no solo al ser el obrero despojado del producto de su trabajo, sino particionando el proceso de fabricación del mismo entre varios obreros (Marx, 1844 y 1845). La repartición igualitaria de ingresos se vincula aquí con la multifuncionalidad y rotación de las tareas de producción, y en este sentido opera una socialización de la producción y también del proceso de producción.

Otro rasgo de importancia observado es el relajamiento de la disciplina fabril tradicional, visible en varias de las nuevas prácticas obreras en su antiguo lugar de trabajo; por ejemplo, la posibilidad de retirarse previo aviso por cuestiones personales -ligadas en su mayoría a situaciones familiares y realización de trámites, poder detener la producción para tomar mate, escuchar música, charlar, hacer chistes. Todas estas cuestiones estaban prohibidas en ambas plantas de procesamiento de pescado a excepción de los escuetos tiempos de descanso, mientras que las salidas "por causas particulares" no estaban contempladas más que como ausencias injustificadas. Esto es particularmente vivido como una obtención de libertades y autonomía, estar menos "atados" al trabajo y por ello también menos alienados como personas-más-allá-del-trabajo.

Como rasgo negativo se ubica la incertidumbre sobre el ritmo y los tiempos de la producción, incertidumbre dada no solo por la obtención de mayor o menor cantidad de materia prima para procesar, sino de clientes que compren lo procesado. En el caso de La Recuperada, la necesidad de una rápida venta es crucial dado el carácter perecedero del pescado fresco. En el caso de Engraucoop, hemos verificado que los últimos períodos de funcionamiento se caracterizaron por la tercerización de la producción. Entonces, la empresa contratante fija tiempos de producción cuyo pago radica en el trabajo a destajo:

Claudia: Nosotros somos una cooperativa de trabajo que brindamos el servicio de mano de obra, eso significa que nosotros tenemos las instalaciones y

123 Verónica, filetera de Engraucoop, entrevista 2013 
tenemos nuestro servicio. Lo que no tenemos es materia prima ni insumos ni nada que nosotros podamos vender. Nosotros en vez de salir a trabajar como hacen otras cooperativas que prestan servicios y mano de obra en distintos lugares como lo hacen en Mar del Plata, que la mayoría son truchas o están en negro, nosotros qué hacemos? Que los clientes vengan hacia nosotros. Nosotros recibimos todo lo que ellos nos traen, todos los insumos, la materia prima, lo procesamos y después cobramos el servicio por mano de obra y se los enviamos a ellos producto terminado.

Entrevistadora: $¿ 0$ sea que la misma empresa que comercializa el producto es la que les da la materia prima?

Claudia: Exactamente.

Entrevistadora: ¿Y cómo cobran ustedes por su trabajo?

Claudia: Es un acuerdo que tenemos nosotros las cooperativistas, de tener un buen jornal digno que valga la pena por todo el sacrificio que hemos hecho de tener todas estas instalaciones, y somos monotributistas y vamos facturando. Nos pareció una manera justa y acorde a todos que es: trabajás, cobrás. Si no venís, lo lamentamos mucho pero nosotros no podemos pagarle a alguien porque nosotros no tenemos un capital, no tenemos absolutamente nada. 0 sea que a mayor producción, mayor beneficio, es por producción o pago a destajo, como vos quieras llamarlo (Claudia, 54 años, trabajadora de Engraucoop) ${ }^{124}$.

Asimismo, cuando el pedido supera la capacidad productiva del colectivo obrero integrante de la cooperativa, suelen contratar grandes grupos de trabajadoras quienes reciben menor paga que las cooperativizadas, generando una diferenciación tanto en el formato laboral (cooperativistas vs contratadas temporarias), como en el salario obtenido por igual trabajo.

y tenemos fuentes de trabajo y tenemos monotributistas y hoy por hoy hay 90 y pico de mujeres adentro y en plena temporada somos casi doscientas y pico más los hombres (...) La mayoría somos monotributistas, están las que somos cooperativistas y el resto nos factura a la cooperativa, alguna que otra no puede ser porque puede perder algún plan, pero la gran mayoría sí, le factura a la cooperativa mensualmente (Claudia, 54 años, trabajadora de Engraucoop) ${ }^{125}$.

Esta práctica es rechazada por trabajadores de La Recuperada, quienes, como vimos en el capítulo 2, reservan la contratación sin asociación a la cooperativa para las primeras semanas de trabajo de nuevos integrantes, en el marco de un mutuo conocimiento a través de la experiencia laboral de lo que significa el trabajo cooperativo en una empresa recuperada.

En el caso de la planta fresquera, los destinatarios de la producción son generalmente vecinos, integrantes de la comunidad, quienes reciben el pescado en su domicilio mediante pedidos efectuados por teléfono. El límite mayormente

${ }^{124}$ Entrevista a Claudia, trabajadora de Engraucoop, realizada en marzo de 2018.

125 Entrevista a Claudia, trabajadora de Engraucoop, realizada en marzo de 2018. 
señalado por los trabajadores es la escasa materia prima obtenida para procesar y/o vender, y, en segundo lugar, aparece como obstáculo la falta de una cámara de frío y de congelado, que les permitiría almacenar pescado fresco en las ocasiones en las que obtuvieran una cantidad de materia prima que superase sus posibilidades de procesamiento y venta inmediata.

En general, la imposibilidad de predecir la disponibilidad de materia prima y su comercialización generan ritmos de producción dispares, que pueden ser más breves o mucho más extensos, intensos y por ello extenuantes. Esta situación termina redundando en escasos ingresos para los trabajadores a pesar del gran esfuerzo y tiempo invertido en la búsqueda de rentabilidad de la empresa autogestiva. En el caso de Engraucoop, sin embargo, nuestras últimas indagaciones han mostrado que desde 2014 en adelante la obtención de nuevos clientes les ha permitido una continuidad en la producción para casi 100 trabajadoras, con un "jornal digno"126. En este aspecto, una trabajadora destaca tres motivos para el éxito del proyecto autogestivo una vez superados los primeros arduos años iniciales:

- La escasa competencia en el rubro salado/conservas;

- la buena calidad del producto elaborado previamente bajo el sello Engraulis, cuyas buenas referencias atrajeron nuevos clientes;

- el conocimiento de las trabajadoras administrativas que luego conformaron el proyecto autogestivo, las cuales pudieron hacer uso de esos saberes en beneficio de la cooperativa de trabajo ${ }^{127}$.

A estos aspectos señalados por la obrera, nos parece pertinente agregar un cuarto factor determinante de la rentabilidad continua de este emprendimiento a partir del año 2014, esto es, la inversión millonaria en la planta realizada por sus antiguos propietarios un año antes de iniciar el proceso de quiebra, la cual permitió a los obreros contar con un equipamiento e instalaciones más renovados y menos obsoletos que los de la gran mayoría de casos de ERT.

Vemos entonces que la pertenencia de estas empresas recuperadas a un sector económico en el que predomina el gran capital transnacional y la exportación impactó de forma diferenciada en ambos casos. En La Recuperada, significó, con el correr del tiempo, que los trabajadores no puedan adquirir suficiente materia prima como para asegurar una producción acorde a los ingresos mínimos esperados, ya que su venta en Puerto Quequén se encuentra en su mayoría monopolizada por grandes empresarios marplatenses. Entonces, no lograron alcanzar una producción propia de una industria pesquera, sino aspirar a la venta minorista de pescado a domicilio, con la que aún no cubren sus necesidades de reproducción. En Engraucoop se generó una dependencia de la tercerización laboral y, por ende, de las grandes empresas del rubro. En su caso, primó la supervivencia como empresa ante la independencia de los empresarios capitalistas, los cuales no se sitúan en el interior de la planta sino en su exterior. En este aspecto, entonces, las subjetividades

126 Entrevista a Claudia, trabajadora de Engraucoop, marzo de 2018.

127 Entrevista a Claudia, trabajadora de Engraucoop, marzo de 2018. 
obreras no se diferencian en gran medida de las subjetividades del trabajo asalariado. Si bien tienen mayor autonomía respecto de las condiciones de trabajo, el clima laboral y los lazos entre los pares, el disciplinamiento del capital continúa operando desde afuera. En Engraucoop, al contratar el empresariado a la fuerza de trabajo regula así el proceso de producción. En la Recuperada, aunque son los propios trabajadores los que manejan todo el circuito desde la obtención de materia prima hasta su comercialización, el capital externo limita tanto el inicio como el último eslabón del proceso, por lo que también actúa como condicionante del emprendimiento autogestivo.

\section{- Dispositivos de toma de decisiones}

Otro rasgo que se destaca en estos procesos es la experiencia de democracia directa en las asambleas, como instancias de conducción obrera y toma de decisiones. Si bien en ambas plantas pesqueras estas reuniones se realizaban con frecuencia en los tiempos previos al conflicto por cierre, como método de información y discusión colectiva en el marco de reclamos hacia la patronal, con la recuperación de la empresa se convirtieron también en el método de autoorganización del trabajo. Por ello consideramos que, si bien son métodos obreros con un largo historial de aplicación, las subjetividades obreras que transitan procesos de recuperación les imprimen un nuevo carácter a las asambleas, tanto por la diversificación en sus objetivos como por la asiduidad con que se realizan. Ya no son acciones enmarcadas exclusivamente en un momento de lucha o conflicto, sino un dispositivo de toma de decisiones sobre del funcionamiento del emprendimiento autogestivo que se instala en la cotidianeidad laboral y a su vez mantiene el formato de debate y resolución grupal en el que el conjunto obrero participa. Tanto en La Recuperada como en Engraucoop se realizan en forma periódica, pero también pueden operativizarse según las necesidades diarias, según una obrera de Engraucoop: "por temas especiales algún compañero llama a asamblea", "se dice: vamos a una asamblea"128. Este mecanismo de conducción colectiva se flexibiliza en los casos analizados no solo en función de la coyuntura sino también en cuanto a los espacios y tiempos en que se efectúa, configurando lo que algunos autores denominan "estado asambleario", que incluye espacios informales y tiempos descanso: "continuamente hacemos asambleas, todos los días, cada día que paramos a tomar mate hacé de cuenta que estamos en asamblea porque ya estamos charlando de qué vamos a hacer"129, comenta un trabajador de La Recuperada.

En cuanto a las operaciones subjetivas para la toma de decisiones, se comparte con la generalidad de fábricas recuperadas que en ambos casos prevalece la decisión de la mayoría, con variaciones entre las dos empresas: mientras que en Engraucoop se toman las resoluciones por "asimilación" del posicionamiento mayoritario

\footnotetext{
${ }^{128}$ Entrevista grupal a Engraucoop, 2013.
}

${ }^{129}$ Entrevista grupal a la Recuperada 2013. 
expresado en la discusión colectiva, en La Recuperada se recurre al voto a mano alzada luego del debate. Ambos son métodos adoptados dentro del universo actual de empresas recuperadas.

Por otro lado, en el caso de Engraucoop, el Consejo de Administración se conformó como otra instancia activa de toma de decisiones. Si bien este organismo está previsto en la normativa legal de las cooperativas, no todas las empresas recuperadas lo implementan efectivamente, manteniendo a las asambleas generales como el principal organismo decisorio. En este caso, las trabajadoras le imprimen la función resolutiva de cuestiones cotidianas de orden administrativo, y aclaran que con frecuencia semanal realizan asambleas en las que no solo están presentes los miembros del consejo directivo sino también Analía, quien ocupa el rol de gerente coordinadora del grupo, y también algunas de las trabajadoras del área de producción.

En general, aunque las decisiones sean tomadas exclusivamente en asambleas generales, ello no impide la constitución de nuevos liderazgos y desiguales grados efectivos de participación, como lo expone una trabajadora:

\begin{abstract}
Al principio se hablaba menos, yo no soy de hablar. Siempre me dio cosa, pero lo que pasa es que si cada una no habla cómo vas a hacer para... porque por ahí siempre son las mismas que hablan y otras piensan, si yo digo... mejor no lo digo... pero tenés que decirlo porque si no después cómo... Nos vamos soltando (Verónica, filetera de Engraucoop) ${ }^{130}$.
\end{abstract}

El pasaje de la sumisión diaria a una patronal hacia la gestión obrera colectiva mediante la participación en asambleas, se realiza de forma particular en cada trabajador y trabajadora, cuyo espectro de formatos de participación incluye desde el personalismo hasta el retraimiento. No obstante, todos los trabajadores entrevistados valoran positivamente el dispositivo asambleario y la posibilidad de incidir en las decisiones de la empresa autogestiva. Esta cuestión se vincula con el repliegue del colectivo obrero hacia el interior de la fábrica que contrasta con los momentos iniciales de lucha, cuyo accionar se orientaba hacia el exterior para difundir el conflicto y entablar alianzas sociales. Una vez entablado cierto mecanismo de funcionamiento del emprendimiento autogestivo, emerge una tendencia a la delegación y a la desigualdad en cuanto a determinados roles en la planta, instalándose un verticalismo que suplanta en parte a la horizontalidad inicial del proceso. Como veremos en los puntos posteriores, este verticalismo no se inmiscuye en general en el proceso de producción, sino en el resto del proceso de trabajo, las decisiones administrativas y de circulación de la producción. La jerarquía del accionar colectivo va cediendo lugar, entonces, a la importancia de la actividad de determinados miembros que se enquistan en esa posición preponderante con respecto al resto. Como veremos en el siguiente punto, la instalación del dispositivo asambleario no es garantía de la mantención o

${ }^{130}$ Entrevista grupal a Engraucoop, 2013. 
profundización de las prácticas igualitarias, y la aparición de ciertas prácticas tales como vaciamiento de la presencia colectiva en las asambleas o realización de instancias de reunión separadas entre algunos pocos miembros (generalmente quienes ocupan los cargos en el consejo de administración) constriñen la horizontalidad y el carácter democrático del dispositivo.

Tal como señalamos en el estado de la cuestión, en gran parte estas limitaciones de las asambleas realizadas en el marco de empresas recuperadas provienen del mismo proceso de circulación mercantil (Ghigliani, 2007), y aquí agregamos algunas de las razones subjetivas que se refieren a estas restricciones. Una cuestión referida reiteradamente fue la dificultad para expresar la opinión propia en el marco de una reunión, lo cual remite a las largas trayectorias de las ex-asalariadas bajo una disciplina y sumisión patronal, cuyo cuestionamiento era evaluado como comprometedor de la continuidad laboral. Pero junto a esta praxis obrera de evitar exponer la propia posición, coexiste otra tendencia visible vinculada a la adjudicación de un saber hacia determinados miembros, sin otro fundamento que la experiencia pasada de haber ocupado dicho lugar de conocimiento. Entonces, el saber obrero y su expresión en las instancias asamblearias son en general considerados como propiedad posible de unos pocos, prevaleciendo así una lógica asimétrica que se expresa en las prácticas, los discursos y las concepciones obreras. El enquistamiento de ciertos trabajadores en funciones consideradas superiores con respecto a las tareas de producción contribuye a la retroalimentación de esta lógica, así como los factores estructurales que verificamos anteriormente.

\section{- Funciones administrativas}

En el caso de Engraucoop vemos que las tareas administrativas y de gestión no se resituaron del mismo modo en que lo hicieron las tareas de producción, sino que quedaron en manos de quienes se desempeñaban como trabajadoras administrativas en Engraulis y luego integraron el consejo de administración, demostrando una desigual división de poder al interior de la unidad productiva obrera.

Podemos estar capacitados para muchas cosas, pero no por eso humanamente
no vamos a ser compañeros, yo no tengo ningún drama de ir allá a sentarme a
tomar mate ni hacer lo que sea. Que después venga acá porque jerárquicamente
o porque haya estudiado o haya tenido la posibilidad para poder estar en otro
nivel para poder llevar esto administrativamente no quiere decir que
humanamente no seamos iguales y podemos tener muchas cosas en común de
hijos, de trabajo, lo que sea charlar (Claudia, 54 años, trabajadora de
Engraucoop) ${ }^{131}$.

En el caso de La Recuperada también vemos una diferencia entre las tareas de producción y las de gestión /administración. Mientras en el circuito productivo

131 Entrevista a Claudia, trabajadora de Engraucoop, marzo de 2018. 
predomina la multifuncionalidad y se abolió la diferenciación entre fileteros y peones, en lo administrativo en un principio todas las funciones eran desempeñadas por Darío, y luego se repartieron con Mario y Natalia.

\begin{abstract}
Claro yo como presidente me tocó durante bastante tiempo ser presidente, secretario y tesorero, desde el comienzo que arranqué con un montón de cosas y que se fueron dejando, pero para mí y para todos es importante que de a poquito... yo jamás fui presidente de una cooperativa, ni ninguno fue tesorero de una cooperativa ni ninguno de los cargos que podemos llegar tener, y todo se aprende y ya ahora se está haciendo más repartido, y es mejor para la organización, para el funcionamiento de la cooperativa... Yo antes también hacía gestiones, un montón de cosas más, y ahora ella está haciendo las gestiones (Darío, 35 años, filetero de La Recuperada) ${ }^{132}$.
\end{abstract}

Vemos entonces que las tareas que anteriormente eran propias de los obreros y realizadas de forma fragmentada sí fueron democratizadas en un reparto colectivo tanto de las labores en sí como de los ingresos y horarios, mientras que las tareas realizadas por administrativos y propietarios continúan concentradas en pocos trabajadores, quienes no obstante también se desempeñan en el sector de la producción. La administración y gestión son actividades más vinculadas al circuito de circulación del capital que al de producción, lo que demuestra nuevamente la persistencia de ciertos rasgos capitalistas en las ERT. Este aspecto lo vinculamos, a su vez, con el hecho de que no se logró efectuar un circuito de comercialización basado en la producción en función de necesidades sociales. Por el contrario, la producción de La Recuperada entró en competencia con pescaderías locales, y en ocasiones revendiendo productos procesados por grandes empresas marplatenses -dada la imposibilidad de obtener pescado en el puerto local-. Engraucoop, como vimos, trabaja de forma tercerizada para otras empresas, contribuyendo a las ganancias de la empresa capitalista contratante. Claro está, ambas modalidades no resultaron de una decisión obrera en base a un abanico de posibilidades de producción y comercialización, sino que se ‘presentaron como las opciones posibles para subsistir en el mercado, y a duras penas. La convivencia de la autogestión con modos que fomentan la supervivencia e incluso crecimiento del gran capital concentrado demuestran que, por sí mismas, estas experiencias no son anticapitalistas, ni incluso no capitalistas, ya que el capital externo a la unidad productiva actúa como marco regulador de la cotidianeidad obrera en el terreno de la producción y comercialización. Este aspecto demuestra la importancia de analizar caso a caso, y de forma longitudinal, los devenires de cada uno de los procesos de recuperación, para lograr una caracterización y una comprensión profundas de cada experiencia y de la heterogeneidad propia del movimiento de ERT.

La concentración de las funciones administrativas en unos pocos trabajadores se vincula a su vez con los prejuicios obreros referidos a la necesidad del patrón capitalista, su carácter irremplazable y la incapacidad obrera para llevar adelante

132 Entrevista grupal a La Recuperada, febrero de 2013. 
sin patrón un emprendimiento productivo rentable. En la práctica, se aplicó la premisa de que solo unos pocos trabajadores eran capaces de vencer estas restricciones, tal como ocurrió con el saber obrero adjudicado en cuanto a la intervención en las instancias asamblearias. La contrapartida de que "no cualquier trabajador sería capaz de llevar adelante una empresa" no se resolvió de forma colectiva, sino otorgando lugares preponderantes a ciertos obreros. En ambos casos, este lugar fue adjudicado y asumido por los trabajadores que habían conducido la lucha por la recuperación, los delegados de planta y, en el caso de Engraucoop, también por las antiguas trabajadoras administrativas (cuya función, como vimos, se consideraba jerárquica en relación al trabajo en el sector de la producción). En La Recuperada, con el correr de los meses la transformación en la composición del colectivo obrero entre "viejos" integrantes (los ex-trabajadores de Industrial Pesquera) y los "nuevos" (en su mayoría jóvenes que nunca se habían desempeñado en el sector pesquero ni habían tenido experiencias de trabajo asalariado en relación de dependencia) se trasladó a una preminencia de los "viejos" en las funciones administrativas, y en general en la conducción grupal.

\section{- El devenir del colectivo obrero}

Como adelantamos en el párrafo anterior, el correr de los meses y los años, los colectivos obreros se modificaron con respecto los grupos que inicialmente conformaron la empresa autogestiva. En el caso de La Recuperada, 6 de sus 9 miembros originarios se retiraron de la empresa por diversas razones. Los trabajadores mencionan como principales motivos del alejamiento el haber obtenido otro empleo, la desesperanza ante la falta de tareas laborales cotidiano o dificultades que se les presentaron en cuanto a la rentabilidad, y en el caso de Matías por la ruptura del lazo con la organización Cruz del Sur. Los que permanecieron fueron Darío, Natalia y Mario, quienes mencionaron con desazón los nombres de obreros que se retiraron. La frustración que esto implica, ya que también es remarcado el desgaste y las expectativas puestas en juego, consiste en otro de los causales de sufrimiento en estas modalidades laborales, el cual aparece a su vez vinculado con el compañerismo como forma de sortear el pesar cotidiano. En este sentido, los "chicos nuevos" que ingresaron luego de la partida de los miembros originales del proyecto, tres jóvenes desocupados, renovaron temporariamente la esperanza de que la empresa autogestiva funcionase en quienes permanecieron:

\footnotetext{
Hoy en día hemos formado otro grupo, también creo que las bajas que hemos tenido por el tema de no tener continuidad, que se vayan los compañeros que empezaron, nos debilitó bastante, pero hoy ya estamos de vuelta, hemos armado otro grupo bien de vuelta y estamos con todas las ganas bien digamos, de vuelta de salir adelante, así que... (Darío, 35 años, filetero de La Recuperada) ${ }^{133}$.
}

${ }^{133}$ Entrevista grupal a La Recuperada, febrero de 2014. 
El vínculo asiduo entre compañeros de trabajo, con la fuerte identificación entre obreros que trae aparejada esta forma de lucha laboral, se resalta como otro de los rasgos positivos de estos procesos de recuperación, compañerismo no solo resultante de compartir la autogestión y de la eliminación de la figura del patrón/empresario, sino también producto de haber realizado una lucha conjunta contra la desocupación y el cierre de las plantas procesadoras.

En el caso de Engraucoop, el colectivo original permaneció prácticamente íntegro, solo algunas de las obreras hicieron uso de permisos temporarios por estudios, enfermedad o situaciones personales que impidieron la continuidad laboral, no obstante lo cual siguen teniendo su lugar en la cooperativa para regresar una vez resuelto el motivo del permiso. Aquí lo que sucedió, como vimos, fue que el grupo inicial se quintuplicó luego de los primeros dos años de funcionamiento -en los cuales tuvieron dificultades similares a las de La Recuperada. Al aumentar en grandes cantidades el trabajo, las obreras incorporaron más de 70 trabajadoras en el formato de monotributistas, y en la época de zafra llegan a ser 200 obreras elaborando las conservas y el salado de anchoas. Muchas de las nuevas trabajadoras integraban el agrupamiento liderado por Patricia Ortega, es decir, eran también ex trabajadoras de Engraulis. La diferenciación entre cooperativistas y monotributistas permanentes y temporarias expresa una división entre el grupo inicial y las trabajadoras que se sumaron luego del año 2013, lo cual evidencia la conformación de capas obreras con desiguales grados de poder, toma de decisiones y también de remuneración, al igual que ocurrió en el caso de La Recuperada entre los "viejos" y los "nuevos". Esta división y la lógica que conlleva no se problematiza al interior del colectivo obrero, ni se vislumbra posibilidad de revertirse, en palabras de una trabajadora: "Las cooperativistas siempre somos las mismas y nuestro objetivo es no separarnos nunca"134. En este sentido vuelve a aparecer aquí el contraste entre la unidad obrera con preminencia de una lógica basada en la horizontalidad, propia de los primeros momentos de la lucha, con la posterior tendencia a la instalación de nuevos verticalismos. Este viraje se encuentra mediado por la diferenciación de algunas posiciones obreras que cobran el lugar de conductoras o portavoces del colectivo inicial, que con el correr del tiempo reforzaron este lugar diferenciado mediante la asunción y adjudicación de estos roles, ante las necesidades inmediatas de subsistencia y la lógica mercantil que impone condicionantes estructurales a las empresas recuperadas.

Por otra parte, observamos también que resaltan en el decir obrero de ambas empresas recuperadas determinados significantes, vinculados a la apropiación y el sentido de pertenencia en el trabajo, dados por la resistencia y el accionar de los trabajadores para no perder su posición como tales ni su lugar de desempeño laboral. Este sentimiento de pertenencia suponemos que guarda un cariz diferente al que pueda estar presente en las subjetividades del trabajo asalariado: en estos

${ }^{134}$ Entrevista a Claudia, 54 años, trabajadora de Engraucoop, marzo de 2018. 
casos los trabajadores lograron retener su fuente de trabajo en un contexto en el que la amenaza era su arrebatamiento, y al mismo tiempo como resultado de la lucha obrera los patrones y el Estado les ceden -temporariamente, en principio- la empresa y el lugar físico de funcionamiento. El sentido de pertenencia está vinculado aquí con la subversión de la exclusión social dada por la amenaza de desocupación y la restitución de la posición simbólica de trabajadores, por lo que las "ganas de irse" ante las adversidades que se parecieran refrenadas no solo por el compañerismo del presente, sino por las acciones de resistencia subjetiva pasadas, por su historia de lucha, y también por la temporaria expropiación de la propiedad privada empresarial. La recuperación de la empresa se considera una conquista propia y colectiva a la que no es fácil renunciar a pesar de los grandes costes subjetivos y económicos cotidianos, lo cual lleva a continuar apostando a la autogestión buscando nuevas formas de enfrentar o sobrellevar las dificultades. Así lo expresa una trabajadora de La Recuperada:

...es el sentimiento que tenés adentro, hay veces que más de uno a mí me ha dicho Naty, por qué, qué haces, y a mí me costó un montón entrar por un montón de cosas que me pasaron, que me fueron sucediendo, pero una vez que entré le puse la fuerza y la garra y lo siento mío acá, no me puedo ir (Natalia, 37 años, filetera de La Recuperada) ${ }^{135}$.

En cuanto a las valoraciones acerca del trabajo en la industria pesquera, encontramos nuevas evidencias de valoración positiva desde los y las trabajadores acerca de su oficio específico como obreros en la rama, labor de la que poseen un saber especial que requiere aprendizaje y destreza singular, y que se resisten también a abandonar. El cambio hacia otra actividad se considera solo luego de sucesivas frustraciones, fracasos y dificultades para obtener materia prima y compradores, no por una valoración negativa de la tarea en sí. Este aspecto del análisis nos resitúa en la vertiente del trabajo como actividad humana en sentido general -separándola de la dimensión actual del trabajo asalariado- como actividad generadora de placer y deseo, aspecto que también permite a la subjetividad obrera resistir los embates del capital.

Sin embargo, esta orientación basada en la valoración positiva de la tarea y su carácter colectivo y autogestivo contrasta con la autoexplotación, la incertidumbre y los bajos ingresos que caracterizan estos primeros años de las empresas pesqueras recuperadas y las sitúan en condiciones similares a las de la precarización laboral propia de las cooperativas fraudulentas marplatenses. Este contraste entre las expectativas de superar las características precarias del trabajo en la industria pesquera y la realidad se conjuga con la discrepancia entre los momentos iniciales en los que primaron las prácticas obreras de lucha contra el destino de desocupación impuesto y la adaptación a la cual estos colectivos son empujados mediante las dificultades cotidianas propias de procesos de producción autogestiva, generando

135 Entrevista grupal a La Recuperada, febrero de 2013. 
una frustración colectiva obrera basada en dicha discordancia. Las transformaciones subjetivas producto de aquellos tiempos iniciales chocan con la realidad de la supervivencia diaria y los nuevos formatos disciplinadores del capital desde la externalidad de la planta. Así lo expresa un trabajador de La Recuperada:

nosotros hemos perdido esa parte, que tuvimos al principio, de lucha. Somos concientes también, que hemos ido a hablar directamente, a veces muy pacíficamente creo, y eso puede ser también que no recibamos a veces buenos resultados...Pasa que ya tres años viste y se complica, mucho desgaste, mucho esfuerzo... Está bueno la Recuperada, es parte de mi vida, me abrió la cabeza en un montón de cosas, me cambió un montón de cosas, pero también uno tiene que vivir, hubiera sido lindo que... Justo en el rubro que nosotros estamos que es la pesca va en contra de los intereses de otros, si esto hubiera sido fábrica de otra cosa, capaz que hubiéramos estado exportando, con las ganas que hemos puesto, la garra (Darío, 35 años, filetero en La Recuperada) ${ }^{136}$

Enlazando este fragmento expuesto con otros testimonios de las entrevistas realizadas, vemos que el contraste con los primeros momentos de lucha también se vincula con los fracasos y/o dificultades en la rentabilidad, y esto es puesto en relación tanto con el desguace de la rama a nivel local, la preminencia del gran capital transnacional en el sector pesquero, y la falta de acompañamiento estatal y portuario al emprendimiento obrero. La soledad y el aislamiento en los que quedan subsumidas las empresas recuperadas "en funcionamiento" junto con las múltiples consecuencias del desenlace fallido a nivel económico vuelve a su vez a implantar prejuicios relativos a la incapacidad obrera y necesidad del patrón capitalista, y en su conjunto estos factores cuestionan la consecución misma del proyecto autogestivo. En diversos pasajes de entrevistas en ambos colectivos obreros se observa esta "desmoralización" basada en la conclusión de que "con la garra no alcanza", y aunque las decepciones se vinculan con factores estructurales, ajenos a los obreros, también hay una carga de responsabilidad autoadjudicada referida a un "no saber" y al abandono de los métodos de lucha de los comienzos.

En síntesis, comparando los casos abordados, se observa que los cambios en situación laboral conllevan cambios en las subjetividades obreras. El lugar posible para la decisión tanto de la organización del trabajo en la esfera de la producción, la vivencia del compañerismo tanto como acompañamiento mutuo-y no meramente como oposición a una patronal-, gozar de nuevas libertades y autonomía en el ámbito de trabajo, el aprendizaje del funcionamiento general de las unidades productivas, el sentido de pertenencia en relación al trabajo y a la producción, creemos que son modificaciones de importancia en la cotidianeidad laboral, que a su vez generan movilizaciones en las subjetividades obreras que integran procesos de recuperación de empresas. Asimismo, la valorización de la tarea laboral

\footnotetext{
136 Entrevista grupal a La Recuperada, realizada en febrero de 2014.
} 
específica que se lleva a cabo es un aspecto que merece la profundización de su abordaje a fin de elaborar avances y desarrollos al respecto.

No obstante, las características de la producción, la circulación y la lógica mercantil hacen del devenir diario de las empresas autogestivas una lucha tan o más dificultosa que la que implicaron sus momentos iniciales, ya que aún se encuentran operando las restricciones que el mercado y -en última instancia- el sistema capitalista imponen. El desánimo que expresan algunos obreros abre interrogantes acerca de la valoración de la fuente laboral autogestiva, si es considerada como una forma de trabajo diferente del formato asalariado, promotora de emancipación en algún sentido, o bien sigue actuando como último recurso para evitar el desempleo, y en este punto no guarda muchas diferencias con los formatos más precarizados del trabajo en la industria pesquera.

La dificultad y la duda continua sobre la subsistencia diaria le imprimen una considerable carga al testimonio de algunos obreros en términos de sufrimiento laboral. En otros discursos, en donde quizás esta dificultad se encuentra menos presente -o cuenta con el paliativo de los ingresos de los cónyuges- pueden resaltarse rasgos positivos en términos de ganancia subjetiva, tales como el aprendizaje del funcionamiento fabril y diversas tareas implicadas en el mismo, la obtención de poder al interior de la unidad productiva en términos de participación efectiva, cotidiana y palpable en la toma de decisiones y el gozo de mayores libertades y autonomía en el trabajo. También se contrasta la posición actual autogestiva con la anterior en términos menor grado de deshumanización y alienación que supone el trabajo mecanizado, opresor y bajo vigilancia que llevaban a cabo las obreras bajo patrón. Considerando retrospectivamente la relación de dependencia laboral, se recuerdan como robots y soldados, sin lugar para la propia subjetividad involucrada en la tarea.

En este punto, el saber obrero aparece resignificado: antes "no sabían nada", "ni cómo entraba la pesca", ahora "todas hacen todo"137, ubicándose desde un lugar de poseedores de conocimiento laboral, aunque el saber vinculado a la gestión y administración empresarial continúa en la práctica y en la conciencia vedado para la amplia mayoría de trabajadores.

Se observa también que en las plantas se utilizaba un modelo de organización obrera más cercano al fordismo y taylorismo, y que actualmente el trabajo autogestivo tiene particularidades que lo emparentan con el toyotismo, en cuanto a la multifuncionalidad, descentralización, participación, involucramiento y flexibilidad. La diferencia con las grandes corporaciones empresariales de la actualidad se la otorga el componente autogestivo obrero enmarcado en la mayor horizontalidad y la democratización, lo cual opone resistencia a la docilidad, el autoritarismo y la alienación propia de los trabajadores asalariados con respecto a la patronal y al producto de su trabajo. Sin embargo, esta cuestión es discutible, ya que los ritmos de trabajo los impone la obtención de materia prima y las posibilidades de

${ }^{137}$ Entrevista grupal a Engraucoop, octubre de 2013. 
comercialización de los productos, la captación de clientes, las empresas contratantes y los tiempos de circulación, por lo que, cuanto menor es el tiempo en que las trabajadoras concurren a la planta, menor es el ingreso salarial, y cuando deben generar mayores volúmenes de venta deben extender la jornada laboral, recayendo en la autoexplotación.

En este sentido, en relación al disciplinamiento observamos que, por un lado, hay un relajamiento con respecto a las anteriores pautas de realización colectiva de las tareas, dado por el retiro de las cámaras de seguridad, la posibilidad de utilizar la totalidad de las instalaciones de la planta y los anteriores rasgos señalados. Pero, a su vez, opera un disciplinamiento desde el capital externo o del mismo funcionamiento mercantil que impone ritmos de producción muchas veces extenuantes o bien bajos ingresos ante la escasez de trabajo.

Otra cuestión que no incluimos anteriormente pero no queremos dejar de destacar aquí es la necesidad de tener otro trabajo aparte del autogestivo, situación presente en varios trabajadores de La Recuperada. Esto cuestiona nuevamente el supuesto componente emancipatorio de estos emprendimientos, ya que son los mismos trabajadores que integran empresas recuperadas los que se sienten sobrecargados por las tareas, frustrados por la falta ventas y de ingresos, y a la vez son explotados en los trabajos paralelos que desempeñan ante estas carencias.

El sufrimiento y el desgaste que conllevan la cotidianeidad laboral se articula con otra situación que se desprende del discurso: el desamparo estatal en el que quedan los colectivos obreros, el aislamiento y la desprotección como contracara del trabajo autogestivo enmarcado en el capitalismo. Luego de obtenido el permiso legal/estatal -provisorio- para continuar con la producción en las instalaciones de la empresa fallida, quedan abandonados a su suerte en la tarea de obtener una mínima rentabilidad que les permita subsistir, y eso también le imprime una carga en términos de fracaso del emprendimiento autogestivo. Si bien, en el decir obrero esta falla no es atribuida a los trabajadores, quedan dudas vinculadas al modo en que esta decepción opera en las subjetividades en juego. Aparece aquí un interrogante que plantea si la consecución de la empresa recuperada se asienta en un más allá del desempleo, ya sea en el sentimiento de pertenencia generado, la esperanza de un futuro rentable basado más en el tiempo, dedicación y esfuerzo invertido que en las leyes del mercado capitalista.

Por último, no queremos dejar de mencionar que, en los dos casos, vemos un aspecto para nosotros crucial de la conciencia de clase operando en las subjetividades obreras: el enfrentamiento con la patronal, la diferencia entre ser trabajador y ser empresario/empleador, y la detección del carácter de la explotación capitalista de la fuerza de trabajo. Esta cuestión se hace presente en el discurso, en Claudia de Engraucoop cuando dice: "con el otro grupo no ocurría, siempre estaba como que eran grandes jefes y el resto eran los laburantes, y yo no soy de esas, yo soy laburante"138. También vuelve a referirse a ello cuando menciona que ahora la

138 Entrevista a Claudia, trabajadora de Engraucoop, marzo de 2018. 
cooperativa no tiene capital financiero ni ahorros, sino que la ganancia se reparte como salario exclusivamente. Julio y Darío, sobre este aspecto, mencionan lo siguiente:

Julio: Y sí, ellos siempre tenían alguna excusa, que en Europa, por ahí pueden ser cosas ciertas, pero siempre amenazaban con que iban a cerrar para que entendamos si se atrasaban en el pago de alguna quincena por equis motivo, te lloraban... Cuando en realidad el que necesitaba era el trabajador, no ellos, con algo compraron el campo que tienen, una chata, una camioneta de más de cien lucas...

Darío: Eso es lo que tienen los patrones, te hacen socio cuando van en pérdida o no ganan lo que tienen que ganar, ahora cuando ganan mucho no te hacen socio, de compartir las ganancias o darte más plata cuando hubo una buena exportación. Yo creo que no era que perdían plata, perdían de ganar, y ahí nos hacían socio a nosotros ${ }^{139}$.

El carácter explotador y la desigualdad intrínseca al sistema capitalista es expuesta con claridad por ambos obreros. La ganancia, el dinero, siempre estaba del lado del patrón. Las pérdidas, de acuerdo a la lógica patronal, debían recaer sobre los trabajadores. Subvertir el carácter deshumanizado del lugar del capitalista en las empresas es un desafío que los trabajadores toman en sus manos, con las modificaciones impresas al proceso de producción, el relajamiento de la disciplina y la repartición igualitaria de ingresos, desafío que se plantea como compensador de los contratiempos del devenir autogestivo.

Por todo ello, consideramos que la dualidad propia de la actividad laboral se encuentra particularizada en el caso de los procesos de recuperación de empresas, en la medida en que la autogestión supone ganancias y pérdidas, ventajas y desventajas con respecto al trabajo asalariado y a los formatos de precarización laboral tan instalados en la industria pesquera durante las últimas décadas. Hasta el momento los trabajadores pesqueros necochenses han optado mantener la conquista autogestiva, no sin sufrimiento.

A modo de conclusión provisoria, podemos decir que, a pesar de las limitaciones que el sistema capitalista impone a estas experiencias y las dificultades propias del ámbito de la producción autogestiva, los obreros destacan el mantenimiento de su lugar como trabajadores. Desde nuestra perspectiva, creemos que no debemos perder de vista ni el sufrimiento subjetivo particular que se presenta en estos casos, ni tampoco los factores valorados de la autogestión que actúan como contrapeso, reduciendo en las subjetividades la percepción de las pérdidas o malestares propios de este tipo de experiencias. En términos generales, la resignificación y revaloración del trabajo como una conquista producto de la lucha -y no como mera venta de fuerza de trabajo al mejor postor- mantiene un alto grado de importancia para los

139 Entrevista grupal a La Recuperada, realizada en octubre de 2011. 
trabajadores de las empresas pesqueras recuperadas, y por ello consideramos que también debemos valorarlo en justa medida.

Finalizaremos este recorrido con las conclusiones de las tesis, que expondrán una síntesis de cada capítulo en clave comparada, buscando detectar interrogantes abiertos para futuras investigaciones. 


\section{Conclusiones}


Nuestra intención inicial fue la de llevar a cabo un análisis interpretativo, crítico y multicausal que permitiera profundizar sobre el problema de investigación planteado. Para ello adoptamos una perspectiva transdisciplinar, psico-sociohistórica. Buscaremos ahora sintetizar lo expuesto, a fin de detectar nuevos interrogantes generados a partir del recorrido realizado.

En el primer capítulo actuó a modo de guía la pregunta ¿Cuáles fueron las condiciones objetivas en las que se encontraron los trabajadores cooperativizados de la industria pesquera bonaerense entre los años 1997 y 2012? Para responder este interrogante recurrimos a su contextualización histórica, al análisis macro socioeconómico sobre los efectos de la reestructuración capitalista en la economía nacional, y en particular en la actividad pesquera, que desde los 70 hasta el final del período estudiado caracterizamos como una etapa de crisis y reconfiguración en el marco de la fase imperialista neoliberal. Desde este punto de partida, ahondamos en los cambios y continuidades en los enclaves portuarios/pesqueros de Mar del Plata y Necochea, y su impacto en las subjetividades obreras.

Vimos que, con el correr de las décadas, la última reestructuración capitalista situó a Puerto Quequén como un enclave casi exclusivamente cerealero, mientras que Mar del Plata continuó con su rol de puerto pesquero por excelencia. Esto se vincula con la concentración y división nacional de la operatoria pesquera en dos grandes centros, Mar del Plata y la Patagonia, política que fue producto de la decisión conjunta entre los gobiernos y las grandes empresas, que en el contexto de la reestructuración capitalista impusieron una creciente especialización portuaria hacia determinadas actividades económicas en detrimento de la diversificación. En el período estudiado concluimos que, si bien esto produjo la evaporación de la industria pesquera necochense, no sucedió lo mismo con su sector extractivo, el cual si bien mermó con respecto a antaño continúa desarrollándose, pero no con destino local. Por el contrario, su funcionalidad residió en el aporte al complejo engranaje de la gran empresa pesquera nacional, cuya integración vertical se expandió más allá de las fronteras locales, absorbiendo recursos pesqueros de otras ciudades portuarias. En este sentido, la mayor parte de la extracción pesquera realizada en Puerto Quequén se destina a los grandes grupos económicos con asiento tanto en Mar del Plata como en la Patagonia. La contracara del desguace del sector pesquero local fue la acentuación del predominio del sector agroexportador en Puerto Quequén, actividad que a pesar de su marcado crecimiento post 2000, no logró absorber las fuentes de trabajo perdidas por la industria pesquera desaparecida. Esta cuestión se explica, en parte, por características de la rama agroexportadora, cuyo desarrollo tecnológico alcanzado generó que los procesos productivos requieran un volumen de fuerza de trabajo muy inferior al de la actividad pesquera. El cambio en el tipo de flota predominante desde la década del 60 fue otro de los factores que redundó en la trasmutación de Puerto Quequén, mediante políticas cuyo efecto fue el de resignar desarrollo local para transformarlo en un apéndice de los grandes grupos económicos anclados en Mar del Plata y la Patagonia. 
Las transformaciones en el sector pesquero propias de las últimas décadas se llevaron a cabo por diversos mecanismos, tales como la diferenciación de los costos del capital fijo en los distintos enclaves portuarios y la ausencia de medidas proteccionistas para los pescadores y la industria en las localizaciones en donde su desarrollo era de menor envergadura. Como resultante, la industria pesquera se evaporó en Necochea mientras que en Mar del Plata se condensó, dada la creciente concentración del gran capital y el cierre y/o absorción de pequeñas y medianas empresas. Mientras que los empresarios desplazados fueron impelidos a destinar sus capitales hacia otros sectores, la clase trabajadora quedó condenada a la precarización laboral en sus distintos formatos, o a la desocupación.

Estos cambios se ligan, a su vez, con la migración del sector extractivo de las grandes potencias pesqueras hacia otros caladeros a causa de la sobredepredación de los propios. La excesiva presión sobre el recurso pesquero provocó que una crisis similar, de menor magnitud -hasta el momento-, se trasladara a localizaciones caracterizadas por un capitalismo dependiente como Argentina. El extractivismo y la transformación del recurso pesquero en commodity se conjugaron para que, hasta la actualidad, el sector pesquero continúe teniendo una presencia importante en el comercio internacional y en la economía nacional, a costa de una gran presión sobre el recurso y una creciente precarización de su fuerza de trabajo. La excesiva depredación de los recursos pesqueros continúa, dada la lógica capitalista de maximización de las ganancias como criterio predominante y la falta de controles estatales, que siguen permitiendo de hecho que los empresarios extraigan el recurso de acuerdo a sus necesidades de comercialización, así como también la pesca furtiva. Ante ello ¿sobrevendrán nuevas crisis en los caladeros nacionales? ¿Será necesaria una nueva reconfiguración de la operatoria pesquera y portuaria? ¿Entrará en juego la comercialización de nuevas especies, que, así como el langostino y el calamar, reimpulsen el desarrollo de la actividad pesquera en todo el mundo?

Las mutaciones en las condiciones objetivas impactaron en el proceso de trabajo ligado a la industria pesquera. Por un lado, generaron una revalorización del "semioficio" del filetero, ya que la innovación tecnológica no logró aún igualar a la capacidad humana para el fileteado, cuya demanda se incrementó con respecto a antaño, dado el aumento en los volúmenes de pescado procesado con respecto a los años 70 y 80. Sin embargo, esta revalorización no redundó en el mejoramiento salarial o laboral. Por el contrario, la avanzada capitalista sobre las condiciones de trabajo y contratación a fin de extraer mayor plusvalía propias de la fase neoliberal, decantaron en la superexplotación de la fuerza de trabajo, que no solo se masificó, sino que además se consolidó como característica estructural de la rama. La tercerización laboral, la generalización del pago a destajo y la contratación temporaria se conjugaron, a su vez, con la disminución de puestos de trabajo. De acuerdo con las estimaciones a partir de la información disponible, en Mar del Plata se redujeron al menos a la mitad las fuentes laborales en la industria pesquera con respecto a los 70, empleando menos obreros para cumplir jornadas laborales más extensas, en peores condiciones de trabajo y contratación, o atando las mismas a la 
disponibilidad del recurso. El período que comprende desde el año 1982 hacia adelante se caracteriza por una disminución de puestos de trabajo, pero no tan significativa en cuanto a la cantidad sino en relación con la calidad de los mismos, ya que para 1996 al menos un $40 \%$ se encontraba cooperativizado/tercerizado, y para de 2012 esta proporción ascendía al 67\% (Garrone, 2012). En Necochea, el 99\% de los puestos de trabajo fueron suprimidos, de la mano del cierre una a una de la totalidad de empresas pesqueras radicadas en la ciudad. Engraucoop, hasta ahora, es la única sobreviviente que continúa desarrollando una producción industrial. De acuerdo a nuevos sondeos, hemos verificado el funcionamiento clandestino y ocasional de una o dos plantas de fileteado en la ciudad, cuyo fin es la utilización de mano de obra tercerizada para empresas marplatenses. El empresariado llevó al límite sus estrategias para aprovechar al máximo los ritmos y tiempos de producción, trasladando a los trabajadores la incertidumbre y los riesgos propios de la actividad haliéutica. El impacto negativo en el polo laboral se correlaciona con las consecuencias generales de la avanzada capitalista iniciada en los 70 y reforzada en los 90, que logró instalar una dualización de la fuerza de trabajo que contribuyó a la fragmentación obrera y también permitió extraer mayor plusvalía a un creciente sector de trabajadores precarizados con respecto a quienes poseen empleo asalariado registrado.

Observamos, entonces, realidades contrapuestas en la industria pesquera de ambas localizaciones en este punto: mientras que en Necochea solo perduraron los pequeños colectivos de trabajadores de las dos empresas recuperadas, en Mar del Plata no varió tanto el número desde 1982 en adelante sino el tipo de contratación y las condiciones de trabajo. El impacto en las subjetividades obreras no solo se tradujo en el aumento y consolidación de esta precarización laboral, sino también en un desmedro del puesto de trabajo y del lugar obrero, en los cuales los trabajadores continúan experimentando una gran exposición a enfermedades y alto riesgo laboral con peores salarios y menos derechos laborales con respecto a antaño. Ante esta realidad, las experiencias autogestivas necochenses, ¿generarán una repercusión en la fuerza de trabajo cooperativizada de Mar del Plata? ¿Surgirán nuevas empresas pesqueras recuperadas marplatenses, ante eventuales nuevos cierres de pequeñas y medianas firmas de la rama? ¿Resultarán los obreros autogestivos de Necochea subsumidos por los grandes grupos económicos de la pesca?

En el segundo capítulo profundizamos acerca de la vinculación entre precarización laboral y dualización de la fuerza de trabajo en el marco de la reestructuración capitalista, que logró instalar al empleo no registrado como parte fundamental de las fuerzas productivas, $y$, a su vez, enmarcarlo en políticas laborales implementadas por los Estados para justificarlo y perpetuarlo. La intención de responsabilizar al propio trabajador desempleado por encontrar una salida a su situación de desocupación e imposibilidad de reproducción diaria y la de su núcleo conviviente, se conjugó con el fomento de la cooperativización y los microemprendimientos, 
dando como resultado un aumento de este tipo de formatos laborales y también de su utilización empresarial con fines fraudulentos. En Argentina, tanto la Ley de Quiebras como la Ley de Cooperativas actuaron como marcos institucionales para ocluir los incumplimientos en materia de derechos laborales en pos de una mayor superexplotación obrera.

Los valores demográficos vinculados al desempleo, el trabajo no registrado y el cuentapropismo entre los años 1991-2012 demostraron que tanto Mar del Plata como Necochea compartieron las tendencias nacionales, las cuales expresaron hacia el final del período abordado al menos un 30\% de empleo no registrado y un alto índice de precariedad para el grupo de trabajadores por cuenta propia, entre los cuales se incluyen los cooperativistas de la industria pesquera.

Mientras que para la clase trabajadora la autogestión se presentó como la única alternativa ante determinadas situaciones de desempleo, el fomento estatal de estas "formas de la Economía Social" se basó en el acatamiento de la ofensiva capitalista, desligándose a su vez de la responsabilidad por las condiciones de subsistencia de una gran parte de la clase trabajadora.

La promoción gubernamental y estatal de la ES guarda un carácter perverso en varios sentidos. Por un lado, porque la actual configuración capitalista, con su creciente monopolización y concentración del capital, deja poco margen para la rentabilidad de la producción cooperativa. Por otra parte, porque su promoción inicial no guarda una continuidad en el tiempo, dejando en soledad a los trabajadores autogestivos en su desigual competencia con el gran capital. Además, por el encubrimiento a formatos de fraude laboral y/o tercerización laboral. Finalmente, por la ideología meritocrática que promueve, adjudicando a los propios trabajadores la responsabilidad de la rentabilidad empresarial y de su condición ocupada, trasladando al plano personal obrero el problema estructural del capitalismo actual que representa el desempleo. En materia previsional e impositiva, la monotributización de los otrora trabajadores asalariados, consecuencia del incremento de cooperativas, también depositó en los obreros el propio pago de sus cargas sociales, aportes jubilatorios y otros derechos laborales. Por ello concluimos que los incentivos estatales para este tipo de empleos tienen como finalidades la contención social y la salvaguarda del capital, perpetuando la inestabilidad y precarización laboral a la vez que la dualización de la fuerza de trabajo.

A diferencia de otros momentos de la historia en los que la conformación de cooperativas residió en una estrategia que se pretendía disruptiva con respecto al capital, actualmente los obreros recurren a ellas como estrategias laborales para evitar o impedir el desempleo. Por ello, también puede suponerse en ellas una intencionalidad corporativa, pero que no va más allá de la mera subsistencia. Como contrapartida, las intenciones empresariales para la contratación cooperativa residen en la superexplotación y la división la clase obrera.

Los vínculos entre cooperativas e informalidad laboral y entre economía social y trabajo precarizado se expresan claramente tanto en los casos de cooperativización 
fraudulenta de Mar del Plata como en las empresas pesqueras recuperadas en Necochea. Ambas conllevan un empeoramiento en las condiciones laborales con respecto al trabajo asalariado, ya que la inestabilidad, la autoexplotación, los bajos ingresos y la pérdida de derechos propios del trabajo asalariado registrado son características que con frecuencia se reiteran, conformando la regla y no la excepción de las experiencias cooperativas y/o autogestivas.

Para los trabajadores marplatenses, la noción y vivencia del trabajo cooperativo lejos está de la igualdad, democracia, eliminación del capital y resolución de problemas comunes que se plantearon quienes inicialmente materializaron este formato laboral en el sector pesquero. Por el contrario, su praxis las conceptualiza como las máscaras legales que el empresariado utiliza para llevar a cabo su superexplotación. Para los obreros de las empresas recuperadas necochenses, la cooperativización logró enlazarse con nuevos sentidos, vinculados a la autogestión y a la lucha obrera contra el desempleo, desafiando la propiedad privada capitalista al ocuparla y ponerla a producir bajo su propia gestión. Sin embargo, las pérdidas tanto con respecto a las condiciones de trabajo asalariada como con las características del trabajo en la industria pesquera hasta los 70 confluyen para acentuar nuevamente su carácter precarizante con respecto a otras modalidades laborales.

Los resultados obtenidos a partir de los desarrollos en estos capítulos iniciales permitieron perfilar una hipótesis que se verificó en el capítulo siguiente en relación a la industria pesquera marplatense: los empresarios, en la década del 90, buscaron erradicar la contratación obrera bajo el CCT №161/75, y lograron llevarlo a cabo en un gran porcentaje de la fuerza de trabajo de la rama. De esta forma, impusieron un proceso de trabajo que logró extraer mayor plusvalía absoluta y relativa y también disminuir la cantidad de fuerza de trabajo necesaria de forma permanente en las plantas procesadoras. Los mecanismos por los cuales los capitalistas lograron imponer estas transformaciones se encuadraron en la pérdida de derechos laborales propios del empleo no registrado.

Los obreros intentaron mejorar su situación de precarización mediante acciones de combate y también mediante salidas individuales. La conclusión de que en la generalidad de las cooperativas fraudulentas se comparten similares condiciones laborales destaca la derrota obrera vivida en el destino de cooperativización impuesto. Al mismo tiempo, la resignación es acompañada por una persistente esperanza de modificar dicha realidad, contradicción que expresa una de las características de esta subjetividad colectiva obrera. De los diversos testimonios se desprende también que la orientación de la lucha de los obreros cooperativizados radica fundamentalmente en la recuperación de las condiciones de trabajo perdidas, resaltando la añoranza de un pasado mejor. Es decir, lo que los obreros cuestionan y a lo que se rebelan no es a la explotación capitalista, sino a la superexplotación diferenciada que coexiste en la industria pesquera con la explotación bajo el convenio №161/75. 
Queda como interrogante cómo se expresarán estas subjetividades obreras en las próximas décadas si no cambia esta situación, y, por ende, termina de extinguirse el convenio №161/75 y los trabajadores que conocieron su aplicación ¿Experimentarán de la misma manera la precarización con respecto a antaño quienes iniciaron su recorrido laboral en la cooperativización fraudulenta, desde los 90 en adelante?

En cuanto a la cooperativización propia de las empresas recuperadas, vimos que las subjetividades obreras expresan la precarización laboral propia de este formato laboral inmerso en el sistema capitalista. La inestabilidad y la incertidumbre constantes, las intermitencias en el proceso productivo $\mathrm{y}$, por ende, en los ingresos percibidos provoca que la única alternativa para un funcionamiento cotidiano radique en la sumisión en el trabajo informal mediante la venta de fuerza de trabajo a otras empresas. A diferencia de las cooperativas marplatenses, esta directriz no proviene directamente del empresariado, sino de la propia conclusión obrera de que es la única manera de obtener ingresos suficientes y constantes para su reproducción diaria, como se expresa en el caso de Engraucoop. Concluimos que esta es una resultante de las características de la rama en la que se inscriben estas empresas recuperadas, ya que es un sector económico en el que predomina el gran capital y la tercerización de la fuerza de trabajo.

Esto genera vivencias y expectativas encontradas, ya que, si bien los colectivos de trabajadores que recuperaron sus empresas pesqueras destacan su autonomía y su lucha por la conservación de sus puestos de trabajo, las dificultades y las características que adquiere su cotidianeidad laboral producen vivencias de fracaso, frustración y derrota, que requieren un cuestionamiento constante para proseguir el camino autogestivo. Esta sensación de derrota, luego del atravesamiento de dificultades que implican la inmersión de las cooperativas en la lógica mercantil capitalista, contrasta con la vivencia de victoria al lograr continuar trabajando mediante su propia gestión. Mientras que en el caso de La Recuperada los obreros adoptaron como "solución" a su discontinuidad laboral la obtención de otro trabajo aparte del autogestivo, los trabajadores de Engraucoop tercerizaron su propia fuerza de trabajo a fin de controlar el proceso de producción al interior de la planta, mientras que su producto es comercializado por grandes empresas ¿Lograrán los trabajadores continuar con estos procesos autogestivos? ¿Qué factores externos impactarán en su situación laboral durante los próximos años? ¿Cómo se desarrollará el vínculo entre ambas empresas recuperadas a través del tiempo? ¿Qué dinámicas adquirirán la cooperativización, el funcionamiento de los consejos de administración y los vínculos entre socios y otros trabajadores? Estas preguntas emergen de un primer estudio sobre estos casos, superados los años iniciales y luego de haberse instalado una cierta estabilidad en el desarrollo laboral diario.

Al comparar ambos tipos de cooperativas, mientras que en el caso marplatense las mismas se presentan como claramente impuestas desde arriba por la patronal, con la permisividad del Estado, en Necochea se conceptualizan como un logro obrero. En ambos casos se vinculan con la lucha obrera contra la desocupación, pero solo en 
Necochea se vive como conquista, ya que el empresariado buscó evitar su constitución a fin de disponer de sus medios de producción. La apropiación, aunque sea temporaria e incierta, de las instalaciones de las plantas procesadoras, generó esta vivencia obrera de victoria y obtención no solo de una continuidad laboral, sino de los medios con los cuales subsistir y disputarle al empresariado un resarcimiento económico luego de los despidos. Por ello, la precarización laboral se experimenta de forma diferenciada en ambos tipos de subjetividades obreras cooperativas, porque justamente la misma se enlaza con su historia y contexto de surgimiento, y con el accionar tanto obrero como empresarial en ambos casos.

Luego, en el capítulo tres profundizamos acerca de la conflictividad que trajo aparejada la crisis empresarial y la precarización laboral en la ciudad de Mar del Plata, exponiendo su desarrollo mediante ciclos y campos de disputa intrincados. Vimos que el conflicto sociolaboral no solo se manifestó entre la clase obrera y los capitalistas, sino también intraclase, entre distintas fracciones de la burguesía y entre fuerzas sociales obreras, desarrollándose en diferentes escenarios: las fábricas, las calles, los puertos de Mar del Plata y Buenos Aires, agencias estatales locales, provinciales y nacionales, y también al interior del sindicato.

Mientras que el primer ciclo se enmarcó en una crisis neoliberal internacional que en términos nacionales confluyó con el agotamiento de un modelo basado en la paridad cambiaria, los ciclos siguientes se caracterizaron por un crecimiento económico de la rama pesquera a nivel mundial, con el aumento del precio internacional del pescado y de los montos de exportación. Sin embargo, esta recuperación y crecimiento económicos no alteró la previa avanzada empresarial sobre las condiciones de trabajo, las cuales continuaron altamente precarizadas bajo nuevas legislaciones. Las condiciones de contratación, con respecto a la cooperativización fraudulenta, fueron mejoradas en parte de la fuerza de trabajo, mediante nuevos modos de registración laboral. Sin embargo, estos formatos aún representan un claro retroceso con respecto a lo alcanzado con el CCT №161/75. Por ello, consideramos que esta arremetida empresarial sobre las condiciones de producción y contratación fue la orientación de la estrategia burguesa, que se implementó con fuerza desde iniciados los 90 y perduró luego bajo diversas configuraciones.

Al analizar específicamente las acciones conflictivas emprendidas por la clase obrera, identificamos la expresión de una subjetividad beligerante, dispuesta a resistir de múltiples maneras las duras condiciones impuestas por el empresariado. En el ciclo1997-2001, las tendencias de la lucha quedaron representadas por dos fuerzas sociales obreras: una conducida por la dirigencia del SOIP, de línea saravista, que emprendió una alianza con el sector más débil de la burguesía pesquera local; la otra, encabezada por la UOP con participación de otras organizaciones y trabajadores por fuera de la dirigencia gremial, que impuso una performance de mayor combatividad y oposición contra el conjunto de la patronal pesquera. Sobre el final del ciclo, la derrota obrera y la unificación del empresariado orientaron el 
conflicto capital/trabajo hacia el campo intragremial, cuando hacia mediados del año 2000 un grupo de obreros encabezados por la UOP tomaron la sede sindical. Dos años después, la lista impulsada por dicha agrupación ganó las elecciones del SOIP. Llegado este punto, la consolidación de la cooperativización fraudulenta como rasgo estructural de la fuerza de trabajo de la industria pesquera ya se había instalado fuertemente.

Con el recambio dirigencial y la tácita tregua interempresarial, desde 2002 la conflictividad se expresó mayormente entre capital/trabajo. La recuperación y crecimiento económicos confluyeron con la devaluación y la pérdida de masa salarial que trajo aparejada, generando un marco de disputa que pivoteó entre una demanda de recomposición salarial y la persistente lucha por la registración laboral. Este vaivén expresa la consolidación de una fuerza de trabajo dualizada, con la consiguiente desprotección tanto legal como gremial del grupo obrero en peores condiciones de trabajo y contratación. Por ello, mientras que las recomposiciones salariales lograron ser obtenidas con mediación de huelgas, bloqueos y piquetes, a veces tras largos conflictos con la patronal, la registración solo se obtuvo en una pequeña proporción de los obreros no registrados, bajo condiciones muy distintas al convenio 161/75, y en gran parte similares a la precarización laboral propia de la cooperativización fraudulenta. Aquí las disputas repercutieron a su vez en nuevos conflictos intragremiales, con divisiones sucesivas de la originaria lista victoriosa en 2002, y generaron nuevas fuerzas sociales obreras en pugna, con distintos programas políticos. La diferencia fundamental entre los mismos residió en el abandono o mantención de la consigna y la lucha por la registración bajo el convenio vigente para la rama, demanda que las dirigencias del SOIP, hasta el final del período abordado, propusieron posponer en vistas de obtener registraciones parciales bajo los nuevos convenios. Los acuerdos entre dirigencia gremial y el empresariado que implicaron la elaboración de dichos convenios fueron la base para una nueva fuerza social en construcción, pero que no logró hasta el momento imponerse sobre la política del SOIP. Por ello, desde 2002 hasta 2012, las acciones realizadas por la base obrera de la industria pesquera de forma conjunta se vincularon al reclamo salarial, mientras que la demanda de registración laboral se efectuó mediante acciones más corporativas, por lugar de trabajo, con menores lazos de solidaridad y predominio del sector obrero más precarizado.

Analizando tanto los discursos de los trabajadores como las acciones emprendidas y las disputas intraclase, observamos varias tendencias que se superponen, incluso se contraponen, pero que confluyen en la caracterización de la subjetividad obrera de la industria pesquera marplatense. Por un lado, la pasivización de las bases que actúa como contracara de la burocratización de las dirigencias gremiales y políticas. Desde otro ángulo, la predisposición obrera tanto general como del sector más precarizado a expresar su ira contra la superexplotación impuesta por la patronal, por medio de formatos de acción con alto grado de radicalidad. La continuidad de las condiciones objetivas propias de la precarización y dualización de la fuerza de trabajo en la rama siguieron conspirando contra la unidad obrera. A la vez, una 
dirigencia gremial que ante las limitaciones estructurales adoptó una dirección política adaptada a las concesiones que la patronal estaba dispuesta a otorgar, contribuyó a sostener el corporativismo impuesto por el capitalismo neoliberal. El mantenimiento de la exclusión gremial del amplio sector aún cooperativizado reproduce su desigual posición ante las luchas contra el capital, reduciendo sus posibilidades de victoria.

En cuanto al vínculo entre la dirigencia gremial y las bases, coexisten dos perspectivas principales. Por un lado, la que radican en una deslegitimación del lugar dirigencial basadas en su asociación con actos de sumisión y acuerdos con el empresariado, contra los intereses obreros. Por otro, la que aún guardan una expectativa que continúa situando a quienes ocupan la conducción gremial en una posición de liderazgo y combatividad, delegando así la dirección de las luchas obreras y prestando obediencia a sus dictámenes. Otras concepciones que parten desde los mismos trabajadores se refieren a la desigualdad en cuanto a saberes, capacidades y posibilidades entre dirigencias y bases, aspecto que reaparece también en los casos de empresas pesqueras recuperadas.

Los problemas de fondo que atravesaron la conflictividad en la industria pesquera entre 1997 y 2012 continúan vigentes. La demanda de blanqueo, la falta de derechos sindicales y laborales, la inestabilidad, el permanente riesgo de desocupación y expulsión de la fuerza de trabajo en la rama del fileteado y la crisis del recurso pesquero permanecen latentes y palpitan con cada latido del corazón del sector pesquero marplatense. Por ello, las acciones obreras con o sin participación de la dirección gremial continúan multiplicándose en el frondoso escenario beligerante de la pesca marplatense.

A partir de estos desarrollos, nos quedan varios interrogantes planteados para investigaciones futuras, como, por ejemplo: ¿Los obreros buscarán superar el reclamo defensivo de recuperación de ciertas condiciones de trabajo vigentes antaño? ¿Los obreros cooperativizados, lograrán finalmente el reconocimiento gremial? ¿Se producirá en la conducción gremial el pasaje de la lucha por el convenio Pyme al CCT №161/75? ¿Se constituirá una fuerza social obrera de oposición a la fuerza social obrera hegemónica, capaz de imponer una nueva dirección en las luchas? ¿Lograrán los obreros ampliar los fundamentos para una unificación de los distintos sectores más o menos precarizados? ¿Podrán superar los obstáculos que tanto las condiciones materiales como las concepciones dominantes imponen para obstruir una ofensiva obrera? ¿Se generarán nuevas disputas entre la burguesía en los nuevos contextos de incertidumbre económica global?

Finalmente, en el último capítulo nos centramos en el análisis de los procesos que conllevaron como resultado la conformación de dos empresas pesqueras recuperadas en Necochea. En estos casos, a diferencia del destino de cooperativización fraudulenta impuesto durante los 90 a la fuerza de trabajo marplatense, dos grupos de trabajadores propusieron una cooperativización en el marco de la continuidad laboral autogestiva de las últimas firmas empresariales que 
se encontraban en pie en Necochea. Las quiebras masivas en el contexto del desguace de la rama necochense/quequenense obstruían posibilidades de continuar trabajando en la industria pesquera, presentando a la recuperación de las empresas como la única opción viable ante la desocupación y reinserción laboral incierta en otro sector económico. La resolución autogestiva desentonó con la precarización y dualización de la fuerza de trabajo que el empresariado logró imponer en Mar del Plata. Nos preguntamos, entonces, sobre los factores objetivos y subjetivos que produjeron dicho desenlace, prestando especial atención a la perspectiva de las subjetividades obreras en su expresión colectiva.

En este punto identificamos experiencias compartidas por los obreros en riesgo de inminente desocupación en Necochea, las cuales generaron una praxis colectiva de resistencia que, con el correr de las semanas, decantó en el proyecto autogestivo. Además de la vivencia del desguace del sector pesquero a nivel local y lo que implicaba para sus opciones laborales, el haber atravesado trayectorias laborales bajo el modo de contratación asalariado registrado en el rubro del fileteado y procesado de pescado fue otro de los elementos de importancia hallados en relación con la conformación de las ERT necochenses. El riesgo de pérdida inminente y permanente del puesto de trabajo generó ansias de continuar realizando la tarea ante el sentimiento de pertenencia despertado y la incertidumbre ante posibilidades reales de obtener otro empleo. A su vez, las experiencias previas de precarización laboral en cooperativas fraudulentas u otros formatos de trabajo en negro, junto con los factores anteriormente señalados, condujeron a la conclusión de que la apuesta autogestiva era la mejor opción viable. El historial de luchas previas compartidas fue otra de las variables que influyeron en la concreción de la recuperación de la empresa. Los delegados de planta que actuaron como portavoces obreros en luchas precedentes se valieron de esa referencia preconstituida para impulsar el proceso de recuperación, asumiendo un lugar de conducción que también les fue adjudicado por otros trabajadores.

El haber logrado una organización capaz de imponer como dirección de la lucha la recuperación de la empresa, producto de la conjunción de todos estos procesos señalados, generó la superación no solo de la dirección impuesta por la patronal, sino del boicot y la indiferencia de una gran parte de compañeros de trabajo, que se negaron o descreyeron de la salida autogestiva como opción laboral posible. La perspectiva de lucha más allá de los despidos junto con la alianza social conformada otorgó, en el caso de La Recuperada, la fuerza moral para alcanzar la radicalidad en pocos meses. En Engraucoop, la carencia de lazos con otras organizaciones generó que el conflicto se circunscriba más rápidamente al interior de la planta procesadora. Allí, la disputa con la segunda cooperativa conformada por trabajadores que rechazaban la recuperación de la empresa refrenó temporalmente la salida autogestiva.

Luego, al comenzar a visualizar la materialización del proyecto de recuperación desde la práctica y la conciencia colectivas, los obreros se enfrentaron con prejuicios íntimamente intrincados: por un lado, los referidos a la necesidad del patrón 
capitalista para el funcionamiento adecuado de una empresa, y, por otra parte, los vinculados a una cierta incapacidad obrera para emprender esta tarea sin patrón, por falta de "formación". El requerimiento de "saberes ajenos" fue un prejuicio a vencer durante la lucha, y para ello en ambos casos de recuperación actuaron como facilitadores actores diversos. En el caso de La Recuperada, el impulso para transformar estos saberes vedados en plausibles de ser adquiridos provino de las alianzas sociales constituidas al calor de la lucha, fundamentalmente con la dirigencia gremial y la organización social y política que se involucró en los primeros momentos del proceso. En Engraucoop, la alianza intraobrera entre trabajadoras del proceso de producción y trabajadoras administrativas, el conocimiento del caso de La Recuperada y el impulso estatal inicial fueron los propulsores de la autogestión y del vencimiento de los preconceptos que la obstaculizaban.

Estudiando el desarrollo de ambos procesos de recuperación durante sus dos primeros años de funcionamiento, observamos una diferenciación entre los primeros momentos de la lucha, en los que prevalecieron la solidaridad, las alianzas sociales generadas, acciones diversas y radicales contra la patronal y una lógica horizontal, y los momentos posteriores, en los que el aislamiento de las empresas autogestivas retrotrajeron las acciones de rebelión al ceñirse a la búsqueda de un funcionamiento cotidiano rentable y constante. Esta diferenciación y los obstáculos a la autogestión que surgieron a lo largo del tiempo provocaron una desmoralización e imposibilitaron la aplicación de los saltos en la conciencia logrados, y de la praxis combativa que los acompañaba.

En los inicios de ambos procesos predominaron ciertos formatos de rebelión que implicaron manifestaciones en la vía pública, ocupación de los lugares de trabajo y reuniones entre partes, cuyos destinatarios fueron la patronal y el Estado, a fin de lograr la continuidad laboral. Con el correr de los meses las mismas mutaron hacia los festivales y peñas en la planta a fin de obtener ingresos y apoyo de la comunidad para la subsistencia obrera. Las ocupaciones, que comenzaron como acciones ilegales contra la propiedad privada capitalista, se transformaron en acciones legales al obtener el permiso judicial para la puesta en marcha de la producción autogestiva obrera. La legitimidad que adquirieron estas luchas se expresó mediante el apoyo político, social y gubernamental obtenido, y se corresponde con la tendencia general del movimiento nacional de empresas recuperadas, en donde el valor del trabajo y la lucha contra la desocupación inminente logra vencer aspectos del sistema de pensamiento hegemónico, que implica la sumisión al empresariado, a la propiedad y la explotación capitalista. Sin embargo, esta legitimidad inicial no se corresponde con un acompañamiento posterior, quedando las experiencias de autoorganización productiva obreras aisladas, y coartadas en las posibilidades de llevar a cabo acciones por fuera de las destinadas a la supervivencia diaria. Los apoyos económicos estatales son escasos y escuetos con respecto a las necesidades de rentabilidad de las empresas recuperadas, y la fuerza social obrera inicial tiende a diluirse con el tiempo, sin ser suplida con otras alianzas que contribuyan a la consolidación y fortalecimiento de estas experiencias. De aquí se 
explica el surgimiento de nuevas contradicciones en el seno de las subjetividades obreras propias de trabajadores de empresas recuperadas. Las mismas se expresan en ciertas tendencias, tales como la vivencia de la recuperación como una conquista y un fracaso a la vez, la frustración por la falta de rentabilidad y retiro de trabajadores que conformaron el proyecto inicial a la vez que el enaltecimiento de la conquista obtenida por medio de la lucha, un resurgimiento de prejuicios obreros previamente superados al mismo tiempo que la vivencia de autonomía ante determinados logros autogestivos, y una decepción que coexiste con la dignidad obrera obtenida mediante la lucha y retención del puesto de trabajo. Asimismo, la reaparición de praxis vinculadas al individualismo y al verticalismo, junto con una auto-responsabilización por las falencias que se presentan, se contraponen con los altos niveles de solidaridad alcanzada, el nuevo clima laboral basado en la ausencia de la figura del patrón y el relajamiento de la disciplina fabril tradicional.

Estas contradicciones expresan características de la dualidad laboral propia de las empresas recuperadas abordadas: los trabajadores gozan de mayor autonomía y a la vez mantienen una sujeción con respecto del capital externo a la fábrica, y a la vez conforman procesos de trabajo que guardan tanto diferencias como similitudes con respecto a los formatos de precarización laboral impuestos en la industria pesquera durante el período abordado ¿Cómo se manifestarán estas subjetividades obreras en los próximos años de funcionamiento de las empresas recuperadas? ¿Podrán superar la sumersión en la búsqueda de rentabilidad cotidiana por otros objetivos? ¿Lograrán revertirse las tendencias a depositar en unos pocos miembros funciones de conducción, gestión y administración de la producción autogestiva? ¿Se generarán nuevos contextos de combatividad similares a los de los primeros momentos de lucha? ¿Surgirán en los trabajadores de las empresas recuperadas nuevos sentidos y prácticas vinculadas a la actividad laboral autogestiva? ¿La recuperación saltará la barrera del más allá del desempleo? ¿Sobrevendrá una nueva oleada de empresas recuperadas ante la profundización de la crisis económica en los próximos años?

Adoptamos como premisa que las circunstancias hacen a los sujetos tanto como sujetos hacen a las circunstancias, y ahora estamos convencidos de esa implicancia recíproca. A lo largo de estas páginas expusimos cómo la confluencia de condiciones objetivas y subjetivas crearon y recrearon el escenario de la industria pesquera en Mar del Plata y Necochea, entre 1997 y 2012.

En su conjunto, los avatares de las subjetividades obreras, la conflictividad sociolaboral que las atraviesa y su interrelación con el desarrollo de este sector económico expresan un dinamismo con rasgos propios y a la vez compartidos con otras experiencias obreras en diferentes coordenadas temporales y espaciales. La industria pesquera marplatense expresa su preponderancia en esta ciudad portuaria, por la gran cantidad de trabajadores en la rama que confluyen diariamente en el epicentro portuario y por su gran empresariado oligopólico, que utiliza a su favor el poder estatal. En ello mismo reside la potencia de su fuerza de 
trabajo organizada para paralizar sectores concentrados de la economía y los circuitos de producción y de circulación capitalista, nucleados en el puerto, ese "lugar soñado". La predisposición obrera hacia la combatividad apuesta por reiterarse y reinventarse a fin de subvertir la superexplotación aun impuesta por el empresariado. En Necochea, el desguace progresivo de la rama no impidió que dos colectivos obreros resistan y mantengan sus fuentes de trabajo, cuestionando la directriz dominante y también la tendencia imperialista del capital. El dinamismo propio de los procesos históricos y las fuertes contradicciones que conllevan avecinan nuevas crisis y reconfiguraciones en la industria pesquera bonaerense, así como renovados formatos de rebelión obrera contra las duras condiciones impuestas por el capital. Quedamos expectantes de las nuevas luchas por venir. 


\section{Bibliografía y fuentes}




\section{Bibliografía:}

Abramovich, A. (2008). Emprendimientos productivos de la economía social en Argentina: funcionamiento y potencialidades. En A. C. (Comp.), La economía política de la pobreza (págs. 221-241). Buenos Aires: CLACSO.

Aguiar, S. (2009). El caso de la huelga larga de los trabajadores del salmón en Chile. Estructura y función de la huelga en el paso de clase en sí a clase para sí. Conflicto Social, Año 2, № 2, 292-329.

Aguila, G. (2012). La Historia Reciente en la Argentina. Un balance. Historiografías, №3, 62-76.

Alfaro, M. (1991). Carnaval. Una historia social de Montevideo desde la perspectiva de la fiesta (1800-1872). Montevideo: Ediciones Trilce.

Allen, A. (2010). ¿Sustentabilidad ambiental o sustentabilidad diferencial? La reestructuración neoliberal de la industria pesquera en Mar del Plata. Argentina. Revista de estudios marítimos y sociales, Año 3, № 3, 151-158.

Altamira, C. (2006). Los marxismos del nuevo siglo. Buenos Aires: Biblos.

Álvarez, A. et al. (1991). Mar del Plata. Una Historia Urbana. Ed. Fundación: Buenos Aires.

Antón, G. (2010). Conflicto y poder en la Argentina: 2005-2008. Análisis de la emergencia del kirchnerismo como fuerza política a partir de una lectura del diario La Nación. Tesis de doctorado. Argentina: Material Inédito.

Antón, G. y Rebón, J. (2005). El conocimiento en los procesos sociales. Una aproximación a la conciencia de clase operante entre los trabajadores de Empresas Recuperadas. LabourAgain, http://www.iisg.nl/labouragain/documents/anton rebon.pdf

Antunes, R. (1999). ¿Adiós al trabajo? Ensayo sobre las metamorfosis y el rol central del mundo del trabajo. Argentina: Editorial Antídoto.

Antunes, R. (2005). Los sentidos del trabajo. Ensayo sobre la afirmación y la negación del trabajo. Buenos Aires: Ediciones Herramienta.

Antunes, R. (2007). Diez tesis sobre el trabajo del presente y una hipótesis sobre el futuro del trabajo. Revista Realidad Económica, № 232, 29-49.

Ardila, R. (1986). La psicología en América Latina: pasado, presente y futuro. México: Siglo XXI Editores.

Arias, C. (2008). Representación sindical y fábricas recuperadas: un mapa de la cuestión. Kairos, revista deTemas sociales, Año 12, № 22, 1-20. 
Aruguete, N. (2011). Framing. La perspectiva de las noticias. La Trama de la Comunicación, Vol. 15, 67-80.

Atzeni, Mauricio y Pablo Ghigliani . (2007). Labour process and decision-making in factories under workers' self-management: empirical evidence from Argentina . Rev. Work, Employment and Society, vol. 21, 653-673.

Balbi, F. (1998). ...esos son acopiadores: Moralidad y conflicto en una cooperativa de pescadores entrerrianos. Una etnografía. Tesis para optar por el grado de Magister en Antropología Social. Misiones, Argentina: Facultad de Humanidades y Ciencias Sociales, Universidad Nacional de Misiones.

Barrault, O. (2007). Los espacios de encuentro en la psicología comunitaria y sus implicaciones en la subjetividad. Revista de Ciencias Humanas, UTP, № 37, 155-168.

Bastidas Delgado, O., y Richer, M. (2001). Economía social y economía solidaria: intento de definición. Cayapa. Revista Venezolana de Economía Social, 1 (1), 0 .

Basualdo, V. (2012). Avances y desafíos de la clase trabajadora en la Argentina de la posconvertibilidad, 2003-2010. Derechos humanos en argentina. Informe 2012, 429-459.

Beccaria A. et al. (2011). Protecciones y desprotecciones: la seguridad social en la Argentina 1990-2010. Los Polvorines: Universidad Nacional de General Sarmiento.

Belkin, A. y Ghigliani, P. (2010). Burocracia Sindical: aportes para una discusión en ciernes. Nuevo Topo, № 7, 103-116.

Benente, M. (2011). Las fuentes de la protesta social. Teoría crítica y hermenéutica. Revista Fundamentos en Humanidades, vol. XII, núm. 23, 9-23.

Bértola, L. y Ocampo, J. (2010). Desarrollo, Vaivenes y Desigualdad. Una Historia Económica de América Latina desde la Independencia. Madrid: Secretaría Iberoamericana.

Bertolino, E. y Perelli, L. (2006). Lenguaje, subjetividad y cultura. Autores: ; Localización:. La trama de la comunicación, №10, 281-290.

Bertolotti, G. y Col. (1987). La actividad industrial pesquera "Procesamiento y Transformación industrial" Capacidades de producción, empleo y posibilidades de aprovechamiento de las especies más importantes del mar argentino. Parte I: Período 1981/1982. . Revista Contribución No 438, INIDEP, 4-20. 
Bertolotti, M. I. (2001). Algunas consideraciones preliminares sobre el estado del sector pesquero. Informe Técnico $N^{\circ} 71$. Buenos Aires: INIDEP.

Bertolotti, M., Erratzi, E. Y Pagani A. (1997). Resultados preliminares del Censo Nacional Industrial Pesquero - año 1996. Provincia de Buenos Aires. Plantas instaladas en tierra. Mar del Plata, Buenos Aires: Informe técnico interno № 34, INIDEP.

Bertolotti, M. I., Piergentili, G. y Cabut, D.(1987). El sector pesquero argentino. Rev. Investigación Pesquera , № 51 (Supl. 2), 193-221.

Bertolotti, M. y Manca, E. (1986). Procesamiento y comercialización de la anchoíta (Engraulis anchoíta) del Mar Argentino. Revista de Investigación y Desarrollo Pesquero, №5 224- 247.

Betancourt, C. E. (1990). Gramsci y el concepto del bloque histórico. Historia crítica, №4, 113-126.

Borakievch, S. y Rivera, L. (2007). Devenires de las fábricas sin patrón: La cooperativa 'La nueva esperanza' (Ex Grissinopoli). Memorias de las XIV Jornadas de Investigación - III Encuentro de Investigadores en Psicología en el Mercosur (págs. 178-182). Buenos Aires: UBA.

Brunet, I. y Pizzi, C. (2011). Capitalismo y subjetividad obrera. El movimiento de empresas recuperadas en Argentina. Madrid, España: Biblioteca Nueva.

Butler, J. (1997). Mecanismos psíquicos del poder. Madrid: Cátedra.

Cabrera, C. (2007). CabDevenires de las fábricas sin patrón: Buenos Aires una empresa nacional (BAUEN). Memorias de las XIV Jornadas de Investigación III Encuentro de Investigadores en Psicología en el Mercosur. La investigación en psicología, su relación con la práctica profesional y la enseñanza (págs. 173177). Buenos Aires: UBA.

Calloway, C. (2007). Devenires de las fábricas sin patrón: Cooperativa Chilavert Artes Gráficas. Memorias de las XIV Jornadas de Investigación - III Encuentro de Investigadores en Psicología en el Mercosur. La investigación en psicología (págs. 167-172). Buenos Aires: UBA.

Calloway, Colombari y Iorio. (2015). Cooperativas en los márgenes: posibilidades y dificultades en torno al acceso de políticas públicas. Revista del Observatorio Social sobre Empresas Recuperadas y Autogestionadas, № 11, 4-21.

Cambiasso, Mariela y Andrada, Georgina. (2014). Toque timbre y un compañero me abrió la puerta, Entrevista a Gonzalo, trabajador de Donnelley. Revista Ideas de Izquierda , № 13, 6-10. 
Campana, M. y Giavedoni, J. (2014). Debates sobre Estado, gobierno y control social. Rosario: PEGUES.

Campione, D. (1994). La Clase Obrera De Alfonsín A Menem . Buenos Aires: CEAL.

Candia, J. (2006). De vuelta al trabajo. Las Empresas Recuperadas en Argentina. Trayectorias, , 34-45, Año VII Num. 22.

Carretero Miramar, J. L. (2010). Las Empresas recuperadas. Hacia una comprensión de la autogestión obrera real . Nómadas, núm. 25, 25-32.

Castel, R. (1998). Centralidad del trabajo y cohesión social. En J. e. Boutet, El mundo del trabajo. París: La Découverte.

Castro, M. (1997). La emigración de las Marcas a Mar del Plata en la segunda posguerra. Redes sociales y movilidad ocupacional (1947-1960). Congreso "Le Marche fuori dalle Marche. Migrazioni interne ed emigrazione all'estero tra XVIII e XX secolo". Italia: Universitá di Ancona, Fermo y Fabriano.

Chazarreta, V. (2009). Empresas recuperadas rosarinas. Una nueva identidad cultural que cuestiona los paradigmas tradicionales de la administración . Tesis de Grado, Licenciatura en Ingeniería Comercial. Rosario, Santa Fe, Argentina: Universidad abierta interamericana.

Cifuentes-Lemus, J. y Cupul-Magaña F. (2002). Un vistazo a la historia de la pesca en México: administración, legislación y esfuerzos para su investigación. Historia de la ciudad de México. En Ciencia Ergo Sum, Vol. 9-1, pp. 112-118.

Cimadamore A. (comp.). (2008). La economía política de la pobreza . Buenos Aires : Clacso.

Clarke, S. (1992). The global accumulation of capital and the periodisation of the capitalist state form. En W. G. Bonefeld, Open Marxism, Volume I (págs. 133179). London: Pluto.

Colombo G. y Nieto, A. (2008). Aproximación a las formas de la lucha obrera en la industria de la pesca, Mar del Plata 1997-2007 . LabourAgain, 1-15.

Colombo, G. (2008). Hasta que el recurso nos falló. Crisis de la merluza y protesta obrera. La dinámica de los enfrentamientos en el puerto marplatense (19972002). Tesina de licenciatura en Historia. Mar del Plata, Argentina: UNMDP.

Colombo, G. (2011). De clasistas a burócratas: el devenir de una traición. Acerca de la construcción moral del enemigo político en un sindicato de la industria del pescado (Mar del Plata - Argentina, 1997-2007). Revista Colombiana de Antropología, № 47, 45-68. 
Colombo, G. (2014). De la revolución productiva a la crisis de la merluza: El conflicto social en la industria pesquera marplatense. Años 1989-2001. Tesis de posgrado. La Plata, Argentina: Universidad Nacional de La Plata. Facultad de Humanidades y Ciencias de la Educación.

Colombo, G. y Nieto, A. (2006). Bases sociales y económicas de la protesta. La industria de la pesca en Mar del Plata. De la convertibilidad a la devaluación (1991-2002). XX Jornadas de Historia Económica. Mar del Plata: UNMDP.

Coraggio, J.L. (1998). El trabajo desde la perspectiva de la Economía Popular, en: J.L. Coraggio, Economía Popular Urbana: una nueva perspectiva para el desarrollo local, Programa de Desarrollo Local, Cartilla № 1, Instituto del ConurbanoUNGS.

Coraggio, J.L. (1994). La construcción de una economía popular: vía para el desarrollo humano. Revista de Economía y Trabajo, Año II, № 3, 24-47.

Coriat, B. (1982). El taller y el cronómetro. Ensayo sobre el taylorismo, el fordismo y la producción en masa. Madrid: Siglo XXI.

Coriat, B. (1993). Pensar al revés. Trabajo y organización en la empresa japonesa. España: Siglo XXI Editores.

Coriat, B. (2003). El taller y el cronometro . Buenos Aires: Siglo XXI.

Coscia, V.; Perbellini, M. y Spina, E. (2012). Ocupaciones de fábricas en tiempos de crisis: el caso italiano a la luz de la experiencia argentina. III Jornadas Internacionales de Problemas Latinoamericanos: Movimientos Sociales, Estados y Partidos Políticos en América Latina (págs. 1-20). Mendoza: Universidad Nacional de Cuyo.

Cuesta Bustillo, J. (2010). La historia del tiempo presente: estado de la cuestión. Studia Historica. Historia ContemporáNea, 227-241.

Cutuli, R. (2009). Trayectorias laborales precarizadas. Mujeres de la industria pesquera marplatense. 1980-2008. II Jornadas de Género y Pobreza,. Buenos Aires.

Cutuli, R. (2012). “Feas, sucias y malas". Miradas “de" y "sobre" las trabajadoras del sector pesquero (Mar del Plata, 1990-2010). Ankulegi, 141 - 157.

Cutuli, R. (2015 ). Tercerización, flexibilización y fraude laboral en la industria pesquera marplatense. Un estudio a través de la justicia laboral (Mar del Plata, 1990-2010) . 12º Congreso Nacional de Estudios del Trabajo (págs. 127). Buenos Aires : ASET. 
D’Adamo, 0.; García Beaudopux, V. y Montero M.(coords.) . (1995). Psicología de la acción política. Buenos Aires: Paidós.

Dalle, P. ( 2012). Cambios recientes en la estratificación social en Argentina (20032011). Inflexiones y dinámicas emergentes de movilidad social . Argumentos. Revista de Crítica Social, 14: 77-114.

Dasten, J. (2014 ). La precariedad laboral, modernidad y modernización capitalista: Una contribución al debate desde América Latina . Trabajo y Sociedad, №23, 147-169.

Dávolos, P. y Perelman, L. (2004). Acción colectiva y representaciones sociales: los trabajadores de empresas recuperadas. LabourAgain, 1-16.

De la Fuente Lavín, M. y Zubiri Rey, J. B. (2016). Significado histórico y actualidad de las políticas de reducción del tiempo de trabajo. Lan Harremanak, Revista de Relaciones Laborales, №34, 79-105.

De La Garza Toledo, E. y Neffa, J. (Comp.). (2010). Trabajo y modelos productivos en América Latina. Argentina, Brasil, Colombia, México y Venezuela luego de las crisis del modo de desarrollo neoliberal. Buenos Aires: CLACSO.

Dejours, C. (2012). Trabajo vivo. Tomo I - Sexualidad y trabajo. Buenos Aires: Editorial Topia.

Dejours, C. (2013). Trabajo vivo, Tomo II -Trabajo y emancipación. Buenos Aires: Topía.

Dejours, C. y Gernet, I. (2014). Psicopatología del trabajo. Buenos Aires: Editorial Miño y Davila.

Delfini, M.; Drolas, A. y Medina, J. (2013). Continuidades y rupturas en las relaciones laborales de Argentina tras la crisis del neoliberalismo . Observatorio Laboral Revista Venezolana, Vol 6, № 11, 47-66.

Dinerstein, A. (2007). Workers' factory takeovers and new state policies in Argentina: towards an 'institutionalisation' of non-governmental public action? Policy y Politics, vol 35, no 3, 529-550.

Engels, F. (1895-1896). El papel del trabajo en la transformación del mono en hombre . Revista Die Neue Zeit, Bd. 2, N 44.

Engels, F. (1981). El origen de la familia, la propiedad privada y el Estado . En K. y. Marx, Obras Escogidas (págs. 203-352). Moscú: Progreso.

Entman, R. (1993). Framing: Toward a Clarification of a Fractured Paradigm. Journal of Communication, núm. 43 (3), 51-58). 
Errazti, E., Bertolotti, M. I. y Pagani, A. (2000). Industria Pesquera de la Región Bonaerense. Revista Frente Marítimo, 18, sección B: 153-164.

Esponda, A. y Basualdo, V. (2014). Abordajes sobre la tercerización laboral en América Latina: aportes y perspectivas. VII Jornadas de Sociología de la UNLP. Ensenada: UNLP.

Fajn, G. y Rebón, J. (2005). El taller ¿sin cronómetro? Apuntes acerca de las empresas recuperadas. En Herramienta № 28, 47-66.

Favero, B. (2013). La última inmigración. Italianos en Mar del Plata (1945-1960). Buenos Aires: Imago Mundi.

Federico Sabaté, A. (2003). Las empresas sociales: ¿Un componente sustancial para consolidar la economía social?, en Abramovich, A.L., D. Cassano, A.F. Sabaté, S. Hintze, A. Montequín y G. Vázquez, Empresas sociales y economía social. Una aproximación a sus rasgos fundamentales, Cartillas 6. Buenos Aires: Instituto del Conurbano, Universidad Nacional de General Sarmiento.

Fernández Álvarez, M. (2007). De la recuperación como acción a la recuperación como proceso: prácticas de movilización social y acciones estatales en torno a las fábricas recuperadas. Cuadernos de Antropología Social , Num. 25, 89110.

Fernández, A. M. y col. (2006). Política y subjetividad. Asambleas barriales y fábricas recuperadas. Buenos Aires: Editorial Biblos.

Fernández, F. (2000). Cambios en el proceso de trabajo en la gran industria capitalista: una aproximación a partir del análisis de la industria automotriz argentina. Documento de trabajo № 22. Buenos Aires: PIMSA.

Ferrer, A. (2012). La construcción del Estado Neoliberal en la Argentina . Revista de Trabajo, Año 8, № 10, 99-107.

Fontecoba, A. y Gonzalez, G. (2014). Los desafíos de la producción autogestiva en la Argentina. Voces en el Fénix, № 38, 62-67.

Freud, S. (1921). Psicología de las masas y análisis del yo. En S. Freud, Obras completas, Tomo XVIII. Buenos Aires: Amorrortu Editores.

Freud, S. (1927). El porvenir de una ilusión. En S. Freud, OC, Tomo XXI . Buenos Aires: Amorrortu Editores.

Freud, S. (1930). El malestar en la cultura . En S. Freud, OC, Tomo XXI . Buenos Aires: Amorrortu Editores.

Freud, S. (1940). Esquema del psicoanálisis. En S. Freud, OC, Tomo XXIII . Buenos Aires: Amorrortu Editores. 
Galende, E. (1997). De un horizonte incierto. Psicoanálisis y salud mental en la sociedad actual. Buenos Aires: Editorial: Paidós.

Galende, E. (1997). De un horizonte incierto. Psicoanálisis y salud mental en la sociedad actual. Buenos Aires: Paidós.

Gandulfo, A. (2014 ). Finanzas solidarias en la profundización del proyecto nacional y popular. Voces en el Fénix, № 38, 28-37.

Gans, H. J. (1979). Deciding what is Notice. A Study of CBS Evenig News, NBC Nightly News, Nesweek and Time. New York: VintageBooksEdition.

García Allegrone, V. (2007). Los procesos de recuperación del trabajo en fábricas y empresas del Gran Buenos Aires. Continuidades y discontinuidades en las prácticas y representaciones de los trabajadores. Un estudio de caso. Tesis de Maestría en Ciencias Sociales del Trabajo. Buenos Aires: UBA.

García, M. I. (2007). Subjetividad y Trabajo en empresas recuperadas. El caso BAUEN. Tesis presentada para la obtención del grado de Licenciada en Sociología . La Plata, Argentina: FAHCE-UNLP .

Ghibaudi, J. (2004). Una aproximación comparativa a las empresas recuperadas argentinas y las autogeridas en Brasil. Labour Again Publications, 1-16.

Ghigliani, P. (2003). Nuovo movimento operaio e l'occupazione delle fabbriche in Argentina. Revista Proteo, vol. VII, 74 - 94.

Ghigliani, P. (2007). Autogestión y circulación mercantil. Actas de las VII Jornadas de Sociología. Pasado, presente y futuro, (págs. 1-18). Buenos Aires.

Ghigliani, P. (2009). Acerca de los estudios cuantitativos sobre conflictos laborales en Argentina (1973-2009): reflexiones sobre sus premisas teóricometodológica. Revista Conflicto Social, Año 2, № 2, 76-97.

Giavedoni, J. (2015). Economía social y solidaria, trabajo y capitalismo. Relación entre forma de trabjo y patrón de acumulación en el gobierno de la fuerza de trabajo . Trabajo y Sociedad, №25, 195-214 .

Gil, G. (2007). Tiempos violentos. Memoria y presente sobre una hinchada de un club del interior. En Etnía, 39 - 62.

Goffman, E. (1974). Frame analysis: An essay on the organization of experience. Cambridge : Harvard UniversityPress.

Gourevitch, P. (1986). Politics in hard time. Ithaca, N.Y.: Cornell University Press.

Gracia, A. (2009). El nacimiento de la comunidad. Experiencias de recuperación del trabajo y la producción en Argentina. OSAL, Año X, NNo 26, 95-124. 
Gramsci, A. (1970). Antología. Buenos Aires: Siglo XXI.

Grassi, E. (2012). La política social y el trabajo en la Argentina contemporánea. Revista e-l@tina, Vol. 10, núm.39, s/n.

Grigera, J. (2011). Desindustrialización, ¿agresión a la manufactura o reestructuración capitalista? En A. Bonnet, El país invisible: debates sobre la Argentina reciente, 81-102. Buenos Aires: Peña Lillo/Continente.

Grigera, J., y Álvarez, L. (2013). Extractivismo y acumulación por desposesión. Un análisis de las explicaciones sobre agronegocios, megaminería y territorio en la Argentina de la postconvertibilidad. Theomai, 80-97.

Grigera, J. y Eskenazi, M. (2013). La acumulación de capital durante la posconvertibilidad. En e. J. Grigera, Argentina después de la convertibilidad (2002-2011) (págs. 165-193). Buenos Aires: Imago Mundi.

Hernandez, M. (2013). El movimiento de autogestión obrera en Argentina. Empresas recuperadas y movimientos de trabajadores desocupados. CABA: Editorial Topía.

Hopp, M. V. (2012). Políticas de promoción del trabajo asociativo y autogestionado en la Argentina actual: un balance. Revista OSERA , № 9, 13-31.

Hudson, J. P. (2012). Empresas Recuperadas en la Argentina: una década de lucha de los trabajadores por autogestionarse. CIRIEC-España, Revista de Economía Pública, Social y Cooperativa, 158-180.

Huertas, O., Davila, R. y Castillo, D. (2011). Transformaciones en las subjetividades de los trabajadores: casos de empresas colombianas recuperadas. Universitas Psychologica, Vol. 10, No. 2, 581-594.

Husson, M. (1997). Empleo: Modelos y tratectorias. Documento de trabajo. Seminario intensivo de investigación dictado entre el 4 al 8 de agosto de 1997 en el Centro de Altos Estudios Franco-Argentino.

Hyman, R. (1978). El marxismo y la sociología del sindicalismo, México DF: Ediciones Era.

Iñigo Carrera, N. y Donaire, R. (2003). ¿Qué interés se manifiesta en las centrales sindicales argentinas? Pimsa Documentos y Comunicaciones.Vol. 6, 132-192.

Izaguirre, I. (1994). Los desaparecidos: recuperación de una identidad expropiada. Buenos Aires: Centro Editor de América Latina.

Kingdon, J. (1984). Agendas, alternatives, and public policies. Little: Brown.

Lacan, J. (1971/72). El Seminario. Libro 19. ... o peor. Buenos Aires: Ed. Siglo XXI. 
Lacan, J. (1988). Escritos 1 y 2. Buenos Aires: Siglo XXI.

Lacan, J. (1999). El Seminario - Libro V: Las formaciones del inconsciente. Buenos Aires: Paidós.

Lacan, J. (1999). El Seminario - Libro V: Las formaciones del inconsciente. Buenos Aires: Paidós.

Lagiu, Solero, Tavello y Valentino. (2008). De empresas recuperadas, movimientos sociales y conflictividad. Un estudio de caso. Jornadas Internacionales de problemas latinoamericanos: "Los Movimientos Sociales en América Latina. Pasado, presente y perspectivas" (págs. 78-94). Mar del Plata: UNMDP.

Lahera Parada, E. (2002). Introducción a las políticas públicas. Santiago de Chile: FCE.

Lahille, F. (1895). Notas sobre la industria de la pesca en la Provincia de Buenos Aires. Excursión de setiembre-octubre 1895. Revista del Museo de La Plata, 312.

Lanari, E. y Cutuli, R. (2010). Trabajadores de la industria pesquera procesadora: conserva y fileteado en el puerto de Mar del Plata. En Concurso: El estado de la clase trabajadora en la Provincia de Buenos Aires (págs. 1-52). Buenos Aires: Ministerio de Trabajo de la Provincia de Buenos Aires.

Lanari, E. (2010). Crecimiento y derechos sociales fundamentales. Un estudio comparado sobre las oportunidades de empleo a nivel local y regional desde la perspectiva del trabajo decente. En Ferrari, Marcela y Nuñez, Ana E., (Eds.), Pasado y presente de la Mar del Plata social. Coloquio III (pp. 143-160). Mar del Plata: EUDEM.

Lanari, E. (2015). Argentina: las implicaciones de las políticas públicas y la regulación laboral sobre el trabajo 2008-2013. Cuadernos del CENDES , AÑO 32. $\mathrm{N}^{\circ} 89: 1-16$.

Lascano, 0. (1989). Cien años de pesca costera en la Argentina. Análisis de los principales factores económicos que han obstaculizado y/o promovido el desarrollo de la pesca en pequeña escala en la Argentina. España: Informe de la FAO.

LaVaca, C. (2007). Sin patrón. Fábricas y empresas recuperadas por sus trabajadores. Buenos Aires: LaVaca Editora.

Lenin, V. (1961). Obras escogidas. Tomos I, II y III. Moscú: Editorial Progreso.

Madaria, E. (2001). El sector pesquero argentino. Buenos Aires: PIGPP.

Magnani, E. (2003). El cambio silencioso. Empresas recuperadas en Argentina. Buenos Aires: Prometeo. 
Mance, E. A. (2001). La revolución de las redes. La colaboración solidaria como una alternativa pos-capitalista a la globalización actual. Petrópolis: Editora Vozes.

Mancini, M. y Lavarello, P. (2013). Heterogeneidad estructural: origen y evolución del concepto frente a los nuevos desafíos en el contexto de la mundialización del capital. Entrelineas de la política económica, № 37, 28-34.

Mandel, E. (1979). Introducción al marxismo . Madrid: Akal.

Mandel, E. (2005). Escritos de Ernest Mandel: el lugar del marxismo en la historia y otros textos. Madrid: Los Libros de la Catarata.

Marín, J. C. (2009). Leyendo a Clausewitz/Cuaderno 8. Buenos Aires:: Colectivo Ediciones/PICaSo.

Marini, R. (1973) Dialéctica de la dependencia, en CLACSO, América Latina, dependencia y globalización. Buenos Aires: CLACSO.

Martín-Baró, I. (1983). Acción e ideología. Psicología social desde Centroamérica. San Salvador: UCA Editores.

Martínez Valle, L. (2009). La economía social y solidaria: ¿mito o realidad? Íconos, 107-113.

Marugán Pintos, B. (2013). Sociología rural vs Sociología pesquera. Encrucijadas. Revista Crítica de Ciencias Sociales , №6, 86-100.

Marx, K. (1844). Manuscritos económico-filosóficos de 1844. Buenos Aires: Ediciones Colihue.

Marx, K. y Engels, F. . (1845-46). La ideología alemana. Montevideo: Pueblos Unidos.

Marx, K., y Engels, F. (1846). La sagrada familia. La situación de la clase obrera en Inglaterra. España: Editorial Crítica.

Marx, K. (1859). Contribución a la crítica de la economía política. Madrid: Siglo XXI Editores.

Marx, K. M. (1867). El Capital. 3 Tomos. España: Siglo XXI Editores.

Marx, K. y Engels, F. (1975) Obras escogidas, Moscú: Editorial Progreso.

Mateo, J. M. (2003). De espaldas al Mar. La pesca en el Atlántico sur (siglos XIX y XX) . Tesis propuesta para el doctorado en historia. Barcelona : Universitat Pompeu Fabra.

Mateo, J. M. (2011). Cosechando el mar en lanchas amarillas. Alemania: Editorial Académica Española. 
Mateo, J. M. y Yurkevich, G. (2010). Estrategias de la anchoíta en un mar de tiburones: Las pymes conserveras marplatenses durante la valoración financiera (1975-2006) . Trabajos y Comunicaciones, (36), 141-164.

Mateo, J. M.; Nieto, A. y Colombo, G. (2010). Capítulo 10: Precarización y fraude laboral en la industria pesquera marplatense. El caso de las cooperativas de fileteado de pescado. Estado actual de la situación y evolución humana de la rama 1989-2010. En Concurso Bicentenario de la Patria, Premio Juan Bialett Massé (págs. 177-203). Buenos Aires: Ministerio de Trabajo de la Provincia de Buenos Aires.

McCarthy, J., McPhail, C. y Smith, J. (1996). Images of Protest: Dimension of Selection Bias in Media Coverage of Washington Demostrations, 1982 and 1991. American Sociological Review, vol. 61, 478-499.

Mendíaz, M. G. (2007). El Estado y las políticas públicas: las visiones desde el Neoinstitucionalismo. Rosario: Biblioteca Virtual Puntoedu. UNR.

Millones Espinosa, M. (2012). Límites del Trabajo Decente: la precarización laboral como problema estructural en América Latina. Revista Gaceta Laboral, № 18, 87-106.

Molinari, I. (1998). El mundo del trabajo: la vida de las obreras de la conserva en función de los tiempos de la fábrica. La sociabilidad en la fábrica, el hogar, el barrio, el tiempo libre en Mar del Plata, 1940/1983. Anais Eletrônicos do III Encontro da ANPHLAC (págs. 1-11). Sao Pablo: AMPHLAC.

Molinari, I. (2008). Obreras, operarias y empleadas. El trabajo de las mujeres en Mar del Plata, entre los años 1940 y 1960. Trabajos y Comunicaciones, (34) 153171.

Monereo Pérez, J. (2000). El Derecho Social en el umbral del siglo XXI: la nueva fase del Derecho del Trabajo. Lan Harremanak, № 2: 237-300.

Monereo Pérez, J. (2011). El trabajo precario: segmentación y dualización de los mercados de trabajo y políticas de flexibilidad laboral, en Luis Enrique de la Villa Gil, El trabajo, 383-429. España: Editorial Universitaria Ramón Areces.

Montero, M. (1991). Concientización, conversión y desideologización en el trabajo psicosocial comunitario. Boletín de la AVEPSO, XIV, 3-12.

Montero, M. (2002). Construcción del Otro, liberación del sí-mismo. Utopía y Praxis Latinoamericana, № 7, 41-51.

Montero, M. (2003). teoría y práctica de la psicología comunitaria (La tensión entre la comunidad y la sociedad). Buenos Aires: Paidós. 
Montes, V. y Ressel, A. (2003). Presencia del cooperativismo en Argentina. Revista UNIRCOOP; vol. 1, № 2, 9-26.

Morán-Angulo, R; J. Téllez-López y J. Cifuentes-Lemus. (2010). La investigación pesquera: una reflexión epistemológica. Revista THEOMAI. Estudios sobre Sociedad y Desarrollo , 21:97-112.

Moscovici, S. (1979). El psicoanálisis, su imagen y su público. Buenos Aires: Editorial Huemul.

Muñiz Terra, L.; Roberti, E.; Deleo, C. y Hasicic, C. (2013). Trayectorias laborales en Argentina: una revisión de estudios cualitativos sobre mujeres y jóvenes. Revista Lavboratorio, 57 - 79.

Mutuberría Lazarini, V. y Plotinsky, D. (comps.). (2015). La Economía social y Solidaria en la Historia de América Latina y el Caribe. Tomos I y II. CABA: Ediciones Idelcoop.

Neffa, J. (Coord.), Brown, B. y López, E. (2012). Empleo, desempleo y políticas de empleo. Políticas activas de empleo durante la posconvertibilidad. Buenos Aires: CEIL CONICET.

Neffa, J. (1988). ¿Qué son las condiciones y medio ambiente de trabajo? Propuesta de una nueva perspectiva. Buenos Aires: Humanitas.

Newberry, P.E. (1893-4). Beni Hasan (Archaeological Survey Memoirs) Vol I. Londres: Egypt Exploration Society.

Nieto, A. (2010). Amotinados. Ira obrera en la industria pesquera argentina, 1997 2007. Revista Lavboratorio, Año XI, Número 23: 95-135.

Nieto, A. (2010). Notas críticas en torno al sentido común historiográfico sobre 'el anarquismo argentino. A Contracorriente: Revista de Historia Social y Literatura en América Latina , Vol. 7, No. 3, 219-248.

Nieto, A. (2014). Industria pesquera y mundo obrero. En O. (. Barreneche, Historia de la provincia de Buenos Aires. Del primer peronismo a la crisis de 2001 (págs. 329-357). Argentina: Edhasa/Unipe.

Nieto, A. (2015). Asociacionismo obrero y popular en la aldea, Mar del Plata 19401960. En O. A. Quiroga, Asociaciones y política en la Argentina del siglo veinte. Entre prácticas y expectativas (págs. 179-200). Buenos Aires: Prometeo.

Nieto, A. (2015). Vida asociativa a ras del suelo en una aldea peronista. Activismo obrero y popular en Mar del Plata, 1943-1955. Revista Páginas, 41-61. 
Nieto, A. (2017). La historia de la clase obrera latinoamericana: notas para una agenda de investigación. Algarrobo, revista en línea de la Maestría en Estudios Latinoamericanos FCPyS-UNCuyo, 1-26.

Nogueira, M. L. (2018). Constelaciones conflictivas en la industria pesquera bonaerense. Análisis comparativo entre Mar del Plata y Necochea, Argentina (1997-2012). Revista Trabajos y Comunicaciones, 2da. Época, № 47, e052, 54-76.

Nogueira, M. L. (2018). Mar del Plata y Necochea: cara y ceca de la industria pesquera argentina tras la reestructuración capitalista (1970-2013). Revista de Estudios Marítimos y Sociales № 12, 127-159.

Nogueira, M. L. (2017). Políticas públicas para la conservación del empleo en Argentina pos 2002. Los Programas de Recuperación Productiva (REPRO) y de trabajo autogestionado (PTA). I Jornadas de Sociología de la UNMDP, Mar del Plata, 30 y 31 de marzo de 2017.

Nogueira, M. L. (2017). Las trincheras de la resistencia obrera en la industria pesquera bonaerense. Análisis comparativo a partir de una conflictividad social heterogénea (1997-2012). Ponencia presentada en las VII Jornadas Interdisciplinares de Estudios Portuarios. Universidad de Cadiz, Cadiz, 13, 14 y 15 de septiembre de 2017.

Nogueira, M. L. y Schulze, M. S. (2016). Conflictividad social y “recuperación” de empresas pesqueras, Necochea/Quequén (2010-2012), ponencia presentada en las XI Jornadas de Investigadores en Historia, publicado en Actas de las Jornadas, UNMDP, Mar del Plata, 16 a 18 de noviembre de 2016.

Nogueira, M. L. (2016) La prensa gráfica como fuente de datos y de discursos: Análisis a partir del caso de una empresa pesquera recuperada, en Revista Papeles de Trabajo № 31, 79-92.

Nogueira, M. L. (2016). Reconfiguración laboral, reconfiguración subjetiva: discursos y praxis de trabajadores de las empresas pesqueras recuperadas de Necochea y Quequén, en Straniero, Cristina; Tosi Cecilia; Luna Mauricio (comps.) Psicología y compromiso social 2016 - XVI Congreso Argentino de Psicología, Mendoza, 28, 29 y 30 de abril.

Nogueira, M. L. (2016). Crece el monopolio, crece la precarización laboral: devenires de la industria pesquera en las ciudades-puerto Necochea y Mar del Plata en el marco de la reestructuración capitalista (1970-2013), ponencia presentada en el V CONGRESO LATINOAMERICANO DE HISTORIA ECONOMICA São Paulo, 19, 20 y 21 de junio. 
Nogueira, M. L. (2015). Civilización o barbarie. La prensa gráfica local y la empresa de autogestión obrera "La Recuperada" Necochea 2012-2014, ponencia presentada en las IV Jornadas Interdisciplinarias de Estudios Portuarios, organizada por la Red de Estudios Portuarios (REDEP), UNR, Rosario, 19 al 21 de agosto.

Nogueira, M. L. (2014). Recuperando espacios comunitarios, resignificando posicionamientos subjetivos obreros: La Fiesta Recuperada de los Pescadores 2012-2014, ponencia presentada en el XI Congreso Argentino de Antropología Social. UNR, Rosario, 23 al 26 de julio.

Nogueira, M. L. (2014). Recuperación de fábricas y subjetividades obreras: el caso de las trabajadoras de Engraucoop (Quequén), en GRANDE, Eduardo, Cuerpo y subjetividad, 1ํㅡ. Ed., CABA: Asociación Argentina de Profesionales de la Salud Mental.

Nogueira, M. L. (2013). Deconstruyendo la organización interna en dos fábricas pesqueras recuperadas de Necochea y Quequén, ponencia presentada en las V Jornadas Interdisciplinarias de Estudios Portuarios, organizada por la Red de Estudios Portuarios (REDEP). Quequén, Necochea, 6 al 8 de noviembre.

Nogueira, M. L. (2012). ¿Otro adiós al proletariado? El caso de las obreras de Engraucoop, ponencia presentada en las IV Jornadas Interdisciplinarias de Estudios Portuarios, organizada por la Red de Estudios Portuarios (REDEP), UNLP, La Plata, 8 al 10 de noviembre.

Nogueira, M. L. (2012). La Recuperada. Primeros pasos en la experiencia de autogestión de trabajadores/as del procesamiento pesquero. En M. (. Weisser, Temas de Patrimonio Cultural 30. Argentina de Puertos III Jornadas Red de Estudios Portuarios (págs. 283-290). Buenos Aires: Ministerio de Cultura CABA.

Nogueira, M. L. (2011). La Recuperada. Crónica genética de una fábrica pesquera recuperada, ponencia presentada en las III Jornadas Interdisciplinarias de Estudios Portuarios organizadas por la Red de Estudios Portuarios (REDEP), Universidad Maimónides, CABA, 10 al 12 de noviembre.

Novaes, H. (2009). Capítulo 17. Un balance de las Fábricas Recuperadas brasileñas frente a un contexto de crisis avasalladora. En A. (. Ruggeri, Las empresas recuperadas: autogestión obrera en Argentina y América Latina (págs. 203220). Buenos Aires: Editorial de la Facuntad de Filosofía y Letras (UBA).

Núñez, A. (2006). Lo que el agua (no) se llevó. Política urbana, Estado del poder, violencia e identidades sociales. Mar del Plata, entre siglos. Buenos Aires: Flacso. 
Oliver, P. y Myers, D. (1999). How Events Enter in Public Sphere: Conflict, Location and Spontsorship in Local Newspaper Coverage of Public Events. American Journal of Sociology, vol. 105, núm. 1, 38-87.

Ortegón, E. F., y Prieto, A. . (2005). Metodología del marco lógico para la planificación, el seguimiento y la evaluación de proyectos y programas. Santiago de Chile: Instituto Latinoamericano y del Caribe de Planificación Económica y Social (ILPES) .

Parra, M. (2005,). Resistiendo al desempleo. Las experiencias colectivas de trabajo en córdoba. LabourAgain, Factory takeovers in Argentina, 1-13.

Parra, M. (2012). Argentina, un país en movimiento... Sujetos, acciones y articulaciones en torno a diciembre de 2001. Tesis doctoral. Barcelona, España: Universitat Autónoma de Barcelona.

Pascucci, S. (2005). Capitalismo desde abajo. El Aromo, 4-6.

Pastore, R. y Altschuller, B. (2015) La Economía Social y Solidaria y los debates en el desarrollo en clave territorial. Reflexiones sobre experiencias y desafíos a partir de una práctica socioeducativa universitaria. Revista Idelcoop № 217, 34-50.

Patrouilleau, M. M. (2007). Crisis del trabajo y gestión de los trabajadores. Las dinámicas colectivas de gestión en unidades productivas recuperadas de Argentina (1996-2006). Trabajo y Sociedad , № 9, vol. IX, 1-19.

Pradas, E. (2006). Un acercamiento a la problemática pesquera marplatense. Buenos Aires: Ediciones El Mensajero.

Pegoraro, J. (1979 ). Los conflictos laborales, 1973-1976. Cuadernos de Marcha, 2: 89-98.

Peiró, J. M. y Prieto, F. (1996). Tratado de Psicología del Trabajo. Vol. II. . Madrid: Síntesis Psicológica.

Perbellini, M. (2010). 'Cuerpos' y 'lógicas autogestivas': el caso de los trabajadores de empresas recuperadas. Revista Latinoamericana de Estudios sobre Cuerpos, Emociones y Sociedad, №4, 65-77.

Perbellini, M. y Tifni, E. (2007). Nuevas formas de organización del trabajo: las empresas recuperadas. El caso de la cooperativa de trabajo cristalería Vitrofín Ltda. $8^{o}$ Congreso de la ASET. Rosario: UNR.

Perelman, L. y Vargas, P. (2013) Imputaciones morales y precarización laboral entre los jóvenes trabajadores de una fábrica siderúrgica en la Argentina. Revista Trabajo y Sociedad №21, 403-413. 
Perez Comesaña, J. E. y Nogueira, J.L. (2013). Evolución de la pesca costera de arrastre de fondo en Puerto Quequén, provincia de Buenos Aires, Argentina: Periodo 1999-2010. Rev. Mus. Argent. Cienc. Nat. , vol.15, n.2.

Pichetti, V. y Xiques, M. (2003). Ocupación de fábricas y construcción política. En ASET, Los trabajadores y el trabajo en crisis (págs. 1-16). Buenos Aires: ASET.

Piva, A. (2016). La desorganización de la acción de clase en la Argentina reciente y los problemas conceptuales para el estudio del conflicto obrero . Estudios Políticos, № 48, 73-93.

Plotinsky, D. (2015). Orígenes y consolidación del cooperativismo en la Argentina. Obtenido de www.idelcoop.org.ar Revista Idelcoop 215 [en línea]: www.idelcoop.org.ar/sites/default/files/revista/articulos/pdf/revista-

215-con-membretes-

origenes_y_consolidacion_del_cooperativismo_en_la_argentina.pdF consultado el 17/06/2017

Quenan, C. y Velut, S. (2014). Les enjeux du développement en Amérique latine. Dynamiques socioéconomiques et politiques publiques. Paris: Collec A savoir $\mathrm{N}^{\circ} 24, \mathrm{IdA} / \mathrm{AFD}$.

Quijano, A. (2011). ¿Sistemas alternativos de producción? En B. (. De Souza Santos, Producir para vivir Los caminos de la producción no capitalista, 369-399. México : FCE.

Razeto, L. (1990). Economía popular de solidaridad. Santiago: Area Pastoral Social de la Conferencia Episcopal de Chile, Programa de Economía del Trabajo (PET).

Rebón, J. (2004). Desobedeciendo al desempleo. La experiencia de las Empresas Recuperadas. Buenos Aires: La rosa blindada y PICASO.

Rebón, J. (2004). Una empresa de trabajadores. Apuntes acerca de los determinantes de las empresas recuperadas. LabourAgain, 1-12, www.iisg.nl/labouragain/documents/rebon.pdf.

Rebón, J. (2005). Trabajando sin patrón. Las empresas recuperadas y la producción. Documento de Trabajo No 44 IIGG. Buenos Aires: Facultad de Ciencias Sociales, UBA.

Rebón, J. (2006). La empresa de la autonomía. Apuntes acerca de la recuperación de empresas por sus trabajadores en Argentina. OSAL, Año VII, No22, 263-276.

Rebón, J. y Salgado, R. (2007). Transformaciones emergentes del proceso de recuperación de empresas por sus trabajadores. Labouragain, http://www.iisg.nl/labouragain/argentineantakeovers.php 
Rebón, J. y Antón, G. (2007). Rebón, JuliáFormas de lucha y construcción de ciudadanía: la acción directa en la Argentina reciente. En R. S. Perez, Voces y letras en insumisión, 197-230. Buenos Aires: El Aleph.

Río, M. (2008). Usos y abusos de la prensa como fuente de datos sobre acciones colectivas. Revista Empiria, № 16, 59-84.

Ríos, T. y Picone, J. (2010). Empresas Recuperadas de la República Bolivariana de Venezuela: Una Realidad Compleja y un Desafío Liberador. OSERA, № 4, 1835.

Ríspoli, F. y Nogueira, J. L. . (2007). Puerto Quequén: operación de la flota costera, caracterización del trabajo y estrategias familiares de los pescadores. Rev. Zainak. Cuadernos de Antropología-Etnografía, № 29: 65-79.

Rivas, A. (2005). Del trabajo como valor de inscripción social al trabajo como factor de desestructuración social: el caso de los trabajadores y trabajadoras desplazados por la deslocalización industrial dentro del estado español. Cuadernos de relaciones laborales, 63-82.

Robertazzi, Ferrari, Pertierra y Calcagno. (2004). Reactualización de las luchas obreras en las ERT. En U. Facultad de psicología, XII Anuario de Investigaciones, 97-105. Buenos Aires: Secretaría de investigaciones.

Robertazzi; Ferrari; Kalpschtre; Cebey; Aduco. (2007). La experiencia de recuperación de empresas. Diversidad de perspectivas del trabajo, las organizaciones y la comunidad. Memorias de las XIV Jornadas de Investigación - III Encuentro de Investigadores en Psicología en el Mercosur (págs. 169-171). Buenos Aires: UBa.

Rudé, G. (1981). Revuelta popular y conciencia de clase. Barcelona: Editorial Crítica.

Ruggeri, A. (comp.). (2009). Las empresas recuperadas: autogestión obrera en Argentina y América Latina. Buenos Aires: Editorial de la Facultad de Filosofía y Letras.

Ruggeri, A. (2005). Informe del Segundo Relevamiento del programa Facultad Abierta "Las empresas recuperadas en Argentina". CABA: Chilavert.

Ruggeri, A. (2010). Informe del Tercer Relevamiento del programa Facultad Abierta en el marco del programa "Las empresas recuperadas en Argentina". CABA: Chilavert.

Ruggeri, A. (2014). Una aproximación a las empresas recuperadas por sus trabajadores. Voces en el Fénix , № 38, 38-45. 
Ruggeri, A. (2014). ¿Qué son las empresas recuperadas? Buenos Aires: Editorial Continente.

Ruggeri, A. (2014). Informe del Cuarto Relevamiento del programa Facultad Abierta. las empresas recuperadas en Argentina 2010-2013. CABA: Chilavert.

Ruocco, L. (2010). Reivindicaciones de las mujeres obreras de la industria del pescado. Una perspectiva de clase y género a partir de los convenios colectivo de trabajo (Mar del Plata, 1942-1975). Revista de Estudios marítimos y sociales, 93-105.

Saavedra, Fernandez, Herrán y Quartulli. (2005). El sector empresas recuperadas: condiciones de existencia, modos de vidas y tendencias posibles. Estudio de casos del área metropolitana del GBA. Foro: Trayectos y territorios de desempleo (págs. 70-83). Mar del Plata: UNMDP.

Saavedra, L. (2005). Entre la desocupación y la recuperación autogestiva de empresas: la configuración del espacio de las fábricas recuperadas. En F. y. Mallimaci, Los nuevos rostros de la marginalidad. La supervivencia de los desplazados (págs. 167-183). Buenos Aires: Biblos.

Salvia, A. (2005). Argentina siglo XXI: Segregación y nueva marginalidad en tiempos de cambio social. CLACSO (págs. 1-22). Rio de Janeiro: ASET.

Santella, A. (2011). Un aporte al debate teórico sobre la burocracia sindical, №8 , 133-148. Revista Nuevo topo, №8, 133-148.

Santella, A. (2015). Teorías e historias de los trabajadores en los años setenta en Argentina. Notas sobre los debates recientes entre historiografía y sociología histórica. XI Jornadas de Sociología (págs. 1-14). CABA: Facultad de Ciencias Sociales, Universidad de Buenos.

Schneider, A. (comp.) (2009). Trabajadores. Un análisis sobre el accionar de la clase obrera argentina en la segunda mitad del siglo XX. Buenos Aires: Herramienta.

Schujman, M. (2010). Políticas Públicas para el tercer sector: Empresas Recuperadas y Cajas de Crédito Cooperativas. CABA: Facultad de Ciencias Económicas de la Universidad de Buenos Aires.

Schulze, M. (2014). Representaciones obreras sobre las condiciones laborales en la industria pesquera de Mar del Plata (2007-2012) . Conflicto Social, Vol. 7, N $12,146-171$.

Schvastein, L. y Leopold, L. (Comps.). (2005). Trabajo y subjetividad: entre lo existente y lo necesario. Buenos Aires: Paidós. 
Silver, B. (2003). Fuerzas de trabajo. Los movimientos obreros y la globalización desde 1870. . Madrid: AKAL.

Singer, P. (2014 ). La construcción de la economía solidaria como alternativa al capitalismo en Brasil . Voces en el Fénix , № 38, 18-27.

SISMOS (2014). Manual de carga. Mar del Plata: GESMar.

Slutzky, Di Loreto y Rofman. (2003). Experiencias autogestionarias en el marco de crisis económico social inédita: Las empresas recuperadas. En ASET, Los trabajadores y el trabajo en crisis (págs. 50-62). Buenos Aires: ASET.

Soul, M. J. Et. Al. . (2012). El mundo del trabajo en América Latina: Tendencias y resistencias. CABA: CLACSO.

Subirats, J. et al. . (2008). Análisis y gestión de políticas públicas. Barcelona: Editorial Ariel.

Svampa, M. (2005). La sociedad excluyente: la Argentina bajo el signo del neoliberalismo. Buenos Aires: Taurus.

Tarrow, S. (2002). Ciclos de acción colectiva: entre los momentos de locura y el repertorio de contestación. En M. Traugott, Protesta social. Repertorios y ciclos de acción colectiva. Barcelona: Hacer Editorial.

Tauss, A. (2015). Revisiting Argentina's recuperated factories - Reflections on over a decade of workers' control . Desafíos, 27(1), 185-205.

Thompson, E. (1963). La formación de la clase obrera en Inglaterra. España: Capitán Swing Libros.

Thompson, E. (1979). Tradición, revuelta y conciencia de clase. Estudios sobre la crisis de la sociedad preindustrial. España: Editorial Crítica.

Tilly, C. (1993). European revolutions, 1492-1992. Oxford: Blackwell.

Tiriba, L. (2012). Escuelas del trabajo. Reflexiones sobre fábricas ocupadas y recuperadas por los trabajadores. Revista OSERA № 6, 1-15.

Torme, M. (2015 ). Reflexión teórico-política sobre burocracia sindical. Hic Rhodus No $5,79-89$.

Valette, L. (1921). Apuntes sobre la industria pesquera nacional. Someras consideraciones. Buenos Aires: Boletín del Ministerio de Agricultura de la Nación, t. XXVI, № 1. 
Varela, P. (2010). Entre la fragmentación de los trabajadores y los negocios propios (o sobre qué se sostiene la actual burocracia sindical) . Revista Nuevo topo, № 7, 4-29.

Vieitez, Cándido y Dal Ri, Neusa Maria. (2004). Elementos da história da ANTEAG. Revista ORG y DEMO, Vol.5, №2, 267-272.

Virno, P. (2003). Gramática de la multitud. Madrid: Traficantes de sueños.

Visacovsky, S. (2002). El Lanús, Memoria y política en la construcción de una tradición psiquiátrica y psicoanalítica argentina. Buenos Aires: Alianza.

Visacovsky, S. (2007). Cuando las sociedades conciben el pasado como "memoria": un análisis sobre verdad histórica, justicia y prácticas sociales de narración a partir de un caso argentino. Antípoda, núm. 4: 49-74.

Vitoli, A. (2013). Empresas recuperadas y su impacto en las relaciones laborales. Un recorrido sobre las experiencias argentina y latinoamericana enter 20022010. Tesis presentada para obtener el grado de Magister en Ciencias Sociales del Trabajo. Buenos Aires: UBA.

Vuotto, M. (2008). La co-construcción de políticas públicas en el campo de la economía social. Buenos Aires: Prometeo.

Vuotto, M. (2014). La economía social y las cooperativas en la Argentina. Voces en el Fénix, № 38, 46-53.

Williams, R. (1997). Marxismo y literatura. Barcelona: Ediciones Península.

Wyczykier, G. (2007). De la dependencia a la autogestión laboral: sobre la reconstrucción de experiencias colectivas de trabajo en la argentina contemporánea . Tesis para la obtención del título de Doctora en Ciencias Sociales . Facultad Latinoamericana de Ciencias Sociales (FLACSO).

Zapata, F. (2000). La historia del movimiento obrero en América Latina y sus formas de investigación. En D. l. (coord.), Tratado Latinoamericano de sociología del trabajo. México: Fondo de Cultura Económica.

Zelaya, M. (2013). La cooperativización del trabajo en la industria del pescado marplatense. Trabajo integrador final. Mar del Plata, Buenos Aires, Argentina: Facultad de Ciencias Económicas y sociales. 


\section{Fuentes:}

\section{Prensa gráfica y digital:}

Ecos Diarios, Necochea, archivos gráfico y digital disponibles en Biblioteca Andrés Ferreira y www.ecosdiariosweb.com.ar

Diario La Capital, Mar del Plata.

Diario El Atlántico, Mar del Plata.

Revista Puerto, La otra cara de la pesca. Ejemplares correspondientes al período 2003-2012. Mar del Plata.

Revista Redes de la industria Pesquera Nacional (2) №14, Estadísticas 1985 y 1986.

Revista OSERA. Ejemplares correspondientes al período 2009-2015.

www.nuestromar.org

www.perfil.com

www.lanacion.com

www.mdphoy.com

www.agencianova.com

Revista De acá, año I, septiembre de 2007, №9.

\section{Documentos oficiales:}

Ministerio de Trabajo, Empleo y Seguridad Social (2011). PROGRAMA DE RECUPERACIÓN PRODUCTIVA. MEMORIA 2003-2010. Argentina.

Ministerio de Trabajo, Empleo y Seguridad Social (2012). Guía de empresas recuperadas y autogestionadas por sus trabajadores. Argentina.

Ministerio de Trabajo, Empleo y Seguridad Social (2013). Informe del Programa de Trabajo Autogestionado del Ministerio de Trabajo, Empleo y Seguridad Social de la Nación. Noviembre 2013. Argentina

Subsecretaría de Programación Técnica y Estudios Laborales- Ministerio de Trabajo, Empleo y Seguridad Social, Diagnóstico del empleo no registrado, año 2004.

Subsecretaría de Programación Técnica y Estudios Laborales- Ministerio de Trabajo, Empleo y Seguridad Social de la República Argentina (SPTyEL) (2011) Evolución del Empleo registrado del Sector privado en los principales centros urbanos. Primer trimestre 2011.Informe en base a Encuesta de Indicadores Laborales. Argentina. 
Ministerio de Economía de la Provincia de Buenos Aires - Dirección Provincial de Estadística (2005) Informe total. Medición de la economía provincial. Provincia de Buenos Aires y sus municipios, 1993-2004.

MINISTERIO DE AGRICULTURA, GANADERÍA Y PESCA DE LA NACIÓN (2012) Estadísticas de la pesca marina en Argentina. Evolución de los desembarques 18982010, Buenos Aires.

MINISTERIO DE ECONOMÍA, SECRETARÍA DE ESTADO DE INTERESES MARÍTIMOS, SUBSECRETARÍA DE PESCA (1983) Sector pesquero argentino año 1982. Revista Argentina Pesca Marítima, año 1983, Buenos Aires.

MECON, Informes técnicos disponibles en www.mecon.gov.ar

MINAGRI, Informes técnicos disponibles en www.minagri.gov.ar

SECRETARIA DE AGRICULTURA, GANADERÍA Y PESCA, Informes técnicos y evolución de los desembarques, Pesca Marítima, disponibles en:

https://www.agroindustria.gob.ar/sitio/areas/pesca maritima/

Bertolotti, G. y Col. (1987). La actividad industrial pesquera "Procesamiento y Transformación industrial" Capacidades de producción, empleo y posibilidades de aprovechamiento de las especies más importantes del mar argentino. Parte I: Período 1981/1982. Revista Contribución №438, INIDEP, 4-20.

Bertolotti, M. I. (2001). Algunas consideraciones preliminares sobre el estado del sector pesquero. Informe Técnico $\mathrm{N}^{\circ} 71$. Buenos Aires: INIDEP.

Bertolotti, M., Erratzi, E. Y Pagani A. (1997). Resultados preliminares del Censo Nacional Industrial Pesquero - año 1996. Provincia de Buenos Aires. Plantas instaladas en tierra. Mar del Plata, Buenos Aires: Informe técnico interno № 34, INIDEP.

Bertolotti, María Isabel, Piergentili, G. y Cabut, D. (1987). El sector pesquero argentino. Rev. Investigación Pesquera, №51 (Supl. 2), 193-221.

Bertolotti, María y Manca, Emilio. (1986). Procesamiento y comercialización de la anchoíta (Engraulis anchoíta) del Mar Argentino. Revista de Investigación y Desarrollo Pesquero, №5 224- 247.

Decreto presidencial №721/2000.

Ley de Cooperativas №20.337, año 1973.

Ley de Régimen Laboral №25877, año 2004.

Ley de Régimen de Contrato de Trabajo №20.744, año 1976.

Decreto presidencial №390/1976.

Decreto presidencial №94/2015.

Resolución №584/2007, Secretaría de Trabajo de la provincia de Buenos Aires. 
CCT №161/75 para el trabajo en la industria pesquera.

CCT №506/07 para la pequeña y mediana empresa (rama fileteros).

INDEC, Censo Nacional, Año 1991.

INDEC, Censo Nacional, Año 2001.

INDEC, Censo Nacional, Año 2010.

INDEC, Base REDATAM disponible online en: https://www.indec.gob.ar/bases-dedatos.asp

INDEC, EPH, disponible online en: https://www.indec.gob.ar/bases-de-datos.asp

INDEC, Anuario Estadístico de la República Argentina 2013, Buenos Aires, marzo de 2015.

INDEC, Anuario Estadístico de la República Argentina 2004, Buenos Aires, marzo de 2005.

INDEC, Anuario Estadístico de la República Argentina 1997, Buenos Aires, marzo de 1998.

\section{Otros documentos:}

FAO. (1998). The state of world fisheries and aquaculture. http://www.fao.org/docrep/w9900e/w9900e00.html

FAO. (2014). Perfíles de Pesca y Acuicultura por Países. Argentina. Hojas de datos de perfiles de los países. In: Departamento de Pesca y Acuicultura de la FAO [en línea]. Roma.

FAO. (2016). Estadísticas de pesca y acuicultura. Departamento de Pesca y Acuicultura. http://www.fao.org/publications

FAO. (2017). El comercio y la pesca. Departamento de Pesca y Acuicultura http://www.fao.org/fishery/trade/es 1/1

\section{Archivos judiciales:}

Causa judicial ENGRAULIS S.A. S/QUIEBRA №3574-7011. Expediente №37489.

Causa judicial INDUSTRIAL PESQUERA NECOCHEA S.A.I.C. S/ QUIEBRA (GRANDE). Expediente №29758

\section{Archivos sindicales y obreros:}

SOIP: Resultados de las elecciones del SOIP, año 2002. 
Boletín Lista Celeste, 2006.

La Recuperada: Empresas de la industria necochense cerradas desde 1970 hasta 2012

\section{Fuentes Audiovisuales:}

"Días de furia", documental elaborado por el Grupo de Estudios Sociales y Marítimos (GESMar), año 2009.

"La Recuperada: una historia de lucha, trabajo y dignidad", documental realizado por integrantes de la Cooperativa COOMUNICCAR, año 2011.

"Engraucoop, empresa recuperada por los trabajadores", documental realizado por la Cooperativa COOMUNICCAR, año 2012, disponible en: https://www.youtube.com/watch?v=tPb4vk2UFgQ

"Lucha y autogestión, La Recuperada", documental realizado por los egresados 2014 del Curso Operador Audiovisual del Centro de Formación Profesional Cooperativa COOMUNICCAR, disponible en: https://youtu.be/Ztia8YXVwy4

\section{Entrevistas:}

Realizadas por la autora:

Entrevista grupal a La Recuperada, realizada por la autora el 24 de octubre de 2011.

Entrevista a Mario, 52 años, filetero en La Recuperada, realizada por la autora el 27 de octubre de 2011.

Entrevista a Julián, 29 años, filetero en la Recuperada, realizada por la autora el 30 de octubre de 2011.

Entrevista grupal a La Recuperada, realizada por la autora el 18 de octubre de 2013.

Entrevista grupal a La Recuperada, realizada por la autora el 25 de abril de 2014.

Entrevista a Darío, 35 años, filetero en La Recuperada y ex delegado sindical, realizada por la autora el 25 de abril de 2014.

Entrevista a Natalia, 37 años, filetera en La Recuperada, realizada por la autora el 28 de abril de 2014.

Entrevista a Mario, 56 años, filetero en La Recuperada, realizada por la autora el 15 de febrero de 2015.

Entrevista grupal a Engraucoop, realizada por la autora el 8 de octubre de 2012.

Entrevista grupal a Engraucoop, realizada por la autora el 22 de octubre de 2013. 
Entrevista a Roque, 45 años, pescadero y propietario de embarcación, realizada por la autora el 19 de febrero de 2015.

Entrevista a Guillermo, 42 años, abogado del STIA sede Necochea, realizada por la autora el 4 de abril de 2017.

Entrevista a Claudia, 54 años, trabajadora de Engraucoop, realizada el 17 de marzo de 2018.

\section{Realizadas por terceros:}

Entrevista a Nancy, de 54 años, desempleada, trabajadora en el área pesquera desde 1976 hasta 2007, militante del Partido Obrero, realizada por Estefanía Martynowskyj el 18 de mayo 2009.

Entrevista a Marta, 49 años, trabajadora manual del puerto, realizada por Maia Morgenstern el 15 de mayo 2009.

Entrevista a Eduardo, filetero, 60 años, realizada por Martina Castro el 14 de mayo de 2009.

Entrevista a María, filetera, 42 años, realizada por Cristian Tibaldi el 23 de mayo del año 2009.

Entrevista a Natividor, 59 años, filetero, realizada por María Soledad Schulze el 6 de mayo del año 2009.

Entrevista a Mirta, 54 años, filetera, realizada por Claudia Marcela Bruschetti el 15 de mayo del año 2009.

Entrevista a Héctor, 42 años, filetero, realizada por Gladys Marcela Luca el 21 de mayo del año 2009.

Entrevista a Ana María y Julio Cesar, fileteros, de 60 y 64 años respectivamente, realizada por Carolina Dumrauf el 27 de mayo del año 2009.

Entrevista a Sonia, filetera, 49 años, realizada por María Soledad Schulze el 28 de mayo del año 2009.

Entrevista a Soledad, envasadora, 36 años, realizada por Humberto Lohiol el 15 de mayo del año 2009.

Entrevista a Luis Verón, exmilitante del Partido Obrero y asesor gremial del SOIP, realizada por Guillermo Colombo el 12 de febrero de 2009. 